Técnicas de combinação para agrupamento centralizado e distribuído de dados 


\title{
Técnicas de combinação para agrupamento centralizado e distribuído de dados
}

\author{
Murilo Coelho Naldi
}

Orientador: Prof. Dr. Ricardo José Gabrielli Barreto Campello Co-orientador: Prof. Dr. André Carlos Ponce de Leon Ferreira de Carvalho

Tese apresentada ao Instituto de Ciências Matemáticas e de Computação - ICMC-USP, como parte dos requisitos para obtenção do título de Doutor em Ciências - Ciências de Computação e Matemática Computacional. VERSÃO REVISADA. 
Ficha catalográfica elaborada pela Biblioteca Prof. Achille Bassi e Seção Técnica de Informática, ICMC/USP, com os dados fornecidos pelo(a) autor(a)

\begin{tabular}{|c|c|}
\hline \multirow[t]{3}{*}{ N166t } & $\begin{array}{l}\text { Naldi, Murilo Coelho } \\
\text { Técnicas de combinação para agrupamento } \\
\text { centralizado e distribuído de dados / Murilo Coelho } \\
\text { Naldi; orientador Ricardo José Gabrielli Barreto } \\
\text { Campello-- São Carlos, } 2011 . \\
\quad 245 \text { p. }\end{array}$ \\
\hline & $\begin{array}{l}\text { Tese (Doutorado - Programa de Pós-Graduação em } \\
\text { Ciências de Computação e Matemática Computacional) -- } \\
\text { Instituto de Ciências Matemáticas e de Computação, } \\
\text { Universidade de São Paulo, } 2011 .\end{array}$ \\
\hline & $\begin{array}{l}\text { 1. Agrupamento de dados. 2. Combinação de } \\
\text { Agrupamentos. 3. Combinação de Índices de Validação. } \\
\text { 4. Computação Evolutiva. } 5 \text {. computação Distribuída. I. } \\
\text { Campello, Ricardo José Gabrielli Barreto, orient. } \\
\text { II. Título. }\end{array}$ \\
\hline
\end{tabular}




\section{Resumo}

A grande quantidade de dados gerada em diversas áreas do conhecimento cria a necessidade do desenvolvimento de técnicas de mineração de dados cada vez mais eficientes e eficazes. Técnicas de agrupamento têm sido utilizadas com sucesso em várias áreas, especialmente naquelas em que não há conhecimento prévio sobre a organização dos dados. Contudo, a utilização de diferentes algoritmos de agrupamento, ou variações de um mesmo algoritmo, pode gerar uma ampla variedade de resultados. Tamanha variedade cria a necessidade de métodos para avaliar e selecionar bons resultados. Uma forma de avaliar esses resultados consiste em utilizar índices de validação de agrupamentos. Entretanto, uma grande diversidade de índices de validação foi proposta na literatura, o que torna a escolha de um único índice de validação uma tarefa penosa caso os desempenhos dos índices comparados sejam desconhecidos para a classe de problemas de interesse.

Com a finalidade de obter um consenso entre resultados, é possível combinar um conjunto de agrupamentos ou índices de validação em uma única solução final. Combinações de agrupamentos (clustering ensembles) foram bem sucedidas em obter soluções robustas a variações no cenário de aplicação, o que faz do uso de comitês de agrupamentos uma alternativa interessante para encontrar soluções de qualidade razoável, segundo diferentes índices de validação. Adicionalmente, utilizar uma combinação de índices de validação pode tornar a avaliação de agrupamentos mais completa, uma vez que uma maioria dos índices combinados pode compensar o fraco desempenho do restante.

Em alguns casos, não é possível lidar com um único conjunto de dados centralizado, por razões físicas ou questões de privacidade, o que gera a necessidade de distribuir o processo de mineração. Combinações de agrupamentos também podem ser estendidas para problemas de agrupamento de dados distribuídos, uma vez que informações sobre os dados, oriundas de diferentes fontes, podem ser combinadas em uma única solução global.

O principal objetivo desse trabalho consiste em investigar técnicas de combinação de agrupamentos e de índices de validação aplicadas na seleção de agrupamentos para combinação e na mineração distribuída de dados. Adicionalmente, algoritmos evolutivos de agrupamento são estudados com a finalidade de selecionar soluções de qualidade dentre os resultados obtidos. As técnicas desenvolvidas possuem complexidade computacional 
reduzida e escalabilidade, o que permite sua aplicação em grandes conjuntos de dados ou cenários em que os dados encontram-se distribuídos. 


\section{Abstract}

The large amount of data resulting from different areas of knowledge creates the need for development of data mining techniques increasingly efficient and effective. Clustering techniques have been successfully applied to several areas, especially when there is no prior knowledge about the data organization. Nevertheless, the use of different clustering algorithms, or variations of the same algorithm, can generate a wide variety of results, what raises the need to create methods to assess and select good results. One way to evaluate these results consists on using cluster validation indexes. However, a wide variety of validation indexes was proposed in the literature, which can make choosing a single index challenging if the performance of the compared indexes is unknown for the application scenario.

In order to obtain a consensus among different options, a set of clustering results or validation indexes can be combined into a single final solution. Clustering ensembles successfully obtained results robust to variations in the application scenario, which makes them an attractive alternative to find solutions of reasonable quality, according to different validation indexes. Moreover, using a combination of validation indexes can promote a more powerful evaluation, as the majority of the combined indexes can compensate the poor performance of individual indexes.

In some cases, it is not possible to work with a single centralized data set, for physical reasons or privacy concerns, which creates the need to distribute the mining process. Clustering ensembles can be extended to distributed data mining problems, since information about the data from distributed sources can be combined into a single global solution.

The main objective of this research resides in investigating combination techniques for validation indexes and clustering results applied to clustering ensemble selection and distributed clustering. Additionally, evolutionary clustering algorithms are studied to select quality solutions among the obtained results. The techniques developed have scalability and reduced computational complexity, allowing their usage in large data sets or scenarios with distributed data. 


\section{Agradecimentos}

Agradeço ao meu orientador Prof. Dr. Ricardo J. G. B. Campello, pela perseverança e pelos grandes ensinamentos que transcendem o escopo deste trabalho. Também agradeço ao meu co-orientador Prof. Dr. André C. P. L. F. de Carvalho pela orientação e apoio, essenciais para a realização deste trabalho. É importante agradecer também ao Prof. Dr. Eduardo R. Hruschka, por tamanha dedicação e pelos momentos de descontração.

Não posso deixar de agradecer aos colegas Prof. Dra. Katti Faceli, Msc. Danilo Horta, Msc. Vinícius Alves, Lucas Vendramin, Pablo Jaskowiak, André Fontana e César Salgado pela colaboração ${ }^{1}$ durante o desenvolvimento do projeto. Também agradeço aos meus colegas de laboratório, amigos, família e a Kémilly D. Garcia, que apoiaram minhas idéias e me encorajaram a seguir meus ideais. Em especial, meu pai, José R. Naldi, que me apresentou um computador pessoal aos 10 anos e iniciou a paixão que culminou neste trabalho. Agradeço à Fapesp pelo apoio financeiro essencial ao projeto.

\footnotetext{
${ }^{1}$ A estrutura deste documento foi gentilmente cedida pelo Prof. Dr. Ronaldo Prati.
} 


\section{Sumário}

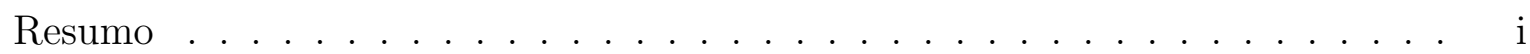

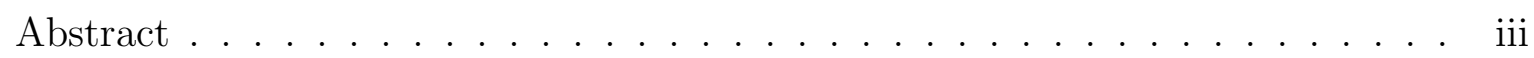

Sumário . . . . . . . . . . . . . . . . . . . xi

Notação . . . . . . . . . . . . . . . . . . . . . . . . . . . xvii

Lista de figuras . . . . . . . . . . . . . . . . xix

Lista de tabelas . . . . . . . . . . . . . . . . . . . xxiv

Lista de abreviaturas . . . . . . . . . . . . . . . . . . xxvii

Lista de algoritmos . . . . . . . . . . . . . . . . . xxvii

1 Introdução 1

1.1 Motivação . . . . . . . . . . . . . . . . . . . . 1

1.2 Hipóteses relacionadas à pesquisa . . . . . . . . . . . . . . . . . . . . 4

1.3 Organização do trabalho . . . . . . . . . . . . . . . . . . . . . 4

2 Agrupamento de dados $\quad 7$

2.1 Definição e aspectos principais . . . . . . . . . . . . . . . . . . . 8

2.2 Preparação dos dados . . . . . . . . . . . . . . . . . . . . . . . 10

2.2.1 Conjuntos de dados de expressão gênica . . . . . . . . . . . . . . 12

2.2.2 Conjuntos de dados de mineração de textos . . . . . . . . . . . . . 13

2.3 Medidas de similaridade e dissimilaridade . . . . . . . . . . . . . . . . 16

2.3.1 Medidas para atributos qualitativos . . . . . . . . . . . . . . 17

2.3.2 Medidas para atributos quantitativos . . . . . . . . . . . . . . 19

2.3 .3 Medidas para grupos . . . . . . . . . . . . . . . . 21

2.4 Algoritmos clássicos de agrupamento . . . . . . . . . . . . . . . . 22

2.4.1 A classe de algoritmos $k$-medóides . . . . . . . . . . . . . . 22

2.4.2 Estimação de densidade com Expectation Maximization (EM) . . . 23

2.4.3 Density Based Spatial Clustering of Applications with Noise (DBS$C A N) \ldots \ldots \ldots \ldots \ldots \ldots \ldots$

2.4.4 CLuster Identification via Connectivity Kernels (CLICK) . . . . . . 25

2.4.5 Algoritmos de agrupamento hierárquico . . . . . . . . . . . . 26 
2.4.5.1 Ward

2.4.5.2 Balanced Iterative Reducing and Clustering using Hierarchies $(B I R C H) \ldots \ldots \ldots \ldots . \ldots 27$

2.4.5.3 Clustering Using REpresentatives (CURE) . . . . . . . 28

2.4.6 Algoritmo k-médias . . . . . . . . . . . . . . . . . . . . . 29

2.4.6.1 Métodos sistemáticos para estimar o número de grupos $k$. 31

2.4.6.2 Bisecting k-means . . . . . . . . . . . . 32

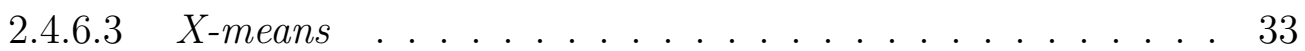

2.5 Validação de agrupamentos . . . . . . . . . . . . . . . . . . 34

2.5 .1 Índices Externos _. . . . . . . . . . . . . . . . . . . 34

2.5.1.1 Índice Jaccard . . . . . . . . . . . . . . . . . . . 35

2.5.1.2 Índice Rand . . . . . . . . . . . . . . . . . . . . 35

2.5.1.3 Índice Rand Ajustado . . . . . . . . . . . . . . . . . 36

2.5 .2 Índices internos relativos . . . . . . . . . . . . . . . . 36

2.5.2.1 Critério de razão das variâncias . . . . . . . . . . 36

2.5.2.2 Índice Davis-Bouldin . . . . . . . . . . . . . . . . 37

2.5.2.3 Índices Dunn . . . . . . . . . . . . . . . . . . . . . 38

2.5.2.4 Índice PBM . . . . . . . . . . . . . . . . . . 39

2.5.2.5 Índices silhueta . . . . . . . . . . . . . . 40

2.6 Considerações finais . . . . . . . . . . . . . . . . . . . . . . . . . 41

3 Algoritmos Evolutivos para Agrupamento 43

3.1 Definição e aspectos principais . . . . . . . . . . . . . . . . . . . . 44

3.2 Agrupamento com número fixo de grupos . . . . . . . . . . . . . . . 46

3.2 .1 Codificações . . . . . . . . . . . . . . . . . . 46

3.2.2 Operadores . . . . . . . . . . . . . . . . . . . . . 49

3.2.3 Outras características . . . . . . . . . . . . . . . 52

3.3 Agrupamento com um número variável de grupos . . . . . . . . . . . . . 54

3.3 .1 Codificação . . . . . . . . . . . . . . . . . 54

3.3 .2 Operadores . . . . . . . . . . . . . . . 56

3.3.3 Outras características . . . . . . . . . . . . . . 58

3.4 Fast Evolutionary Algorithm for Clustering (F-EAC) . . . . . . . . . . 60

3.4 .1 Codificação e estruturas auxiliares . . . . . . . . . . . . 62

3.4 .2 Operadores de mutação . . . . . . . . . . . . . . 63

3.4.3 Busca local do F-EAC . . . . . . . . . . . . . . . . . 66

3.5 Considerações finais . . . . . . . . . . . . . . . . . . . . . 67

4 Questões de eficiência do agrupamento evolutivo $\quad 69$

4.1 Motivação . . . . . . . . . . . . . . . . . . . . 70

4.2 Análise de complexidade assintótica . . . . . . . . . . . . . . . . 71

4.2.1 Análise de complexidade do OMRk . . . . . . . . . . . . . . . 71 
4.2.2 Análise de complexidade do $M R k$. . . . . . . . . . . . . . . . 72

4.2 .3 Análise de complexidade do F-EAC . . . . . . . . . . . . . . . . 74

4.3 Aprimoramento do $F-E A C \ldots \ldots \ldots \ldots$. . . . . . . . . . 75

4.3.1 Modificações feitas no F-EAC . . . . . . . . . . . . . 75

4.3 .2 Comparação entre versões . . . . . . . . . . . . . . . . . 77

4.3.2.1 Metodologia . . . . . . . . . . . . 78

4.3.2.2 Conjuntos de dados . . . . . . . . . . . . . . . 79

4.3.2.3 Experimentos . . . . . . . . . . . . . . 80

4.4 Análise de tempo computacional . . . . . . . . . . . . . . . . . . 80

4.4.1 Metodologia . . . . . . . . . . . . . . . . 81

4.4 .2 Conjuntos de dados . . . . . . . . . . . . . . . . . . 82

4.4 .3 Experimentos . . . . . . . . . . . . . . 85

4.4.3.1 Gauss $9 \ldots \ldots \ldots \ldots . \ldots . \ldots . \ldots . \ldots 5$

4.4.3.2 Spherical_4_3.................. 88

4.4.3.3 ARTICLES . . . . . . . . . . . . . . . 89

4.4 .4 Análise dos resultados . . . . . . . . . . . . . . . . . . 92

4.5 Comparação entre abordagens baseadas em $k$-médias . . . . . . . . . . . . 92

4.5.1 Variantes dos algoritmos . . . . . . . . . . . . . . . 93

4.5.1.1 Variantes do Bisecting k-means . . . . . . . . . . 93

4.5.1.2 Variantes do X-means . . . . . . . . . . . . . . 94

4.5.1.3 Algoritmos de busca local estocástica . . . . . . . . . . . . 94

4.5.2 Experimentos . . . . . . . . . . . . . . . . . . 95

4.5.3 Análise dos resultados . . . . . . . . . . . . . . . . . . 100

4.6 Considerações finais . . . . . . . . . . . . . . . . . . . . . 101

5 Combinação de agrupamentos $\quad 103$

5.1 Definição e aspectos principais . . . . . . . . . . . . . . . . . . . . . . . 104

5.2 Diversidade dos agrupamentos base . . . . . . . . . . . 106

5.3 Determinação da função de consenso . . . . . . . . . . . . . . . . . 108

5.3.1 Funções baseadas em co-associação . . . . . . . . . . . . . . . . . 108

5.3.2 Funções baseadas em votação . . . . . . . . . . . . . . . . . . . . . 111

5.3.3 Funções baseadas em grafo/hipergrafo . . . . . . . . . . . . . . . . 114

5.3 .4 Outras funções . . . . . . . . . . . . . . . . . 118

5.4 Avaliação da combinação . . . . . . . . . . . . . . . . . . . . . . . 119

5.5 Comparações entre funções de consenso . . . . . . . . . . . . . . . . . . 120

5.6 Combinações de agrupamentos e AEs . . . . . . . . . . . . . . . . . . . . 123

5.7 Considerações finais . . . . . . . . . . . . . . . . . . . 124

6 Índices de validação na combinação de agrupamentos 125

6.1 Motivação . . . . . . . . . . . . . . . . . . . 126

6.2 Conjuntos de dados . . . . . . . . . . . . . . . . . . . . . . . . . . 128 
6.3 Uso individual de índices em CES . . . . . . . . . . . . . . . . . 130

6.3.1 Correlação entre índices relativos e externo . . . . . . . . . . . . . . 132

6.3.2 Experimentos . . . . . . . . . . . . . . . 133

6.3.2.1 Avaliação dos conjuntos seleção . . . . . . . . . . . . . 134

6.3.2.2 Combinação dos conjuntos seleção . . . . . . . . . . . . . 138

6.4 Combinação de índices de validação relativos . . . . . . . . . . . . . . . . . 145

6.4.1 Diversidade na seleção de partições . . . . . . . . . . . . . . . . 147

6.4.2 Métodos propostos . . . . . . . . . . . . . . . . 148

6.4.3 Experimentos . . . . . . . . . . . . . . . 150

6.5 Síntese dos resultados e aplicação . . . . . . . . . . . . . . . . . . . . 154

6.5.1 Aplicação em conjuntos de dados reais . . . . . . . . . . . . . . . 157

6.6 Considerações finais . . . . . . . . . . . . . . . . . . . . . . 163

7 Agrupamento distribuído de dados $\quad 165$

7.1 Motivação . . . . . . . . . . . . . . . . . . . . 166

7.2 Contextualização . . . . . . . . . . . . . . . . . . . . . 168

7.3 Distributed Fast Evolutionary Algorithm for Clustering (DF-EAC) . . . . . 171

7.3.1 Codificação e estruturas auxiliares . . . . . . . . . . . . . . . . 172

7.3 .2 Inicialização . . . . . . . . . . . . . . . . . . . . . . . 174

7.3 .3 Busca local . . . . . . . . . . . . . . . . . . 175

7.3 .4 Cálculo da aptidão . . . . . . . . . . . . . . . . . . . . 178

7.3.5 Operadores de mutação . . . . . . . . . . . . . . . . . . . . . . 179

7.3.6 Análise de complexidade do DF-EAC . . . . . . . . . . . . . . 181

7.4 Combinações de Agrupamentos Distribuídos (CAD) . . . . . . . . . . . . . 181

7.4.1 Geração dos modelos locais . . . . . . . . . . . . . . . 183

7.4 .2 Combinação de partições . . . . . . . . . . . . . . . . . . 183

7.4.3 VRC como função de avaliação . . . . . . . . . . . . . . . . . 185

7.4.4 Análise de complexidade dos algoritmos CAD . . . . . . . . . . . . 187

7.5 Experimentos . . . . . . . . . . . . . . . . . . . . . 189

7.5.1 Conjuntos de dados . . . . . . . . . . . . . . . . . . 189

7.5.2 Critérios de parada e algoritmos comparados . . . . . . . . . . . 191

7.5.3 Resultados com silhueta simplificada . . . . . . . . . . . . . 194

7.5.4 Resultados com $V R C$. . . . . . . . . . . . . . . . . . . . . . 201

7.6 Considerações Finais . . . . . . . . . . . . . . . . . . 206

8 Conclusões $\quad 209$

8.1 Trabalhos Futuros . . . . . . . . . . . . . . . . . 211

$\begin{array}{ll}\text { Apêndice I } & 213\end{array}$

$\begin{array}{ll}\text { Apêndice II } & 217\end{array}$ 
Referências Bibliográficas 


\section{Notação}

A notação utilizada neste documento segue a seguinte convenção:

- Valores escalares: itálico minúsculo.

- Vetores: negrito minúsculo.

- Matriz: negrito maiúsculo.

- Conjunto: itálico maiúsculo.

Notação utilizada:

$|\cdot|: \quad$ Cardinalidade

$a\left(\mathbf{x}_{i}\right): \quad$ Dissimilaridade entre o objeto $\mathbf{x}_{i}$ e seu grupo

$b\left(\mathbf{x}_{i}\right)$ : Menor dissimilaridade entre o objeto $\mathbf{x}_{i}$ e outros grupos

$\mathbf{c}_{i}: \quad$ Centróide do grupo $C_{i}$

$C_{i}: \quad i$-ésimo grupo

$C_{s}$ : $\quad$ Grupo a ser eliminado por operadores de mutação

$\hat{C}_{s}$ : $\quad$ O maior grupo a ser eliminado por operadores de mutação

$C_{i}^{z}: \quad i$-ésimo grupo da $z$-ésima partição

C: $\quad$ Matriz formada pelos centróides de todos os grupos da partição

$C_{t}$ : $\quad$ Grupo temporário

$\left|C_{i}[j]\right|: \quad \quad \quad \quad$ úmero de objetos do $i$-ésimo grupo no $j$-ésimo nó de dados

$\operatorname{con}_{j l}$ : Contribuição do objeto $x_{j}$ na escolha do $x_{l}$ para medóide

con $_{j i h}$ : Contribuição do objeto $x_{j}$ na permutação de papéis entre $x_{i}$ e $x_{h}$

D: $\quad$ Matriz de dissimilaridade

$d^{i}$ : $\quad$ Dissimilaridade entre os grupos a serem aglomerados no $i$-ésimo

nível da hierarquia de um algoritmo hierárquico 
$\mathbf{d}_{i}$ :

$d\left(\mathbf{x}_{i}, \mathbf{x}_{j}\right)$ :

$d\left(\mathbf{x}_{i}(z), \mathbf{x}_{j}(z)\right):$

$d\left(C_{j}, C_{y}\right):$

$\delta_{z}\left(\mathbf{x}_{i}, \mathbf{x}_{j}\right):$

$\delta\left(C_{i}, C_{j}\right)$ :

$\Delta_{i}$ :

$f(\cdot)$ :

fit:

$g$ :

$g_{\max }$ :

g:

$\mathbf{g}[i]$ :

$G_{l, g}$ :

$k$ :

$k_{i}$ :

$k^{*}$ :

$k_{\text {max }}$ :

$\hat{k}_{\text {max }}$ :

$k_{\text {min }}$ :

$k_{\text {temp }}$ :

inter:

$l i_{f}:$

$l i_{z}$ :

$l s_{z}$ :

$\mathbf{m}_{i}$ :

M:

$\mathbf{M}^{(z)}$ :

$M C_{i}$ :

mc $_{i}$ :

$m k$ :

$M \pi$ :

$M O_{1}$ :

$\mathrm{MO}_{2}$ :

$\mathrm{MOA}_{2}$ :

$M X$ :
Vetor com as frequências dos termos do $i$-ésimo documento

Função de distância ou dissimilaridade entre $\mathbf{x}_{i}$ e $\mathbf{x}_{j}$

Contribuição do z-ésimo atributo para a dissimilaridade entre

$\mathbf{x}_{i}$ e $\mathbf{x}_{j}$

Dissimilaridade entre o $j$-ésimo e o $y$-ésimo grupo

Índice de discordância do atributo $z$ entre os objetos $\mathbf{x}_{i}$ e $\mathbf{x}_{j}$

Índice de discordância entre os grupos $C_{i}$ e $C_{j}$

Diferença para efetuar a aglomeração de grupos na $i$-ésima iteração

Função de aptidão

Vetor com aptidão do genótipo e aptidão de seus grupos

Geração atual

Número máximo de gerações

Genótipo

Genótipo do $i$-ésimo nó de dados

Conjunto de genótipos da geração $g$ que foram mutados pelo

operador $M O_{l}$

Número de grupos

Número de grupos do $i$-ésimo cenário

Número de grupos a ser estimado ou conhecido

Valor máximo permitido para o número de grupos

Número máximo de grupos codificado por um genótipo durante a

busca evolutiva

Valor mínimo permitido para o número de grupos

Número de grupos formados pelo algoritmo até determinado ponto

Número de vezes que o algoritmo $k$-médias é aplicado

Frequência de grams para o limite inferior do corte de Luhn

Limite inferior do z-ésimo atributo

Limite superior do z-ésimo atributo

Medóide do $i$-ésimo grupo

Matriz de co-associação

Matriz de associação da z-ésima partição

i-ésimo meta-grupo

meta-centróide do i-ésimo meta-grupo

Número de meta-grupos

Meta-partição

Operador de mutação 1

Operador de mutação 2

Operador de mutação alternativo 2

Coleção de centróides resultante da primeira etapa dos algoritmos $C A D$ 


\begin{tabular}{|c|c|}
\hline$n_{a}:$ & Número de atributos \\
\hline$n_{a}^{\{i j\}}:$ & $\begin{array}{l}\text { Número de atributos com valor i para o primeiro objeto e valor j } \\
\text { para o segundo }\end{array}$ \\
\hline$n_{c}:$ & Número de cenários \\
\hline$n_{\mathbf{c}}:$ & Número de centróides \\
\hline $\mathbf{n}_{C}:$ & Vetor que contém o número de objetos de cada grupo da partição \\
\hline $\mathbf{n}_{C}[i]:$ & $\begin{array}{l}\text { Vetor com o número de objetos em cada grupo no } i \text {-ésimo } \\
\text { nó de dados }\end{array}$ \\
\hline$n_{d}\left(t_{j}\right):$ & Número de documentos nos quais o $j$-ésimo termo está contido \\
\hline$n_{d n}:$ & Número de nós de dados (data nodes) ou subconjuntos de dados \\
\hline$n_{g}:$ & Número de gerações \\
\hline$n_{m}:$ & Número de genótipos mutados \\
\hline$n_{o}:$ & Número de objetos no conjunto de dados \\
\hline$n_{o, \max }:$ & Maior número de objetos contido em um nó de dados \\
\hline$n_{o}[i]:$ & Número de objetos no subconjunto contido no $i$-ésimo nó de dados \\
\hline$n_{o s}:$ & Número de objetos selecionados \\
\hline$n_{\pi}:$ & Número de partições \\
\hline$n_{\pi, k}:$ & Número de partições para cada número de grupos $k$ \\
\hline$n_{\pi, s}:$ & Número de partições base selecionadas \\
\hline$n_{v}:$ & Número de vizinhos mais próximos a serem considerados no cálculo \\
\hline nodeI $D$ : & Número identificador do nó de dados \\
\hline$n p:$ & Número de pares de objetos \\
\hline$n q:$ & Número de quádruplas de objetos \\
\hline$p_{C_{i}}:$ & Proporção de objetos do $i$-ésimo grupo em relação a base de dados \\
\hline$p_{C_{i}}[j]:$ & $\begin{array}{l}\text { Proporção de objetos do } i \text {-ésimo grupo em relação ao subconjunto } \\
\text { de dados contido no } j \text {-ésimo nó de dados }\end{array}$ \\
\hline$P_{g}:$ & População da $g$-ésima geração \\
\hline p: & Protótipo \\
\hline $\mathbf{p}_{i}$ : & Protótipo do $i$-ésimo grupo \\
\hline$p p_{i j}$ : & $\begin{array}{l}\text { Proporção de vezes em que o par composto pelo } i \text {-ésimo e o } \\
j \text {-ésimo objetos estão inseridos no mesmo grupo }\end{array}$ \\
\hline$\phi\left(\mathbf{x}_{i}, \mathbf{x}_{j}\right)$ & Correlação entre os objetos $\mathbf{x}_{i}$ e $\mathbf{x}_{j}$ \\
\hline$\pi:$ & Partição \\
\hline$\pi_{i}:$ & $i$-ésima partição do conjunto $\Pi$ \\
\hline$\pi_{r}:$ & Partição resultante \\
\hline$\pi_{g}:$ & Partição referência ou "gold standard" \\
\hline$\pi_{f}:$ & Partição consenso ou final \\
\hline$\Pi:$ & Conjunto de partições \\
\hline$\Pi_{b}:$ & Conjunto de partições base \\
\hline
\end{tabular}




\begin{tabular}{|c|c|}
\hline$\Pi_{t}:$ & Conjunto total de partições base \\
\hline$\Pi_{s}:$ & Conjunto seleção de partições base \\
\hline$\rho:$ & Parâmetro utilizado pelas métricas de Minkowski \\
\hline$\varepsilon$ : & Limiar utilizado por um critério de parada do algoritmo $k$-médias \\
\hline $\mathbf{v}_{\mathbf{d}}:$ & Índice com os rótulos dos grupos da partição $\mathbf{g}_{d}^{\prime}$ \\
\hline$v_{V C}:$ & Valor retornado pelo índice de validação para uma partição \\
\hline$v_{V C}^{*}:$ & $\begin{array}{l}\text { Maior valor de validação encontrado durante a execução do } \\
\text { algoritmo }\end{array}$ \\
\hline$v_{\min }:$ & Menor valor possível para índice de validação escolhido \\
\hline$v_{R}:$ & Valor de referência do índice de validação \\
\hline r: & Vetor de números aleatórios \\
\hline S: & Matriz de similaridade \\
\hline$s\left(\mathbf{x}_{i}, \mathbf{x}_{j}\right):$ & Função de similaridade entre $\mathbf{x}_{i}$ e $\mathbf{x}_{j}$ \\
\hline $\mathbf{s}_{C_{j}}:$ & Soma dos objetos do grupo $C_{j}$ \\
\hline $\mathbf{s}_{C_{j}}[i]:$ & Soma dos objetos do grupo $C_{j}$ no $i$-ésimo nó de dados \\
\hline $\mathbf{s}_{\text {fit }}:$ & Vetor com as somas das silhuetas dos objetos para cada grupo \\
\hline $\mathbf{s}_{\text {fit }}[i]:$ & $\begin{array}{l}\text { Vetor com as somas das silhuetas dos objetos no } i \text {-ésimo nó } \\
\text { de dados para cada grupo }\end{array}$ \\
\hline $\mathrm{S}_{\mathrm{C}}$ & Critério de parada \\
\hline$S C_{i}$ : & $i$-ésimo sub-grupo \\
\hline sum $_{d}$ : & $\begin{array}{l}\text { Soma das dissimilaridades entre os objetos e os protótipos mais } \\
\text { próximos }\end{array}$ \\
\hline $\operatorname{suml}_{i}$ : & Soma linear dos objetos do $i$-ésimo sub-grupo \\
\hline sums $_{i}$ : & Soma quadrática dos objetos do $i$-ésimo sub-grupo \\
\hline$t:$ & Número máximo de iterações executadas pelo algoritmo \\
\hline w: & Vetor de pesos \\
\hline $\mathbf{x}:$ & Objeto do conjunto de dados \\
\hline$\overline{\mathbf{x}}$ : & Média de todos os objetos do conjunto $X$ \\
\hline $\mathbf{x}_{j}$ : & j-ésimo objeto do conjunto de dados \\
\hline $\mathbf{x}_{j}(z)$ & $z$-ésimo atributo do objeto $\mathbf{x}_{j}$ \\
\hline $\mathbf{x}[l]$ & Objeto do l-ésimo nó de dados \\
\hline $\mathbf{x}_{j}[l]$ & $j$-ésimo objeto do l-ésimo nó de dados \\
\hline $\mathbf{x}_{i j}$ : & $j$-ésimo objeto do $i$-ésimo grupo \\
\hline$\overline{\mathbf{x}}_{j}$ : & Média entre os valores dos atributos do objeto $\mathbf{x}_{j}$ \\
\hline$X:$ & Conjunto de dados \\
\hline$\hat{z}:$ & $\begin{array}{l}\text { A maior quantidade de grupos eliminados em uma partição } \\
\text { pelos operadores de mutação }\end{array}$ \\
\hline
\end{tabular}




\section{Lista de Figuras}

2.1 Etapas do processo de agrupamento . . . . . . . . . . . . . . . . . 9

2.2 (a) Curva de Zipf; (b) Corte de Luhn; (Adaptada de Matsubara et al. (2003)) 16

2.3 Exemplo de dendrograma . . . . . . . . . . . . . . . . . 26

3.1 Visão geral de um Algoritmo Evolutivo. . . . . . . . . . . . . . . . . . . . . 44

3.2 Partição $\pi_{d}$ formada a partir da base de dados didática (Tabela 3.1). . . 46

3.3 Representação por vetor binário e matriz de elementos binários. . . . . . . 47

3.4 Representações inteiras baseadas em rótulos e medóides. . . . . . . . . . . 48

3.5 Representações reais baseadas em protótipos. . . . . . . . . . . . . . . . . . 49

3.6 Cruzamento simples entre progenitores iguais gerando descendentes distintos. 49

3.7 Cruzamento simples entre progenitores renumerados gerando descendente inválido. . . . . . . . . . . . . . . . . . . 50 50

3.8 Cruzamento simples sob codificação real gerando descendentes inválidos. 50

3.9 Cruzamento simples insensível ao contexto dividindo os atributos de um dos protótipos dos progenitores. . . . . . . . . . . . . . . 52

3.10 Exemplo de genótipo que representa regras. . . . . . . . . . . . . . 55

3.11 Exemplo do esquema de codificação do F-EAC . . . . . . . . . . . . . . 63

3.12 Silhueta simplificada da partição $\pi_{d}$ (Tabela 3.1) e de cada um de seus grupos. 64

4.1 Exemplo de matriz de dissimilaridade D. . . . . . . . . . . . . . 76

4.2 Conjunto de dados Gauss9. . . . . . . . . . . . . . . . . . . 79

4.3 Conjunto de dados Spherical_4_3. . . . . . . . . . . . . . . . . 80

4.4 Valores para os índices silhueta simplificada e Jaccard para cortes de Luhn distintos. . . . . . . . . . . . . . . . . . . 84

4.5 Projeções bi-dimensionais do conjunto de dados ARTICLES depois de seu pré-processamento para os cortes de Luhn escolhidos. . . . . . . . . . 85

4.6 Histogramas típicos do tempo computacional (em segundos). . . . . . . . . 87 
4.7 Resultados obtidos pelo teste Wilcoxon/Mann-Whitney com $\alpha=5 \%$ para Gauss9 (OMRk contra F-EAC). $\triangle-F-E A C$ é estatísticamente mais rápido do que $O M R k ; \nabla-F-E A C$ é estatísticamente mais lento que OMRk; $\bigcirc$ — não há evidência estatística de diferença. . . . . . . . . . . . 87

4.8 Resultados obtidos do teste Wilcoxon/Mann-Whitney com $\alpha=5 \%$ para Spherical_4_3 $(O M R k$ contra F-EAC). $\triangle-F$-EAC é estatísticamente mais rápido do que $O M R k ; \nabla-F-E A C$ é estatísticamente mais lento que OMRk; $\bigcirc$ — não há evidência estatística de diferença. . . . . . . . . . . .

4.9 Resultados obtidos do teste Wilcoxon/Mann-Whitney com $\alpha=5 \%$ para ARTICLES-1442-5 (OMRk contra F-EAC).F-EAC). $\triangle-F$-EAC é estatísticamente mais rápido do que $O M R k ; \nabla-F$-EAC é estatísticamente mais lento que $O M R k ; \bigcirc$ - não há evidência estatística de diferença. . . .

4.10 Resultados obtidos do teste Wilcoxon/Mann-Whitney com $\alpha=5 \%$ para ARTICLES-1442-80 (OMRk contra F-EAC). $\triangle-F$-EAC é estatísticamente mais rápido do que $O M R k ; \nabla-F$-EAC é estatísticamente mais lento que $O M R k ; \bigcirc$ — não há evidência estatística de diferença. . . . . . . 91

5.1 Exemplo de hipergrafo gerado pelas partições $\pi_{1}, \pi_{2}, \pi_{3}$ e $\pi_{4} \ldots \ldots$. . . 115

5.2 Exemplo de metagrafo para as partições $\pi_{1}, \pi_{2}, \pi_{3}$ e $\pi_{4} \ldots \ldots 117$

6.1 Partições escolhidas pelos índices PBM e silhueta simplificada para a base de dados 2d-40c-no3. . . . . . . . . . . . . . . . . . . 133

6.2 Valores médios obtidos pelos índices estudados para partições de bases do conjunto Artificial1. . . . . . . . . . . . . . . . . . . . . . . . . . . . . . . 135

6.3 Valores médios obtidos pelos índices estudados para partições de bases do conjunto Artificial2. . . . . . . . . . . . . . . . . . . . 136

6.4 Valores médios obtidos pelos índices estudados para partições de bases do conjunto Artificials. . . . . . . . . . . . . . . . . . . . . . . . . . . . . . 137

6.5 Valores médios de Jaccard para combinações de partições geradas a partir de $C A A$ e $C A S \ldots \ldots \ldots$. . . . . . . . . . . . . . . . . . . 140

6.6 Valores médios de Jaccard para combinações de partições geradas a partir de $C S P A$ e $H G P A . \quad \ldots \ldots \ldots$

6.7 Valores médios de Jaccard para combinações de partições geradas a partir de $M C L A$. . . . . . . . . . . . . . . . . . . . . . . . . . . . . . . . . . . . . 142

6.8 Partições consenso geradas pelas funções de consenso $M C L A$ e $H G P A$ para diferentes tamanhos de conjunto seleção. . . . . . . . . . . . . . . . . . . . 144

6.9 Valores médios de Jaccard para combinações de partições geradas por meio de $C A A$ e $C A S \ldots \ldots \ldots \ldots$. . . . . . . . . . . . . . . . . . . . . . . . . . .

6.10 Valores médios de Jaccard para combinações de partições geradas por meio de $C S P A$ e $H G P A$. 
6.11 Valores médios de Jaccard para combinações de partições geradas por meio de MCLA . . . . . . . . . . . . . . . . . . . . . . . 153

6.12 Arcabouço proposto para melhor utilização de métodos de CES. . . . . . . 156

6.13 Ilustração da aplicação do método MA . . . . . . . . . . . . . . . . . . . . 160

7.1 Exemplo de algoritmo de DDM. . . . . . . . . . . . . . . . . . . . . 169

7.2 Exemplo da estrutura do DF-EAC . . . . . . . . . . . . . . . . . . . . 172

7.3 Exemplo das estruturas de dados do DF-EAC . . . . . . . . . . . . . . 173

7.4 Visão global da busca local distribuída. . . . . . . . . . . . . . . . 176

7.5 Topologia de comunicação entre nós. . . . . . . . . . . . . . . . . . . . 178

7.6 Etapas e topologia de comunicação entre nós dos algoritmos CAD. . . . . . 182

7.7 Exemplos para o cálculo de meta-centróides: (a) partição exemplo, (b) centróides, (c) meta-centróide calculado pela média dos centróides e (d) meta-centróide calculado pela média ponderada dos centróides. . . . . . . . 185

7.8 Exemplo de base de dados e centróides obtidos a partir da primeira etapa dos algoritmos CAD para distribuições em 80, 20 e 5 nós. . . . . . . . . . . 197

7.9 Histogramas com o número de centróides obtidos na primeira etapa dos algoritmos CAD com avaliação por silhueta simplificada e $V R C$, para cada execução do algoritmo e distribuição das bases em 80 nós de dados. ... . 204 


\section{Lista de Tabelas}

2.1 Exemplo de representação de conjunto de dados. . . . . . . . . . . . . . . . . 12

2.2 Parte de uma matriz de expressão de genes. . . . . . . . . . . . . . . . . . 13

2.3 Representação bag-of-words de documentos. . . . . . . . . . . . . . . . . 14

2.4 Exemplo de stopwords para a língua inglesa. . . . . . . . . . . . . . . . 15

2.5 Complexidade assintótica dos algoritmos apresentados. . . . . . . . . . . . 42

3.1 Conjunto didático de dados. . . . . . . . . . . . . . . . . . . . 46

4.1 Medidas de complexidade para as estruturas do F-EAC. . . . . . . . . . 75

4.2 Tempo computacional em segundos para as implementações do F-EAC: média e desvio padrão sobre 50 execuções. . . . . . . . . . . . . . . . . 80

4.3 Corpus do conjunto de dados ARTICLES. . . . . . . . . . . . 83

4.4 Tempo computacional do OMRk em segundos $\left(k_{\max }=n_{o}^{1 / 2}=30\right)$ para Gauss9: $\mu$ e $\sigma$ são a média e o desvio padrão sobre as 50 execuções, respectivamente. . . . . . . . . . . . . . . 86

4.5 Resultados do F-EAC para Gauss9: média (desvio padrão) sobre 50 execuções. . . . . . . . . . . . . . . . . . . . . 86

4.6 Tempo computacional do OMRk em segundos $\left(k_{\max }=n_{o}^{1 / 2}=20\right)$ para Spherical_4_3: $\mu$ e $\sigma$ são a média e o desvio padrão sobre as 50 execuções, respectivamente. ..................... 88

4.7 Resultados do F-EAC para Spherical_4_3: média (desvio padrão) sobre 50 execuções. . . . . . . . . . . . . . . . . . . . . . . . . 88

4.8 Tempo computacional do $O M R k$ em segundos $\left(k_{\max }=16 \simeq n_{o}^{1 / 2}\right)$ para ARTICLE-1442-5: $\mu$ e $\sigma$ são a média e o desvio padrão sobre as 50 execuções, respectivamente. . . . . . . . . . . . . . . . . . . 90

4.9 Resultados do F-EAC para ARTICLE-1442-5: média (desvio padrão) sobre 50 execuções. . . . . . . . . . . . . . . . . . . . . . 90

4.10 Tempo computacional do OMRk em segundos $\left(k_{\max }=16 \simeq n_{o}^{1 / 2}\right)$ para ARTICLES-1442-80: $\mu$ e $\sigma$ são a média e o desvio padrão sobre as 50 execuções, respectivamente. 
4.11 Resultados do F-EAC para ARTICLES-1442-80: média (desvio padrão) sobre 50 execuções. . . . . . . . . . . . . . . . . . . . . . . . . . . 91

4.12 Médias dos valores de Jaccard obtidos pelos algoritmos comparados. . . . . 97

4.13 Diferença estatística entre as médias dos ranks dos valores de Jaccard obtidos pelos algoritmos sob investigação. . . . . . . . . . . . . . . . 98

4.14 Médias dos tempos de execução obtidos pelos algoritmos comparados. . . . 99

4.15 Diferença estatística entre as médias dos ranks dos tempos de execução dos algoritmos comparados. . . . . . . . . . . . . . . . . 100

5.1 Exemplo de partições. . . . . . . . . . . . . . . . . . . . . 109

5.2 Exemplo de matrizes de co-associação para as partições apresentadas na Tabela 5.1. . . . . . . . . . . . . . . . . . . . . . . . . . 109

5.3 Exemplo de matriz de co-associação consenso . . . . . . . . . . . . . . . . 110

5.4 Problema ilustrativo de combinação das partições $\pi_{1}, \pi_{2}, \pi_{3}$ e $\pi_{4}$ : vetores representando as partições originais à esquerda e o hipergrafo equivalente com 11 hiperarestas à direita (exemplo adaptado de Strehl \& Ghosh (2002b)).115

5.5 Exemplo do MCLA - metahiperarestas e vetores de associação . . . . . . . 117

6.1 Características dos conjuntos de dados reais utilizados. . . . . . . . . . 129

6.2 Média e desvio padrão das correlações entre os valores dos índices de validação relativos e do índice Jaccard sobre os conjuntos de dados artificiais estudados. . . . . . . . . . . . . . . . . . . . . . . . . . 132

6.3 Média e desvio padrão dos valores do índice de Jaccard obtidos pelas partições melhor avaliadas pelos índices de validação para cada conjunto artificial.138

6.4 Médias das similaridades entre os conjuntos seleção gerados por meio dos índices estudados para o Artificial1. . . . . . . . . . . . . . . . . 147

6.5 Médias das similaridades entre os conjuntos seleção gerados por meio dos índices estudados para o Artificial2. . . . . . . . . . . . . . . . 147

6.6 Médias das similaridades entre os conjuntos seleção gerados por meio dos índices estudados para o Artificials. . . . . . . . . . . . . . . . . . . 147

6.7 Médias das similaridades entre os conjuntos seleção formados por meio das CIR e de cada índice de validação individualmente para o conjunto Artificial1.149

6.8 Médias das similaridades entre os conjuntos seleção formados por meio das CIR e de cada índice de validação individualmente para o conjunto Artificial2.149

6.9 Médias das similaridades entre os conjuntos seleção formados por meio das CIR e de cada índice de validação individualmente para o conjunto Artificial3.149

6.10 Características das funções de consenso estudadas. . . . . . . . . . . . 155

6.11 Correlações entre os valores dos índices de validação relativos e do índice Jaccard sobre os conjuntos de dados reais estudados. . . . . . . . . . . . 158

6.12 Médias e desvios padrões dos valores do índice Jaccard para combinações resultantes da função CAA . . . . . . . . . . . . . . . . . . . 160 
6.13 Médias e desvios padrões dos valores do índice Jaccard para combinações resultantes da função CAS . . . . . . . . . . . . . . . . . . . . . . . . . . 161

6.14 Médias e desvios padrões dos valores do índice Jaccard para combinações resultantes da função CSPA. . . . . . . . . . . . . . . . . . . . . . . . . 162

6.15 Médias e desvios padrões dos valores do índice Jaccard para combinações resultantes da função HGPA . . . . . . . . . . . . . . . . . . . 162

6.16 Médias e desvios padrões dos valores do índice Jaccard para combinações resultantes da função MCLA . . . . . . . . . . . . . . . . . . . . . 163

7.1 Valores médios e desvios padrões obtidos pelos algoritmos comparados, para o conjunto Artificial2 distribuído em 5 nós de dados.

7.2 Velocidade de transferência $(K B / s)$ necessária para que o algoritmo indicado pela linha possa ter um melhor desempenho do que o algoritmo indicado pela coluna, em média, para o conjunto Artificial2 distribuído em 5 nós de dados.

7.3 Valores médios e desvios padrões obtidos pelos algoritmos comparados, para o conjunto Artificial2 distribuído em 20 nós de dados. . . . . . . . . . . . . 198

7.4 Velocidade de transferência $(K B / s)$ necessária para que o algoritmo indicado pela linha possa ter um melhor desempenho do que o algoritmo indicado pela coluna, em média, para o conjunto Artificial2 distribuído em

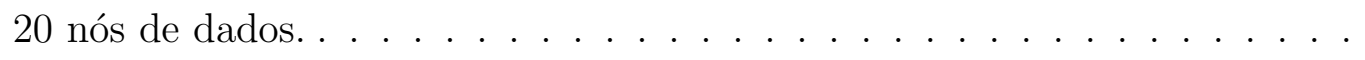

7.5 Valores médios e desvios padrões obtidos pelos algoritmos comparados, para o conjunto Artificial2 distribuído em 80 nós de dados. . . . . . . . . . . . . 200

7.6 Velocidade de transferência $(K B / s)$ necessária para que o algoritmo indicado pela linha possa ter um melhor desempenho do que o algoritmo indicado pela coluna, para o conjunto Artificial2 distribuído em 80 nós de dados.

7.7 Valores médios e desvios padrões obtidos pelos algoritmos comparados, para o conjunto Artificial2 distribuído em 5 nós de dados.

7.8 Velocidade de transferência $(K B / s)$ necessária para que o algoritmo indicado pela linha possa ter um melhor desempenho do que o algoritmo indicado pela coluna, em média, para o conjunto Artificial2 distribuído em 5 nós de dados

7.9 Valores médios e desvios padrões obtidos pelos algoritmos comparados, para o conjunto Artificial2 distribuído em 20 nós de dados. . . . . . . . . . . . . 203

7.10 Velocidade de transferência $(K B / s)$ necessária para que o algoritmo indicado pela linha possa ter um melhor desempenho do que o algoritmo indicado pela coluna, em média, para o conjunto Artificial2 distribuído em 20 nós de dados.

7.11 Valores médios e desvios padrões obtidos pelos algoritmos comparados, para o conjunto Artificial2 distribuído em 80 nós de dados. . . . . . . . . . . . . 205 
7.12 Velocidade de transferência $(K B / s)$ necessária para que o algoritmo indicado pela linha possa ter um melhor desempenho do que o algoritmo indicado pela coluna, em média, para o conjunto Artificial2 distribuído em 80 nós de dados. . . . . . . . . . . . . . . . . . . . . . . . 206

8.1 Valor médio e desvio padrão de Jaccard para partições consenso geradas a partir do conjunto Artificial2. . . . . . . . . . . . . . . . . . . . . . . 214

8.2 Valor médio e desvio padrão de Jaccard para partições consenso geradas a partir do conjunto Artificials. . . . . . . . . . . . . . . . . . . . . . . . 214

8.3 Média e desvio padrão sobre os números de gerações obtidos com 2 operadores comparados. . . . . . . . . . . . . . . . . . . . 218 


\section{Lista de Abreviaturas}

AEs: $\quad$ Algoritmos Evolutivos

ANOVA: $\quad$ ANalysis OF VAriance

ANMI: $\quad$ Average Normalized Mutual Information

AR: $\quad$ Ajusted Rand

ASWC: Average Silhouette Width Criterion

AUC: $\quad$ Area Under Curve

BGSS: Between-Groups Sum of Squares

BIC: Bayesian Information Criterion

BIRCH: Balanced Iterative Reducing and Clustering using Hierarchies

BLS: $\quad$ Busca Local eStocástica

CAA: Co-Association with Average-link

CAD: $\quad$ Combinações de Agrupamentos Distribuídos

CAS: Co-Association with Single-link

CES: Cluster Ensemble Selection

CLARA: $\quad$ Clustering LARge Applications

CLARANS: Clustering LARge Applications based on Randomized Search

CLICK: $\quad$ CLuster Identification via Connectivity Kernels

CIR: Combinação de Índices Relativos

CSPA: Cluster-based Similarity Partitioning Algorithm

CURE: Clustering Using Representatives

$D B$ : Índice Davies-Bouldin

DBSCAN: Density Based Spatial Clustering of Applications with Noise 


\begin{tabular}{|c|c|}
\hline$D-E A C:$ & Distributed Evolutionary Algorithm for Clustering \\
\hline$D F-E A C:$ & Distributed Fast Evolutionary Algorithm for Clustering \\
\hline$D D M:$ & Distributed Data Mining \\
\hline$E A C:$ & Evolutionary Algorithm for Clustering \\
\hline$E M:$ & Expectation Maximization \\
\hline$F-E A C:$ & Fast Evolutionary Algorithm for Clustering \\
\hline$G K:$ & Índice Goodman-Kruskal \\
\hline GO: & Gene Ontolgology \\
\hline$H B G F:$ & Hybrid Bipartite Graph Formulation \\
\hline$H G P A:$ & HiperGraph-Partitioning Algorithm \\
\hline$K L:$ & Kullback-Leibler \\
\hline$L A N:$ & Local Area Network \\
\hline$M A N$ : & Metropolitan Area Network \\
\hline$M C L A:$ & Meta-CLustering Algorithm \\
\hline METIS: & Unstructured Graph Partitioning and Sparse Matrix Ordering System \\
\hline MI: & Média dos Índices relativos \\
\hline MOCK: & Multi-Objective Clustering with automatic $k$-determination \\
\hline MOCLE: & Multi-Objective Clustering Ensemble \\
\hline MA: & Melhor Avaliado \\
\hline MP: & Melhor Posição \\
\hline$M S T:$ & Mininum Spanning Tree \\
\hline$M R k:$ & Multiple Runs of k-means \\
\hline MRI: & Maior Resultado dos Índices relativos \\
\hline$N M I:$ & Normalized Mutual Information \\
\hline$N S G A-I I$ : & Nondominated Sorting Genetic Algorithm \\
\hline OMRk: & Ordered Multiple Runs of k-means \\
\hline$P D M:$ & Parallel Data Mining \\
\hline$P A M:$ & Partitioning Around Medoids \\
\hline PESA: & Pareto Envelope based Selection Algorithm \\
\hline PEx: & Projection Explorer \\
\hline$S N M I$ & Sum of Normalized Mutual Information \\
\hline SD: & Soma com Diversidade \\
\hline SR: & Soma dos Ranks \\
\hline SPEA: & Strength Pareto Evolutionary Algorithm \\
\hline TIDIA: & Tecnologia da Informação no Desenvolvimento da Internet Avançada \\
\hline$V A C:$ & Voting Active Clusters \\
\hline VIENNA: & Voronoi Initialized Evolutionary Nearest-Neighbor Algorithm \\
\hline$V R C:$ & Variance Ratio Criterion \\
\hline$W A N:$ & Wide Area Network \\
\hline$W G S S:$ & Within-Group Sum of Squares \\
\hline
\end{tabular}




\section{Lista de Algoritmos}

1 Algoritmo $k$-médias . . . . . . . . . . . . . . . . . . 30

2 Algoritmo $(O M R k) \ldots \ldots \ldots \ldots \ldots \ldots \ldots$

3 Multiplas Execuções de $k$-médias $(M R k) \ldots \ldots \ldots$. . . . . . . . . 32

4 Fast Evolutionary Algorithm for Clustering (F-EAC). . . . . . . . . . . 61

5 Operador de Mutação $1\left(M O_{1}\right) \ldots \ldots \ldots$. . . . . . . . . . . 64

6 Operador de Mutação $2\left(M O_{2}\right) \ldots \ldots \ldots$. . . . . . . . . . 65

7 Cálculo de centróides com distorção dos dados. . . . . . . . . . . . . . . . . 177

8 Operador Alternativo de Mutação $2\left(M O A_{2}\right)$. . . . . . . . . . . . 217 


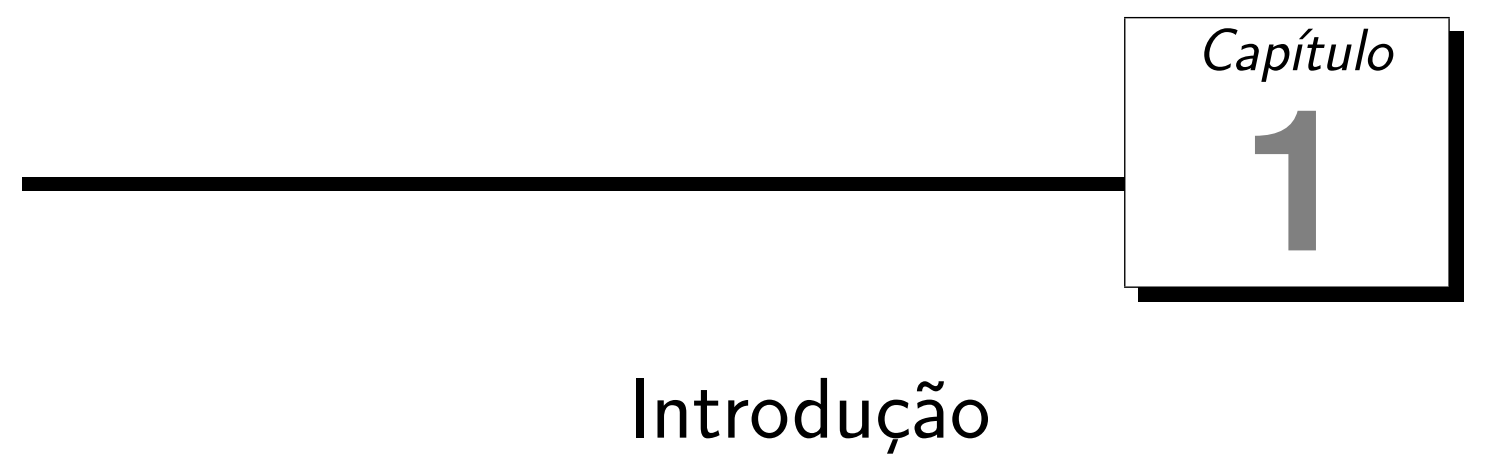

\subsection{Motivação}

Técnicas de agrupamento de dados consistem na classificação não supervisionada de objetos (padrões, observações, instâncias, exemplos, itens de dados ou vetores de características) em grupos, sem a necessidade de conhecimento prévio sobre as suas classes ou categorias (Jain \& Dubes, 1988). Também conhecidas como clustering ou categorização, essas técnicas têm como objetivo obter grupos que apresentem padrões semelhantes e que possam refletir a forma como os dados são estruturados. O aprendizado não supervisionado é vantajoso para o estudo de problemas em várias áreas do conhecimento, em especial para a solução de problemas que estão em estágios iniciais, com pouco ou nenhum conhecimento prévio sobre as possíveis classes existentes nos dados. Dentre as áreas em que estes algoritmos foram aplicados com sucesso, podem ser citadas: segmentação de mercados (Bigus, 1996; Heilman \& Bowman, 2002; Bhatnagar \& Ghose, 2004; Kim \& Ahn, 2004), bioinformática (Baldi \& Brunak, 1998; Golub et al., 1999; Pan, 2002; Sharan et al., 2002; Molla et al., 2004; Lu et al., 2004a; Gesú et al., 2005; Lin \& Chien, 2009); mineração de textos (Larsen \& Aone, 1999; Feldman \& Sanger, 2006; Saraçoğlu et al., 2007; Hammouda \& Kamel, 2009); detecção de intrusão (Liu et al., 2004; Ma, 2005; Cabrera et al., 2008); processamento de imagens (Bandyopadhyay \& Maulik, 2002b; Pakhira et al., 2005); taxonomia (Sneath \& Sokal, 1973); computação distribuída (Dong et al., 2009; de Vega \& Cantú-Paz, 2010).

Diversos algoritmos de agrupamento foram apresentados na literatura (Mitchell, 1997; Jain et al., 1999; Everitt et al., 2001a; Xu \& Wunsch, 2005; Wu, 2009). De maneira intuitiva, um agrupamento é formado a partir de um princípio indutivo. Esse princípio indutivo, também conhecido como critério de agrupamento ou função-objetivo, consiste 
em uma forma de selecionar um modelo ou estrutura para representar o agrupamento que melhor se ajusta a um determinado conjunto de dados. A associação de uma funçãoobjetivo a um conjunto de dados gera um problema de otimização, a ser tratado pelo algoritmo de agrupamento.

O problema de agrupamento é um dos mais difíceis e desafiadores na área de aprendizado de máquina, devido à sua natureza não supervisionada. Isto implica a falta de conhecimento estrutural dos dados, exceto quando algum conhecimento do domínio está previamente disponível. Especificamente, a distribuição espacial dos dados em termos numéricos, volumes, densidades, formatos e orientação de grupos (se houver) é desconhecida (Fralley \& Raftery, 1998). Estas adversidades são agravadas pela necessidade de lidar com diferentes tipos de atributos, condições ou escalas (Jain \& Dubes, 1988; Jain et al., 1999). Encontrar um agrupamento ótimo, segundo um determinado critério, a partir da combinação de objetos em grupos pode ser intratável em aplicações práticas com grande número de objetos e de atributos (Falkenauer, 1998).

Tamanha complexidade estimulou a pesquisa por algoritmos eficientes de busca, incluindo heurísticas ad-hoc, aplicadas em casos particulares de classes ou instâncias de problemas, e meta-heurísticas ${ }^{1}$ (Rayward-Smith, 2005). Particularmente, algoritmos evolutivos (AEs) são meta-heurísticas amplamente conhecidas por serem efetivas para problemas de grande complexidade, aptas a obter soluções sub-ótimas em tempo computacional razoável. Sob esta ótica, um grande número de algoritmos evolutivos foi proposto na literatura para resolver problemas de agrupamento (Naldi et al., 2007; Hruschka et al., 2009). Estes algoritmos também são baseados em um tipo de função-objetivo, conhecida como função de aptidão, que guia a busca evolutiva. Esta função pode ou não estar relacionada com a função-objetivo de um algoritmo de agrupamento tradicional. O desenvolvimento e o uso eficiente de AEs em agrupamento de dados é um tópico importante dentro do escopo maior da presente tese de doutorado, descrito a seguir.

Muitos algoritmos podem gerar diferentes resultados para um mesmo conjunto de dados. Dentre os motivos para tal, podem ser considerados, por exemplo, o uso de funções objetivo distintas, inicializações distintas, ou diferentes valores para os parâmetros livres de configuração. Além disso, existem diversos algoritmos diferentes que podem ser aplicados a um mesmo conjunto de dados. Esta diversidade gera a seguinte questão: Qual agrupamento é o mais apropriado? Apesar de um agrupamento poder ser escolhido como "melhor" segundo algum critério, este não seria absolutamente melhor do que os outros, pois diferentes agrupamentos são corretos para propósitos distintos (Hartigan, 1985) e existem diferentes critérios de avaliação.

Uma alternativa a escolher o agrupamento mais apropriado consiste em combinar um conjunto de agrupamentos, oriundos de um mesmo algoritmo ou não, em comitês (Kuncheva, 2004). A combinação de agrupamentos objetiva gerar, a partir de relações comuns entre objetos, um agrupamento final ou consenso que agregue maior evidência sobre o con-

\footnotetext{
${ }^{1}$ Meta-heurísticas são heurísticas de propósito geral que visam aprimorar uma solução candidata por meio de alguma medida de qualidade, podendo ser aplicadas sobre outras heurísticas.
} 
junto de dados do que os agrupamentos originais individualmente (Fred \& Jain, 2002a). A combinação de agrupamentos pode possuir vários propósitos, como robustez a variações do cenário de aplicação (Fred \& Jain, 2005), estabilidade dos resultados obtidos em um mesmo cenário (Strehl \& Ghosh, 2002b), consistência em relação ao resultado esperado (Dimitriadou et al., 1999a), além de aumento de desempenho (Topchy et al., 2003) e computação distribuída (Topchy et al., 2004). Vários métodos de combinação de agrupamentos foram propostos na literatura e comparados entre si (Fred \& Jain, 2005; Kuncheva et al., 2006), mas os resultados publicados mostram que não há uma combinação em particular que obtenha resultados satisfatórios para todos os tipos de dados (Hadjitodorov \& Kuncheva, 2007). Uma das contribuições desta tese é um estudo detalhado das diferentes técnicas de combinação de agrupamento que permitiu identificar cenários de aplicação nos quais uma ou mais técnicas são potencialmente mais apropriadas que outras.

Da mesma forma que não é possível determinar o agrupamento ou combinação de agrupamentos mais apropriado para todos os cenários de aplicação, não há como determinar qual o melhor critério de validação de agrupamentos a ser utilizado para avaliar agrupamentos obtidos por diferentes algoritmos em conjuntos de dados de natureza distintas. Assim como é feito em combinações de agrupamentos, é possível combinar diferentes índices de validação em comitês, de forma a gerar uma avaliação mais robusta a variações do cenário de aplicação. A principal hipótese relativa à combinação de índices consiste em pesquisar se a maioria dos índices combinados pode compensar o fraco desempenho do restante, independentemente do cenário de aplicação. Adicionalmente, comitês de índices de validação podem ser utilizados para selecionar agrupamentos dentre os contidos em um conjunto, considerando diferentes formas para medir características esperadas em bons agrupamentos de dados, como coesão dos grupos e separabilidade entre eles. Utilizar esse tipo de seleção em métodos de combinação de agrupamentos constitui uma pesquisa inédita, que se insere diretamente no escopo desta tese.

Adicionalmente, devido ao crescente volume de dados a serem minerados, bom desempenho computacional, escabilidade e eficácia devem ser os principais objetivos de técnicas de agrupamento propostas para aplicações práticas. Em virtude desse crescimento, existe uma tendência cada vez maior de se distribuir grandes conjuntos de dados em sítios separados. Isso faz com que as técnicas de agrupamento desenvolvidas na atualidade também visem lidar com esse tipo de conjuntos de dados. Para esse tipo de problema, combinar informações oriundas de sítios distintos em um agrupamento que represente a estrutura de todo o conjunto de dados é uma solução atraente. A principal hipótese relacionada à essa pesquisa é que o uso desse tipo de combinação pode obter um agrupamento de consenso que seja próximo ou idêntico ao agrupamento resultante de técnicas equivalentes aplicadas sobre dados centralizados. Sendo assim, desenvolver algumas as técnicas investigadas para cenários com dados distribuídos e propor novos métodos que combinem agrupamentos obtidos em diferentes sítios em uma única solução final consiste em um dos objetivos principais desta tese. 


\subsection{Hipóteses relacionadas à pesquisa}

A partir da motivação apresentada na Seção 1.1, as seguintes hipóteses foram investigadas na pesquisa contemplada nesta tese:

- Devido à quantidade massiva de dados gerados na atualidade, tornam-se necessárias soluções eficientes e escaláveis em aplicações práticas. Adicionalmente, os grupos gerados devem ser facilmente interpretáveis.

- Por utilizarem informações sobre a qualidade dos agrupamentos gerados, algoritmos evolutivos podem ser mais eficientes do que algoritmos sistemáticos quando aplicados no agrupamento de dados.

- Ao combinar métodos, sejam eles algoritmos de agrupamento ou índices de validação, é esperado que o bom desempenho da maioria dos métodos combinados possa compensar o fraco desempenho do restante.

- A combinação de informações sobre os dados, quando obtidas de forma distribuída, pode gerar agrupamentos equivalentes ou próximos dos que seriam obtidos de forma centralizada.

\subsection{Organização do trabalho}

Esta tese está organizada em 8 capítulos, de forma que o conteúdo possa ser apresentado da maneira mais auto-contida possível. Este capítulo introduz as motivações, as hipóteses de pesquisa e as contribuições da tese, além da estrutura do documento.

O Capítulo 2 é composto de um levantamento teórico sobre técnicas de agrupamento de dados. Nele é feito uma descrição das principais etapas do processo de agrupamento, desde a preparação dos conjuntos de dados até a validação do agrupamento. Também é feita uma descrição sumarizada do processo de preparação de conjuntos de dados de expressão gênica e de textos, ambos de interesse para este trabalho. Esse capítulo inclui uma revisão sobre uma variedade de medidas, algoritmos de agrupamento e índices de validação frequentemente utilizados na literatura, abrangendo não só as técnicas utilizadas neste trabalho, mas também técnicas que possuem potencial para serem utilizadas ou comparadas com as propostas apresentadas aqui.

Um estudo sobre a utilização de algoritmos evolutivos (AEs) aplicados em problemas de agrupamento de dados é apresentado no Capítulo 3, baseado na divisão proposta por Hruschka et al. (2009) entre algoritmos que estimam o número de grupos da base de dados e algoritmos que não estimam. Esse capítulo serve como base teórica sobre AEs para o desenvolvimento de parte da tese. Nele também são apresentados detalhes sobre o algoritmo evolutivo de interesse para este trabalho, o $F$-EAC. 
No Capítulo 4, são discutidas questões de eficiência computacional envolvendo alguns dos algoritmos de agrupamento investigados e uma versão aprimorada do algoritmo $F$ EAC. Uma das contribuições deste trabalho consiste em comparar o desempenho desses algoritmos no âmbito teórico, por meio da complexidade assintótica dos algoritmos, e prático, por meio de experimentos envolvendo o tempo computacional e a qualidade dos resultados obtidos. Ao final do capítulo, uma extensão dessa contribuição é feita por meio da comparação de variantes do $F-E A C$ e um conjunto de algoritmos de propósito similar ao $F$-EAC, em termos da qualidade de agrupamento e desempenho computacional, por meio de um grande conjunto de bases de dados.

Os tópicos relacionados ao Capítulo 5 fazem referência a algoritmos de combinação de agrupamentos. Nesse capítulo, é feita uma revisão sobre alguns métodos utilizados para combinar agrupamentos propostos na literatura, incluindo formas de gerar a diversidade inicial necessária entre os agrupamentos a serem combinados. Em seguida, trabalhos publicados na literatura que comparam os métodos apresentados são analisados.

Uma das principais contribuições do trabalho é propor o uso de índices de validação na seleção de agrupamentos, individualmente ou combinados, quando a seleção é aplicada durante e após o processo de combinação de agrupamentos. Essa proposta é abordada no Capítulo 6, juntamente com experimentos originais que mostram o impacto da seleção baseada em índices de validação na qualidade de algoritmos de combinação de agrupamentos conhecidos na literatura, tanto por meio do uso individual destes índices quanto pelo uso combinado. A partir das conclusões resultantes da análise dos experimentos, um arcabouço foi concebido para guiar o uso da seleção de agrupamentos no processo de combinação.

A segunda contribuição principal deste trabalho consiste em estender algumas das técnicas de agrupamento investigadas e propor outras inéditas para encontrar soluções em problemas que envolvem conjuntos de dados distribuídos. Essa contribuição é detalhada no Capítulo 7. Dentre as técnicas propostas, são apresentadas variações de algoritmos que combinam agrupamentos de partes distribuídas do conjunto de dados em uma única solução final. Resultados obtidos por meio das técnicas propostas são comparados de acordo com diferentes parâmetros e variações de cenários de aplicação.

Por último, as conclusões obtidas durante o desenvolvimento da tese e possíveis temas para trabalhos futuros são apresentados no Capítulo 8. 


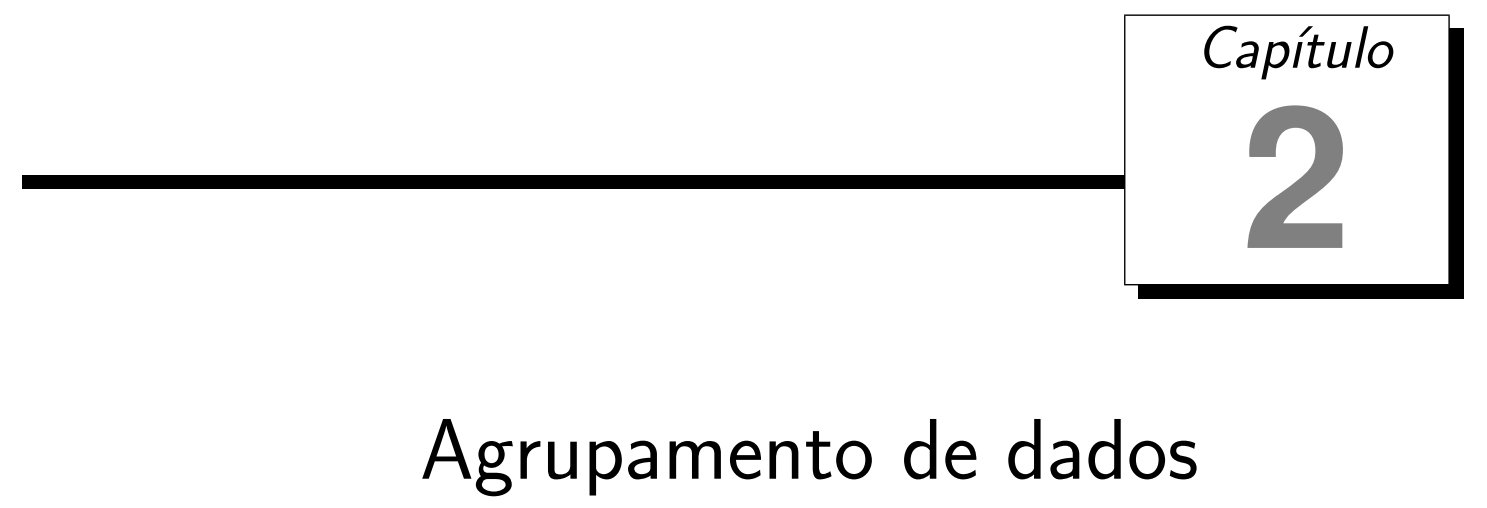

Como escrito anteriormente, técnicas de agrupamento são vantajosas para o estudo de problemas em várias áreas do conhecimento, em especial para a solução de problemas que estão em estágios iniciais, com pouco conhecimento prévio sobre as possíveis classes existentes nos dados. Essas técnicas são capazes de obter grupos de objetos semelhantes de maneira não supervisionada, ou seja, sem a necessidade de conhecimento prévio sobre suas classes ou categorias (Jain \& Dubes, 1988).

O principal objetivo deste capítulo é introduzir as etapas do processo de agrupamento, por meio da revisão de uma variedade de medidas, algoritmos de agrupamento e índices de validação frequentemente utilizados na literatura. A Seção 2.1 inicia-se com a apresentação de técnicas de seleção e preparação dos objetos para viabilizar ou melhorar o processo de agrupamento. Na Seção 2.2 são apresentados métodos de preparação de conjuntos de dados de expressão gênica e documentos textuais, áreas de aplicação de interesse para este trabalho. Em seguida, na Seção 2.3 são descritas algumas medidas de similaridade e dissimilaridade utilizadas para quantificar a relação entre objetos e grupos formados. Na Seção 2.4, é descrito sucintamente um conjunto de algoritmos de agrupamento bem conhecidos na literatura especializada. Dentre eles, estão presentes os algoritmos utilizados como a base da pesquisa deste projeto, além de técnicas que possuem potencial para serem utilizadas ou comparadas com as propostas apresentadas neste trabalho. Alguns índices de validação de agrupamentos são apresentados na Seção 2.5, que serão utilizados para aferir a qualidade de agrupamentos obtidos e, posteriormente, investigados de maneira combinada. As considerações finais deste capítulo são feitas na Seção 2.6. 


\subsection{Definição e aspectos principais}

Agrupamento é a classificação não-supervisionada de objetos ou padrões em grupos, ou clusters em inglês (Jain et al., 1999). O termo agrupamento também é usado para referenciar o conjunto de grupos resultante desse processo de classificação. O objetivo dessa classificação é obter grupos que apresentem objetos que sejam semelhantes entre si e possam refletir a forma como os dados são estruturados. No processo de agrupamento, os grupos são formados a partir de um princípio indutivo, também conhecido como funçãoobjetivo ou critério de agrupamento. A função-objetivo é utilizada para selecionar um modelo ou estrutura capaz de indicar os grupos que melhor se ajustem a um determinado conjunto de dados. Uma vez determinada a função-objetivo, o problema de agrupamento consiste em otimizar esta função para o conjunto de dados em estudo. Na maioria das vezes, encontrar a solução ótima para este problema a partir da análise de possíveis soluções é intratável ou apresenta uma complexidade muito elevada para grandes conjuntos de dados. Para ilustrar tamanha complexidade, considere o problema de agrupar os $n_{o}$ objetos de um conjunto $X=\left\{\mathbf{x}_{1}, \mathbf{x}_{2}, \ldots, \mathbf{x}_{n_{o}}\right\}$ em um conjunto de $k$ grupos $\pi=\left\{C_{1}, C_{2}, \ldots, C_{k}\right\}$ distintos entre si, de maneira que:

$$
C_{1} \cup C_{2} \cup \ldots \cup C_{k}=X, C_{i} \neq \emptyset \text {, e } C_{i} \cap C_{j}=\emptyset \text { para } i \neq j \text { e } i, j=1, \ldots k
$$

O número de maneiras que os $n_{o}$ objetos podem ser agrupados em $k$ grupos é dado pelos números de Stirling de segunda espécie (Jr, 1968), e podem ser obtidos pela Equação (2.1) (Liu, 1968):

$$
N S\left(n_{o}, k\right)=\frac{1}{k !} \sum_{i=0}^{k}(-1)^{i}\left(\begin{array}{c}
k \\
i
\end{array}\right)(k-i)^{n_{o}}
$$

Logo, encontrar o agrupamento ótimo, segundo um critério estabelecido, por meio de busca em todo o espaço de agrupamentos possíveis (também chamadas de soluções candidatas), não é uma tarefa trivial, mesmo quando o número de grupos $k$ é conhecido. Se $k$ é desconhecido, diferentes valores de $k$ aumentam ainda mais o espaço de soluções. Considerando $n_{c}$ como o número de cenários distintos para o número de grupos da partição e $k_{i}$ o número de grupos para o $i$-ésimo cenário, o número de possíveis soluções para o agrupamento de $n_{o}$ objetos é dado pela Equação (2.2) (Liu, 1968):

$$
\sum_{i=1}^{n_{c}} N S\left(n_{o}, k_{i}\right)
$$

A partir das Equações (2.1) e (2.2), conclui-se que encontrar um agrupamento ótimo, segundo um critério, pela análise de todas as possíveis soluções é computacionalmente inviável. Na maioria dos casos, existe uma falta de conhecimento estrutural dos dados, que poderia ser utilizado para amenizar tamanha complexidade. Especificamente, a distribuição espacial dos dados em termos numéricos, volumes, densidades, formatos e orientação 
de grupos (se houver) geralmente é desconhecida (Fralley \& Raftery, 1998). Essas adversidades são agravadas pela necessidade de lidar com diferentes tipos de atributos, condições ou escalas (Jain \& Dubes, 1988; Jain et al., 1999).

Os algoritmos de agrupamento se propõem a solucionar esse problema de otimização, segundo uma perspectiva diferente daquela combinatorial/exaustiva descrita acima. Para isso, esses algoritmos definem uma medida de similaridade e um método de busca para encontrar soluções de acordo com uma função de agrupamento (Jain et al., 1999). Por meio da medida de similaridade, método de busca e função de agrupamento, esses algoritmos são utilizados para explorar as relações entre os dados e inferir sua estrutura.

Uma visão geral do processo de construção de um agrupamento está ilustrada na Figura 2.1 e suas etapas são resumidas a seguir (Jain et al., 1999; Faceli, 2006) e detalhadas nas próximas subseções:

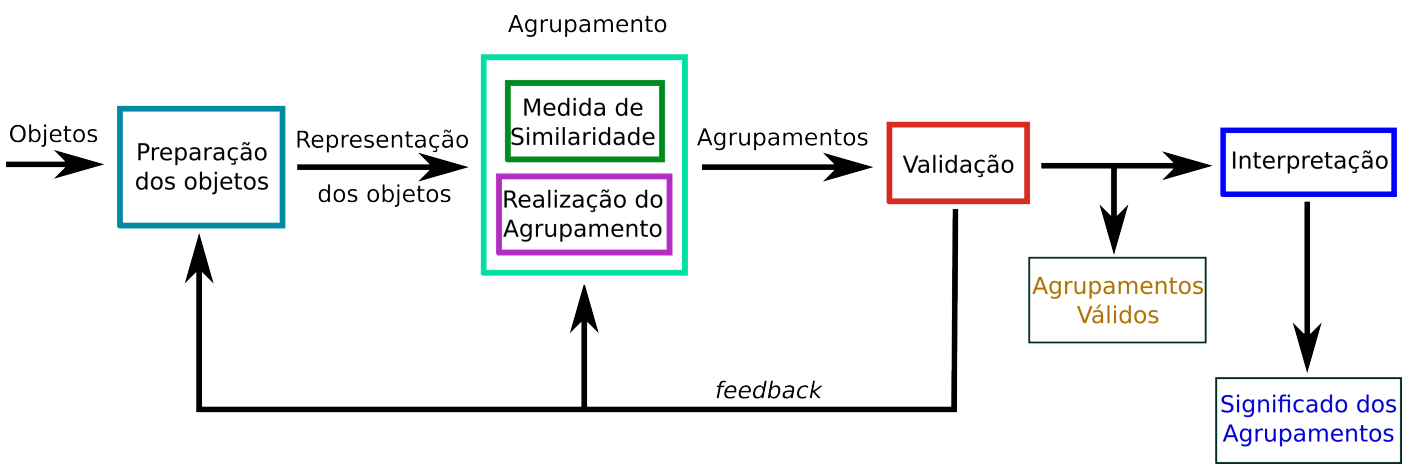

Figura 2.1: Etapas do processo de agrupamento

1. Preparação dos Dados: Determina como os objetos serão representados. Às vezes é aplicado algum tipo de transformação nos dados, como normalizações, conversões de tipos, seleção e/ou extração de características, imputação de valores, dentre outros (Tan et al., 2005).

2. Medida de similaridade/dissimilaridade: A medida de similaridade/dissimilaridade é calculada, em geral, por meio de uma função de similaridade/dissimilaridade definida entre pares de objetos. É possível incluir na medida de similaridade/dissimilaridade aspectos conceituais (qualitativos) ou numéricos (quantitativos).

3. Realização do agrupamento: Consiste em aplicar o algoritmo de agrupamento escolhido, podendo ser realizado de diversas maneiras. Os resultados desta etapa podem ser exclusivos (hard ou crisp em inglês), em que um objeto pertence ou nãopertence a um dado grupo, ou não exclusivos (fuzzy ou soft), em que os objetos podem pertencer a múltiplos grupos ou possuir um grau de pertinência em cada grupo.

4. Validação: Se refere à avaliação da qualidade dos resultados obtidos. Os índices de validação medem a qualidade dos grupos ou estimam o grau com que a estrutura 
resultante reflete o conjunto de dados. A estrutura resultante de um agrupamento é válida se apresenta valores elevados de qualidade, segundo algum nível de referência.

5. Interpretação: Nessa etapa, os grupos resultantes são examinados com relação aos seus padrões, com o objetivo de descrever a natureza do grupo. A interpretação de grupos pode permitir avaliações subjetivas que tenham um significado prático para os grupos. Ou seja, diferentes semânticas podem ser adotadas de acordo com a distribuição dos objetos em cada grupo. Dependendo do objetivo do agrupamento, a realização dessa etapa não é necessária. Quando for, usualmente é realizada por um especialista de domínio.

\subsection{Preparação dos dados}

De forma geral, um conjunto de dados é formado por objetos, também conhecidos como padrões ou instâncias. Estes objetos podem ser físicos, como pacientes ou genes, ou noções abstratas, como iterações entre pessoas. A fase de preparação dos objetos determina como eles serão representados no conjunto de dados durante o processo de agrupamento.

Objetos são geralmente descritos por vetores de atributos (características), que podem ser físicas, como cor e peso, ou abstratas, como idoneidade. Atributos podem ser divididos inicialmente em dois tipos básicos: qualitativos ou quantitativos. Atributos qualitativos são utilizados para expressar qualidades dos objetos, enquanto atributos quantitativos expressam quantidade, relações ou medidas. Cada um desses tipos pode ainda ser subdividido em (Gowda \& Diday, 1991):

\section{Atributos qualitativos ou categóricos:}

- Nominais: representam características que não possuem ordem intrínseca. Exemplos: cor dos olhos, profissão.

- Ordinais: representam qualidades/propriedades que refletem uma sequência ou ordem. Exemplos: quente e frio, ou ruim, regular e bom.

\section{Atributos quantitativos ou numéricos:}

- Contínuos: número infinito e não enumerável de valores. Exemplo: altura, peso.

- Discretos: número finito ou infinito porém enumerável de valores. Exemplo: número de rodas, número de pessoas, números ímpares.

O conhecimento do tipo do atributo é importante na escolha da medida de similaridade e do algoritmo a serem empregados para definir um agrupamento, bem como na interpretação dos resultados. Objetos bem representados podem permitir facilmente a 
interpretação de grupos formados por um algoritmo de agrupamento, enquanto uma representação complexa ou equivocada dos atributos pode arruinar esta interpretação. Por este motivo, às vezes é necessário efetuar a transformação dos atributos, que pode ser feita por meio de normalizações, conversão de tipos e a redução do número de atributos por seleção ou extração (Kononenko \& Kukar, 2007).

Algumas vezes os padrões apresentam atributos de escalas diferentes ou a representação dos dados não é adequada para o algoritmo de agrupamento utilizado. Quando um ou mais atributos apresentam um intervalo de valores muito maior do que os outros, estes podem dominar o resultado do agrupamento, minimizando a significância de atributos com escalas menores. Nesses casos, se faz necessária a aplicação de algumas transformações antes da utilização desses dados, como normalizações (Jain \& Dubes, 1988; Kaufman \& Rousseeuw, 2005).

A maioria dos conjuntos utilizados na mineração de dados não foi gerada com a finalidade de ser minerada. Nem sempre todos os atributos dos objetos são de interesse para o agrupamento e podem apresentar problemas para os algoritmos, como a falta de valores ou erros gerados na obtenção ou transcrição destes valores. Além disso, vários algoritmos não obtêm bons resultados para dados com grande número de atributos ("maldição da dimensionalidade"). Na tentativa de amenizar estes problemas, atributos podem ser selecionados, extraídos ou substituídos (Alpaydin, 2004). A seleção de atributos consiste no processo de identificação do subconjunto mais efetivo de atributos para descrever os objetos. A extração de atributos se refere ao uso de uma ou mais transformações junto aos atributos de modo a salientar características presentes nos dados. Valores ausentes podem ser estimados por meio de técnicas de imputação, também conhecidas como técnicas de substituição de valores ausentes (Grzymala-Busse \& Hu, 2001; Little \& Rubin, 2002). A utilização desses métodos possibilita encontrar um conjunto de atributos que melhor represente as similaridades e dissimilaridades entre objetos.

Geralmente, o conjunto de dados $X$ é representado por um conjunto de vetores, em que cada vetor representa um objeto e contém seus atributos, ou em forma de matriz, em que cada linha representa um objeto e suas colunas representam atributos. Um exemplo de conjunto de dados é ilustrado na Tabela 2.1. Muitas vezes, estes objetos são interpretados como pontos em um espaço de características de dimensão $n_{a}$, em que $n_{a}$ é o número de atributos dos objetos. Cada atributo é representado por um conjunto de eixos ortogonais, cada objeto é visto como um ponto neste espaço e um grupo é formado por pontos próximos ou que satisfazem uma relação espacial.

Outra forma de representar objetos consiste em utilizar uma matriz ou grafo de similaridade/proximidade. Esta matriz ou grafo contém os valores da similaridade/dissimilaridade entre os objetos do conjunto, dois a dois. Nessa matriz de tamanho $n_{o} \times n_{o}$, o valor da similaridade entre o $i$-ésimo e o $j$-ésimo objeto está representado na linha $i$ e coluna $j$. No caso do grafo, o valor dessa similaridade é representado pela aresta entre os vértices $i$ e $j$. Estes tipos de representação por relação dois a dois entre objetos 


\begin{tabular}{|lllll|}
\hline nomes & atributo 1 & atributo 2 & $\ldots$ & atributo $n_{a}$ \\
objeto 1 & 593 & 372737 & $\ldots$ & 4875 \\
objeto 2 & 507 & 138593 & $\ldots$ & 6851 \\
objeto 3 & 461 & 107003 & $\ldots$ & 986 \\
objeto 4 & 244 & 182476 & $\ldots$ & 3257 \\
objeto 5 & 209 & 334477 & $\ldots$ & 6895 \\
objeto 6 & 154 & 59498 & $\ldots$ & 1574 \\
$\ldots$ & $\ldots$ & $\ldots$ & $\ldots$ & $\ldots$ \\
objeto $n_{o}$ & 130 & 118194 & $\ldots$ & 2359 \\
\hline
\end{tabular}

Tabela 2.1: Exemplo de representação de conjunto de dados.

são bastante utilizados nos casos em que informações sobre os objetos do conjunto de dados não estão disponíveis, seja por motivos de segurança, privacidade ou outros.

\subsubsection{Conjuntos de dados de expressão gênica}

O genoma de um organismo é o conjunto completo de cromossomos que reside em sua(s) célula(s) (Setúbal \& Meidanis, 1997). Os cromossomos codificam informações para construir proteínas, ou seja, moléculas que desempenham papel estrutural ou funcional no organismo. Essas informações são chamadas de genes, utilizados para gerar cadeias de moléculas chamadas aminoácidos. Uma sequência de aminoácidos forma uma proteína. A expressão gênica está relacionada com o processo de produção de proteínas.

A produção de proteínas é controlada por uma série de mecanismos que são ativados/desativados de acordo com informações presentes no $D N A$. Esses mecanismos de controle determinam quando, onde e em que quantidade as proteínas são sintetizadas (Mount, 2004). Mudanças no ambiente da célula, alterações em sua forma ou comportamento, idade, infecção ou doenças são fatores que influenciam nesses mecanismos de controle. Dentre as doenças, pode ser citado o câncer. A análise de expressão gênica é feita por meio dos níveis de proteínas produzidos pela célula ou tecido estudado e pode determinar a presença de fatores que influenciaram nesta produção.

Diversas técnicas têm sido propostas para a obtenção da expressão gênica a partir de uma amostra. Uma das mais conhecidas é a técnica de microarray, capaz de medir expressões de genes por meio de um processo de hibridização (Murphy, 2002). O processo do microarray consiste em imobilizar sequências de $D N A$ de maneira organizada. As sequências de DNA são previamente conhecidas e fixadas em conjuntos de sondas, uma correspondente a cada gene, chamadas spots. Dessa forma, cada spot irá representar um gene conhecido, que é identificado pela sua posição no microarray. Várias fontes de variação (e.g., sensibilidade ao calor e à luz, tempo de meia vida) podem afetar os níveis de expressão medidos em experimentos com microarrays. Algumas normalizações podem ser aplicadas para reduzir ou remover essa variação (Yang et al., 2001). Contudo, neste trabalho será dada uma maior ênfase na aplicação de métodos de agrupamento em bases previamente processadas. 
Os dados de expressão de genes são geralmente representados por meio de uma matriz, com linhas representando os genes e as colunas representando as diferentes condições amostrais de expressão de cada gene. Geralmente, essas diferentes condições amostrais são variações de fatores que influenciam nos mecanismos de produção de proteínas (e.g., amostras distintas de tecidos de pacientes enfermos e saudáveis ou obtidas em diferentes temperaturas). Os valores contidos em cada posição dessa matriz representam, assim, o nível de expressão de um gene particular em uma amostra. Uma matriz de expressão geralmente é composta por um grande número de genes (milhares) e poucas amostras (dezenas), devido ao alto custo associado à coleta de dados. O nível de expressão de um determinado gene é medido de forma relativa, em relação à um nível de referência, o que pode ser utilizado para classificar as amostras como sub-expressas ou sobre-expressas. Um exemplo típico de matriz de expressão de genes pode ser visto na Tabela 2.2.

\begin{tabular}{|lllll|}
\hline GENES & AMOSTRA 1 & AMOSTRA 2 & $\ldots$ & AMOSTRA N \\
GTGATACGCC & 393 & 312027 & $\ldots$ & 4172 \\
GCTGTAATGC & 507 & 138593 & $\ldots$ & 6831 \\
TCACTGCACT & 361 & 107003 & $\ldots$ & 2861 \\
GCGACTCACT & 244 & 182476 & $\ldots$ & 3052 \\
$\ldots$ & $\ldots$ & $\ldots$ & $\ldots$ & $\ldots$ \\
TAGGCCAGGC & 130 & 118194 & $\ldots$ & 2359 \\
\hline
\end{tabular}

Tabela 2.2: Parte de uma matriz de expressão de genes.

Um exemplo típico de classificação supervisionada de dados de expressão gênica consiste em treinar um indutor com amostras de tecidos obtidas de pessoas em diferentes condições (e.g., doente, saudável, diferentes idades, etc.), de forma que, posteriormente, o indutor seja capaz de reconhecer esses tipos de tecidos (Baldi \& Brunak, 1998; Brown et al., 2000; Furey et al., 2000; Naldi \& Carvalho, 2005). No paradigma de aprendizado não-supervisionado, uma prática comum consiste em encontrar grupos de genes com o objetivo de estabelecer relações entre eles (Pan et al., 2002; Bolshakova et al., 2006; Stav et al., 2008; McLachlan et al., 2008) ou reduzir a dimensionalidade do conjunto de dados (Lin \& Chien, 2009).

\subsubsection{Conjuntos de dados de mineração de textos}

Mineração de textos é o processo de descoberta de conhecimento em documentos de uma coleção de textos. Devido à sua natureza não estruturada, estes documentos necessitam de um pré-processamento que possibilite a aplicação de algoritmos de aprendizado. A obtenção de uma representação mais adequada desta coleção é uma etapa de suma importância, por influenciar na generalização do algoritmo de aprendizado, a partir dos exemplos utilizados (Sebastiani, 2002).

Uma das representações mais conhecidas e utilizadas na área de mineração de textos é a bem conhecida bag-of-words (Manning \& Schütze, 1999; Matsubara et al., 2003), na qual cada documento é representado pela presença ou pelas frequências de suas palavras 
organizadas em um vetor. Um exemplo deste tipo de representação é mostrado na Tabela 2.2.2 para um conjunto de $n_{o}$ documentos $D=\left\{\mathbf{d}_{1}, \ldots, \mathbf{d}_{n_{o}}\right\}$ representados por $n_{a}$ termos $T=\left\{t_{1}, \ldots, t_{n_{a}}\right\}$. Cada documento $\mathbf{d}_{i}$ é um vetor $\mathbf{d}_{i}=\left(\mathbf{d}_{i}(1), \mathbf{d}_{i}(2), \ldots, \mathbf{d}_{i}\left(n_{a}\right)\right)$, no qual o valor de $\mathbf{d}_{i}(j)$ refere-se à influência relativa do termo $t_{j}$ no documento $\mathbf{d}_{i}$.

\begin{tabular}{|c|cccc|}
\hline & $t_{1}$ & $t_{2}$ & $\ldots$ & $t_{n_{a}}$ \\
\hline $\mathbf{d}_{1}$ & $\mathbf{d}_{1}(1)$ & $\mathbf{d}_{1}(2)$ & $\ldots$ & $\mathbf{d}_{1}\left(n_{a}\right)$ \\
$\mathbf{d}_{2}$ & $\mathbf{d}_{2}(1)$ & $\mathbf{d}_{2}(2)$ & $\ldots$ & $\mathbf{d}_{2}\left(n_{a}\right)$ \\
$\vdots$ & $\vdots$ & $\vdots$ & $\ddots$ & $\vdots$ \\
$\mathbf{d}_{n_{o}}$ & $\mathbf{d}_{n_{o}}(1)$ & $\mathbf{d}_{n_{o}}(2)$ & $\ldots$ & $\mathbf{d}_{n_{o}}\left(n_{a}\right)$ \\
\hline
\end{tabular}

Tabela 2.3: Representação bag-of-words de documentos.

O valor de $\mathbf{d}_{i}(j)$ pode ser calculado de várias maneiras. A seguir, encontram-se algumas das mais utilizadas (Salton \& Buckley, 1988; Manning \& Schütze, 1999; Matsubara et al., 2003):

- booleana - A medida booleana indica se o termo $j$ pertence ao documento $\mathbf{d}_{i}$ quando o valor de $\mathbf{d}_{i}(j)=1$, caso contrário $\mathbf{d}_{i}(j)=0$.

- $\boldsymbol{t f}$ - A medida term frequency $(t f)$ é o número de ocorrências do termo $t_{j}$ no documento $\mathbf{d}_{i}$, de forma que $\mathbf{d}_{i}(j)=t f\left(t_{j}, \mathbf{d}_{i}\right)$.

- $t$ fidf - Um termo muito frequente pode ocorrer em quase todo o conjunto de documentos, dificultando a classificação destes. Assim um fator de ponderação conhecido como inverse document frequency ( $i d f)$, definido pela Equação (2.3), é utilizado para favorecer termos significativos que aparecem em uma quantidade menor de documentos do conjunto.

$$
i d f\left(t_{j}\right)=\log \frac{n_{o}}{n_{d}\left(t_{j}\right)}
$$

em que $n_{o}$ é o número de documentos e $n_{d}\left(t_{j}\right)$ é o número de documentos nos quais o $j$-ésimo termo está contido. Assim, o fator de ponderação $i d f$ pode ser combinado com a medida $t f$ para formar uma nova medida chamada $t$ fidf, calculada pela Equação (2.4):

$$
\mathbf{d}_{i}(j)=t f i d f\left(t_{j}, \mathbf{d}_{i}\right)=t f\left(t_{j}, \mathbf{d}_{i}\right) \cdot i d f\left(t_{j}\right)
$$

Documentos pequenos possuem poucos termos, enquanto documentos grandes possuem muitos termos. Dessa forma, a probabilidade das frequências dos termos serem maiores em documentos grandes é mais alta do que em documentos pequenos. A simples contagem de termos faz com que um documento maior seja mais relevante do que um pequeno, mas todos os documentos devem ser tratados com a mesma importância independente de seu tamanho. Portanto, um fator importante é normalizar os valores de $\mathbf{d}_{i}(j)$ para que documentos grandes e pequenos possam ser comparados. É importante 
notar que essa normalização deve equilibrar os valores de $\mathbf{d}_{i}(j)$ entre documentos e não apenas mudar a escala dos atributos. Um tipo de normalização apropriado para este caso consiste em transformar os vetores que representam os documentos em versores, ou seja, padronizar o tamanho dos vetores para valores unitários.

O uso da representação bag-of-words pode não ser muito indicado sem a seleção/redução de termos, uma vez que o vetor que representa cada documento irá conter todos os termos presentes no conjunto de documentos. Logo, quanto maior a coleção de documentos, maior será a dimensão dos vetores e mais esparsa será a matriz da representação, pois a frequência de vários termos será baixa ou possivelmente nula na maioria dos documentos.

Um dos métodos de seleção de termos consiste na eliminação de termos claramente consideradas como irrelevantes para o processo de classificação, como artigos, conjunções e preposições. Esses termos são chamados stopwords e são dependentes da língua adotada no documento (Blanchard, 2007). As stopwords são termos comuns e com alta frequência, que devem ser eliminados. A Tabela 2.4 contém alguns exemplos de stopwords para a língua inglesa.

\begin{tabular}{|lll|}
\hline a & be & can \\
all & because & clearly \\
also & before & consequently \\
an & better & contain \\
any & but & could \\
are & by & $\ldots$ \\
\hline
\end{tabular}

Tabela 2.4: Exemplo de stopwords para a língua inglesa.

Outra forma de reduzir a dimensão é utilizar algoritmos de stemming que aplicam uma normalização linguística, na qual as variantes de um termo são reduzidas a uma forma comum denominada stem (Yu, 2008). Essas variantes são semanticamente equivalentes e podem ser tratadas como um único termo. Esses algoritmos removem sufixos e prefixos, obtendo uma forma comum do termo. Por exemplo, os termos escrever, escrito, escrevendo, escrita, escritas são similares e devem ser transformados para o stem escr. Dentre os algoritmos mais conhecidos de stemming para a língua inglesa, merece destaque o algoritmo de Porter (Porter, 1980).

Procurar por termos pouco representativos e descartá-los também é uma forma de reduzir a dimensionalidade de um conjunto de dados. Zipf (1949) postulou que o comportamento humano segue o princípio do menor esforço, o qual, por sua vez, justifica uma tendência humana a usar um pequeno conjunto de termos com alta frequência e outros termos poucas vezes. Além disso, termos que são comuns ou frequentemente usados na maioria dos documentos tendem a possuir pouco impacto na representatividade dos documentos. Por outro lado, termos raros, presentes somente em documentos isolados, também tendem a ser pouco importantes na indução dos grupos, pois são demasiadamente específicos. 
Uma forma de se aplicar a teoria de Zipf (1949) consiste em contar o número de vezes que cada termo aparece no conjunto e formar um histograma (Manning \& Schütze, 1999). Esse histograma deve ser então ordenado de forma decrescente para que os termos mais frequentes apareçam primeiro. A frequência dos termos na coleção de documentos em ordem decrescente é denominada de "Curva de Zipf", ilustrada na Figura 2.2(a), onde o eixo cartesiano $r$ representa os termos ordenados decrescentemente por sua frequência e o eixo cartesiano $f$ representa a frequência desses termos.

Luhn (1958) usou a lei de Zipf como hipótese para especificar pontos de corte (superior e inferior) na curva e remover termos pouco representativos, como ilustrado na Figura 2.2(b). Os termos cuja freqüência excedem o corte superior são considerados pouco representativos por serem muito comuns. Já os termos com freqüência abaixo do corte inferior são considerados pouco representativos por serem raros e não contribuirem na discriminação dos documentos.

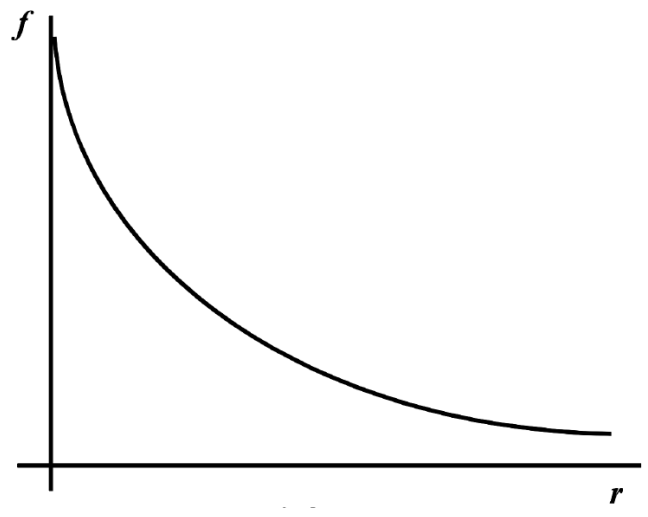

(a)

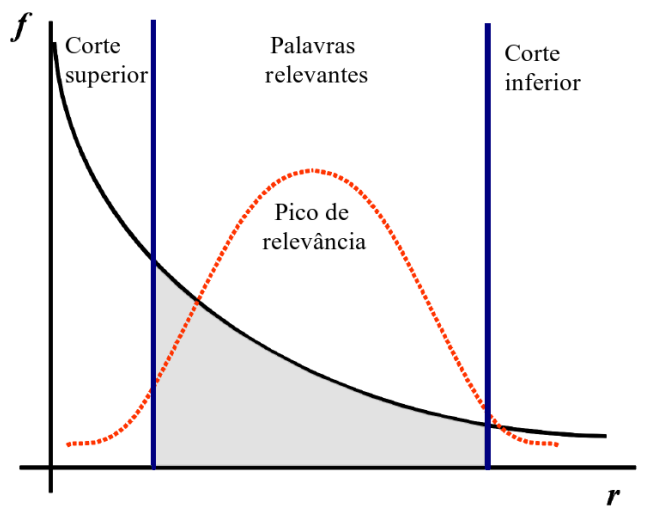

(b)

Figura 2.2: (a) Curva de Zipf; (b) Corte de Luhn; (Adaptada de Matsubara et al. (2003))

Dessa forma, o corte de Luhn supõe a existência de um pico imaginário o meio dos dois cortes, no qual se encontram os termos mais representativos. No entanto, a determinação dos valores do corte superior e do corte inferior é arbitrária e baseada em tentativa e erro.

\subsection{Medidas de similaridade e dissimilaridade}

Como grupos são formados por objetos mais similares entre si do que objetos de outros grupos, similaridade é um conceito fundamental para o processo de agrupamento. Contudo, diferentes tipos e escalas de atributos fazem com que a escolha da medida de similaridade a ser empregada no processo de agrupamento deva ser feita cuidadosamente. Algumas dessas medidas não são ponderadas, ou seja, consideram que todos os atributos contribuem para o cálculo da similaridade na mesma proporção. Portanto, o sucesso do uso de uma determinada medida de similaridade é dependente de uma preparação adequada dos dados.

As medidas podem se referir à similaridade ou dissimilaridade, sendo que as mais comumente empregadas em agrupamento calculam a dissimilaridade, geralmente a partir 
de distâncias. Dados os objetos $\mathbf{x}_{i}, \mathbf{x}_{j}$ e $\mathbf{x}_{l}$, uma medida de dissimilaridade entre pares geralmente (nem sempre) satisfaz as três primeiras propriedades a seguir (Kononenko \& Kukar, 2007):

1. $d\left(\mathbf{x}_{i}, \mathbf{x}_{j}\right) \geq 0$, para todo $\mathbf{x}_{i}$ e $\mathbf{x}_{j} ;\{$ positividade $\}$

2. $d\left(\mathbf{x}_{i}, \mathbf{x}_{j}\right)=d\left(\mathbf{x}_{j}, \mathbf{x}_{i}\right) ;\{$ simetria $\}$

3. $d\left(\mathbf{x}_{i}, \mathbf{x}_{j}\right)=0$, se e somente se $i=j$;

4. $d\left(\mathbf{x}_{i}, \mathbf{x}_{l}\right) \leq d\left(\mathbf{x}_{i}, \mathbf{x}_{j}\right)+d\left(\mathbf{x}_{j}, \mathbf{x}_{l}\right)$, para todo $\mathbf{x}_{i}, \mathbf{x}_{j}$ e $\mathbf{x}_{l} ;\{$ desigualdade triangular $\}$

Se, além disso, a medida de dissimilaridade satisfaz a propriedade 4, ela é considerada uma métrica. As medidas de dissimilaridade mais frequentemente utilizadas em problemas de agrupamento são métricas. Para conjuntos de dados em que todos os atributos são contínuos ou discretos, geralmente são utilizadas distâncias baseadas na métrica de Minkowski, como a distância Euclidiana e a distância de Manhattan. A última também é conhecida como distância de Hamming quando todos os atributos são binários. Vários trabalhos (Gordon, 1999; Faceli et al., 2005a; Kononenko \& Kukar, 2007) apresentam diversas medidas apropriadas para objetos que tenham atributos de um mesmo tipo. Nesta seção, para a descrição de medidas utilizadas para diferentes tipos de atributos, serão considerados dois objetos $\mathbf{x}_{i}$ e $\mathbf{x}_{j}$ pertencentes a uma base de dados com dimensão $n_{a}$, ou seja, com $n_{a}$ atributos.

\subsubsection{Medidas para atributos qualitativos}

Atributos nominais e ordinais são atributos categóricos que representam estados ou categorias. Caso eles possuam somente dois estados, esses podem ser representados por números binários e, portanto, representados por atributos binários. Por exemplo, atributos bivalentes como frio e quente, alto e baixo, doente e saudável, podem ser convertidos em dígitos binários, de forma que um valor seja representado pelo dígito 1 e o outro pelo dígito 0.

Uma vez representados por valores binários, algumas medidas de similaridade podem ser aplicadas. Considere as seguintes variáveis:

- $n_{a}^{\{11\}}$ : número de atributos com valor 1 para ambos os objetos;

- $n_{a}^{\{01\}}$ : número de atributos com valor 0 para o objeto $\mathbf{x}_{i}$ e valor 1 para o objeto $\mathbf{x}_{j}$;

- $n_{a}^{\{10\}}$ : número de atributos com valor 1 para o objeto $\mathbf{x}_{i}$ e valor 0 para o objeto $\mathbf{x}_{j}$;

- $n_{a}^{\{00\}}$ : número de atributos com valor 0 para ambos os objetos.

A seguir, duas medidas de similaridade são propostas para atributos binários, dadas pelas Equações (2.5) e (2.6). Elas são diferenciadas no tratamento da variável $n_{a}^{\{00\}}$. O 
coeficiente de Jaccard (1908) não utiliza este valor, o que é justificável em casos nos quais o dígito 0 representa apenas a ausência de uma característica (e.g., asas em um estudo de insetos (Everitt et al., 2001a)) e que, portanto, não é indício de similaridade. Nesses casos, os atributos são considerados assimétricos. Em outros casos, pode-se utilizar o coeficiente de casamento simples.

- Coeficiente de Jaccard:

$$
s\left(\mathbf{x}_{i}, \mathbf{x}_{j}\right)=\frac{n_{a}^{\{11\}}}{n_{a}^{\{01\}}+n_{a}^{\{01\}}+n_{a}^{\{11\}}}
$$

\section{- Coeficiente de Casamento Simples:}

$$
s\left(\mathbf{x}_{i}, \mathbf{x}_{j}\right)=\frac{n_{a}^{\{11\}}+n_{a}^{\{00\}}}{n_{a}^{\{00\}}+n_{a}^{\{01\}}+n_{a}^{\{01\}}+n_{a}^{\{11\}}}
$$

É importante ressaltar que as Equações (2.5) e (2.6) representam medidas de similaridade entre objetos. Se necessário, é possível obter a dissimilaridade entre estes objetos a partir do cálculo do complemento dessa similaridade $\left(1-s\left(\mathbf{x}_{i}, \mathbf{x}_{j}\right)\right)$.

Em alguns casos, atributos nominais e ordinais podem assumir mais de dois estados (e.g., frio, gelado, morno e quente). Uma alternativa consiste em representar estes atributos com um conjunto de valores binários. Um exemplo deste tipo de representação consiste em formar uma sequência de dígitos binários, de forma que cada estado seja representado por um deles, mantida uma ordem pré-estabelecida. Neste caso, somente o valor que representa o estado que caracteriza o objeto se difere dos outros (e.g., assume 1 enquanto os outros são 0). O problema deste tipo de alternativa é o aumento da dimensão dos dados representados.

Outra opção às medidas de similaridade consiste em calcular a discordância entre os atributos dos objetos, como mostrado a seguir. Ao final, a soma das discordâncias indica a dissimilaridade entre esses objetos.

- Índice de discordância: sendo $\mathbf{x}_{i}(z)$ o $z$-ésimo atributo do objeto $\mathbf{x}_{i}$, o índice de discordância é calculado pela Equação (2.7).

$$
\delta_{z}\left(\mathbf{x}_{i}, \mathbf{x}_{j}\right)= \begin{cases}1, & \text { se } \mathbf{x}_{i}(z) \neq \mathbf{x}_{j}(z) \\ 0, & \text { caso contrário. }\end{cases}
$$

No caso de valores ordinais, é necessário alterar os valores $\delta_{z}$ de modo a satisfazer a seguinte condição monotônica: $\delta_{z}\left(\mathbf{x}_{i}, \mathbf{x}_{j}\right)<\delta_{z}\left(\mathbf{x}_{i}, \mathbf{x}_{v}\right)$, se $\mathbf{x}_{i}(z)>\mathbf{x}_{j}(z)>\mathbf{x}_{v}(z)$ ou $\mathbf{x}_{i}(z)<\mathbf{x}_{j}(z)<\mathbf{x}_{v}(z)$. 
- Dissimilaridade nominal/ordinal geral: definida como a soma da discordância de todos os atributos dos padrões $\mathbf{x}_{i}$ e $\mathbf{x}_{j}$, dada pela Equação (2.8).

$$
d\left(\mathbf{x}_{i}, \mathbf{x}_{j}\right)=\sum_{z=1}^{n_{a}} \delta_{z}\left(\mathbf{x}_{i}, \mathbf{x}_{j}\right)
$$

\subsubsection{Medidas para atributos quantitativos}

As medidas mais comuns para esse tipo de atributo são as métricas de Minkowski. Elas tratam objetos como pontos no espaço e medem a distância entre esses pontos, o que faz com que as magnitudes dos atributos sejam importantes em termos absolutos. Outro tipo de medida são as medidas de correlação, que são baseadas na forma em que os objetos estão dispostos no espaço de características que os descrevem. Nessas medidas, os atributos dos objetos são comparados em termos relativos. Ambos os tipos de medidas são descritos a seguir:

- Métricas de Minkowski: as métricas de Minkowski são derivadas da Equação (2.9), de acordo com um valor escolhido para $\rho$, com $1 \leq \rho<\infty$. Como as métricas de Minkowski são sensíveis a variações de escala dos atributos, pode ser aplicada a normalização dos atributos ou esquemas de ponderação por um peso $w_{z}$, relacionado ao $z$-ésimo atributo (Kononenko \& Kukar, 2007), para casos em que alguns atributos são representados em maior escala. É interessante mencionar o caso particular no qual $w_{z}=\frac{1}{\sigma_{z}}$, no qual $\sigma_{z}$ é o desvio padrão dos valores do $z$-ésimo atributo para todos os objetos do conjunto de dados. Neste caso, o uso de $w_{z}$ funciona de forma análoga à normalização dos atributos.

$$
d\left(\mathbf{x}_{i}, \mathbf{x}_{j}\right)=\left(\sum_{z=1}^{n_{a}} w_{z}^{\rho}\left|\mathbf{x}_{i}(z)-\mathbf{x}_{j}(z)\right|^{\rho}\right)^{1 / \rho} \quad(\rho \geq 1)
$$

As parametrizações mais comuns são:

- $\rho=1$ : Distância de Manhattan: também conhecida como distância quarteirão-cidade, dada pela Equação (2.10).

$$
d\left(\mathbf{x}_{i}, \mathbf{x}_{j}\right)=\left(\sum_{z=1}^{n_{a}} w_{z}\left|\mathbf{x}_{i}(z)-\mathbf{x}_{j}(z)\right|\right)
$$

A distância de Manhattan induz grupos com formas de losango e, por esse motivo, é utilizada com menos frequência do que a distância Euclidiana (discutida a seguir).

- $\rho=2$ : Distância Euclidiana: uma das medidas de distância mais comuns, é apropriada para conjuntos de dados que possuem grupos volumétricos aproxi- 
madamente esféricos. É dada pela Equação (2.11).

$$
d\left(\mathbf{x}_{i}, \mathbf{x}_{j}\right)=\left(\sum_{z=1}^{n_{a}} w_{z}^{2}\left|\mathbf{x}_{i}(z)-\mathbf{x}_{j}(z)\right|^{2}\right)^{1 / 2}
$$

Utilizar $w_{z}=\frac{1}{\sigma_{z}}$ faz com que a distância Euclidiana seja ponderada pelo inverso da variância dos atributos dos objetos (Pedrycz, 2002a).

- Medidas de correlação: estas medidas são baseadas em informações sobre a magnitude relativa de diferentes atributos. Para essas medidas, os objetos são considerados vetores espaciais ou sequências temporais com $n_{a}$ componentes.

- Separação angular: essa medida é calculada por meio do cosseno do ângulo formado entre dois vetores que representam os objetos (Everitt et al., 2001b). O cálculo do ângulo entre estes vetores é feito a partir da origem e o coeficiente é obtido pela Equação (2.12), no intervalo [-1,1]. A medida de dissimilaridade pode ser dada pela Equação (2.13), caso seja de interesse mapear os resultados no intervalo $[0,1]$.

$$
\begin{gathered}
\phi\left(\mathbf{x}_{i}, \mathbf{x}_{j}\right)=\frac{\sum_{z=1}^{n_{a}} \mathbf{x}_{i}(z) \mathbf{x}_{j}(z)}{\sqrt{\sum_{z=1}^{n_{a}} \mathbf{x}_{i}(z)^{2} \sum_{z=1}^{n_{a}} \mathbf{x}_{j}(z)^{2}}} \\
d\left(\mathbf{x}_{i}, \mathbf{x}_{j}\right)=\frac{1-\phi\left(\mathbf{x}_{i}, \mathbf{x}_{j}\right)}{2}
\end{gathered}
$$

- Coeficiente de correlação de Pearson: sob uma perspectiva matemática, assim como a medida de separação angular, esta medida pode ser vista como o cosseno do ângulo formado entre dois vetores que representam os objetos (Everitt et al., 2001b). Porém, diferentemente da separação angular, o cálculo é feito a partir da média do vetor, dado pela Equação (2.14). Isso torna a medida útil quando se deseja medir a tendência de duas sequências (e. g., de expressão gênica) para as quais os valores de magnitude absolutos não são relevantes, apenas os valores relativos. O coeficiente é calculado pela Equação (2.15) e o resultado se encontra no intervalo $[-1,1]$. A medida de dissimilaridade pode ser dada pela Equação (2.16), caso seja de interesse mapear os resultados no intervalo $[0,1]$.

$$
\begin{gathered}
\overline{\mathbf{x}}_{i}=\frac{1}{n_{a}} \sum_{z=1}^{n_{a}} \mathbf{x}_{i}(z) \\
\phi\left(\mathbf{x}_{i}, \mathbf{x}_{j}\right)=\frac{\sum_{z=1}^{n_{a}}\left(\mathbf{x}_{i}(z)-\overline{\mathbf{x}}_{i}\right)\left(\mathbf{x}_{j}(z)-\overline{\mathbf{x}}_{j}\right)}{\sqrt{\sum_{z=1}^{n_{a}}\left(\mathbf{x}_{i}(z)-\overline{\mathbf{x}}_{i}\right)^{2} \sum_{z=1}^{n_{a}}\left(\mathbf{x}_{j}(z)-\overline{\mathbf{x}}_{j}\right)^{2}}} \\
d\left(\mathbf{x}_{i}, \mathbf{x}_{j}\right)=\frac{1-\phi\left(\mathbf{x}_{i}, \mathbf{x}_{j}\right)}{2}
\end{gathered}
$$


- Correlação de Spearman: a correlação de Spearman é uma alternativa para o coeficiente de correlação de Pearson (Hollander \& Wolfe, 1999; Campello \& Hruschka, 2009). Ela é útil por sofrer menos variação à dados irregulares (outliers) que a correlação de Pearson. Para calcular a correlação de Spearman, basta ordenar os atributos dos objetos segundo seus próprios valores. Em seguida, o coeficiente de correlação de Pearson é calculado utilizando as ordens dos atributos no lugar de seus valores.

- Coeficiente de Tanimoto: assim como a separação angular, o coeficiente de Tanimoto é uma medida de similaridade entre vetores (Tanimoto, 1958). O coeficiente de Tanimoto também é conhecido como índice de Jaccard estendido, uma vez que ele calcula o coeficiente de Jaccard quando utilizado em vetores binários. Para dois vetores $\mathbf{x}_{i}$ e $\mathbf{x}_{j}$, o coeficiente de Tanimoto é dado por:

$$
d\left(\mathbf{x}_{i}, \mathbf{x}_{j}\right)=\frac{\mathbf{x}_{i} \cdot \mathbf{x}_{j}}{\left\|\mathbf{x}_{i}\right\|^{2}+\left\|\mathbf{x}_{j}\right\|^{2}-\mathbf{x}_{i} \cdot \mathbf{x}_{j}}
$$

Cada medida de similaridade possui suas vantagens e desvantagens, dependendo da situação em que é aplicada, podendo ser mais (ou menos) apropriada para uma determinada análise. Para conjuntos de dados de expressão gênica (Seção 2.2.1), a correlação de Pearson geralmente obtém bons resultados quando a tendência da expressão de certos genes é mais importante do que sua magnitude (Eisen et al., 1998; Xu \& Wunsch, 2005). Caso contrário, medidas como a distância Euclidiana são mais apropriadas. A medida de separação angular também mede a magnitude relativa dos atributos entre objetos, porém trata os objetos como vetores direcionais e não como sequenciais. Por isso, é comumente utilizada em conjuntos de documentos textuais (Seção 2.2.2) (Xu \& Wunsch, 2005).

\subsubsection{Medidas para grupos}

Algumas técnicas de agrupamento utilizam a dissimilaridade entre grupos de objetos. Para isso, várias medidas de dissimilaridade entre grupos comparam as dissimilaridades entre os objetos destes grupos e seus protótipos. Dentre os tipos de protótipos utilizados para representar grupos, merecem destaque o centróide, que é a média dos vetores de objetos de um determinado grupo, e o medóide, o objeto central do grupo. Outra forma de se calcular este tipo de dissimilaridade consiste em utilizar a menor, maior ou a média das dissimilaridades entre os objetos dos grupos a serem comparados.

Dois tipos de dissimilaridade para grupos são bastante utilizados, especialmente em funções objetivo e índices de validação de agrupamentos (a serem apresentados na Seção 2.5). Elas são as dissimilaridade intra-grupo e inter-grupo, e podem ser calculadas de diversas formas. Duas das formas de se calcular estas dissimilaridades a partir de objetos 
são dadas pelas Equações (2.18) e (2.19):

$$
d_{\text {intra }}\left(C_{i}\right)=\sum_{y=1}^{\left|C_{i}\right|} \sum_{l=y+1}^{\left|C_{i}\right|} d\left(\mathbf{x}_{i y}, \mathbf{x}_{i l}\right)
$$

em que $\left|C_{i}\right|$ é a cardinalidade do conjunto $C_{i}$ que representa o $i$-ésimo grupo, os padrões $\mathbf{x}_{i y}$ e $\mathbf{x}_{i l}$ são o $y$-ésimo e o $l$-ésimo objetos contidos no grupo $C_{i}$.

$$
d_{\text {inter }}\left(C_{i}, C_{j}\right)=\sum_{y=1}^{\left|C_{i}\right|} \sum_{l=1}^{\left|C_{j}\right|} d\left(\mathbf{x}_{i y}, \mathbf{x}_{j l}\right)
$$

em que $\left|C_{j}\right|$ é a cardinalidade do conjunto $C_{j}$, os padrões $\mathbf{x}_{i y}$ e $\mathbf{x}_{j l}$ são o $y$-ésimo e o $l$-ésimo objetos contidos nos grupos $C_{i}$ e $C_{j}$, respectivamente, com $i \neq j$.

Alguns algoritmos utilizam outros métodos para calcular as dissimilaridades intragrupo e inter-grupo a partir de dissimilaridades entre protótipos, objeto-protótipo, ou mesmo variações utilizando dissimilaridades entre objetos. Quando for o caso neste trabalho, esses métodos serão especificados nas descrições dos algoritmos que os utilizam.

\subsection{Algoritmos clássicos de agrupamento}

Nesta seção, são detalhados os algoritmos de agrupamento de potencial interesse para utilização neste trabalho. Em geral, os algoritmos de agrupamento podem ser divididos em exclusivos (crisp) e não exclusivos (fuzzy ou soft) (Jain et al., 1999). Um agrupamento exclusivo é a partição de um conjunto de dados em grupos nos quais cada objeto pertence exclusivamente a um único grupo. Um agrupamento não exclusivo pode associar um objeto a vários grupos, sendo que cada objeto pode ter um grau de pertinência a cada um dos grupos (fuzzy ou probabilístico) ou não (soft).

Além da relação de exclusividade dos objetos, os algoritmos de agrupamento também podem ser divididos em hierárquicos e particionais, de acordo com a estrutura em que os dados são divididos. A estrutura de um algoritmo hierárquico resulta em uma sequência de partições aninhadas hierarquicamente, enquanto os algoritmos particionais resultam em uma única partição dos dados.

Existe uma variedade enorme de algoritmos de agrupamento na literatura (Jain et al., 1999). Cada um desses algoritmos emprega um critério de agrupamento que impõe uma estrutura nos dados e possui uma complexidade computacional e paramétrica particular. A seguir, são apresentados alguns destes algoritmos resumidamente.

\subsubsection{A classe de algoritmos k-medóides}

A classe de algoritmos $k$-medóides (Kaufman \& Rousseeuw, 2005) é formada por algoritmos que particionam o conjunto de dados $X$ em $k$ grupos exclusivos com base na dissimilaridade entre seus objetos e medóides. De forma geral, os algoritmos têm como 
função-objetivo reduzir o erro quadrático calculado pela dissimilaridade entre os objetos dos grupos e seus medóides, dado pela Equação (2.20).

$$
\min _{\mathbf{m}_{1}, \ldots, \mathbf{m}_{k}} o b j_{k m e d o i d s}=\sum_{i=1}^{k} \sum_{\mathbf{x}_{j} \in C_{i}} d\left(\mathbf{x}_{j}, \mathbf{m}_{i}\right)
$$

Um exemplo de um algoritmo $k$-medóides típico é descrito pelos seguintes passos:

1. O algoritmo inicia com a seleção arbitrária de $k$ objetos distintos da base de dados, de forma que estes objetos se tornem os medóides dos grupos iniciais;

2. Depois da seleção dos $k$ medóides, cada objeto é associado ao grupo cujo medóide seja menos dissimilar a ele;

3. Atualiza-se o medóide para o objeto com a mínima dissimilaridade média em relação aos objetos de seu grupo;

4. O término da execução ocorre se a convergência for alcançada ou se o número de iterações exceder um limite $t$. Caso contrário, retorna ao Passo 2.

Uma vantagem deste algoritmo é que ele pode trabalhar com qualquer medida de dissimilaridade. Também não há a necessidade de conhecimento dos valores dos atributos dos objetos a serem agrupados, pois, devido ao uso de medóides, basta a matriz de dissimilaridade entre seus objetos para executar o algoritmo. Uma versão bem conhecida de $k$-medóides é o $k$-modes, utilizado principalmente no agrupamento de atributos (Au et al., 2005). Sua complexidade computacional é quadrática em relação ao número de objetos do conjunto de dados $\left(O\left(n_{o}^{2}\right)\right)$.

Dentre outros algoritmos que pertencem à classe $k$-medóides podem ser citados: o algoritmo Partitioning Around Medoids (PAM); o algoritmo Clustering LARge Applications $(C L A R A)$ e sua variante Clustering LARge Applications based on Randomized Search (CLARANS) (Kaufman \& Rousseeuw, 2005). Segundo Halkidi et al. (2001); ShuChuan Chu \& Pan (2002) e Xu \& Wunsch (2005), esses algoritmos possuem complexidade computacional $O\left(k\left(n_{o}-k\right)^{2}\right), O\left(k^{2}+k\left(n_{o}-k\right)\right)$ e $O\left(k \cdot n^{2}\right)$, respectivamente.

\subsubsection{Estimação de densidade com Expectation Maximization (EM)}

O algoritmo Expectation Maximization (EM) (Mitchell, 1997; Bishop, 2007) é popular para problemas de estimação estatística envolvendo dados incompletos ou problemas de estimação de misturas (McLachlan \& Peel, 2000). De maneira geral, o EM é um método iterativo utilizado para estimar o valor de variáveis desconhecidas a partir dos valores conhecidos de variáveis correlacionadas. Supondo que estas variáveis seguem uma determinada distribuição de probabilidade, o procedimento adotado pelo $E M$ é resumido nos principais passos a seguir:

1. Inicializam-se os parâmetros relativos às distribuições; 
2. Expectation: estima-se o valor da esperança das variáveis desconhecidas, dados os valores estimados dos parâmetros relativos às distribuições;

3. Maximization: estima-se o valor dos parâmetros das distribuições de forma a maximizar a verossimilhança das variáveis, dadas as estimativas dos valores das variáveis desconhecidas.

4. Calcula-se a verossimilhança;

5. Repetem-se os passos 2, 3 e 4 até a convergência da verossimilhança, das variáveis ou dos parâmetros:

Um exemplo de uso bem conhecido de $E M$ consiste na sua aplicação no problema de estimação de misturas gaussianas (Bishop, 2007). Neste caso, o objetivo do algoritmo é maximizar a função de verossimilhança em relação aos parâmetros das distribuições (médias, covariâncias e coeficientes de mistura). Aplicado ao problema de agrupamento, cada grupo é representado por uma destas distribuições.

É importante notar que a complexidade do $E M$ varia com o tipo de distribuição. O algoritmo é capaz de encontrar grupos de vários formatos, que variam de acordo com o tipo das distribuições estimadas. Quando aplicado ao problema de estimação de misturas de gaussianas, a complexidade do $E M$ é $O\left(n_{o} \cdot n_{a}^{3}\right)$ (Sakuma \& Kobayashi, 2002). Segundo Bishop (2007), o algoritmo EM demora mais iterações para convergir do que o algoritmo $k$-médias (Seção 2.4.6) e cada ciclo requer um dispêndio computacional significativamente maior. As principais desvantagens do $E M$ são a sensibilidade para a seleção dos parâmetros iniciais, a possibilidade de convergência para um mínimo local e a baixa taxa de convergência (McLachlan \& Krishnan, 1996).

\subsubsection{Density Based Spatial Clustering of Applications with Noise (DBSCAN)}

O algoritmo DBSCAN (Ester et al., 1996) é um dos mais conhecidos algoritmos baseados em densidade, no qual grupos de alta densidade de objetos são separados por regiões de baixa densidade. Sua principal idéia é baseada em dois tipos de objetos, os objetos do núcleo e os objetos da borda, e na relação de densidade entre eles. Objetos do núcleo de um grupo são objetos cuja vizinhança contém um número mínimo de objetos. Objetos da borda são objetos próximos a um objeto do núcleo, mas que não contenham um número mínimo de objetos em sua vizinhança. Objetos que não são objetos do núcleo ou da borda são considerados ruídos do conjunto de dados. Os grupos formados pelo algoritmo são compostos por objetos do núcleo ou da borda, ligados por meio de uma medida de densidade.

$D B S C A N$ pode lidar com ruído ou outliers e detectar grupos de formatos arbitrários. Além disso, DBSCAN é utilizado como base para um algoritmo incremental proposto por Ester et al. (1998) pois, devido à sua natureza baseada em densidade, a inserção ou 
remoção de objetos afeta o agrupamento apenas na região do grupo afetado e, portanto, facilita modificações incrementais.

A complexidade computacional do algoritmo é $O\left(n_{o} \log n_{o}\right)$ no caso médio (se $n_{a}<<$ $\left.n_{o}\right)$ e $O\left(n_{o}^{2}\right)$ no pior caso (Halkidi et al., 2001; Xu \& Wunsch, 2005). Ester et al. (1996) demonstram que o $D B S C A N$ é significativamente mais eficiente em descobrir grupos de formas arbitrárias do que o algoritmo CLARANS, além de ser aproximadamente 100 vezes mais rápido. Porém, é necessário determinar o tamanho da região de vizinhança dos objetos e o número mínimo de objetos que ela deve conter, o que implica indiretamente em determinar o número de grupos. Adicionalmente, o $D B S C A N$ não opera bem em bases de dados com elevada dimensão e em cenários nos quais os grupos possuem densidades muito distintas (Tan et al., 2005).

\subsubsection{CLuster Identification via Connectivity Kernels (CLICK)}

O algoritmo baseado em grafos CLICK (Sharan \& Shamir, 2000) não necessita do número de grupos a priori para gerar uma partição. O principal objetivo deste algoritmo é particionar recursivamente um grafo ponderado em componentes menores (grupos) por meio de cortes de custo mínimo. Os pesos das arestas e o critério de parada são obtidos probabilisticamente. A primeira fase do algoritmo consiste em estimar a distribuição dos parâmetros de média e desvio padrão dos grupos, a partir de conhecimento prévio sobre a estrutura de parte dos dados ou por meio do uso de um algoritmo de EM (Seção 2.4.2). Nesta fase, define-se a probabilidade de pares de objetos do conjunto de dados pertecerem ao mesmo grupo. Em seguida, o peso da aresta entre os nós que representam os objetos $\mathbf{x}_{i}$ e $\mathbf{x}_{j}$ é definido por:

$$
w_{\mathbf{x}_{i}, \mathbf{x}_{j}}=\log \frac{p_{(\text {parceiros })} f\left(s\left(\mathbf{x}_{i}, \mathbf{x}_{j}\right) \mid \mathbf{x}_{i}, \mathbf{x}_{j} \text { são parceiros }\right)}{\left(1-p_{(\text {parceiros })}\right) f\left(s\left(\mathbf{x}_{i}, \mathbf{x}_{j}\right) \mid \mathbf{x}_{i}, \mathbf{x}_{j} \text { não são parceiros }\right)}
$$

em que $p_{(\text {parceiros })}$ é a probabilidade dos objetos $\mathbf{x}_{i}$ e $\mathbf{x}_{j}$ pertencerem ao mesmo grupo, $s\left(\mathbf{x}_{i}, \mathbf{x}_{j}\right)$ é a similaridade entre $\mathbf{x}_{i}$ e $\mathbf{x}_{j}$ e $f$ é a função de densidade entre os objetos. O CLICK ainda considera que os valores intra-grupos e entre grupos seguem distribuições gaussianas com médias e variâncias diferentes. Portanto, a Equação (2.21) pode ser descrita por meio do teorema de Bayes como:

$$
w_{\mathbf{x}_{i}, \mathbf{x}_{j}}=\log \frac{p_{(\text {parceiros })} \sigma_{B}}{\left(1-p_{(\text {parceiros })}\right) \sigma_{W}}+\frac{\left(s\left(\mathbf{x}_{i}, \mathbf{x}_{j}\right)-\mu_{B}\right)^{2}}{2 \sigma_{B}^{2}}-\frac{\left(s\left(\mathbf{x}_{i}, \mathbf{x}_{j}\right)-\mu_{W}\right)^{2}}{2 \sigma_{W}^{2}}
$$

em que $\mu_{B}, \sigma_{B}^{2}, \mu_{W}$ e $\sigma_{W}^{2}$ são as médias e as variâncias das similaridades entre grupos e intra-grupos, respectivamente. Estes parâmetros podem ser estimados por conhecimento prévio ou por meio de métodos de estimação (Duda et al., 2001). CLICK checa recursivamente os subgrafos gerados e constrói uma lista de componentes satisfazendo uma função-objetivo. Subgrafos que incluem apenas um nó formam seus próprios grupos e são 
separados para manipulação futura. CLICK é baseado no algoritmo de corte no peso mínimo publicado por Hao \& Orlin (1994), que possui complexidade $O\left(n_{o}^{2} \sqrt{n_{a}}\right)$. Heurísticas adicionais podem ser adotadas para acelerar o desempenho do algoritmo.

\subsubsection{Algoritmos de agrupamento hierárquico}

Algoritmos hierárquicos (Duda et al., 2001) resultam em uma sequência aninhada de partições. Eles podem ser divididos em duas abordagens: a aglomerativa e a divisiva. A abordagem aglomerativa começa com $n_{o}$ grupos com um único objeto e forma a sequência de partições aglomerando os grupos a cada nível. A abordagem divisiva começa com um grupo com todos os objetos e forma a sequência de partições dividindo os grupos sucessivamente.

No agrupamento hierárquico, as soluções são tipicamente representadas por um dendrograma (Jain et al., 1999). Um dendrograma consiste de camadas de nós, cada nó representando um grupo. Algumas linhas conectam os nós, representando grupos aninhados. O corte de um dendrograma na horizontal significa uma partição ou agrupamento em um número específico de grupos. A Figura 2.3 ilustra o processo (Jain et al., 1999).

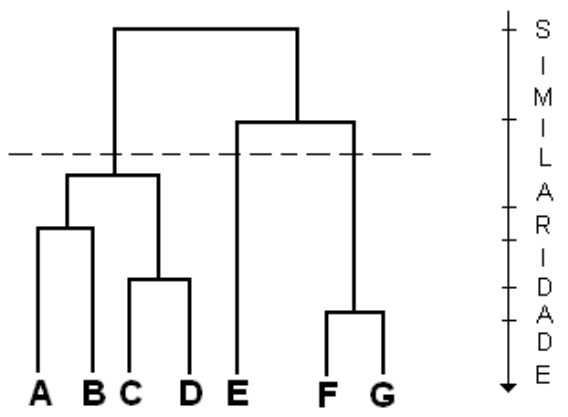

Figura 2.3: Exemplo de dendrograma

Algumas vantagens do agrupamento hierárquico são a sua flexibilidade em relação ao nível de granularidade, possibilidade de uso de qualquer medida de similaridade e aplicação a qualquer tipo de atributo, uma vez que os algoritmos não utilizam os valores dos atributos diretamente, mas sim as dissimilaridades entre os objetos. Em geral os algoritmos são determinísticos e não possibilitam a alteração dos grupos uma vez que esses sejam construídos.

Dentre os algoritmos hierárquicos, merecem destaque os algoritmos que utilizam métricas de integração (linkage metrics), bastante utilizados em combinação de agrupamentos (Fred \& Jain, 2002a; Kuncheva et al., 2006). As métricas de integração são medidas de proximidade entre subconjuntos de pontos, utilizadas para gerar grupos de formas arbitrárias entre objetos similares (Jain et al., 1999).

Basicamente, algoritmos que utilizam métricas de integração dividem a base de dados em $n_{o}$ grupos com apenas um objeto cada (singleton). Em seguida, estes grupos são aglomerados iterativamente com grupos similares, formando grupos maiores a cada itera- 
ção. A similaridade entre os grupos é obtida por meio da métrica de integração utilizada. Quando a métrica utilizada é a ligação simples (single-link), a similaridade entre os grupos é dada pela maior similaridade entre objetos de grupos distintos. O algoritmo hierárquico de ligação completa (complete-link) obtém a similaridade entre grupos pela menor similaridade entre objetos destes grupos, e o algoritmo de ligação média (average-link) considera a similaridade média entre os objetos dos grupos como a similaridade entre os grupos. O processo é repetido até que um determinado critério de parada seja atingido.

Os algoritmos que utilizam métricas de integração apresentam complexidade computacional $O\left(n_{o}^{2} \cdot \log n_{o}\right)$ em relação ao número de objetos, se os resultados dos cálculos das similaridades entre grupos forem armazenados em todas as iterações do algoritmo. Por serem baseadas na similaridade entre um par de objetos, as métricas single-link e complete-link são particularmente sensíveis a ruídos e outliers (Jain et al., 1999).

\subsubsection{Ward}

O algoritmo de agrupamento de variância mínima de Ward é um dos métodos de agrupamento hierárquicos mais conhecidos (Ward, 1963). Assim como outros algoritmos, o algoritmo tem como principal objetivo a redução da variância dos grupos formados. Por ser aglomerativo, o algoritmo é iniciado com $n_{o}$ grupos de um único objeto e termina com um único grupo contendo todo o conjunto de dados. A cada passo, ele aglomera a dupla de grupos que resultará no menor incremento da variância dos grupos, ou seja, o menor aumento na soma das dissimilaridades entre os objetos do grupo e seu centróide. Este índice também é minimizado pelo algoritmo $k$-médias (Seção 2.4.6) e é dado pela Equação (2.25). Para escolher qual dupla será aglomerada, o algoritmo irá tentar todas as aglomerações de duplas possíveis, calcular o valor da variância para cada aglomeração e selecionar a menor. O processo é repetido até que um único grupo seja formado.

Por ser um algoritmo hierárquico, o algoritmo de Ward possui complexidade computacional $O\left(n_{o}^{2} \cdot \log n_{o}\right)$, no pior caso, e propaga os grupos formados durante suas iterações (Romesburg, 2004).

\subsubsection{Balanced Iterative Reducing and Clustering using Hierarchies (BIRCH)}

O objetivo do algoritmo BIRCH (Zhang et al., 1996) consiste em gerar pequenos subgrupos iniciais que serão posteriormente agrupados para formar grupos maiores. Devido ao uso de uma estrutura de dados chamada árvore $\mathrm{CF}$, o algoritmo reduz o custo de agrupar grandes conjuntos de dados, de forma a resultar em uma complexidade linear em relação ao número de objetos $\left(O\left(n_{o}\right)\right)$ (Zhang et al., 1996). Entretanto, essa complexidade é multiplicada por constantes relacionadas à construção e utilização da árvore $\mathrm{CF}$.

Cada subgrupo $S C_{i}$ é representado por uma tripla $\left(\left|S C_{i}\right|, \mathbf{s u m l}_{i}\right.$, sums $\left._{i}\right)$ que resume as informações a respeito dos objetos que ele representa. Nesta tripla, $\left|S C_{i}\right|$ é a cardinalidade do sub-grupo, $\mathbf{s u m l}_{i}$ é a soma linear dos objetos do subgrupo, dada pela Equação (2.23), e sums $_{i}$ é a soma quadrática dos objetos do subgrupo, calculada pela Equação (2.24). 
Adicionalmente, $\mathbf{x}_{i j}$ representa o $j$-ésimo objeto do $i$-ésimo grupo e $\mathbf{x}_{i j}^{T} \cdot \mathbf{x}_{i j}$ é produto interno do vetor $\mathbf{x}_{i j}$ por ele mesmo.

$$
\begin{gathered}
\text { suml }_{i}=\sum_{j=1}^{\left|S C_{i}\right|} \mathbf{x}_{i j} \\
\text { sums }_{i}=\sum_{j=1}^{\left|S C_{i}\right|} \mathbf{x}_{i j}^{T} \cdot \mathbf{x}_{i j}
\end{gathered}
$$

Essas triplas são armazenadas nos nós de uma árvore, cuja hierarquia é utilizada para representar os grupos formados. Os objetos são adicionados a essa árvore sequencialmente, de forma a construí-la dinamicamente. Quando adicionado, o objeto irá pertencer ao subgrupo do nó folha mais similar a ele, se esse subgrupo não resultar em um diâmetro maior que um limiar pré-definido. Caso o diâmetro ultrapasse esse limiar, o objeto formará um novo subgrupo, se o nó folha não tiver ultrapassado um número máximo de subgrupos pré-determinado. Porém, se o nó folha tiver ultrapassado esse número máximo, ele é dividido em dois nós e sua divisão é propagada pelos nós anteriores até a raiz. A construção da árvore também possui um procedimento para a remoção de outliers.

Uma deficiência desse algoritmo é o fato de apresentar um desempenho ruim quando os grupos não possuem tamanho e forma uniformes (Faceli et al., 2005a) e não convexa (Halkidi et al., 2001). O algoritmo apresenta alguns parâmetros a serem definidos, como fator de divisão e limiar dos diâmetros dos grupos, que restringem o tamanho dos grupos e o formato do agrupamento gerado, resultando em partições não naturais (Halkidi et al., 2001). Além disso, o resultado do algoritmo depende da ordem em que os dados são apresentados (Halkidi et al., 2001).

\subsubsection{Clustering Using REpresentatives (CURE)}

Com o objetivo de aumentar a robustez à presença de outliers, o algoritmo CURE (Guha et al., 1998) utiliza um conjunto de objetos para representar os grupos a que pertencem. De modo geral, o algoritmo inicia com $n_{o}$ grupos, cada um contendo um único objeto, e aglomera o par mais similar a cada passo. Ao determinar a dissimilaridade entre os pares de grupos, um número pré-definido de objetos representativos é armazenado para cada grupo. Estes objetos são obtidos pela escolha de pontos bem espalhados no grupo, na tentativa de capturar a forma física e geométrica do grupo. Em seguida, a dissimilaridade destes objetos à média do grupo a que pertencem é reduzida por meio da divisão por uma constante, com o objetivo de reduzir a influência de anomalias da superfície do grupo e outliers. Em seguida, a dissimilaridade entre dois grupos se torna a dissimilaridade entre os objetos que os representam.

O algoritmo necessita da definição prévia de parâmetros como o número de objetos representantes por grupos e a razão utilizada na divisão das dissimilaridades entre estes objetos e o centro de seu grupo. O algoritmo possui complexidade computacional de 
$O\left(n_{o}^{2} \log n_{o}\right)$ (Halkidi et al., 2001; Xu \& Wunsch, 2005).

\subsubsection{Algoritmo k-médias}

Um dos algoritmos de maior impacto na área de mineração de dados (Wu et al., 2008; Wu, 2009), o método $k$-médias e suas variantes vêm sendo investigados a quase meio século (Steinley, 2006). Atualmente, ele é o algoritmo particional mais usado na prática por ser simples, de fácil entendimento, escalável e pode ser facilmente modificado para lidar com fluxo e grandes bases de dados (Wu et al., 2008; Wu, 2009). Por estes motivos, o algoritmo $k$-médias será um dos algoritmos de agrupamento de maior interesse deste trabalho.

O principal objetivo do algoritmo consiste em particionar o conjunto de dados $X$ em $k$ grupos com base em uma medida de dissimilaridade fornecida (Jain \& Dubes, 1988). Inicialmente, cada objeto pertencente ao conjunto de dados é tratado como um ponto em um espaço $n_{a}$-dimensional, em que $n_{a}$ é o número de atributos deste objeto. O algoritmo básico inicializa os grupos por meio de um conjunto de $k$ protótipos, ou seja, pontos que representam estes grupos. Ao contrário do algoritmo $k$-medóides, esse protótipo não é necessariamente um objeto do conjunto de dados, mas a média dos objetos do grupo chamada de centróide. De acordo com a medida de similaridade utilizada, os objetos são adicionados ao grupo cujo protótipo seja mais similar, aplicando algum critério de desempate caso seja necessário. A cada iteração do $k$-médias, um vetor média, chamado de centróide, é calculado para cada grupo. Em seguida, os objetos são realocados ao grupo com centróide mais similar, seguindo o mesmo critério de desempate aplicado anteriormente. O recálculo dos centróides e a realocação de objetos são repetidos até que algum critério de parada seja satisfeito.

A função-objetivo do $k$-médias é descrita pela Equação (2.25), em que $\mathbf{c}_{i}$ é o centróide do grupo $C_{i}$ e $d\left(\mathbf{x}_{j}, \mathbf{c}_{i}\right)$ é a distância Euclidiana ao quadrado entre o objeto $\mathbf{x}_{j}$ e o centróide $\mathbf{c}_{i}$. A meta do algoritmo é minimizar a distância Euclidiana ao quadrado entre cada ponto e o centróide do grupo ao qual ele pertence, ou seja, minimizar o valor da função-objetivo obj dada pela Equação (2.25) para $k$ grupos. Essa função-objetivo tende a formar grupos de formato hiperesférico de mesmo tamanho e bem separados (Halkidi et al., 2001).

$$
\min _{\mathbf{c}_{1}, \ldots, \mathbf{c}_{k}} o b j=\sum_{i=1}^{k} \sum_{\mathbf{x}_{j} \in C_{i}} d\left(\mathbf{x}_{j}, \mathbf{c}_{i}\right)
$$

O Algoritmo 1 detalha uma versão típica do algoritmo $k$-médias. A medida que os valores resultantes da Equação (2.25) decrescem, o algoritmo converge de forma que não haja diferença significativa nos valores de $\mathbf{c}_{i}$ entre duas iterações consecutivas do algoritmo. Para isto, pode-se utilizar um limiar $\varepsilon$ para determinar se esta diferença é significativa ou não. Além disso, o algoritmo pode ser limitado a um número máximo de iterações $t$, determinado a priori.

Inicializar os protótipos dos grupos de maneira aleatória pode fazer com que alguns 


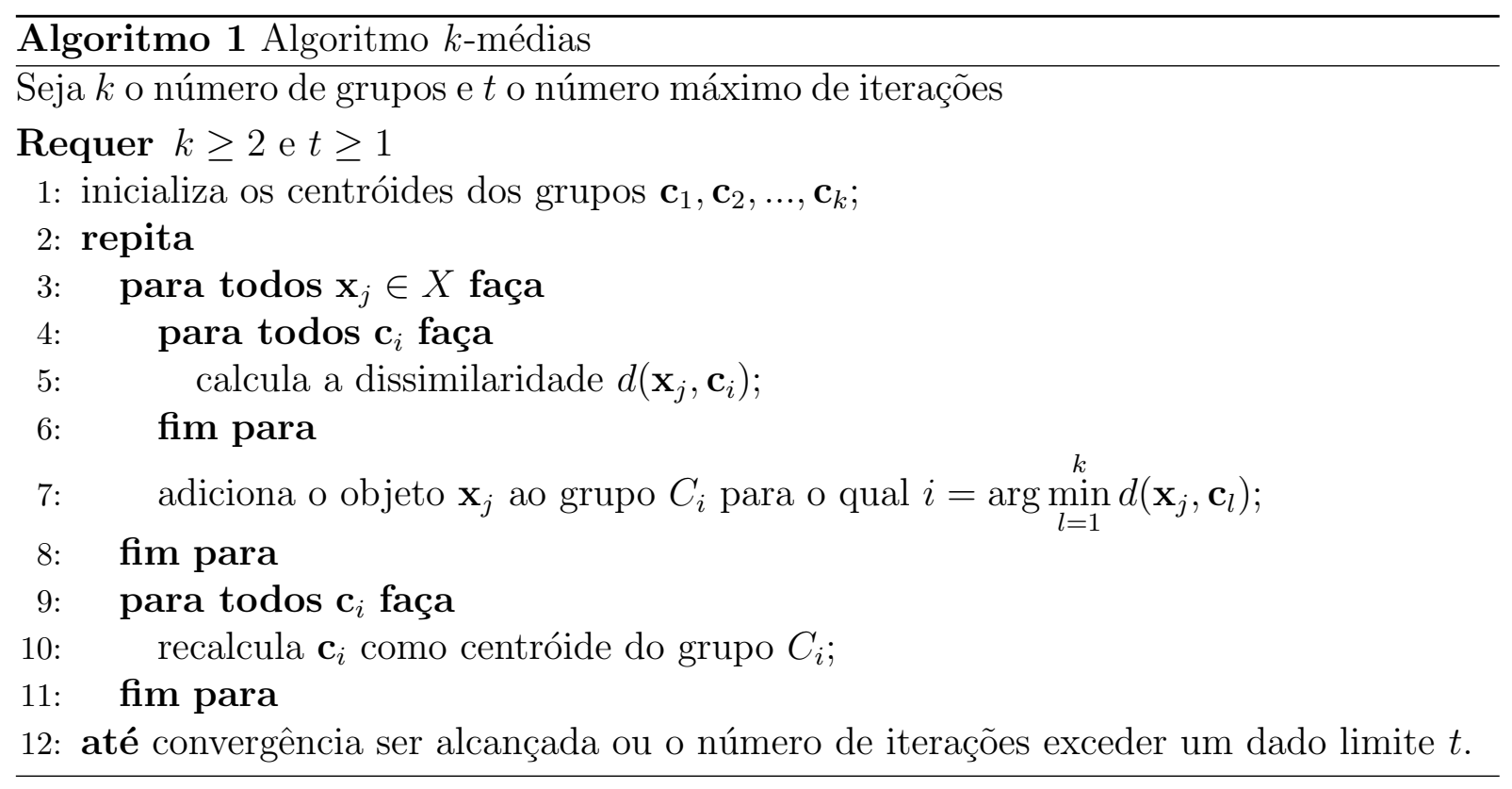

grupos se tornem vazios, especialmente quando o número de grupos é superestimado. Neste caso, alguns protótipos podem se tornar mais distantes dos objetos do que os demais. Estes objetos são, portanto, adicionados a outros grupos, o que torna o grupo de origem vazio e faz com que ele seja descartado. Isto pode gerar uma partição com um número de grupos diferente do parâmetro pré-estabelecido $k$, o que pode ser interessante caso o valor utilizado do parâmetro $k$ seja superestimado. Porém, nem sempre se espera obter um número de grupos diferente do pré-estabelecido (e.g. no caso de experimentos com número de grupos fixo), o que faz com que seja importante manter ao menos um objeto em cada grupo.

Desconsiderando o cálculo da dissimilaridade entre objetos e centróides, o tempo computacional do algoritmo $k$-médias é estimado como $O\left(t \cdot n_{o} \cdot k\right)$, em que $n_{o}$ é o número total de objetos na base de dados e $t$ o número máximo de iterações (Wu et al., 2008; Wu, 2009). Se considerarmos, por exemplo, a distância Euclidiana (Seção 2.3.2) como a medida de dissimilaridade utilizada, o algoritmo atinge complexidade total de $O\left(t \cdot n_{o} \cdot k \cdot n_{a}\right)$, em que $n_{a}$ é o número total de atributos.

Apesar das vantagens, como simplicidade e complexidade linear em relação ao número de objetos, o algoritmo $k$-médias também apresenta alguns problemas: (i) o número de grupos deve ser escolhido a priori; (ii) o algoritmo é sensível à inicialização dos protótipos e pode ficar preso em mínimos locais. Dentre as formas de se estimar o número de grupos $k$ e amenizar a sensibilidade do algoritmo à inicialização de protótipos, podemos citar estratégia de execuções múltiplas aleatórias e ordenadas do algoritmo (Seção 2.4.6.1) ou a utilização de heurísticas, como feito nos algoritmos Bisecting k-means (Seção 2.4.6.2) e Xmeans (Seção 2.4.6.3). Outra forma de se estimar $k$ e reduzir a sensibilidade à inicialização é por meio de uso de algoritmos evolutivos, a serem apresentados no Capítulo 3. 


\subsubsection{Métodos sistemáticos para estimar o número de grupos $k$}

Determinar o número de grupos $k$ de forma prática geralmente é um procedimento baseado em dois passos. Primeiramente o algoritmo é executado múltiplas vezes, de forma que o número de grupos $k$ das partições geradas varie dentro de um intervalo prédefinido, para diferentes inicializações de protótipos. Segundo, é necessário utilizar um índice de validação para estimar a qualidade das partições geradas. Alguns destes índices são apresentados na Seção 2.5 .

Uma vez que tenha sido escolhida uma medida apropriada para avaliar a qualidade relativa das partições, é possível estudar estratégias para estimar o número de grupos com o algoritmo $k$-médias. Um dos métodos consiste em executar o algoritmo $k$-médias para um número crescente de grupos $k$, dentro de um determinado intervalo. Para cada valor de $k$, um número $n_{\pi, k}$ de partições devem ser geradas com diferentes inicializações. A partição final é escolhida dentre o conjunto obtido, por meio da qualidade aferida pelo índice de validação relativo. Um procedimento análogo consiste em procurar uma inflexão em um gráfico com as médias dos resultados de validação pelo número de grupos.

Um exemplo de pseudo-código deste tipo de execução, aqui chamado de Múltiplas Execuções Ordenadas de $k$-médias (OMRk, do inglês Ordered Multiple Runs of $k$-means), é apresentado no Algoritmo 2. Esse método foi originalmente desenvolvido por Campello et al. (2009) para o algoritmo fuzzy c-means e adaptado para o $k$-médias em Naldi et al. (2009, 2011).

\begin{tabular}{l}
$\overline{\text { Algoritmo } 2 \text { Algoritmo }(O M R k)}$ \\
\hline Sendo $k_{\max }$ o número máximo de grupos permitido, $k^{*}$ o número de grupos a ser \\
estimado pelo algoritmo, $\mathrm{S}_{C}$ o critério de parada para uma execução de $k$-médias, \\
$v_{V C}$ o valor retornado pelo índice de validação para uma determinada partição, $v_{V C}^{*}$ \\
o maior valor encontrado pelo índice de validação escolhido e $n_{\pi, k}$ o número de parti- \\
ções geradas com diferentes inicializações pelo algoritmo para cada $k \leq k_{\max }$. Sabendo \\
que o menor valor possível para $v_{V C}$ é $v_{m i n}$, o algoritmo $O M R k$ pode ser resumido a seguir:
\end{tabular}

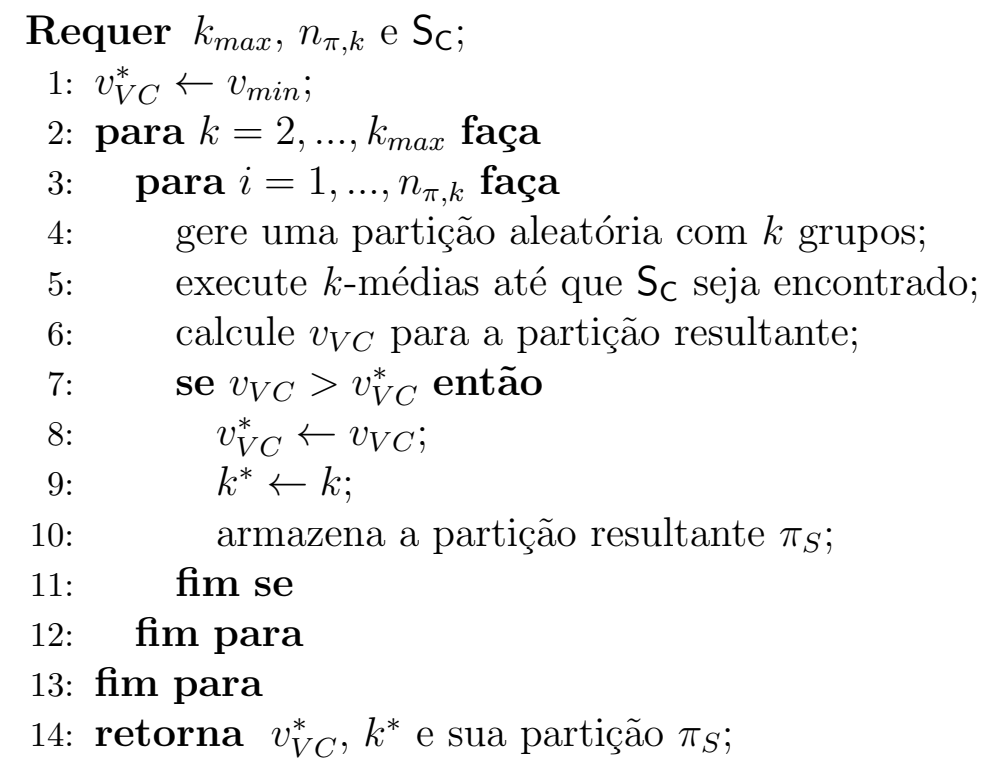


Outro método prátic consiste em executar $k$-médias múltiplas vezes com valores aleatórios de $k$, distribuídos entre 2 e $k_{\max }$. Também é importante que as inicializações dos protótipos possuam certa diversidade. Assim como no algoritmo $O M R k$, as partições geradas serão avaliadas com algum índice de validação relativo, de forma a possibilitar a escolha de uma partição dentre as resultantes. Dentre os critérios de parada que podem ser utilizados pelo algoritmo, podemos citar a interrupção depois de um determinado número de execuções $(e)$ de $k$-médias ou após a geração de uma partição com um valor de validação igual ou maior que um determinado valor de referência $v_{R}$. Um exemplo de execução aleatória de $k$-médias é ilustrado no Algoritmo 3, chamado de Múltiplas Execuções de $k$-médias ( $M R k$, do inglês Multiple Runs of k-means). Assim como o OMRk, esse método foi originalmente desenvolvido por Campello et al. (2009) para o algoritmo fuzzy c-means e adaptado para o $k$-médias em Naldi et al. $(2009,2011)$.

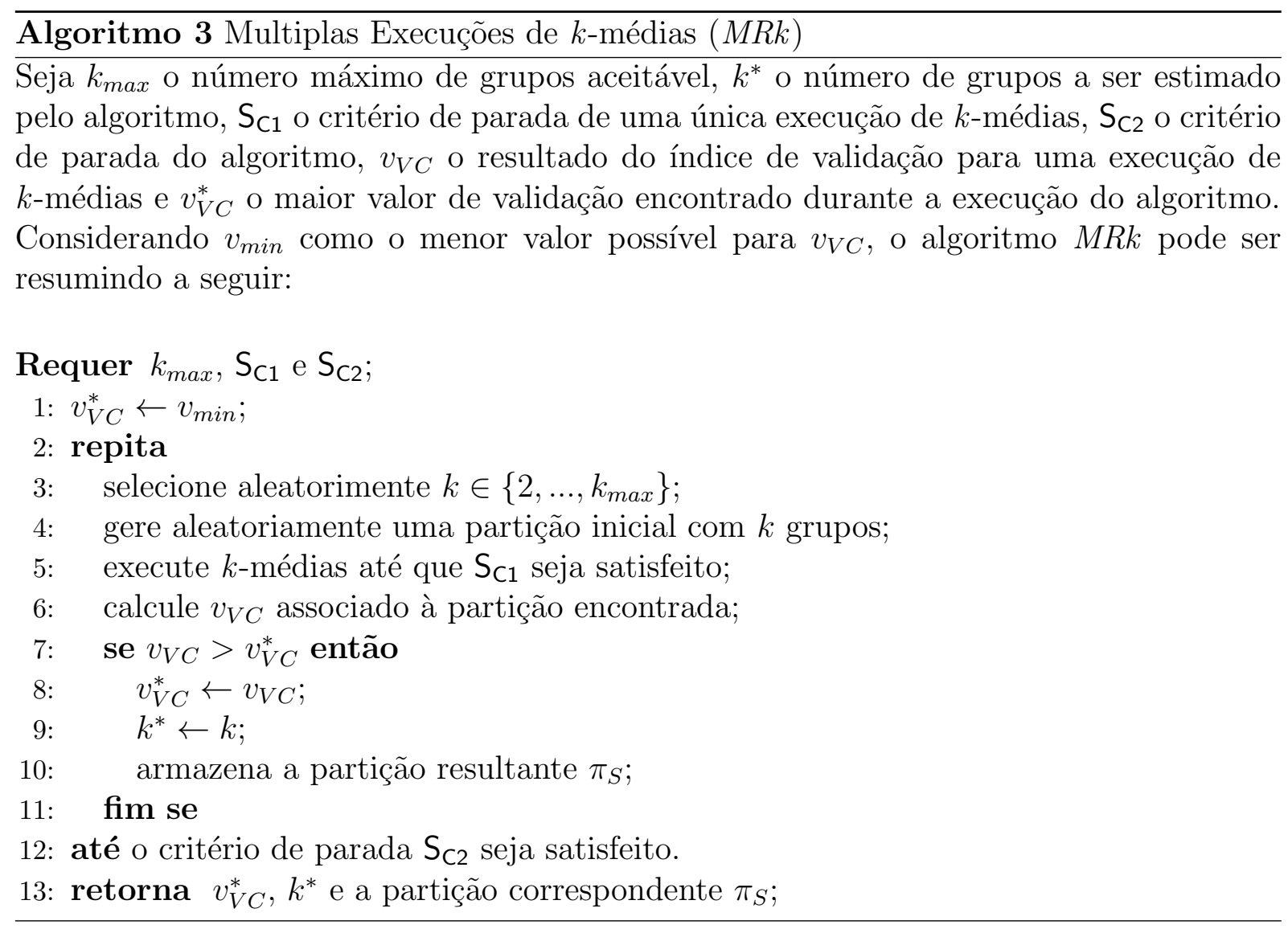

Estima-se que a complexidade dos algoritmos $O M R k$ e $M R k$ seja $O\left(n_{o} \cdot k_{\max }^{2}\right)$. Detalhes da análise de complexidade assintótica destes algoritmos são descritos na Seção 4.2.

\subsubsection{Bisecting k-means}

O algoritmo Bisecting k-means (Steinbach et al., 2000) consiste em uma variação hierárquica do algoritmo $k$-médias (Seção 2.4.6). Em cada iteração, ele seleciona um grupo e o divide, de forma a gerar uma hierarquia. Seu funcionamento pode ser descrito pelos passos: 
1. O algoritmo é inicializado com um único grupo que contenha todos os objetos do conjunto de dados.

2. Seleciona-se um grupo $C_{s}$.

3. Divide-se $C_{s}$ por meio da aplicação de $k$-médias, com $k=2$.

4. Repete-se o passo anterior por inter vezes e seleciona-se a divisão que produza o agrupamento com a maior similaridade entre objetos e os centros de seus grupos.

5. Repete-se os passos 2,3,4 até que o número de grupos desejado seja alcançado.

O grupo $C_{s}$ pode ser escolhido de diversas formas, seja pelo maior tamanho (e.g., número de objetos ou diâmetro) ou menor similaridade entre os objetos e centróide (e.g. volume). O número de vezes que o algoritmo $k$-médias é aplicado por iteração, inter, e o número de grupos da partição final são parâmetros a serem definidos pelo usuário. O Bisecting k-means pode resultar em uma única partição ou em uma hierarquia e sua complexidade varia com o método de seleção de $C_{s}$. Se a seleção for feita a partir da quantidade de objetos do grupo, a complexidade do algoritmo é linear $\left(O\left(n_{o} \cdot k\right)\right)$ (Steinbach et al., 2000). O uso de métodos mais sofisticados, como diâmetro ou volume, pode aumentar a complexidade do algoritmo para $O\left(n_{o}^{2} \cdot k\right)$, no pior caso. Assim como outros algoritmos hierárquicos, uma vez que um grupo seja formado, sua estrutura se propaga pelas iterações posteriores.

\subsubsection{X-means}

O algoritmo X-means foi proposto por Pelleg \& Moore (2000) para gerar uma partição do conjunto de dados por meio do uso de $k$-médias. O algoritmo recebe como parâmetro de entrada a base de dados a ser particionada e um intervalo de número de grupos, aqui representado como $\left[k_{\min }, k_{\max }\right]$ e pode ser descrito pelos seguintes passos:

1. Inicializa-se o algoritmo por meio da aplicação de $k$-médias ao conjunto de dados, de forma a gerar uma partição com $k_{\text {min }}$ grupos.

2. A partição resultante é avaliada, armazenando-a em seguida.

3. Realiza-se a divisão de cada grupo em dois, por meio de $k$-médias.

4. Cada divisão efetuada é avaliada e as divisões que geraram as melhores partições são mantidas, de forma a não gerar mais do que $k_{\text {max }}$ grupos.

5. Caso nenhuma partição seja mantida, divide-se uma proporção dos grupos formados inicialmente (usualmente a metade), a partir das divisões que resultem nas melhores avaliações. Respeita-se o limite de $k_{\max }$ grupos.

6. O algoritmo $k$-médias é aplicado para o refinamento da partição resultante. 
7. Se a partição resultante for a melhor avaliada, ela é armazenada.

8. Caso a partição resultante possua $k_{\max }$ grupos, o algoritmo pára retornando a partição melhor avaliada. Caso contrário, o algoritmo retorna ao Passo 3.

O índice BIC (Mirkin, 2005) é utilizado por Pelleg \& Moore (2000) para avaliar as partições durante a execução do algoritmo. Os protótipos fornecidos ao $k$-médias são iniciados na mesma posição do centróide original do grupo a ser dividido e, em seguida, são deslocados no sentido oposto de uma direção escolhida aleatoriamente dentro do espaço de dados. O valor do deslocamento deve ser proporcional ao tamanho da região do grupo. Em geral, essas divisões são avaliadas pelo índice $B I C$, que indica se a divisão realizada gerou melhora, ou não, para a qualidade da partição. O algoritmo possui complexidade $O\left(n_{o} \cdot k^{2}\right)$.

\subsection{Validação de agrupamentos}

Para determinar se os grupos são significativos ou não, o resultado do agrupamento é validado para aferir a qualidade da solução encontrada. Vários trabalhos citam índices comumente empregados (Milligan \& Cooper, 1985; Yeung et al., 2001; Jiang \& Zhang, 2004; Handl et al., 2005; Faceli et al., 2005b; Meilă, 2007; Vendramin et al., 2008, 2009, 2010). Estes trabalhos avaliam a qualidade dos grupos formados, com base na idéia de que, se eles refletirem a estrutura dos dados, então os índices de validação devem indicar um bom resultado.

Os índices de validação podem ser divididos em três tipos: externos, internos e relativos. Índices externos medem a similaridade entre dois agrupamentos de um mesmo conjunto de dados, geralmente utilizados para comparar o agrupamento obtido com um agrupamento conhecido, também chamado de "real" ou "gold standard", construído com base na intuição ou conhecimento prévio sobre a estrutura dos dados. Já os índices internos avaliam o agrupamento resultante a partir dos próprios dados unicamente, sem nenhum conhecimento externo ao agrupamento analisado. Os índices relativos são índices internos que podem ser utilizados para comparar a qualidade relativa entre agrupamentos, por meio da diferença quantitativa entre os valores de validação obtidos.

Nas Seções 2.5.1 e 2.5.2, são descritos alguns índices externos e internos de interesse para este trabalho. Esses índices podem ser utilizados tanto para medir a qualidade das partições geradas quanto para compará-las e por isso são relativos.

\subsection{1 Índices Externos}

Como dito anteriormente, índices de validação externos objetivam mensurar quanto um agrupamento obtido se aproxima da estrutura conhecida dos dados. Para isso, os índices externos mais tradicionais comparam a partição resultante $\pi_{r}$ com uma partição referência $\pi_{g}$ ("gold standard "), construída com base na intuição ou conhecimento a priori 
sobre a estrutura real dos dados. Estes índices se baseiam em informações a respeito da relação entre os objetos de ambas as partições.

Não é possível determinar a equivalência entre grupos de partições distintas unicamente por meio de seus rótulos, pois grupos idênticos podem possuir rótulos distintos. Para estabelecer esta equivalência, é necessário considerar a relação entre seus objetos. Por este motivo, os índices de validação externos apresentados aqui consideram a relação entre pares de objetos para determinar esta equivalência. Dado o par de objetos $\mathbf{x}_{i}$ e $\mathbf{x}_{j}$ pertencente ao conjunto de dados $X$, tal que $i \neq j$, os grupos $C_{r} \in \pi_{r}$ e $C_{g} \in \pi_{g}$, consideremos as quatro situações apresentadas a seguir:

- 11: $\left(\mathbf{x}_{i} \in C_{r}\right)$ e $\left(\mathbf{x}_{j} \in C_{r}\right)$ em $\pi_{r},\left(\mathbf{x}_{i} \in C_{g}\right)$ e $\left(\mathbf{x}_{j} \in C_{g}\right)$ em $\pi_{g}$

- 01: $\left(\mathbf{x}_{i} \in C_{r}\right)$ e $\left(\mathbf{x}_{j} \notin C_{r}\right)$ em $\pi_{r},\left(\mathbf{x}_{i} \in C_{g}\right)$ e $\left(\mathbf{x}_{j} \in C_{g}\right)$ em $\pi_{g}$

- 10: $\left(\mathbf{x}_{i} \in C_{r}\right)$ e $\left(\mathbf{x}_{j} \in C_{r}\right)$ em $\pi_{r},\left(\mathbf{x}_{i} \in C_{g}\right)$ e $\left(\mathbf{x}_{j} \notin C_{g}\right)$ em $\pi_{g}$

- 00: $\left(\mathbf{x}_{i} \in C_{r}\right)$ e $\left(\mathbf{x}_{j} \notin C_{r}\right)$ em $\pi_{r},\left(\mathbf{x}_{i} \notin C_{g}\right)$ e $\left(\mathbf{x}_{j} \in C_{g}\right)$ em $\pi_{g}$

Seja $n p_{t}$ o número de todas as possíveis combinações de pares de objetos do conjunto de dados $\left(n p_{t}=n_{o}\left(n_{o}-1\right) / 2\right), n p_{11}$ o número de pares de objetos na situação $11, n p_{01}$ o número de pares de objetos na situação 01, $n p_{10}$ e $n p_{00}$ os números de pares de objetos nas situações 10 e 00, respectivamente. Algumas destas variáveis serão utilizadas nos índices a serem definidos nesta seção.

\subsubsection{1 Índice Jaccard}

O índice Jaccard, também conhecido como coeficiente de similaridade de Jaccard (1908), consiste em um índice utilizado para comparar a similaridade entre conjuntos de amostras. Quando utilizado para calcular a probabilidade de dois objetos pertencerem ao mesmo grupo em ambas as partições, o índice Jaccard é dado pela Equação (2.26):

$$
\operatorname{Jaccard}\left(\pi_{r}, \pi_{g}\right)=\frac{n p_{11}}{n p_{11}+n p_{01}+n p_{10}}
$$

O índice de Jaccard resulta em valores entre [0,1], de forma que quanto mais diferentes as partições, mais próximo de 0 será o valor retornado, e partições idênticas resultam no

valor 1. É importante destacar que o índice de Jaccard é diferente do coeficiente de Jaccard utilizado para atributos binários, dado pela Equação 2.5.

\subsubsection{2 Índice Rand}

O índice Rand (Rand, 1971; Halkidi et al., 2001) também mede a similaridade entre duas partições. O índice Rand é calculado segundo a Equação (2.27).

$$
\operatorname{Rand}\left(\pi_{r}, \pi_{g}\right)=\frac{n p_{00}+n p_{11}}{n p_{00}+n p_{10}+n p_{01}+n p_{11}}
$$


Vale a pena observar que o índice Rand valoriza igualmente pares de objetos que estão no mesmo grupo $\left(n p_{11}\right)$ ou em grupos distintos $\left(n p_{00}\right)$ em ambas as partições (Youness \& Saporta, 2004). Essa política é questionável, especialmente se uma partição for interpretada como um conjunto de grupos de elementos unidos, o que torna a separação entre objetos uma consequência do processo de agrupamento (Denoeud, 2006).

\subsubsection{3 Índice Rand Ajustado}

Outra forte crítica ao índice Rand é que o índice não retorna valores próximos de zero para partições formadas aleatoriamente. O Rand Ajustado ( $A R$, do inglês Ajusted Rand) foi proposto por Hubert \& Arabie (1985) e faz com que o índice resulte em valores próximos de 0 quando o agrupamento é selecionado ao acaso e 1 quando o agrupamento é idêntico ao agrupamento real (Jain \& Dubes, 1988; Gordon, 1999). Contudo, o índice pode retornar valores no intervalo $[-1,1]$. Este índice é dado pela Equação (2.28):

$$
A R\left(\pi_{r}, \pi_{g}\right)=\frac{n p_{11}-\frac{\left(n p_{11}+n p_{01}\right)\left(n p_{11}+n p_{10}\right)}{n p_{t}}}{\frac{\left(n p_{11}+n p_{01}\right)+\left(n p_{11}+n p_{10}\right)}{2}-\frac{\left(n p_{11}+n p_{01}\right)\left(n p_{11}+n p_{10}\right)}{n p_{t}}}
$$

\subsection{2 Índices internos relativos}

Como descrito anteriormente, índices relativos possuem a finalidade de avaliar a qualidade relativa de partições oriundas de métodos de agrupamento distintos. Nesta seção, são apresentados alguns destes índices, que são muito utilizados na literatura.

\subsubsection{Critério de razão das variâncias}

O critério de razão das variâncias ( $V R C$, do inglês Variance Ratio Criterion) valoriza a coesão interna dos grupos e a separação externa entre grupos (Calinski \& Harabasz, 1974). A coesão interna é calculada por meio da soma das distâncias quadráticas internas aos grupos e a separação é obtida por meio da soma das distâncias quadráticas entre os grupos (Duda et al., 2001). Dada uma partição $\pi=\left\{C_{1}, C_{2}, \ldots, C_{k}\right\}$ do conjunto de dados $X=\left\{\mathbf{x}_{1}, \mathbf{x}_{2}, \ldots, \mathbf{x}_{n_{o}}\right\}$, pode se obter a soma das distâncias quadráticas internas aos grupos de uma partição $\pi$ por meio da Equação (2.29):

$$
W G S S(\pi)=\sum_{i=1}^{k} W G S S\left(C_{i}\right)
$$

em que $W G S S\left(C_{i}\right)$ é a soma das distâncias quadráticas relacionadas ao grupo $C_{i}$, calculada por meio da Equação (2.30):

$$
W G S S\left(C_{i}\right)=\sum_{\mathbf{x}_{j} \in C_{i}}\left(\mathbf{x}_{j}-\mathbf{c}_{i}\right)^{T}\left(\mathbf{x}_{j}-\mathbf{c}_{i}\right)
$$

em que $\mathbf{c}_{i}$ é o centróide do grupo $C_{i}$. Como existe uma relação direta entre calcular a 
distância entre todos os centróides dos grupos e calcular a distância entre os centróides e a média de todos os pontos do conjunto de dados, é possível calcular a soma das distâncias quadráticas entre os grupos de uma partição $\pi$ por meio da Equação (2.31) (Tan et al., 2005):

$$
B G S S(\pi)=\sum_{i=1}^{k} B G S S\left(C_{i}\right)
$$

em que $B G S S\left(C_{i}\right)$ é a soma das distâncias quadráticas entre o grupo $C_{i}$ e a média dos objetos, calculada por meio da Equação (2.32) (Tan et al., 2005):

$$
\operatorname{BGSS}\left(C_{i}\right)=\left|C_{i}\right|\left(\mathbf{c}_{i}-\overline{\mathbf{x}}\right)^{T}\left(\mathbf{c}_{i}-\overline{\mathbf{x}}\right)
$$

em que $\left|C_{i}\right|$ representa a cardinalidade do grupo $C_{i}$, utilizada como peso no cálculo de $B G S S(\pi)$, e $\overline{\mathbf{x}}$ é a média de todos os objetos do conjunto $X$. É esperado que grupos compactos e separados possuam pequenos valores de $W G S S\left(C_{i}\right)$ e grandes valores de $B G S S\left(C_{i}\right)$. O índice $V R C$ para os $n_{o}$ objetos do conjunto de dados $X$ é calculado por meio da Equação (2.33):

$$
\operatorname{VRC}(\pi)=\frac{B G S S(\pi)}{W G S S(\pi)} \times \frac{\left(n_{o}-k\right)}{(k-1)}
$$

Quanto melhor a qualidade da partição $\pi$, maior será o valor da razão entre $B G S S(\pi)$ e $W G S S(\pi)$. O termo de normalização $\left(n_{o}-k\right) /(k-1)$ previne o aumento monotônico do índice em relação ao número de grupos, o que faz do $V R C$ um índice de otimização em relação a $k$. Isso significa que, se utilizado em um agrupamento com número não conhecido (não fixo) de grupos, o $V R C$ pode ajudar a determinar este número para conjunto de dados. Também pode ser utilizado para comparar os resultados de diferentes algoritmos aplicados ao mesmo conjunto de dados, e é recomendado para grupos compactos e separados.

\subsubsection{2 Índice Davis-Bouldin}

O índice Davis-Bouldin $(D B)$ (Davies \& Bouldin, 1979) é uma função que calcula a razão entre a soma da dispersão dentro dos grupos pela dispersão entre os grupos e, por isto, está relacionado ao $V R C$. A Equação (2.34) calcula a soma da dispersão dentro dos grupos, enquanto o valor do índice para o $i$-ésimo grupo é dado pela Equação (2.35), em que $\mathbf{c}_{i}$ é o centróide do grupo $C_{i}$. O índice $D B$ para a partição $\pi$ é dado pela Equação (2.36).

$$
\begin{aligned}
S\left(C_{i}\right) & =\left(\frac{1}{\left|C_{i}\right|} \sum_{\mathbf{x}_{l} \in C_{i}} d\left(\mathbf{x}_{l}, \mathbf{c}_{i}\right)\right) \\
R\left(C_{i}\right) & =\max _{j \neq i}\left\{\frac{S\left(C_{i}\right)+S\left(C_{j}\right)}{d\left(\mathbf{c}_{i}, \mathbf{c}_{j}\right)}\right\}
\end{aligned}
$$




$$
D B(\pi)=\frac{1}{k} \sum_{i=1}^{k} R\left(C_{i}\right)
$$

O índice $D B$ não apresenta tendência monotônica em relação ao aumento ou redução do número de grupos, o que o torna propício para determinar o número de grupos mais apropriado ao conjunto de dados. O valor resultante do índice decresce conforme a qualidade da partição aumenta. O índice $D B$ não é apropriado para grupos de formas arbitrárias, sendo recomendado para grupos compactos e separados (Jain \& Dubes, 1988).

\subsubsection{3 Índices Dunn}

O índice Dunn também é apropriado para a identificação de clusters compactos e separados. O índice Dunn pode ser obtido por meio da Equação $(2.37)$, em que $\delta\left(C_{i}, C_{j}\right)$ é o índice de discordância entre os grupos $C_{i}$ e $C_{j}$, dado pela Equação $(2.38)$, e $\Delta\left(C_{i}\right)$ mede a dispersão do i-ésimo grupo e é dado pela Equação (2.39).

$$
\begin{gathered}
\operatorname{Dunn}(k)=\min _{i=1, \ldots, k}\left\{\min _{j=1, \ldots, k}\left\{\frac{\delta\left(C_{i}, C_{j}\right)}{\max _{z=1, \ldots, k} \Delta\left(C_{z}\right)}\right\}\right\} \\
\delta\left(C_{i}, C_{j}\right)=\min _{\mathbf{x}_{y} \in C_{i}, \mathbf{x}_{l} \in C_{j}} d\left(\mathbf{x}_{y}, \mathbf{x}_{l}\right) \\
\Delta\left(C_{i}\right)=\max _{\mathbf{x}_{y}, \mathbf{x}_{l} \in C_{i}} d\left(\mathbf{x}_{y}, \mathbf{x}_{l}\right)
\end{gathered}
$$

Valores altos obtidos pelo índice Dunn indicam a presença de grupos compactos e separados. Assim como outros índices relativos, este índice não apresenta tendência em relação ao número de grupos. Portanto, se o índice Dunn for utilizado para validar partições com número de grupos distintos, este poderá indicar o valor mais apropriado para $k$. Porém, o índice Dunn original, com as definições de $\delta(2.38)$ e $\Delta(2.39)$, apresenta uma alta sensibilidade a ruído. Por isto, foram desenvolvidas variações do índice mais robustas à presença de ruído e outliers. Bezdek \& Pal (1998) propuseram variações do índice e as compararam com índices $\Gamma$ modificado, $D B$ e Dunn original. Estes índices são baseados em diferentes combinações de diferentes distâncias intra-grupo e inter-grupo. As definições alternativas para $\delta\left(C_{i}, C_{j}\right)$ são:

$$
\begin{gathered}
\delta\left(C_{i}, C_{j}\right)=\max _{\mathbf{x}_{y} \in C_{i}, \mathbf{x}_{l} \in C_{j}} d\left(\mathbf{x}_{y}, \mathbf{x}_{l}\right) \\
\delta\left(C_{i}, C_{j}\right)=\frac{1}{\left|C_{i}\right|\left|C_{j}\right|} \sum_{\mathbf{x}_{y} \in C_{i}} \sum_{\mathbf{x}_{l} \in C_{j}} d\left(\mathbf{x}_{y}, \mathbf{x}_{l}\right) \\
\delta\left(C_{i}, C_{j}\right)=d\left(\mathbf{c}_{i}, \mathbf{c}_{j}\right)
\end{gathered}
$$




$$
\begin{gathered}
\delta\left(C_{i}, C_{j}\right)=\frac{1}{\left|C_{i}\right|+\left|C_{j}\right|}\left(\sum_{\mathbf{x}_{y} \in C_{i}} d\left(\mathbf{x}_{y}, \mathbf{c}_{j}\right)+\sum_{\mathbf{x}_{l} \in C_{j}} d\left(\mathbf{x}_{l}, \mathbf{c}_{i}\right)\right) \\
\delta\left(C_{i}, C_{j}\right)=\max \left\{\max _{\mathbf{x}_{y} \in C_{i}} \min _{\mathbf{x}_{l} \in C_{j}} d\left(\mathbf{x}_{y}, \mathbf{x}_{l}\right), \max _{\mathbf{x}_{l} \in C_{j}} \min _{\mathbf{x}_{y} \in C_{i}} d\left(\mathbf{x}_{y}, \mathbf{x}_{l}\right)\right\}
\end{gathered}
$$

É importante notar que a definição original dada pela Equação (2.38) é equivalente à métrica de ligação simples, enquanto as Equações (2.40), (2.41) e (2.43) são equivalentes às métricas de ligação completa e média, respectivamente, e uma versão híbrida delas. Já as Equações (2.42) e (2.44) são equivalentes à medida de distância inter-grupo do critério Davies-Bouldin (Seção 2.5.2.2) e à métrica de Hausdorff. As definições alternativas para $\Delta\left(C_{i}\right)$ são:

$$
\begin{gathered}
\Delta\left(C_{i}\right)=\frac{1}{\left|C_{i}\right|\left(\left|C_{i}\right|-1\right)} \sum_{\mathbf{x}_{y}, \mathbf{x}_{l} \in C_{i}} d\left(\mathbf{x}_{y}, \mathbf{x}_{l}\right) \\
\Delta\left(C_{i}\right)=\frac{2}{\left|C_{i}\right|} \sum_{\mathbf{x}_{y} \in C_{i}} d\left(\mathbf{x}_{y}, \mathbf{c}_{i}\right)
\end{gathered}
$$

Um estudo mais profundo dos possíveis 18 índices gerados pela combinação das medidas apresentadas é feito em Azuaje (2002), onde são utilizados no desenvolvimento de uma ferramenta capaz de determinar o melhor número de grupos para o particionamento de uma base de dados.

\subsubsection{4 Índice PBM}

Outro critério que se baseia na comparação intra-grupo e inter-grupo é o PBM (Pakhira et al., 2004), definido como:

$$
P B M=\left(\frac{1}{k} \frac{E_{1}}{E_{K}} D_{K}\right)^{2}
$$

onde $E_{1}$ representa as distâncias entre os objetos ao ponto médio da base de dados, dado pela Equação (2.48), $E_{K}$ representa as distâncias intra-grupo e é definida pela Equação (2.49) e $D_{K}$ representa a máxima distância entre os centróides dos grupos, dada pela Equação (2.50). As melhores partições são obtidas com os máximos valores do critério PBM, o que implica em maximizar as distâncias inter-grupo $\left(D_{K}\right.$ e $\left.E_{1}\right)$ e minimizar as distâncias intra-grupo $\left(E_{K}\right)$.

$$
\begin{gathered}
E_{1}=\sum_{i=1}^{n_{o}} d\left(\mathbf{x}_{i}, \overline{\mathbf{x}}\right) \\
E_{K}=\sum_{l=1}^{k} \sum_{\mathbf{x}_{i} \in \mathbf{C}_{l}} d\left(\mathbf{x}_{i}, \mathbf{c}_{l}\right)
\end{gathered}
$$




$$
D_{K}=\max _{l=1, \cdots, k} \max _{m=1, \cdots, k} d\left(\mathbf{c}_{l}, \mathbf{c}_{m}\right)
$$

\subsubsection{5 Índices silhueta}

Os índices do tipo silhueta definem a qualidade dos agrupamentos com base na proximidade entre os objetos de um determinado grupo e na distância desses objetos ao grupo mais próximo. Publicado por Rousseeuw (1987), o índice silhueta original é calculado para cada objeto de um grupo, mostrando quais objetos estão bem situados no mesmo e quais seriam situados melhor em outro grupo. O índice silhueta pode ser calculado com qualquer medida de dissimilaridade/similaridade.

Seja um objeto $\mathbf{x}_{i}$ e o grupo $C_{A}$ tal que $\mathbf{x}_{i} \in C_{A}$. Seja $a\left(\mathbf{x}_{i}\right)$ a dissimilaridade média do objeto $\mathbf{x}_{i}$ em relação a todos os demais objetos do grupo $C_{A}$ e $b\left(\mathbf{x}_{i}\right)$ a menor dissimilaridade média de $\mathbf{x}_{i}$ aos objetos de um outro grupo $C_{B}, C_{B} \neq C_{A}$. A silhueta de um objeto $\mathbf{x}_{i}$ é obtida pela Equação (2.51).

$$
\operatorname{silhouette}\left(\mathbf{x}_{i}\right)=\frac{b\left(\mathbf{x}_{i}\right)-a\left(\mathbf{x}_{i}\right)}{\max \left\{a\left(\mathbf{x}_{i}\right), b\left(\mathbf{x}_{i}\right)\right\}}
$$

Se $\mathbf{x}_{i}$ for o único objeto do grupo a que pertence, então silhouette $\left(\mathbf{x}_{i}\right)$ se torna indefinido e uma escolha neutra seria assumir silhouette $\left(\mathbf{x}_{i}\right)=0$ (Rousseeuw, 1987). O resultado obtido pela Equação (2.51) estará no intervalo [-1,1]. Se um objeto está bem situado em seu grupo, sua silhueta será positiva, caso contrário, se o objeto estiver mais próximo de outro grupo, ela será negativa. Logo, se o algoritmo utilizado garantir que os objetos estejam no grupo mais próximo, o resultado da Equação (2.51) estará no intervalo $[0,1]$.

Como a silhueta depende apenas do agrupamento resultante e não do algoritmo de agrupamento empregado, ela pode ser usada para executar uma análise dos grupos obtidos, para comparar partições geradas por diferentes algoritmos, ou diferentes execuções do mesmo algoritmo, em um mesmo conjunto de dados. Para isso, é possível calcular a silhueta de um grupo ou partição ( $A S W C$, do inglês Average Silhouette Width Criterion), por meio da média das silhuetas de seus objetos. A $A S W C$ é dada pela Equação (2.52), para um grupo $C_{j}$ a partir de seu $i$-ésimo objeto $\mathbf{x}_{j i}$, e pela Equação (2.53), para uma partição $\pi$.

$$
\begin{aligned}
A S W C\left(C_{j}\right) & =\sum_{i=1}^{\left|C_{j}\right|} \frac{\text { silhouette }\left(\mathbf{x}_{j i}\right)}{\left|C_{j}\right|} \\
A S W C(\pi) & =\sum_{i=1}^{n_{o}} \frac{\text { silhouette }\left(\mathbf{x}_{i}\right)}{n_{o}}
\end{aligned}
$$

Quanto maior o valor de $A S W C(\pi)$, melhor o posicionamento dos objetos dentro dos seus grupos, o que pode ser usado para determinar o melhor número $k$ de grupos, por 
exemplo. Para isso, um algoritmo de agrupamento pode ser utilizado para gerar partições do conjunto de dados com diversos valores de $k$ e comparar o $A S W C$ obtido entre as partições. Essa comparação pode ser feita por meio de um gráfico $(A S W C(\pi) \times k)$, onde um pico indica o valor de $k$ mais apropriado, provavelmente o maior valor para $A S W C(\pi)$.

Uma versão simplificada do índice silhueta é proposta por Hruschka et al. (2004a), onde há uma modificação nos cálculos de $a\left(\mathbf{x}_{i}\right)$ e $b\left(\mathbf{x}_{i}\right)$. Nesta versão, $a\left(\mathbf{x}_{i}\right)$ é a dissimilaridade entre o objeto $\mathbf{x}_{i}$ e o centróide $\mathbf{c}_{A}$ do grupo $C_{A}$, tal que $\mathbf{x}_{i} \in C_{A}$. Além disso, $b\left(\mathbf{x}_{i}\right)$ é a menor dissimilaridade entre $\mathbf{x}_{i}$ e o centróide $\mathbf{c}_{B}$ de um outro grupo $C_{B}, C_{B} \neq C_{A}$. Esta implementação visa reduzir o custo computacional da execução do índice de $O\left(n_{o}^{2}\right)$ para $O\left(n_{o}\right)$ e, segundo os autores, mantém uma qualidade próxima do índice original, o que é confirmado nos experimentos de Vendramin et al. (2009, 2010). Hruschka et al. (2004b) mostram que uma versão alternativa pode ser utilizada, substituindo a silhueta dada pela Equação (2.51) pela silhueta dada pela Equação (2.54), em que $\varepsilon$ é uma pequena constante necessária para o calculo de silhouette $\left(\mathbf{x}_{i}\right)$ quando $a\left(\mathbf{x}_{i}\right)=0$.

$$
\operatorname{silhouette}\left(\mathbf{x}_{i}\right)=\frac{b\left(\mathbf{x}_{i}\right)}{a\left(\mathbf{x}_{i}\right)+\varepsilon}
$$

A versão alternativa aparenta ser mais sensível a pequenas mudanças em $a\left(\mathbf{x}_{i}\right)$ e $b\left(\mathbf{x}_{i}\right)$, que, por sua vez, correspondem a mudanças significativas no agrupamento. Porém, o índice modificado não mais retorna resultados no intervalo $[-1,+1]$. Além disso, uma versão híbrida pode ser facilmente obtida a partir da combinação das versões simplificada e alternativa da silhueta.

O índice silhueta é mais apropriado para agrupamentos volumétricos com grupos gerados de acordo com distribuições Gaussianas multidimensionais hiperesféricas ou moderadamente alongadas. Vendramin et al. $(2008,2009,2010)$ mostram que o índice silhueta obtém resultados comparáveis ou melhores do que o índice $V R C$, e significantemente melhores do que os índices $D B$, Dunn e variantes para partições com estas características. Porém, assim como a maioria dos índice relativos apresentados nesta seção, ela não obtém bons resultados para grupos com formatos arbitrários (Rousseeuw, 1987).

\subsection{Considerações finais}

O principal objetivo deste capítulo foi fazer uma revisão sobre agrupamento de dados que possa guiar o leitor pelas principais etapas do processo de agrupamento. Seu foco ultrapassa a apresentação do conjunto de técnicas utilizadas neste trabalho e inclui uma análise de técnicas bem conhecidas na literatura sobre agrupamento de dados. A complexidade computacional assintótica dessas técnicas é reapresentada para o pior caso ${ }^{1}$ na Tabela 2.5 (Jain \& Dubes, 1988; Halkidi et al., 2001; Shu-Chuan Chu \& Pan, 2002).

\footnotetext{
${ }^{1}$ Como apresentado na Seção 2.4.5.2, o algoritmo BIRCH possui constantes relacionadas ao uso de árvores CF que, apesar de omitidas no cálculo assintótico da complexidade do algoritmo, podem impactar em seu desempenho.
} 
Nela, é possível notar que são poucas as técnicas que possuem complexidade computacional linear em relação a todos os parâmetros críticos ao desempenho do processo de agrupamento. Sendo assim, é importante ter em mente que um dos objetivos desta tese é investigar técnicas de agrupamentos de dados computacionalmente eficientes. Lembrando que $n_{o}$ é o número de objetos, $n_{a}$ é o número de atributos, $k$ é o número de grupos, $k_{\text {max }}$ é o número de grupos máximo a ser estimado.

\begin{tabular}{|l|c|}
\hline Algoritmo & Complexidade \\
\hline$k$-medóides & $O\left(n_{o}^{2}\right)$ \\
PAM & $O\left(k\left(n_{o}-k\right)^{2}\right)$ \\
$C L A R A$ & $O\left(k^{2}+k\left(n_{o}-k\right)\right)$ \\
$C L A R A N S$ & $O\left(k \cdot n_{o}^{2}\right)$ \\
$E M$ & $O\left(n_{o} \cdot n_{a}^{3}\right)$ \\
$D B S C A N$ & $O\left(n_{o}^{2}\right)$ \\
$C L I C K$ & $O\left(n_{o}^{2} \sqrt{n_{a}}\right)$ \\
Ward & $O\left(n_{o}^{2} \cdot \log n_{o}\right)$ \\
BIRCH & $O\left(n_{o}\right)+\mathrm{CFtree}$ \\
$C U R E$ & $O\left(n_{o}^{2} \log n_{o}\right)$ \\
$k$-médias & $O\left(n_{o} \cdot k\right)$ \\
OMRk & $O\left(n_{o} \cdot k_{\max }^{2}\right)$ \\
MRk & $O\left(n_{o} \cdot k_{\max }^{2}\right)$ \\
Bisecting k-means & $O\left(n_{o}^{2} \cdot k\right)$ \\
$X$-means & $O\left(n_{o} \cdot k^{2}\right)$ \\
\hline
\end{tabular}

Tabela 2.5: Complexidade assintótica dos algoritmos apresentados.

Nos próximos capítulos, são mostrados o desenvolvimento e aprimoramento de técnicas evolutivas de agrupamentos de dados computacionalmente eficientes. Nesses capítulos, a eficiência dessas técnicas será rigorosamente comparada com técnicas que produzem resultados de qualidade e possuem baixo custo computacional apresentadas neste capítulo. 


\section{$-\overline{3}$ \\ Algoritmos Evolutivos para Agrupamento}

Nos capítulos anteriores foi mostrado que técnicas de agrupamento de dados podem ser úteis para o estudo de problemas em várias áreas do conhecimento, porém é um dos problemas mais difíceis e desafiadores na área de aprendizado de máquina. Algoritmos Evolutivos (AEs) são meta-heurísticas amplamente conhecidas por serem efetivas para problemas de grande complexidade, aptas a obter soluções sub-ótimas em tempo computacional razoável. Investigar o uso eficiente de AEs em agrupamento de dados é parte integrante desta tese.

No Capítulo 2, foi feita uma descrição dos principais conceitos e a análise de um conjunto de técnicas de agrupamento de dados. Neste capítulo é feita uma revisão sobre a utilização de algoritmos evolutivos (AEs) aplicados a problemas de agrupamento de dados, baseada nos conceitos fundamentados e discutidos em Falkenauer (1998); Cole (1998); Naldi et al. (2007) e, principalmente, em Hruschka et al. (2009).

O capítulo é dividido da seguinte maneira: na Seção 3.1, são apresentados a definição de $\mathrm{AE}$ e os aspectos principais de sua aplicação em problemas de agrupamento de dados. $\mathrm{Na}$ Seção 3.2, é feita uma revisão de AEs que se propõem a solucionar problemas de agrupamentos particionais com um número de grupos fixo, conhecido ou arbitrado $a$ priori. Na Seção 3.3, é feita uma revisão de AEs da literatura que visam estimar um valor adequado para o número de grupos natural de um conjunto de dados e suas partições correspondentes. O AE que servirá de base para os algoritmos a serem desenvolvidos nesta tese será apresentado na Seção 3.4, incluindo detalhes da representação utilizada, estruturas auxiliares e operadores evolutivos. Para finalizar, na Seção 3.5 são feitas as considerações finais sobre o capítulo. 


\subsection{Definição e aspectos principais}

AEs são técnicas de busca e otimização utilizadas para gerar novas soluções por meio da combinação ou alteração de características daquelas que obtiverem melhor desempenho em iterações (gerações) anteriores, com o objetivo de produzir novas soluções com desempenho melhor a cada geração. Esses algoritmos são baseados na concepção darwiniana de sobrevivência do mais apto e seleção natural das espécies (Eiben \& Smith, 2007; Beasley et al., 1993).

O primeiro passo na construção de um AE típico é a construção de uma população inicial $P$ formada por indivíduos, codificados por cromossomos, que representam possíveis soluções do problema a ser resolvido. Durante o processo evolutivo, essa população é avaliada e cada indivíduo recebe uma nota (aptidão), refletindo a qualidade de sua solução para o problema em questão. Em geral, os indivíduos mais aptos são ou possuem maior probabilidade de serem selecionados e os menos aptos possuem maior probabilidade de serem descartados. Os membros selecionados podem sofrer transformações em suas características fundamentais por meio de operadores genéticos, tais como os operadores de cruzamento e mutação, gerando descendentes para a próxima geração. Em alguns casos, estratégias elitistas são utilizadas para preservar as melhores soluções. O processo é repetido até que um critério de parada seja satisfeito. Uma visão geral do funcionamento do AE típico é apresentada na Figura 3.1.

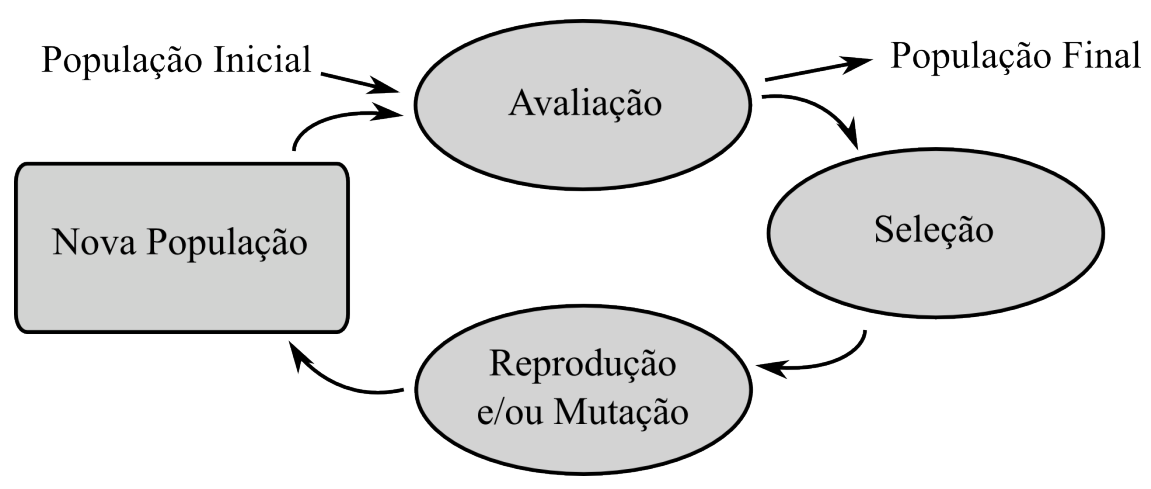

Figura 3.1: Visão geral de um Algoritmo Evolutivo.

Abordagens evolutivas têm se mostrado muito eficientes para a obtenção de soluções para problemas de agrupamento (Hruschka et al., 2009). Essas abordagens merecem destaque para resolver esse tipo de problema porque:

1. Podem evitar mínimos locais durante a busca, pois esses algoritmos procuram por várias soluções em paralelo. Mesmo que algumas dessas soluções sejam mínimos locais, novas soluções são geradas por meio de operadores genéticos;

2. Utilizam procedimentos de busca probabilísticos ao invés de regras determinísticas. Essa abordagem permite ao AE uma maior diversidade de soluções; 
3. Podem obter um grupo de soluções em potencial para um dado problema, permitindo uma análise entre elas. Essas soluções podem ser combinadas em novas soluções, com o objetivo de resultar em soluções mais robustas ou consistentes.

4. Não requerem necessariamente o emprego de conceitos de agrupamentos para implementar a busca.

Dentre os poucos trabalhos voltados a levantar o perfil da área que aborda o uso de técnicas de computação evolutiva em problemas de agrupamento, pode ser destacada uma revisão extensa feita por Hruschka et al. (2009), cuja taxonomia será utilizada neste trabalho. Outros trabalhos merecem ser citados por revisarem algoritmos genéticos, uma subdivisão dos algoritmos evolutivos, como em Falkenauer (1998); Cole (1998) e Naldi et al. (2007).

Neste trabalho, será dada ênfase em AEs aplicados em problemas de agrupamento particional exclusivo. Como discutido no Capítulo 2, os algoritmos particionais exclusivos são aqueles para os quais uma partição em $k$ grupos do conjunto de dados é obtida como resultado. Métodos utilizados para representar essas soluções, bem como operadores evolutivos, funções de aptidão e procedimentos de inicialização serão apresentados nas próximas seções. Alguns conceitos importantes, originalmente abordados por Falkenauer (1998) e definidos formalmente por Hruschka et al. (2009), são apresentados a seguir:

- Operadores orientados ou não orientados a grupos: operadores orientados a grupos trabalham diretamente na organização dos grupos, como operadores que replicam, dividem, aglomeram e eliminam grupos, enquanto operadores orientados a objetos inserem, retiram objetos de seus grupos. Operadores convencionais não orientados simplesmente alteram bits ou valores sem se preocuparem com a estrutura do agrupamento.

- Operadores sensíveis ao contexto e insensíveis ao contexto: a sensibilidade ao contexto é uma característica relacionada a operadores de cruzamento, de forma que operadores sensíveis ao contexto são: (i) orientados a grupos; e (ii) o cruzamento de dois cromossomos (distintos ou não) que codificam um mesmo agrupamento não resulta em um agrupamento distinto.

- Operadores guiados ou não guiados: ao ser aplicado, um operador guiado considera informações relativas à qualidade dos grupos, da partição ou sobre seu próprio desempenho em iterações anteriores.

Para facilitar a compreensão dos conceitos a serem a apresentados nas próximas seções, será considerada a base didática apresentada na Tabela 3.1, formada por 10 objetos $\mathbf{x}_{i}$ $(i=1,2, \ldots, 10)$ com 2 atributos, $a_{1}$ e $a_{2}$. Esses objetos foram divididos na partição didática $\pi_{d}$, contendo três grupos $\left(C_{1}, C_{2}\right.$ e $\left.C_{3}\right)$, apresentados na Figura 3.2. 


\begin{tabular}{|c|c|c|c|c|c|c|c|c|c|c|}
\hline Objeto & $\mathbf{x}_{1}$ & $\mathbf{x}_{2}$ & $\mathbf{x}_{3}$ & $\mathbf{x}_{4}$ & $\mathbf{x}_{5}$ & $\mathbf{x}_{6}$ & $\mathbf{x}_{7}$ & $\mathbf{x}_{8}$ & $\mathbf{x}_{9}$ & $\mathbf{x}_{10}$ \\
\hline$a_{1}$ & 1 & 2 & 1 & 4 & 5 & 4 & 5 & 9 & 10 & 10 \\
\hline$a_{2}$ & 1 & 1 & 2 & 4 & 4 & 5 & 5 & 1 & 1 & 2 \\
\hline Grupo & $C_{1}$ & $C_{1}$ & $C_{1}$ & $C_{2}$ & $C_{2}$ & $C_{2}$ & $C_{2}$ & $C_{3}$ & $C_{3}$ & $C_{3}$ \\
\hline
\end{tabular}

Tabela 3.1: Conjunto didático de dados.

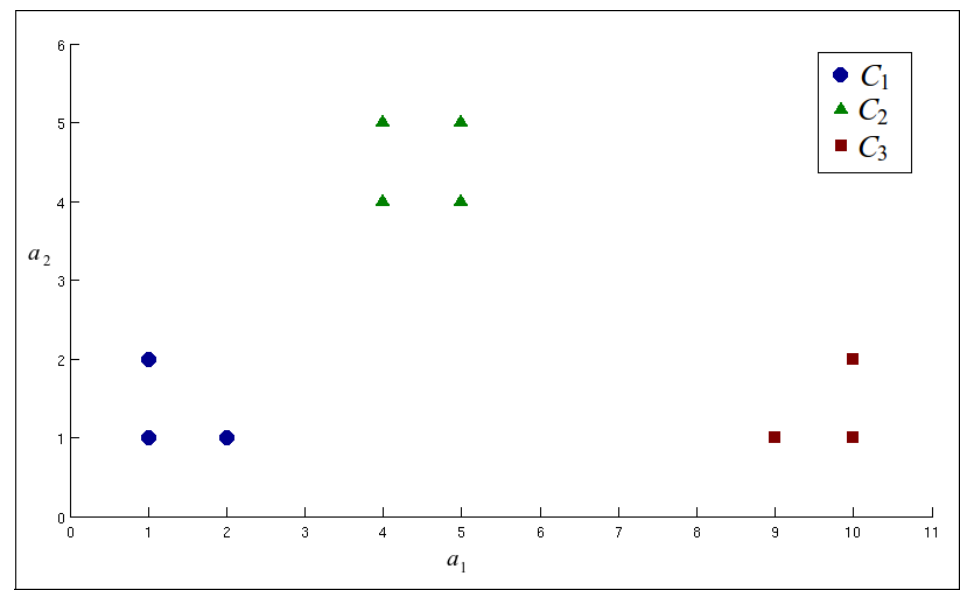

Figura 3.2: Partição $\pi_{d}$ formada a partir da base de dados didática (Tabela 3.1).

\subsection{Agrupamento com número fixo de grupos}

Boa parte dos AEs para agrupamento de dados propõem solucionar problemas com um número fixo de grupos, conhecido ou estimado a priori. Esses algoritmos são apropriados para domínios nos quais um determinado valor de $k$, ou um conjunto limitado de valores, são interessantes. Nesses problemas, algoritmos de agrupamento convencionais para um valor fixo de $k$ podem ser aplicados. Contudo, boa parte desses algoritmos são baseados em protótipos e são sensíveis à inicialização desses. Uma inicialização ruim dos protótipos pode fazer com que os algoritmos fiquem presos em soluções sub-ótimas. Avaliar todas as possíveis configurações para essas inicializações é um problema computacionalmente proibitivo (Falkenauer, 1998) e executar esses algoritmos para um conjunto limitado de protótipos iniciais pode ser ineficaz.

Como dito anteriormente, AEs mostraram-se alternativas promissoras, dentre outros métodos, para agrupamento de dados com um número fixo de grupos. A seguir, são descritas as principais características de AEs aplicados nesse tipo de problema.

\subsubsection{Codificações}

Para que uma solução seja utilizada em um AE, primeiramente é necessário que esta seja representada de alguma forma, ou seja, codificada. O resultado do processo de codificação é chamado de genótipo (geralmente composto por um único cromossomo), e representa um indivíduo na população. Os três tipos de codificação mais comuns para AEs com um número fixo de grupos são: 
- Binária: nessa codificação, cada partição é representada por um vetor binário de tamanho $n_{o}$. Cada posição desse vetor está associada a um objeto em particular, ou seja, a $i$-ésima posição do vetor corresponde ao $i$-ésimo objeto. Uma maneira de interpretar esse vetor consiste em considerar o $i$-ésimo objeto como um protótipo (nesse caso, um medóide) caso o valor da $i$-ésima posição seja 1. Caso o valor dessa posição seja 0, o $i$-ésimo objeto é inserido no grupo cujo protótipo é mais similar a ele. Para ilustrar, considere a partição didática $\pi_{d}$ (Tabela 3.1) representada pelo vetor binário [1000010001], no qual os objetos $\mathbf{x}_{1}, \mathbf{x}_{6}$ e $\mathbf{x}_{10}$ representam, respectivamente, os protótipos dos grupos $C_{1}, C_{2}$ e $C_{3}$. Os objetos $\mathbf{x}_{2}$ e $\mathbf{x}_{3}$, representados por 0 , serão adicionados ao grupo $C_{1}$, pois são mais similares ao protótipo $\mathbf{x}_{1}$ do que aos outros, com a similaridade medida por meio da distância. Da mesma forma, os objetos $\mathbf{x}_{4}$, $\mathbf{x}_{5}$ e $\mathbf{x}_{7}$ serão adicionados ao grupo $C_{2}$, enquanto os objetos $\mathbf{x}_{8}$ e $\mathbf{x}_{9}$ serão inseridos no grupo $C_{3}$. A codificação binária é uma das mais tradicionais e pode ser utilizada com operadores evolutivos tradicionais (Goldberg, 1989; Mitchell, 1998). Outra forma de representar uma solução por meio de dígitos binários consiste em utilizar uma matriz binária $\mathbf{M}$ de tamanho $k \times n_{o}$, em que $\mathbf{M}(i, j)$ assume 1 caso o $i$-ésimo grupo contenha o $j$-ésimo objeto e 0 caso contrário (Bezdek et al., 1994). A representação por matriz pode ser vantajosa em relação ao uso de um vetor por reduzir o custo de recuperação da partição e possibilitar a representação de partições não exclusivas. Contudo, ela gera redundância, ou seja, matrizes diferentes podem representar o mesmo agrupamento. Um exemplo ilustrativo de vetor binário e matriz binária é apresentado na Figura 3.3, para a partição didática presente na Tabela 3.1.

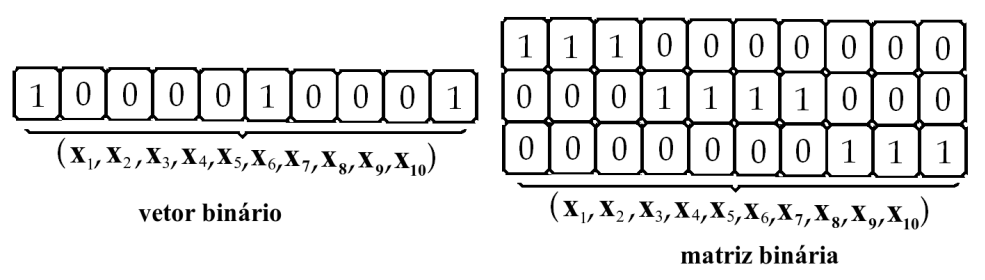

Figura 3.3: Representação por vetor binário e matriz de elementos binários.

- Inteira: esse tipo de representação pode ser implementado de duas formas. A primeira consiste em representar a partição por meio de um vetor contendo $n_{o}$ números inteiros. Assim como na representação binária, cada posição do vetor corresponde a um objeto em particular. Em outras palavras, a $i$-ésima posição do vetor corresponde ao $i$-ésimo objeto. Considerando que a partição é formada por $k$ grupos, cada posição do vetor contém o rótulo do grupo ao qual o objeto correspondente pertence, que varia de 1 a $k$. Nesse caso, a partição didática ilustrada na Figura 3.2 pode ser representada pelo vetor [ $\left.\begin{array}{llllllllll}1 & 1 & 1 & 2 & 2 & 2 & 2 & 3 & 3 & 3\end{array}\right]$, por exemplo. Essa representação, conhecida como representação baseada em rótulo, é adotada por Krovi (1992); Krishna \& Murty (1999); Lu et al. (2004a,b). Porém, essa representação é naturalmente redundante, de forma que a mesma partição pode ter $k$ ! representações. Por 
exemplo, além da representação $\left[\begin{array}{llllllllll}1 & 1 & 1 & 2 & 2 & 2 & 2 & 3 & 3 & 3\end{array}\right]$, a mesma partição didática pode ser representada pelos vetores $\left[\begin{array}{llllllllll}1 & 1 & 1 & 3 & 3 & 3 & 3 & 2 & 2\end{array}\right]$, [ [ [ $\left.\begin{array}{lllllllll}2 & 2 & 2 & 1 & 1 & 1 & 1 & 3 & 3\end{array}\right]$, [ [ [ 3

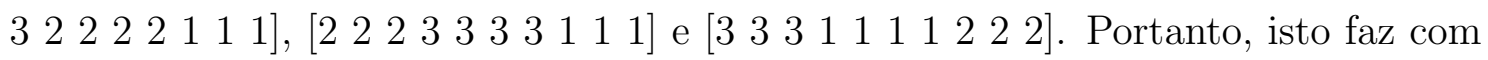
que o espaço de busca seja maior do que o espaço de soluções original. O problema da redundância pode ser evitado por meio de renumeração (Falkenauer, 1998), ao preço de um esforço computacional adicional.

A segunda forma consiste em representar os grupos por meio de seus medóides, ou seja, utilizar objetos como protótipos. Nesse caso, um vetor com $k$ posições é formado e as posições contêm os índices dos objetos utilizados como protótipo de cada grupo. Por exemplo, o vetor [ $\left[\begin{array}{lll}1 & 6 & 10\end{array}\right]$ representa uma partição feita com medóides formados pelo primeiro, sexto e décimo objetos do conjunto de dados. O restante dos objetos são inseridos no grupo cujo protótipo apresenta maior similaridade, resultando na partição representada pela Figura 3.2. Esse tipo de representação é utilizada por Lucasius et al. (1993); Estivill-Castro \& Murray (1997); Sheng \& Liu (2004). Ela pode apresentar redundância caso seja permitido o uso de vetores desordenados, de forma que os vetores [ $\left[\begin{array}{lll}1 & 6 & 10\end{array}\right],\left[\begin{array}{lll}6 & 1 & 10\end{array}\right],\left[\begin{array}{lll}6 & 10 & 1\end{array}\right],\left[\begin{array}{lll}10 & 1 & 6\end{array}\right],\left[\begin{array}{lll}10 & 6 & 1\end{array}\right]$ e [1 10 6] representem a mesma partição. Essa redundância pode ser evitada por meio de renumeração ou reordenação. Exemplos ilustrativos das representações inteiras baseadas em rótulos e por medóides são apresentados na Figura 3.4.

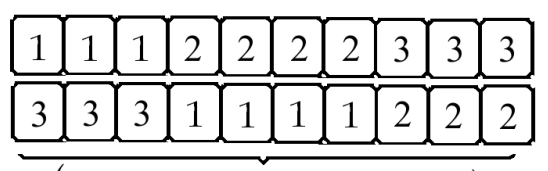

$\left(\mathbf{x}_{1}, \mathbf{x}_{2}, \mathbf{x}_{3}, \mathbf{x}_{4}, \mathbf{x}_{5}, \mathbf{x}_{6}, \mathbf{x}_{7}, \mathbf{x}_{8}, \mathbf{x}_{9}, \mathbf{x}_{10}\right)$

Baseadas em rótulos

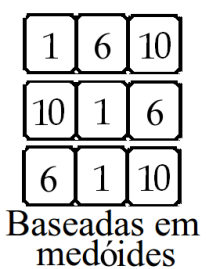

medóides

Figura 3.4: Representações inteiras baseadas em rótulos e medóides.

Ao comparar as duas formas, apesar da codificação por medóides requerer menos memória $\left(O(k)\right.$, em comparação com $O\left(n_{o}\right)$ da representação por rótulos), ela não mantém nenhum registro de a qual grupo cada objeto pertence. Isto faz com que essa informação tenha que ser obtida quando necessária, o que geralmente acontece durante o cálculo da aptidão dos indivíduos e/ou para guiar a aplicação por meio de operadores evolutivos. Portanto, dependendo do custo computacional envolvido, uma codificação em particular pode ser mais vantajosa.

- Real: nessa codificação, os genótipos são compostos de números reais, utilizados para representar as coordenadas dos protótipos dos grupos. Contudo, os protótipos não necessariamente representam medóides apenas, podendo assumir valores de centróides, por exemplo. Nesse caso, a codificação é conhecida como representação por centróides e utiliza uma matriz $k \times n_{a}$. Cada linha da matriz contém o conjunto de atributos de um protótipo, de forma que cada coluna representa um atributo. Para ilustrar essa representação, considere o genótipo [1,33 1,33; 4,5 4,5; 9,66 1,33] 
que codifica os protótipos $(1,331,33),(4,54,5)$ e $(9,661,33)$ dos grupos $C_{1}, C_{2}$ e $C_{3}$ da Tabela 3.1, respectivamente. Dados os protótipos, os grupos correspondentes podem ser obtidos por meio da regra do protótipo mais similar. Esse tipo de codificação é utilizado por Scheunders (1997); Maulik \& Bandyopadhyay (2000); Merz \& Zell (2002); Bandyopadhyay \& Maulik (2002a). Em conjunto com a representação baseada em centróide, Fränti et al. (1997) e Kivijärvi et al. (2003) armazenam uma tabela particional que descreve os índices dos grupos aos quais cada objeto pertence. A codificação por centróides apresenta características similares à codificação inteira baseada em medóide, com a desvantagem de ocupar espaço de memória $O\left(n_{a} \cdot k\right)$.

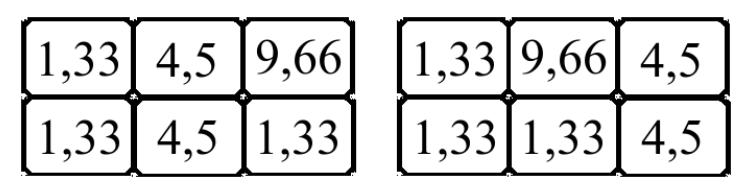

Figura 3.5: Representações reais baseadas em protótipos.

É importante notar que a adequação da codificação para o problema investigado também depende da existência de operadores competentes associados, que possibilitem a evolução das soluções codificadas.

\subsubsection{Operadores}

Operadores evolutivos de cruzamento (também conhecidos como recombinação) e mutação são utilizados para gerar a diversidade necessária para a busca evolutiva. Alguns operadores de cruzamento e mutação foram investigados e suas principais características serão apresentadas a seguir, de acordo com a codificação na qual são aplicados.

- Cruzamento: Hruschka et al. (2009) formalizaram o conceito de insensibilidade ao contexto em seu trabalho. Esse conceito, descrito na Seção 3.1, é usado para caracterizar uma codificação cujos genes definidos no cromossomo não apresentam informação útil que possa ser explorada pelo processo de amostragem implícito realizado pelo algoritmo evolutivo. Para ilustrá-lo, os genótipos de codificação inteira

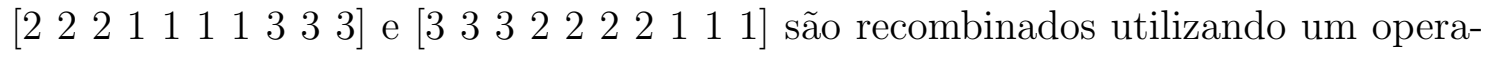
dor tradicional de cruzamento simples, na Figura 3.6. Esses genótipos representam partições do conjunto didático presente na Tabela 3.1 .

$$
\begin{array}{|l|l|l|l|l|l|l|l|l|l|}
\hline 2 & 2 & 2 & 1 & 1 & 1 & 1 & 3 & 3 & 3 \\
\hline \hline 3 & 3 & 3 & 2 & 2 & 2 & 2 & 1 & 1 & 1 \\
\hline \begin{array}{l|l|l|l|l|l|l|l|l|l}
2 & 2 & 2 & 1 & 1 & 1 & 1 & 1 & 1 & 1 \\
\hline 3 & 3 & 3 & 2 & 2 & 2 & 2 & 3 & 3 & 3 \\
\hline
\end{array} \text { progenitores } \\
\text { descendentes }
\end{array}
$$

Figura 3.6: Cruzamento simples entre progenitores iguais gerando descendentes distintos. 
No exemplo ilustrado pela Figura 3.6, os genótipos resultantes (descendentes) deveriam manter a mesma partição representada pelos genótipos originais (progenitores), já que os progenitores codificam a mesma partição dos dados. Contudo, os genótipos descendentes representam partições distintas entre si e em relação aos progenitores. Além disso, esses genótipos resultam em partições com menos de 3 grupos, o que os torna inválidos dentro do paradigma de número fixo de grupos. O uso de renumeração antes da aplicação do cruzamento pode amenizar o problema de insensibilidade ao contexto. Porém, não garante sua solução. Isso é ilustrado pela Figura 3.7, onde o genótipo descendente mais acima apresenta um número inválido de grupos, apesar da ordem dos rótulos de ambos os progenitores.

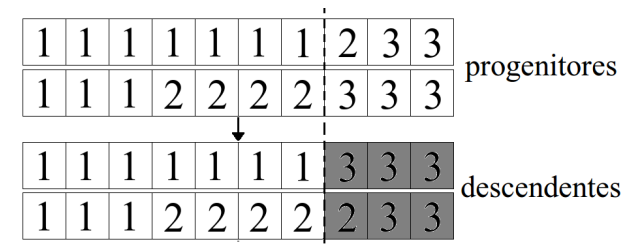

Figura 3.7: Cruzamento simples entre progenitores renumerados gerando descendente inválido.

Insensibilidade ao contexto também pode ocorrer em operadores que utilizam outros tipos de codificação. Para ilustrar esse problema, consideremos o genótipo real baseado em centróide $[1,33$ 1,33; 4,5 4,5; 9,66 1,33], representando a partição didática da Tabela 3.1, e uma permutação desse genótipo $[4,54,5 ; 9,661,33 ; 1,331,33]$. A Figura 3.8 apresenta a utilização de cruzamento simples nesses dois genótipos, que resulta em genótipos descendentes com protótipos de grupos repetidos, ou seja, que representam o mesmo grupo. Isso faz com que esses genótipos sejam invalidados por não possuírem o número de grupos pré-estabelecido. O problema de insensibilidade ao contexto pode ser visto para codificação binária ou inteira baseada em medóides, mesmo com renumeração. Por exemplo, considere os genótipos de codificação inteira por medóides [llll $\left.\begin{array}{lll}1 & 2 & 3\end{array}\right]$ e $\left[\begin{array}{lll}2 & 4 & 5\end{array}\right]$. O cruzamento simples desses genótipos pode gerar os descendentes $\left[\begin{array}{lll}2 & 2 & 3\end{array}\right]$ e $\left[\begin{array}{lll}1 & 4 & 5\end{array}\right]$, de forma que o primeiro genótipo apresenta dois protótipos iguais.

\begin{tabular}{|l|l|l|l|l|l|l|}
\hline 1,33 & 4,5 & 9,66 \\
\hline 1,33 & 4,5 & 1,33 \\
\hline \hline 4,5 & 9,66 & 1,33 \\
\hline 4,5 & 1,33 & 1,33 \\
\hline $\begin{array}{l}\text { progenitores } \\
\text { proger }\end{array}$
\end{tabular} \begin{tabular}{|l|l|l|l|}
\hline, 33 & 4,5 & 1.33 \\
\hline 1,33 & 4,5 & 1,33 \\
\hline 4,5 & 9,66 & 9,66 \\
\hline $\begin{array}{l}4,5 \\
\text { descendentes }\end{array}$ & 1,33 & 1,33 \\
\hline
\end{tabular}

Figura 3.8: Cruzamento simples sob codificação real gerando descendentes inválidos.

Em resumo, quando operadores evolutivos tradicionais são aplicados em problemas de agrupamento, eles apenas manipulam os valores dos genes sem considerar sua relação com outros genes. Porém, é necessário notar que a interconexão dos os valores dos genes constitui o objetivo genuíno do problema de agrupamento. Por esse 
motivo, é importante dar atenção ao desenvolvimento de operadores evolutivos feitos especialmente para agrupamento, ou seja, operadores orientados a grupos. Uma alternativa consiste em descartar as soluções inválidas ou substituí-las por outras. Esse tipo de solução, no entanto, implica em um alto custo computacional, devido à necessidade de verificação da validade das soluções e sua possível substituição. Como o real impacto do custo computacional da busca evolutiva se concentra em vários aspectos difíceis de estimar teoricamente, somente as características conceituais comuns entre os algoritmos abordados na literatura serão consideradas nesta seção.

Cruzamento uniforme foi aplicado por Kuncheva \& Bezdek (1997) sobre codificação por vetor binário. Como o trabalho considera um número fixo de grupos, essa aplicação é insensível ao contexto. Contudo, como esse operador é baseado na troca de informação sobre os medóides dos grupos, ele é orientado a grupos. Bezdek et al. (1994) utilizam um operador que move aleatoriamente os objetos de um grupo para o outro.

Vários operadores de cruzamento para codificação inteira foram propostos. Utilizar cruzamento simples, como feito por Krovi (1992) e Murthy \& Chowdhury (1996), gera problemas de sensibilidade ao contexto como os mostrados nas Figuras 3.6 e 3.7. Operadores que envolvem a mistura de medóides codificados por cromossomos progenitores são propostos por Lucasius et al. (1993); Sheng \& Liu (2004) e Estivill-Castro \& Murray (1997). Entretanto, os autores não tratam o problema de objetos repetidos no conjunto de dados (ou seja, um multiconjunto), o que pode gerar representações com medóides repetidos (inválidas).

Em relação aos operadores desenvolvidos para codificação real, Scheunders (1997) utiliza o operador de cruzamento ilustrado pela Figura 3.8. Apesar desse operador não ser sensível ao contexto, ele pode ser considerado um operador orientado a grupos, pois esses são representados por seus centros.

Maulik \& Bandyopadhyay (2000) e Bandyopadhyay \& Maulik (2002a) representam os centróides dos agrupamentos em um vetor de tamanho $k \cdot n_{a}$, composto pelos atributos dos centróides. O procedimento consiste em aplicar cruzamento simples nos genótipos formados, mesmo que esse divida parte dos atributos dos centróides entre cada genótipo. Um exemplo desse operador é ilustrado na Figura 3.9 para as partições progenitores de centróides $(1,33$ 1,33), (4,5 4,5) e $(9,66$ 1,33), formados pelos grupos da Tabela 3.1. Nele, os atributos dos centróides $(4,54,5)$ do primeiro genótipo e $(9,66$ 1,33) do segundo genótipo são divididos entre os descendentes, o que gera centróides sem relação alguma com os grupos presentes nos progenitores. Sendo assim, esse operador não é sensível ao contexto nem orientado a grupos.

Fränti et al. (1997) estudaram cinco operadores de cruzamento que, fundamentalmente, selecionam $k$ centróides de dois progenitores. O operador melhor avaliado 


\section{\begin{tabular}{|l|l|l|l|l|l|l|}
\hline 1,33 & 1,33 & 4,5 & 4,5 & 9,66 & 1,33 \\
\hline \hline 4,5 & 4,5 & 9,66 & 1,33 & 1,33 & 1,33 \\
\hline
\end{tabular} \\ \begin{tabular}{|l|l|l|l|l|l|l|l|l|}
\hline 1,33 & 1,33 & 4,5 & 1,33 & 1,33 & 1,33 \\
\hline \hline 4,5 & 4,5 & 9,66 & 4.5 & 9.66 & 1.33 \\
descendentes
\end{tabular}}

Figura 3.9: Cruzamento simples insensível ao contexto dividindo os atributos de um dos protótipos dos progenitores.

pelos autores consiste em reagrupar os $2 k$ centróides dos progenitores em $k$ grupos, gerando assim o genótipo descendente. Kivijärvi et al. (2003) utilizam os cinco operadores estudados por Fränti et al. (1997), mais cruzamento simples. Merz \& Zell (2002) utilizam dois operadores de cruzamento, sendo que o primeiro consiste em cruzamento uniforme e o segundo substitui alguns centróides de um progenitor no outro utilizando o conceito de vizinhos mais próximos. Apesar de orientados a grupos, esses operadores são afetados por insensibilidade ao contexto.

- Mutação: seguindo a tipologia de Falkenauer (1998), operadores de mutação podem ser categorizados como orientados a objetos ou orientados a grupos. Operadores equivalentes a mudar objeto(s) de grupo(s) (Murthy \& Chowdhury, 1996; Krishna \& Murty, 1999; Lu et al., 2004a,b) são considerados como operadores orientados a objetos. De forma análoga, operadores equivalentes a criar, destruir ou alterar protótipos (Lucasius et al., 1993; Kuncheva \& Bezdek, 1997; Estivill-Castro \& Murray, 1997; Sheng \& Liu, 2004) são orientados a grupos. Dentre os operadores orientados a grupos, são bastante utilizados aqueles que substituem protótipos por objetos do conjunto de dados. Esses objetos podem ser escolhidos de forma aleatória (Fränti et al., 1997; Kivijärvi et al., 2003; Merz \& Zell, 2002), ou a partir de sua similaridade com os protótipos a serem mutados (Merz \& Zell, 2002).

\subsubsection{Outras características}

Existem outras características importantes em AEs aplicados a problemas de agrupamento com um número fixo de grupos. Dentre elas podem ser citadas:

- Função de Aptidão: vários critérios de validação de agrupamentos (Seção 2.5) podem ser utilizados para medir a qualidade de partições com um número fixo de grupos $k$. Muitos deles podem ser facilmente adaptados como função de aptidão para evoluir partições de dados. Portanto, as funções de aptidão utilizadas por algoritmos evolutivos, descritas na literatura e apresentadas aqui, são apenas um subconjunto das possíveis funções de aptidão que podem ser utilizadas na prática. Boa parte dos autores utilizam como função de aptidão a redução da soma das distâncias Euclidianas quadráticas entre os objetos e os protótipos de seus respectivos grupos (Murthy \& Chowdhury, 1996; Estivill-Castro \& Murray, 1997; Maulik \& Bandyopadhyay, 2000; Bandyopadhyay \& Maulik, 2002a; Merz \& Zell, 2002; Sheng 
\& Liu, 2004). Outros autores minimizam uma medida de distorção dos grupos equivalente a essa redução (Fränti et al., 1997; Scheunders, 1997; Kivijärvi et al., 2003; Krishna \& Murty, 1999; Lu et al., 2004b,a). Reduzir esse tipo de função de aptidão corresponde a reduzir a função-objetivo do algoritmo $k$-médias (Equação (2.25)) e só faz sentido sob o paradigma de número de grupos $(k)$ fixo. Quando o número de grupos é variável, as distâncias entre objetos e os protótipos dos seus grupos tendem a diminuir com o aumento de $k$, até chegar a 0 para grupos com apenas um objeto, ou seja, tantos grupos quanto objetos.

Apesar da maioria das funções utilizadas sob o paradigma de número de grupos fixo ser baseada nas distâncias entre os objetos e os centros dos grupos, esse tipo de função apresenta algumas desvantagens (Hruschka et al., 2009). Se a distância utilizada for Euclidiana, os grupos formados tenderão a ser esféricos, o que pode ser inapropriado para alguns tipos de aplicação. Entretanto, o uso conjunto de protótipos de grupos e distância Euclidiana permite uma maior escalabilidade computacional do algoritmo e interpretabilidade dos grupos formados, pois os grupos gerados são bem comportados. Ambas as características são necessárias para problemas que envolvem grandes conjuntos de dados.

Uma alternativa a esse tipo de função consiste em utilizar critérios de validade baseados em densidades. O objetivo desses critérios é procurar por regiões densas de grupos, separados por regiões não densas. Esses critérios são conhecidos por serem suficientemente flexíveis para descobrir grupos de formatos variados (Ester et al., 1996). Contudo, geralmente esses critérios são computacionalmente mais complexos e exigem a configuração de parâmetros (de Oliveira et al., 2007).

- Seleção: Seleção proporcional (e.g., método da roleta)) (Bäck et al., 2000) foi utilizada por vários autores (Krovi, 1992; Lucasius et al., 1993; Murthy \& Chowdhury, 1996; Estivill-Castro \& Murray, 1997; Fränti et al., 1997; Kivijärvi et al., 2003; Krishna \& Murty, 1999; Maulik \& Bandyopadhyay, 2000; Bandyopadhyay \& Maulik, 2002a; Lu et al., 2004b,a). Algumas variantes elitistas (Mitchell, 1998) para selecionar genótipos também são investigadas em Murthy \& Chowdhury (1996); Fränti et al. (1997); Kivijärvi et al. (2003). Seleções do tipo $(\mu+\lambda)$ e $(\mu, \lambda)$, bastante comuns em estratégias evolutivas (Bäck et al., 2000; de Jong, 2006), também foram aplicados em AEs voltados ao agrupamento de dados (Kuncheva \& Bezdek, 1997; Merz \& Zell, 2002). Sheng \& Liu (2004) utilizam seleção por torneio para escolher os genótipos para reprodução.

- População inicial: A inicialização aleatória de protótipos apresenta uma boa escolha devido à simplicidade, à efetividade e ao baixo custo computacional. Por esse motivo, essa estratégia é bastante utilizada (Lucasius et al., 1993; Kuncheva \& Bezdek, 1997; Scheunders, 1997; Estivill-Castro \& Murray, 1997; Maulik \& Bandyopadhyay, 2000; Bandyopadhyay \& Maulik, 2002a; Merz \& Zell, 2002; Kivijärvi et al., 
2003; Sheng \& Liu, 2004). Em outros trabalhos (Krovi, 1992; Murthy \& Chowdhury, 1996; Krishna \& Murty, 1999; Bezdek et al., 1994; Lu et al., 2004b,a), a população inicial é gerada a partir da distribuição aleatória dos objetos entre os grupos, que pode ser desfavorável, pois os grupos iniciais tendem a ficar misturados, com seus centros próximos do centro dos dados.

- Busca local por $\boldsymbol{k}$-médias: a combinação de busca evolutiva com o algoritmo de agrupamento $k$-médias (Seção 2.4.6) é bastante comum. Por exemplo, uma iteração do algoritmo $k$-médias é aplicada no lugar do operador de cruzamento em (Krishna \& Murty, 1999; Lu et al., 2004a). Fränti et al. (1997) e Bandyopadhyay \& Maulik (2002a) também aplicam $k$-médias para fazer a sintonia fina das partições encontradas pelos operadores genéticos. Merz (2003) aplica $k$-médias em conjunto para fazer uma busca local que evolui iterativamente por meio de seleção determinística do tipo $(\mu=1, \lambda=1)$.

\subsection{Agrupamento com um número variável de grupos}

Todos os AEs apresentados na Seção 3.2 consideram um número de grupos fixo para formar partições. Porém, nem sempre há informação disponível sobre o domínio que possa refletir em valores adequados para $k$. Outros AEs vão além desse pré-requisito e estimam qual o melhor número de grupos $\left(k^{*}\right)$ e suas partições correspondentes. Hipoteticamente, as soluções apresentadas na Seção 3.2 poderiam ser utilizadas para estimar o valor de $k^{*}$, a partir de sua execução em $n_{c}$ cenários com valores distintos de $k$. Porém, o aumento da complexidade do espaço de soluções pode tornar a busca computacionalmente indesejada ou inviável, como discutido na Seção 2.1.

AEs que visam estimar um valor adequado para o número de grupos $k^{*}$ e suas partições correspondentes são descritos em trabalhos feitos por Cole (1998); Cowgill et al. (1999); Bandyopadhyay \& Maulik (2001, 2002b); Hruschka \& Ebecken (2003); Casillas et al. (2003); Hruschka et al. (2006, 2004b,a); Ma et al. (2006); Alves et al. (2006); Tseng \& Yang (2001); Naldi \& Carvalho (2007); Handl \& Knowles (2007) e Pan \& Cheng (2007). Uma meta-heurística é descrita em alto nível por Falkenauer (1998) em seu livro, que pode ser adaptada para lidar com diversos problemas de agrupamento, mostrando-se bastante útil para várias aplicações. As principais características desse tipo de aplicação de AEs são apresentadas nas próximas seções.

\subsubsection{Codificação}

A maioria dos esquemas de codificação utilizados para AEs capazes de estimar $k^{*}$ é semelhante às codificações utilizadas por AEs com número de grupos fixo. Portanto, o conteúdo desta seção apenas complementa o já apresentado na Seção 3.2.1. 
Uma codificação bastante utilizada por AEs para agrupamento com um número variável de grupos é a inteira baseada em rótulos. Semelhante aos AEs para um número fixo de grupos, ela consiste em um vetor de inteiros cujo conteúdo da $i$-ésima posição representa o valor do rótulo do grupo ao qual o $i$-ésimo objeto pertence. $\mathrm{O}$ valor dos rótulos varia entre 1 e $k$, sendo $k$ o número de grupos representado pelo genótipo, que é fixo para um determinado genótipo, mas varia de genótipo para genótipo. Essa representação é utilizada por Cole (1998); Cowgill et al. (1999); Hruschka et al. (2006, 2004b,a); Hruschka \& Ebecken (2003); Naldi \& Carvalho (2007) e Alves et al. (2006). Alguns desses autores também armazenam o valor de $k$ no genótipo, para evitar recontagem.

Um tipo especial de genótipo foi desenvolvido por Sarafis (2005) e Sarafis et al. (2007) para representar regras, utilizadas para identificar em qual grupo o objeto se encontra. As regras são representadas por $n_{a}$ genes, em que $n_{a}$ é o número de atributos dos objetos. Cada gene se relaciona a um atributo dos objetos e armazena duas informações: o limite superior $(l s)$ e o limite inferior $(l i)$ do atributo para que o objeto seja aceito pela regra. Os números inteiros codificados nos campos $l i$ e $l s$ representam limites de intervalos produzidos durante um estágio anterior à execução do AE. A Figura 3.10 apresenta um exemplo de genótipo.

\begin{tabular}{|cc|cc|cc|cc|cc|cc|}
\hline \multicolumn{3}{|c|}{ Regra 1 $\left(C_{1}\right)$} & \multicolumn{4}{|c|}{ Regra $2\left(C_{2}\right)$} & \multicolumn{4}{|c|}{ Regra $3\left(C_{3}\right)$} \\
\hline$l i_{1}$ & $l s_{1}$ & $l i_{2}$ & $l s_{2}$ & $l i_{1}$ & $l s_{1}$ & $l i_{2}$ & $l s_{2}$ & $l i_{1}$ & $l s_{1}$ & $l i_{2}$ & $l s_{2}$ \\
1 & 2 & 1 & 2 & 4 & 5 & 4 & 5 & 9 & 10 & 1 & 2 \\
\hline
\end{tabular}

Figura 3.10: Exemplo de genótipo que representa regras.

Considerando o genótipo representado pela Figura 3.10, para um determinado objeto $\mathbf{x}_{i}$, a Regra 1 pode ser interpretada como: SE $\left(l i_{1} \leq \mathbf{x}_{i}(1) \leq l s_{1}\right)$ E SE $\left(l i_{2} \leq \mathbf{x}_{i}(2) \leq l s_{2}\right)$ ENTÃO $\left(\mathbf{x}_{i} \in C_{1}\right)$. Uma vantagem desse tipo de representação é sua natureza simbólica, o que possibilita uma fácil interpretação do genótipo. O algoritmo garante que as regras formam grupos disjuntos. Essa representação equivale a dividir o espaço de busca no formato de uma malha de $n_{a}$ dimensões, o que restringe o espaço de busca. Essa restrição ocorre porque não é possível subdividir a malha, o que faz com que objetos presentes em uma mesma parte da malha estejam sempre em um mesmo grupo.

A codificação real é utilizada por Bandyopadhyay \& Maulik (2001) para representar os centróides dos grupos em uma matriz de tamanho $k \cdot n_{a}$, como descrito na Seção 3.2. Para utilizar esse tipo de representação de forma a manter o mesmo tamanho de genótipo, porém variar o número de grupos, o usuário deve assumir um intervalo $\left[k_{\min }, k_{\max }\right]$ para valores de $k^{*}$. Isso faz com que os genótipos armazenem $k_{\max }-k_{\min }$ posições obrigatoriamente, marcando espaços vazios com o símbolo \#, o que gera um desperdício de memória para intervalos muito grandes. Se o intervalo for muito pequeno, pode ser que $k^{*}$ não esteja contido em $\left[k_{\min }, k_{\max }\right]$, o que o deixaria fora de alcance.

Tseng \& Yang (2001) propõem gerar um conjunto de pequenos grupos iniciais, utilizados como base para a busca evolutiva. Esses grupos iniciais são obtidos por meio de uma estratégia baseada em vizinhos mais próximos e são representados no genótipo por 
um número binário. Se o $i$-ésimo grupo for codificado pelo genótipo, o $i$-ésimo bit será 1. Caso contrário será 0. A desvantagem desse tipo de representação binária é limitar a busca evolutiva aos grupos gerados inicialmente. Pan \& Cheng (2007) também utilizam codificação binária, baseada no número máximo de grupos a ser utilizado. Cada posição do genótipo corresponde a um agrupamento inicial, sendo que o número total de 1s corresponde ao número de grupos iniciais.

Codificações também podem representar estruturas de dados utilizadas no processo de agrupamento como, por exemplo, grafos. Casillas et al. (2003) utilizam árvores geradoras mínimas (MST - Mininum Spanning Tree), em que cada um dos $n_{o}$ nós da árvore representa um objeto do conjunto de dados e as arestas possuem pesos correspondentes às dissimilaridades entre esses objetos. O genótipo adotado possui $n_{o}-1$ bits que indicam a presença (1) ou ausência (0) de uma determinada aresta na $M S T$. Dois objetos estão no mesmo grupo se houver um caminho entre eles, o que torna possível obter a partição representada a partir do genótipo em conjunto com a MST. Handl \& Knowles (2007) aplicam uma representação baseada em grafos na qual o genótipo é composto de um vetor de inteiros. Cada posição do genótipo corresponde a um objeto do conjunto de dados. Nessa codificação, o valor $j$ presente no $i$-ésimo gene indica que há uma ligação entre o $i$-ésimo e o $j$-ésimo objeto. A partição codificada no genótipo é recuperada por meio da identificação das conexões entre todos os componentes do grafo. Essa codificação é particularmente vantajosa para problemas que utilizam grafos, como alguns tipos de combinação de agrupamentos, a serem descritos na Seção 5.3.3.

\subsubsection{Operadores}

Vários operadores de cruzamento e mutação foram propostos para problemas de agrupamento para o qual o número de grupos não é conhecido antecipadamente. Nesta seção, serão abordadas as principais propriedades desses operadores comumente encontrados na literatura.

- Cruzamento: considerando codificação inteira, Cole (1998) utiliza um cruzamento sensível ao contexto baseado em margens, no qual dois objetos estão conectados pela mesma margem caso estejam no mesmo grupo. O operador de cruzamento gera os genótipos descendentes pela combinação das margens formadas entre os genótipos progenitores, ou seja, a partir de interseções entre os grupos dos genótipos progenitores.

O operador sensível ao contexto proposto em Hruschka \& Ebecken (2003) para codificações inteiras é inspirado no trabalho de Falkenauer (1998). Ele combina as partições $\pi_{1}$ e $\pi_{2}$ representadas pelos dois genótipos progenitores, o primeiro com $k_{1}$ grupos e o segundo com $k_{2}$ grupos. Primeiramente, o operador copia $k^{\prime}$ grupos $(0<$ $k^{\prime}<k_{1}$ ) aleatoriamente da partição $\pi_{1}$ para a partição $\pi_{2}$. Os grupos da partição $\pi_{2}$ que não forem afetados são mantidos, enquanto os objetos dos grupos afetados 
são inseridos nos grupos com centróides mais próximos. A partição resultante é codificada no primeiro genótipo descendente. Em seguida, o processo é repetido para gerar um segundo descendente, desta vez copiando os grupos da partição $\pi_{2}$ para a $\pi_{1}$. Esse operador também é utilizado em Hruschka et al. (2004b,a, 2006).

Operadores clássicos como o cruzamento uniforme, simples ou em dois pontos são aplicados por Cowgill et al. (1999); Tseng \& Yang (2001); Bandyopadhyay \& Maulik (2001, 2002b); Pan \& Cheng (2007). Como mostrado na Seção 3.2.2, esses operadores não são orientados a grupos, nem sensíveis ao contexto. Uma exceção é a aplicação de cruzamento simples feita por Casillas et al. (2003) que, devido à representação de árvores geradoras adotada, pode dividir e unir grupos de maneira sensível ao contexto.

- Mutação: dentre os operadores orientados a grupos propostos para codificação inteira, merecem destaque os baseados no trabalho de Falkenauer (1998). Um deles é o operador de divisão, que consiste em selecionar probabilisticamente um grupo de uma partição particular e mover objetos desse grupo para formar um novo grupo (Cole, 1998; Hruschka \& Ebecken, 2003; Hruschka et al., 2004b). Outro consiste em desfazer um grupo escolhido e inserir seus objetos nos grupos remanescentes mais próximos (Hruschka \& Ebecken, 2003; Hruschka et al., 2004b) ou em um único grupo (Cole, 1998). Versões modificadas desses operadores são utilizadas em outros trabalhos (Hruschka et al., 2004a, 2006), de forma a possibilitar a aplicação desses operadores em vários grupos da partição mutada. Em Alves et al. (2006), esses operadores são aprimorados pela inclusão de um mecanismo de auto-ajuste da probabilidade do tipo de mutação, de acordo com o sucesso relativo de cada tipo durante as gerações. Essa versão é descrita em maiores detalhes na Seção 3.4.2.

De maneira análoga ao trabalho de Falkenauer (1998), Casillas et al. (2003) dividem ou aglomeram grupos mudando os bits do genótipo, devido à representação adotada. Tseng \& Yang (2001) também alteram os valores dos bits dos genótipos, o que conceitualmente significa que os grupos codificados nesses bits são ou deixam de ser inseridos ou não inseridos em genótipos descendentes. Pan \& Cheng (2007) adotam uma abordagem semelhante, que altera o número de grupos e, consequentemente, seus centros.

Operadores de mutação orientados a objetos concentram-se em mudar os valores presentes nos genes dos cromossomos. Em Cowgill et al. (1999), elementos de cada genótipo são modificados segundo uma baixa probabilidade, o que consiste em modificar o valor do rótulo do grupo presente no gene mutado.

Alguns operadores não são orientados a grupos ou centróides. É o caso do operador de mutação proposto por Bandyopadhyay \& Maulik (2001, 2002b), que consiste em modificar aleatoriamente as coordenadas dos centros dos grupos. Também é o caso do operador de mutação baseado em vizinhos próximos proposto por Handl et al. 
(2005). Em particular, cada objeto pode ser ligado probabilisticamente a um de seus $n_{v}$ vizinhos mais próximos. Como esse procedimento pode afetar grupos, objetos, ou nenhum dos dois, não pode ser conceituado estritamente como orientado a grupos ou objetos.

\subsubsection{Outras características}

Existem outras características importantes em AEs aplicados a problemas de agrupamento com um número variável de grupos, dentre elas:

- Função de aptidão: a princípio, qualquer índice de validação relativo (Seção 2.5.2) que não mude monotonicamente com o aumento ou redução do número de grupos pode ser utilizado como função de aptidão. Esse tipo de índice foi extensivamente investigado na literatura e, apesar do fato de que suas características particulares o fazem dependente do problema em estudo (Pal \& Bezdek, 1995; Vendramin et al., 2009, 2010), alguns deles apresentam resultados satisfatórios em vários cenários de aplicação.

Dentre os autores que utilizam índices de validação conhecidos na literatura, podem ser citados Cole (1998); Cowgill et al. (1999) e Casillas et al. (2003), que utilizam como função de aptidão o índice VRC (Calinski \& Harabasz, 1974) (definido na Seção 2.5.2). Em Hruschka \& Ebecken (2003); Hruschka et al. (2004b), o índice silhueta proposto por Rousseeuw (1987) é utilizado para calcular a aptidão dos genótipos. Adicionalmente, Hruschka et al. (2004b,a, 2006) propuseram outros índices de validação para guiar a busca evolutiva, incluindo a versão simplificada e modificada do índice silhueta, todas descritas na Seção 2.5.2.5. A versão simplificada também é utilizada por Alves et al. (2006).

Outros autores utilizam funções de aptidão baseadas em medidas inter-grupo e intra-grupo. Tseng \& Yang (2001) definem a função de aptidão dada para um genótipo g a partir da Equação (3.1):

$$
f i t(\mathbf{g})=\sum_{i=1}^{k} d_{\text {inter }}\left(C_{i}\right) \cdot w-d_{\text {intra }}\left(C_{i}\right)
$$

em que $d_{\text {inter }}\left(C_{i}\right)$ e $d_{\text {intra }}\left(C_{i}\right)$ são as distâncias inter-grupo e intra-grupo, respectivamente, dadas pelas Equações (2.18) e (2.19), e w é um parâmetro que define a influência das medidas inter-grupo e intra-grupo no resultado, definido pelo usuário.

Bandyopadhyay \& Maulik (2001) propõem o índice de validação $I(k)$ dado pela Equação (3.2), para obter a validação de um genótipo com $k$ grupos.

$$
I(k)=\left(\frac{1}{k} \frac{E_{1}}{E_{k}} D_{k}\right)^{2}
$$


Os termos $E_{k}$ e $D_{k}$ são dados pelas Equações (3.3) e (3.4), respectivamente.

$$
\begin{gathered}
E_{k}=\sum_{j=1}^{k} \sum_{i=1}^{n_{o}} \mu_{j i}\left\|\mathbf{x}_{i}-\mathbf{c}_{j}\right\| \\
D_{k}=\max _{i, j=1}^{k}\left\|\mathbf{c}_{i}-\mathbf{c}_{j}\right\|
\end{gathered}
$$

em que $\left[\mu_{i j}\right]_{k \times n_{o}}$ é a matriz de partição para o conjunto de dados $X$ e $\mathbf{c}_{j}$ é o centróide do $j$-ésimo grupo. Uma variante de $I(k)$, definida na Equação (3.2), é utilizada como função de aptidão em Pan \& Cheng (2007).

- Seleção: assim como no caso de número de grupos $k$ fixo, seleção proporcional (e. g., método da roleta) é utilizada por vários autores (Cole, 1998; Cowgill et al., 1999; Tseng \& Yang, 2001; Bandyopadhyay \& Maulik, 2001, 2002b; Casillas et al., 2003; Hruschka \& Ebecken, 2003; Hruschka et al., 2004b,a, 2006; Ma et al., 2006; Alves et al., 2006; Naldi \& Carvalho, 2007). Alves et al. (2006) também mencionam o uso de uma seleção determinística do tipo $(\mu+\lambda)$ (Fogel, 1995). O AE multiobjetivo proposto por Handl et al. (2005) é baseado no algoritmo PESA-II (Corne et al., 2001), cuja seleção ocorre pela relação entre duas populações: uma população interna, que explora novas soluções pelo processo padrão de reprodução e variação; e uma população externa, que explora boas soluções por meio de elitismo. Pan \& Cheng (2007) adotam um procedimento de seleção baseado em busca tabu.

As vantagens e desvantagens dos mecanismos de seleção tradicionais são bem conhecidas na literatura (Jain \& Dubes, 1988; Fogel, 1995; Mitchell, 1998) e não há indícios de que estes mecanismos se comportem de maneira distinta no contexto de problemas de agrupamento.

- População inicial: nos trabalhos publicados por Cole (1998); Cowgill et al. (1999); Hruschka \& Ebecken (2003); Hruschka et al. (2004b,a, 2006); Ma et al. (2006); Alves et al. (2006) e Naldi \& Carvalho (2007), a população inicial é gerada por meio da escolha aleatória de grupos para cada objeto. Como discutido na Seção 3.2.2, esse tipo de inicialização geralmente resulta em partições iniciais não favoráveis, uma vez que os grupos iniciais tendem a ser misturados. Porém, essa estratégia é eficiente para testar algoritmos contra cenários de difícil avaliação.

Em Tseng \& Yang (2001), a população de genótipos binários é gerada aleatoriamente de forma que o número de bits 1 sejam distribuídos uniformemente entre os genes. As partições iniciais são geradas aleatoriamente no trabalho publicado por Pan \& Cheng (2007). Bandyopadhyay \& Maulik (2001, 2002b) selecionam objetos aleatoriamente do conjunto de dados para se tornarem protótipos iniciais dos grupos a serem evoluídos pelo algoritmo. Handl et al. (2005) aplicam os algoritmos de MST e $k$-médias para gerar as soluções iniciais. 
- Busca local por $\boldsymbol{k}$-médias: alguns algoritmos evolutivos criados para estimar o número de grupos utilizam o algoritmo $k$-médias para efetuar uma busca local por melhores soluções (Hruschka et al., 2004b,a; Alves et al., 2006; Hruschka et al., 2006; Naldi \& Carvalho, 2007). Essa busca local consiste no refinamento de soluções obtidas pela busca evolutiva, acelerando a convergência. De forma geral, pode-se gerar uma sinergia entre os operadores evolutivos e o $k$-médias. De um lado, o $k$ médias reduz a variância dos grupos obtidos pelos operadores evolutivos, gerando grupos mais compactos. De outro lado, AEs podem amenizar duas características do algoritmo $k$-médias: ele pode ficar preso em centróides que formam partições sub-ótimas; e o número de grupos $k$ da partição a ser gerada deve ser previamente especificado. Como os operadores evolutivos podem eliminar, dividir ou aglomerar grupos durante a busca evolutiva, eles são capazes de aprimorar partições tanto em termos de número de grupos, quando de centróides. Essas partições tendem a prover melhores centróides iniciais para o $k$-médias, reduzindo a probabilidade do algoritmo ficar preso em uma solução sub-ótima.

\subsection{Fast Evolutionary Algorithm for Clustering (F-EAC)}

O algoritmo evolutivo rápido para agrupamento ( F-EAC, do inglês Fast Evolutionary Algorithm for Clustering) é um algoritmo desenvolvido por Alves et al. (2006) para evoluir partições de dados de forma eficiente. F-EAC é essencialmente uma extensão do algoritmo evolutivo para agrupamento ( $E A C$, do inglês Evolutionary Algorithm for Clustering), publicado em Hruschka et al. (2004a, 2006). Originalmente proposto em Alves et al. (2006); Alves (2007), o F-EAC apresentou um melhor desempenho do que o seu predecessor em termos de tempo computacional. Nesta seção será apresentada uma descrição conceitual detalhada do algoritmo.

O F-EAC consiste em evoluir partições geradas por meio do algoritmo k-médias (Seção 2.4.6) e operadores evolutivos. Esses operadores utilizam regras probabilísticas para processar partições amostradas do espaço de soluções. De forma geral, partições mais aptas possuem uma probabilidade maior de serem amostradas. Em outras palavras, a busca evolutiva é voltada para soluções mais promissoras. Portanto, a busca evolutiva tende a apresentar uma busca computacionalmente mais eficiente do que métodos sistemáticos para executar $k$-médias (e.g., os métodos descritos na Seção 2.4.6.1). Esses métodos normalmente não fazem uso da informação sobre a qualidade das partições obtidas anteriormente para gerar novas partições potencialmente melhores. Isso faz com que esses algoritmos tendam (em termos probabilísticos) a ser menos eficientes do que uma busca evolutiva. A estrutura geral do F-EAC, em alto nível, é descrita pelo Algoritmo 4.

Como pode ser visto no Passo 2 do Algoritmo 4, o número de grupos e os protótipos das partições iniciais são escolhidos aleatoriamente no F-EAC. Contudo, outras heurísticas podem ser facilmente adaptadas. Números de grupos superestimados ou subestimados 


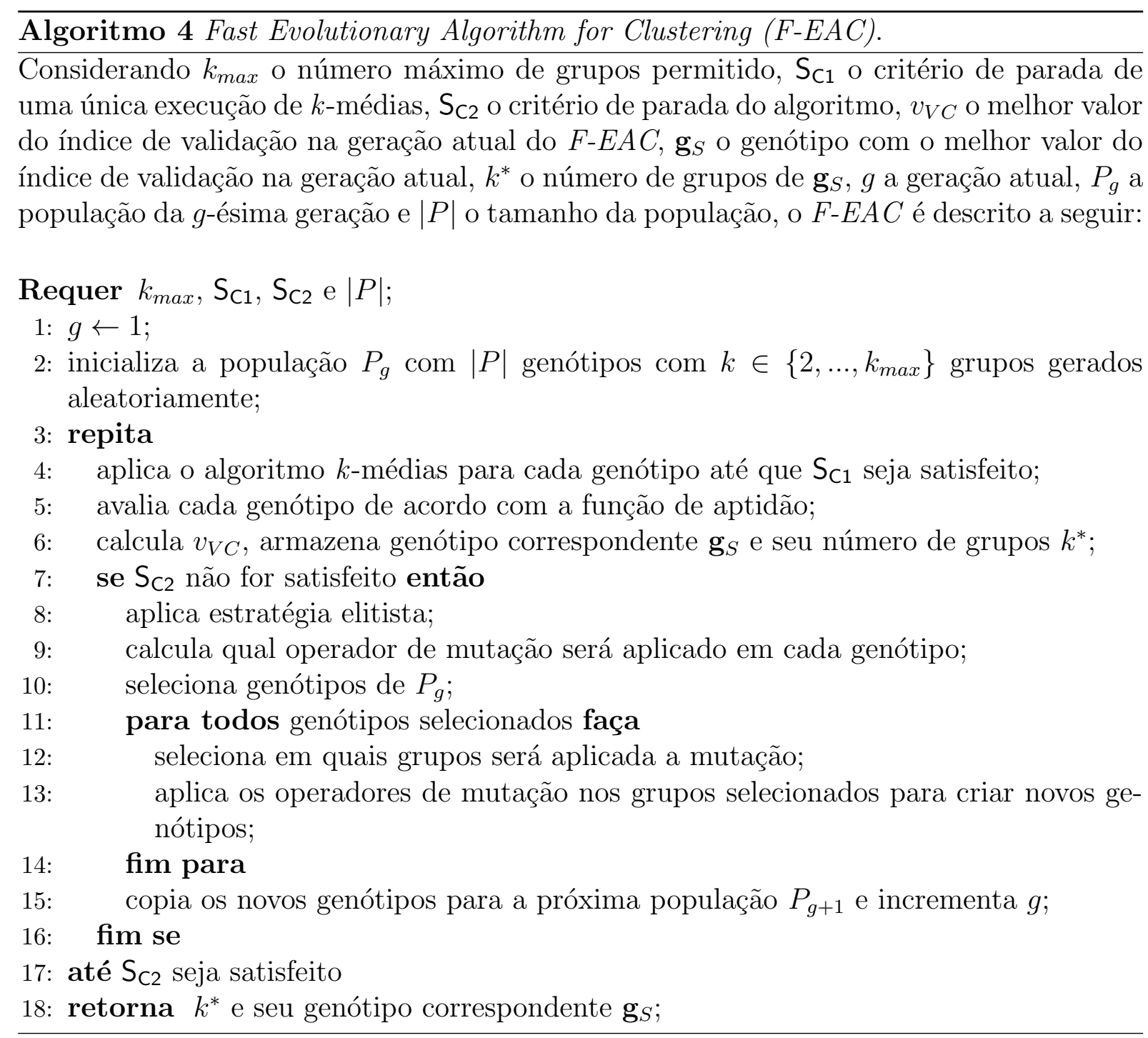


podem ser ajustados pelo algoritmo, guiado pela função-objetivo. Isso define o $F$-EAC como um AE que trabalha com um número variável de grupos. A função de aptidão (Passo 5) deve ser capaz de avaliar tanto as partições obtidas pelo algoritmo, como cada grupo dessas partições, devido ao fato dos operadores de mutação adotados serem guiados

pelos valores de aptidão dos grupos (a ser discutido na Seção 3.4.2). Originalmente, a função de aptidão utilizada pelo algoritmo é a silhueta simplificada, descrita na Seção 2.5.2.5. Porém qualquer outro índice relativo ou mesmo outras funções também podem ser adaptadas. O algoritmo mantém a melhor solução por meio de uma estratégia elitista (Passo 8 do Algoritmo 4) (Mitchell, 1998). O resto das soluções é selecionado por meio de seleção proporcional (e.g., método da roleta (Mitchell, 1998)), porém outros tipos de seleção, como a seleção determinística, podem ser adotados (Passo 10). Em particular, resultados obtidos experimentalmente sugerem que o uso da estratégia $(\mu+\lambda)$ (Fogel, 1995) produz resultados similares (Alves et al., 2006; Alves, 2007).

Dentre os possíveis critérios de parada utilizados pelo F-EAC (Passo 17 do Algoritmo 4 ), pode ser definido um valor de referência $v_{R}$ para a qualidade das soluções encontradas, um número máximo $g_{\max }$ de gerações ou um número máximo de gerações sem aumento na qualidade da melhor solução, a estabilidade da aptidão em um certo valor, um limiar para a diversidade da população, dentre outros (Falkenauer, 1998).

Nas Seções 3.4.1 e 3.4.2, serão feitas as descrições da codificação do $F$-EAC, estrutura de dados e operadores evolutivos.

\subsubsection{Codificação e estruturas auxiliares}

O F-EAC utiliza codificação inteira baseada em rótulos, apresentada na Seção 3.3.1. Ou seja, o genótipo é composto por um vetor de números inteiros $\mathbf{g}$ com $n_{o}$ posições (genes), no qual o valor da $i$-ésima posição corresponde ao rótulo do grupo que contém o $i$-ésimo objeto do conjunto de dados.

A codificação inteira baseada em rótulos no $F$-EAC é herança de seu antecessor, o algoritmo $E A C$, e é utilizada para calcular informações cruciais para sua execução, como o número de grupos, seus centróides e o número de objetos que cada grupo contém. Contudo, uma vez calculadas, essas informações podem ser armazenadas em estruturas auxiliares para evitar recálculo, o que aumenta o desempenho do algoritmo e uso de memória. Um exemplo das estruturas auxiliares que podem ser utilizadas pelo $F-E A C$ é dado na Figura 3.11 para a partição didática da Figura 3.2. Essas estruturas são:

- g é o genótipo que representa a partição;

- $k$ é o número de grupos representado, para evitar a recontagem a partir de g durante a execução do algoritmo;

- $\mathbf{n}_{C}$ é um vetor contendo o número de objetos de cada grupo da partição; 
- $\mathbf{C}$ é a matriz formada pelos centróides $\mathbf{c}_{i}$ para $i=1, \ldots, k$, de forma que $\mathbf{C}=$ $\left(\mathbf{c}_{1} ; \mathbf{c}_{2} ; \ldots ; \mathbf{c}_{k}\right)$;

- fit é a aptidão do genótipo $f(\mathbf{g})$ e a aptidão dos grupos $f\left(C_{i}\right)$ para $i=1, \ldots, k$.

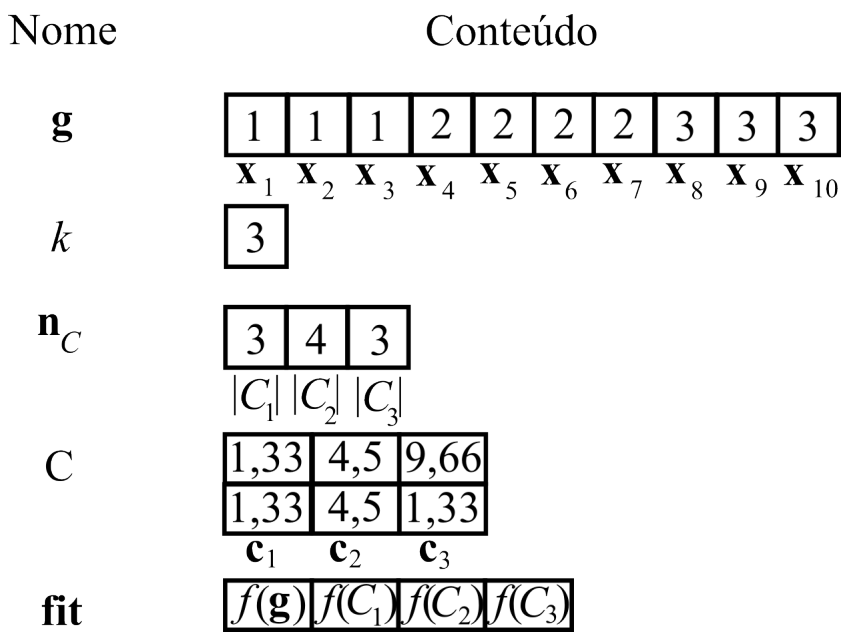

Figura 3.11: Exemplo do esquema de codificação do F-EAC.

É importante observar que as informações presentes em algumas das estruturas presentes na Figura 3.11 podem ser obtidas por meio de outras estruturas, o que torna a utilização de cada estrutura opcional.

\subsubsection{Operadores de mutação}

Os operadores de mutação do $F$-EAC são baseados nos operadores desenvolvidos para o $E A C$. Contudo, os operadores de mutação originais do $E A C$ foram feitos para selecionar aleatoriamente os grupos a serem mutados (busca aleatória) (Hruschka et al., 2006). No desenvolvimento do $F-E A C$, supõe-se que quanto melhor o grupo, menor deve ser sua probabilidade de ser modificado pelo operador de mutação. Com isso, grupos de boa qualidade tendem a ser mantidos durante o processo evolutivo, enquanto grupos de qualidade baixa tendem a ser mutados, na esperança de gerar partições de melhor qualidade (busca guiada).

No Passo 5 do Algoritmo 4, tanto a qualidade das partições obtidas, como a qualidade dos grupos de cada partição são avaliadas por uma função de aptidão $f(\cdot)$. Qualquer índice relativo ou função que seja capaz de avaliar a qualidade relativa das partições obtidas e a qualidade de cada um de seus grupos pode ser adaptado e utilizado como função de aptidão (e.g., o índice silhueta simplificada, descrito na Seção 2.5.2.5). Para ilustrar essa avaliação, o índice silhueta simplificada foi utilizado para avaliar a partição didática $\pi_{d} \mathrm{e}$ cada um de seus grupos, presentes na Tabela 3.1. Os valores resultantes dessa avaliação são apresentados na Figura 3.12. Nela, é possível notar que $f\left(C_{3}\right)$ é maior do que $f\left(C_{1}\right)$ e $f\left(C_{2}\right)$, pois $C_{3}$ encontra-se mais isolado e, portanto, é considerado um grupo de qualidade relativamente maior do que os outros. 


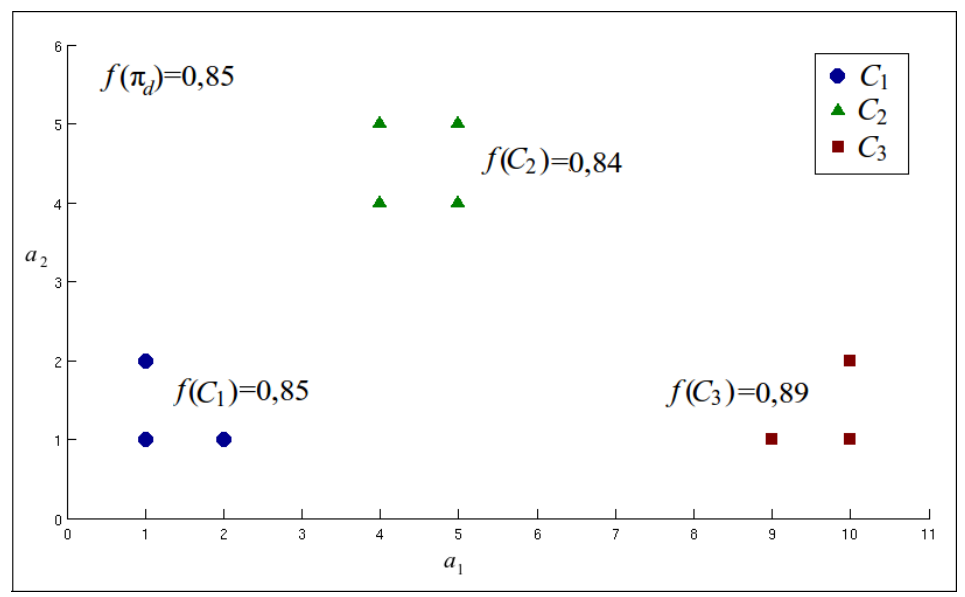

Figura 3.12: Silhueta simplificada da partição $\pi_{d}$ (Tabela 3.1) e de cada um de seus grupos.

Depois de calculadas, as aptidões das partições são utilizadas no processo de seleção de genótipos para a próxima geração (discutida na Seção 3.4). Por sua vez, as aptidões dos grupos são utilizadas para guiar os operadores de mutação, sendo normalizadas no intervalo $[0,1]$ quando não estiverem neste intervalo. Considerando que um valor alto de $f\left(C_{i}\right)$ deva estar associado com uma baixa probabilidade de mutação do grupo $C_{i}$, o complemento $\left(1-f\left(C_{i}\right)\right)$ pode ser utilizado para calcular esta probabilidade. Entretanto, antes desse cálculo, é sugerido aplicar um procedimento de normalização linear (Davis, 1996) para evitar a convergência prematura dos dados, balanceando a pressão seletiva em diferentes estágios da busca evolutiva. Em seguida, um método de seleção probabilística pode ser utilizado na escolha dos grupos a serem mutados, como a estratégia da roleta (Mitchell, 1998).

O F-EAC utiliza dois operadores de mutação. O primeiro operador de mutação $\left(M O_{1}\right)$ elimina um ou mais grupos com probabilidade inversamente proporcional à aptidão desses grupos. Por esse motivo, esse operador só pode ser aplicado em genótipos que codificam mais do que dois grupos. Um maior detalhamento do $M O_{1}$ é apresentado no Algoritmo 5.

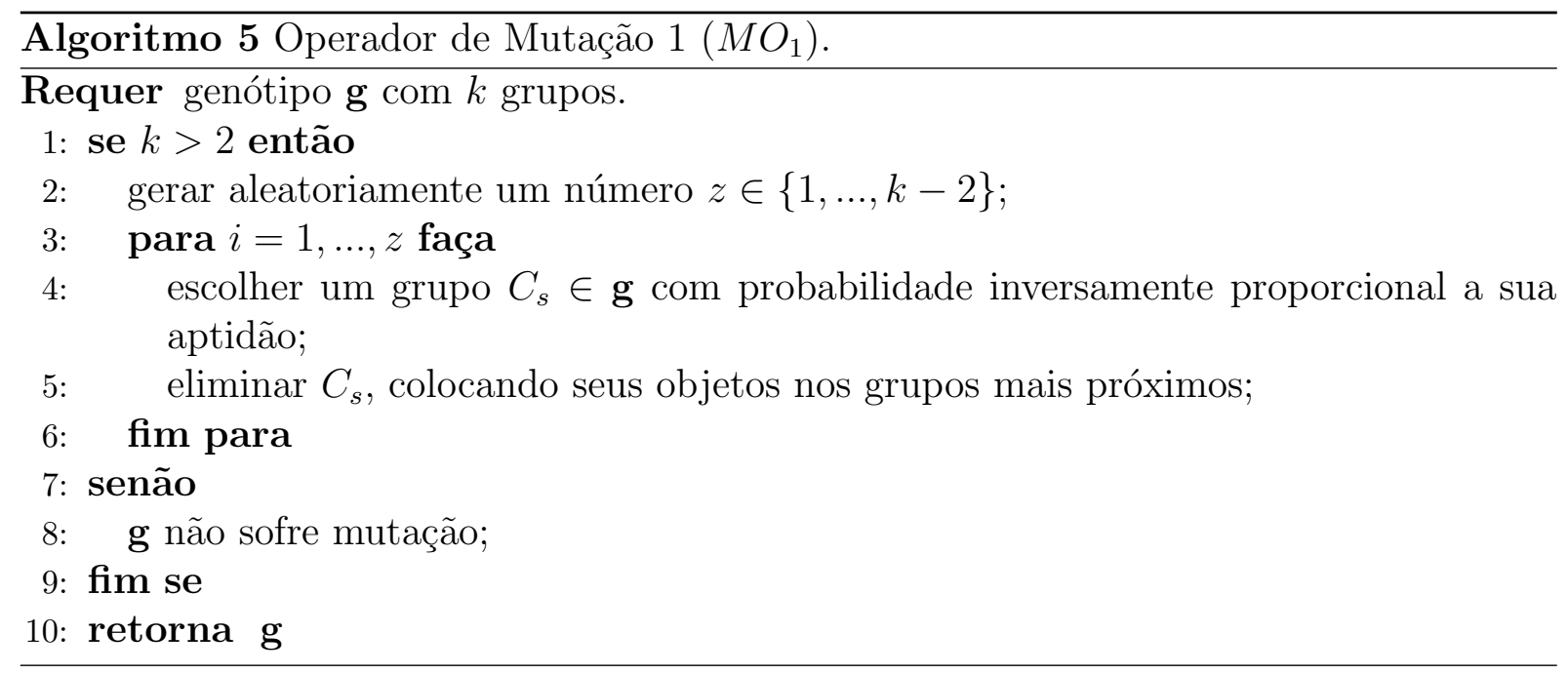

O segundo operador de mutação $\left(M O_{2}\right)$ divide um ou mais grupos selecionados de 
$\left(C_{1}, \ldots, C_{k}\right)$ em dois novos grupos cada. Por esse motivo, somente é aplicado em grupos formados por dois objetos ou mais. Em resumo, supondo que o grupo $C_{s}$ seja selecionado para mutação, dois objetos pertencentes a esse grupo são escolhidos para se tornarem os protótipos dos novos grupos. O primeiro objeto é selecionado aleatoriamente e se tornará o protótipo do primeiro grupo a ser criado $C_{s}^{\prime}$. O segundo objeto escolhido será o objeto mais distante do primeiro objeto escolhido e se tornará o protótipo do segundo grupo a ser criado $C_{s}^{\prime \prime}$. Detalhes sobre o $\mathrm{MO}_{2}$ são apresentados no Algoritmo 6. É importante notar que novos grupos obtidos por meio do $\mathrm{MO}_{2}$ não podem ser escolhidos para divisão até o final da execução do operador. No Algoritmo 6, utiliza-se um genótipo auxiliar $\left(\mathbf{g}^{\prime}\right)$ para manter os novos grupos até o Passo 15, em que eles são reinseridos em g.

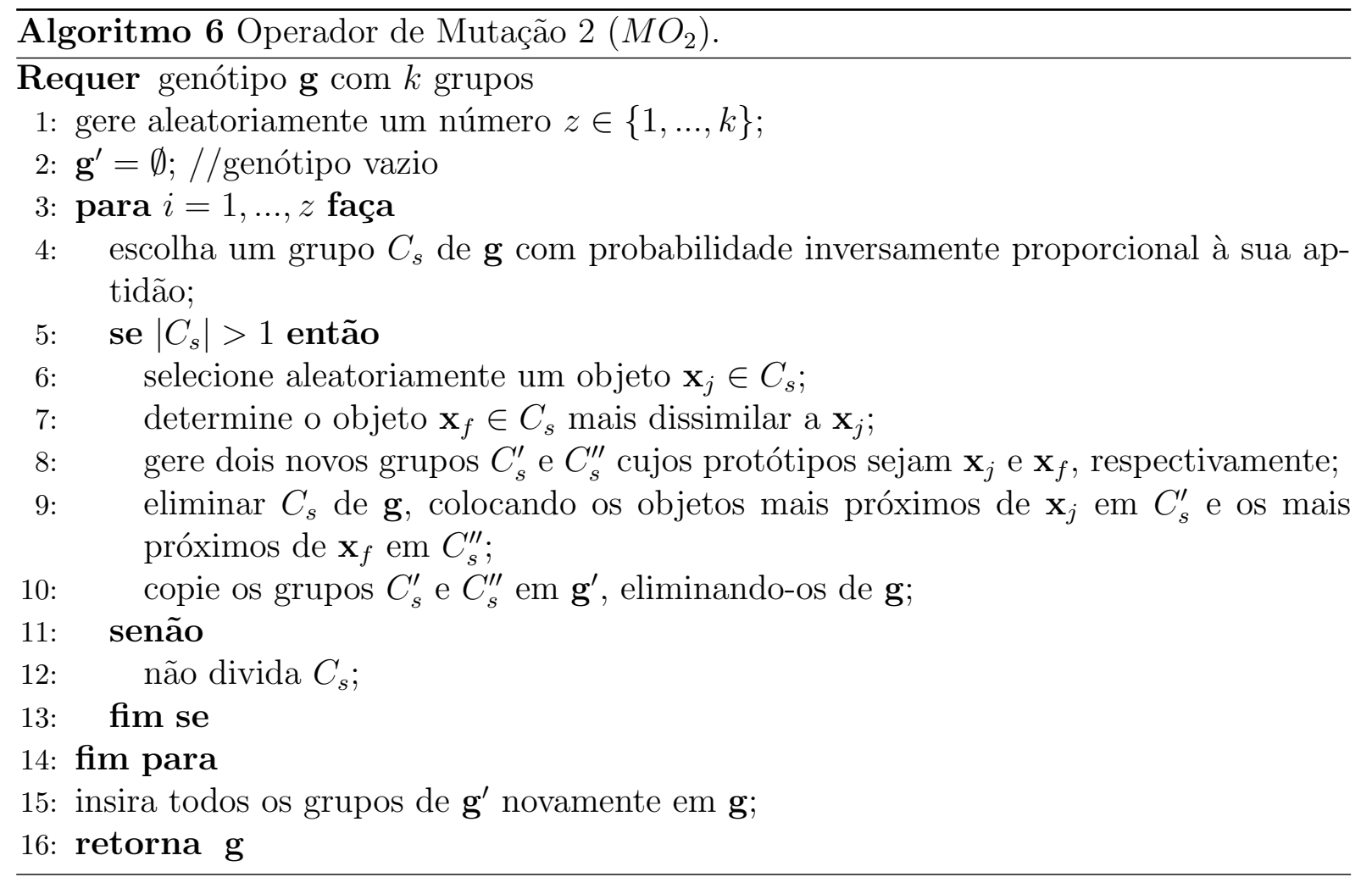

No $E A C, 50 \%$ dos genótipos de uma dada população são mutados por meio do operador $M O_{1}$ e o restante pelo operador $M O_{2}$. Essa metodologia foi modificada no $F-E A C$, por meio de uma taxa auto-ajustável do uso de cada operador de mutação, de acordo com seu desempenho durante a busca evolutiva. Sob essa perspectiva, é considerado que, quanto maior o sucesso de um dado operador na população $P_{g}$, de uma geração $g$, maior deve ser sua taxa de aplicação correspondente na população $P_{g+1}$. Para isso, é particularmente interessante utilizar informação relacionada com a média da aptidão dos genótipos para os quais cada operador foi aplicado.

Mais precisamente, supondo que $M O_{1}$ foi aplicado em alguns genótipos na geração $g$, denotamos $G_{1, g}$ como o conjunto dos genótipos da geração $g$ que foram mutados pelo operador $M O_{1}$. Seja $S U M_{1, g}^{b}$ a soma da aptidão dos genótipos no conjunto $G_{1, g}$ antes da aplicação do $M O_{1}$ e $S U M_{1, g}^{a}$ como a soma de todas as aptidões dos genótipos no conjunto $G_{1, g}$ depois da aplicação do $M O_{1}$. A diferença relativa entre essas somas, ocasionada pela 
aplicação de $M O_{1}$, é chamada de $D A F_{1, g}$ e é calculada como $D A F_{1, g}=\frac{\left(S U M_{1, g}^{a}-S U M_{1, g}^{b}\right)}{S U M_{1, g}^{b}}$. De forma análoga, $D A F_{2, g}$ pode ser definida para $M O_{2}$, que foi aplicado em $(|P|-$ $\left.\left|G_{1, g}\right|\right)$ genótipos. Dadas as definições anteriores, as proporções em que $M O_{1}$ e $M O_{2}$ serão aplicados na geração $(g+1)$ podem ser calculadas por meio das Equações $(3.5)$ e (3.6), respectivamente.

$$
\begin{gathered}
P M O_{1, g+1}= \begin{cases}\frac{D A F_{1, g}}{D A F_{1, g}+D A F_{2, g}} & \text { se } D A F_{1, g}>0 \wedge D A F_{2, g}>0 \\
0 & \text { se } D A F_{1, g} \leq 0 \wedge D A F_{2, g}>0 \\
1 & \text { se } D A F_{1, g}>0 \wedge D A F_{2, g} \leq 0 \\
0,5 & \text { se } D A F_{1, g} \leq 0 \wedge D A F_{2, g} \leq 0\end{cases} \\
P M O_{2, g+1}=1-P M O_{1, g+1} .
\end{gathered}
$$

Em resumo, as Expressões (3.5) e (3.6) mostram que, se um operador de mutação em particular obtém melhores resultados em uma dada geração $g$, ele será aplicado com maior probabilidade na geração $(g+1)$. Contudo, essa metodologia ajusta a probabilidade de aplicação dos operadores de mutação considerando seu desempenho na população por inteiro, desconsiderando o impacto dos operadores em cada genótipo. Outra forma de selecionar o operador de mutação a ser aplicado em um genótipo consiste em considerar apenas o impacto que o operador obteve sobre o indivíduo em questão, desconsiderando o resto da população. Para isso, se um operador de mutação foi aplicado a um genótipo e o genótipo resultante possuir maior aptidão, o mesmo operador será aplicado no genótipo resultante se este sofrer mutação na próxima geração. Caso contrário, o outro operador será aplicado. Em casos em que o genótipo a sofrer mutação não originou de um operador de mutação ou foi mantido na população por meio de elitismo, ambos os operadores podem ser aplicados com igual probabilidade. Esse método de escolha foi aplicado em (Horta \& Campello, 2009) e obteve resultados melhores ou equivalentes aos obtidos pelo métodos descritos anteriormente.

\subsubsection{Busca local do F-EAC}

Assim como outros algoritmos descritos na Seção 3.3.2, o $F$-EAC utiliza o $k$-médias para ajuste das partições encontradas, de forma a executar uma busca local. Dessa forma, o algoritmo reduz a variância dos grupos obtidos pelos operadores evolutivos, mantendo a característica desses operadores de ajustar o número de grupos e os protótipos iniciais das partições. Além disso, é esperado que um número baixo de iterações de $k$-médias seja suficiente para obter bons resultados, pois a busca evolutiva executada pelo algoritmo favorece um refinamento acumulativo das partições obtidas. 


\subsection{Considerações finais}

Neste capítulo, foi feita uma revisão de AEs baseada na taxonomia definida em Hruschka et al. (2009) e sua aplicação para problemas de agrupamentos particionais exclusivos. Aspectos essenciais para a construção e uso de AEs, como codificação das soluções por meio de genótipos, operadores evolutivos e funções de aptidão, foram apresentados. Vantagens e desvantagens dos tipos de codificação mais comuns foram discutidas. Problemas comuns, como insensibilidade ao contexto, e vantagens de operadores evolutivos foram relatados. Em especial, outras questões discutidas em Falkenauer (1998); Hruschka et al. (2009) também foram apresentadas com o intuito de categorizar operadores entre sensíveis ao contexto, orientados a grupo e a objeto, e a divisão dos algoritmos pela capacidade de estimar o número de grupos ou não.

A maioria dos trabalhos revisados neste capítulo se preocupa apenas com a qualidade do resultado obtido pelo algoritmo. Poucos dão atenção à eficiência computacional desses algoritmos, o que pode se tornar um problema sério quando aplicado a problemas de grande escala. Visando uma melhoria na eficiência computacional, o $F$-EAC foi aprimorado por meio de algumas modificações feitas na codificação do algoritmo e modificações nas estruturas de dados. Essas modificações serão apresentadas e discutidas no Capítulo 4. Adicionalmente, questões de eficiência computacional associadas ao $F$-EAC, métodos sistemático para a execução do algoritmo $k$-médias e outros algoritmos conhecidos da literatura também são apresentados no Capítulo 4.

Visando a aplicação do F-EAC em grande escala, o algoritmo foi adaptado para problemas que consideram conjuntos de dados distribuídos. A apresentação da versão do $F$ $E A C$ distribuído, juntamente com um conjunto de variantes desenvolvidas com a mesma finalidade, é feita no Capítulo 7. 


\section{Capítulo}

\section{4}

\section{Questões de eficiência do agrupamento evolutivo}

O agrupamento de dados pode ser útil no estudo de problemas com pouco ou nenhum conhecimento prévio sobre as possíveis categorias existentes nos dados. Pela análise apresentada no Capítulo 2, é possível concluir que algoritmos de agrupamento utilizam diferentes metodologias que podem gerar resultados distintos. Além disso, são poucas as técnicas que possuem baixa complexidade computacional em relação a todos os parâmetros críticos ao processo de agrupamento. Portanto, encontrar uma solução adequada em tempo computacional razoável é uma tarefa que merece atenção. Uma das formas de tratar tal problema consiste em utilizar meta-heurísticas como AEs. Uma revisão envolvendo características conhecidas de AEs foi apresentada no Capítulo 3. Contudo, a maioria dos trabalhos revisados naquele capítulo se preocupa apenas com a qualidade do resultado obtido pelo algoritmo, sendo poucos os que dão atenção à eficiência computacional.

Este capítulo possui como objetivo principal mostrar que algoritmos evolutivos para agrupamento podem ser mais eficientes do que abordagens repetitivas baseadas em múltiplas execuções do algoritmo $k$-médias, quando o número de grupos no conjunto de dados é desconhecido. Nele são discutidas questões de eficiência computacional envolvendo alguns dos algoritmos de agrupamento investigados e uma versão aprimorada do algoritmo F-EAC. A discussão envolve questões de desempenho no âmbito teórico, por meio da complexidade assintótica dos algoritmos apresentada na Seção 4.2, e experimentos em que são comparados o tempo computacional e a qualidade dos resultados obtidos, apresentados na Seção 4.4. Ao final do capítulo, na Seção 4.5, variantes do F-EAC e um conjunto de algoritmos de propósito similar ao $F$-EAC são comparados em termos da qualidade de agrupamento e desempenho computacional por meio de um grande conjunto de bases de 
dados. Por último, algumas considerações finais são feitas na Seção 4.6.

\subsection{Motivação}

Como pode ser visto no Capítulo 2, cada algoritmo de agrupamento possui uma função ou um conjunto de funções objetivo e utiliza um método de busca para otimizar essa função. Dentre todos os algoritmos analisados, o algoritmo $k$-médias merece destaque por ter sido recentemente eleito e listado como um dos dez algoritmos mais utilizados e influentes na área de mineração de dados (Wu et al., 2008; Wu, 2009). Esse fato é justificado pela simplicidade do algoritmo e por esse ser bastante escalável, já que possui tempo de execução assintótico linear em relação à qualquer variável envolvida no problema, o que não foi o caso da maioria dos algoritmos apresentados no Capítulo 2. O algoritmo possui a limitação de buscar por grupos bem comportados (volumétricos com formas aproximadamente hiperesféricas), o que não é um problema em aplicações práticas de grande escala, pois é exatamente este o tipo de grupo que frequentemente se deseja encontrar, seja pelas restrições computacionais, seja pelas restrições de interpretabilidade impostas pelo analista/especialista de domínio. Por esses motivos, o algoritmo $k$-médias foi escolhido como o foco do estudo descrito neste capítulo.

Contudo, o $k$-médias é sensível à seleção dos protótipos dos grupos iniciais, podendo convergir para soluções sub-ótimas caso estes protótipos não sejam selecionados apropriadamente. Além disso, o algoritmo requer que o número de grupos seja pré-definido. Isto pode ser bastante restritivo na prática, uma vez que o número de grupos contido nos dados é geralmente desconhecido, especialmente em aplicações reais que envolvem dados com várias dimensões.

Visando este tipo de aplicação, $k$-médias é comumente executado múltiplas vezes para valores distintos de $k$, e a melhor partição obtida por todas as execuções, de acordo com algum índice de validação, é selecionada como a solução do problema (Jain et al., 1999). Dois métodos deste tipo de execução são apresentados na Seção 2.4.6.1. O primeiro método, $O M R k$, consiste em executar o algoritmo $k$-médias $n_{\pi, k}$ vezes para um número crescente de grupos $k$, dentro de um determinado intervalo (e.g., 2 a $k_{\max }$ ). Apesar deste procedimento ser eficiente se o número ótimo de grupos for pequeno, o que permitiria o uso de um intervalo pequeno para o número de grupos, este pode não ser o caso e, mesmo que seja, dificilmente será previamente conhecido. O segundo método, $M R k$, consiste em executar $k$-médias múltiplas vezes com valores aleatórios para $k$, distribuídos dentro de um determinado intervalo (e.g., 2 a $k_{\max }$ ). Porém, esses métodos apresentam um problema: se por um lado, o número ótimo de grupos não estiver no intervalo escolhido, a solução correspondente nunca será encontrada. Por outro lado, se o intervalo for superestimado, o pior caso (e até o caso médio) do tempo de execução do algoritmo pode ser proibitivo, especialmente se o número de grupos $k$ for sorteado com reposição devido à sensibilidade do algoritmo $k$-médias à posição inicial dos protótipos. 
Vários algoritmos foram investigados na literatura na tentativa de superar as limitações dos métodos sistemáticos (repetitivos) citados acima. Estes métodos incluem a hibridização do $k$-médias com algum tipo de meta-heurística de propósito geral adaptada para o problema de agrupamento (Rayward-Smith, 2005). Merece destaque entre estas meta-heurísticas o uso de AEs para o problema de agrupamento, como discutido no Capítulo 3. São de especial interesse para esta pesquisa, dentre os AEs apresentados, os algoritmos baseados no uso do $k$-médias como busca local para refinar a busca global executada pelo método evolutivo.

O estudo apresentado neste capítulo envolve o problema de mostrar que algoritmos evolutivos para agrupamento podem ser mais eficientes do que abordagens repetitivas baseadas em múltiplas execuções do algoritmo $k$-médias, quando o número de grupos no conjunto de dados é desconhecido. Nele é mostrado que o algoritmo $F$-EAC (apresentado na Seção 3.4 e aprimorado neste trabalho, conforme descrito na Seção 4.3) pode ser computacionalmente mais eficiente do que $O M R k$ e $M R k$ sob duas perspectivas distintas: a computacional, por meio da análise da complexidade assintótica dos algoritmos investigados (Seção 4.2); e a experimental, por meio de uma rigorosa avaliação comparativa dos resultados obtidos de uma coleção de experimentos, análise da sensibilidade de parâmetros e testes estatísticos (Seção 4.4). Os resultados obtidos indicam que AEs aplicados ao agrupamento são uma alternativa mais promissora para aplicações práticas, nas quais conjuntos de dados que apresentam grandes quantidades de objetos e/ou atributos são comuns e o número de grupos é desconhecido.

Adicionalmente, outra metodologia experimental voltada para a aplicação prática do algoritmo é usada para comparar o $F$-EAC aprimorado com algoritmos baseados em $k$ médias e capazes de estimar o número de grupos $k$, a saber: os algoritmos OMRk e $M R k$; variações do Bisecting k-means, variações do $X$-means; e variações do próprio $F$ $E A C$ que recaem em procedimentos de busca local estocástica. Todos os algoritmos são comparados em termos da qualidade da partição gerada e desempenho computacional para 324 bases de dados, uma quantidade expressivamente maior de bases do que a utilizada no experimento anterior. Os resultados obtidos são apresentados na Seção 4.5 e confirmam o bom desempenho dos AEs investigados.

\subsection{Análise de complexidade assintótica}

Nesta seção será feita uma comparação do algoritmo F-EAC com os algoritmos $O M R k$ e $M R k$ sob a perspectiva computacional, por meio de análise da complexidade assintótica. Essa análise segue de perto aquela apresentada em (Campello et al., 2009).

\subsubsection{Análise de complexidade do OMRk}

Considerando $k$ como o número de grupos da partição formada e desconsiderando a complexidade da medida de dissimilaridade utilizada, a complexidade total do algoritmo 
$k$-médias é $O\left(t \cdot n_{o} \cdot k\right.$ ) (Seção 2.4.6), lembrando que $t$ é o número de iterações, $n_{o}$ é o número de objetos e $k$ é o número de grupos. Como $O M R k$ executa $k$-médias $n_{\pi, k}$ vezes para cada valor de $k$ até $k_{\max }$, seu custo computacional total é estimado na Expressão (4.1).

$$
O\left(n_{\pi, k} \cdot t \cdot n_{o} \cdot\left(2+3+\cdots+k_{\max }\right)\right) \Rightarrow O\left(n_{\pi, k} \cdot t \cdot n_{o} \cdot k_{\max }^{2}\right) .
$$

O número de diferentes inicializações $n_{\pi, k}$ geradas para cada valor de $k$ e o número de iterações $t$ do $k$-médias são constantes pequenas, geralmente escolhidas de maneira $a d$ hoc, dependendo da complexidade esperada do problema de agrupamento a ser resolvido e dos recursos computacionais disponíveis. Tomando $n_{o}$ e $k_{\max }$ como as variáveis críticas para o desempenho do algoritmo, o custo computacional total do algoritmo OMRk pode ser estimado como $O\left(n_{o} \cdot k_{\text {max }}^{2}\right)$, se apenas estas variáveis forem consideradas para fins de simplificação.

\subsubsection{Análise de complexidade do MRk}

Para estimar a complexidade assintótica do algoritmo $M R k$, se torna necessário estabelecer qual critério de parada será utilizado pelo algoritmo. Dois cenários distintos serão considerados: no primeiro, o algoritmo pára depois de gerar um determinado número de partições $n_{\pi}$. No segundo, o algoritmo pára após a geração de uma partição com um valor de validação igual ou maior que um determinado valor de referência $v_{R}$.

No primeiro cenário, $n_{\pi}$ é conhecido e estabelecido pelo usuário. Lembrando que o algoritmo $k$-médias apresenta complexidade $O\left(t \cdot n_{o} \cdot k\right)$, desconsiderando a complexidade da medida de dissimilaridade adotada, a ordem de magnitude do tempo de execução total do $M R k$ pode ser escrita como $t \cdot n_{o} \cdot\left(k_{1}+k_{2}+\ldots+k_{n_{\pi}}\right)$, em que $k_{i}$ é o número de grupos (selecionado aleatoriamente) da partição avaliada na $i$-ésima iteração do algoritmo. Como $k_{i}$ é uma variável, o tempo de execução esperado do algoritmo tem ordem de magnitude dada pela equação:

$$
E\left\{t \cdot n_{o} \cdot\left(k_{1}+k_{2}+\ldots+k_{n_{\pi}}\right)\right\}=t \cdot n_{o} \cdot \sum_{i=1}^{n_{\pi}} E\left\{k_{i}\right\}
$$

no qual $E\{\cdot\}$ denota esperança matemática. Dado que o domínio de valores discretos para a variável aleatória $k_{i}$ esteja no intervalo $\left\{2, \ldots, k_{\max }\right\}$, isto é, $k_{i} \in\left\{2,3, \ldots, k_{\max }\right\}=$

$\left\{k_{i, 1}, k_{i, 2}, \ldots, k_{i, k_{\max }-1}\right\}$, e dado que $k_{i}$ seja sorteado pelo $M R k$ com distribuição uniforme sobre este intervalo, segue que:

$$
p\left(k_{i}=k_{i, j}\right)=\frac{1}{k_{\max }-1} ; j=1,2 \ldots, k_{\max }-1 .
$$


Então, a esperança do lado direito da Equação (4.2) pode ser escrita como:

$$
E\left\{k_{i}\right\}=\sum_{j=1}^{k_{\max }-1} k_{i, j} p\left(k_{i}=k_{i, j}\right)=\frac{1}{k_{\max }-1}\left(2+3+\ldots+k_{\max }\right)
$$

e, como $\sum_{j=1}^{y} j=(1+y) y / 2$, o que implica que $\left(2+3+\ldots+k_{\max }\right)$ é $O\left(k_{\max }^{2}\right)$, a partir da Equação (4.4) conclui-se que $E\left\{k_{i}\right\}$ é $O\left(k_{\max }\right)$. Sendo assim, segue a partir da Equação (4.2) que o tempo computacional para $n_{\pi}$ iterações de $M R k$ é $O\left(n_{\pi} \cdot t \cdot n_{o} \cdot k_{\max }\right)$. Por último, se for considerado que $n_{\pi}$ seja escolhido de forma linearmente proporcional a $k_{\max }$, o que é uma maneira prática e intuitiva de tentar manter constante a probabilidade de se sortear uma inicialização favorável do número de grupos e protótipos, a complexidade resultante se torna $O\left(t \cdot n_{o} \cdot k_{\text {max }}^{2}\right)$.

No segundo cenário, o algoritmo pára após a geração de uma partição com um valor de validação igual ou maior que um determinado valor de referência $v_{R}$. Neste caso, o número de partições $n_{\pi}$ geradas pelo algoritmo é desconhecido a priori. Contudo, é possível estimar seu valor esperado, pois $n_{\pi}$ segue uma distribuição probabilística geométrica. Em verdade, $n_{\pi}$ pode ser visto como um número de tentativas de Bernoulli necessárias para se obter sucesso, de forma que uma tentativa de Bernoulli neste caso se refere ao sorteio do número de grupos e dos protótipos inicias do $k$-médias. O sucesso é obtido se estas quantidades forem sorteadas de forma que o $k$-médias convirja para uma partição com valor de validação $v_{R}$ ou maior em $t$ ou menos iterações. A probabilidade de sucesso $p_{s}$ pode ser estimada assumindo que $v_{R}$ seja grande o suficiente para ser encontrado apenas por partições que apresentem o número correto de grupos. Esta hipótese é particularmente válida no contexto dos experimentos apresentados nesta monografia.

Dada as considerações anteriores, segue que a probabilidade de sucesso $p_{s}$ de que o número de grupos seja correto e a inicialização seja favorável (em termos de evitar mínimos locais), é tal que $p_{s}=p_{v \mid c} \cdot p_{c}$, em que $p_{c}$ é a probabilidade de sortear o número correto de grupos e $p_{v \mid c}$ é a probabilidade condicional de sortear protótipos inicias favoráveis dado que o número correto de grupos tenha sido sorteado. Sendo $p_{c}=1 /\left(k_{\max }-1\right)$ e, portanto, $p_{s}=p_{v \mid c} /\left(k_{\max }-1\right)$, então o valor esperado para $n_{\pi}$, como média de uma distribuição geométrica, é dado por $E\left\{n_{\pi}\right\}=1 / p_{s}=\left(k_{\max }-1\right) / p_{v \mid c}$. O tempo computacional de $M R k$, previamente estimado como $O\left(n_{\pi} \cdot t \cdot n_{o} \cdot k_{\max }\right)$, agora passa a ser dado pela Expressão $(4.5)$.

$$
O\left(\frac{t \cdot n_{o} \cdot k_{\max }^{2}}{p_{v \mid c}}\right)
$$

A Equação (4.5), como esperado, reflete o fato que o tempo de execução do algoritmo tende a infinito quando $p_{v \mid c}$ tende a zero (devido ao aumento de $v_{R}$ em direção a um valor não alcançável). Assumindo $p_{v \mid c}$ constante e não nula, o tempo de execução esperado do $M R k$ é estimado novamente como $O\left(n_{o} \cdot k_{\max }^{2}\right)$ se apenas $n_{o}$ e $k_{\max }$ forem considerados para fins de simplificação. Isso significa que o tempo médio de $M R k$ é equivalente ao tempo do pior caso que, por sua vez, é equivalente àquele do OMRk (Seção 4.2.1). 


\subsubsection{Análise de complexidade do F-EAC}

Em relação ao tempo de execução, o uso do $k$-médias em cada genótipo apresenta o maior peso computacional do F-EAC. Portanto, desconsiderando a medida de dissimilaridade adotada, o custo computacional total do F-EAC é estimado como $O\left(n_{g} \cdot|P| \cdot t \cdot n_{o} \cdot \hat{k}_{\text {max }}\right)$ no pior caso, em que $n_{g}$ é o número de gerações, $|P|$ é o tamanho da população (número de genótipos), $n_{o}$ o número de objetos, $\hat{k}_{\text {max }}$ é o número máximo de grupos codificado por um genótipo durante a busca evolutiva e $t$ é o número de iterações do algoritmo $k$-médias. As quantidades representadas por $n_{g}$ e $|P|$ são tipicamente inversamente interdependentes, pois aumentar o tamanho da população geralmente reduz o número de gerações necessárias para convergência e vice-versa. Seu produto, $n_{g} \cdot|P|$, apresenta pouca variação para valores práticos de $n_{o}$ e $\hat{k}_{\max }$ (como será mostrado na Seção 4.4.3) e, portanto, a hipótese de que esses termos são interdependentes pode ser assumida sob este aspecto. Neste caso, o custo computacional do F-EAC pode ser estimado, em termos de quantidades potencialmente críticas ao problema como $O\left(n_{o} \cdot \hat{k}_{\text {max }}\right)$.

Considerando que um valor máximo $k_{\max }$ para $k$ (definido pelo usuário) seja imposto à busca evolutiva, tem-se que $\hat{k}_{\max } \leq k_{\max }$ e, nesse caso, validadas as hipóteses feitas anteriormente, o custo computacional do $F$-EAC se torna $O\left(n_{o} \cdot k_{\max }\right)$, menor do que o custo dos algoritmos $O M R k$ e $M R k$ que, como demonstrado nas Seções 4.2.1 e 4.2.2, é $O\left(n_{o} \cdot k_{\max }^{2}\right)$.

Como descrito na Seção 3.4.1, algumas estruturas de dados foram desenvolvidas visando o aumento da eficiência computacional do F-EAC por meio da redução da necessidade de recálculo do conteúdo armazenado nestas estruturas. Apesar de não haver mudança no custo computacional do algoritmo em termos assintóticos, isto gerou um custo adicional: o aumento da memória necessária para o uso destas estruturas. Por este motivo, uma análise da complexidade das estruturas de dados do algoritmo também é feita nesta seção.

A Tabela 4.1 considera o custo computacional das informações armazenadas e a quantidade de memória alocada para cada estrutura do F-EAC apresentada na Seção 3.4.1. Nesta análise, será considerada como medida de dissimilaridade a distância Euclidiana. Seguindo a notação adotada, $n_{o}$ é o número de objetos da base de dados, $n_{a}$ é o número de atributos e $k$ é o número de grupos. Essa análise leva em consideração apenas uma instância de cada estrutura, ou seja, o custo total do conjunto de estruturas para o algoritmo é dado pelo custo de cada indivíduo, presente na Tabela 4.1, vezes o tamanho da população $|P|$.

Estimar a complexidade de se obter o genótipo $\mathbf{g}$ depende do método escolhido para inicializar a partição. Se a inicialização for feita aleatoriamente, a complexidade computacional necessária será $O\left(n_{o}\right)$, equivalente ao espaço de memória alocado. Contudo, se os rótulos forem obtidos por meio do protótipo mais próximo, a inicialização terá custo $O\left(k \cdot n_{a} \cdot n_{o}\right)$, o que justifica o uso da estrutura durante a execução do algoritmo.

Obter o número de grupos $k$ ou o número total de objetos em cada grupo $C_{i}$ por meio 


\begin{tabular}{|l|r|r|}
\hline Estrutura & Complexidade de tempo & Alocação de memória \\
\hline $\mathbf{g}$ & $O\left(n_{o}\right)$ & $O\left(n_{o}\right)$ \\
$k$ & $O\left(n_{o}\right)$ & $O(1)$ \\
$\mathbf{n}_{C}$ & $O\left(n_{o}\right)$ & $O(k)$ \\
$\mathbf{C}$ & $O\left(n_{o} \cdot n_{a}\right)$ & $O\left(k \cdot n_{a}\right)$ \\
fit & $O\left(n_{o} \cdot k \cdot n_{a}\right)$ & $O(k)$ \\
\hline
\end{tabular}

Tabela 4.1: Medidas de complexidade para as estruturas do F-EAC.

do genótipo g têm custo de tempo computacional $O\left(n_{o}\right)$. Devido a memória necessária para estas estruturas ser relativamente pequena, $O(1)$ para $k$ e $O(k)$ para $\mathbf{n}_{C}$, armazenar essas informações é de extrema importância para o desempenho do algoritmo.

A informação armazenada na matriz de centróides $\mathbf{C}$ é calculada principalmente durante a execução de $k$-médias, a partir dos valores dos rótulos armazenados no genótipo g e tem complexidade $O\left(n_{o} \cdot n_{a}\right)$. Como os centróides possuem dimensionalidade $n_{a}$, a matriz $\mathbf{C}$ aloca $O\left(k \cdot n_{a}\right)$ de memória, um valor consideravelmente alto em comparação com estruturas mais simples como $k$ e $\mathbf{n}_{C}$. Contudo, a informação sobre os centróides é crucial para um algoritmo que utiliza $k$-médias e calcula a aptidão a partir dos centróides, o que faz desta uma estrutura fundamental ao algoritmo.

O cálculo da aptidão (fit) por meio do índice silhueta simplificada (Seção 2.5.2.5) depende da dissimilaridade entre os objetos e centróides e, portanto, possui complexidade computacional $O\left(n_{o} \cdot k \cdot n_{a}\right)$. Manter a aptidão dos indivíduos é necessário para o processo de seleção e mutação do algoritmo, o que torna a alocação de complexidade $O(k)$ de memória para a estrutura uma necessidade do algoritmo.

\subsection{Aprimoramento do F-EAC}

Ao implementar o F-EAC, o autor desenvolveu algumas modificações na codificação do algoritmo e modificações nas estruturas de dados do $F$-EAC, que possibilitaram uma redução considerável no tempo computacional em relação à versão original do algoritmo, publicada em Alves et al. (2006); Alves (2007) e apresentada na Seção 3.4. Essas modificações são apresentadas em detalhes na Seção 4.3.1. Para medir o impacto do aprimoramento feito no algoritmo, experimentos comparativos foram feitos com as implementações original e aprimorada e os resultados obtidos são apresentados na Seção 4.3.2.

\subsubsection{Modificações feitas no F-EAC}

O aprimoramento do F-EAC, feito neste trabalho, envolve essencialmente duas modificações. A primeira está relacionada à matriz de dissimilaridades entre os objetos do conjunto de dados e os centróides dos grupos de cada partição da população. Essa matriz, aqui referenciada como $\mathbf{D}$, tem dimensões $\left(n_{o} \times k\right)$ e a posição $\mathbf{D}(j, i)$ contém a dissimilaridade entre o $j$-ésimo objeto e o centróide do $i$-ésimo grupo. Um exemplo desta matriz é ilustrado na Figura 4.1. 


\begin{tabular}{|c|c|c|c|}
\hline $\mathrm{d}\left(\mathbf{x}_{1}, \mathbf{c}_{1}\right)$ & $\mathrm{d}\left(\mathbf{x}_{1}, \mathbf{c}_{2}\right)$ & $\ldots$ & $\mathrm{d}\left(\mathbf{x}_{1}, \mathbf{c}_{k}\right)$ \\
\hline $\mathrm{d}\left(\mathbf{x}_{2}, \mathbf{c}_{1}\right)$ & $\mathrm{d}\left(\mathbf{x}_{2}, \mathbf{c}_{2}\right)$ & $\ldots$ & $\mathrm{d}\left(\mathbf{x}_{2}, \mathbf{c}_{k}\right)$ \\
\hline$\ldots$ & $\ldots$ & $\ldots$ & $\ldots$ \\
\hline $\mathrm{d}\left(\mathbf{x}_{h_{o}}, \mathbf{c}_{1}\right)$ & $\mathrm{d}\left(\mathbf{x}_{h_{o}}, \mathbf{c}_{2}\right)$ & $\ldots$ & $\mathrm{d}\left(\mathbf{x}_{n_{o}}, \mathbf{c}_{k}\right)$ \\
\hline
\end{tabular}

Figura 4.1: Exemplo de matriz de dissimilaridade D.

O cálculo das dissimilaridades entre objetos e os centróides dos grupos da partição é necessário durante a busca local feita com o algoritmo $k$-médias, o cálculo da aptidão e aplicação dos operadores de mutação. Ou seja, na prática, é preciso manter $\mathbf{D}$ em memória durante essas etapas do algoritmo, o que causa um custo de memória da ordem de $O\left(n_{o} \cdot k\right)$. Entretanto, como o processamento dessas etapas é feito de forma sequencial em relação aos indivíduos da população $P$, a versão original do $F$-EAC utiliza somente uma matriz $\mathbf{D}$, que armazena apenas as dissimilaridades correspondentes ao indivíduo que está sendo processado. Isso faz com que as dissimilaridades calculadas para um determinado indivíduo sejam perdidas no cálculo referente ao próximo indivíduo, que gera a necessidade do recálculo dessas dissimilaridades na etapa seguinte do algoritmo.

Uma vez que calcular as dissimilaridades entre os objetos e os centróides dos grupos é uma das partes de maior custo computacional do algoritmo, armazenar essas informações para todos os indivíduos durante a execução do $k$-médias evita a necessidade de reprocessamento durante as outras etapas do algoritmo, em especial durante o cálculo da aptidão. Por esse motivo, o primeiro aprimoramento feito no F-EAC implementado neste trabalho consiste em armazenar uma matriz $\mathbf{D}$ para cada indivíduo da população. Isso fez com que o processamento total do algoritmo fosse reduzido em pelo menos $O\left(n_{o} \cdot k \cdot n_{a} \cdot|P| \cdot n_{g}\right)$, a um custo de memória de ordem $O\left(n_{o} \cdot k \cdot|P|\right)$.

O segundo aprimoramento do $F$-EAC está relacionado à implementação dos operadores de mutação, apresentados nos Algoritmos 5 e 6. Estes algoritmos apresentam uma função de "eliminar" grupos (presente nos Passos 5 e 9 dos Algoritmos 5 e 6), que é aplicada aos grupos selecionados se eles preencherem os pré-requisitos necessários. Sendo $\hat{C}_{s}$ o maior grupo a ser eliminado por operadores de mutação e $\hat{z}$ a maior quantidade de grupos eliminados em uma partição pelos operadores de mutação, inserir os objetos oriundos de grupos eliminados pelos operadores de mutação em outros grupos possui complexidade assintótica $O\left(\left|\hat{C}_{s}\right| \cdot \hat{z} \cdot|P| \cdot n_{g}\right)$, no pior caso. A fim de evitar esse custo computacional, o segundo aprimoramento do F-EAC consiste em apagar toda informação relacionada aos grupos eliminados e tornar seus objetos não agrupados. Objetos não agrupados encontram-se em um estado temporário, criado para evitar o processamento necessário para inserir os objetos oriundos dos grupos que sofreram mutação em outros grupos. Estes objetos são representados por zeros no genótipo g. Na etapa seguinte do algoritmo, que consiste na busca local por meio do algoritmo $k$-médias, todos os objetos (agrupados ou não) são inseridos nos grupos com os centróides mais similares.

Adicionalmente aos aprimoramentos descritos, dois aprimoramentos menores foram 
feitos na implementação do $F$-EAC. O primeiro está relacionado ao $M O_{1}$. Depois de aplicar esse operador, os grupos selecionados são eliminados e seus rótulos deixam de ser utilizados. Para exemplificar esse problema, suponhamos que o cromossomo $\mathbf{g}_{d}=[3$ $\begin{array}{lllllll}3 & 3 & 2 & 1 & 1 & 2 & 2\end{array}$ ], que codifica 4 grupos, seja afetado pelo $M O_{1}$ de forma a eliminar o grupo de rótulo 2. Um possível resultado da mutação é o cromossomo $\mathbf{g}_{d}^{\prime}=\left[\begin{array}{lllll}3 & 3 & 3 & 1\end{array}\right.$ $\left.\begin{array}{lllll}1 & 1 & 3 & 4 & 4\end{array}\right]$. Como as próximas etapas do algoritmo só podem ser aplicadas nos grupos remanescentes, é preciso utilizar algum método que retorne quais são os rótulos que não foram eliminados. Uma forma de fazer isso é percorrendo $\mathbf{g}_{d}^{\prime}$ em busca desses rótulos, o que possui complexidade $O\left(n_{o}\right)$. Outra forma consiste em montar um índice $\mathbf{v}_{\mathbf{d}}=\left[\begin{array}{lll}1 & 3 & 4\end{array}\right]$ contendo os rótulos da partição $\mathbf{g}_{d}^{\prime}$, o que reduz o custo da consulta pelos rótulos presentes em $\mathbf{g}_{d}^{\prime}$ para $O(k)$.

Entretanto, qualquer operação que envolva buscar por grupos no genótipo $\mathbf{g}_{d}^{\prime}$ necessita de uma consulta pelos rótulos presentes nesse genótipo. Adicionalmente, esse tipo de operação é bastante comum durante toda a execução do $F$-EAC. Para agravar a situação, não se sabe quais genótipos possuem todos os rótulos enumerados sequencialmente de 1 até $k$ e quais os genótipos em que os rótulos não são sequenciais, como é o caso de $\mathbf{g}_{d}^{\prime}$. Isso gera a necessidade de sempre efetuar uma consulta pelos rótulos presentes em todos os genótipos do algoritmo, o que aumenta seu custo computacional.

Para evitar esse custo computacional, foi aplicada a renumeração dos genótipos após a mutação, o que constitui o primeiro aprimoramento menor citado anteriormente. A renumeração consiste em alterar alguns rótulos dos cromossomos que sofreram mutação de forma que os grupos sempre sejam rotulados com valores que vão de 1 a $k$. Por exemplo, se $\mathbf{g}_{d}^{\prime}$ for renumerado de forma a gerar a partição $\mathbf{g}_{d}^{\prime \prime}=\left[\begin{array}{lllllllll}3 & 3 & 3 & 1 & 1 & 1 & 3 & 2 & 2\end{array}\right]$, elimina-se a necessidade de consultar quais rótulos estão presentes em $\mathbf{g}_{d}^{\prime \prime}$, pois sabe-se que o primeiro grupo sempre será representado pelo rótulo 1, o segundo grupo pelo rótulo 2 , e assim sucessivamente, até o rótulo $k$ (neste caso, $k=3$ ). Além disso, a partição $\mathbf{g}_{d}^{\prime \prime}$ é equivalente à partição $\mathbf{g}_{d}^{\prime}$, pois possuem os mesmos grupos. O processo de renumeração tem complexidade $O(n)$ e, ao contrário da consulta por rótulos, é aplicado apenas uma vez para cada genótipo mutado.

O segundo aprimoramento menor consiste em calcular as dissimilaridades entre objetos ou centróides por meio de operações matriciais, que utilizam rotinas especializadas para o processamento matricial eficiente. Como o cálculo das dissimilaridades é uma das funções de maior custo computacional do algoritmo, esse de aprimoramento auxiliou na redução do tempo médio necessário para a execução do algoritmo.

\subsubsection{Comparação entre versões}

Apesar das melhorias feitas no F-EAC não mudarem o custo computacional do algoritmo em termos assintóticos, elas reduziram o tempo de execução em termos de constantes. Nesta seção são apresentados experimentos que indicam essa redução. 


\subsubsection{Metodologia}

Como a comparação de eficiência computacional deste experimento tem em vista duas implementações do mesmo algoritmo, no qual a única diferença entre estas consiste no método de implementação, é razoável assumir que ambas são capazes de encontrar partições de qualidade equivalente. Um meio de se medir esta qualidade consiste em utilizar índices de validação de agrupamentos (Seção 2.5). Uma vez escolhido o índice, ainda é um problema encontrar um valor alvo para esse índice que indique uma qualidade de partição aceitável e sirva de valor de referência para os algoritmos analisados. Ou seja, é preciso que os algoritmos analisados encontrem partições que possam superar essa qualidade mínima aceitável, refletida quantitativamente pelo índice de validação escolhido.

Pode ser assumido que, para que uma partição com tal valor de validação seja gerada por meio de $k$-médias, é necessário que esta possua número de grupos $k$ e inicialização favoráveis. Com o objetivo de se obter tal partição e, consequentemente, seu valor de validação, o algoritmo $O M R k$ (Algoritmo 2) foi executado com valores crescentes de $k$ que vão de 2 até $k_{\max }$. Uma prática comum consiste em utilizar $k_{\max }=n_{o}^{1 / 2}(\mathrm{Pal} \&$ Bezdek, 1995; Pakhira et al., 2005; Campello et al., 2009), adotada aqui. O OMRk gera $n_{\pi, k}$ partições para cada valor de $k$, com o objetivo de evitar inicializações que fiquem presas em mínimos locais. Estudos preliminares sugerem que $n_{\pi, k}=20$ seja suficiente para encontrar partições de qualidade razoável para os conjuntos de dados utilizados neste experimento e, portanto, essa configuração será adotada aqui. Além disso, juntamente com $n_{\pi, k}=10$, esse é um dos valores mais adotados na prática (Hand \& Krzanowski, 2005). As partições geradas pelo algoritmo são avaliadas pelo índice silhueta simplificada (Seção 2.5.2.5), por ser um índice que obtém bons resultados para grupos volumétricos (como os gerados por $k$-médias). O valor mais alto de silhueta encontrado dentre todas as $n_{\pi, k} \cdot\left(k_{\max }-2+1\right)=20 \cdot\left(n_{o}^{\frac{1}{2}}-1\right)$ partições é utilizado como valor de referência $v_{R}$ pelas implementações do $F$-EAC, que pára quando gera uma partição com um valor igual ou superior ao valor de referência $v_{R}$.

Também é necessário determinar o(s) critério(s) de parada do algoritmo $k$-médias, utilizado tanto para gerar o valor de referência por meio do $O M R k$ como durante a execução da busca local do F-EAC. Partindo do princípio que o algoritmo convirja, um critério de parada efetivo consiste em obter uma diferença máxima absoluta de valores dos centróides $\mathbf{c}_{i}$ entre iterações consecutivas do algoritmo abaixo de um determinado limiar $\varepsilon$. Um valor utilizado com frequência, também adotado nos experimentos apresentados neste trabalho, é utilizar $\varepsilon=10^{-3}$ (Hall et al., 1999) para dados normalizados. Nos experimentos descritos neste capítulo, $k$-médias ainda executa um número máximo de iterações $t$, definido a priori. Evidência empírica sugere que $t=5$ é suficiente para que o algoritmo encontre soluções satisfatórias (Anderberg, 1973), especialmente considerando que será inicializado múltiplas vezes a partir de protótipos iniciais distintos, portanto este valor será utilizado aqui.

A população de ambas as implementações do $F-E A C$ é inicializada por meio do sorteio 
aleatório do número de grupos $k$ e dos protótipos dos grupos dentre os objetos do conjunto de dados, para cada indivíduo. Esta metodologia favorece a diversidade na população inicial, criando partições inicias que representam números de grupos distintos. Experimentos com diferentes valores de tamanho de população $|P|$ foram executados. Como discutido na Seção 4.2.3, existe uma relação de interdependência entre $|P|$ e o número de gerações $n_{g}$ do algoritmo, de forma que o aumento do valor de uma variável tende a causar a redução do valor da outra. Portanto, $|P|$ não é considerado um parâmetro crítico para o F-EAC.

A função de aptidão utilizada pelo algoritmo é a silhueta simplificada e optou-se por utilizar a estratégia $(\mu+\lambda)$ (Fogel, 1995) para seleção dos genótipos. Os valores $\mu=0.4$ e $\lambda=0.6$ mostraram bons resultados em (Alves et al., 2006; Alves, 2007) e em experimentos preliminares deste autor, e serão utilizados neste experimento.

\subsubsection{Conjuntos de dados}

Os experimentos apresentados nesta seção são executados em dois conjuntos de dados artificiais. O primeiro, chamado Gauss9, é composto por 900 objetos distribuídos em nove grupos balanceados, gerados por distribuições Gaussianas com desvios padrões 0,5 e centros $(1,1),(1,3),(1,5),(3,1),(3,3),(3,5),(5,1),(5,3)$, e $(5,5)$ (Hruschka et al., 2004a; Campello \& Hruschka, 2006). Seus grupos podem ser reconhecidos por inspeção visual, como ilustrado na Figura 4.2. Devido à sobreposição natural deste conjunto de dados, o $k$-médias não é capaz de produzir partições perfeitamente compatíveis com a distribuição original dos rótulos.

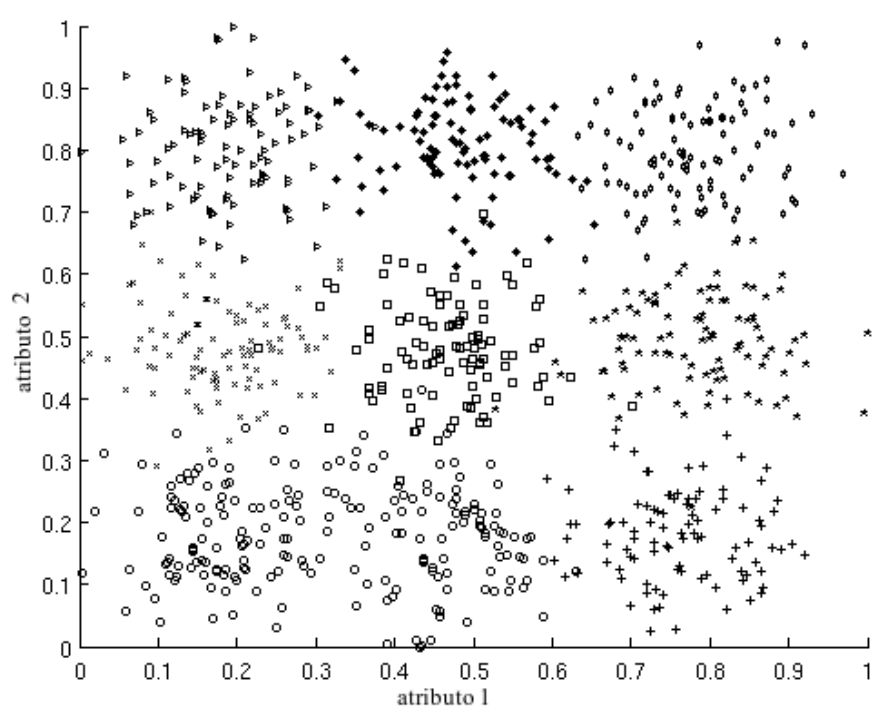

Figura 4.2: Conjunto de dados Gauss9.

O segundo conjunto de dados, Spherical_4_3, possui três dimensões e é composto por 400 objetos igualmente distribuídos em quatro grupos Gaussianos (Bandyopadhyay \& Maulik, 2002b; Pakhira et al., 2005), como ilustrado na Figura 4.3. 


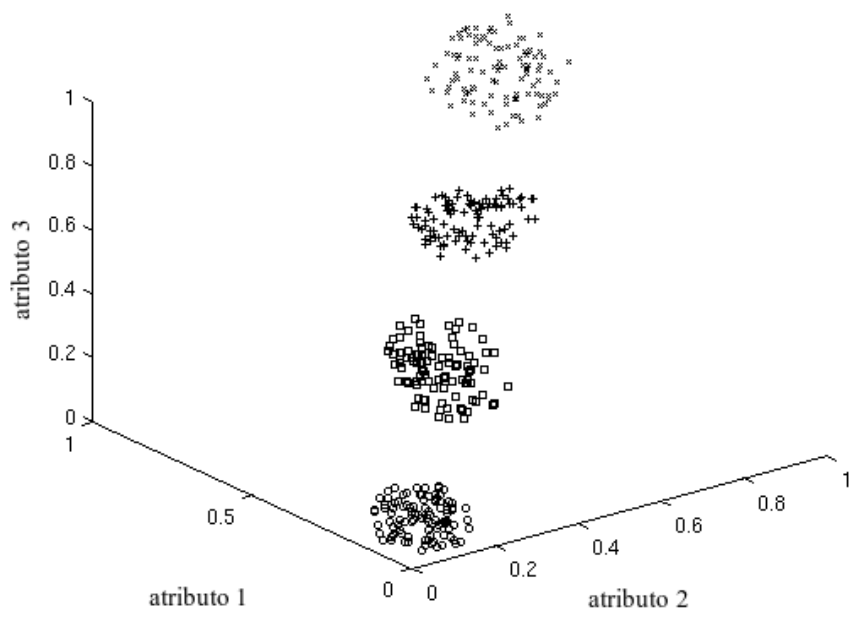

Figura 4.3: Conjunto de dados Spherical_4-3.

\subsubsection{Experimentos}

A Tabela 4.2 apresenta o tempo computacional médio e desvio padrão em segundos para as implementações original e aprimorada do $F$-EAC, obtidos de 50 execuções para populações de tamanhos 5, 10, 15 e 20. Todos os algoritmos foram implementados em Matlab (versão 7.8.0 R2009a) e os experimentos foram executados em um mesmo computador: processador de dois núcleos de $3 \mathrm{Ghz}$, 4Gb RAM e sistema operacional linux.

\begin{tabular}{|l|c|c|c|c|}
\hline Tamanho da & \multicolumn{2}{|c|}{ Original $F$-EAC } & \multicolumn{2}{c|}{$F$-EAC aprimorado } \\
\cline { 2 - 5 } População $(|P|)$ & Gauss9 & Spherical_4_3 & Gauss9 & Spherical_4_3 \\
\hline 20 & $112.04(62.33)$ & $26.80(7.79)$ & $5.26(2.93)$ & $1.02(0.31)$ \\
15 & $96.36(51.63)$ & $20.03(5.80)$ & $4.78(2.93)$ & $0.45(0.82)$ \\
10 & $92.66(65.17)$ & $14.80(5.29)$ & $4.18(2.29)$ & $0.62(0.29)$ \\
5 & $74.02(66.96)$ & $13.24(23.07)$ & $3.12(2.33)$ & $0.33(0.14)$ \\
\hline
\end{tabular}

Tabela 4.2: Tempo computacional em segundos para as implementações do F-EAC: média e desvio padrão sobre 50 execuções.

Os resultados apresentados na Tabela 4.2 mostram que a implementação aprimorada pode ser ordens de magnitude mais rápida que a versão predecessora. Em contrapartida, por armazenar a matriz de dissimilaridade $\mathbf{D}$, a implementação aprimorada necessita de $O\left(n_{o} \cdot k\right)$ memória a mais para cada indivíduo.

\subsection{Análise de tempo computacional}

Na Seção 4.2, a complexidade assintótica do F-EAC foi comparada com a dos algoritmos $O M R k$ e $M R k$. Nesta seção é mostrado que AEs para agrupamentos podem ser computacionalmente mais eficientes do que tais abordagens sistemáticas em termos práticos. A metodologia de comparação adotada, descrita na Seção 4.4.1, foi proposta em (Campello et al., 2009). 


\subsubsection{Metodologia}

Comparações de eficiência computacional não devem negligenciar a qualidade das partições obtidas. Com isto em mente, é razoável assumir que comparações justas podem ser feitas se os algoritmos analisados forem capazes de encontrar partições de qualidade equivalente, sendo esta a mais alta possível. Assim como a metodologia utilizada na Seção 4.3.2, critérios de validação de agrupamentos podem ser utilizados para determinar se as partições encontradas pelos algoritmos possuem qualidade similar ou não. Para isto, é necessário encontrar um valor alvo aceitável para o índice de validação. Por aceitável, definimos um valor que: (i) seja o maior possível; e (ii) todos os algoritmos sob investigação sejam capazes de encontrá-lo. Desta forma, os tempos computacionais dos algoritmos para encontrar este valor de referência podem ser comparados.

Outro problema a ser considerado é que o desempenho de alguns algoritmos depende de parâmetros definidos pelo usuário, cujos valores podem influenciar a análise. Por exemplo, o desempenho do algoritmo $O M R k$ é afetado pelo número de partições distintas $n_{\pi, k}$ geradas para cada número de grupos $k$ (ver Algoritmo 2). Como mostrado na Seção 2.4.6, normalmente é necessário executar o $k$-médias um certo número de vezes (com diferentes protótipos iniciais) de forma a escapar de ótimos locais. Claramente, este parâmetro tem impacto significativo na análise comparativa em relação à eficiência computacional dos algoritmos sob avaliação. De forma geral, não há um método prático para guiar o usuário a escolher um valor $n_{\pi, k}$ que gere bons resultados. Por um lado, se $n_{\pi, k}$ for subestimado, partições de baixa qualidade podem ser geradas. Por outro lado, valores superestimados podem levar a um desperdício de tempo computacional. Em relação ao desempenho do F-EAC, embora de maneira não crítica (conforme será mostrado), este pode ser afetado pelo tamanho da população escolhido pelo usuário. De maneira geral, grandes populações tendem a fazer com que a busca evolutiva convirja para boas soluções em poucas gerações (cada uma delas computacionalmente dispendiosa devido ao grande tamanho da população). Pequenas populações, ao contrário, possivelmente farão com que o algoritmo convirja em um número maior de gerações, que tendem a ser, contudo, individualmente computacionalmente menos dispendiosas, pois apenas alguns genótipos são avaliados. Esse contra-balanceamento, no entanto, não é perfeito, podendo influenciar os tempos totais de execução do algoritmo. Por último, o valor máximo permitido para o número de grupos $k_{\text {max }}$ é crítico para o desempenho do $O M R k$ e $M R k$ pois estes algoritmos possuem tempo quadrático em relação a este parâmetro e inexoravelmente não poderão resolver o problema se este parâmetro for subestimado (por exemplo, se o valor escolhido for menor do que o valor mais apropriado do número de grupos). Diferentemente, $F$-EAC é robusto à escolha de $k_{\max }$ para a sua população inicial, uma vez que seus operadores de busca evolutivos são capazes de aumentar ou reduzir o número de grupos de forma apropriada.

De forma a lidar com os apectos mencionados na comparação do F-EAC com OMRk e $M R k$, a metodologia de comparação adotada pode ser resumida nos três passos a seguir: 
1. Execute $O M R k$ (Algoritmo 2) e armazene o maior valor encontrado $v_{V C}$ para o índice de validação escolhido (silhueta simplificada neste trabalho) e sua respectiva partição. Armazene o tempo computacional e faça o maior valor de validação encontrado, $v_{V C}$, se tornar o valor de referência $v_{R}\left(v_{R}=v_{V C}\right)$.

2. Execute $M R k$ (Algoritmo 3) e F-EAC (Algoritmo 4) até que o valor de referência $v_{R}$, obtido no Passo 1, seja encontrado. Armazene o tempo computacional dos algoritmos.

3. Repita os passos acima um número de vezes com diferentes valores para os parâmetros dos algoritmos e faça uma avaliação estatística dos resultados.

Estes passos permitem fazer com que os três algoritmos sejam capazes de encontrar partições de qualidade equivalente, com diferentes configurações de seus parâmetros. Os parâmetros a serem variados são $n_{\pi, k}(O M R k)$ e o tamanho da população $|P|$ do $F$-EAC. Outras características do $F$-EAC, como tipo de inicialização e o operador de seleção, foram configuradas da forma descrita na metodologia da Seção 4.3.2. Mais uma vez, $k_{\max }=n_{o}^{1 / 2}$ será adotado para $O M R k, M R k$ e para a população inicial do $F-E A C$, pois esta regra garante que o número natural de grupos $k^{*}$ seja tal que $k^{*}<k_{\max }$ nos experimentos a serem relatados na sequência, além de se tratar de uma regra prática usualmente adotada na literatura (Pal \& Bezdek, 1995; Pakhira et al., 2005).

Um número significativo de experimentos (50) foi executado para cada algoritmo sob interesse para o estudo (OMRk, MRk e F-EAC). Todos os algoritmos foram implementados em Matlab (versão 7.8.0 R2009a) e os experimentos foram executados no mesmo computador utilizado nos experimentos apresentados na Seção 4.3.2: processador de dois núcleos de $3 \mathrm{Ghz}$, 4Gb RAM e sistema operacional linux.

\subsubsection{Conjuntos de dados}

Para os experimentos apresentados nesta seção, foram utilizados os conjuntos de dados artificiais Gauss9 e Spherical_4_3, descritos na Seção 4.3.2.2. Antes dos conjuntos de dados serem agrupados, os atributos destes foram normalizados para valores no intervalo $[0,1]$.

Além desses conjuntos artificiais, um conjunto de dados composto por documentos textuais foi utilizado. Para tanto, 253 artigos foram obtidos de 5 periódicos internacionais, todos na língua inglesa, conforme indicado na Tabela 4.3. Cada periódico está relacionado a uma área de pesquisa distinta e, por esse motivo, serão utilizados para determinar a partição de referência ou conhecida ("gold standard") deste conjunto de dados. Em outras palavras, cada grupo da partição conhecida é formado por todos os artigos de um determinado periódico. Esses grupos serão posteriormente utilizados, juntamente com um índice externo, para medir a similaridade das partições obtidas com a partição de referência. 
Para cada artigo, as seguintes seções foram selecionadas para montar um corpus no bem conhecido formato bag-of-words: título, autores, resumo, palavras chaves e referências. Cada documento é representado pela frequência dos termos que ele contém (ou seja, uma representação baseada na frequência dos termos é adotada, vide Seção 2.2.2). Medidas de dissimilaridade baseadas em cosseno (descritas na Seção 2.3.2) são muito comuns na área de mineração de texto (Feldman \& Sanger, 2006). Portanto, a dissimilaridade expressada pela Equação (2.13) será utilizada para os experimentos envolvendo este conjunto de dados.

\begin{tabular}{|l|r|r|}
\hline Periódico & Volumes (Números) & N $^{o}$ de artigos \\
\hline $\begin{array}{l}\text { American Political Science Review } \\
\text { (Cambrigde Journals) }\end{array}$ & $102(1$ até 4$)$ & 62 \\
\hline $\begin{array}{l}\text { DNA Research } \\
\text { (Oxford Journals) }\end{array}$ & $15(1$ e 2$)$ & 51 \\
& $14(1$ até 6$)$ & \\
\hline $\begin{array}{l}\text { Monthly Weather Review } \\
\text { (American Meteorological Society) }\end{array}$ & $136(1$ e 2$)$ & 42 \\
\hline $\begin{array}{l}\text { British Food Journal } \\
\text { (Emerald) }\end{array}$ & $110(1$ até 5$)$ & 50 \\
\hline $\begin{array}{l}\text { Transactions on Mobile Computing } \\
\text { (IEEE) }\end{array}$ & $7(2$ até 11$)$ & 48 \\
\hline
\end{tabular}

Tabela 4.3: Corpus do conjunto de dados ARTICLES.

Em seguida, o algoritmo de stemming de Porter (1980) foi aplicado nas palavras do conjunto e os termos de uma lista de stop-words foram eliminadas, por meio do programa Projection Explorer (PEx) (Paulovich et al., 2007). O conjunto de dados resultante continha 23.818 stems (termos resultantes do processo de stemming). Após a geração da curva de Zipf, cortes de Luhn (vide Seção 2.2.2) foram feitos seguindo duas metodologias experimentais:

1. O primeiro método consiste em eliminar stems cuja frequência for maior que 1.442 ou menor que 5 em todo corpus, baseado em inspeção visual da curva de Zipf. Esta eliminação inclui stems comuns, como "pp." e "vol.", ou específicos, como os oriundos do nome de alguns autores. Esta metodologia é tradicionalmente utilizada para mineração de textos (Losee, 2001; Martins et al., 2003; Linger et al., 2004) e a versão resultante deste conjunto será conhecida aqui como ARTICLES-14425, com 4636 stems. É importante notar que nenhum conhecimento prévio sobre as categorias dos documentos presentes no conjunto de dados foi utilizado para propósito de pré-processamento.

2. O segundo método consiste em gerar várias partições do conjunto de dados com corte de Luhn em pontos distintos por meio de $k$-médias e selecionar a base resultante por meio de um índice de validação externo, em relação a partição de referência. Para esta finalidade, foi utilizado o índice Jaccard (Jaccard, 1908), descrito na Seção 2.5.1. 
Particularmente, escolher os corte de Luhn nas frequências 1.442 e 80 resultaram em um valor de Jaccard alto e manteve a base de dados com um número considerável de stems. A versão resultante desta metodologia será referenciada como ARTICLES1442-80, com 388 stems.

Apesar da segunda metodologia experimental não ter um apelo prático, pois a maioria dos problemas reais não possuem uma estrutura conhecida a priori (partição de referência), ela favorece a criação de um cenário particularmente interessante para avaliar a eficiência computacional de algoritmos baseados em $k$-médias, como é o caso do estudo em questão.

Vale a pena enfatizar que a segunda metodologia gera um cenário que envolve o uso de partições de boa qualidade. Para ser preciso, foram analisados valores para os índices silhueta simplificada e Jaccard resultantes dentre 50 execuções de $k$-médias (com $k=5)$. Considerando $l i_{f}$ como a frequência de stems para o limite inferior do corte de Luhn, a Figura 4.4 apresenta a média e o melhor do valores obtidos dentre 50 execuções de $k$ médias para os índices em questão (com $l i_{f}$ variando entre 5 e 140), depois da remoção dos stems com frequência superior do que 1.442. Adicionalmente, são apresentados os valores para a silhueta simplificada para as partições com melhor Jaccard dentre 50 execuções de $k$-médias e vice-versa. Pode ser verificado pela Figura 4.4 que as partições com os maiores valores do Jaccard também apresentam valores altos de silhueta simplificada. O inverso também é verdadeiro, o que sugere uma relação próxima entre os valores da silhueta simplificada e a estrutura conhecida do conjunto de dados estudado, representada pelo índice Jaccard, o que de fato é comprovado por meio de uma grande quantidade de experimentos apresentados nos trabalhos de Vendramin et al. (2008, 2009, 2010).

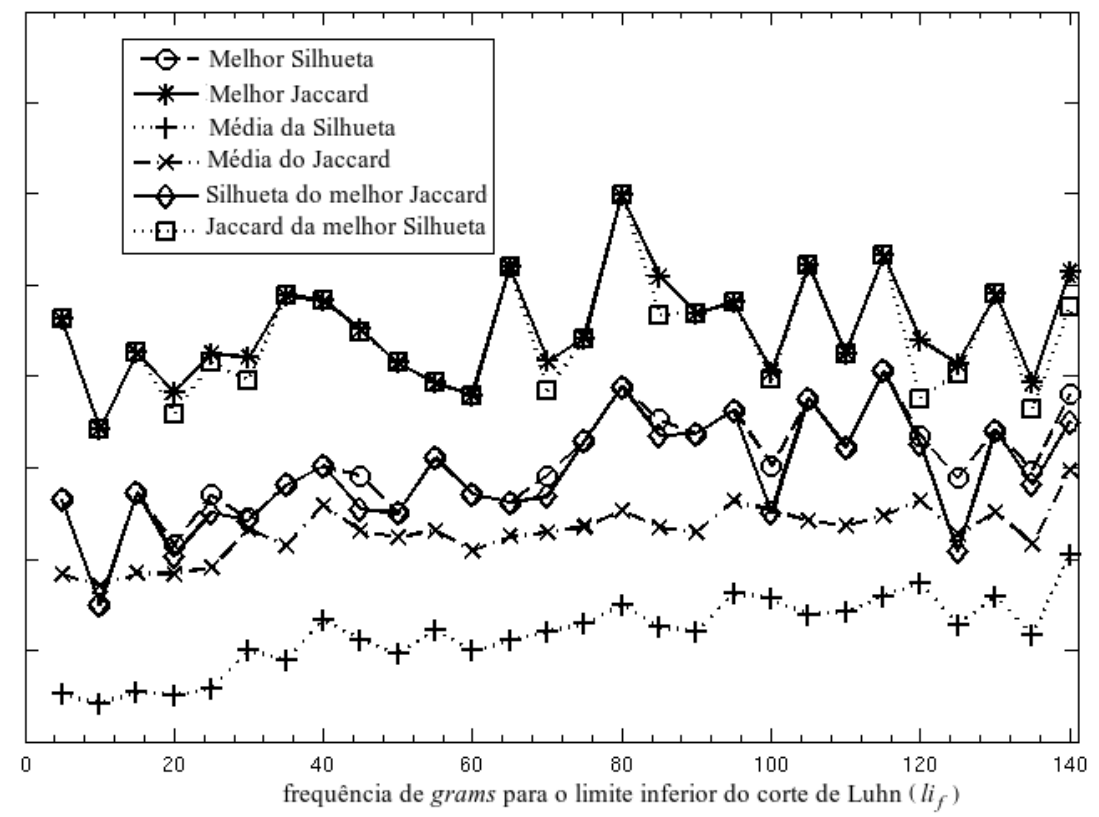

Figura 4.4: Valores para os índices silhueta simplificada e Jaccard para cortes de Luhn distintos. 
Antes de serem utilizadas nos experimentos, as duas versões do conjunto de dados foram normalizadas de forma a transformar os vetores que representam os objetos em versores, conforme descrito na Seção 2.2.2. Para ilustrar o conjunto de dados depois de pré-processado, o programa $P E x$ foi utilizado para mapeá-lo em duas dimensões e criar suas representações visuais por meio de um método de projeção não linear chamado de Interactive Document Map (IDMAP) (Minghim et al., 2006). Nesta representação, mostrada na Figura 4.5, cada categoria é identificada com um símbolo e a distância entre os artigos no plano são proporcionais à sua dissimilaridade.

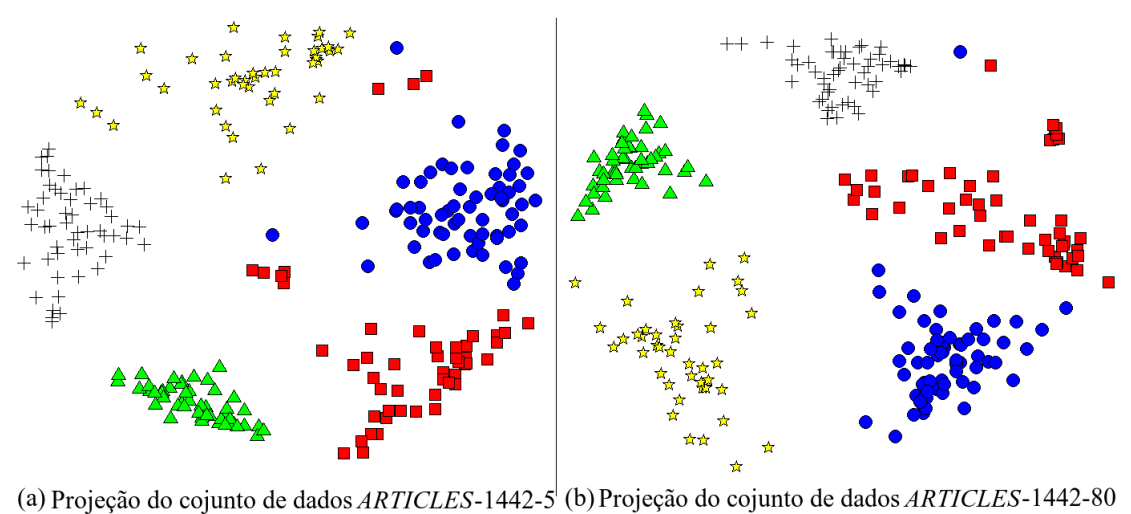

Figura 4.5: Projeções bi-dimensionais do conjunto de dados ARTICLES depois de seu pré-processamento para os cortes de Luhn escolhidos.

\subsubsection{Experimentos}

Nesta seção são apresentados os resultados dos experimentos comparativos em termos de complexidade computacional, por meio da metodologia descrita na Seção 4.4.1. Estes resultados serão apresentados para os conjuntos de dados descritos nas Seções 4.3.2.2 e 4.4.2.

\subsubsection{Gauss9}

Devido à estrutura sobreposta do conjunto de dados Gauss9 (Seção 4.3.2.2), k-médias não é capaz de obter exatamente os mesmos grupos mostrados na Figura 4.2. Apesar disto, $k$-médias é capaz de produzir partições que são bastante compatíveis com a distribuição espacial dos dados. Especificamente, a média dos valores obtidos pelo índice Jaccard para as partições obtidas pelo $O M R k$ foi 0,76 , enquanto as médias obtidas por outros métodos $(M R k$ e $F$-EAC) é próximo de 0,79 .

Como discutido na Seção 4.4.1, alguns parâmetros definidos pelo usuário podem afetar a análise comparativa da eficiência computacional do algoritmos. Por esta razão, a análise de sensibilidade destes parâmetros é feita. No $O M R k$, o parâmetro $n_{\pi, k}$ foi variado entre 1 e 20. Para cada valor de $n_{\pi, k} \in\{1, \ldots, 20\}$, são feitas 50 execuções de $O M R k$ e o seu respectivo tempo computacional é armazenado. Um resumo dos resultados obtidos pode ser visto na Tabela 4.4 . 


\begin{tabular}{lrrrrrrrrrr}
\hline$n_{\pi, k}$ & 01 & 02 & 03 & 04 & 05 & 06 & 07 & 08 & 09 & 10 \\
\hline$\mu$ & 1.18 & 2.36 & 3.55 & 4.74 & 5.92 & 7.11 & 8.29 & 9.48 & 10.66 & 11.85 \\
$\sigma$ & 0.01 & 0.01 & 0.01 & 0.02 & 0.02 & 0.02 & 0.02 & 0.02 & 0.03 & 0.04 \\
\hline$n_{\pi, k}$ & 11 & 12 & 13 & 14 & 15 & 16 & 17 & 18 & 19 & 20 \\
\hline$\mu$ & 13.03 & 14.21 & 15.39 & 16.58 & 17.76 & 18.94 & 20.13 & 21.31 & 22.50 & 23.68 \\
$\sigma$ & 0.04 & 0.04 & 0.04 & 0.05 & 0.05 & 0.05 & 0.06 & 0.06 & 0.06 & 0.06 \\
\hline
\end{tabular}

Tabela 4.4: Tempo computacional do OMRk em segundos $\left(k_{\max }=n_{o}^{1 / 2}=30\right)$ para Gauss9: $\mu$ e $\sigma$ são a média e o desvio padrão sobre as 50 execuções, respectivamente.

De acordo com a metodologia descrita na Seção 4.4.1, os valores do índice silhueta simplificada para todas as partições encontradas pelo $O M R k$ foram armazenados e o maior agora será utilizado como valor de referência para ser obtida pelo $M R k$ e $F$-EAC. Uma vez que que o desempenho do $F$-EAC pode ser sensível ao tamanho da população, este parâmetro foi variado de acordo com os valores mostrados na Tabela 4.5.

\begin{tabular}{lll}
\hline Tamanho da & Tempo & $\begin{array}{l}\text { Número de } \\
\text { Gerações }\end{array}$ \\
\hline População $(|P|)$ & Computacional $(s)$ & $3.77(2.67)$ \\
15 & $5.26(2.93)$ & $4.8(3.51)$ \\
10 & $4.78(2.93)$ & $6.59(4.26)$ \\
5 & $4.18(2.29)$ & $10.12(8.48)$ \\
\hline
\end{tabular}

Tabela 4.5: Resultados do F-EAC para Gauss9: média (desvio padrão) sobre 50 execuções.

Comparando os resultados para os diferentes tamanhos de populações apresentados na Tabela 4.5 é possível observar que, conforme esperado, grandes populações tendem a fazer como que o F-EAC convirja para boas soluções em menos gerações, as quais, por sua vez, necessitam de um custo computacional maior do que o custo relacionado a populações menores. Em outras palavras, populações pequenas favorecem a convergência do algoritmo em um número maior de gerações, que por sua vez tendem a possuir um menor custo computacional.

Histogramas dos resultados obtidos sugerem que a hipótese de normalidade é raramente satisfeita. Alguns histogramas típicos para os tempos computacionais para todos os algoritmos são mostrados na Figura 4.6. De fato, o teste de aderência de KolmogorovSmirnov rejeita esta hipótese para a maioria dos resultados. Apesar do teorema do limite central poder ser utilizado para dar suporte à nomalidade das médias dos dados, ainda não é garantido que os tamanhos das amostras sejam suficientes para aproximar os resultados de um distribuição normal. Por esses motivos, o conhecido teste estatístico não-paramétrico Wilcoxon/Mann-Whitney foi adotado aqui. A eficiência do teste Wilcoxon/Mann-Whitney é próxima de $95 \%$ em relação a testes paramétricos como o teste $\mathbf{t}$ ou o teste $\mathbf{z}$, mesmo quando os dados seguem uma distribuição normal (Triola, 1999). Portanto, mesmo quando é válido assumir normalidade para os dados, será dada preferência ao teste de Wilcoxon/Mann-Whitney. 
(a) $\operatorname{OMRk}\left(n_{\pi, k}=1\right)$
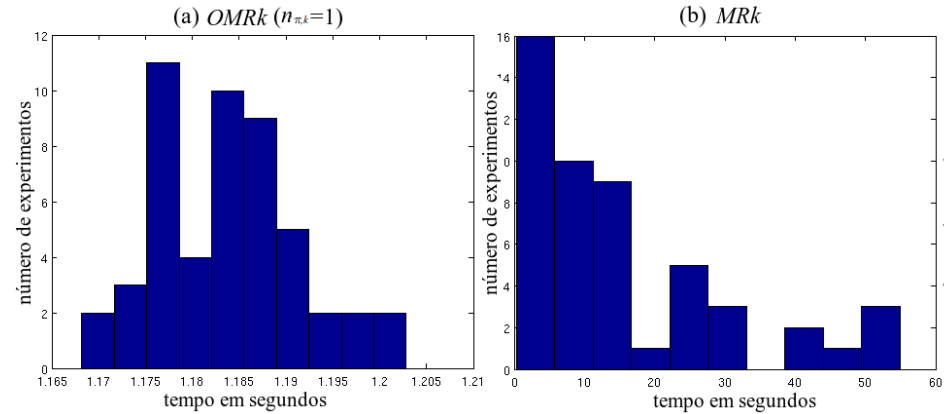

(c) F-EAC $(|P|=10$ genótipos $)$

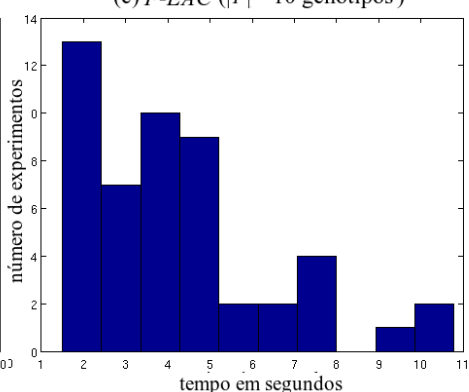

Figura 4.6: Histogramas típicos do tempo computacional (em segundos).

A Figura 4.7 ilustra a comparação de resultados entre o $O M R k$ e o $F$-EAC. Estes resultados são derivados do teste de Wilcoxon/Mann-Whitney com $\alpha=5 \%$ (teste unilateral), para configurações distintas dos algoritmos (parâmetros $n_{\pi, k}$ e tamanho da população do $F$-EAC). Configurações nas quais o $F$-EAC é estatisticamente mais rápido do que o $O M R k$ são indicadas pelo símbolo " $\triangle$ ", enquanto configurações para as quais $F-E A C$ é estatisticamente mais lento do que $O M R k$ são indicadas pelo símbolo " $\nabla$ ". Se a diferença entre o tempo computacional dos algoritmos não possui significância estatística, então a configuração correspondente é indicada pelo símbolo " $\bigcirc$ ".

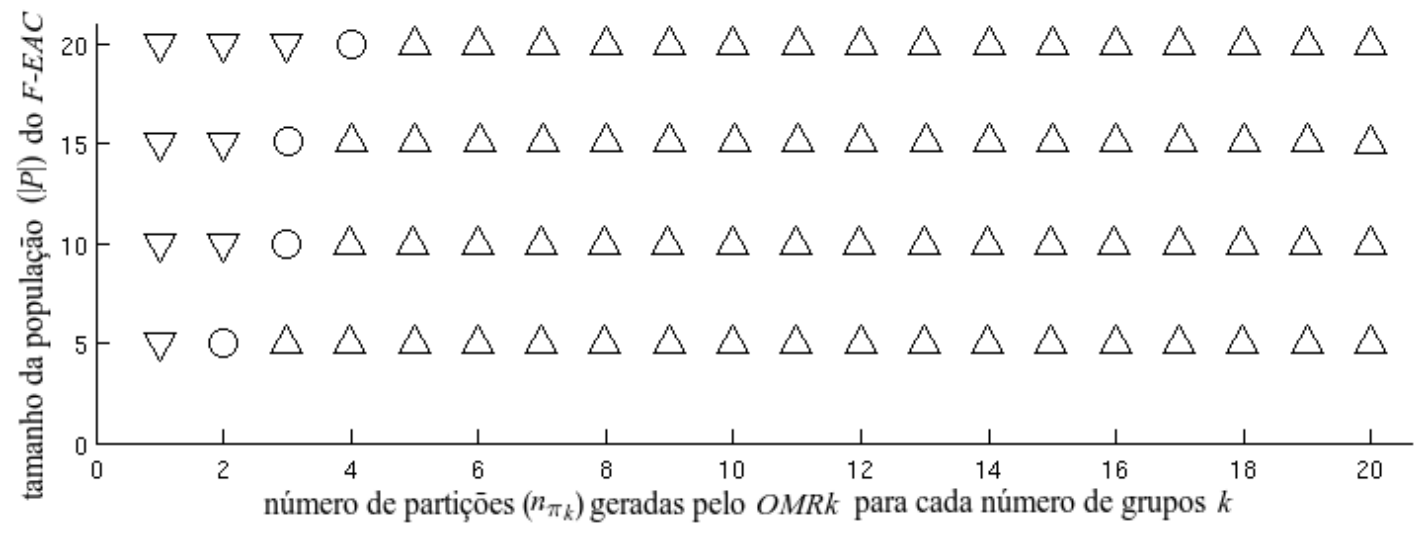

Figura 4.7: Resultados obtidos pelo teste Wilcoxon/Mann-Whitney com $\alpha=5 \%$ para Gauss9 (OMRk contra F-EAC). $\triangle-F$-EAC é estatísticamente mais rápido do que $O M R k ; \nabla-F$-EAC é estatísticamente mais lento que $O M R k ; \bigcirc$ — não há evidência estatística de diferença.

A evidência estatística ilustrada pela Figura 4.7 mostra que o tempo computacional do $F$-EAC com populações 15 e 10 são comparáveis ou melhores do que as obtidas pelo OMRk $\operatorname{com} n_{\pi, k}>2$. A Figura 4.7 também sugere que há evidência estatística para mostrar que os tempos computacionais do F-EAC com populações 5 e 20 são comparáveis ou melhores do que as obtidas pelo OMRk $\operatorname{com} n_{\pi, k}>1$ e $n_{\pi, k}>3$, respectivamente. Vale a pena lembrar que todos os valores de silhueta simplificada obtidos pelo $F$-EAC são iguais ou maiores do que o valor de referência $v_{R}$ que é o maior valor obtido pelo $O M R k$ em todas as suas execuções. Nesse sentido, é evidente que o $O M R k$ é favorecido na análise, ao determinar o valor máximo de referência a ser superado pelo $F-E A C$. Em relação ao $M R k$, 
F-EAC se mostrou mais eficiente com qualquer tamanho de população. De fato, o tempo médio computacional sobre 50 execuções do $M R k$ é 15.35 segundos, com desvio padrão igual a 14.83 (ver Tabela 4.5 para comparação).

\subsubsection{Spherical_4_3}

O procedimento experimental descrito na Seção 4.4.1 é repetido aqui. A Tabela 4.6 resume os tempos computacionais sobre 50 execuções do $O M R k$ para diferentes valores do parâmetro $n_{\pi, k}$. A média do valor de Jaccard para as partições obtidas pelo OMRk é 0.982 , enquanto os outros métodos ( $M R k$ e $F$-EAC) produziram partições com valores máximos (unitários) para o coeficiente de Jaccard em todas as execuções.

\begin{tabular}{lrrrrrrrrrr}
\hline$n_{\pi, k}$ & 01 & 02 & 03 & 04 & 05 & 06 & 07 & 08 & 09 & 10 \\
\hline$\mu$ & 0.36 & 0.72 & 1.09 & 1.45 & 1.81 & 2.17 & 2.54 & 2.90 & 3.26 & 3.62 \\
$\sigma$ & 0.01 & 0.01 & 0.01 & 0.01 & 0.01 & 0.01 & 0.01 & 0.01 & 0.01 & 0.02 \\
\hline$n_{\pi, k}$ & 11 & 12 & 13 & 14 & 15 & 16 & 17 & 18 & 19 & 20 \\
\hline$\mu$ & 3.98 & 4.35 & 4.71 & 5.07 & 5.43 & 5.80 & 6.16 & 6.52 & 6.88 & 7.24 \\
$\sigma$ & 0.02 & 0.02 & 0.02 & 0.03 & 0.03 & 0.03 & 0.03 & 0.03 & 0.03 & 0.03 \\
\hline
\end{tabular}

Tabela 4.6: Tempo computacional do OMRk em segundos $\left(k_{\max }=n_{o}^{1 / 2}=20\right)$ para Spherical_4_3: $\mu$ e $\sigma$ são a média e o desvio padrão sobre as 50 execuções, respectivamente.

A Tabela 4.7 mostra o desempenho do F-EAC em função do tamanho da população. Como pode ser visto nesta tabela, os resultados estão basicamente de acordo com os relatados e analisados para o experimento anterior.

\begin{tabular}{lll}
\hline Tamanho da & Tempo & $\begin{array}{l}\text { Número de } \\
\text { Gerações }\end{array}$ \\
\hline 20 & Compulação $(|P|)$ & $1.70(0.70)$ \\
15 & $0.45(0.82)$ & $1.89(0.67)$ \\
10 & $0.62(0.29)$ & $2.29(1.29)$ \\
5 & $0.33(0.14)$ & $2.57(1.21)$ \\
\hline
\end{tabular}

Tabela 4.7: Resultados do F-EAC para Spherical_4-3: média (desvio padrão) sobre 50 execuções.

A Figura 4.8 ilustra a comparação de resultados entre $O M R k$ e $F$-EAC, baseados no teste unilateral Wilcoxon/Mann-Whitney com $\alpha=5 \%$, para diferentes configurações dos algoritmos, usando a mesma simbologia adotada na Figura 4.7. Os resultados mostram que o $F$-EAC é mais rápido do que $O M R k$ quando $n_{\pi, k}>2$, não importando o tamanho da população. Contudo, $F$-EAC é superado pelo $M R k$, cujo tempo computacional é 0.5497 segundos, com desvio padrão igual a 0.66 (referir a Tabela 4.7 para comparação). O principal motivo para isso é que o conjunto de dados Spherical_4-3 é formado por grupos bem separados que podem ser facilmente encontrados pelo $k$-médias, mesmo quando o número de grupos é superestimado $\left(k \geq k^{*}\right)$, pois grupos excedentes podem ser eliminados pelo algoritmo em cenários simples como este (conforme detalhado na Seção 2.4.6). Conforme 
esperado, este resultado reforça a idéia que o uso de uma estratégia de busca sofisticada (como a evolutiva) não é justificado nestes casos.

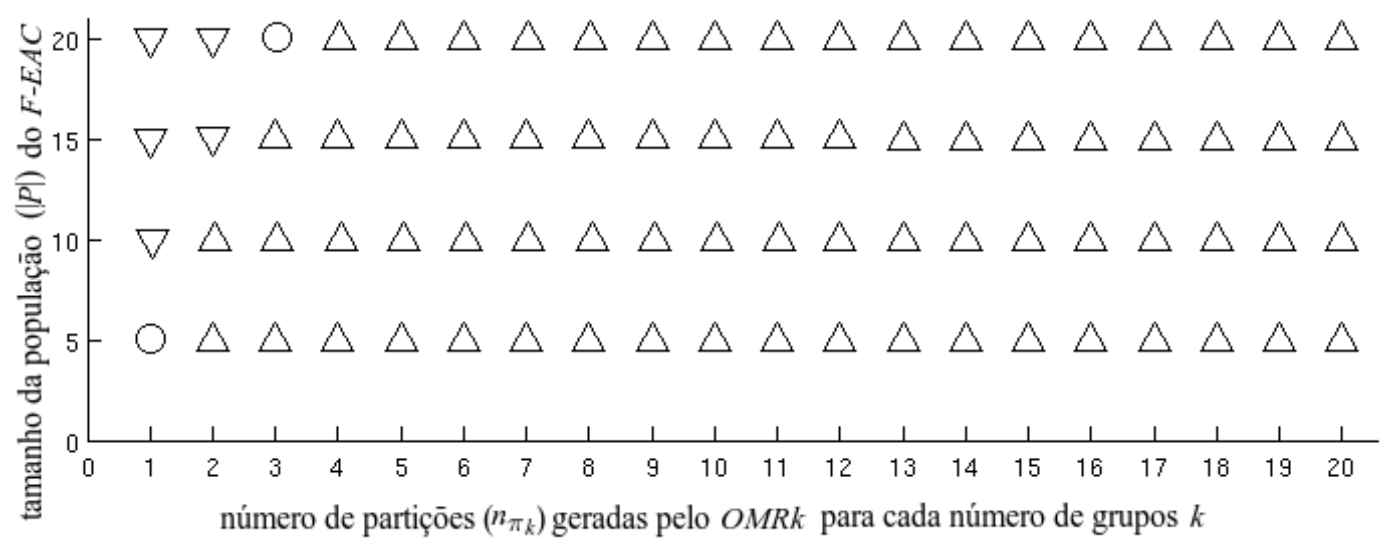

Figura 4.8: Resultados obtidos do teste Wilcoxon/Mann-Whitney com $\alpha=5 \%$ para Spherical_4_3 (OMRk contra F-EAC). $\triangle-F-E A C$ é estatísticamente mais rápido do que $O M R k ; \nabla-F-E A C$ é estatísticamente mais lento que $O M R k ; \bigcirc$ não há evidência estatística de diferença.

O baixo número de gerações executadas pelo $F-E A C$ e o desempenho evidentemente superior para população de tamanho mínimo (5), apresentados na Tabela 4.7, também sugerem que uma estratégia de busca sofisticada não é necessária nestes casos ${ }^{1}$.

Em resumo, problemas simples não requerem algoritmos sofisticados. Contudo, algoritmos tradicionais podem não ser suficientes para problemas do mundo real, como agrupamento de textos. A seguir, o desempenho dos algoritmos estudados serão avaliados em experimentos com conjuntos de mineração de texto.

\subsubsection{ARTICLES}

Seguindo a metodologia descrita na Seção 4.4.1, OMRk, MRk e F-EAC foram aplicados nas duas versões do conjunto de dados textual descrito na Seção 4.4.2, ARTICLE-14425 e ARTICLE-1442-80. Se o número e o posicionamento dos protótipos iniciais forem escolhidos apropriadamente, o algoritmo $k$-médias é capaz de encontrar partições similares às partições de referência para os conjuntos de dados. Para ser mais específico, as médias dos valores obtidos com o índice Jaccard para as partições obtidas com o OMRk estão próximas de 0.93 , enquanto os valores médios obtidos por outros métodos $(M R k$ e $F$ $E A C)$ estão próximos de 0.94. Serão considerados primeiramente os resultados obtidos para ARTICLE-1442-5, os quais são resumidos nas Tabelas 4.8 e 4.9.

A Figura 4.9 ilustra os resultados comparativos entre $O M R k$ e o $F-E A C$ baseados em testes unilaterais de Wilcoxon/Mann-Whitney com $\alpha=5 \%$, para diferentes configurações dos algoritmos, e utilizando a mesma terminologia adotada na Figura 4.7. Os resultados mostram que o F-EAC executou em tempo maior do que $O M R k$ apenas para algumas

\footnotetext{
${ }^{1}$ Apesar do cojunto Spherical_4_3 ser utilizado na literatura para avaliar algoritmos sofisticados (Bandyopadhyay \& Maulik, 2002b; Pakhira et al., 2005)
} 


\begin{tabular}{lrrrrrrrrrr}
\hline$n_{\pi, k}$ & 01 & 02 & 03 & 04 & 05 & 06 & 07 & 08 & 09 & 10 \\
\hline$\mu$ & 4.29 & 8.53 & 12.88 & 17.17 & 21.38 & 25.72 & 30.09 & 34.41 & 38.72 & 43.06 \\
$\sigma$ & 0.93 & 1.92 & 2.94 & 3.88 & 4.83 & 5.89 & 6.89 & 7.77 & 8.80 & 9.84 \\
\hline$n_{\pi, k}$ & 11 & 12 & 13 & 14 & 15 & 16 & 17 & 18 & 19 & 20 \\
\hline$\mu$ & 47.28 & 51.59 & 55.86 & 60.19 & 64.48 & 68.77 & 73.16 & 77.55 & 81.83 & 86.15 \\
$\sigma$ & 10.72 & 11.79 & 12.79 & 13.78 & 14.75 & 15.63 & 16.56 & 17.58 & 18.51 & 19.45 \\
\hline
\end{tabular}

Tabela 4.8: Tempo computacional do OMRk em segundos $\left(k_{\max }=16 \simeq n_{o}^{1 / 2}\right)$ para ARTICLE-1442-5: $\mu$ e $\sigma$ são a média e o desvio padrão sobre as 50 execuções, respectivamente.

\begin{tabular}{lll}
\hline Tamanho da & Tempo & $\begin{array}{l}\text { Número de } \\
\text { Gerações }\end{array}$ \\
\hline 20 & $13.33(7.41)$ & $3.68(2.90)$ \\
15 & $10.60(5.40)$ & $4.05(2.81)$ \\
10 & $6.48(3.51)$ & $3.66(2.97)$ \\
5 & $4.15(2.35)$ & $5.26(3.48)$ \\
\hline
\end{tabular}

Tabela 4.9: Resultados do F-EAC para ARTICLE-1442-5: média (desvio padrão) sobre 50 execuções.

configurações específicas de parâmetros, apenas 5 dentre as 80 apresentadas. Adicionalmente, $F-E A C$ mostrou ser, em média, 4 vezes mais rápido do que o $M R k$, que resultou em um tempo computacional médio de 34.65 sobre 50 execuções, com desvio padrão de 51.49 (como mostrado na Tabela 4.9).

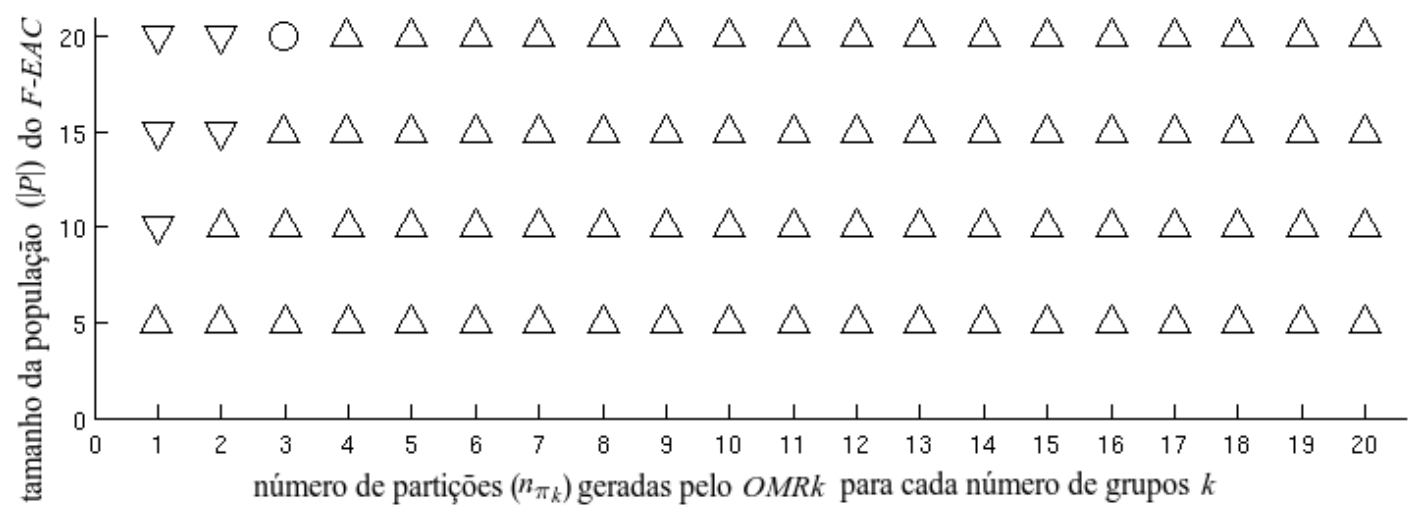

Figura 4.9: Resultados obtidos do teste Wilcoxon/Mann-Whitney com $\alpha=5 \%$ para ARTICLES-1442-5 (OMRk contra F-EAC).F-EAC). $\triangle-F$-EAC é estatísticamente mais rápido do que $O M R k ; \nabla-F-E A C$ é estatísticamente mais lento que OMRk; $\bigcirc-$ não há evidência estatística de diferença.

Os resultados obtidos para $A R T I C L E-1442-80$ seguem a mesma metodologia experimental da utilizada pelo ARTICLE-1442-5. A Tabela 4.10 resume o tempo computacional obtido pelo $O M R k$, enquanto a Tabela 4.11 resume o tempo computacional obtido pelo $F-E A C$.

A Figura 4.10 ilustra a comparação dos resultados obtidos para $O M R k$ e $F$-EAC baseados no teste unilateral de Wilcoxon/Mann-Whitney com $\alpha=5 \%$, para diferentes con- 


\begin{tabular}{lrrrrrrrrrr}
\hline$n_{\pi, k}$ & 01 & 02 & 03 & 04 & 05 & 06 & 07 & 08 & 09 & 10 \\
\hline$\mu$ & 0.36 & 0.72 & 1.08 & 1.45 & 1.81 & 2.19 & 2.55 & 2.92 & 3.29 & 3.66 \\
$\sigma$ & 0.03 & 0.06 & 0.10 & 0.14 & 0.17 & 0.20 & 0.24 & 0.27 & 0.30 & 0.32 \\
\hline$n_{\pi, k}$ & 11 & 12 & 13 & 14 & 15 & 16 & 17 & 18 & 19 & 20 \\
\hline$\mu$ & 4.03 & 4.40 & 4.77 & 5.13 & 5.50 & 5.87 & 6.24 & 6.60 & 6.97 & 7.33 \\
$\sigma$ & 0.35 & 0.38 & 0.41 & 0.44 & 0.48 & 0.51 & 0.54 & 0.57 & 0.60 & 0.63 \\
\hline
\end{tabular}

Tabela 4.10: Tempo computacional do $O M R k$ em segundos $\left(k_{\max }=16 \simeq n_{o}^{1 / 2}\right)$ para ARTICLES-1442-80: $\mu$ e $\sigma$ são a média e o desvio padrão sobre as 50 execuções, respectivamente.

\begin{tabular}{lll}
\hline $\begin{array}{l}\text { Tamanho da } \\
\text { População }(|P|)\end{array}$ & $\begin{array}{l}\text { Tempo } \\
\text { Computacional }(s)\end{array}$ & $\begin{array}{l}\text { Número de } \\
\text { Gerações }\end{array}$ \\
\hline 20 & $1.20(0.66)$ & $3.40(2.61)$ \\
15 & $0.86(0.51)$ & $3.48(2.68)$ \\
10 & $0.67(0.33)$ & $3.92(2.51)$ \\
5 & $0.39(0.19)$ & $4.63(3.01)$ \\
\hline
\end{tabular}

Tabela 4.11: Resultados do F-EAC para ARTICLES-1442-80: média (desvio padrão) sobre 50 execuções.

figurações dos algoritmos, e utilizando a mesma simbologia da Figura 4.7. Os resultados mostram que o $F$-EAC foi mais lento do que o $O M R k$ em apenas 4 de 80 configurações de parâmetros. Em relação ao $M R k$ (que possui um tempo computacional médio de 1.99 segundos, com desvio padrão de 2.49), F-EAC mostrou melhor desempenho para populações de tamanhos 5 e 10. Diferenças significativas não foram observadas para outros tamanhos de população.

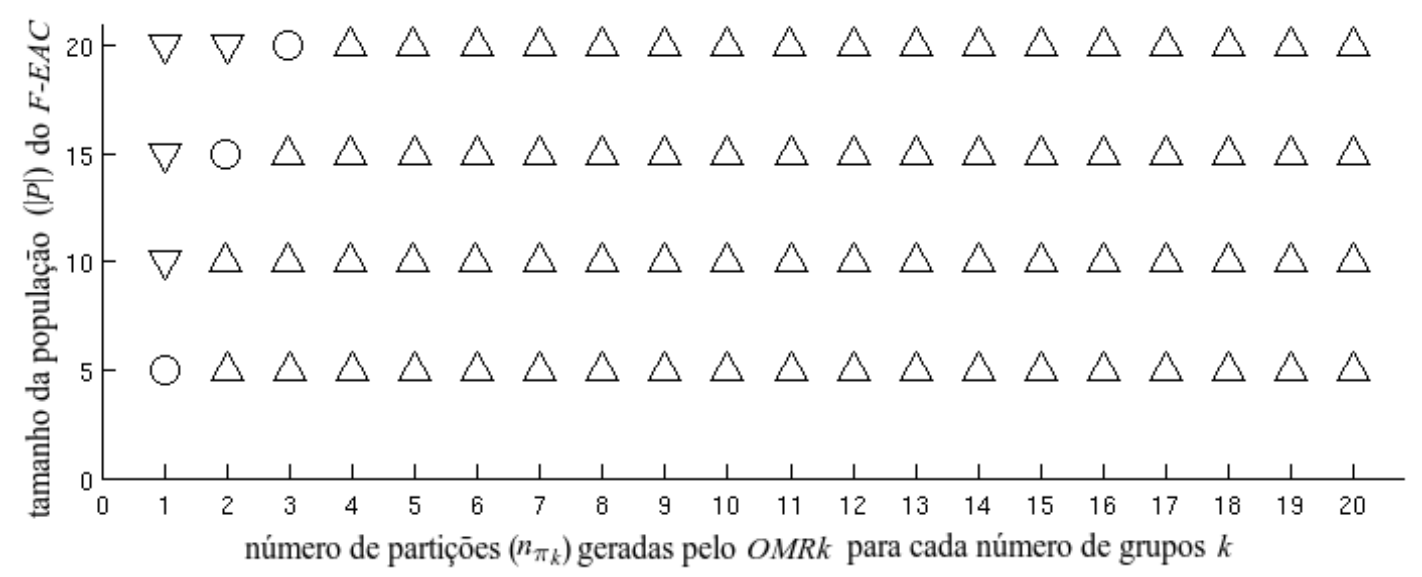

Figura 4.10: Resultados obtidos do teste Wilcoxon/Mann-Whitney com $\alpha=5 \%$ para ARTICLES-1442-80 (OMRk contra F-EAC). $\triangle-F-E A C$ é estatísticamente mais rápido do que $O M R k ; \nabla-F-E A C$ é estatísticamente mais lento que $O M R k ; \bigcirc$ — não há evidência estatística de diferença. 


\subsubsection{Análise dos resultados}

Os resultados apresentados na Seção 4.4.3 mostraram que o F-EAC frequentemente obtém resultados de qualidade equivalentes aos métodos sistemáticos $O M R k$ e $M R k$ em tempo computacional significativamente menor. Esses resultados estão de acordo com a comparação computacional feita na Seção 4.2, em que o F-EAC mostra menor complexidade assintótica entre os algoritmos investigados. Esse resultados foram validados em (Naldi et al., 2011).

A metodologia apresentada na Seção 4.4 .1 permite aos três algoritmos comparados encontrar partições de qualidade equivalente, com diferentes configurações de seus parâmetros, o que resulta em uma comparação justa de seus tempos de execução. Entretanto, para utilizar essa metodologia, é preciso que os algoritmos comparados sejam capazes de encontrar partições com qualidade igual ou superior ao valor de referência $v_{R}$, o que nem sempre é possível. Além disso, apesar dessa metodologia ser apropriada para comparar algoritmos, utilizar um valor de referência $v_{R}$ nem sempre é interessante em aplicações práticas. Isso porque é preciso executar alguma metodologia para obter uma partição que possua um valor de validação $v_{R}$, o que exige um dispêndio de um tempo computacional que pode não estar disponível nesses cenários. Em outros casos, em que há tempo disponível para determinar um valor para $v_{R}$, a partição encontrada com esse valor de validação pode ser suficiente para a aplicação prática em questão.

Em resumo, objetiva-se estender as comparações experimentais do $F$-EAC com outros algoritmos baseados em $k$-médias que nem sempre são capazes de encontrar partições com um valor de validação igual ou superior ao $v_{R}$ encontrado segundo a metodologia apresentada na Seção 4.4.1. Adicionalmente, objetiva-se adotar critérios de parada semelhantes aos que poderiam ser utilizados em aplicações práticas. Novos experimentos envolvendo algumas variantes desses algoritmos são apresentados na Seção 4.5.

\subsection{Comparação entre abordagens baseadas em k-médias}

Pelos resultados apresentados nas Seções 4.2 e 4.4 é possível concluir que o $F$-EAC possui vantagem em relação a métodos sistemáticos baseados em $k$-médias. Isso o torna uma alternativa atraente para aplicações práticas, em que o desempenho computacional é essencial. Contudo, existem outros algoritmos da literatura que são baseados em $k$-médias e aparentam ser potenciais alternativas ao $F-E A C$.

A metodologia apresentada na Seção 4.4.1 efetua uma comparação justa de tempo computacional, uma vez que todos os algoritmos envolvidos devem encontrar partições com qualidade igual ou superior a um valor de referência $v_{R}$. Entretanto, ela não é aplicável em cenários em que os algoritmos comparados sejam incapazes de encontrar partições com qualidade equivalente ou superior ao valor de referência $v_{R}$ em todas as suas execuções. Adicionalmente, deseja-se adotar critérios de parada próximos dos que poderiam ser utilizados em aplicações práticas que não visam comparação, em que exista pouco 
apelo em executar um algoritmo para obter uma partição que seja satisfatória o suficiente para determinar o critério de parada de outro algoritmo. Pelos motivos apresentados, os experimentos apresentados na Seção 4.5.2 consideram critérios de parada independentes de $v_{R}$ para os algoritmos comparados, a serem apresentados nas próximas seções.

Nesta seção o algoritmo $F-E A C$ e variações que recaem em procedimentos de busca local estocástica são comparados com outros algoritmos baseados em $k$-médias, sendo eles $O M R k$ e $M R k$, variações do algoritmo Bisecting k-means (Seção 2.4.6.2) e variações do algoritmo $X$-means (Seção 2.4.6.3). Todos os algoritmos são comparados em termos da qualidade da partição gerada e desempenho computacional para 324 bases de dados artificiais.

\subsubsection{Variantes dos algoritmos}

Neste trabalho, algumas variantes dos algoritmos de interesse são apresentadas. Nas próximas seções, será feita uma descrição complementar à descrição desses algoritmos apresentada na Seção 2.4 .

\subsubsection{Variantes do Bisecting k-means}

No segundo passo do algoritmo Bisecting k-means, descrito na Seção 2.4.6.2, faz-se necessário selecionar um grupo $C_{s}$ para ser dividido. Nos experimentos apresentados aqui, $C_{s}$ é escolhido pelo seu diâmetro, calculado de duas formas:

- (a) O diâmetro é calculado como duas vezes a maior distância entre o centróide e os objetos do grupo;

- (b) O diâmetro é calculado como duas vezes a média das distâncias entre o centróide e os objetos do grupo;

Para que o algoritmo interrompa sua execução e estime um valor para $k^{*}$ menor do que o número máximo de grupos permitido, $k<k_{\text {max }}$, o Bisecting $k$-means foi modificado para avaliar se existe ou não a necessidade de prosseguir o processo de divisão de grupos. Com esse objetivo, índices de validação de agrupamentos foram utilizados para medir a qualidade das partições antes e após a divisão do grupo $C_{s}$. O primeiro escolhido foi o índice BIC (Mirkin, 2005), por ser utilizado pelo autor do algoritmo X-means na versão original do algoritmo. O segundo consiste no índice silhueta simplificada, frequentemente utilizado para avaliar partições geradas pelo algoritmo F-EAC. Uma vez definidos os índices de validação, é possível adotar critérios de parada baseados na qualidade das partições obtidas. Neste trabalho serão utilizados os dois critérios de parada a seguir:

- (i) Avalia-se a divisão do grupo com maior diâmetro. Se não houver melhora a divisão não é efetuada e finaliza-se a execução; 
- (ii) Avalia-se a divisão de todos os grupos em ordem decrescente de diâmetro. Se não houver melhora na divisão de nenhum deles, finaliza-se a execução.

A combinação dos métodos de cálculo de diâmetro ((a) ou (b)) com os critérios de parada ((i) ou (ii)) e de validação (BIC ou silhueta simplificada) resultam nas 8 versões do algoritmo Bisecting k-means investigadas aqui.

\subsubsection{Variantes do X-means}

Durante a execução do algoritmo $X$-means, o índice $B I C$ é utilizado por Pelleg \& Moore (2000) nas avaliações das partições e dos grupos. De forma análoga ao que foi feito para o algoritmo Bisecting k-means (ver Seção 4.5.1.1), o X-means também foi adaptado neste trabalho para utilizar a silhueta simplificada como critério de avaliação. Entretanto, diferentemente do critério $B I C$, que pode ser calculado localmente apenas para o grupo subdividido em uma dada iteração (já que a divisão não afeta o $B I C$ dos demais grupos), o cálculo do índice silhueta deve ser feito considerando toda a partição. Basicamente, a silhueta anterior e posterior à divisão de cada grupo são calculadas e, se houver melhora, a divisão é mantida.

Tanto a versão avaliada pelo índice $B I C$ como a avaliada pelo índice Silhueta foram implementadas na linguagem Matlab, com o objetivo de permitir a comparação de tempo computacional com os outros algoritmos sob investigação neste trabalho. Além dessas versões, que foram implementadas seguindo a descrição do algoritmo no artigo original (Pelleg \& Moore, 2000)2 , outras duas versões do algoritmo também foram consideradas com o propósito de comparar a qualidade das partições obtidas. Uma delas é a versão em C disponibilizada pelo próprio Dan Pelleg por meio de correspondência pessoal. A outra versão, desenvolvida em Java, é disponibilizada na versão do desenvolvedor da ferramenta Weka (versão 3.5) (Witten \& Frank, 2005). Existem diferenças entre essas implementações e o artigo original (Pelleg \& Moore, 2000), que são discutidas na forma de comentários internos aos respectivos códigos fonte, na lista de discussão do autor sobre o algoritmo e também no relatório técnico (Fontana \& Naldi, 2009). Em todas as versões, são utilizados os valores padrões para os parâmetros livres do algoritmo (maiores detalhes são descritos em Pelleg \& Moore (2000); Fontana \& Naldi (2009); Naldi et al. (2009)).

\subsubsection{Algoritmos de busca local estocástica}

Além do F-EAC, duas variantes desse algoritmo que recaem em algoritmos de busca local estocástica (BLS) serão avaliados nesta seção. Tais variantes usam métodos de seleção determinística por meio de rank: o $(\mu, \lambda)$ e o $(\mu+\lambda)$ (Bäck et al., 2000). A seleção $(\mu, \lambda)$ consiste em gerar $\lambda$ soluções filhas a partir do uso de operadores evolutivos em $\mu$ soluções pais. Em seguida, as $\mu$ melhores soluções são selecionadas dentre as soluções

\footnotetext{
${ }^{2}$ Exceto pela implementação do índice $B I C$, cujo cálculo da função de verossimilhança segue a descrição clássica (Bishop, 2006), ao invés da aproximação adotada em (Pelleg \& Moore, 2000).
} 
filhas geradas. Já o método $(\mu+\lambda)$ seleciona as $\mu$ melhores soluções do conjunto formado pela união das soluções pais com as soluções filhas. Além da seleção determinística, as variantes do $F$-EAC utilizam $\mu=1$, com o objetivo de efetuar a busca evolutiva sem o uso de uma população, o que recai em uma estratégia de busca local do tipo hill-climbing estocástico. Diferentes valores de $\lambda$ são considerados neste trabalho. A solução inicial é gerada da mesma forma que cada um dos indivíduos da população do $F$-EAC, ou seja, uma partição com $k \in\left\{2, \ldots, k_{\max }\right\}$ grupos com protótipos sorteados aleatoriamente.

\subsubsection{Experimentos}

Para avaliar experimentalmente o algoritmos investigados, 324 conjuntos de dados foram gerados a partir da metodologia proposta por Milligan \& Cooper (1985) e utilizada por Vendramin et al. (2009, 2010). Às bases geradas são permitidas sobreposições em todas as dimensões, exceto a primeira. A distribuição espacial dos objetos intra-grupo segue uma distribuição normal multivariada truncada. Isto faz com que a estrutura gerada contenha grupos naturais que exibem as propriedades de separação externa e coesão interna. As principais características das bases de dados desse conjunto são:

- Cada base de dados contém $n_{o}=1000$ objetos;

- Todos os grupos são disjuntos (sem sobreposição na primeira dimensão) com distribuições Gaussianas (que podem ser levemente elipsoidais);

- Variedade em relação ao número de grupos $k \in\{2, \ldots, 10\}$;

- Para cada valor de $k$, o número de atributos assume os valores $n_{a} \in\{4,6,8,10\}$;

- Três métodos de divisão dos objetos entre grupos são utilizados:

- Objetos divididos uniformente entre os grupos;

- Um grupo sempre contém 10\% dos objetos;

- Um grupo sempre contém $60 \%$ dos objetos.

- Valores dos atributos foram normalizados no intervalo [0, 1].

- Para cada combinação das características acima foram geradas três instâncias, produzindo um total de 324 bases de dados.

As qualidades das partições obtidas são mensuradas com relação às partições ideais, utilizando o critério externo de Jaccard. É importante observar que os algoritmos OMRk e $M R k$ executam $k$-médias um número fixo de vezes $n_{\pi, k}$ para cada valor de $k$ e os algoritmos F-EAC e BLS utilizam como critério de parada um número máximo de gerações sem aumento na qualidade da melhor solução obtida, aqui referenciado como $g_{\mathrm{S}_{c}}$. Saliento que $g_{\mathrm{S}_{\mathrm{c}}}$ não é um parâmetro do algoritmo $F$-EAC original (Alves et al., 2006; Alves, 2007). 
Ele é utilizado no experimento apresentado nesta seção apenas para avaliar o desempenho do algoritmo independentemente de um valor de referência $v_{R}$. Adicionalmente, o $F$-EAC utilizado nos experimentos apresentados nesta seção aplica seleção proporcional (método da roleta) (Bäck et al., 2000) para escolher os genótipos que serão transmitidos para a próxima geração. Isso foi feito para diferenciá-lo em relação às variantes BLS (que aplicam seleção determinística) e permitir uma comparação entre os resultados obtidos pelas duas técnicas. Foram comparadas 27 versões dos algoritmos de interesse ${ }^{3}$ :

1. Bisecting k-means (Seções 2.4.6.2 e 4.5.1.1) com cálculo de diâmetro (a), critério de parada (i) e avaliação por Silhueta.

2. Bisecting k-means com cálculo de diâmetro (a), critério de parada (ii) e avaliação por Silhueta.

3. Bisecting k-means com cálculo de diâmetro (b), critério de parada (i) e avaliação por Silhueta.

4. Bisecting k-means com cálculo de diâmetro (b), critério de parada (ii) e avaliação por Silhueta.

5. Bisecting k-means com cálculo de diâmetro (a), critério de parada (i) e avaliação por BIC.

6. Bisecting k-means com cálculo de diâmetro (a), critério de parada (ii) e avaliação por BIC.

7. Bisecting k-means com cálculo de diâmetro (b), critério de parada (i) e avaliação por BIC.

8. Bisecting k-means com cálculo de diâmetro (b), critério de parada (ii) e avaliação por BIC.

9. OMRk (Seção 2.4.6.1) com $n_{\pi, k}=10$ e avaliação por Silhueta.

10. OMRk $\operatorname{com} n_{\pi, k}=20$ e avaliação por Silhueta.

11. MRk (Seção 2.4.6.1) com $n_{\pi, k}=10$ e avaliação por Silhueta.

12. $M R k \operatorname{com} n_{\pi, k}=20$ e avaliação por Silhueta.

13. BLS (Seção 4.5.1.3): $g_{\mathrm{S}_{\mathrm{C}}}=3$ e seleção $\left(1, \lambda_{1}\right) \operatorname{com} \lambda_{1}=5$.

14. BLS: $g_{\mathrm{S}_{\mathrm{C}}}=5$ e seleção $\left(1, \lambda_{1}\right) \operatorname{com} \lambda_{1}=5$.

15. BLS $g_{\mathrm{S}_{\mathrm{C}}}=3$ e seleção $\left(1, \lambda_{1}\right) \operatorname{com} \lambda_{1}=10$.

16. BLS: $g_{\mathrm{S}_{\mathrm{C}}}=5$ e seleção $\left(1, \lambda_{1}\right) \operatorname{com} \lambda_{1}=10$.

17. BLS: $g_{\mathrm{S}_{\mathrm{C}}}=3$ e seleção $\left(1+\lambda_{2}\right) \operatorname{com} \lambda_{2}=4$.

18. BLS: $g_{\mathrm{S}_{\mathrm{C}}}=5$ e seleção $\left(1+\lambda_{2}\right) \operatorname{com} \lambda_{2}=4$.

19. BLS: $g_{\mathrm{S}_{\mathrm{C}}}=3$ e seleção $\left(1+\lambda_{2}\right) \operatorname{com} \lambda_{2}=9$.

20. BLS: $g_{\mathrm{S}_{\mathrm{C}}}=5$ e seleção $\left(1+\lambda_{2}\right) \operatorname{com} \lambda_{2}=9$.

21. $F-E A C \operatorname{com}|P|=10$ e $g_{\mathrm{S}_{\mathrm{C}}}=1$ (Seção 3.4).

22. $F-E A C \operatorname{com}|P|=10$ e $g_{\mathrm{S}_{\mathrm{C}}}=3$.

23. $F-E A C \operatorname{com}|P|=10$ e $g_{\mathrm{S}_{\mathrm{C}}}=5$.

24. X-means com avaliação por BIC (Seções 2.4.6.3 e 4.5.1.2).

25. X-means com avaliação por Silhueta.

26. X-means disponibilizado pelo autor (código em C).

27. $X$-means distribuído no software Weka (código em Java).

\footnotetext{
${ }^{3}$ Observe que as seleções $\left(1, \lambda_{1}\right)$ e $\left(1+\lambda_{2}\right)$ operam sobre um mesmo número de soluções candidatas se $\lambda_{2}=\lambda_{1}-1$, o que foi feito aqui.
} 
Cada algoritmo implementado foi executado 30 vezes para cada uma das 324 bases de dados, armazenando-se o tempo de execução e os valores do critério externo de Jaccard das partições geradas (com relação às partições conhecidas dos dados artificiais). Devido às diferenças de plataformas, os Algoritmos 26 (em C) e 27 (em Java) não foram comparados com os demais (em Matlab) em termos de tempo computacional. Os algoritmos implementados em Matlab (versão 7.8.0 R2009a) e as outras versões foram executadas no mesmo computador utilizado nos experimentos apresentados na Seção 4.3.2: processador de dois núcleos de $3 \mathrm{Ghz}$, 4Gb RAM, sistema operacional linux.

Todos os algoritmos foram executados com o número de grupos limitado entre $k_{\text {min }}=2$ e $k_{\max }=\sqrt{n_{o}}$ (Pal \& Bezdek, 1995; Pakhira et al., 2005; Campello et al., 2009). No caso dos algoritmos evolutivos ( $F-E A C$ e BLS) esse intervalo diz respeito apenas às soluções iniciais, uma vez que esses algoritmos podem aumentar ou diminuir livremente o número de grupos da(s) solução(ões) durante o processo evolutivo.

Os valores médios do critério externo de Jaccard obtidos por cada um dos algoritmos são apresentados na Tabela 4.12 .

\begin{tabular}{|c|c|c|c|c|c|c|c|c|}
\hline $\mathbf{1 2}$ & $\mathbf{1 1}$ & $\mathbf{1 0}$ & $\mathbf{9}$ & $\mathbf{1 6}$ & $\mathbf{2 3}$ & $\mathbf{2 0}$ & $\mathbf{1 5}$ & $\mathbf{2 2}$ \\
\hline 0.9639 & 0.9636 & 0.9600 & 0.9562 & 0.9522 & 0.9495 & 0.9468 & 0.9463 & 0.9417 \\
\hline \hline $\mathbf{1 9}$ & $\mathbf{1 4}$ & $\mathbf{1 8}$ & $\mathbf{1 3}$ & $\mathbf{2 1}$ & $\mathbf{1 7}$ & $\mathbf{2 7}$ & $\mathbf{7}$ & $\mathbf{5}$ \\
\hline 0.9387 & 0.9371 & 0.9274 & 0.9270 & 0.9197 & 0.9107 & 0.8714 & 0.8593 & 0.8555 \\
\hline \hline $\mathbf{6}$ & $\mathbf{8}$ & $\mathbf{2}$ & $\mathbf{4}$ & $\mathbf{2 4}$ & $\mathbf{2 5}$ & $\mathbf{2 6}$ & $\mathbf{3}$ & $\mathbf{1}$ \\
\hline 0.8505 & 0.8475 & 0.8387 & 0.8387 & 0.8188 & 0.7530 & 0.7230 & 0.7162 & 0.7110 \\
\hline
\end{tabular}

Tabela 4.12: Médias dos valores de Jaccard obtidos pelos algoritmos comparados.

Para determinar se existe diferença estatística entre os valores de Jaccard obtidos pelos algoritmos, testes de hipóteses foram utilizados. O teste de análise de variância ( ANOVA, do inglês ANalysis OF VAriance) (Walpole et al., 2006) assume que as amostras sejam obtidas de populações com distribuições normais e que as variáveis aleatórias testadas possuam variâncias semelhantes (Demšar, 2006). Como esses requisitos não são garantidos aqui, o teste não paramétrico de Friedman (Hollander \& Wolfe, 1999) foi utilizado com $\alpha=5 \%$.

Uma vez que as hipóteses nulas foram rejeitadas, o que indica que algumas das médias obtidas são significativamente distintas, testes post-hoc foram efetuados para encontrar quais diferenças foram significativas. Comparações que envolvam múltiplas médias simultaneamente quando feitas aos pares (duas-a-duas) podem não ser precisas porque o nível de significância do teste é desvirtuado. De fato, quanto maior o número de comparações aos pares realizadas, maior a probabilidade de se obterem rejeições por mera casualidade (Walpole et al., 2006). Por este motivo, o teste post-hoc de Nemenyi (Demšar, 2006) foi aplicado de modo a permitir o controle do nível de significância, que no caso dos experimentos deste trabalho é de $95 \%$.

As diferenças significativas entre as médias dos ranks de Jaccard obtidas pelo teste de Friedman são apresentadas na Tabela 4.13, em ordem decrescente. O símbolo contido na posição $i j$ desta tabela indica a relação entre as médias obtidas pelos $i$-ésimo e $j$ - 
ésimo algoritmos. Se o símbolo for $\nabla$, a média do $i$-ésimo algoritmo é estatisticamente menor, se for $\triangle$ ela é maior e $\bigcirc$ indica que não há diferença estatística entre as médias. É importante salientar que, diferentemente da Tabela 4.12, a Tabela 4.13 considera a médias dos ranks (por ser baseada em um teste não paramétrico) e não a média dos valores de Jaccard.

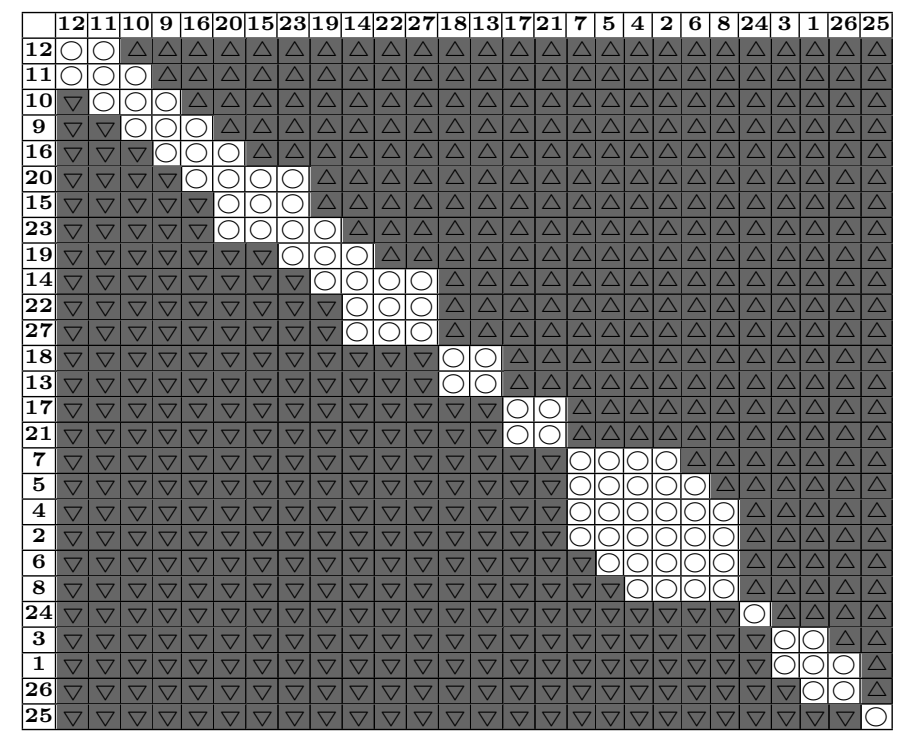

Tabela 4.13: Diferença estatística entre as médias dos ranks dos valores de Jaccard obtidos pelos algoritmos sob investigação.

Os resultados apresentados nas Tabelas 4.12 e 4.13 mostram que os valores médios de Jaccard mais elevados foram obtidos pelos algoritmos sistemáticos de múltiplas execuções de $k$-means (algoritmos 9 a 12), seguidos pelos algoritmos evolutivos (AEs 13 a 23), não havendo diferença estatística entre os algoritmos 9 e 16. Dentre os AEs, valores maiores de $g_{\mathrm{S}_{\mathrm{c}}}$ e $\lambda$ permitiram produzir valores médios de Jaccard também maiores. Esse resultado era esperado, pois quanto maiores forem os valores de $g_{\mathrm{S}_{\mathrm{c}}}$ e $\lambda$, maior será a quantidade de partições avaliadas pela busca evolutiva, o que aumenta a probabilidade de encontrar partições com valores de validação mais altos.

Quando se considera um valor fixo de $g_{\mathrm{S}_{\mathrm{c}}}$, não se observa qualquer hegemonia de desempenho, em termos dos valores médios de Jaccard, entre o F-EAC e suas variantes BLS. É importante lembrar que, no experimento apresentado nesta seção, esses algoritmos se diferenciam apenas pelo tipo de seleção (proporcional para o $F$-EAC e determinístico para o BLS) e pelo uso ou não de uma população de soluções. No que tange ao mecanismo de seleção, esse resultado era esperado, pois evidência empírica sugere que o uso de seleção determinística no F-EAC em geral leva a resultados equivalentes àqueles obtidos com o uso de seleção proporcional (Alves et al., 2006; Naldi et al., 2011). No que diz respeito à população, os experimentos presentes na Seção 4.4 .3 e em (Hruschka et al., 2006; Naldi et al., 2011) indicam que os operadores de mutação guiados e orientados a grupos do $F-E A C$ são agressivos e ao mesmo tempo eficazes o suficiente para que esse tipo de algoritmo apresente bons resultados mesmo utilizando populações extremamente pequenas, tais como $|P|=4$ ou $|P|=5$. De fato, extensivas análises experimentais, presentes na 
Seção 4.4.3 e em (Alves et al., 2006; Campello et al., 2009; Naldi et al., 2011), indicam que esses algoritmos são robustos à escolha de $|P|$. Dado que o uso de uma única solução é um caso particular em que $|P|=1$, não é surpreendente que não se observou diferenças expressivas nos resultados, especialmente considerando que as bases de dados em questão são bem comportadas (grupos volumétricos com distribuições Normais). As observações acima valem independente do valor do parâmetro $\lambda$, que claramente não é crítico.

De forma geral, os algoritmos $X$-means e Bisecting k-means resultaram nas menores médias para o índice Jaccard em relação aos outros algoritmos, o que é comprovado pelo teste aplicado. Em geral, o Bisecting k-means apresenta melhores resultados do que a maioria das implementações do X-means. As únicas exceções se referem ao algoritmo disponibilizado pelo Weka (no. 27) e as versões de Bisecting k-means implementadas com critério de parada (i) e avaliação por Silhueta (no. 1 e 3). O primeiro apresentou uma média de ranks de Jaccard elevada, próxima àquelas de alguns dos AEs (a saber, 14 e 22), muito embora a média dos seus valores de Jaccard, apresentada na Tabela 4.12, seja visualmente inferior às médias daqueles algoritmos. Os algoritmos 1 e 3 , por sua vez, resultaram nas piores médias encontradas dentre os algoritmos estudados.

Além dos valores de Jaccard, foram comparadas as médias dos tempos de execução dos algoritmos implementados em Matlab, apresentados na Tabela 4.14 em ordem ascendente. Para determinar se existe significância estatística entre os tempos de execução encontrados, a mesma metodologia executada anteriormente com o teste de Friedman foi utilizada. Os resultados são apresentados na Tabela 4.15, de forma análoga à apresentação feita na Tabela 4.13. Contudo, o símbolo $\nabla$ na posição ij é utilizado para indicar que a média (de tempo) do $i$-ésimo algoritmo é maior do que a média do $j$-ésimo algoritmo. O símbolo $\triangle$ indica o contrário.

\begin{tabular}{|c|c|c|c|c|c|c|c|c|}
\hline $\mathbf{1}$ & $\mathbf{3}$ & $\mathbf{4}$ & $\mathbf{2}$ & $\mathbf{7}$ & $\mathbf{5}$ & $\mathbf{6}$ & $\mathbf{8}$ & $\mathbf{1 7}$ \\
\hline 0.2210 & 0.2249 & 0.4811 & 0.4834 & 0.4914 & 0.4930 & 1.3153 & 1.3394 & 1.7381 \\
\hline \hline $\mathbf{1 3}$ & $\mathbf{1 8}$ & $\mathbf{2 1}$ & $\mathbf{1 4}$ & $\mathbf{1 9}$ & $\mathbf{1 5}$ & $\mathbf{2 2}$ & $\mathbf{2 0}$ & $\mathbf{2 5}$ \\
\hline 2.0934 & 2.3146 & 2.7049 & 2.8228 & 3.4297 & 4.1392 & 4.1517 & 4.4671 & 5.0549 \\
\hline \hline $\mathbf{2 3}$ & $\mathbf{1 6}$ & $\mathbf{2 4}$ & $\mathbf{1 1}$ & $\mathbf{9}$ & $\mathbf{1 2}$ & $\mathbf{1 0}$ \\
\hline \multicolumn{2}{|c|}{5.4596} & 5.5563 & 7.8515 & 11.3113 & 11.4646 & 22.6472 & 22.9463 \\
\hline
\end{tabular}

Tabela 4.14: Médias dos tempos de execução obtidos pelos algoritmos comparados.

Os resultados apresentados nas Tabelas 4.14 e 4.15 permitem concluir que as versões do algoritmo Bisecting k-means foram as mais rápidas dentre os algoritmos considerados. Porém, tais tempos de execução estão associados aos piores valores obtidos com o índice Jaccard (vide Tabelas 4.12 e 4.13). Com médias de tempos computacionais maiores do que as do Bisecting k-means, os AEs (algoritmos 13 a 23) resultaram em tempos de execução menores do que os demais algoritmos. Os tempos médios dos AEs aumentam com o aumento de $g_{\mathrm{S}_{\mathrm{c}}}, \lambda$ e, consequentemente, com a qualidade obtida, medida pelo índice de Jaccard. O teste de Friedman sugere que há diferenças entre as médias dos ranks dos AEs. 


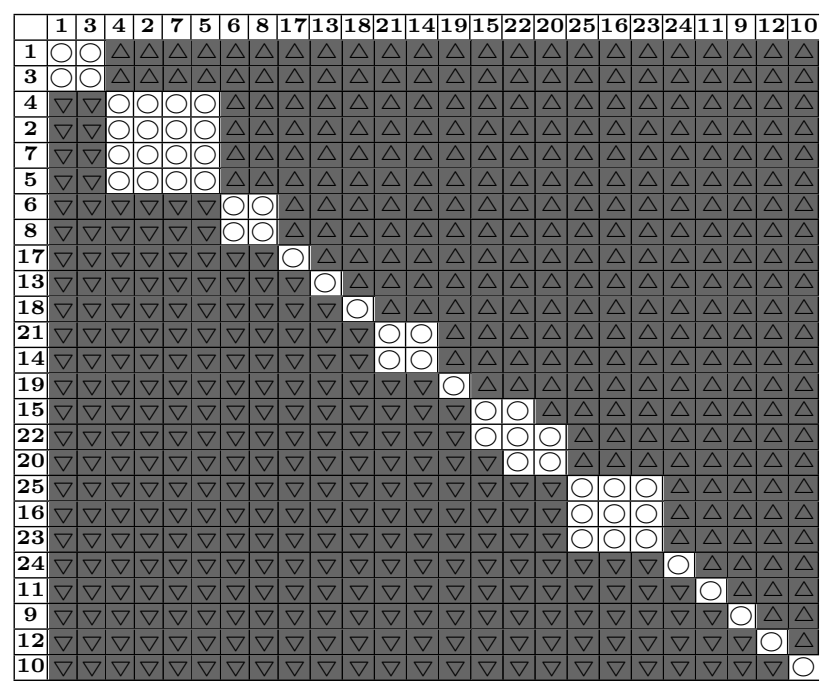

Tabela 4.15: Diferença estatística entre as médias dos ranks dos tempos de execução dos algoritmos comparados.

Os algoritmos $X$-means implementados apresentaram médias de tempos de execução maiores do que aquelas da maioria dos algoritmos evolutivos. As únicas exceções foram os AEs 16 e 23, que resultaram em médias de tempo equivalentes à obtida pelo algoritmo X-means de número 25. Contudo, os AEs de números 16 e 23 apresentaram médias de valores de Jaccard elevadas, próximas ou estatisticamente equivalentes às médias dos algoritmos sistemáticos baseados em múltiplas execuções de $k$-médias (OMRk e $M R k$ ), o que não ocorre com nenhuma versão do $X$-means.

Como esperado, os algoritmos sistemáticos baseados em múltiplas execuções de $k$ médias, de número 9 a 12, foram os algoritmos com maior tempo de execução. Apesar de serem os algoritmos com maiores valores médios de Jaccard, as médias de tempo obtidas por estes algoritmos ultrapassam em uma dezena de vezes as médias de alguns AEs e chegam a ser uma centena de vezes maiores do que algumas versões do algoritmo Bisecting k-means.

\subsubsection{Análise dos resultados}

De maneira geral, os métodos sistemáticos de múltiplas execuções de $k$-médias produziram as partições de melhor qualidade em relação a partições ideais dos dados (conhecidas a priori), porém com alto custo computacional associado. O algoritmo evolutivo F-EAC e suas variantes BLS foram capazes de obter partições cujas qualidades são próximas ou equivalentes àquelas obtidas por métodos sistemáticos, em um tempo computacional consideravelmente menor. Além disso, as qualidades das partições obtidas pelos AEs foram significativamente superiores às obtidas pelas versões dos algoritmos Bisecting k-means e $X$-means investigadas neste trabalho. De maneira geral, as versões do algoritmo Bisecting k-means se mostraram as mais rápidas dentre todos os algoritmos considerados na análise, porém, produziram as partições de pior qualidade, em média. 


\subsection{Considerações finais}

Os resultados apresentados neste capítulo mostram que algoritmos evolutivos podem ser aplicados em problemas de agrupamento e serem mais eficientes do que abordagens sistemáticas ou até mesmo algoritmos conhecidos da literatura, tanto no âmbito teórico quanto prático. Os resultados obtidos com a versão aprimorada do $F$-EAC e variantes mostram resultados equivalentes ou muito próximos dos obtidos por métodos sistemáticos (que obtiveram os resultados de maior qualidade) em pequenas frações dos tempos computacionais que esses últimos necessitaram.

Contudo, algumas aplicações práticas resultam não apenas em um único agrupamento do conjunto de dados, mas em um conjunto de agrupamentos. Uma alternativa a escolher o agrupamento mais apropriado consiste em combinar um conjunto de agrupamentos, oriundos ou não de um mesmo algoritmo, em comitês. A combinação de agrupamentos gera, a partir de relações comuns entre objetos, um agrupamento final ou consenso que agregue maior evidência sobre o conjunto de dados do que os agrupamentos originais individualmente. Um dos objetivos desta tese consiste em investigar o uso conjunto de algoritmos evolutivos, incentivado pelo sucesso de sua aplicação apresentado neste capítulo, e a combinação de agrupamentos. No próximo capítulo, de número 5, será apresentada um revisão conceitual sobre alguns dos métodos de combinação presentes na literatura. Essa revisão fornece a fundamentação metodológica necessária para as investigações e propostas feitas nos capítulos restantes deste trabalho. 


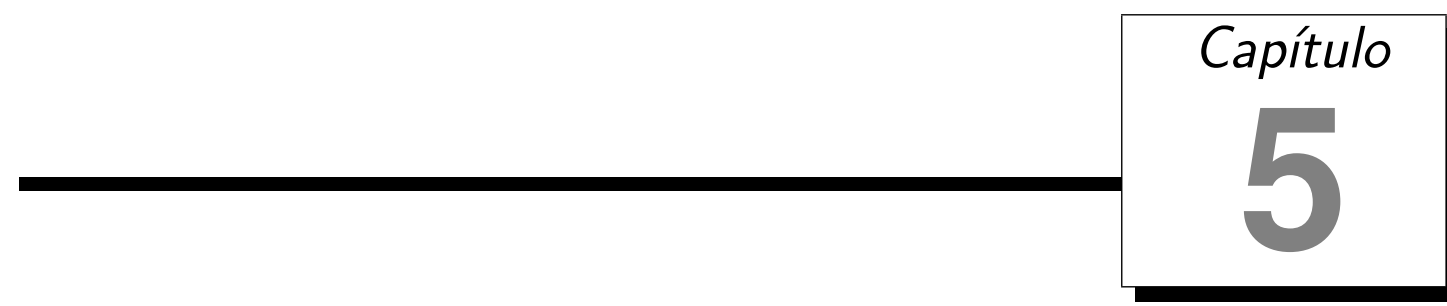

\section{Combinação de agrupamentos}

Como mostrado no Capítulo 2, existe uma grande diversidade de técnicas de agrupamento de dados, que envolvem o uso de diferentes medidas de similaridade e índices de validação. Tamanha diversidade reflete a complexidade de encontrar um agrupamento ideal para um determinado conjunto de dados. Em alguns casos, não é possível obter um único agrupamento, mas um conjunto de agrupamentos que evidenciam diferentes características do conjunto de dados. Nesses casos, é possível combinar os agrupamentos encontrados em uma única solução final, que represente um consenso entre os grupos obtidos.

Neste capítulo, é feita uma revisão sobre os principais métodos de combinação de agrupamentos encontrados na literatura, de forma a desenvolver a fundamentação conceitual necessária para o desenvolvimento da pesquisa apresentada nos capítulos a seguir. Assim como no Capítulo 2, alguns dos algoritmos descritos serão aplicados nas investigações feitas neste projeto, enquanto outros são apresentados porque possuem potencial interesse para este trabalho ou para fundamentar a análise aqui presente.

Os objetivos mais comuns da combinação de agrupamentos, bem como seus aspectos principais, serão discutidos na Seção 5.1. Em seguida, na Seção 5.2, serão apresentados os principais métodos para gerar agrupamentos a serem combinados e obter a diversidade necessária para o processo de combinação. As funções de consenso, utilizadas diretamente no processo de combinação dos agrupamentos, serão discutidas brevemente na Seção 5.3. Métodos de avaliação dos resultados de combinações são apresentados na Seção 5.4. Em seguida, uma sumarização de trabalhos que comparam diferentes tipos de combinação é feita na Seção 5.5. Como a utilização conjunta de AE e técnicas de combinação de agrupamento é de interesse para este projeto, alguns trabalhos que utilizam ambas as técnicas são apresentados na Seção 5.6. Finalmente, as considerações finais sobre o capítulo são feitas na Seção 5.7. O conteúdo apresentado neste capítulo conta com a colaboração da 
prof. Dr. Katti Faceli e deu origem à publicação Naldi et al. (2009).

\subsection{Definição e aspectos principais}

A combinação ou ensemble de estimadores independentes em comitês é uma técnica que visa gerar um único resultado a partir das soluções obtidas por estes estimadores, de forma a obter um melhor aproveitamento das características de cada um (Krogh \& Vedelsby, 1995; Kuncheva, 2004). Topchy et al. (2003) apresentam uma definição simplificada de combinação de algoritmos de agrupamento: dado um conjunto de $n_{\pi}$ partições, chamadas de partições base, $\Pi=\left\{\pi_{1}, \pi_{2}, \ldots, \pi_{n_{\pi}}\right\}$, resultantes de várias aplicações de um ou mais algoritmos de agrupamento em um determinado conjunto de dados $X$, encontrar uma partição consenso $\pi_{f}$ de melhor qualidade do que as partições iniciais (partições base). Essa "melhor qualidade" depende do critério de validação escolhido e está relacionada a algum objetivo que se deseja atingir, que pode ser (Faceli, 2006):

- Robustez: obter um método de combinação que resulte em uma partição consenso mais robusta do que as partições base, ou seja, cuja qualidade não varie muito com mudanças no cenário de aplicação, se possível sem a necessidade de ajustes feitos pelo usuário (Strehl \& Ghosh, 2002b; Topchy et al., 2004; Fern \& Brodley, 2004; Fred \& Jain, 2005; Punera \& Ghosh, 2008). Também pode-se objetivar uma partição consenso com menor sensibilidade a ruídos, outliers, variações de amostragem ou à variabilidade dos algoritmos (Monti et al., 2003; Topchy et al., 2004; Fred \& Jain, 2005; Kuncheva \& Vetrov, 2006).

- Novidade: gerar uma partição consenso inédita, inspirada pelos grupos das partições base, mas que dificilmente poderia ser obtida pelos algoritmos utilizados para gerar as partições base individualmente (Topchy et al., 2003; Law et al., 2004).

- Reaproveitamento de conhecimento: re-utilizar conhecimento prévio para construir uma partição resultante única. Dependendo do domínio da aplicação, várias partições de conjuntos de dados já são conhecidas, algumas oriundas da análise prévia dos dados, outras resultantes de regras de agrupamento pré-definidas. Estas partições representam conhecimento prévio sobre a estrutura do conjunto analisado que pode ser utilizado para a construção da partição consenso (Dimitriadou et al., 2002b; Strehl \& Ghosh, 2002b; Ghosh et al., 2002; Topchy et al., 2004).

- Computação distribuída: gerar partições distintas por meio de métodos distribuídos e combinar o resultado em uma única partição consenso. Esse tipo de algoritmo geralmente é aplicado quando, por algum motivo, não é possível executar o agrupamento de todo o conjunto de dados de forma centralizada ou é desejável a execução paralela dos agrupamentos. Segundo Kuncheva (2004), dois subdomínios importantes da área de agrupamento distribuído são o agrupamento de atributos 
distribuídos e o agrupamento de objetos distribuídos. Em cada subdomínio, diferentes subconjuntos do conjunto de dados são gerados contendo parte dos atributos ou dos objetos do conjunto de dados, respectivamente. As partições base são obtidas a partir do agrupamento destes subconjuntos. A mesma estratégia pode ser utilizada para gerar paralelização e escalabilidade nos algoritmos (Strehl \& Ghosh, 2002b; Topchy et al., 2004; Tumer \& Agogino, 2008). Detalhes sobre a aplicação de combinação de agrupamentos em computação distribuída são apresentados no Capítulo 7 .

- Consistência: obter uma partição consenso tal que, de alguma forma, esteja em concordância com as partições base. Uma forma de medir a consistência da partição consenso é por meio da análise da informação mútua entre as partições base (Dimitriadou et al., 1999a; Fred, 2001; Fred \& Jain, 2002b, 2003, 2005).

- Desempenho e custo computacional: com o objetivo de se obter um melhor desempenho computacional, algoritmos mais simples e de baixo custo computacional podem ser executados e seus resultados combinados, de forma a objetivar uma partição consenso de maior qualidade do que as partições base (Topchy et al., 2003).

A combinação de estimadores é comumente empregada sob o paradigma de aprendizado supervisionado, isto é, em problemas de classificação e regressão (Ruta \& Gabrys, 2004; Kuncheva \& Whitaker, 2003). Porém, devido à falta de conhecimento a priori sobre a classe dos dados, muitas vezes a aplicação direta das técnicas de combinação de estimadores supervisionados no paradigma não-supervisionado não é possível (Kuncheva \& Whitaker, 2003). Além disso, técnicas de agrupamento diferentes podem produzir grupos incompatíveis, o que resulta em problemas de correspondência entre os rótulos cuja solução pode ser de elevada complexidade computacional ou, algumas vezes, intratável (Topchy et al., 2003).

Por estes motivos, combinações de agrupamentos requerem novas técnicas ou a adaptação de técnicas já utilizadas no paradigma supervisionado. Para isso, é preciso considerar dois aspectos importantes (Topchy et al., 2004; Kuncheva et al., 2006; Hadjitodorov et al., 2006):

- Diversidade do agrupamento: para justificar o custo computacional do uso de múltiplos algoritmos de agrupamento, é preciso se certificar que os mesmos apresentem um certo grau de diversidade em relação ao método utilizado para agrupar os dados. Desta forma, caso haja um consenso entre as partições formadas, o agrupamento resultante combina evidência sobre a estrutura natural dos dados, gerando um resultado intermediário em relação aos agrupamentos obtidos. Além disso, Kuncheva \& Hadjitodorov (2004) observaram que combinações com maior diversidade tendem a obter melhor qualidade. 
- Função de consenso: é preciso estabelecer um método para combinar diferentes agrupamentos, de forma a garantir consenso simétrico e balanceado em relação a todos os componentes do agrupamento, além de solucionar problemas como diferentes representações dos grupos obtidos. A escolha da função de consenso determina diretamente o resultado da combinação e, portanto, deve ser feita cautelosamente.

Nas Seções 5.2 e 5.3 são apresentadas as abordagens mais comuns descritas na literatura para gerar a diversidade necessária nas partições iniciais e encontrar a partição consenso.

\subsection{Diversidade dos agrupamentos base}

Ao buscar um agrupamento consenso, é preciso ter muito claro o(s) objetivo(s) da combinação e conhecer bem os algoritmos a serem combinados, a fim de garantir que os algoritmos escolhidos possam contribuir para atingir esse(s) objetivo(s). Assim, de acordo com o objetivo da combinação, deve-se escolher algoritmos de agrupamento, ou formas de aplicação de um algoritmo, que forneçam a diversidade necessária.

É preciso enfatizar que a diversidade necessária se refere à forma ou metodologia utilizada para gerar os agrupamentos base, não aos agrupamentos resultantes destas. O fato de metodologias distintas resultarem em partições semelhantes pode ser resultado da presença de uma forte estrutura nos dados agrupados, identificada nestas partições. Além disso, Greene et al. (2004) observaram que, apesar de necessária, a diversidade entre os membros de uma combinação não é suficiente para gerar uma solução melhorada sem a seleção de um método de integração efetivo.

Os métodos mais utilizados para se obter essa diversidade são (Kuncheva, 2004; Kuncheva et al., 2006; Hadjitodorov et al., 2006; Faceli, 2006):

- Utilizar diferentes algoritmos convencionais de agrupamento para gerar as partições (Qian \& Suen, 2000; Kellam et al., 2001; Strehl \& Ghosh, 2002b; Weingessel et al., 2003; Asur et al., 2006).

- Executar várias vezes um mesmo algoritmo convencional, com diferentes inicializações ou ordem de apresentação dos dados, de forma a se obter partições distintas (Fred, 2001; Fred \& Jain, 2002b, 2003; Frossyniotis et al., 2002; Weingessel et al., 2003; Topchy et al., 2004; Kasturi \& Acharya, 2004; Hadjitodorov et al., 2006).

- Utilizar diferentes conjuntos de dados, que podem ser formados por:

- Objetos com diferentes subconjuntos dos atributos originais (Strehl \& Ghosh, $2002 b)$.

- Projeções do conjunto original em um espaço de dimensão menor (Fern \& Brodley, 2004). 
- Reamostragem, referente a subconjuntos de objetos de um mesmo conjunto de dados (Strehl \& Ghosh, 2002b; Monti et al., 2003; Fern \& Brodley, 2004; Hadjitodorov et al., 2006).

- Inserção de ruído ou perturbação para aumentar a diversidade no conjunto de dados (Topchy et al., 2004; Hadjitodorov et al., 2006; Dimitriadou et al., 1999a; Gablentz et al., 2000).

Se as partições base forem oriundas de algoritmos distintos, a combinação é considerada heterogênea. Neste caso, os algoritmos devem apresentar características distintas, para que as partições resultantes possam ser diversificadas. Nos casos em que as partições base são geradas por um mesmo algoritmo, a combinação é dita homogênea. Dependendo das características de cada algoritmo, deve ser estabelecido um conjunto de condições iniciais com o qual o algoritmo deve ser executado para gerar as partições.

Um exemplo de combinação homogênea pode ser feita com o uso do conhecido algoritmo $k$-médias (Seção 2.4.6). Como seu resultado varia com o número de grupos $k$ e seus protótipos iniciais, pode-se gerar diferentes partições base por meio da variação destes parâmetros (Fred \& Jain, 2002a).

Dentre as funções utilizadas para medir a diversidade entre agrupamentos base presentes na literatura, podemos citar a medida de entropia proposta por Greene et al. (2004). Por meio dessa medida, a diversidade é dada segundo a Equação (5.1) para um conjunto de dados de $n_{o}$ objetos, em que $p p_{i j}$ representa a proporção de vezes em que o par composto pelo $i$-ésimo e o $j$-ésimo objetos do conjunto de dados estão inseridos no mesmo grupo, para todas as partições base. O resultado do uso de divent pode ser interpretado como a quantidade de desinformação, ou seja, entropia, presente no conjunto de partições base.

$$
d i v_{\text {ent }}=\frac{2}{n_{o}\left(n_{o}-1\right)} \sum_{i=1}^{n_{o}} \sum_{j=i+1}^{n_{o}}-\left(p p_{i j} \log _{2} p p_{i j}+\left(1-p p_{i j}\right) \log _{2}\left(1-p p_{i j}\right)\right)
$$

Hadjitodorov et al. (2006) estudaram o uso do índice Rand Ajustado (AR) (Seção 2.5.1.3) como função de diversidade entre duas partições. A partir deste estudo, os autores propuseram quatro funções de diversidade entre conjuntos de partições e as compararam, de forma a medir qual dentre elas é capaz de avaliar melhor a entropia entre as partições comparadas. Seja $1-A R\left(\pi_{i}, \pi_{j}\right)$ a diversidade entre os agrupamentos $\pi_{i}$ e $\pi_{j}$, a primeira função $D_{1}$ proposta por Hadjitodorov et al. (2006) consiste na média das diversidades entre todas as $n_{\pi}$ partições base $\Pi=\left\{\pi_{1}, \pi_{2}, \ldots, \pi_{n_{\pi}}\right\}$ e o agrupamento consenso $\pi_{f}$. De forma semelhante, a segunda função $D_{2}$ consiste no desvio padrão destas diversidades. A terceira e quarta funções são derivadas das duas primeiras, sendo dadas por $D_{3}=\frac{1}{2}\left(1-D_{1}+D_{2}\right)$ e $D_{4}=\frac{D_{2}}{D_{1}}$ respectivamente. Essas medidas foram comparadas com a medida dada pela Equação (5.1) e os resultados destacam a função $D_{3}$, cujos valores médios estão associados à boa qualidade das combinações de partições obtidas. 
Em relação ao número de partições base a serem combinadas, grande parte dos pesquisadores concordam que, quanto maior o número, maior a quantidade de evidência gerada e, portanto, mais precisa será a combinação (Kuncheva et al., 2006; Handl \& Knowles, 2007; Hadjitodorov \& Kuncheva, 2007). Segundo esses autores, é esperado que a maioria dos métodos de combinação dêem bons resultados para conjuntos com mais de 1000 partições (Kuncheva et al., 2006). Porém, alguns autores afirmam que a precisão da partição consenso aumenta pouco com o uso de milhares de partições, se essa for comparada a combinações obtidas com algumas centenas de partições base, o que não justificaria seu alto custo computacional (Hadjitodorov \& Kuncheva, 2007). Experimentos realizados em (Hadjitodorov et al., 2006) concluem que diversidade em excesso leva a combinações pobres e que combinações com níveis moderados de diversidade são mais precisas.

\subsection{Determinação da função de consenso}

A função de consenso é a função utilizada para combinar o conjunto de partições base $\Pi=\left\{\pi_{1}, \pi_{2}, \ldots, \pi_{n_{\pi}}\right\}$ em uma a partição final $\pi_{f}$, também conhecida como partição consenso. Sendo assim, esta constitui a essência da combinação, pois é nela que se concentra a metodologia pela qual as partições serão combinadas. Em Greene et al. (2004), foi observado que, apesar de necessária, a diversidade entre os membros de uma combinação não é suficiente para gerar uma solução melhorada sem a escolha de um método de integração efetivo.

A escolha de uma função de consenso apropriada pode ser uma tarefa árdua, em especial pela ausência de uma classificação intrínseca dos objetos a serem agrupados, o que faz com que não haja uma correspondência explícita entre os grupos das diversas partições base (Topchy et al., 2003). Partições com números de grupos distintos ou a falta de correspondência entre os rótulos dos grupos agravam ainda mais a complexidade deste problema.

Outra característica que deve ser considerada na escolha da função de consenso é sua capacidade de estimar ou não o número de grupos da partição a ser gerada. Caso esse número não seja conhecido, alguma função ou índice pode ser utilizado para estimá-lo. Por exemplo, o exame dos valores de alguns tipos de função objetivo para partições com diferentes números de grupos pode ser utilizado nessa estimação (Kuncheva et al., 2006; Handl \& Knowles, 2007).

Nas próximas seções são apresentadas algumas funções de consenso, divididas pelo tipo de técnica utilizada (Topchy et al., 2004). Parte dos trabalhos envolve o uso de mais de uma função de consenso.

\subsubsection{Funções baseadas em co-associação}

Este tipo de função calcula a similaridade entre dois objetos pelo número de grupos compartilhados entre eles em todas as partições base. Esta similaridade é utilizada 
para representar a força de co-associação entre os objetos e é organizada em uma matriz conhecida como matriz de co-associação (Fred \& Jain, 2005).

Para ilustrar o processo, considere um conjunto de dados $X=\left\{\mathbf{x}_{1}, \mathbf{x}_{2}, \ldots, \mathbf{x}_{n_{o}}\right\}$. São geradas $n_{\pi}$ partições base $\Pi=\left\{\pi_{1}, \pi_{2}, \ldots, \pi_{n_{\pi}}\right\}$ utilizando as técnicas descritas na Seção 5.2, a partir de todos ou um subconjunto de objetos contidos em $X$. Para cada partição $\pi_{z}$, uma matriz de co-associação $\mathbf{M}^{(z)}$, de tamanho $n_{o} \times n_{o}$, é formada de maneira que o conteúdo da posição $\mathbf{M}^{(z)}(i, j)$ seja 1 caso $\mathbf{x}_{i}$ e $\mathbf{x}_{j}$ pertençam ao mesmo grupo na partição $\pi_{z}$ ou 0 caso contrário. Para ilustrar este processo, considere os agrupamentos apresentados na Tabela 5.1 (Strehl \& Ghosh, 2002b; Faceli, 2006). As matrizes de co-associação resultantes destas partições são apresentadas na Tabela 5.2.

\begin{tabular}{|c|l|}
\hline Partição & Grupos \\
\hline$\pi_{1}$ & $C_{1}^{1}=\left\{\mathbf{x}_{1}, \mathbf{x}_{2}, \mathbf{x}_{3}\right\}, C_{2}^{1}=\left\{\mathbf{x}_{4}, \mathbf{x}_{5}\right\}, C_{3}^{1}=\left\{\mathbf{x}_{6}, \mathbf{x}_{7}\right\}$ \\
\hline$\pi_{2}$ & $C_{1}^{2}=\left\{\mathbf{x}_{6}, \mathbf{x}_{7}\right\}, C_{2}^{2}=\left\{\mathbf{x}_{1}, \mathbf{x}_{2}, \mathbf{x}_{3}\right\}, C_{3}^{2}=\left\{\mathbf{x}_{4}, \mathbf{x}_{5}\right\}$ \\
\hline$\pi_{3}$ & $C_{1}^{3}=\left\{\mathbf{x}_{1}, \mathbf{x}_{2}\right\}, C_{2}^{3}=\left\{\mathbf{x}_{3}, \mathbf{x}_{4}\right\}, C_{3}^{3}=\left\{\mathbf{x}_{5}, \mathbf{x}_{6}, \mathbf{x}_{7}\right\}$ \\
\hline$\pi_{4}$ & $C_{1}^{4}=\left\{\mathbf{x}_{1}, \mathbf{x}_{4}\right\}, C_{2}^{4}=\left\{\mathbf{x}_{2}, \mathbf{x}_{5}\right\}$, objetos $\mathbf{x}_{3}, \mathbf{x}_{6}$ e $\mathbf{x}_{7}$ não agrupados \\
\hline
\end{tabular}

Tabela 5.1: Exemplo de partições.

\begin{tabular}{|c|c|c|c|c|c|c|c|}
\hline$\pi_{1}$ & $\mathbf{x}_{1}$ & $\mathbf{x}_{2}$ & $\mathbf{x}_{3}$ & $\mathbf{x}_{4}$ & $\mathbf{x}_{5}$ & $\mathbf{x}_{6}$ & $\mathbf{x}_{7}$ \\
\hline $\mathbf{x}_{1}$ & 1 & 1 & 1 & 0 & 0 & 0 & 0 \\
\hline $\mathbf{x}_{2}$ & 1 & 1 & 1 & 0 & 0 & 0 & 0 \\
\hline $\mathbf{x}_{3}$ & 1 & 1 & 1 & 0 & 0 & 0 & 0 \\
\hline $\mathbf{x}_{4}$ & 0 & 0 & 0 & 1 & 1 & 0 & 0 \\
\hline $\mathbf{x}_{5}$ & 0 & 0 & 0 & 1 & 1 & 0 & 0 \\
\hline $\mathbf{x}_{6}$ & 0 & 0 & 0 & 0 & 0 & 1 & 1 \\
\hline $\mathbf{x}_{7}$ & 0 & 0 & 0 & 0 & 0 & 1 & 1 \\
\hline \hline$\pi_{3}$ & $\mathbf{x}_{1}$ & $\mathbf{x}_{2}$ & $\mathbf{x}_{3}$ & $\mathbf{x}_{4}$ & $\mathbf{x}_{5}$ & $\mathbf{x}_{6}$ & $\mathbf{x}_{7}$ \\
\hline $\mathbf{x}_{1}$ & 1 & 1 & 0 & 0 & 0 & 0 & 0 \\
\hline $\mathbf{x}_{2}$ & 1 & 1 & 0 & 0 & 0 & 0 & 0 \\
\hline $\mathbf{x}_{3}$ & 0 & 0 & 1 & 1 & 0 & 0 & 0 \\
\hline $\mathbf{x}_{4}$ & 0 & 0 & 1 & 1 & 0 & 0 & 0 \\
\hline $\mathbf{x}_{5}$ & 0 & 0 & 0 & 0 & 1 & 1 & 1 \\
\hline $\mathbf{x}_{6}$ & 0 & 0 & 0 & 0 & 1 & 1 & 1 \\
\hline $\mathbf{x}_{7}$ & 0 & 0 & 0 & 0 & 1 & 1 & 1 \\
\hline
\end{tabular}

\begin{tabular}{|c|c|c|c|c|c|c|c|}
\hline$\pi_{2}$ & $\mathbf{x}_{1}$ & $\mathbf{x}_{2}$ & $\mathbf{x}_{3}$ & $\mathbf{x}_{4}$ & $\mathbf{x}_{5}$ & $\mathbf{x}_{6}$ & $\mathbf{x}_{7}$ \\
\hline $\mathbf{x}_{1}$ & 1 & 1 & 1 & 0 & 0 & 0 & 0 \\
\hline $\mathbf{x}_{2}$ & 1 & 1 & 1 & 0 & 0 & 0 & 0 \\
\hline $\mathbf{x}_{3}$ & 1 & 1 & 1 & 0 & 0 & 0 & 0 \\
\hline $\mathbf{x}_{4}$ & 0 & 0 & 0 & 1 & 1 & 0 & 0 \\
\hline $\mathbf{x}_{5}$ & 0 & 0 & 0 & 1 & 1 & 0 & 0 \\
\hline $\mathbf{x}_{6}$ & 0 & 0 & 0 & 0 & 0 & 1 & 1 \\
\hline $\mathbf{x}_{7}$ & 0 & 0 & 0 & 0 & 0 & 1 & 1 \\
\hline \hline$\pi_{4}$ & $\mathbf{x}_{1}$ & $\mathbf{x}_{2}$ & $\mathbf{x}_{3}$ & $\mathbf{x}_{4}$ & $\mathbf{x}_{5}$ & $\mathbf{x}_{6}$ & $\mathbf{x}_{7}$ \\
\hline $\mathbf{x}_{1}$ & 1 & 0 & 0 & 1 & 0 & 0 & 0 \\
\hline $\mathbf{x}_{2}$ & 0 & 1 & 0 & 0 & 1 & 0 & 0 \\
\hline $\mathbf{x}_{3}$ & 0 & 0 & 0 & 0 & 0 & 0 & 0 \\
\hline $\mathbf{x}_{4}$ & 1 & 0 & 0 & 1 & 0 & 0 & 0 \\
\hline $\mathbf{x}_{5}$ & 0 & 1 & 0 & 0 & 1 & 0 & 0 \\
\hline $\mathbf{x}_{6}$ & 0 & 0 & 0 & 0 & 0 & 0 & 0 \\
\hline $\mathbf{x}_{7}$ & 0 & 0 & 0 & 0 & 0 & 0 & 0 \\
\hline
\end{tabular}

Tabela 5.2: Exemplo de matrizes de co-associação para as partições apresentadas na Tabela 5.1.

A matriz de co-associação consenso $\mathbf{M}$ é gerada a partir das matrizes $\mathbf{M}^{(z)}, z=$ $1, \ldots, n_{\pi}$, de forma que $\mathbf{M}=\frac{1}{n_{\pi}}\left(\mathbf{M}_{(1)}+\ldots+\mathbf{M}_{\left(n_{\pi}\right)}\right)$ (Monti et al., 2003), ilustrada na Tabela 5.3 . A partição consenso é obtida por meio do uso de alguma técnica em M. Um exemplo de método utilizado para gerar a partição consenso consiste em estabelecer um limiar $\theta$ tal que $0<\theta<1$ e, caso $\mathbf{M}(i, j) \geq \theta$, inserir os objetos $\mathbf{x}_{i}$ e $\mathbf{x}_{j}$ no mesmo grupo (Kuncheva, 2004). Após o cálculo, se algum objeto $\mathbf{x}_{i}$ não estiver em nenhum grupo com outro objeto, ele formará sozinho um grupo (singleton). Escolher um valor para o limiar 
$\theta$ e aplicá-lo a matriz $\mathbf{M}$ é equivalente ao uso do algoritmo hierárquico de ligação simples com corte da hierarquia em um nível determinado por meio do limiar $\theta$ (Kuncheva, 2004).

\begin{tabular}{|c|c|c|c|c|c|c|c|}
\hline $\mathbf{M}$ & $\mathbf{x}_{1}$ & $\mathbf{x}_{2}$ & $\mathbf{x}_{3}$ & $\mathbf{x}_{4}$ & $\mathbf{x}_{5}$ & $\mathbf{x}_{6}$ & $\mathbf{x}_{7}$ \\
\hline $\mathbf{x}_{1}$ & 1.00 & 0.75 & 0.50 & 0.25 & 0.00 & 0.00 & 0.00 \\
\hline $\mathbf{x}_{2}$ & 0.75 & 1.00 & 0.50 & 0.00 & 0.25 & 0.00 & 0.00 \\
\hline $\mathbf{x}_{3}$ & 0.50 & 0.50 & 1.00 & 0.25 & 0.00 & 0.00 & 0.00 \\
\hline $\mathbf{x}_{4}$ & 0.25 & 0.00 & 0.25 & 1.00 & 0.05 & 0.00 & 0.00 \\
\hline $\mathbf{x}_{5}$ & 0.00 & 0.25 & 0.00 & 0.05 & 1.00 & 0.25 & 0.25 \\
\hline $\mathbf{x}_{6}$ & 0.00 & 0.00 & 0.00 & 0.00 & 0.25 & 1.00 & 0.75 \\
\hline $\mathbf{x}_{7}$ & 0.00 & 0.00 & 0.00 & 0.00 & 0.25 & 0.75 & 1.00 \\
\hline
\end{tabular}

Tabela 5.3: Exemplo de matriz de co-associação consenso.

O uso de co-associação pode se dar em partições geradas por amostras de objetos de $X$ (Monti et al., 2003). Neste caso alguns objetos da base de dados podem não estar presentes na partição, como acontece com a partição $\pi_{4}$ que possui valores "vazios" para estes objetos nas matrizes de co-associação. A matriz de co-associação consenso $\mathbf{M}$ será calculada pela média dos valores presentes nas matrizes geradas pelas partições base, desconsiderando as entradas vazias.

Outra forma de gerar a partição consenso consiste em aplicar algum algoritmo de agrupamento baseado em (dis)similaridade na matriz consenso (Kellam et al., 2001; Strehl \& Ghosh, 2002b; Fred \& Jain, 2002b, 2003; Monti et al., 2003; Kuncheva et al., 2006). Neste caso, $\mathbf{M}$ pode ser interpretada de duas formas: como matriz de similaridade entre os objetos do conjunto $X$ ou como os objetos propriamente ditos. No primeiro caso, a informação contida na matrix $\mathbf{M}$ deve ser tratada de acordo com o algoritmo de agrupamento utilizado (por exemplo, uma estratégia consiste em utilizar 1- $\mathbf{M}$ para algoritmos baseados em dissimilaridade (Kuncheva et al., 2006)). No segundo caso, o algoritmo de agrupamento é aplicado diretamente em $\mathbf{M}$ e utiliza as similaridades como atributos, o que vêm obtendo bons resultados (Pekalska \& Duin, 2005).

O número de grupos da partição consenso pode ser pré-especificado ou encontrado por meio da análise de M. No segundo caso, é possível derivá-lo a partir da análise da hierarquia de partições gerada por um algoritmo de agrupamento hierárquico que utilize as similaridades contidas em M (Fred \& Jain, 2003; Kuncheva, 2004; Greene et al., 2004; Hadjitodorov et al., 2006). Por exemplo, um índice de validação de agrupamentos pode ser aplicado nas partições que representam os níveis dessa hierarquia e o número de grupos escolhido corresponde ao número de grupos da partição melhor avaliada. Outro método consiste em obter, por meio de $\mathbf{M}$, as dissimilaridades entre os grupos aglomerados em cada nível do algoritmo hierárquico e selecionar a partição correspondente ao nível anterior a aglomeração dos grupos de maior dissimilaridade. Em outras palavras, seja $d^{i}$ a dissimilaridade entre os grupos aglomerados no $i$-ésimo nível da hierarquia, calcula-se $\Delta_{i}=d^{i+1}-d^{i}$ para todo $i$ de 1 até $n_{o}-1$ (do primeiro ao último nível da hierarquia). Um $\Delta_{i}$ alto indica que a aglomeração executada na iteração seguinte ao $i$-ésimo nível pode estar forçando uma estrutura que não ocorre nos dados. Portanto, escolhe-se a 
partição correspondente ao $j$-ésimo nível da hierarquia, em que $j=\arg \max _{i=1}^{n_{o}-1} \Delta_{i}$. Um procedimento semelhante também é aplicado por Fred \& Jain (2005), por meio de um corte do dendrograma resultante na posição com maior diferença entre as iterações (lifetime).

Outra forma de se derivar o número de grupos $k$ da partição final consiste em executar diferentes combinações para um conjunto de partições base, de forma a obter um conjunto de partições consenso em que o valor do número de grupos $k$ varie em um determinado intervalo de interesse. Segundo Monti et al. (2003), se houver uma estrutura bem definida no conjunto de dados, as partições serão capazes de identificá-la separadamente e a similaridade entre as partições base e a partição consenso que mais se aproxima dessa estrutura será alta. Portanto, o valor de $k$ será escolhido por meio da partição consenso de maior confidência (similaridade) (Monti et al., 2003) em relação às partições base.

Kuncheva \& Vetrov (2006) fazem uma avaliação da estabilidade da combinação de partições geradas por $k$-médias em relação a inicializações aleatórias de grupos. Essa combinação é feita por meio do uso de matriz de co-associação e a estabilidade entre partições é calculada de duas formas: pareada, por meio do cálculo do índice $A R$ (Seção 2.5.1.3) entre as partições avaliadas, e não pareada, por meio do cálculo da entropia destas partições. Os resultados indicam que, de forma geral, este tipo de combinação é mais estável do que as partições base individualmente, em especial para casos onde o número de grupos do conjunto de dados é grande. Kuncheva \& Vetrov (2006) sugerem o uso da estabilidade das partições na análise do melhor número de grupos para a partição consenso e o conjunto de dados.

Alguns dos problemas da abordagem baseada em co-associação são a falta de uma metodologia para a definição do algoritmo de agrupamento a ser utilizado para a combinação e a baixa confiabilidade da estimativa dos valores de co-associação quando um pequeno número de partições é utilizado.

\subsubsection{Funções baseadas em votação}

Também conhecido como agrupamento pela maioria de votos (Kuncheva, 2004), as funções baseadas em votação utilizam um mecanismo de votação para atribuir os objetos aos grupos da partição consenso. Entretanto, antes que seja possível votar em qual grupo um determinado objeto pertencerá na partição consenso, é necessário obter a correspondência entre os grupos da partição consenso e os grupos de cada partição base. Ou seja, é necessário encontrar a correspondência entre os rótulos dos objetos de partições distintas. Em (Topchy et al., 2004), os autores apresentam argumentos formais sobre a efetividade do uso da combinação de agrupamentos utilizando função de consenso baseada em voto por pluralidade e sobre a perspectiva do uso de uma partição gerada estocasticamente a partir da mudança dos valores dos rótulos. Os autores mostram que, se a probabilidade dos agrupamentos utilizados rotularem corretamente um objeto for maior do que a probabilidade de isso acontecer aleatoriamente, a acurácia da partição consenso em relação à estrutura dos dados aumenta com o aumento do número de partições base, tendendo a 
1 quando o número de partições cresce infinitamente.

Um esquema de votação para partições fuzzy ou crisp com um número de grupos $k$ fixo foi proposto em (Dimitriadou et al., 2002a) e utilizado em outros trabalhos (Dimitriadou, 2003; Weingessel et al., 2003). Para esse esquema, foi proposta uma forma de medir a dissimilaridade entre partições, utilizada para procurar por uma partição $\pi_{f}$ para um dado conjunto de dados $\mathbf{X}=\left\{\mathbf{x}_{1}, \mathbf{x}_{2}, \ldots, \mathbf{x}_{n_{o}}\right\}$ que represente de maneira ótima as $n_{\pi}$ partições iniciais $\Pi=\left\{\pi_{1}, \pi_{2}, \ldots, \pi_{n_{\pi}}\right\}$. Cada partição é representada por uma matriz $\mathbf{U}^{(p)}$, com $p=1, \ldots, n_{\pi}$, em que cada elemento $u_{i j}^{(p)}$ contém o valor de pertinência do objeto $\mathbf{x}_{i}$ para o $j$-ésimo grupo da partição $\pi_{p}$. Da mesma forma, a partição consenso $\pi_{f}$ é representada por uma matriz $\mathbf{F}$ e $f_{i j}$ corresponde a um elemento da matriz $\mathbf{F}$. A função de dissimilaridade entre $\mathbf{U}^{(p)}$ e $\mathbf{F}$ é dada pela média da distância quadrática, calculada pela Equação (5.2).

$$
d\left(\mathbf{U}^{(p)}, \mathbf{F}\right)=\frac{1}{n_{o}} \sum_{i=1}^{n_{o}}\left\|\mathbf{u}_{i}^{(p)}-\mathbf{f}_{i}\right\|^{2}
$$

Deve ser observado que as considerações feitas são válidas apenas para casos em que haja correspondência entre os rótulos dos grupos. Entretanto, encontrar essa correspondência é difícil pois é equivalente a comparar todos os grupos de uma partição com todos os grupos da outra partição e encontrar os grupos correspondentes. Neste caso, resume-se a testar todas as $k$ ! permutações de linhas de $\mathbf{F}$ e $\mathbf{U}$. Para se obter uma aproximação heurística de uma rotulação consistente, todas as partições devem ser re-rotuladas com base em sua melhor concordância com uma partição referência (Dimitriadou, 2003; Weingessel et al., 2003). Essa tarefa pode ser computacionalmente dispendiosa para valores altos de $k$. Uma forma de solucionar este problema consiste em aplicar os passos as seguir (Dimitriadou, 2003):

1. Construir a matriz de confusão entre os grupos de $\mathbf{F}$ e $\mathbf{U}$, de forma que o elemento da posição $i j$ indique a quantidade de objetos em comum entre o grupo representado pela $i$-ésima coluna de $\mathbf{F}$ e o grupo representado pela $j$-ésima coluna de $\mathbf{U}$.

2. Encontrar o maior elemento dessa matriz.

3. Associar os dois grupos correspondentes a esse elemento.

4. Remover os dois grupos da matriz.

5. Se ainda houver grupos na matriz, voltar ao Passo 2.

A partir da correspondência gerada a partir das associações obtidas entre os grupos, gera-se uma função de permutação $\hat{\varepsilon}$, que é utilizada para reodernar as colunas de $\mathbf{U}$, de modo a maximizar a diagonal da matriz de confusão entre $\hat{\varepsilon}(\mathbf{U})$ e $\mathbf{F}$. Esse processo tem por objetivo obter a função de consenso entre as $n_{\pi}$ partições base, de forma que a partição consenso seja calculada na primeira iteração por:

$$
\mathbf{F}^{(1)}=\mathbf{U}
$$


e na $i$-ésima iteração consecutiva por:

$$
\mathbf{F}^{(i)}=\frac{1}{i} \sum_{l=1}^{i} \hat{\varepsilon}_{l}\left(\mathbf{U}^{(l)}\right)=\frac{i-1}{i} \mathbf{F}^{(i-1)}+\frac{1}{i} \hat{\varepsilon}_{i}\left(\mathbf{U}^{(i)}\right)
$$

até que $i=n_{\pi}$. A matriz $\mathbf{F}^{\left(n_{\pi}\right)}$ resultante representa o agrupamento consenso final. Dimitriadou et al. (2002a) chamam esse método de votação porque cada partição base corresponde a um voto que indica em qual grupo deve pertencer cada objeto do conjunto de dados, o que torna $\mathbf{F}^{\left(n_{\pi}\right)}$ o consenso entre os votos/partições. De forma análoga, outros métodos de renumeração (Frossyniotis et al., 2002), ou até mesmo matrizes de co-associação (Fred, 2001), podem ser utilizadas para estabelecer a correspondência entre grupos. Outra forma de solucionar o problema de correspondência dos rótulos se dá por meio da aplicação do método Húngaro (Kuhn, 1955; Frank, 2004), que possui complexidade computacional $O\left(k^{3}\right)$.

Apesar do algoritmo proposto em (Dimitriadou, 2003) inicialmente não estimar o número de grupos do conjunto de dados, uma variante com esse objetivo é proposta em (Dimitriadou et al., 1999b). Essa variante aplica o algoritmo de votação para gerar combinações para um número crescente de grupos, dentro de um intervalo de interesse, e calcular uma medida de certeza das partições consenso encontradas. Essa medida de certeza consiste na média dos percentuais em que os objetos do conjunto de dados se encontram no grupo da partição consenso correspondente a seus grupos de origem nas partições base, referenciada aqui como $\operatorname{certeza}(\cdot)$. Devido a um espalhamento cada vez maior dos objetos entre mais e mais grupos, existe uma tendência desta medida decrescer com o aumento do número de grupos das partições geradas. Por este motivo, os autores propõem o uso de uma medida baseada na diferença dos valores obtidos entre diferentes números de grupos, dada pela Equação (5.5):

$$
\hat{k}=\max _{k}\left\{\left[\operatorname{certeza}\left(\pi_{f}^{(k)}\right)-\operatorname{certe} z a\left(\pi_{f}^{(k-1)}\right)\right]-\left[\operatorname{certe} z a\left(\pi_{f}^{(k+1)}\right)-\operatorname{certe} z a\left(\pi_{f}^{(k)}\right)\right]\right\}
$$

em que certeza $\left(\pi_{f}^{(k)}\right)$ é medida de certeza da partição consenso gerada com $k$ grupos e $\hat{k}$ é o número estimado de grupos para o conjunto de dados.

Uma variante desse algoritmo utiliza perturbação para gerar grupos mais distintos nas partições base, aumentando sua diversidade (Dimitriadou et al., 1999a). Outra variante executa o algoritmo várias vezes para gerar diversas partições consenso e combiná-las em uma única partição final (Dimitriadou et al., 2001), por meio da relação de verossimilhança entre cada par de grupos pertencentes a partições consenso distintas. Nesse caso, pares e sequências dos grupos com maiores verossimilhança são combinados em um único grupo, de forma que a matriz de pertinência do novo grupo seja a soma das matrizes dos grupos originais. O processo é repetido até que um critério de parada seja satisfeito (ex.: um determinado valor de certeza é alcançado). Também foi publicada uma variante para uso 
específico em aprendizado semi-supervisionado (Dimitriadou et al., 2002b).

Tumer \& Agogino (2008) propuseram um algoritmo de combinação de agrupamentos que nomearam de grupos de votação ativa (VAC - do inglês Voting Active Clusters). Nesse algoritmo, cada grupo das partições base é utilizado em um mecanismo de votação para decidir a qual grupo da partição consenso os objetos devem pertencer. Esse mecanismo utiliza aprendizado por reforço, que permite avaliar a partição consenso por meio de sua medida de informação mútua em relação às partições base e, em seguida, recompensar as ações de voto de acordo com o resultado dessa avaliação.

Recentemente, Ayad \& Kamel (2008) utilizaram a idéia de voto cumulativo baseada no trabalho feito em (Dimitriadou, 2003). Eles propuseram um esquema de votação cumulativo baseado no uso de uma matriz de probabilidades, no lugar do tradicional voto um-para-um utilizado por outros algoritmos. Cinco algoritmos baseados neste esquema de votação são descritos e os resultados experimentais mostram melhorias na qualidade das partições encontradas, comparadas com funções baseadas em grafo propostas por Strehl \& Ghosh (2002b) (descritas na Seção 5.3.3).

\subsubsection{Funções baseadas em grafo/hipergrafo}

As funções baseadas em grafos representam as partições base por um grafo ou por um hipergrafo. Nesses casos, a partição consenso é encontrada pelo uso de uma técnica de particionamento de grafos ou hipergrafos (Fern \& Brodley, 2004).

Três algoritmos baseados nesta heurística foram propostos por Strehl \& Ghosh (2002b): CSPA (Cluster-based Similarity Partitioning Algorithm), HGPA (HiperGraphPartitioning Algorithm) e MCLA (metaCLustering Algorithm). Os autores utilizam os três algoritmos, cada um gerando uma partição consenso, e usam uma função supraconsenso baseada em informação mútua compartilhada (a ser descrita na Seção 5.4) para escolher qual delas é a melhor.

Inicialmente, o conjunto de partições é representado em forma de hipergrafo, representado por uma matriz de adjacências na qual cada grupo das partições $\Pi=\left(\pi_{1}, \pi_{2}, \ldots, \pi_{n_{\pi}}\right)$ é representado por uma hiperaresta, ou seja, uma aresta capaz de unir qualquer número de vértices. Essa matriz é construída pela concatenação das matrizes binárias de pertinência de cada partição $\mathbf{H}=\left(\mathbf{H}^{1}, \mathbf{H}^{2}, \ldots, \mathbf{H}^{n_{\pi}}\right)$. As linhas da matriz de pertinência de uma partição correspondem aos objetos e as colunas correspondem aos seus grupos. Cada célula da matriz contém o valor 1 se o objeto pertence ao grupo e 0 caso contrário. A Tabela 5.4 ilustra o hipergrafo formado a partir dos agrupamentos presentes na Tabela 5.1 .

O algoritmo CSPA possui três etapas. A primeira etapa gera a matriz de co-associação consenso entre as partições base. Essa matriz será utilizada na segunda etapa como matriz de similaridade, na construção do grafo de similaridade induzido, em que os pesos das arestas são dados pelos valores dessa matriz. Na terceira etapa, o grafo de similaridade induzido é particionado pelo algoritmo METIS (Karypis \& Kumar, 1999). O objetivo 


\begin{tabular}{|c|c|c|c|c|}
\hline & $\pi_{1}$ & $\pi_{2}$ & $\pi_{3}$ & $\pi_{4}$ \\
\hline $\mathbf{x}_{1}$ & 1 & 2 & 1 & 1 \\
\hline $\mathbf{x}_{2}$ & 1 & 2 & 1 & 2 \\
\hline $\mathbf{x}_{3}$ & 1 & 2 & 2 & $?$ \\
\hline $\mathbf{x}_{4}$ & 2 & 3 & 2 & 1 \\
\hline $\mathbf{x}_{5}$ & 2 & 3 & 3 & 2 \\
\hline $\mathbf{x}_{6}$ & 3 & 1 & 3 & $?$ \\
\hline $\mathbf{x}_{7}$ & 3 & 1 & 3 & $?$ \\
\hline
\end{tabular}

\begin{tabular}{c|ccc|ccc|ccc|cc} 
& $\mathbf{H}^{1}$ & & & $\mathbf{H}^{2}$ & & $\mathbf{H}^{3}$ & & $\mathbf{H}^{4}$ & \\
& $h_{1}$ & $h_{2}$ & $h_{3}$ & $h_{4}$ & $h_{5}$ & $h_{6}$ & $h_{7}$ & $h_{8}$ & $h_{9}$ & $h_{10}$ & $h_{11}$ \\
\hline$v_{1}$ & 1 & 0 & 0 & 0 & 1 & 0 & 1 & 0 & 0 & 1 & 0 \\
$v_{2}$ & 1 & 0 & 0 & 0 & 1 & 0 & 1 & 0 & 0 & 0 & 1 \\
$v_{3}$ & 1 & 0 & 0 & 0 & 1 & 0 & 0 & 1 & 0 & 0 & 0 \\
$v_{4}$ & 0 & 1 & 0 & 0 & 0 & 1 & 0 & 1 & 0 & 1 & 0 \\
$v_{5}$ & 0 & 1 & 0 & 0 & 0 & 1 & 0 & 0 & 1 & 0 & 1 \\
$v_{6}$ & 0 & 0 & 1 & 1 & 0 & 0 & 0 & 0 & 1 & 0 & 0 \\
$v_{7}$ & 0 & 0 & 1 & 1 & 0 & 0 & 0 & 0 & 1 & 0 & 0
\end{tabular}

Tabela 5.4: Problema ilustrativo de combinação das partições $\pi_{1}, \pi_{2}, \pi_{3}$ e $\pi_{4}$ : vetores representando as partições originais à esquerda e o hipergrafo equivalente com 11 hiperarestas à direita (exemplo adaptado de Strehl \& Ghosh (2002b)).

deste particionamento é dividir o grafo em grupos balanceados, cujo quantidade é definida pelo usuário, a partir da eliminação do menor número de arestas ou das arestas com os menores pesos.

No algoritmo $H G P A$, a combinação é tratada como um problema de particionamento de um hipergrafo, no qual as hiperarestas representam grupos das partições base. Diferentemente do algoritmo CSPA, os pesos das hiperarestas e vértices são iguais. Se houver um caminho entre dois vértices no hipergrafo, os objetos representados por esses vértices estarão em um mesmo grupo na partição consenso. O particionamento do hipergrafo é feito por meio de cortes nas hiperarestas, aplicados até que um número de grupos pré-definido seja obtido na partição consenso. Para isso, Strehl \& Ghosh (2002b) utilizam o pacote de particionamento de hipergrafos HMETIS (Karypis et al., 1999), que possui como objetivo utilizar um número reduzido de cortes nas hiperarestas e gerar um balanceamento entre os grupos da partição consenso. Por esse motivo, a função de consenso $H G P A$ pode não ser indicada para gerar partições com grupos desbalanceados.

Um exemplo de hipergrafo gerado a partir das partições presentes na Tabela 5.4 é ilustrado na Figura 5.1. Nela, é possível visualizar que a aplicação de cortes nas hiperarestas $h_{8}, h_{9}, h_{10}$ e $h_{11}$ geram a partição consenso composta pelos grupos $C_{1}=\left\{v_{1}, v_{2}, v_{3}\right\}$, $C_{2}=\left\{v_{4}, v_{5}\right\}$ e $C_{3}=\left\{v_{6}, v_{7}\right\}$.

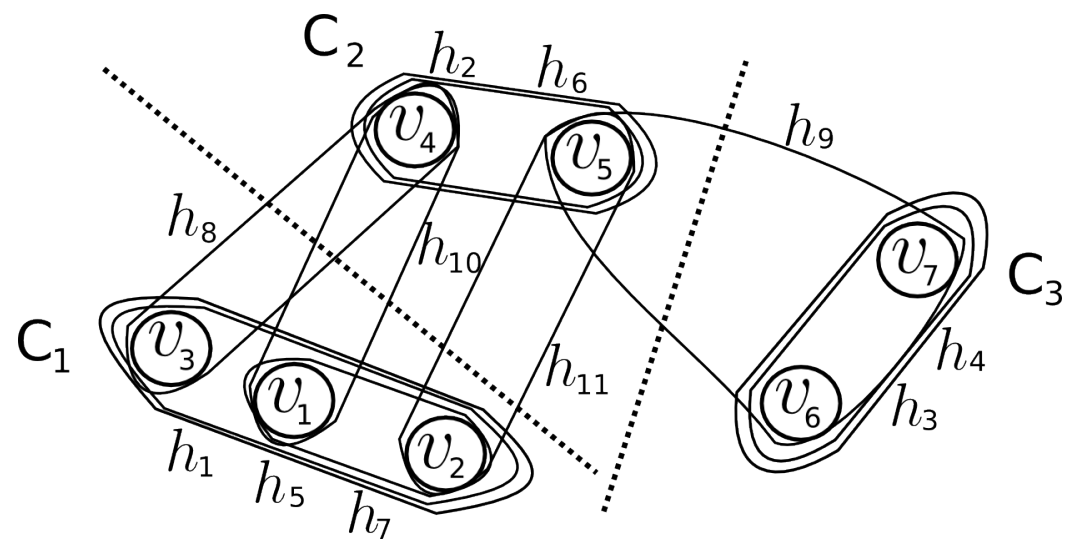

Figura 5.1: Exemplo de hipergrafo gerado pelas partições $\pi_{1}, \pi_{2}, \pi_{3}$ e $\pi_{4}$.

Dentre os três algoritmos propostos em (Strehl \& Ghosh, 2002b), o MCLA resultou em partições de melhor qualidade e robustez em relação a ruído. Por esse motivo, ele será apresentado em maiores detalhes nos passos a seguir: 
- Construir um meta-grafo: cada grupo das partições iniciais (as hiperarestas do hipergrafo descrito) é considerado um vértice de um outro grafo regular não direcionado, o meta-grafo. Seja $C_{j}^{i}$ o $j$-ésimo grupo da $i$-ésima partição, o peso da aresta entre os vértices correspondentes aos grupos $C_{j}^{i}$ e $C_{t}^{s}$ é dado pela medida de Jaccard estendida, também conhecida como coeficiente de Tanimoto (Equação 2.17). Para vetores binários, ela é equivalente à razão da cardinalidade da intersecção pela cardinalidade da união dos objetos pertencentes aos dois grupos, dada conforme a Equação (5.6).

$$
w\left(C_{j}^{i}, C_{t}^{s}\right)=\frac{\left|C_{j}^{i} \cap C_{t}^{s}\right|}{\left|C_{j}^{i} \cup C_{t}^{s}\right|}
$$

- Agrupar as hiper-arestas (grupos): a combinação dos grupos é feita pelo particionamento do meta-grafo em $k$ meta-grupos balanceados, sendo $k$ definido pelo usuário. Para isso, o pacote de particionamento de grafos utilizado no CSPA, METIS (Karypis \& Kumar, 1999), é utilizado com a mesma finalidade. O objetivo desta fase é encontrar os grupos das partições iniciais que são correspondentes. Novos grupos são formados a partir de um conjunto de grupos correspondentes. Estes grupos são chamados meta-grupos.

- Unir os conjuntos de cada meta-grupo: transforma as hiperarestas em uma única meta-hiperaresta para cada meta-grupo. Cada objeto pode pertencer a mais de um meta-grupo. Assim, para cada meta-hiperaresta, é calculado um vetor de associação descrevendo o nível de associação de cada objeto com o meta-grupo. O vetor de associação é obtido calculando-se a média dos vetores que representam as hiperarestas de um meta-grupo. Em outras palavras, o nível de associação de um objeto a um meta-grupo é dado pela média do número de grupos desse meta-grupo, que contêm o objeto.

- Determinar o meta-grupo consenso de cada objeto: cada objeto é associado ao metagrupo para o qual ele possui o maior valor de associação. Desempates são decididos aleatoriamente. A partição dos objetos indicada pelos meta-grupos é a partição consenso $\pi_{f}$ resultante do ensemble. Deve-se notar que não é garantido que todo meta-grupo tenha pelo menos um objeto. Assim, a partição $\pi_{f}$ tem no máximo (e não exatamente) $k$ grupos.

Para exemplificar o uso do $M C L A$, a Figura 5.2 ilustra o metagrafo gerado para as partições da Tabela 5.4 e seus respectivos hipergrafos. Naquela tabela, cada objeto $\mathbf{x}_{i}$ corresponde a um vértice e cada hiperaresta $h_{j}$ representa um dos grupos de uma das partições. No metagrafo da Figura 5.2, cada hiperaresta dos hipergrafos se torna um vértice. Os pesos das arestas entre os vértices são representados por diferentes tipos de linhas. O particionamento desse grafo em 3 partes resulta nos metagrupos $C_{1}^{M}=$ $\left\{h_{3}, h_{4}, h_{9}\right\}, C_{2}^{M}=\left\{h_{2}, h_{6}, h_{8}, h_{10}\right\}$ e $C_{3}^{M}=\left\{h_{1}, h_{5}, h_{7}, h_{11}\right\}$, de forma que as hiperarestas pertencentes ao mesmo metagrupo representem grupos correspondentes. 


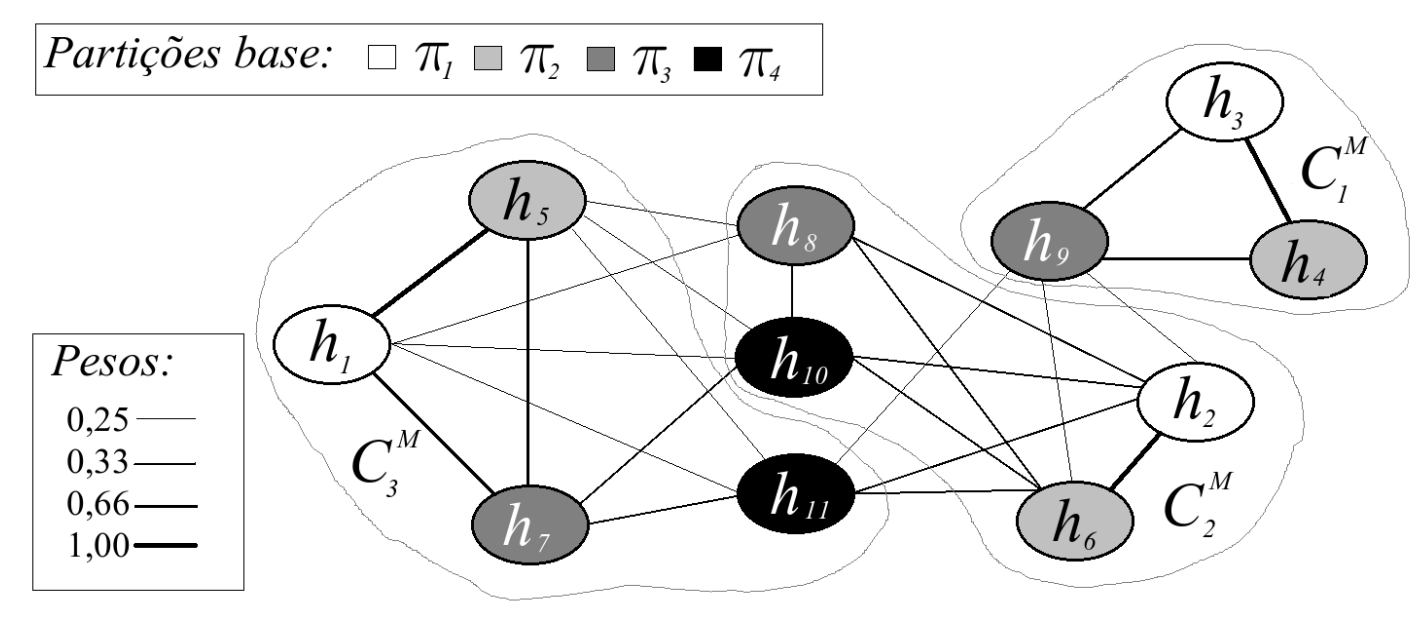

Figura 5.2: Exemplo de metagrafo para as partições $\pi_{1}, \pi_{2}, \pi_{3}$ e $\pi_{4}$.

Em seguida, os grupos correspondentes são unidos, formando as metahiperarestas $h_{i}^{M}$ representadas na Tabela 5.5. Nessa tabela também estão representados os respectivos vetores de associação $a\left(h_{i}^{M}\right)$. Com base nessas informações, o metagrupo final de cada objeto é determinado. Assim, $\mathbf{x}_{1}$, por exemplo, vai pertencer ao metagrupo $C_{3}^{M}$, pois é o metagrupo com o qual $\mathbf{x}_{1}$ tem o maior valor de associação $(0,75)$. O mesmo é feito para cada um dos objetos e a partição consenso $\pi^{f}$ é composta pelos grupos $C_{1}^{f}=\left\{\mathbf{x}_{6}, \mathbf{x}_{7}\right\}$, $C_{2}^{f}=\left\{\mathbf{x}_{4}, \mathbf{x}_{5}\right\}$ e $C_{3}^{f}=\left\{\mathbf{x}_{1}, \mathbf{x}_{2}, \mathbf{x}_{3}\right\}$.

\begin{tabular}{|c|c|c|c|c|c|c|}
\hline \multirow{2}{*}{ Vértices } & \multicolumn{2}{|c|}{$C_{1}^{M}=\left\{h_{3}, h_{4}, h_{9}\right\}$} & \multicolumn{2}{c|}{$C_{2}^{M}=\left\{h_{2}, h_{6}, h_{8}, h_{10}\right\}$} & \multicolumn{2}{c|}{$C_{3}^{M}=\left\{h_{1}, h_{5}, h_{7}, h_{11}\right\}$} \\
\cline { 2 - 7 } & $h_{1}^{M}$ & $a\left(h_{1}^{M}\right)$ & $h_{2}^{M}$ & $a\left(h_{2}^{M}\right)$ & $h_{3}^{M}$ & $a\left(h_{3}^{M}\right)$ \\
\hline \hline $\mathbf{x}_{1}$ & 0 & 0 & 1 & 0,25 & 1 & $\mathbf{0 , 7 5}$ \\
\hline $\mathbf{x}_{2}$ & 0 & 0 & 0 & 0 & 1 & $\mathbf{1}$ \\
\hline $\mathbf{x}_{3}$ & 0 & 0 & 1 & 0,25 & 1 & $\mathbf{0 , 5}$ \\
\hline $\mathbf{x}_{4}$ & 0 & 0 & 1 & $\mathbf{1}$ & 0 & 0 \\
\hline $\mathbf{x}_{5}$ & 1 & 0,33 & 1 & $\mathbf{0 , 5}$ & 1 & 0,25 \\
\hline $\mathbf{x}_{6}$ & 1 & $\mathbf{1}$ & 0 & 0 & 0 & 0 \\
\hline $\mathbf{x}_{7}$ & 1 & $\mathbf{1}$ & 0 & 0 & 0 & 0 \\
\hline
\end{tabular}

Tabela 5.5: Exemplo do $M C L A$ - metahiperarestas e vetores de associação

Várias outras abordagens com funções de consenso baseadas em particionamento de grafos foram publicadas na literatura. Uma delas é o algoritmo proposto em (Fern \& Brodley, 2004), chamado HBGF (Hybrid Bipartite Graph Formulation), que consiste em construir um grafo bipartido a partir do conjunto de partições a serem combinadas. Tanto objetos quanto grupos são modelados simultaneamente como vértices do grafo que, posteriormente, é particionado com uma técnica tradicional. Os autores utilizam duas técnicas de particionamento de grafo distintas: Spectral Graph Partitioning (Ng et al., 2002) e METIS (Karypis \& Kumar, 1999). O número de grupos da partição consenso é definido pelo usuário.

Outro estudo que utiliza função de consenso baseado em grafos foi feito em (Yu et al., 
2007), em que foi proposto o algoritmo GCC (do inglês Graph-based Consensus Clustering). Inicialmente, os autores utilizam o algoritmo $k$-médias e outro algoritmo de agrupamento correlacional (Bansal et al., 2004) para particionar sub-espaços do conjunto de dados formados por amostragens aleatórias dos atributos. Em seguida são geradas as matrizes de frequências de cada uma das diferentes partições obtidas. Uma matriz de co-associação (Seção 5.3.1) é gerada a partir do conjunto de matrizes de frequências e seus valores serão utilizados para compor as arestas de um grafo, cujos nós representam os objetos. Ao final, o algoritmo de corte normalizado proposto em (Shi \& Malik., 2000) é utilizado para particionar o grafo gerado, de forma que a dissimilaridade entre grupos distintos e a similaridade intra-grupos sejam as máximas possíveis. Os autores também propõem um índice de validação, chamado Modified Rand Index, baseado na matriz consensual resultante do algoritmo (Yu et al., 2007). Esse índice é utilizado para determinar o número de grupos $k$ da partição consenso.

Uma abordagem semelhante consiste em, dado um número de grupos $k$ para a partição consenso, calcular a intersecção entre $k$ grupos de $k$ componentes (Hu et al., 2006). O algoritmo pode ser divido em três partes: na primeira os grupos de junção são formados, compostos pela intersecção dos grupos de cada componente (partição base). Cada objeto deve pertencer a apenas um dos grupos de junção e objetos que não fizerem parte de nenhum grupo de junção formam grupos individuais (singletons). Na segunda parte, um grafo é gerado com cada nó representando um grupo de junção ou um grupo original das partições base, e cada aresta liga um grupo de junção ao respectivo grupo original a que ele pertence. Na terceira parte, o grafo é particionado em $k$ grupos por meio do algoritmo METIS (Karypis \& Kumar, 1999), rotulando os objetos segundo seus rótulos originais.

Recentemente, Punera \& Ghosh (2008) estenderam os algoritmos CSPA, MCLA e $H B G F$ para que os objetos possuam uma pertinência a cada grupo da partição. Com este objetivo, as dissimilaridades entre objetos e grupos são calculadas por meio da divergência $K L$ (Kullback \& Leibler, 1951). Os resultados dos algoritmos são comparados com suas contrapartes crisp e, segundo os autores, é possível concluir que os algoritmos estendidos contêm informação fuzzy útil que pode ser utilizada para obter partições consenso melhores.

\subsubsection{Outras funções}

Além desses tipos de função de consenso, Topchy et al. (2004) definem uma função de consenso baseada em uma solução para o problema de probabilidade máxima para um modelo misto finito do conjunto de partições iniciais. Esse conjunto de partições é modelado como uma mistura de distribuições multinomiais no espaço dos rótulos dos grupos. O problema de probabilidade máxima pode ser resolvido com o algoritmo EM.

Outra forma de combinar partições consiste em utilizar agentes para agrupar dados distribuídos e votar em qual grupo da partição consenso os objetos devem pertencer (Agogino \& Tumer, 2006). O objetivo da combinação é maximizar a semelhança entre a 
partição consenso e os grupos gerenciados pelos agentes, cujo cálculo é feito por meio de troca de informações. Os resultados obtidos mostram tolerância a falhas e desempenho próximo das funções baseadas em grafos propostas por Strehl \& Ghosh (2002b), que necessitam de processamento centralizado. O esquema de votação utilizado é detalhado em (Tumer \& Agogino, 2008).

Gao et al. (2007) utilizam informação mútua (Seção 5.4) para calcular a informação comum entre grupos das partições a serem combinadas. Uma vez quantificada, a informação comum entre grupos é utilizada como similaridade entre grupos e um algoritmo similar ao $k$-médias é utilizado para agrupar os grupos mais similares, de forma a gerar uma partição final. Adicionalmente, com o objetivo de aumentar a diversidade entre as partições combinadas, os autores propõem o uso de pesos maiores para partições mais distintas entre as partições base durante o processo de combinação.

Recentemente, Singh et al. (2010) propõem a utilização de protótipos (centróides) como os representantes de cada grupo e utilizam um esquema de seleção para escolher quais protótipos geram a partição com menor o erro mínimo quadrado, a mesma função objetivo do algoritmo $k$-médias dado pela Equação (2.25). Em seguida, a partição gerada é otimizada por meio de programação semidefinida, com o objetivo de aumentar a similaridade entre a partição consenso das partições base que a originaram. O resultados obtidos pelos autores mostram que a técnica supera outras técnicas de combinação em termos de qualidade da partição consenso.

\subsection{Avaliação da combinação}

O sucesso do processo de combinação pode ser medido por meio da similaridade entre a partição final $\pi_{f}$ e o conjunto de partições base П. Quanto maior essa similaridade, melhor o resultado da combinação representa as partições que lhe deram origem. A maioria dos índices de validação externos pode ser utilizada para medir tal similaridade, como mostrado na Seção 2.5.1. Contudo, o método mais utilizado na literatura para calcular tal similaridade é a informação mútua normalizada (NMI, do inglês Normalized Mutual Information) que consiste em uma medida estatística simétrica capaz de quantificar a informação comum entre duas distribuições (Strehl \& Ghosh, 2002b). Essa medida é dada pela Equação (5.7), estimada entre duas partições $\pi_{a}$ e $\pi_{b}$.

$$
\phi^{(N M I)}\left(\pi^{a}, \pi^{b}\right)=\frac{\sum_{h=1}^{k^{a}} \sum_{l=1}^{k^{b}}\left|C_{h}^{a} \cap C_{l}^{b}\right| \log \left(\frac{n_{o}\left|C_{h}^{a} \cap C_{l}^{b}\right|}{\left|C_{h}^{a}\right|\left|C_{l}^{b}\right|}\right)}{\sqrt{\left(\sum_{h=1}^{k^{a}}\left|C_{h}^{a}\right| \log \left(\frac{\left|C_{h}^{a}\right|}{n_{o}}\right)\right)\left(\sum_{l=1}^{k^{b}}\left|C_{l}^{b}\right| \log \left(\frac{\left|C_{l}^{b}\right|}{n_{o}}\right)\right)}}
$$

em que $k^{a}$ e $k^{b}$ são os números de grupos das partições $\pi_{a}$ e $\pi_{b}$, respectivamente, $C_{h}^{a}$ é o $h$-ésimo grupo de $\pi_{a}, C_{l}^{b}$ é o $l$-ésimo grupo de $\pi_{b}$ e $n_{o}$ é o número de objetos do conjunto de dados. 
Em um trabalho anterior (Strehl \& Ghosh, 2002a), os autores definiram a NMI com uma normalização que assume o balanceamento entre grupos. Esta normalização, que também é usada por Fred \& Jain (2005), utiliza média aritmética e assume entropia máxima causada pelo balanceamento perfeito. Porém, em Strehl \& Ghosh (2002b), os autores alteram a $N M I$ de forma que não seja mais necessário considerar grupos balanceados, resultando na Equação (5.7).

Com base na medida de informação mútua entre duas partições, é definida uma medida de informação mútua entre uma partição $\pi_{i}$ e um conjunto $\Pi$ de $n_{\pi}$ partições, como a informação mútua normalizada média $(A N M I)$ (Strehl \& Ghosh, 2002b), dada pela Equação (5.8), ou a soma das informações mútuas (SNMI), dada pela Equação 5.9.

$$
\begin{gathered}
\phi^{(A N M I)}\left(\pi_{i}, \Pi\right)=\frac{1}{n_{\pi}} \sum_{q=1}^{n_{\pi}} \phi^{(N M I)}\left(\pi_{i}, \pi_{q}\right) \\
\phi^{(S N M I)}\left(\pi_{i}, \Pi\right)=\sum_{q=1}^{n_{\pi}} \phi^{(N M I)}\left(\pi_{i}, \pi_{q}\right)
\end{gathered}
$$

Muitos autores adotam maximizar a $A N M I$ ou a SNMI entre a partição consenso e as partições base como o objetivo do processo de combinação (Strehl \& Ghosh, 2002b; Topchy et al., 2003; Fred \& Jain, 2005; Tumer \& Agogino, 2008), ou seja, a partição consenso ideal é aquela cuja $\phi^{(A N M I)}$ é máxima em relação às partições base em $\Pi$. Na maior parte desses trabalhos, o número de grupos da partição consenso é fixo e deve ser escolhido previamente.

Fred \& Jain (2003) contestam a afirmação feita por Strehl \& Ghosh (2002b) de que maximizar a função dada pela Equação (5.8) pode ser uma forma adequada para estimar o valor do número de grupos mais próximo da estrutura real dos dados. Contudo, eles verificam que combinações com número de grupos próximos a esse valor tendem a ser mais robustas (Fred \& Jain, 2005), ou seja, tendem a gerar partições mais semelhantes e, portanto, com menor variância de NMI. Baseados nessa afirmação, os autores propõem o estudo da variância de $\phi^{(A N M I)}\left(\pi_{i}, \Pi\right)$, calculado por meio de pequenas perturbações em $\Pi$. Essas perturbações são obtidas por amostragens de objetos com reposição feitas a partir do conjunto de dados original (bootstrap), para cada valor de número de grupos estudado. Segundo os autores, o valor ótimo consiste no número de grupos da partição consenso de menor variância obtida dentre as combinações analisadas. A variância também tem sido utilizada para identificar partições mais robustas.

\subsection{Comparações entre funções de consenso}

Como pode ser visto nas seções anteriores, existem diversas abordagens para gerar a partição consenso a partir de diferentes tipos de partições iniciais. Na literatura, alguns autores publicaram estudos comparativos evolvendo algumas destas abordagens e suas aplicações em diferentes tipos de conjuntos de dados. A maioria destes estudos se dá por 
meio de uma medida que calcula a semelhança das partições finais com as partições base ou uma estrutura conhecida ("gold standard").

Strehl \& Ghosh (2002b) comparam seus próprios algoritmos, CSPA, MCLA e HGPA, em termos de complexidade, robustez e estabilidade. Considerando particionadores de grafos/hiper-grafos lineares em relação ao número de grupos $n_{o}$, o algoritmo CSPA é o que apresenta maior complexidade, $O\left(n_{o}^{2} \cdot k \cdot n_{\pi}\right)$, seguido pelo algoritmo $H G P A$ com complexidade $O\left(n_{o} \cdot k^{2} \cdot n_{\pi}^{2}\right)$ e $M C L A$ com complexidade $O\left(n_{o} \cdot k \cdot n_{\pi}^{2}\right)$. Os experimentos feitos pelos autores para obter o $N M I$ (Equação (5.7)) e ANMI (Equação (5.8)) de partições consenso oriundas de dados com ruído mostram que o algoritmo HGPA tem a pior performance. Em relação ao $A N M I$, os algoritmos CSPA e MCLA apresentaram performance semelhante em meio a pouco ruído, apesar do algoritmo CSPA se destacar em meio a grandes quantidades de ruído. Porém, o $M C L A$ apresenta melhor $N M I$ em boa parte dos conjuntos de dados.

Fred \& Jain (2005) comparam os algoritmos propostos em (Strehl \& Ghosh, 2002b) com algoritmos que utilizam agrupamento hierárquico sobre matrizes de co-associação. Segundo os autores, as matrizes de co-associação representam o acúmulo de evidência oriundo do conjunto de partições utilizado para gerá-la. Os autores executam experimentos com conjuntos de dados artificiais e das áreas de bioinformática e segmentação de imagens. Houve grande variação em relação a taxa de erros obtida para cada algoritmo nos diferentes conjunto de dados, em relação à estrutura conhecida. Em alguns casos, as abordagens baseadas em grafos obtiveram menores erros, porém as abordagens baseadas em acúmulo de evidência obtiveram melhores resultados para a maioria dos conjuntos.

Nos experimentos apresentados em (Fern \& Brodley, 2004), os autores observaram que sua abordagem, o HBGF, apresentou um desempenho equivalente ou superior ao obtido pelas abordagens de Strehl \& Ghosh (2002b). Hu et al. (2006) comparam o desempenho dos mesmos algoritmos por meio de componentes gerados a partir de agrupamentos hipoteticamente verdadeiros criados por rotulação aleatória. Vários testes foram realizados com esses algoritmos e, em relação ao valor do índice $A R$ (Hubert \& Arabie, 1985), o $M C L A$ obteve resultados ligeiramente melhores. No entanto, os resultados obtidos pelos três algoritmos foram próximos, com casos particulares em que cada um se destaca mais.

Outro trabalho que merece destaque foi publicado por Kuncheva et al. (2006), em que partições base geradas por $k$-médias e algoritmos hierárquicos são utilizadas para gerar matrizes de co-associação. As partições consenso são geradas a partir de seis metodologias distintas: particionamento por $k$-médias sobre matriz de co-associação; particionamento por ligação simples usando a matriz de co-associação como matriz de similaridade; particionamento por ligação simples sobre matriz de co-associação; particionamento por ligação média sobre a matriz de co-associação; os algoritmos CSPA e HGPA. Cem combinações de dez partições foram executadas para cada algoritmo de agrupamento e função de consenso, para 24 conjuntos de dados artificiais e obtidos de dados clínicos médicos. Os resultados foram avaliados por meio da acurácia de classificação e do índice Rand Ajustado e posi- 
cionados em um rank segundo comparações estatísticas feitas com o teste ANOVA. Os melhores resultados foram obtidos por combinações feitas pela aplicação de $k$-médias ou ligação média na matriz de co-associação, geradas a partir de partições base obtidas por meio de $k$-médias. Para estes resultados, o algoritmo de agrupamento é aplicado sobre a matriz de co-associação como se esta fosse composta por objetos. É importante frisar que, dentre os algoritmos propostos por Strehl \& Ghosh (2002b), o único algoritmo não comparado por Kuncheva et al. (2006) foi o $M C L A$, que é justamente o algoritmo que obteve o melhor desempenho em (Strehl \& Ghosh, 2002b).

O trabalho publicado por Souto et al. (2006) compara funções de consenso baseadas em ligação simples sobre matriz de co-associação, renumeração seguido de votação e particionamento de grafos ( $C S P A, H G P A$ e $M C L A)$. Os experimentos utilizam dados de expressão gênica e a avaliação dos resultados foi feita por meio do índice $A R$, tanto para medir precisão, em relação às partições conhecidas, quanto diversidade, em relação às partições obtidas. Porém, a avaliação difere de outros autores por utilizarem validação cruzada com 10 folds, um processo de validação bastante conhecido em classificação supervisionada porém pouco utilizado em classificação não supervisionada. Esse processo consiste em dividir dos dados em 10 folds, de forma que agrupamentos base fossem gerados a partir do conteúdo de 9 desses folds, considerados como conjunto de treinamento. Partições consenso são obtidas a partir dos agrupamentos base e o fold restante, considerado como conjunto de teste, é utilizado para medir a precisão dos agrupamentos encontrados. Os dados do fold de teste são classificados a partir do centróide mais próximo e a partição resultante é comparada com a partição conhecida por meio do índice $A R$. O processo é repetido 10 vezes, permutando os papéis de cada fold. As partições iniciais foram geradas com os algoritmos $k$-médias, EM e agrupamento hierárquico com ligação média. De forma geral, não foi encontrada diferença significativa entre as funções de consenso estudadas, com exceção da aplicação de ligação simples sobre a matriz de co-associação que frequentemente resultou em um pior desempenho, diferentemente do relatado por outros autores anteriormente citados.

Tumer \& Agogino (2008) comparam seu algoritmo de votação, o $V A C$, com os algoritmos de particionamento de grafos CSPA, HGPA e MCLA e a otimização gulosa de Strehl \& Ghosh (2002b). A comparação levou em consideração a NMI das partições consenso resultantes e destacou o desempenho do $V A C$ e do $M C L A$ em relação aos outros algoritmos. Porém, é importante lembrar que, diferentemente dos outros algoritmos comparados, o $V A C$ utiliza a $N M I$ para guiar o processo de construção da partição consenso, o que pode priveligiar o algoritmo neste tipo de avaliação. Nesse trabalho, não são considerados outros tipos de avaliação.

De forma geral, diferentes autores obtiveram resultados distintos com as mesmas funções de consenso. Dentre as causas podem ser citados os diferentes métodos para gerar as partições iniciais, métodos de experimentação distintos e as características desiguais da estrutura dos diferentes conjuntos de dados utilizados pelos autores. Um ponto comum 
entre boa parte das análises foi o desempenho relativamente bom do algoritmo $M C L A$ e do particionamento de matrizes de co-associação.

\subsection{Combinações de agrupamentos e AEs}

Por trabalharem com conjuntos de agrupamentos, AEs são comumente utilizados em combinações, especialmente para gerar partições base. Por um lado, o AE pode ser usado para aprimorar as partições base por meio do processo evolutivo, o que pode resultar em uma partição consenso de melhor qualidade. Por outro lado, a combinação de agrupamentos pode ser utilizada como operador evolutivo de recombinação, de forma a evitar problemas de insensibilidade ao contexto (discutidos no Capítulo 3).

Como discutido na Seção 5.2, é preciso garantir algum nível de diversidade na geração dos agrupamentos base. Em casos em que AEs são utilizados para gerar estas partições, algum método deve ser utilizado com a finalidade de garantir esta diversidade. Com esta finalidade, boa parte dos autores que desenvolveram AEs para combinar agrupamentos utilizam técnicas multi-objetivo. Neste tipo de AE, os agrupamentos não são aprimorados segundo um único objetivo, mas um conjunto deles, o que pode efetivamente gerar a diversidade inicial necessária.

Em um típico AE para combinação, uma população especial é inicializada por partições formadas por alguma técnica de diversidade, como as descritas na Seção 5.2. Em seguida, os agrupamentos são aprimorados durante a execução do AE, que pode ser multi-objetivo ou não. Os agrupamentos resultantes são combinados por meio de uma função de consenso, como as discutidas na Seção 5.3.

Um exemplo de combinação de agrupamentos evolutivos com algoritmos multiobjetivos é o MOCLE (do inglês Multi-Objective Clustering Ensemble) (Faceli, 2006). A autora realiza experimentos com dois obtivos: reduzir a variância entre grupos e conectividade entre objetos. Dois algoritmos evolutivos multi-objetivos populares foram investigados: o SPEA (do inglês Strength Pareto Evolutionary Algorithm) (Zitzler \& Thiele, 1999) e o NSGA-II (do inglês Nondominated Sorting Genetic Algorithm ) (Deb et al., 2002) e opta pelo segundo. O algoritmo proposto por Deb et al. (2002) é mais eficiente, computacionalmente, que a versão anterior $(N S G A)$, pois utiliza elitismo e implementa um operador de povoamento ("crowding") que mantém a diversidade sem a necessidade de parâmetros adicionais.

A codificação utilizada consiste de um vetor de conjuntos que, por sua vez, representam os grupos que formam a partição. Os objetos, representados pela suas posições no conjunto de dados $X$, estão contidos no conjunto que representa o grupo a que eles pertencem, semelhante à codificação utilizada por Ma et al. (2006). Isto evita problemas com ambiguidade de rotulação entre partições. A população inicial é composta por agrupamentos gerados por vários algoritmos, com variação em seus parâmetros. A cada iteração, o algoritmo seleciona as soluções com os melhores valores para as funções obje- 
tivo e aplica operadores evolutivos para formar novas soluções para a próxima geração. Durante a execução do operador de cruzamento, são utilizadas as funções de consenso $M C L A$ e $H B F G$, descritas na Seção 5.3.3.

O algoritmo RGFGA (do inglês Restricted Growth Function Genetic Algorithm) (Swift et al., 2007) é um exemplo de AE que combina partições. As partições base são geradas por um conjunto de algoritmos de agrupamento ( $k$-médias, $P A M$, hierárquicos e outros). Ele é baseado em uma função de crescimento restrita, utilizada para agrupar os objetos em subconjuntos mutuamente exclusivos a partir da função de aptidão. Ela também permite o uso de operadores especiais de recombinação e mutação.

Na tentativa de ampliar ainda mais a diversidade das partições iniciais, Hadjitodorov \& Kuncheva (2007) propõem o uso simultâneo de vários dos métodos apresentados na Seção 5.2 para gerar diversidade. Com este objetivo, os autores desenvolveram um AE para buscar o melhor conjunto de métodos a serem aplicados para gerar as partições base. Cada método é representado por um bit no cromossomo utilizado, de forma que o valor 1 indica o uso do método e 0 o seu desuso. Outros parâmetros como o número de partições e o número de grupos a serem gerados também são representados nesta codificação, apesar do algoritmo não estimar o melhor número de grupos para a partição consenso.

\subsection{Considerações finais}

Neste capítulo foram apresentadas metodologias utilizadas para combinar agrupamentos propostas na literatura, incluindo formas de gerar a diversidade inicial necessária para partições base. Foram discutidas comparações entre as metodologias apresentadas e uma breve revisão sobre o uso de AEs em conjunto com a combinação de agrupamentos.

Na Seção 5.2, é mostrado ser desejável que as partições base a serem combinadas possuam determinadas características de interesse como, por exemplo, qualidade e diversidade. Entretanto, após a construção de partições base, a grande maioria dos trabalhos combina todas as partições geradas em uma partição consenso. Nem sempre esse método é o mais interessante, pois algumas partições base podem possuir baixa qualidade, o que pode afetar a combinação final. Por esse motivo, alguns autores propuseram a seleção de um subconjunto de partições de interesse dentre as partições base obtidas, assunto a ser discutido no próximo capítulo. Índices de validação podem ser utilizados diretamente na seleção de partições base, visando aprimorar a qualidade da partição consenso. Adicionalmente, os próprios índices de validação podem ser combinados para gerar uma avaliação mais robusta a mudanças no cenário de aplicação, especialmente quando o desempenho desses índices não é conhecido. Uma investigação sobre a aplicação de índices de validação em conjunto com a combinação de agrupamentos é apresentada no Capítulo 6. 


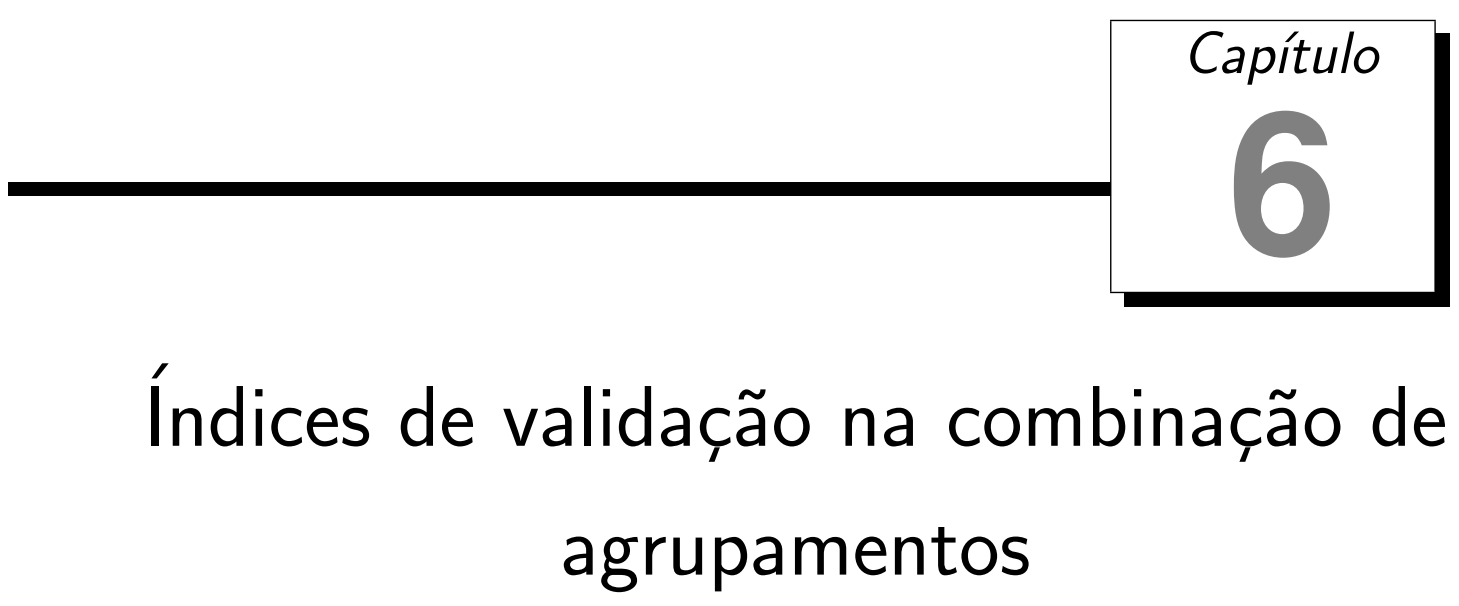

No Capítulo 5, foi mostrado que combinações de agrupamentos são populares na comunidade de mineração de dados, por obterem um agrupamento que represente o consenso entre um conjunto de soluções. Os objetivos da combinação vão de obter uma maior robustez a variações do cenário de aplicação, permitir a reutilização de um conhecimento existente sobre os dados, ou ainda permitir o agrupamento de dados distribuídos. Também foi mostrado que a combinação de agrupamentos é composta por dois passos principais: produzir um conjunto de agrupamentos base e combiná-lo em uma solução final por meio de uma função de consenso. Entretanto, a grande maioria dos trabalhos combina todas as partições produzidas em uma partição consenso. Isso nem sempre é interessante, pois partições base de baixa qualidade não refletem a estrutura dos dados e podem afetar a qualidade da combinação final.

Por esse motivo, alguns autores propuseram técnicas para aumentar a diversidade e qualidade das partições base por meio da seleção de um subconjunto de partições base entre todas as obtidas (Fern \& Lin, 2008; Azimi \& Fern, 2009). Estas técnicas são conhecidas como seleção de partições base (CES - do inglês Cluster Ensemble Selection) e sua finalidade principal é gerar uma combinação de um subconjunto de partições base que execute tão bem ou melhor do que combinações baseadas no uso do conjunto completo de partições base. Elas obtiveram uma melhoria de desempenho significativa, muitas vezes por uma margem substancial, em relação à combinação total e frequentemente superam até mesmo a melhor partição combinada.

Como mostrado na Seção 2.5, índices de validação têm sido utilizados com sucesso há décadas para avaliar quantitativamente a qualidade relativa entre agrupamentos. Neste 
capítulo é apresentada uma das principais contribuições da tese, a investigação sobre a utilização de índices de validação em $C E S$ para aprimorar a qualidade da partição consenso. Adicionalmente, também é proposto o uso combinado de índices de validação com o objetivo de gerar uma avaliação mais robusta a mudanças no cenário de aplicação, especialmente quando o desempenho desses índices não é conhecido para um cenário de interesse.

Este capítulo possui a seguinte divisão: na Seção 6.1, é feita uma revisão sobre trabalhos que propõem e motivam o uso de $C E S$, apresentando as diferenças que estes trabalhos possuem em relação aos métodos propostos neste capítulo. Em seguida, na Seção 6.2, são descritos os conjuntos de dados utilizados para avaliar experimentalmente os métodos propostos. Esses conjuntos de dados são utilizados nos experimentos apresentados na Seção 6.3, que envolvem o uso de índices de validação relativos aplicados individualmente em $C E S$. Métodos para combinar os índices de validação relativos estudados são investigados na Seção 6.4. A partir da análise dos resultados obtidos, foi possível propor um arcabouço para guiar o uso CES no processo de combinação de agrupamentos na Seção 6.5. Por último, as considerações finais do capítulo são apresentadas na Seção 6.6.

\subsection{Motivação}

Vários trabalhos da literatura sugerem que a diversidade e qualidade do conjunto de partições base são cruciais para o sucesso da combinação de agrupamentos. Kuncheva \& Hadjitodorov (2004) propuseram a utilização de partições base com maior número de grupos como um método para melhorar a diversidade da combinação de agrupamentos. Com base nos resultados, os autores observaram que combinações com alta diversidade tendem a ser mais precisas do que combinações de pouca diversidade. Posteriormente, Hadjitodorov et al. (2006) afirmam que a qualidade da combinação não cresce monotonicamente com a diversidade entre partições base e, portanto, sugerem a utilização de combinações de partições com diversidade média.

No paradigma supervisionado, trabalhos mostram que a seleção de um subconjunto de classificadores baseada na qualidade e na diversidade pode obter resultados semelhantes ou melhores do que o uso de todo o conjunto (Margineantu \& Dietterich, 1997; Caruana et al., 2006). Inspirados nesses trabalhos, Fern \& Lin (2008) propuseram o uso da qualidade e diversidade na seleção de partições base para aprimorar o resultado de combinações de agrupamentos. Essa seleção é baseada no NMI (Seção 5.4) entre uma determinada partição e os membros de um conjunto de partições. Segundo Strehl \& Ghosh (2002b), quanto maior o valor entre uma partição final e o conjunto de partições base que a originou, maior a qualidade da combinação. Em Fern \& Lin (2008), a qualidade de uma partição é proporcional à sua SNMI (Equação 5.9) em relação ao conjunto de partições base, enquanto a sua diversidade é inversamente proporcional à sua $N M I$ em relação ao conjunto de partições selecionadas. Os resultados obtidos por Fern \& Lin (2008) indicam que 
considerar explicitamente a qualidade e diversidade no processo de $C E S$ pode obter uma melhoria significante na performance, em comparação com a combinação de todas as partições bases.

Recentemente, Azimi \& Fern (2009) investigaram o uso de CES no aprimoramento de combinações que geram partições finais muito dissimilares às partições base. Segundo os autores, esse tipo de combinação é instável e tende a gerar partições de baixa qualidade. Como uma possível solução para esse problema, eles propõem a seleção das partições base que mais se assemelhem à partição final gerada pela combinação de todas as partições base. Os resultados obtidos mostram que a combinação das partições base selecionadas aprimora a qualidade da partição final, frequentemente acima das melhores partições base.

É importante notar que, apesar desses trabalhos apresentarem investigações cientificamente rigorosas, seus resultados são oriundos de uma ou duas funções de consenso aplicadas em menos de uma dúzia de conjuntos de dados, o que representa uma pequena parte das funções de consenso propostas na literatura (Strehl \& Ghosh, 2002b; Dimitriadou, 2003; Kuncheva et al., 2006; Tumer \& Agogino, 2008). Adicionalmente, medidas de qualidade baseadas em NMI são capazes de mensurar o quão similar uma partição é em relação a um conjunto de partições (Halkidi et al., 2001), mas não são capazes de mensurar diretamente características desejáveis a uma partição como, por exemplo, quão compactos e bem separados são os seus grupos.

Como mostrado na Seção 2.5, índices de validação relativos têm sido utilizados com sucesso há décadas para avaliar quantitativamente a qualidade relativa entre agrupamentos (Milligan \& Cooper, 1985; Halkidi et al., 2001; Vendramin et al., 2009, 2010). Portanto, eles poderiam ser usados diretamente em $C E S$, o que, até onde é conhecimento do autor desta tese, nenhum trabalho anterior investigou. Entretanto, os índices de validação são dotados de características particulares que podem fazer com que determinados índices sejam capazes de superar os demais em classes de problemas específicas. Assim, pode ser uma tarefa difícil para o usuário escolher um índice específico entre tal variedade de possibilidades. Essa tarefa se torna mais árdua à medida que novos índices têm sido propostos ao longo do tempo. Adicionalmente, o uso de um único índice de validação em $C E S$ pode fazer com que as partições base selecionadas apresentem características semelhantes, o que reduz a diversidade do conjunto seleção.

Uma solução possível, para problemas associados à escolha e utilização de um único índice, consiste em combinar as avaliações resultantes de um conjunto de índices de validação relativos em um único resultado. A idéia principal por trás da Combinação de Índices Relativos (CIR) é a obtenção de uma avaliação robusta às alterações no cenário de aplicação, na expectativa de que a maioria dos índices combinados compensem um eventual desempenho fraco do restante. Conforme será mostrado na Seção 6.4, a CIR pode gerar uma avaliação mais robusta às características de cenários de aplicação distintos. Quando aplicada em CES, a CIR pode gerar conjuntos mais diversificados do que o uso de um índice de validação individualmente, pois considera avaliações de diferentes 
índices de validação.

\subsection{Conjuntos de dados}

Para avaliar experimentalmente as metodologias propostas neste capítulo, três grandes conjuntos de bases de dados artificiais foram selecionados para este trabalho. Cada um destes grandes conjuntos contém dezenas de bases de dados geradas artificialmente por meio de metodologias conhecidas na literatura. O primeiro grande conjunto de bases de dados foi gerado por Vendramin et al. (2010) a partir da metodologia proposta por Milligan \& Cooper (1985). Às bases geradas são permitidas sobreposições em todas as dimensões, exceto a primeira. A distribuição espacial dos objetos intra-grupo segue uma distribuição normal multivariada truncada. Isto faz com que a estrutura gerada contenha grupos naturais que exibem as propriedades de separação externa e coesão interna. As principais características das bases de dados desse conjunto são:

- Cada base de dados contém $n_{o}=500$ objetos;

- Todos os grupos são disjuntos (sem sobreposição na primeira dimensão) com distribuições Gaussianas (que podem ser levemente elipsoidais);

- Variedade em relação ao número de grupos $k \in\{2,4,6,12,14,16\}$;

- Para cada valor de $k$, o número de atributos assume os valores $n_{a} \in$ $\{2,3,4,22,23,24\}$;

- Três métodos de divisão dos objetos entre grupos são utilizados:

- Objetos divididos uniformente entre os grupos;

- Um grupo sempre contém 10\% dos objetos;

- Um grupo sempre contém $60 \%$ dos objetos se $k \in\{2,4,6\}$. Caso contrário, contém $20 \%$.

- Para cada combinação das características acima foram geradas três instâncias, produzindo um total de 324 bases de dados.

O conjunto composto pelas 324 base de dados será referenciado aqui como Artificial1 e maiores detalhes sobre sua construção podem ser obtidos em (Vendramin et al., 2010). Além dele, dois conjuntos de bases de dados artificiais analisados em (Handl \& Knowles, 2007) foram selecionados por possuírem as seguintes características:

- Diferentes geradores: O primeiro conjunto de dados é formado a partir de distribuições Gaussianas e será chamado de Artificial2. Os grupos desse conjunto possuem maior variância em uma direção arbitrária e, portanto, são alongados. Entretanto, o método utilizado para gerar o conjunto Artificial2 faz com que a forma dos grupos 
tenda a tornar-se hiperesférica em alta dimensionalidade $\left(n_{a}>10\right)$. Isso ocorre porque a alta variância em uma dimensão dificilmente afeta o cálculo da distância Euclidiana entre pontos com grande número de dimensões (Handl \& Knowles, 2007). Por este motivo, os autores desenvolveram um gerador de grupos elipsoidais de alta dimensionalidade e o utilizaram para gerar o segundo conjunto de dados, aqui chamado de Artificial3. Ambos os conjuntos possuem grupos sobrepostos, ao contrário do que ocorre no Artificial1.

- Variedade em relação ao número de grupos, com $k=\{4,10,20,40\}$;

- Diferentes números de objetos: Os grupos são formados com distribuição uniforme de número de objetos no intervalo [50,500], para bases com $k=\{4,10\}$, e $[10,100]$ para bases com $k=\{20,40\}$.

- Diversidade em relação ao número de atributos, sendo que o conjunto Artificial2 foi gerado com 2 e 10 atributos e o conjunto Artificials foi gerado com 50 e 100 atributos;

- Para cada combinação de número de grupos e atributos foram geradas 10 amostras, totalizando 80 bases de dados para cada conjunto.

Conjuntos de dados reais também foram selecionados para esse experimento, de forma que a grande maioria foi utilizada em trabalhos da área (Azimi \& Fern, 2009; Fern \& Lin, 2008; Hadjitodorov et al., 2006). Quatro deles foram obtidos do repositório da UC Irvine (Asuncion \& Newman, 2007) sendo eles: Iris Data Set (Fisher, 1936), Wine Data Set (Aeberhard et al., 1992), Breast Cancer Wisconsin Data Set sem os 16 objetos com atributos faltantes (Mangasarian \& Wolberg, 1990) e Synthetic Control Chart Time Series Data Set (Alcock \& Manolopoulos, 1999). O último conjunto utilizado aqui é conhecido como Yeast Data Set e foi utilizado em Yeung et al. (2003). A Tabela 6.1 apresenta as principais características desses conjuntos de dados.

\begin{tabular}{|c|c|c|c|c|c|}
\hline Nome & Objetos $\left(n_{o}\right)$ & Atributos $\left(n_{a}\right)$ & Classes $\left(k^{*}\right)$ & Menor Classe & Maior Classe \\
\hline Iris & 150 & 4 & 3 & 50 & 50 \\
\hline Wine & 178 & 13 & 3 & 48 & 71 \\
\hline Breast & 683 & 9 & 2 & 239 & 444 \\
\hline Chart & 600 & 60 & 6 & 100 & 100 \\
\hline Yeast & 205 & 20 & 4 & 14 & 93 \\
\hline
\end{tabular}

Tabela 6.1: Características dos conjuntos de dados reais utilizados.

As classes conhecidas de conjunto de dados reais nem sempre formam grupos ideais, compactos e bem separados. O conjunto Iris, por exemplo, possui duas classes sobrepostas (virginica, versicolor), enquanto a terceira é bem separada das outras. Apesar disso, as classes conhecidas serão consideradas como a estrutura de grupos conhecida ou de referência ("gold standard") para fins dos experimentos apresentados neste capítulo. 


\subsection{Uso individual de índices em CES}

Motivado pelos argumentos presentes na Seção 6.1, foi estudado o uso de índices de validação na seleção de partições base. Os índices escolhidos para tal estudo foram: as versões simplificada e modificada simplificada do índice silhueta (Seção 2.5.2.5); o índice $V R C$ (Seção 2.5.2.1); o índice PBM (Seção 2.5.2.4); a variante do índice Dunn que utiliza a discordância entre grupos dada pela Equação (2.42) e cálculo da dispersão dada pela Equação (2.46) (Seção 2.5.2.3); e o índice DB (Seção 2.5.2.2). Esses índices são considerados de interesse para este trabalho pois possuem tempo computacional de complexidade linear em relação ao número de objetos e são capazes de discriminar entre partições de boa qualidade e partições ruins geradas em bases de dados de interesse (Vendramin et al., 2009, 2010). Contudo, quaisquer índices de validação relativos poderiam ser utilizados.

Adicionalmente ao uso de índices de validação, investigamos o uso explícito da diversidade em CES com base nas metodologias propostas em (Hadjitodorov et al., 2006; Fern \& Lin, 2008; Azimi \& Fern, 2009). Hadjitodorov et al. (2006) medem a diversidade entre um conjunto de partições por meio da média da dissimilaridade entre pares de partições, ou seja, comparando as partições do conjunto duas a duas por meio do índice externo Rand Ajustado (Seção 2.5.1.3). Uma metodologia semelhante é utilizada em (Fern \& Lin, 2008; Azimi \& Fern, 2009), porém a medida NMI (Seção 5.4) é utilizada para comparar as partições do conjunto. Tanto em (Hadjitodorov et al., 2006), como em (Fern \& Lin, 2008; Azimi \& Fern, 2009), o mesmo índice utilizado para calcular diversidade entre partições foi utilizado para avaliar a qualidade das partições consenso obtidas nos experimentos. Neste trabalho, a medida de diversidade entre uma partição $\pi_{i}$ e um conjunto de partições $\Pi$ é representada pela Equação (6.1):

$$
\operatorname{diversidade}\left(\pi_{i}, \Pi\right)=1-\sum_{\pi_{j} \in \Pi, j \neq i} \frac{s\left(\pi_{i}, \pi_{j}\right)}{|\Pi|-1}
$$

em que $|\cdot|$ representa cardinalidade e $s\left(\pi_{i}, \pi_{j}\right)$ é a similaridade entre as partições $\pi_{i}$ e $\pi_{j}$. Um meio de calcular $s\left(\pi_{i}, \pi_{j}\right)$ consiste em utilizar um índice de validação externo, como os apresentados na Seção 2.5.1. É possível calcular o valor da diversidade de um conjunto de partições $\Pi$ por meio da diversidade média entre suas partições, dada pela Equação $(6.2)$ :

$$
\text { diversidade }(\Pi)=\sum_{\pi_{i} \in \Pi} \frac{\text { diver sidade }\left(\pi_{i}, \Pi\right)}{|\Pi|}
$$

Por ser um índice bem conhecido na literatura, resultar em valores no intervalo $[0,1]$ e calcular a similaridade entre partições valorizando unicamente pares de objetos que estão em um mesmo grupo (o que não ocorre com todos os índices externos, como pode ser visto na Seção 2.5.1), optamos por utilizar o índice externo de Jaccard para medir a qualidade das partições resultantes dos experimentos feitos em todos os capítulos desta tese. Para manter a consistência com o resto do trabalho, utilizamos o índice externo de Jaccard 
(Jaccard, 1908) neste capítulo, tanto para avaliar o resultado dos experimentos, como para obter a similaridade entre partições e calcular as diversidades dadas pelas Equações (6.1) e (6.2). Como os valores resultantes do índice de Jaccard encontram-se no intervalo $[0,1]$, os valores resultantes das Equações (6.1) e (6.2) também estão neste intervalo. É importante notar que, apesar do índice externo de Jaccard ser usualmente utilizado para comparar as partições obtidas com a estrutura conhecida dos dados ("gold standard"), nenhum conhecimento externo ao conjunto de partições base é utilizado no cálculo da diversidade ou nos métodos de CIR e CES propostos neste trabalho.

Para cada base de dados contida nos conjuntos Artificial1, Artificial2 e Artificial3, $n_{\pi}$ partições base com diferentes protótipos foram geradas pelo algoritmo $k$-médias para cada valor de $k$ no intervalo $\left[2, \sqrt{n_{o}}\right]$. Esta estratégia garante um número de partições base proporcional ao número de objetos contidos nas bases de dados, $\sqrt{n_{o}}$, ao mesmo tempo que esse intervalo contém o número de grupos a ser estimado ou conhecido das bases de dados estudadas.

A escolha dos valores de $n_{\pi}$ deve ser feita com cautela, pois valores baixos de $n_{\pi}$ podem não ser suficientes para gerar a diversidade necessária para alguns tipos de combinação de agrupamentos. Em contrapartida, valores altos de $n_{\pi}$ podem gerar a necessidade de grande quantidade de memória. Neste trabalho, $n_{\pi}$ foi escolhido de forma a gerar grandes conjuntos de partições que possibilitem aos experimentos não ultrapassar a quantidade de memória disponível. Para isso, $n_{\pi}=10$ é utilizado em experimentos envolvendo o Artificial1 e $n_{\pi}=5$ para os que envolvem os Artificial2 e Artificial3. Experimentos com $n_{\pi}=10$ não puderam ser executados com todos os conjuntos de dados e funções de consenso estudadas neste trabalho devido ao limite de memória disponível. Entretanto, o comportamento dos métodos de CES investigados é análogo para ambos os valores de $n_{\pi}$, o que pode ser visto por meio da análise feita no Apêndice desta tese.

A partir deste ponto, o conjunto de todas as partições geradas para uma determinada base de dados será chamado de conjunto total $\left(\Pi_{t}\right)$ e sua combinação será referenciada como combinação total (equivalente ao termo em inglês full ensemble). Adicionalmente, o subconjunto formado por partições base selecionadas será chamado de conjunto seleção $\left(\Pi_{s}\right)$ e sua combinação referenciada como combinação parcial.

Como os experimentos apresentados nesta seção são aplicados em conjuntos de dados artificiais, cujos grupos são conhecidos, é possível avaliar o desempenho dos índices de validação relativos escolhidos. Por meio dessa avaliação é possível determinar se as partições base selecionadas por esses índices aproximam-se do agrupamento conhecido dos dados. Essa avaliação é apresentada na Seção 6.3.1, onde a correlação entre os índices relativos escolhidos e o índice externo de Jaccard é medida para as partições bases obtidas. Entretanto, aplicações práticas de técnicas de agrupamento não objetivam encontrar um agrupamento conhecido do conjunto de dados, mas sim obter um agrupamento inédito que faça sentido para o conjunto. Por isso, essa avaliação não objetiva aplicações práticas, mas auxiliar na análise dos experimentos apresentados neste capítulo. 


\subsubsection{Correlação entre índices relativos e externo}

Diferentemente de uma aplicação prática, neste trabalho é possível analisar como é o comportamento dos índices de validação relativos escolhidos ao avaliar as partições base obtidas, o que pode auxiliar na análise dos resultados dos experimentos apresentados no restante do capítulo. É esperado que um índice de validação relativo apropriado mensure a qualidade da uma partição de maneira análoga a um índice externo, ou seja, retorne bons valores para partições próximas da estrutura dos dados e valores ruins para partições que não se aproximam dessa estrutura. O nível de concordância entre os valores obtidos pelo índice relativo e o externo podem ser facilmente calculados por meio de um índice de correlação (Vendramin et al., 2009). A correlação entre os valores dos índices de validação relativos e do índice externo Jaccard foi medida aqui por meio da correlação de Pearson (Seção 2.3.2) e as médias e desvios padrões obtidos para cada índice são apresentadas na Tabela 6.2. Esses valores de validação foram obtidos a partir da avaliação das partições base geradas conforme descrição feita na Seção 6.3. É importante lembrar que, ao contrário dos outros índices relativos escolhidos, o valor resultante do índice $D B$ decresce com a qualidade da partição avaliada.

\begin{tabular}{|l|c|c|c|c|c|c|}
\hline & Silhueta S. & Silhueta M.S. & VRC & PBM & Dunn & $D B$ \\
\hline Artificial1 & $0,8443(0,09)$ & $0,8576(0,08)$ & $0,5412(0,27)$ & $0,6954(0,19)$ & $-0,0013(0,55)$ & $-0,5048(0,22)$ \\
\hline Artificial2 & $0,8699(0,07)$ & $0,8575(0,09)$ & $0,6139(0,33)$ & $0,127(0,69)$ & $-0,0767(0,64)$ & $-0,5172(0,17)$ \\
\hline Artificial3 & $0,5851(0,15)$ & $0,7923(0,06)$ & $0,6083(0,22)$ & $-0,1123(0,58)$ & $-0,0906(0,57)$ & $-0,0907(0,13)$ \\
\hline
\end{tabular}

Tabela 6.2: Média e desvio padrão das correlações entre os valores dos índices de validação relativos e do índice Jaccard sobre os conjuntos de dados artificiais estudados.

Os resultados da Tabela 6.2 mostram que os índices baseados em silhueta e VRC apresentam alta correlação com índice Jaccard, para partições base geradas pelo algoritmo $k$-médias sob as condições descritas na Seção 6.3. Apesar de o índice PBM possuir um valor de correlação alto em média para o Artificial1, o mesmo não pode ser afirmado para os outros conjuntos estudados. O principal motivo deste comportamento se deve ao fato do índice não se comportar bem ao avaliar partições com grande número de grupos $(k \geq 20)$, em especial se os grupos forem próximos. O índice mostrou uma tendência de valorizar partições com poucos grupos de formato hiperesférico, mesmo que estas tenham sido obtidas a partir de bases de dados com grande número de grupos conhecidos. Esta tendência foi verificada nos experimentos feitos com o Artificial2 e o Artificial3 por meio da análise dos valores dos índices de validação externos das partições obtidas. O comportamento em questão não ocorre com os índices silhuetas e $V R C$, segundo os resultados obtidos. Com o objetivo de ilustrar esse comportamento, a Figura 6.1 apresenta duas partições da base de dados 2d-40c-no3 (instância de número 3 com 2 dimensões e 40 grupos) do Artificial2 selecionadas como as melhores do conjunto de partições base pelos índices PBM (a) e silhueta simplificada (b). Nela fica evidente a tendência do índice PBM de valorizar um número menor de grupos com formatos hiperesféricos, o que não ocorre com o índice silhueta simplificada, por exemplo. 


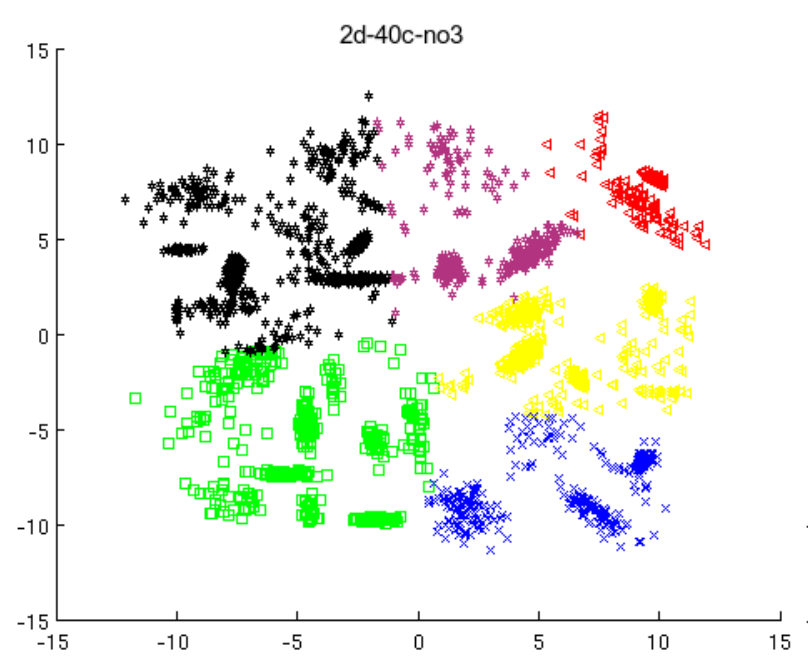

(a) Partição escolhida pelo índice PBM.

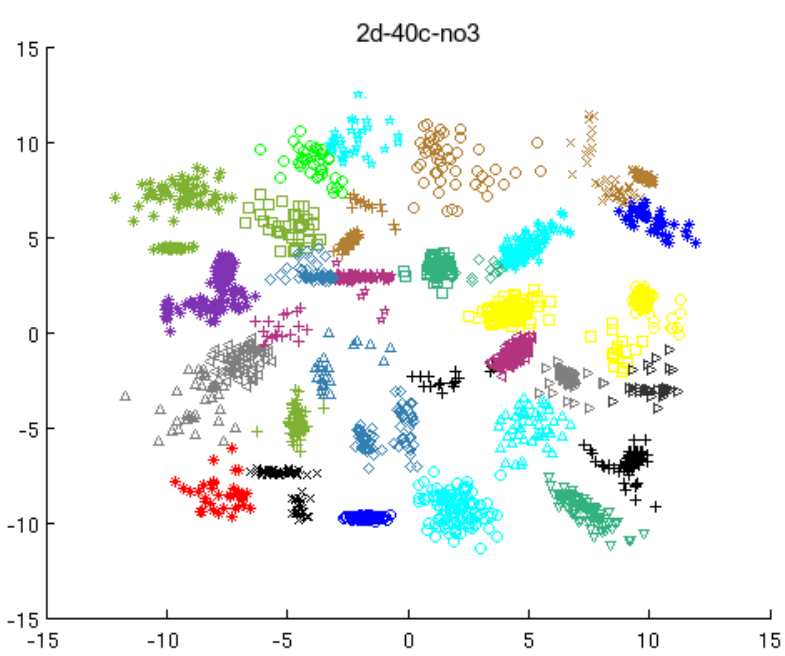

(b) Partição escolhida pelo índice silhueta simplificada.

Figura 6.1: Partições escolhidas pelos índices PBM e silhueta simplificada para a base de dados 2d-40c-no3.

O índice Dunn obteve baixa correlação média com o índice Jaccard para os três conjuntos estudados. Por último, o índice $D B$ obteve valores médios de correlação satisfatórios para o Artificial1 e o Artificial2 e insatisfatório para o conjunto Artificial3. Em todos os casos em que os índices PBM, Dunn e $D B$ resultaram em correlações com valores médios insatisfatórios, existe um alto desvio padrão destes valores, o que indica que o comportamento destes índices em relação ao índice externo é instável.

Uma questão que poderia ser levantada neste ponto da pesquisa é "porque combinar índices de validação que apresentaram avaliações insatisfatórias ou instáveis?". Como argumentado anteriormente, geralmente não se conhece previamente o desempenho de um determinado índice em aplicações práticas e, portanto, nem sempre é possível selecionar "bons" índices. Adicionalmente, uma vez que o objetivo principal do uso combinado de índices neste trabalho consiste em fazer com que a maioria dos índices combinados compense o fraco desempenho de uma minoria, não faz sentido avaliar experimentalmente uma combinação constituída unicamente de índices com bom desempenho conhecido para as partições avaliadas. Portanto, todos os índices relativos analisados serão utilizados nos experimentos, independentemente de seu desempenho.

\subsubsection{Experimentos}

Os experimentos apresentados nesta seção são divididos em duas partes. A primeira parte, apresentada na Seção 6.3.2.1, consiste em medir o desempenho dos índices investigados na avaliação dos conjuntos de partições base, gerados conforme descrição presente na Seção 6.3. Em seguida, na Seção 6.3.2.2, os conjuntos formados pela seleção de partições base são combinados e os resultados analisados. 


\subsubsection{Avaliação dos conjuntos seleção}

Uma vez gerados os conjuntos de partições base, esses foram avaliados com cada um dos índices de validação relativos escolhidos. Em seguida, conjuntos seleção com 10\%, 25\%, $50 \%$ e $75 \%$ do total de partições base geradas foram montados com as partições base melhor avaliadas para cada índice de validação relativo. A qualidade e a diversidade dos conjuntos seleção foram medidas, a primeira por meio da média dos valores do índice Jaccard das partições selecionadas em relação à partição conhecida e a segunda por meio da média da diversidade entre as partições, dada pela Equação (6.1). Os gráficos contidos nas Figuras 6.2, 6.3 e 6.4 apresentam os valores médios obtidos pelos índices relativos estudados para conjuntos seleção gerados. O eixo das abscissas indica a proporção de partições selecionadas do conjunto total, enquanto o primeiro eixo das ordenadas (à esquerda) indica os valores médios do índice Jaccard em relação à partição conhecida e de diversidade destas partições. O segundo eixo das ordenadas (à direita) indica os valores médios dos índices de validação estudados para as partições contidas nos conjuntos seleção.

Como pode ser visto nas Figuras 6.2, 6.3 e 6.4, a seleção de partições baseada em um único índice de validação relativo tende a reduzir a diversidade das partições base selecionadas. Ou seja, as partições melhor avaliadas por um único índice relativo tendem a assemelhar-se. O mesmo acontece com o índice externo de Jaccard, pois a medida que seu valor aumenta, a partição mais assemelha-se à partição conhecida e, portanto, faz com que partições com altos valores de Jaccard tendem a ser semelhantes entre si.

Dentre os índices relativos estudados, apenas a seleção feita pelo índice Dunn não resultou partições de melhor qualidade do que a média do conjunto total. As únicas bases de dados em que o índice resultou em seleções de qualidade foram obtidas para as bases de dados com 4 e 6 grupos do Artificial1, resultado que não pode ser percebido no gráfico da Figura 6.2 devido à qualidade ruim das partições selecionadas para o restante das bases de dados do conjunto. A seleção feita pelo índice PBM foi bem sucedida em formar conjuntos seleção de qualidade média acima do conjunto total apenas para o Artificial1. No Artificial2 e Artificial3, essa seleção só obteve partições de qualidade para bases de dados com poucos grupos, o que, ao considerar todas as bases, resultou em uma média próxima do conjunto total. Esses resultados refletem os resultados discutidos na Seção 6.3.1 e as correlações apresentadas na Tabela 6.2.

Adicionalmente, os valores do índice Jaccard relativos à partição conhecida foram obtidos para as partições base melhor avaliadas pelos índices de validação relativos investigados. A média e desvio padrão desses valores para cada conjunto de dados artificial estão presentes na Tabela 6.3, com a finalidade de possibilitar comparações que envolvam métodos que selecionam apenas a melhor partição base.

Os valores apresentados na Tabela 6.3 refletem os resultados mostrados nas Figuras 6.2, 6.3 e 6.4. Em resumo, utilizar índices de validação relativos individualmente em $C E S$ gera, em média e na maioria dos cenários estudados, subconjuntos de partições base com 

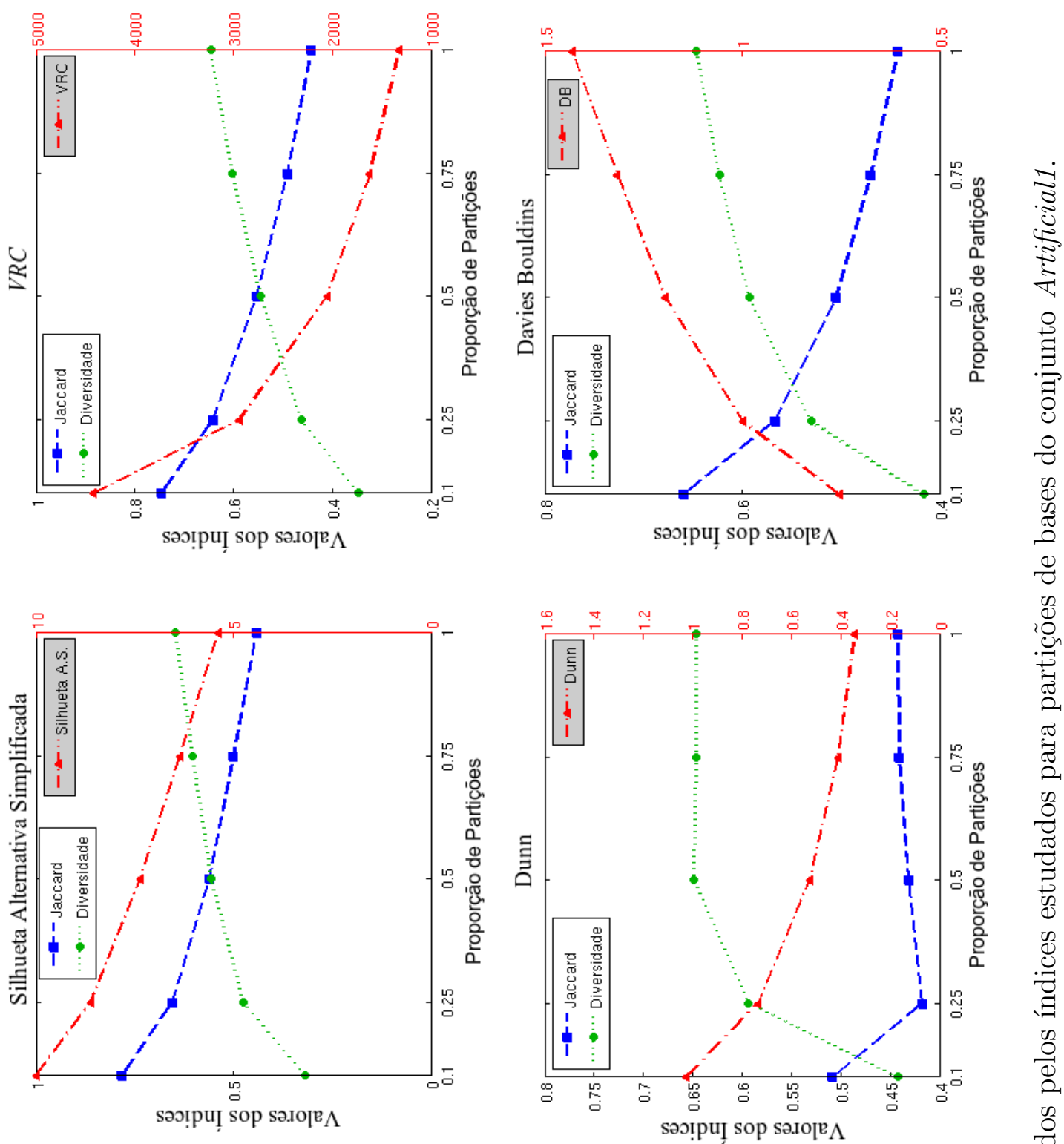

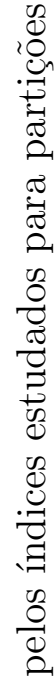
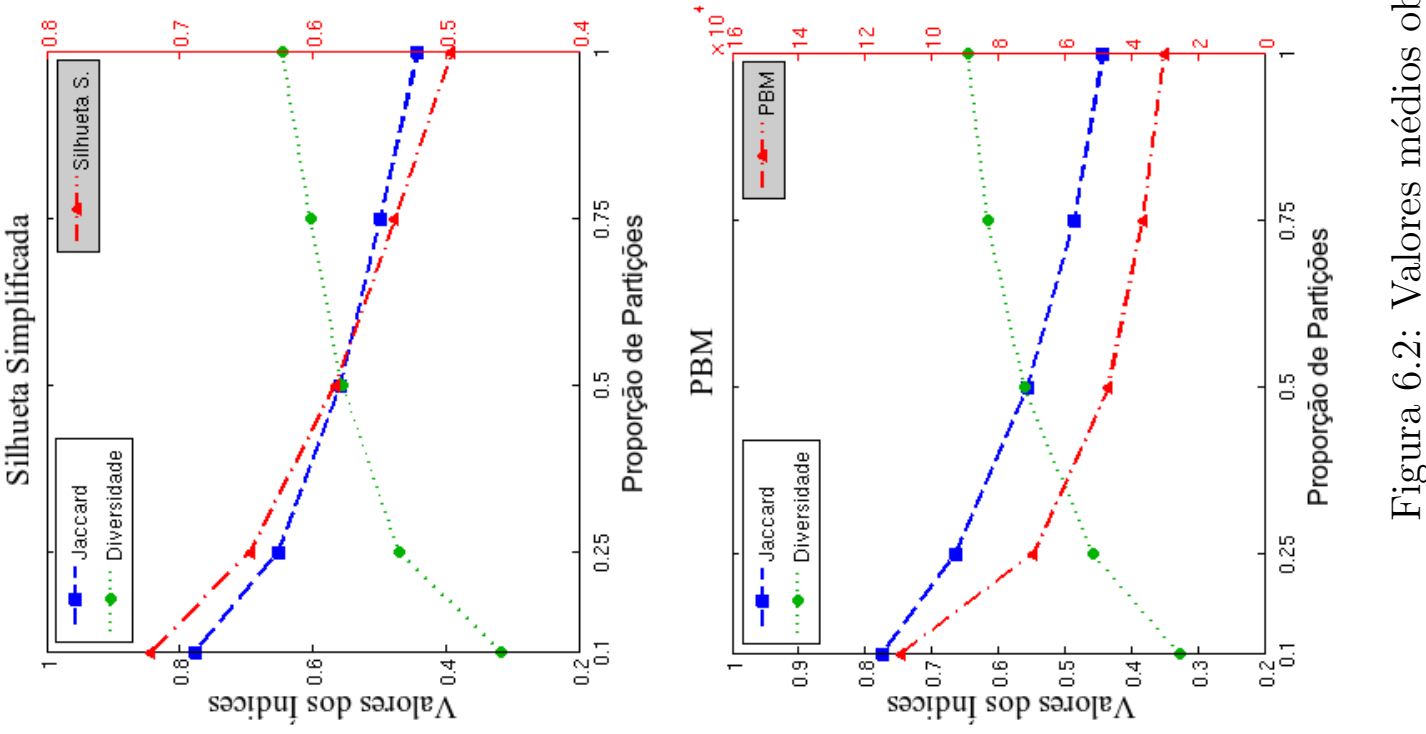

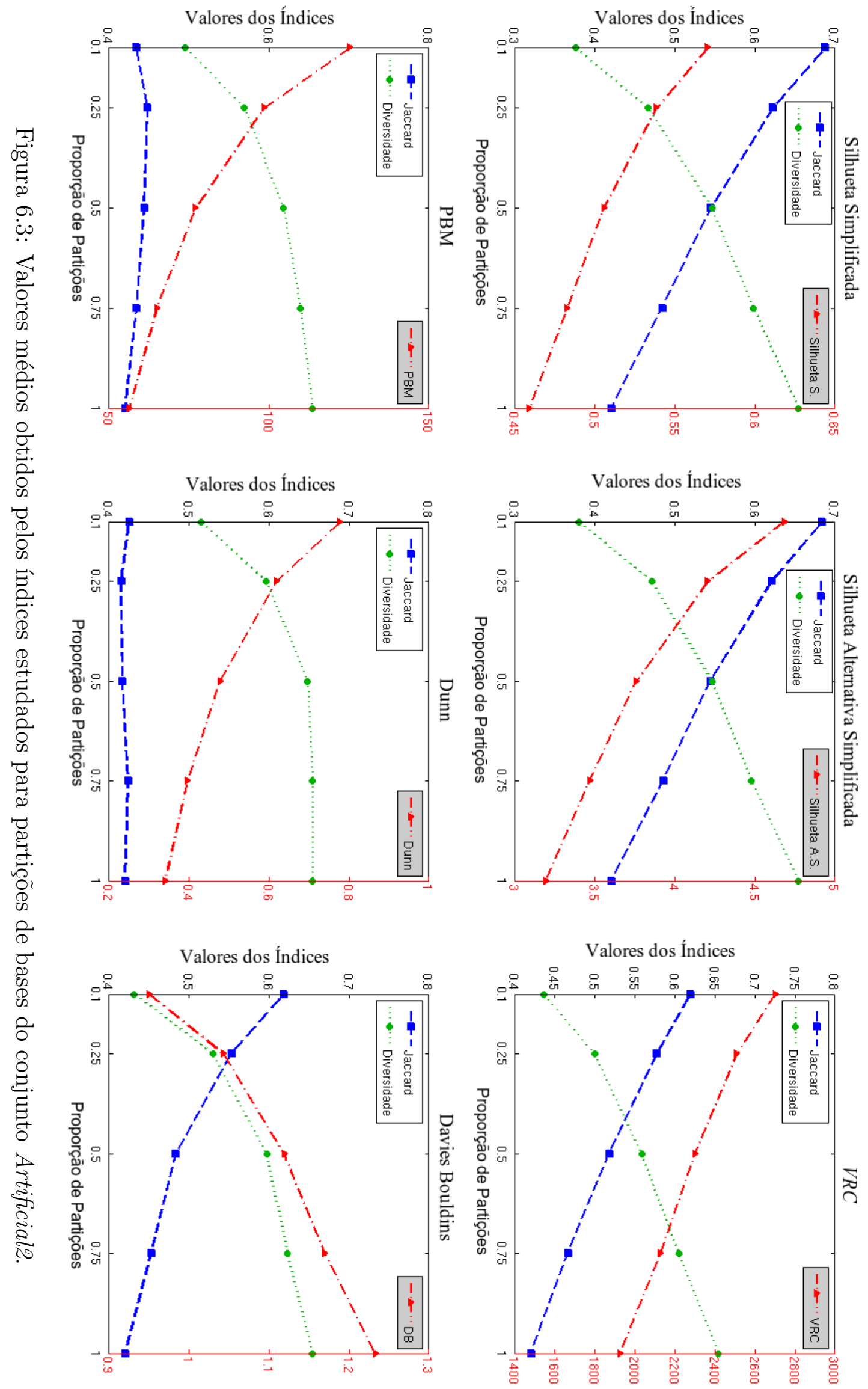

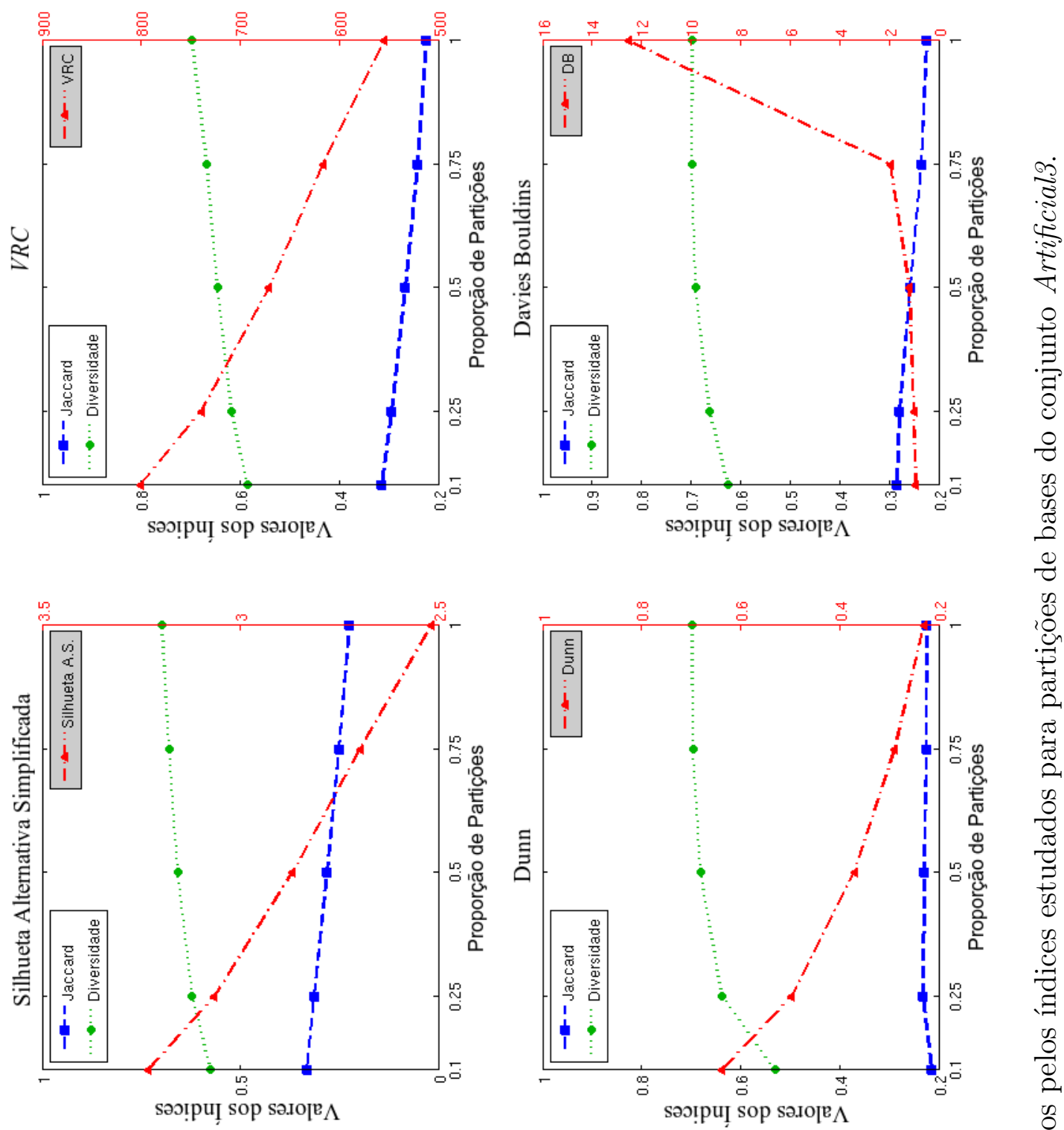

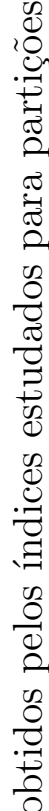
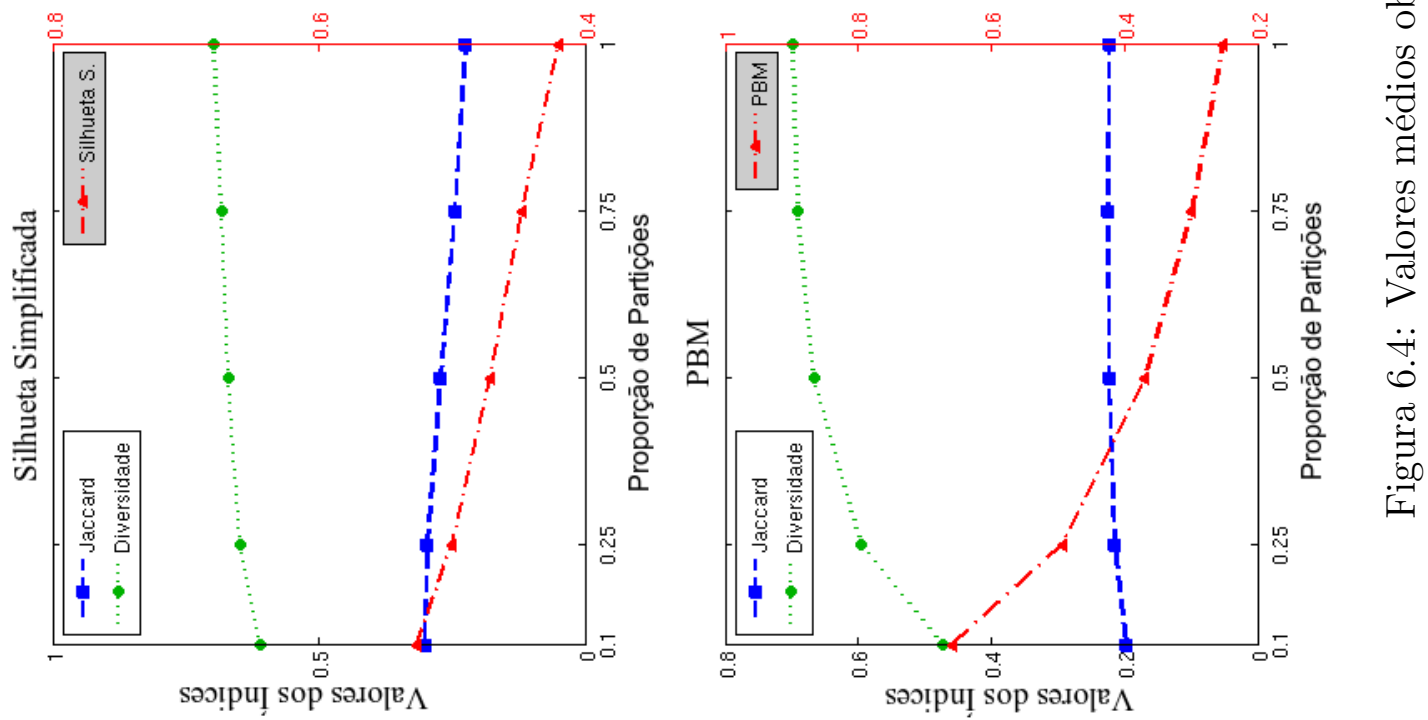


\begin{tabular}{|l|c|c|c|c|c|c|}
\hline & Silhueta S. & Silhueta M.S. & $V R C$ & PBM & Dunn & DB \\
\hline Artificial1 & $0,9232(0,09)$ & $0,9227(0,11)$ & $0,9053(0,13)$ & $0,9209(0,11)$ & $0,7324(0,29)$ & $0,8682(0,16)$ \\
Artificial2 & $0,7745(0,12)$ & $0,7600(0,13)$ & $0,6515(0,22)$ & $0,3935(0,28)$ & $0,4743(0,27)$ & $0,7099(0,17)$ \\
Artificial3 & $0,2201(0,16)$ & $0,3440(0,12)$ & $0,3238(0,08)$ & $0,1618(0,15)$ & $0,1653(0,15)$ & $0,2518(0,16)$ \\
\hline
\end{tabular}

Tabela 6.3: Média e desvio padrão dos valores do índice de Jaccard obtidos pelas partições melhor avaliadas pelos índices de validação para cada conjunto artificial.

maior qualidade e menor diversidade do que o conjunto de todas as partições base.

\subsubsection{Combinação dos conjuntos seleção}

Depois de avaliados, os conjuntos seleção foram combinados em partições finais com $k^{*}$ grupos por meio de funções de consenso, em que $k^{*}$ é o número de grupos conhecido para o conjuntos de dados particionado. Cinco funções de consenso tradicionais foram escolhidas para essa tarefa: o uso do algoritmo de ligação simples sobre matriz de co-associação (CAS, do inglês Co-Association with Single-link), o algoritmo de ligação média sobre matriz de co-associação ( $C A A$, do inglês Co-Association with Average-link), e as funções baseadas em grafo HGPA, MCLA e CSPA, a última também baseada em co-associação. Essas funções foram escolhidas por serem frequentemente utilizadas em trabalhos da área (Strehl \& Ghosh, 2002b; Fred \& Jain, 2005; Kuncheva et al., 2006; Fern \& Lin, 2008; Singh et al., 2010).

Com o objetivo de avaliar comparativamente o desempenho dos métodos de CES investigados para as diferentes funções de consenso estudadas, o índice de Jaccard foi utilizado para mensurar a similaridade entre as partições finais resultantes da combinação de cada conjunto seleção com os grupos conhecidos. Os valores médios do índice Jaccard sobre as partições finais resultantes dos conjuntos seleção são apresentados em forma de curvas nas Figuras 6.5, 6.6 e 6.7, de forma que o eixo das ordenadas indica o valor médio do índice Jaccard e o eixo das abscissas indica a proporção de partições base selecionadas em cada conjunto de dados. Para cada função de consenso, é apresentado um gráfico com os resultados de cada grande conjunto de dados artificiais.

Uma vez obtidos os valores do índice Jaccard para cada índice de validação utilizado em $C E S$, é interessante saber se as diferenças entre esses valores médios são significativas. Para isso, dois testes de hipóteses foram utilizados nas médias das áreas sobre as curvas $(A U C \mathrm{~s})$ obtidas para cada conjunto de dados artificiais. O primeiro teste é o conhecido teste ANOVA (Walpole et al., 2006), comumente adotado em múltiplas comparações. Como escrito na Seção 4.5.2, o teste ANOVA assume que as amostras comparadas sejam obtidas de populações com distribuições normais e que as variáveis aleatórias testadas possuam variâncias semelhantes (Demšar, 2006). Como esses requisitos não são garantidos aqui, o teste não paramétrico de Friedman (Hollander \& Wolfe, 1999) também foi adotado. Nos casos em que ambos os testes indicaram que algumas das amostras comparadas são significativamente distintas, testes post-hoc foram efetuados para encontrar quais dentre estas amostras possuem diferenças estatisticamente significantes. Nesses testes post-hoc, a 
correção de Bonferroni (Demšar, 2006) foi utilizada de modo a permitir o controle do nível de confiança estatística, que neste trabalho é de $95 \%$. Esse teste post-hoc foi escolhido por ser mais conservador do que os testes de Tukey (para o ANOVA) ou Nemenyi (para o teste de Friedman) (Demšar, 2006). Nas Figuras 6.5-6.7, o índice relativo que resultou no maior valor médio de $A U C$ e os índices cujos resultados não possuem diferença estatística significativa em relação a ele são apresentados com uma estrela ( $\mathcal{\xi}$ ) na legenda. Nos casos em que não há diferença estatística entre os índices, todos são apresentados sem estrelas.

Os resultados apresentados nas Figuras 6.5-6.7 mostram que o processo de CES baseado em índices relativos de validação conseguiu bons resultados em alguns cenários e não foi bem sucedido em outros. Os melhores resultados foram obtidos com os índices silhueta simplificada, silhueta modificada simplificada e $V R C$ na maioria dos casos, como comprovam os testes estatísticos. Entretanto, os resultados obtidos variam com a complexidade dos conjuntos de dados e com a função de consenso aplicada.

Quanto à complexidade dos conjuntos, a estrutura conhecida dos dados presentes nos conjuntos Artificial1 e Artificial2 pode ser estimada pelo algoritmo k-médias em conjunto com algum método de seleção do número de grupos e protótipos ${ }^{1}$. Adicionalmente, selecionar a melhor partição, segundo os índices relativos que obtiveram os melhores desempenhos, resulta em partições de qualidade melhor do que combinações feitas com as funções de consenso CSPA e HGPA, em média (como pode ser visto comparando os resultados das Figuras 6.5-6.7 e da Tabela 6.3). Contudo, o uso de $C E S$ com as funções $C A S, C A A$ e $M C L A$ gerou partições consenso com qualidade próxima ou superior às obtidas pela combinação total e às melhores partições indicadas pelos índices de validação individualmente.

As combinações totais aplicadas em partições do conjunto Artificial3 resultaram em valores médios do índice Jaccard (presentes nas Figuras 6.5-6.7) superiores aos obtidos pelas melhores partições base, segundo os índices relativos estudados (como pode ser visto na Tabela 6.3). Isto porque a presença de sobreposições entre grupos e a maior complexidade da estrutura desse conjunto são desfavoráveis ao uso do algoritmo $k$-médias. Por esse motivo, na maioria dos casos, a utilização de $C E S$ não apresentou melhorias na qualidade da partição consenso. Dentre as funções que obtiveram melhores resultados para este conjunto, destacam-se a $C A S$ e a $H G P A$.

Em relação às funções de consenso, os resultados variam significativamente entre as funções investigadas. A CAA obteve um bom desempenho nos conjuntos Artificial1 e Artificial2, em que as partições base refletem bem a estrutura conhecida dos dados. As linhas presentes nos gráficos da Figura 6.5 indicam que o uso de métodos de $C E S$ pode obter partições consenso de qualidade próxima e até mesmo melhor do que o uso da combinação total com essa função, caso o índice de validação escolhido seja adequado.

O desempenho da $C A S$ mostrou sofrer influência do algoritmo de ligação simples, que possui a tendência de unir grupos próximos ou ligados por cadeias de objetos (Jain \&

\footnotetext{
${ }^{1}$ Métodos que possuem essa finalidade são apresentados e comparados no Capítulo 4.
} 

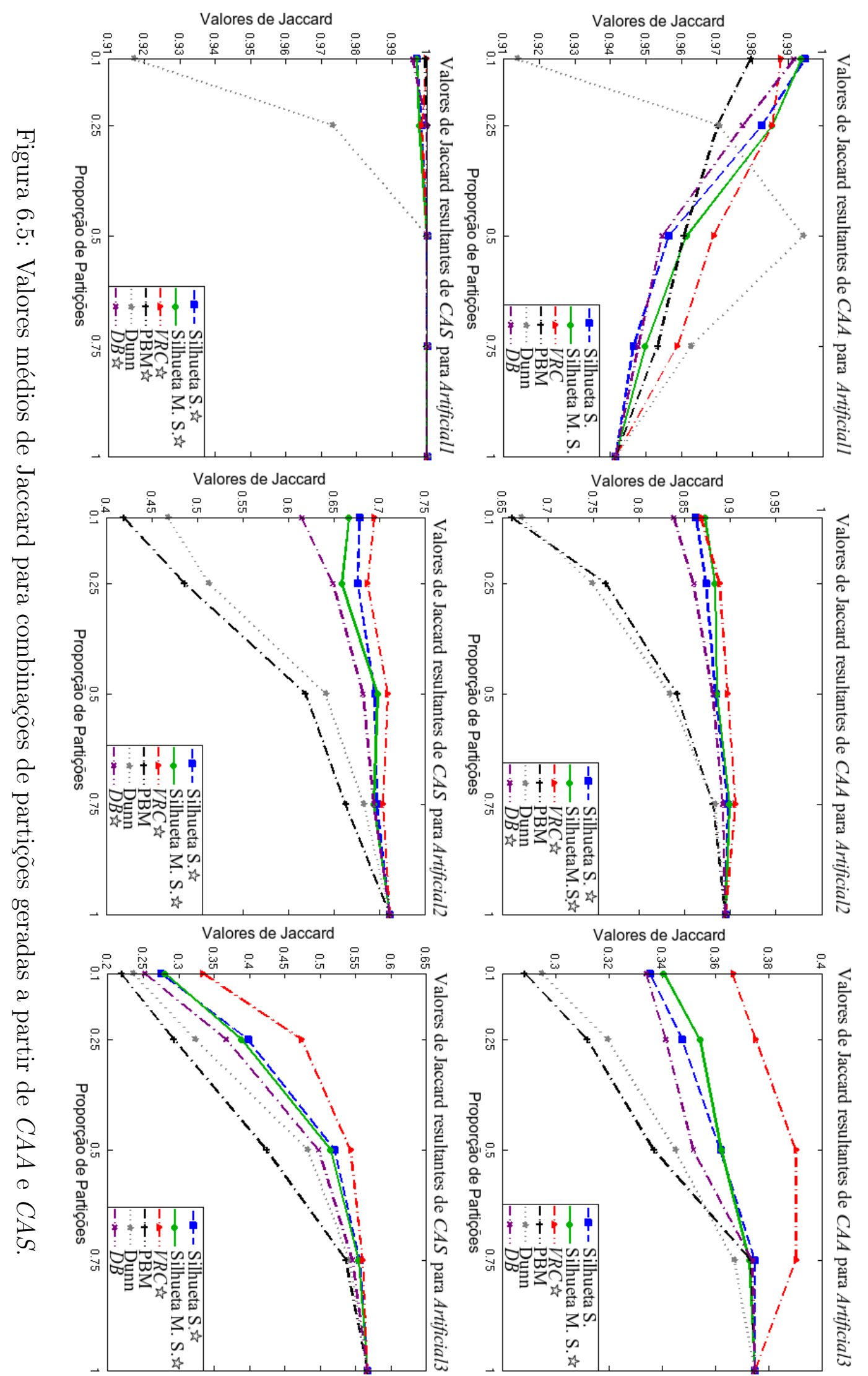

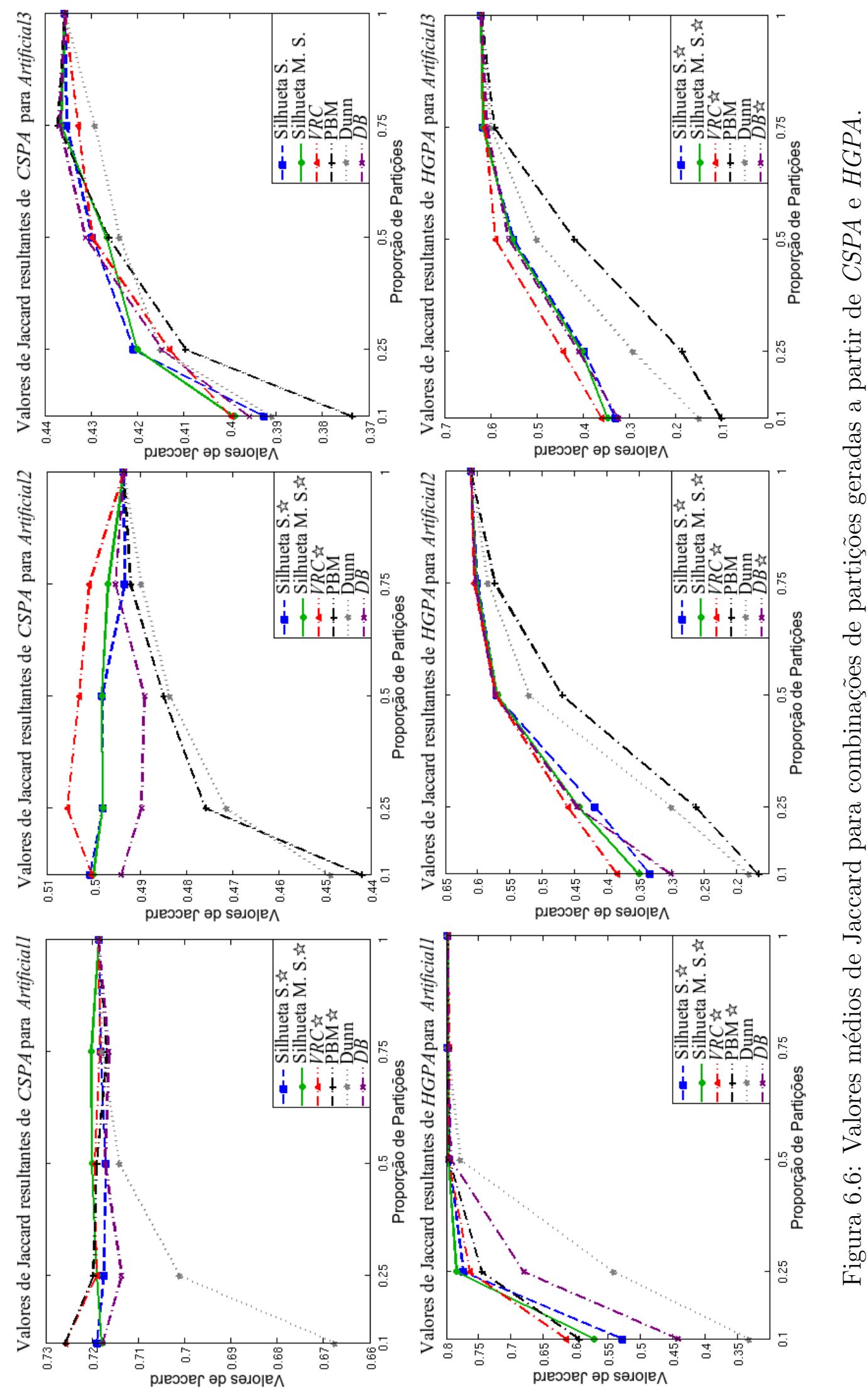


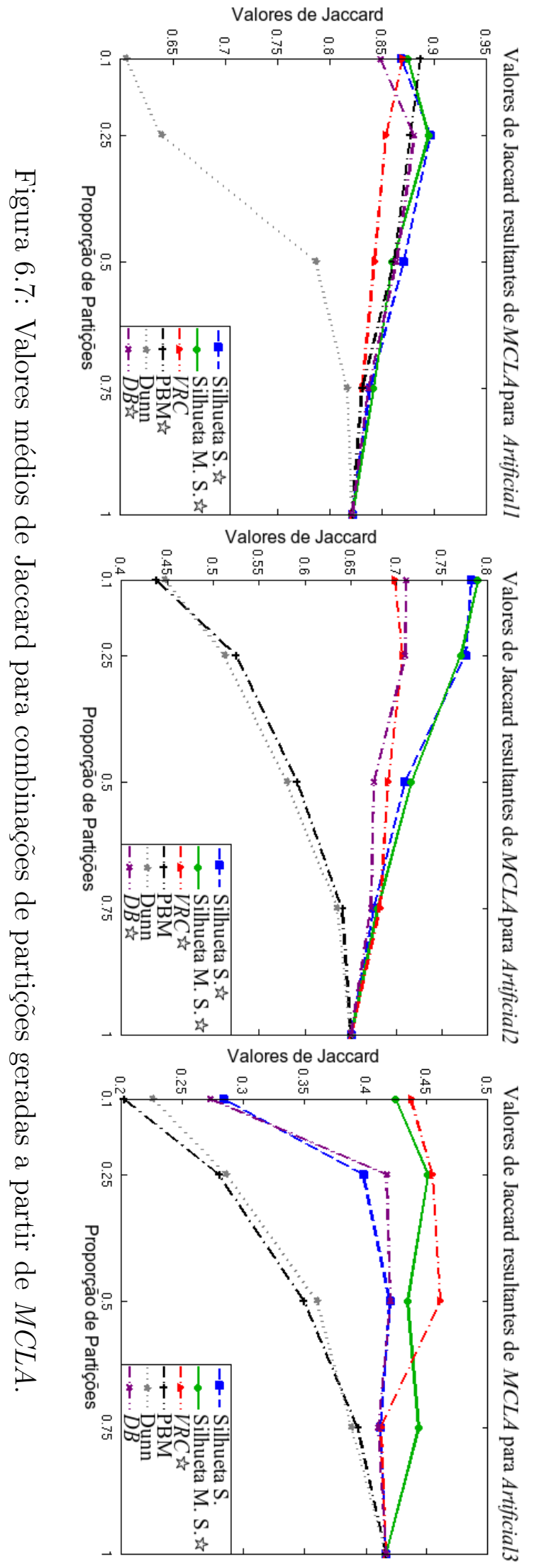


Dubes, 1988). Por esse motivo, destacou-se ao ser aplicada no conjunto Artificial1 pela separação (ausência de sobreposição) dos grupos desse conjunto. Também obteve partições próximas das conhecidas para as bases de dados com 4 e 10 grupos do conjunto Artificial3, com valores médios de Jaccard maiores que 0,9. Entretanto, o mesmo desempenho não foi obtido com o restante das bases de dados, o que reduz o desempenho médio da função para o conjunto, como mostrado na Figura 6.5. Para essa função, os métodos de $C E S$ foram eficazes apenas nos conjuntos Artificial1 e Artificial2.

Os resultados obtidos pela função $C S P A$ variam pouco em relação ao aumento de partições base, para a maioria dos índices de validação investigados. Mesmo para o conjunto Artificial3, a diferença entre as médias de valores de Jaccard das partições consenso gerados pelos conjuntos seleção e a combinação total é inferior a 0.05 na maioria dos casos, como pode ser visto na Figura 6.6, o que sugere que esta função não seja sensível à quantidade (mas sim à qualidade) das partições base. Portanto, utilizar métodos de $C E S$ pode reduzir o custo computacional da combinação sem causar uma redução expressiva da qualidade da partição consenso, se a função de consenso utilizada for favorável à seleção de um subconjunto de partições base de melhor qualidade a partir do conjunto total.

Como mostrado na Figura 6.6, a função HGPA tem a qualidade de sua partição consenso melhorada com o aumento do número de partições base até estabilizar-se em um valor, que varia com a complexidade do conjunto de dados. Ela mostra pouca ou nenhuma sensibilidade à seleção de partições base de maior qualidade. Isso sugere que essa função é favorecida pelo aumento da quantidade (e diversidade) das partições, pouco importando sua qualidade. Como os valores resultantes do índice de Jaccard decrescem expressivamente com a redução da proporção de partições selecionadas, os resultados observados na Figura 6.6 sugerem que o uso de $C E S$ não seja recomendado em conjunto com a função HGPA.

Diferentemente da função $H G P A$, os resultados apresentados na Figura 6.7 mostram que função de consenso $M C L A$ foi a mais aprimorada pelos métodos de $C E S$ investigados, inclusive para o conjunto Artificial3, quando utilizados os índices de validação de melhor desempenho. Para ilustrar como o uso dos $C E S$ investigados influenciam no desempenho das funções de consenso MCLA e HGPA, os resultados obtidos para uma base de dados do conjunto Artificial2 são apresentados na Figura 6.8. Nela é possível visualizar como as partições consenso de conjuntos seleção obtidos pelo uso do índice silhueta simplificada para 10\%, 25\%, 50\%, 75\% e 100\% das partições base. É importante ressaltar que os gráficos presentes na mesma coluna contêm partições obtidas da combinação da mesma seleção de partições base.

Na Figura 6.8, é mostrado que o algoritmo $M C L A$ gera partições consenso próximas da qualidade média das partições base selecionadas, valor que tende a ser reduzido à medida que o número de partições aumenta. Em contrapartida, a função HGPA necessita do acúmulo de uma quantidade razoável de partições base para aprimorar a qualidade da partição consenso, mesmo que o aumento do número de partições selecionadas reduza a 


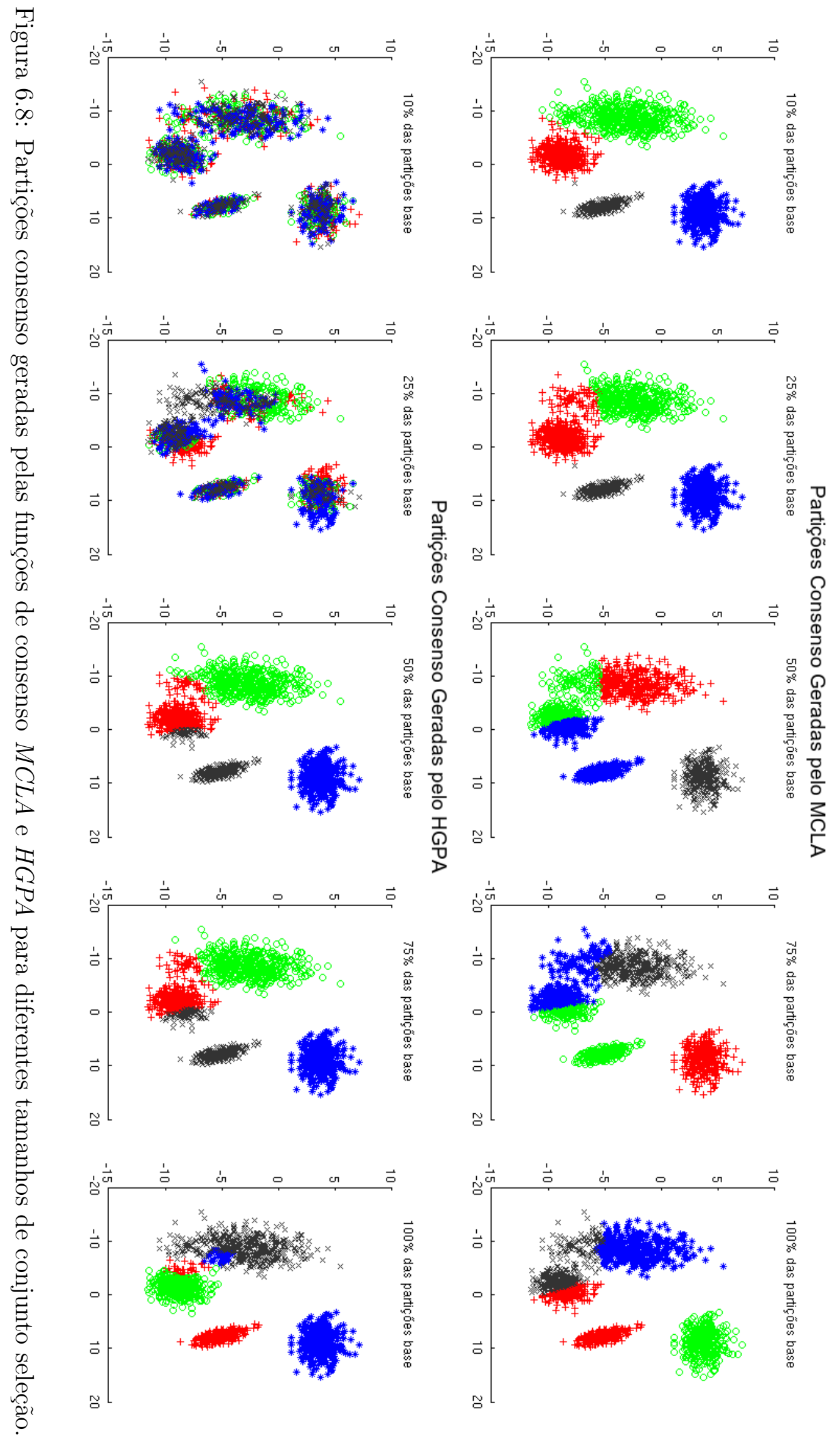

144 
qualidade média do conjunto seleção. A justificativa para que essas funções de consenso obtenham resultados tão distintos a partir do mesmo conjunto seleção reside no método utilizado para combiná-lo. Ambas as funções representam a informação sobre os grupos das partições base como hiperarestas em um hipergrafo. Entretanto, o MCLA agrupa essas hiperarestas em metagrupos antes de aplicar o algoritmo de divisão de grafos, o que não ocorre no $H G P A$. Mais detalhes sobre essas funções de consenso podem ser vistos na Seção 5.3.3.

Em resumo, os resultados obtidos com $C E S$ variam com a função de consenso aplicada. Adicionalmente, alguns índices de validação geram melhores resultados do que outros. Nem sempre é possível conhecer quais índices destacam-se para determinada aplicação. Por esse motivo, a combinação de índices pode ser uma boa alternativa para esse tipo de aplicação.

\subsection{Combinação de índices de validação relativos}

Os resultados apresentados na Seção 6.3 mostram que alguns índices de validação obtêm melhores resultados do que outros para determinados tipos de conjuntos de dados. Isso dá suporte à afirmação de que índices de validação são dotados de características particulares que podem fazer com que cada um seja capaz de superar os outros em classes de problemas específicas. Contudo, nem sempre é possível avaliar como é o comportamento dos índices de validação relativos escolhidos, como feito na Seção 6.3.1, pois nem sempre se conhece a partição "ideal" dos dados, o que ocorre nas aplicações práticas. Adicionalmente, avaliar os conjuntos seleção obtidos a partir do uso de um único índice relativo tende a reduzir a diversidade do conjunto de partições base, como mostrado na Seção 6.3.2.1.

Cardoso \& de Carvalho (2009) afirmam que é difícil estabelecer limiares para índices de validação relativos, de maneira a afirmar que o resultado obtido é alto ou baixo demais para ser "anormal". Para amenizar esse problema, recomendam a comparação de diferentes índices de forma que avaliações adicionais possam aumentar a confiança nos resultados, na tentativa de evitar o fraco desempenho de alguns índices. Se nenhuma informação anterior sobre o desempenho de índices de validação na classe de dados em questão está disponível, combinar avaliações de diversos índices pode produzir bons resultados, na esperança que a maioria dos índices combinados compense o fraco desempenho do restante. A abordagem de CIR proposta aqui é diferenciada das abordagens multi-objetivos em alguns aspectos. O primeiro é que a otimização multi-objetivo busca encontrar um vetor de variáveis de decisão que minimize um conjunto de funções objetivo (Zitzler, 1999), que seriam índices de validação no presente contexto. Em contrapartida, uma CIR pode utilizar qualquer função de consenso adaptada para combinar esses índices. Um exemplo seria uma função baseada em votação, em que cada índice de validação é responsável por votar em uma partição ou número de grupos dentre um conjunto de possibilidades. Nesse contexto, observe que, em geral, nos problemas de otimização multi-objetivo há vários objetivos 
conflitantes que devem ser otimizados, isto é, objetivos para os quais a melhor satisfação de um objetivo frequentemente causa a insatisfação de outro (Zitzler, 1999). Isso não precisa ocorrer necessariamente em uma CIR, ou seja, dois índices de validação podem e devem melhorar em conjunto.

Existe uma grande carência de trabalhos que combinem índices de validação na literatura, o que torna o tema interessante para pesquisa. Dentre os trabalhos relacionados, pode ser citado (Bolshakova \& Azuaje, 2002), que utilizaram um esquema de votação entre variações do índice $D B$ para determinar o número correto de grupos de um conjunto de dados. Outro trabalho que combina índices de validação foi realizado por Machado et al. (2007), que utiliza a média aritmética e votação entre múltiplos índices de validação para determinar automaticamente o número de modelos locais a serem utilizados no processo de agrupamento. Em (Naldi \& Carvalho, 2007), os autores mostram uma melhoria na média dos resultados obtidos por um algoritmo de agrupamento genético com aptidão baseada em dois índices de validação. O primeiro é o índice silhueta, utilizado para avaliar as soluções obtidas. Posteriormente, o segundo índice, $V R C$, é testado para cada solução e, caso a solução candidata apresente um índice abaixo da média das soluções, sua avaliação é penalizada.

Nesta seção é investigado o uso de CIR em $C E S$, voltado a aplicações em que o desempenho dos índices não é conhecido na classe de dados em questão. Para isso, os índices relativos utilizados na Seção 6.3 serão combinados em comitês e utilizados para avaliar e selecionar partições base. Entretanto, ao propor um método de CIR para ser aplicado em $C E S$, é necessário considerar duas características importantes:

- Diversidade entre as partições selecionadas: é esperado que conjuntos seleção obtidos pelos índices a serem combinados possuam algumas partições em comum, o que indica que as partições selecionadas apresentam características consideradas como boas para mais de um índice. Porém, não é justificável combinar índices de validação relativos que selecionem exatamente as mesmas partições. Por este motivo, é preciso que haja alguma diversidade entre as partições selecionadas pelos índices relativos a serem combinados.

- Representatividade da combinação em relação aos índices combinados: o método utilizado para combinar os índices relativos deve considerar todos os índices combinados e não apenas refletir o comportamento de um único índice ou de uma minoria. Caso contrário, é computacionalmente mais eficiente utilizar o índice que possui o comportamento refletido pela combinação.

Portanto, a investigação apresentada nesta seção será dividida em três partes: na primeira, presente na Seção 6.4.1, conjuntos seleção obtidos com os índices relativos estudados serão comparados, de forma a medir a similaridade entre eles. A segunda parte apresenta na Seção 6.4.2 os métodos de CIR propostos neste trabalho e mede a capacidade 
de representação de cada um em relação aos índices combinados. Por último, experimentos em que os métodos de CIR propostos são aplicados na $C E S$ dos conjuntos de dados artificiais são analisados na Seção 6.4.3.

\subsubsection{Diversidade na seleção de partições}

Para que seja possível medir a semelhança entre dois conjuntos de partições, é preciso obter a correspondência entre as partições selecionadas para cada conjunto. Neste trabalho, cada partição do conjunto total é rotulada com um valor único inteiro no intervalo $\left[1,\left|\Pi_{t}\right|\right]$. Por meio desses rótulos, é possível calcular a similaridade entre dois conjuntos seleção. Sejam $\Pi_{s 1}$ e $\Pi_{s 2}$ dois conjuntos seleção com o mesmo número de partições base $n_{\pi, s}$, a similaridade entre $\Pi_{s 1}$ e $\Pi_{s 2}$ é calculada neste trabalho segundo a Equação (6.3):

$$
s\left(\Pi_{s 1}, \Pi_{s 2}\right)=\frac{\left|\Pi_{s 1} \bigcap \Pi_{s 2}\right|}{n_{\pi, s}}
$$

em que $|\cdot|$ indica a cardinalidade de um conjunto. É fácil perceber que $s\left(\Pi_{s 1}, \Pi_{s 2}\right)$ resulta valores no intervalo $[0,1]$.

As Tabelas 6.4, 6.5 e 6.6 apresentam as médias sobre as similaridades entre os conjuntos seleção gerados para cada par de índices relativos estudados, calculadas segundo a abordagem descrita. Cada posição das tabelas contém quatro números, representando (da esquerda para a direita) as médias obtidas para seleções com 10\%, 25\%, 50\% e 75\% do conjunto total de partições bases.

\begin{tabular}{|c|c|c|c|c|c|c|}
\hline & Silhueta S. & Silhueta M.S. & $\overline{V R C}$ & $\overline{\mathrm{PBM}}$ & Dunn & $D B$ \\
\hline Silhueta S. & $1,00 \quad 1,00 \quad 1,00 \quad 1,00$ & $\begin{array}{lllll}0,80 & 0,83 & 0,89 & 0,95 \\
\end{array}$ & $\begin{array}{lllll}0,46 & 0,55 & 0,69 & 0,82\end{array}$ & $\begin{array}{lllll}0,53 & 0,63 & 0,71 & 0,81\end{array}$ & $\begin{array}{llll}0,35 & 0,34 & 0,52 & 0,75\end{array}$ & $\begin{array}{lllll}0,60 & 0,68 & 0,78 & 0,88\end{array}$ \\
\hline Silhueta M.S. & $\begin{array}{llll}0,80 & 0,83 & 0,89 & 0,95\end{array}$ & $\begin{array}{lllllll}1,00 & 1,00 & 1,00 & 1,00\end{array}$ & $\begin{array}{llll}0,53 & 0,62 & 0,72 & 0,83\end{array}$ & $\begin{array}{lllll}0,60 & 0,69 & 0,74 & 0,81\end{array}$ & $\begin{array}{lllll}0,30 & 0,30 & 0,51 & 0,75\end{array}$ & $\begin{array}{lllll}0,51 & 0,59 & 0,72 & 0,85\end{array}$ \\
\hline$V R C$ & $\begin{array}{lllll}0,46 & 0,55 & 0,69 & 0,82\end{array}$ & $\begin{array}{llll}0,53 & 0,62 & 0,72 & 0,83\end{array}$ & $\begin{array}{lllll}1,00 & 1,00 & 1,00 & 1,00\end{array}$ & $\begin{array}{lllll}0,86 & 0,84 & 0,84 & 0,89\end{array}$ & $\begin{array}{llll}0,16 & 0,21 & 0,50 & 0,79\end{array}$ & $\begin{array}{lllll}0,26 & 0,35 & 0,52 & 0,77\end{array}$ \\
\hline PBM & $\begin{array}{lllll}0,53 & 0,63 & 0,71 & 0,81\end{array}$ & $\begin{array}{lllll}0,60 & 0,69 & 0,74 & 0,81\end{array}$ & $\begin{array}{lllll}0,86 & 0,84 & 0,84 & 0,89\end{array}$ & $\begin{array}{lllll}1,00 & 1,00 & 1,00 & 1,00\end{array}$ & $\begin{array}{llll}0,22 & 0,26 & 0,54 & 0,80\end{array}$ & $\begin{array}{lllll}0,33 & 0,44 & 0,59 & 0,78\end{array}$ \\
\hline Dunn & $\begin{array}{lllll}0,35 & 0,34 & 0,52 & 0,75\end{array}$ & $\begin{array}{lllll}0,30 & 0,30 & 0,51 & 0,75\end{array}$ & $\begin{array}{llll}0,16 & 0,21 & 0,50 & 0,79\end{array}$ & $\begin{array}{lllll}0,22 & 0,26 & 0,54 & 0,80\end{array}$ & $1,00 \quad 1,00 \quad 1,00 \quad 1,00$ & $\begin{array}{llll}0,53 & 0,49 & 0,59 & 0,78\end{array}$ \\
\hline$D B$ & $\begin{array}{lllll}0,60 & 0,68 & 0,78 & 0,88\end{array}$ & $\begin{array}{lllll}0,51 & 0,59 & 0,72 & 0,85\end{array}$ & $\begin{array}{lllll}0,26 & 0,35 & 0,52 & 0,77\end{array}$ & $\begin{array}{lllll}0,33 & 0,44 & 0,59 & 0,78\end{array}$ & $\begin{array}{lllll}0,53 & 0,49 & 0,59 & 0,78\end{array}$ & $1,00 \quad 1,00 \quad 1,00 \quad 1,00$ \\
\hline
\end{tabular}

Tabela 6.4: Médias das similaridades entre os conjuntos seleção gerados por meio dos índices estudados para o Artificial1.

\begin{tabular}{|c|c|c|c|c|c|c|}
\hline & Silhueta S. & Silhueta M.S. & $V R C$ & PBM & Dunn & $D B$ \\
\hline Silhueta S. & $\begin{array}{lllll}1,00 & 1,00 & 1,00 & 1,00\end{array}$ & $\begin{array}{lllll}0,78 & 0,85 & 0,91 & 0,95\end{array}$ & $\begin{array}{llll}0,48 & 0,61 & 0,75 & 0,86\end{array}$ & $\begin{array}{lllll}0,37 & 0,51 & 0,67 & 0,82\end{array}$ & $\begin{array}{lllll}0,31 & 0,41 & 0,57 & 0,78\end{array}$ & $\begin{array}{lllll}0,64 & 0,69 & 0,74 & 0,85\end{array}$ \\
\hline Silhueta M.S. & $\begin{array}{llll}0,78 & 0,85 & 0,91 & 0,95\end{array}$ & $\begin{array}{lllll}1,00 & 1,00 & 1,00 & 1,00\end{array}$ & $\begin{array}{llll}0,49 & 0,61 & 0,76 & 0,86\end{array}$ & $\begin{array}{llll}0,33 & 0,47 & 0,63 & 0,80\end{array}$ & $\begin{array}{lllll}0,26 & 0,37 & 0,54 & 0,76\end{array}$ & $\begin{array}{llll}0,54 & 0,62 & 0,70 & 0,84\end{array}$ \\
\hline$V R C$ & $\begin{array}{lllll}0,48 & 0,61 & 0,75 & 0,86\end{array}$ & $\begin{array}{lllll}0,49 & 0,61 & 0,76 & 0,86\end{array}$ & $\begin{array}{lllll}1,00 & 1,00 & 1,00 & 1,00\end{array}$ & $\begin{array}{llll}0,34 & 0,43 & 0.61 & 0,81\end{array}$ & $\begin{array}{llllll}0,26 & 0.31 & 0,52 & 0.77\end{array}$ & $\begin{array}{lllll}0,36 & 0,44 & 0,59 & 0,79\end{array}$ \\
\hline PBM & $\begin{array}{lllllll}0,37 & 0,51 & 0,67 & 0,82\end{array}$ & $\begin{array}{lllll}0,33 & 0,47 & 0,63 & 0,80\end{array}$ & $\begin{array}{lllll}0,34 & 0,43 & 0,61 & 0,81\end{array}$ & $\begin{array}{llllllll}1,00 & 1,00 & 1,00 & 1,00\end{array}$ & $\begin{array}{llllll}0,44 & 0,64 & 0,77 & 0,84\end{array}$ & $\begin{array}{lllll}0,38 & 0,50 & 0,64 & 0,79\end{array}$ \\
\hline Dunn & $\begin{array}{lllll}0,31 & 0,41 & 0,57 & 0,78\end{array}$ & $\begin{array}{llll}0,26 & 0,37 & 0,54 & 0,76\end{array}$ & $\begin{array}{llll}0,26 & 0,31 & 0,52 & 0,77\end{array}$ & $\begin{array}{llll}0,44 & 0,64 & 0,77 & 0,84\end{array}$ & $\begin{array}{lllll}1,00 & 1,00 & 1,00 & 1,00\end{array}$ & $\begin{array}{lllll}0,40 & 0,48 & 0,61 & 0,78\end{array}$ \\
\hline$D B$ & $\begin{array}{llllll}0,64 & 0,69 & 0,74 & 0,85\end{array}$ & $\begin{array}{lllll}0,54 & 0,62 & 0,70 & 0,84\end{array}$ & $\begin{array}{llllll}0,36 & 0,44 & 0,59 & 0,79\end{array}$ & $\begin{array}{lllll}0,38 & 0,50 & 0,64 & 0,79\end{array}$ & $\begin{array}{lllll}0,40 & 0,48 & 0,61 & 0,78\end{array}$ & $\begin{array}{llllll}1,00 & 1,00 & 1,00 & 1,00\end{array}$ \\
\hline
\end{tabular}

Tabela 6.5: Médias das similaridades entre os conjuntos seleção gerados por meio dos índices estudados para o Artificial2.

\begin{tabular}{|c|c|c|c|c|c|c|}
\hline & Silhueta S. & Silhueta M.S. & $V R C$ & PBM & Dunn & $D B$ \\
\hline Silhueta S. & $\begin{array}{llll}1,00 & 1,00 & 1,00 & 1,00\end{array}$ & $\begin{array}{llll}0,68 & 0,81 & 0,89 & 0,93\end{array}$ & $\begin{array}{lllll}0,51 & 0,66 & 0,80 & 0,87\end{array}$ & $\begin{array}{lllll}0,33 & 0,38 & 0,55 & 0,78\end{array}$ & $\begin{array}{lllll}0,40 & 0,47 & 0,61 & 0,77\end{array}$ & $\begin{array}{lllll}0,71 & 0,79 & 0,79 & 0,83\end{array}$ \\
\hline Silhueta M.S & $\begin{array}{llll}0,68 & 0,81 & 0,89 & 0,93\end{array}$ & $1,00 \quad 1,00 \quad 1,00 \quad 1,00$ & $\begin{array}{lllll}0,55 & 0,70 & 0,82 & 0,88\end{array}$ & $\begin{array}{lllll}0,20 & 0,32 & 0,51 & 0,78\end{array}$ & $\begin{array}{lllll}0,24 & 0,38 & 0,56 & 0,76\end{array}$ & $\begin{array}{lllll}0,54 & 0,67 & 0,74 & 0,83\end{array}$ \\
\hline$V R C$ & $\begin{array}{lllll}0,51 & 0,66 & 0,80 & 0,87\end{array}$ & $\begin{array}{lllll}0,55 & 0,70 & 0,82 & 0,88\end{array}$ & $1,00 \quad 1,00 \quad 1,00 \quad 1,00$ & $\begin{array}{lllll}0,16 & 0,26 & 0,48 & 0,76\end{array}$ & $\begin{array}{lllll}0,17 & 0,32 & 0,51 & 0,74\end{array}$ & $\begin{array}{lllll}0,47 & 0,59 & 0,68 & 0,79\end{array}$ \\
\hline PBM & $\begin{array}{lllll}0,33 & 0,38 & 0,55 & 0,78\end{array}$ & $\begin{array}{llll}0,20 & 0,32 & 0,51 & 0,78\end{array}$ & $\begin{array}{lllll}0,16 & 0,26 & 0,48 & 0,76\end{array}$ & $\begin{array}{lllll}1,00 & 1,00 & 1,00 & 1,00\end{array}$ & $\begin{array}{lllll}0,62 & 0,70 & 0,82 & 0,89\end{array}$ & $\begin{array}{llll}0,33 & 0,42 & 0,62 & 0,84\end{array}$ \\
\hline Dunn & $\begin{array}{lllll}0,40 & 0,47 & 0,61 & 0,77\end{array}$ & $\begin{array}{lllll}0,24 & 0,38 & 0,56 & 0,76\end{array}$ & $\begin{array}{lllll}0,17 & 0,32 & 0,51 & 0,74\end{array}$ & $\begin{array}{lllll}0,62 & 0,70 & 0,82 & 0,89\end{array}$ & $1,00 \quad 1,00 \quad 1,00 \quad 1,00$ & $\begin{array}{lllll}0,40 & 0,51 & 0,74 & 0,91\end{array}$ \\
\hline$D B$ & $\begin{array}{llll}0,71 & 0,79 & 0,79 & 0,83\end{array}$ & $\begin{array}{llll}0,54 & 0,67 & 0,74 & 0,83\end{array}$ & $\begin{array}{llll}0,47 & 0,59 & 0,68 & 0,79\end{array}$ & $\begin{array}{llll}0,33 & 0,42 & 0,62 & 0,84\end{array}$ & $\begin{array}{llll}0,40 & 0,51 & 0,74 & 0,91\end{array}$ & $\begin{array}{lllll}1,00 & 1,00 & 1,00 & 1,00\end{array}$ \\
\hline
\end{tabular}

Tabela 6.6: Médias das similaridades entre os conjuntos seleção gerados por meio dos índices estudados para o Artificials. 
Os resultados apresentados nas Tabelas 6.4-6.6 mostram que a grande maioria dos conjuntos seleção construídos com menos de $50 \%$ das partições totais apresentam menos de $60 \%$ de partições em comum. As exceções se concentram em conjuntos selecionados pelos índices silhuetas e $D B$, que apresentaram tendências semelhantes. Contudo, essa semelhança raramente passa de $80 \%$ para conjuntos construídos com menos de $75 \%$ das partições totais, o que indica que ao menos $20 \%$ de partições entre estes conjuntos são distintas. Adicionalmente, é mostrada uma tendência de redução de similaridade entre os conjuntos selecionados à medida que a complexidade das bases de dados aumenta. Portanto, é possível concluir que existe uma razoável diversidade entre as partições escolhidas pelos índices relativos investigados, especialmente para conjuntos de dados Artificial3.

\subsubsection{Métodos propostos}

Verificada a presença de diversidade entre as partições selecionadas por meio dos índices investigados, foram desenvolvidos métodos de CIR voltados para CES. Três métodos foram adotados neste trabalho:

1. Soma dos Ranks (SR): As partições base são avaliadas individualmente pelos índices de validação e, a partir dos resultados obtidos, um rank é montado para cada índice. Em seguida, as partições base são selecionadas para a combinação em ordem ascendente de acordo com a soma dos valores de suas posições nos ranks obtidos no passo anterior.

2. Melhor Posição (MP): Um rank das partições base é montado para cada índice. Contudo, diferentemente do método SR, as partições são selecionadas em ordem ascendente de acordo com a menor posição obtida dentre todos os ranks. Em caso de empate, a menor posição obtida pelas partições empatadas é descartada e a partição selecionada é aquela que apresentar o menor valor entre as posições restantes.

3. Soma com Diversidade (SD): As partições são avaliadas e somas dos ranks de cada índice são calculadas, conforme descrito no método SR. Para cada partição, o valor dos ranks somados é multiplicado pelo complemento da diversidade (1-diver sidade, dada pela Equação (6.1)) entre a partição e o conjunto de partições base. Em seguida, as partições base são selecionadas em ordem ascendente de acordo com o valor da soma de seus ranks multiplicados. O objetivo deste método é proporcionar um aumento na diversidade das partições selecionadas em relação ao método SR.

Retomando o que foi afirmado na Seção 6.4, ao investigar um método para combinar os índices relativos, é preciso que este considere todos os índices combinados e não apenas um único índice ou de uma minoria. Por esse motivo, a mesma metodologia apresentada na Seção 6.4.1 é utilizada nesta seção para comparar conjuntos seleção gerados a partir dos três métodos de CIR propostos e os índices de validação relativos investigados. As similaridades médias (calculadas a partir da Equação 6.3) resultantes dessa comparação 
estão presentes nas Tabelas 6.7, 6.8 e 6.9. Novamente, cada posição das tabelas contém quatro números, representando (da esquerda para a direita) as médias obtidas para seleções com 10\%, 25\%, 50\% e 75\% do conjunto total de partições bases.

\begin{tabular}{|c|c|c|c|}
\hline & Soma dos Ranks (SR) & Melhor Posição (MP) & Soma com Diversidade (SD) \\
\hline Silhueta S. & $\begin{array}{lllll}0,73 & 0,83 & 0,87 & 0,90\end{array}$ & $\begin{array}{lllll}0,65 & 0,69 & 0,75 & 0,82\end{array}$ & $\begin{array}{lllll}0,76 & 0,81 & 0,83 & 0,87\end{array}$ \\
\hline Silhueta M.S. & $\begin{array}{lllll}0,61 & 0,73 & 0,81 & 0,87\end{array}$ & $\begin{array}{lllll}0,55 & 0,63 & 0,70 & 0,80\end{array}$ & $\begin{array}{lllll}0,60 & 0,72 & 0,79 & 0,85 \\
\end{array}$ \\
\hline$V R C$ & $\begin{array}{lllll}0,55 & 0,66 & 0,76 & 0,84\end{array}$ & $\begin{array}{lllll}0,51 & 0,57 & 0,66 & 0,78\end{array}$ & $\begin{array}{llll}0,54 & 0,62 & 0,73 & 0,82\end{array}$ \\
\hline PBM & $\begin{array}{llll}0,31 & 0,42 & 0,66 & 0,86\end{array}$ & $\begin{array}{lllll}0,47 & 0,59 & 0,72 & 0,86\end{array}$ & $\begin{array}{lllll}0,38 & 0,47 & 0,67 & 0,85\end{array}$ \\
\hline Dunn & $\begin{array}{lllll}0,37 & 0,53 & 0,72 & 0,86 \\
\end{array}$ & $\begin{array}{lllll}0,51 & 0,63 & 0,75 & 0,85 \\
\end{array}$ & $\begin{array}{lllll}0,43 & 0,58 & 0,74 & 0,87 \\
\end{array}$ \\
\hline$D B$ & $\begin{array}{llll}0,72 & 0,83 & 0,85 & 0,90\end{array}$ & $\begin{array}{lllll}0,60 & 0,65 & 0,72 & 0,83\end{array}$ & $\begin{array}{llll}0,72 & 0,82 & 0,86 & 0,89\end{array}$ \\
\hline
\end{tabular}

Tabela 6.7: Médias das similaridades entre os conjuntos seleção formados por meio das CIR e de cada índice de validação individualmente para o conjunto Artificial1.

\begin{tabular}{|c|c|c|c|}
\hline & Soma dos Ranks (SR) & Melhor Posição (MP) & Soma com Diversidade (SD) \\
\hline Silhueta S. & $\begin{array}{lllll}0,73 & 0,82 & 0,87 & 0,90\end{array}$ & $\begin{array}{lllll}0,58 & 0,65 & 0,71 & 0,81\end{array}$ & $\begin{array}{lllll}0,64 & 0,71 & 0,75 & 0,83\end{array}$ \\
\hline Silhueta M.S. & $\begin{array}{lllll}0,67 & 0,76 & 0,83 & 0,88\end{array}$ & $\begin{array}{lllll}0,55 & 0,62 & 0,68 & 0,79\end{array}$ & $\begin{array}{lllll}0,58 & 0,65 & 0,72 & 0,81\end{array}$ \\
\hline$V R C$ & $\begin{array}{llllll}0,51 & 0,62 & 0,75 & 0,86\end{array}$ & $\begin{array}{lllll}0,51 & 0,57 & 0,65 & 0,79\end{array}$ & $\begin{array}{lllll}0,48 & 0,56 & 0,66 & 0,80\end{array}$ \\
\hline PBM & $\begin{array}{llll}0,45 & 0,57 & 0,75 & 0,88\end{array}$ & $\begin{array}{llll}0,51 & 0,63 & 0,75 & 0,85\end{array}$ & $\begin{array}{llll}0,56 & 0,68 & 0,81 & 0,87\end{array}$ \\
\hline Dunn & $\begin{array}{lllll}0,37 & 0,49 & 0,68 & 0,84\end{array}$ & $\begin{array}{llll}0,48 & 0,59 & 0,74 & 0,85\end{array}$ & $\begin{array}{lllll}0,44 & 0,59 & 0,78 & 0,87\end{array}$ \\
\hline$D B$ & $\begin{array}{llllll}0,69 & 0,75 & 0,79 & 0,86\end{array}$ & $\begin{array}{lllll}0,55 & 0,61 & 0,68 & 0,81\end{array}$ & $\begin{array}{llll}0,65 & 0,68 & 0,73 & 0,84\end{array}$ \\
\hline
\end{tabular}

Tabela 6.8: Médias das similaridades entre os conjuntos seleção formados por meio das CIR e de cada índice de validação individualmente para o conjunto Artificial2.

\begin{tabular}{|c|c|c|c|}
\hline & Soma dos Ranks (SR) & Melhor Posição (MP) & Soma com Diversidade (SD) \\
\hline Silhueta S. & $\begin{array}{lllll}0,74 & 0,80 & 0,86 & 0,90\end{array}$ & $\begin{array}{lllll}0,66 & 0,68 & 0,73 & 0,81\end{array}$ & $\begin{array}{lllll}0,72 & 0,78 & 0,80 & 0,84\end{array}$ \\
\hline Silhueta M.S. & $\begin{array}{lllll}0,75 & 0,81 & 0,86 & 0,89\end{array}$ & $\begin{array}{lllll}0,65 & 0,66 & 0,71 & 0,80\end{array}$ & $\begin{array}{lllll}0,74 & 0,79 & 0,80 & 0,83\end{array}$ \\
\hline$V R C$ & $\begin{array}{lllll}0,59 & 0,67 & 0,75 & 0,85\end{array}$ & $\begin{array}{lllll}0,53 & 0,55 & 0,64 & 0,79\end{array}$ & $\begin{array}{lllll}0,58 & 0,64 & 0,68 & 0,80\end{array}$ \\
\hline PBM & $\begin{array}{lllll}0,66 & 0,74 & 0,79 & 0,87\end{array}$ & $\begin{array}{lllll}0,59 & 0,63 & 0,71 & 0,84\end{array}$ & $\begin{array}{lllll}0,65 & 0,71 & 0,75 & 0,85\end{array}$ \\
\hline Dunn & $\begin{array}{llll}0,33 & 0,38 & 0,61 & 0,82\end{array}$ & $\begin{array}{llll}0,49 & 0,52 & 0,70 & 0,84\end{array}$ & $\begin{array}{lllll}0,37 & 0,43 & 0,68 & 0,86\end{array}$ \\
\hline$D B$ & $\begin{array}{llll}0,55 & 0,62 & 0,75 & 0,87\end{array}$ & $\begin{array}{lllll}0,58 & 0,65 & 0,71 & 0,81\end{array}$ & $\begin{array}{lllll}0,58 & 0,65 & 0,75 & 0,85\end{array}$ \\
\hline
\end{tabular}

Tabela 6.9: Médias das similaridades entre os conjuntos seleção formados por meio das CIR e de cada índice de validação individualmente para o conjunto Artificials.

Os resultados apresentados nas Tabelas 6.7, 6.8 e 6.9 mostram que a similaridade média entre os conjuntos de partições selecionados pelos métodos de combinação e pelos índices aplicados individualmente está acima de $50 \%$ na grande maioria dos casos estudados. Isto é válido também para os casos em que o conjunto seleção é muito menor do que o conjunto total dos dados (10\% e $25 \%$ do total de partições). Os métodos SR e SD refletem menos as avaliações feitas com os índices Dunn e PBM, o que é esperado, uma vez que a análise feita na Seção 6.3.1 concluiu que esses índices são instáveis e os métodos de CIR devem refletir a avaliação feita pela maioria de seus membros. Em contrapartida, o método MP obteve conjuntos seleção com valores médios de similaridade acima de 0,5 para todos os índices investigados. Em resumo, a análise dos resultados permite concluir que os três métodos de combinação possuem representatividade em relação a todos os índices combinados.

Adicionalmente aos métodos de CIR, foi investigado o uso explícito da diversidade em CES com base nas metodologias propostas em (Hadjitodorov et al., 2006; Fern \& Lin, 2008; Azimi \& Fern, 2009). O método utilizado aqui será referenciado como diversity e consiste nos 3 passos a seguir:

1. Inicializa o conjunto seleção com a partição de maior diversidade média em relação às outras partições do conjunto total, de forma que o valor da diversidade seja calculado pela Equação (6.1). 
2. Iterativamente, adiciona-se ao conjunto seleção a partição de maior diversidade média entre as outras partições do conjunto seleção.

3. O método de seleção termina quando o número desejado de partições base é selecionado.

Assim como todos os outros métodos de CES propostos, o método diversity foi utilizado para gerar conjuntos seleção com 10\%, 25\%, 50\% e 75\% do total de partições base geradas para cada conjunto de dados.

\subsubsection{Experimentos}

Uma vez que os índices de validação combinados mostraram diversidade em relação às partições selecionadas e os métodos de CIR propostos apresentam representatividade em relação aos índices combinados, a metodologia experimental utilizada na Seção 6.3.2 é adotada para avaliar os métodos propostos na Seção 6.4.2.

Partições consenso com $k$ grupos foram geradas com as funções de consenso $C A A, C A S$, CSPA, HGPA e MCLA a partir dos conjuntos seleção contendo $10 \%, 25 \%, 50 \%$ e $75 \%$ do conjunto total, obtidos com os métodos apresentados na Seção 6.4.2. Os valores médios do índice Jaccard das partições finais em relação à partição conhecida são apresentados em forma de curvas nas Figuras 6.9, 6.10 e 6.11, de forma que o eixo das ordenadas indica o valor médio do índice Jaccard e o eixo das abscissas indica a proporção de partições base selecionadas em cada conjunto de dados. Em cada figura são apresentados três gráficos, um para cada grande conjunto de dados artificiais. A primeira linha da legenda, de cima para baixo, indica o maior valor resultante entre todos os CES baseados em um único índice relativo (MRI, Maior Resultado dos Índices relativos), apresentado na Seção 6.3.2.2 e utilizado aqui para fins de comparação. A segunda linha indica a média dos valores obtidos por todos os CES baseados um único índice relativo (MI, Média dos Índices relativos), ou seja, a média dos valores apresentados na Seção 6.3.2.2 e mostrada aqui para permitir comparações. As três linhas seguintes fazem referência aos três métodos de combinação de índices: SR, MP e SD. A última linha indica os valores médios do índice Jaccard para o método de CES diversity. Os mesmos testes utilizados na Seção 6.3.2.2 são adotados aqui para verificar se existe diferença estatisticamente comprovada com 95\% de confiança entre os valores das $A U C$ s obtidas. O método de $C E S$ que resultou no maior valor médio de $A U C$ e os métodos cujos resultados não possuem diferença estatística significante em relação a ele são apresentados com uma estrela ( $\mathcal{\zeta}$ ) na legenda. Nos casos em que não há diferença estatística comprovada, todos os métodos são apresentados sem estrelas.

De maneira geral, em relação às funções de consenso $C A A, C A S$ e $M C L A$, o uso CIR quando aplicado aos conjuntos Artificial1 e Artificial2 obteve resultados com qualidade acima da média dos resultados obtidos com o uso individual dos índices de validação relativos. Para o conjunto Artificial3, CIR apresentou um desempenho equivalente ao 

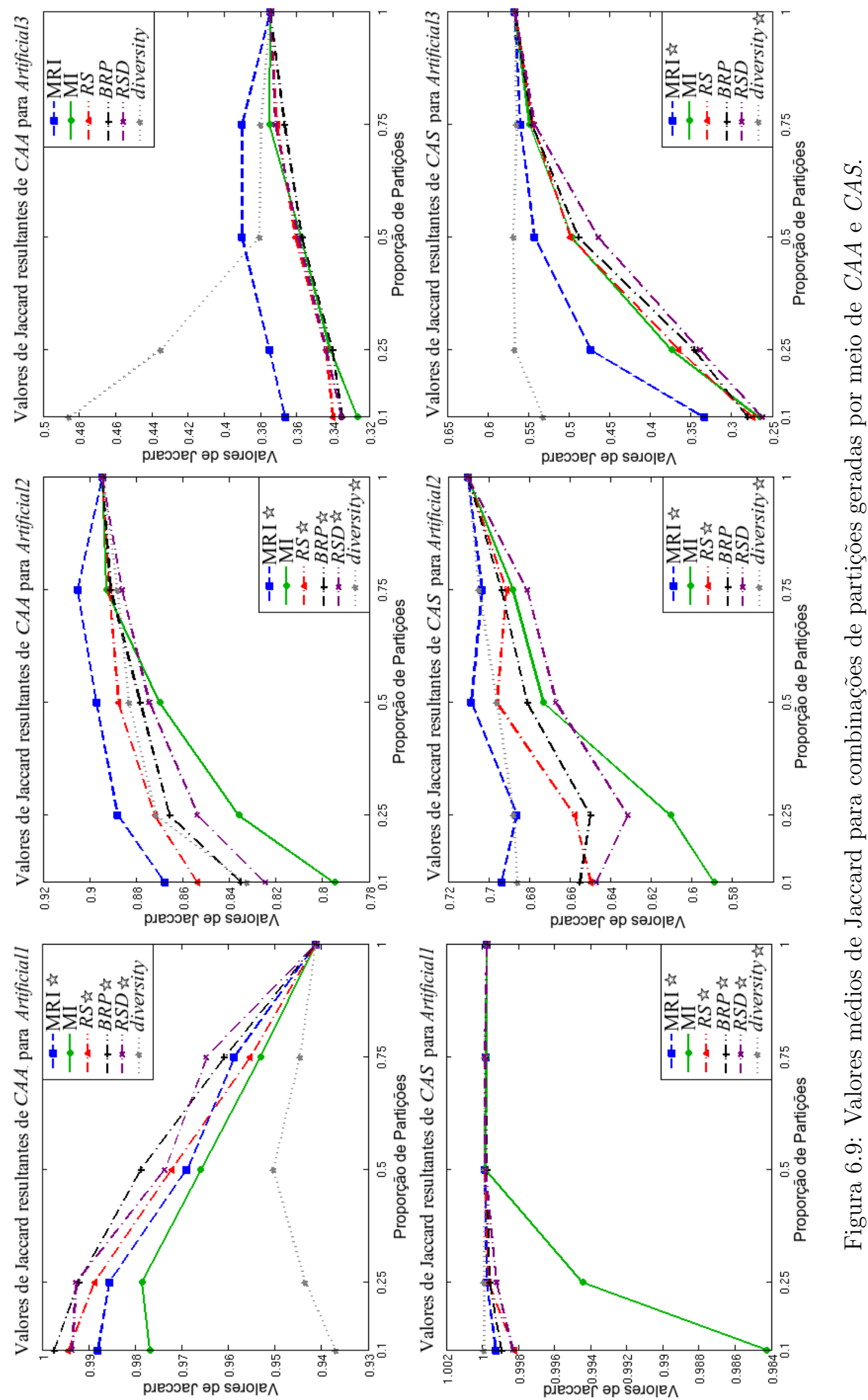

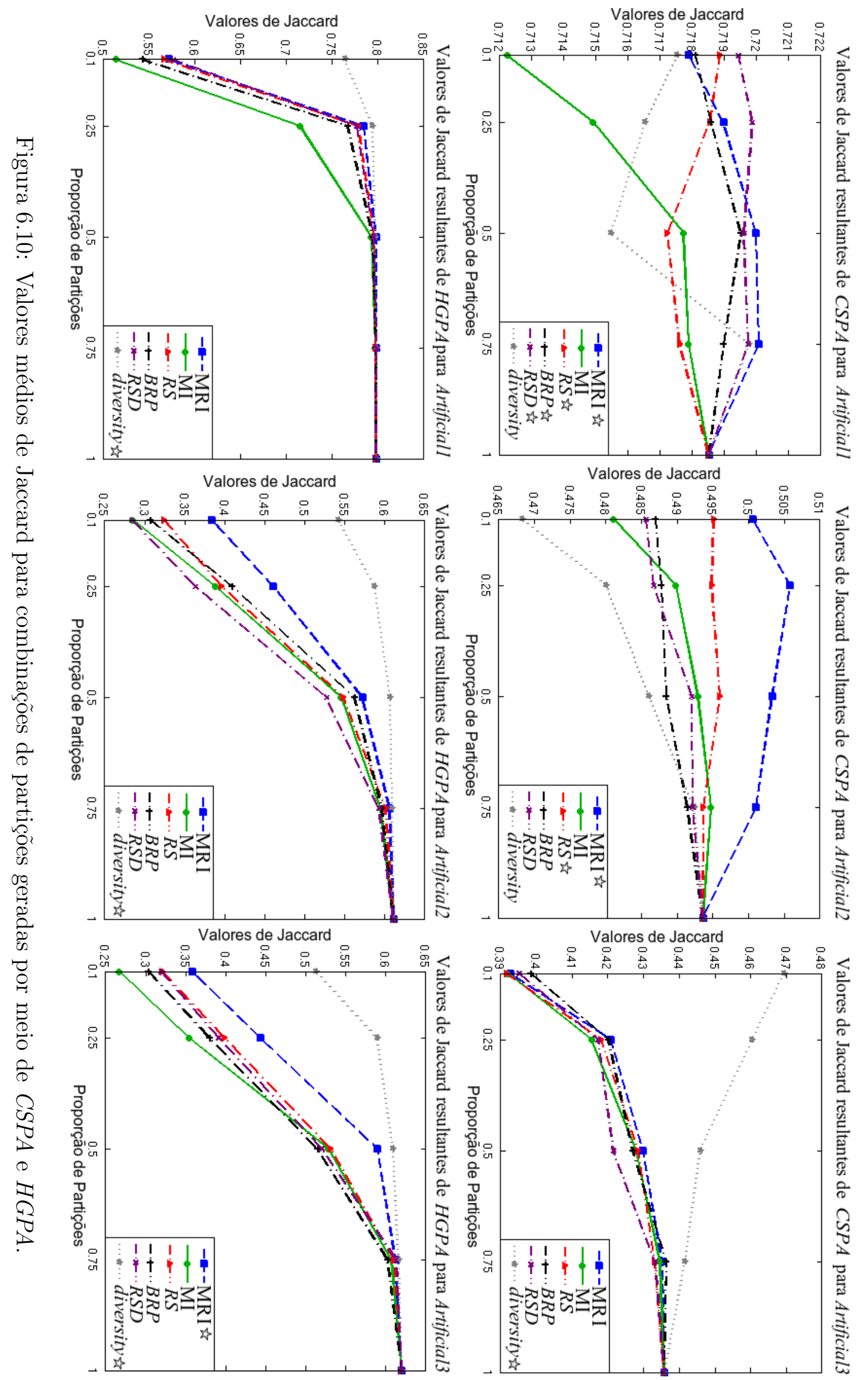

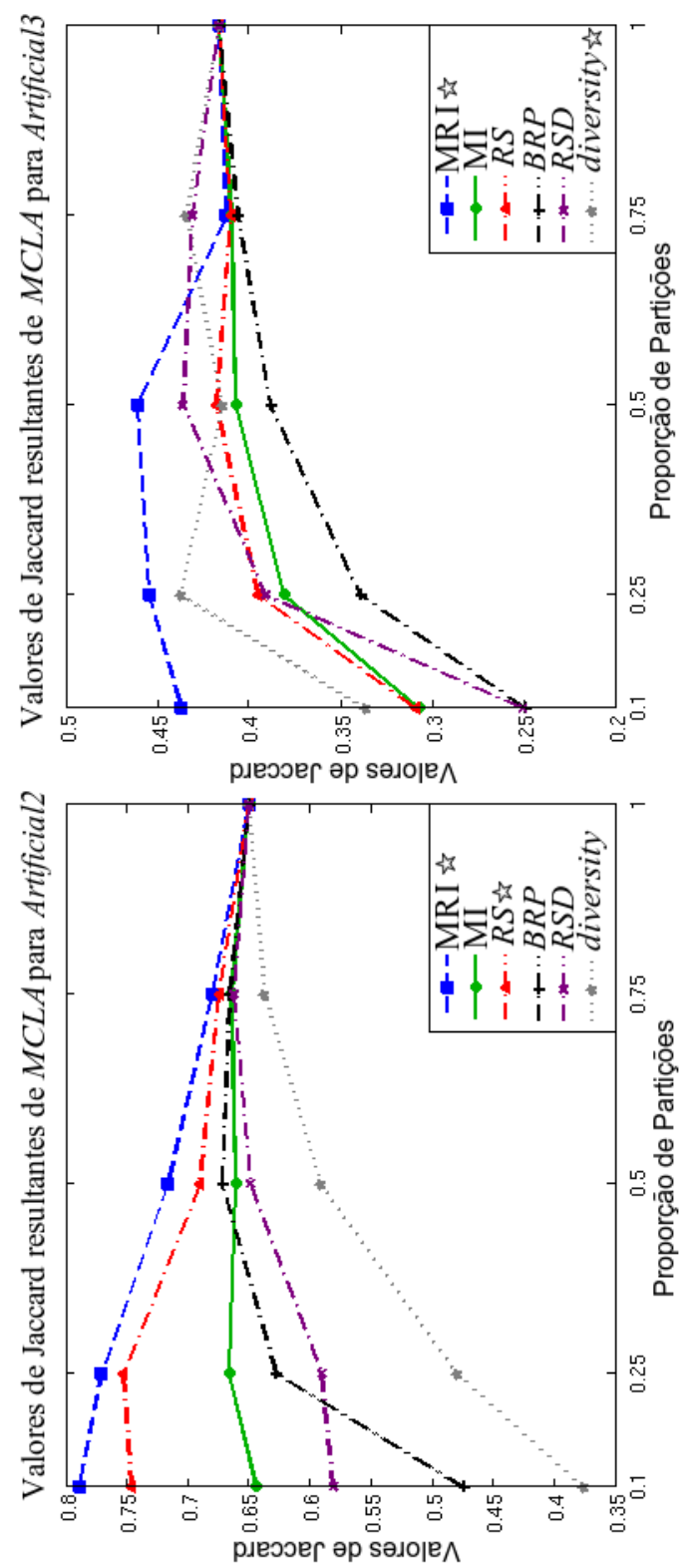

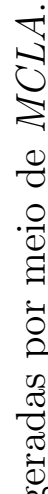

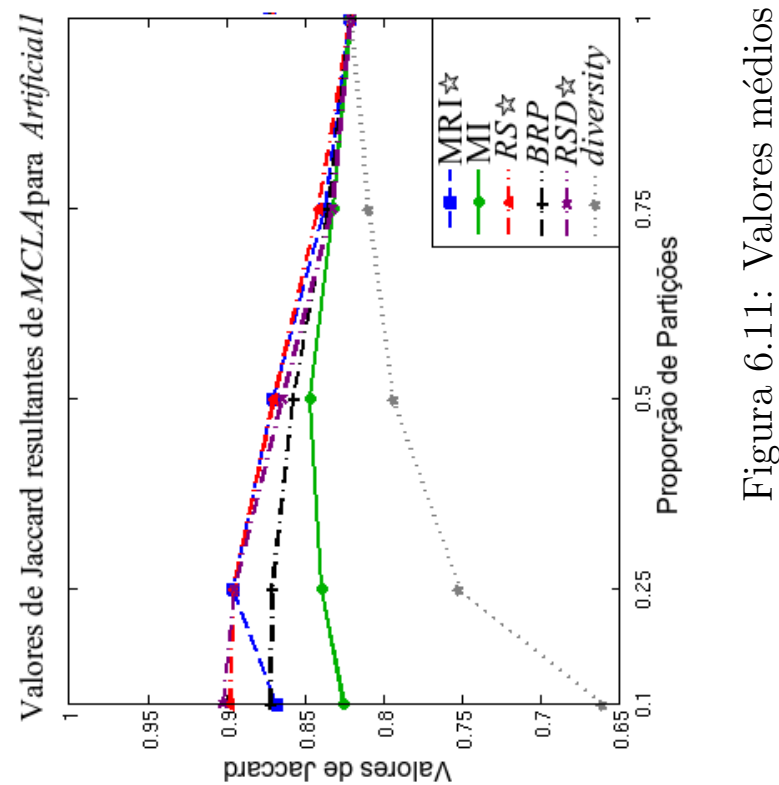


desempenho médio resultante do uso individual dos índices de validação relativos. Esses resultados mostram que o uso de CIR é uma boa alternativa na prática, em que, de maneira geral, não há como saber qual seria o melhor índice de validação a ser escolhido. Destaque para o método SR, que foi considerado equivalente ao melhor resultado em 6 dos 9 gráficos das Figuras 6.9 e 6.11 .

A diferença entre os valores de Jaccard resultantes do uso de CIR em relação à combinação total não foi significativa quando a função CSPA foi utilizada, como é mostrado na Figura 6.10. Esse resultado é interessante em cenários em que objetiva-se reduzir a quantidade de partições base combinadas. Contudo, é possível ver que existe diferença entre os valores obtidos por meio do método diversity e as CIR, que varia com o conjunto de dados, como pode ser visto na Figura 6.10. Para a função $H G P A$, o uso de $C E S$ baseados em CIR reduziu a qualidade das partições consenso obtidas e é desaconselhado, conforme já havia sido discutido para CES com índices de validação individuais na Seção 6.3.2.2.

Em resumo, o desempenho dos métodos de CIR foi próximo do melhor desempenho obtido pelos índices de validação individualmente, o que sugere que o uso de CIR é uma alternativa interessante por garantir um desempenho satisfatório, mais robusto e potencialmente melhor que aquele proporcionado pelos piores índices de validação relativos individualmente.

O método diversity seleciona as partições base mais distintas entre si, que evidenciam informações complementares sobre os conjunto de dados. Isso fez com que seu uso aprimorasse a média da qualidade das partições finais geradas para o conjunto Artificial3, obtendo os melhores resultados na maioria das funções investigadas. Entretanto, como partições base de boa qualidade foram obtidas para os conjuntos Artificial1 e Artificial2, o método diversity reduziu a qualidade da partição final selecionando partições de menor qualidade para a combinação, como pode ser visto nas Figuras 6.9-6.11.

\subsection{Síntese dos resultados e aplicação}

Os resultados apresentados nas Seções 6.3 e 6.4 permitem concluir que os métodos de CES investigados podem gerar partições consenso de qualidade igual ou melhor do que as partições obtidas a partir de todo o conjunto de partições se as partições base selecionadas forem capazes de caracterizar a estrutura procurada do conjunto de dados. De um lado, nos casos em que as partições base apresentam semelhança com a estrutura desejada, como são os casos dos conjuntos Artificial1 e Artificial2, subconjuntos selecionados por métodos de $C E S$ guiados por índices de validação relativos tendem a aprimorar a partição final. Nesses casos, o uso de CIR se mostrou vantajoso se não há conhecimento prévio sobre qual seria o desempenho dos índices de validação escolhidos, o que ocorre em geral na prática. Por outro lado, em casos em que as partições base apresentam pouca similaridade com a estrutura procurada, como é o caso do conjunto Artificial3, utilizar a combinação total gera maior acúmulo de evidência sobre a estrutura do conjunto de 
dados e, consequentemente, soluções melhores. Métodos de $C E S$ baseados em diversidade também mostraram bons resultando para esses casos, pois integram informações complementares sobre a estrutura dos dados. Contudo, dependendo do método utilizado, calcular a diversidade entre partições de um conjunto pode possuir complexidade computacional maior do que efetuar a combinação total. A função diversity, por exemplo, possui custo computacional $O\left(n_{o}^{2} \cdot n_{\pi}^{2}\right)$, o que pode superar a complexidade das funções de consenso utilizadas neste capítulo, presentes na Tabela 6.10 .

Funções consenso distintas apresentaram diferentes resultados para o uso de métodos de $C E S$ baseados em índices de validação. Algumas funções de consenso, como a $M C L A$ e CSPA, resultaram em partições finais de qualidade mais alta ou equivalente ao uso da combinação total para quase todos os conjuntos de dados estudados. Isso só não ocorreu nos conjuntos em que os índices de validação não selecionam partições que se aproximem das partições de referência (minoria dos conjuntos de dados). Aplicar CES é recomendado para essas funções, mesmo que obtenha partições de qualidade equivalente ao uso da combinação total, pois reduz o número de partições base combinadas e, conseqüentemente, o custo computacional da combinação. Já as melhores partições consenso obtidas pela função $H G P A$ foram geradas com uso da combinação total. As funções $C A A$ e $C A S$ obtiveram bons resultados com uso de $C E S$ e com o uso da combinação total para diferentes conjuntos de dados, o que indica que a qualidade da partição final gerada por estas funções também é influenciada por fatores independentes do processo de $C E S$, como a complexidade do conjunto de dados e características intrínsecas aos algoritmos hierárquicos utilizados. Ou seja, para essas funções não foi possível definir qual método obtém melhores resultados, de forma que é recomendado gerar partições consenso com ambos os métodos. O tipo de combinação (com o uso de CES ou combinação total) que obteve os melhores resultados para cada função de consenso na maioria dos experimentos também é apresentado na Tabela 6.10 .

\begin{tabular}{|c|c|c|}
\hline Função & Complexidade & Combinação de melhor resultado \\
\hline \hline CAS & $O\left(n_{o}^{2} \cdot \log n_{o}\right)$ & indefinido \\
\hline CAA & $O\left(n_{o}^{2} \cdot \log n_{o}\right)$ & indefinido \\
\hline CSPA & $O\left(n_{o}^{2} \cdot k \cdot n_{\pi}\right)$ & $C E S$ \\
\hline HGPA & $O\left(n_{o} \cdot k^{2} \cdot n_{\pi}^{2}\right)$ & combinação total \\
\hline MCLA & $O\left(n_{o} \cdot k \cdot n_{\pi}^{2}\right)$ & $C E S$ \\
\hline
\end{tabular}

Tabela 6.10: Características das funções de consenso estudadas.

A grande variedade de resultados obtidos nesse trabalho dificulta encontrar uma solução para seguinte questão: "O que fazer para obter bons resultados com combinações de agrupamentos em situações práticas, em que informações sobre o conjunto de dados, conjunto de partições base, funções de consenso e índices de validação são escassas ou até mesmo não existentes?". Estabelecer uma única metodologia que possa obter os melhores resultados para todos os tipos de cenários sem nenhum conhecimento prévio é uma tarefa temerosa, pois diferentes métodos mostram desempenhos distintos em diferentes cenários. Entretanto, é possível selecionar, dentre um conjunto de soluções obtidas, partições que 
possuam uma maior probabilidade de apresentar boa qualidade. Essas partições serão chamadas neste trabalho de partições candidatas.

Com a finalidade de orientar o uso mais eficiente de métodos de $C E S$, um arcabouço que sintetiza alguns passos a serem utilizados na obtenção de partições candidatas é proposto. Esse arcabouço constitui uma simples generalização, desenvolvida a partir da análise dos resultados apresentados nas Seções 6.3 e 6.4, para a aplicação de métodos de CES. Seus passos principais são resumidos no fluxograma presente na Figura 6.12, de forma que alguns deles são detalhados nos itens enumerados de 1 a 5 .

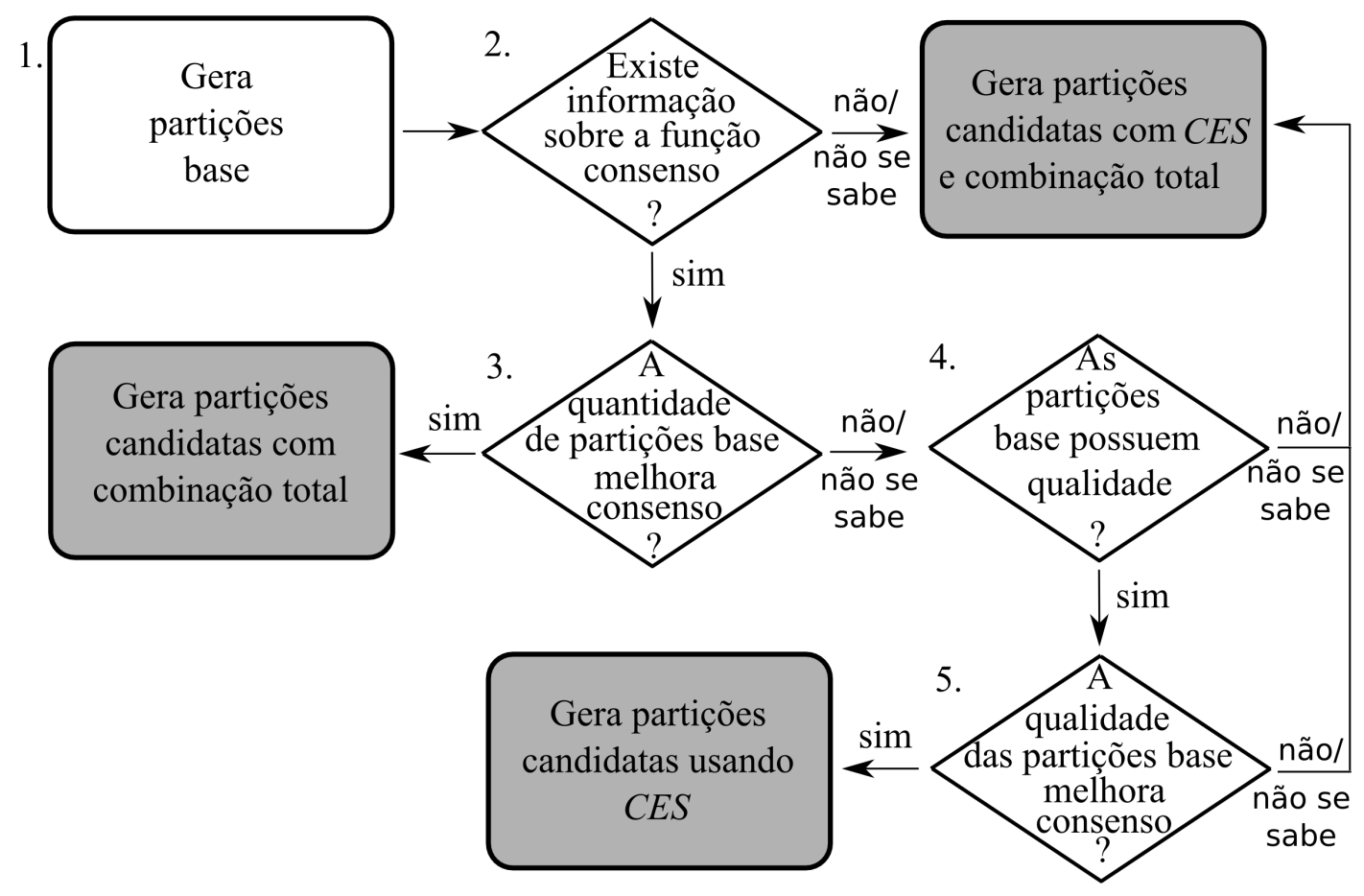

Figura 6.12: Arcabouço proposto para melhor utilização de métodos de $C E S$.

1. O primeiro passo consiste em gerar as partições base. Diversos métodos com esse objetivo foram apresentados na Seção 5.2, sendo que a maioria deles pode ser utilizada aqui.

2. Informações prévias sobre o comportamento da função de consenso podem ser utilizadas para escolher entre o uso de $C E S$ e a combinação total. Caso contrário, ambos os processos podem ser utilizados para gerar partições candidatas.

3. Algumas funções de consenso apresentam melhores resultados com o aumento do número de partições base (segundo os experimentos apresentados neste capítulo, a função $H G P A$ ), o que faz com que utilizar $C E S$ produza resultados de qualidade inferior. Para essas funções, o uso da combinação total mostrou ser a melhor solução.

4. Para que a utilização de CES seja bem sucedida é necessário que o conjunto de partições base selecionado seja capaz de caracterizar a estrutura procurada do conjunto de dados, ou seja, possua qualidade. Uma forma de se obter essa informação 
consiste em consultar um especialista que possa avaliar a qualidade das partições base obtidas. Uma outra forma, requer que haja conhecimento prévio sobre o bom desempenho dos índices de validação escolhidos para o processo de CES quando utilizados em partições de conjuntos de dados semelhantes ao da aplicação. Para isso, são necessárias duas coisas: conhecer a natureza do conjunto de dados e haver estudos sobre o comportamento dos índices de interesse quando aplicados em dados dessa natureza. Por exemplo, os trabalhos publicados por Milligan \& Cooper $(1985)$ e Vendramin et al. $(2009,2010)$ estudam os comportamentos de vários índices de validação relativos (incluindo os índices selecionados para este trabalho) quando aplicados em conjuntos de dados com grupos de distribuição Gaussianas. Caso esse comportamento não seja conhecido, é indicado gerar partições consenso (candidatas) com e sem o uso de CES.

5. Os resultados dos experimentos apresentados neste capítulo mostram que o aumento na qualidade das partições base faz com que algumas funções de consenso, como a MCLA e CSPA, resultem em partições de qualidade melhor ou semelhante às obtidas com a combinação total para a maioria dos cenários investigados. Para esses casos, o uso de $C E S$ é recomendado.

Como afirmado anteriormente, o arcabouço ilustrado na Figura 6.12 consiste apenas em uma generalização e solução indicada deve variar conforme a função de consenso utilizada e a qualidade das partições base. Considerando apenas as funções de consenso investigadas, a combinação total é indicada no caso da função de consenso ser a $H G P A$ (referente ao Passo 3 do arcabouço). Se as funções $M C L A$ ou CSPA forem utilizadas e as partições selecionadas possuírem qualidade, segundo um determinado índice ou CIR, para o conjunto de dados, o uso de CES é indicado (referente aos Passos 4 e 5 do arcabouço). Para os outros casos, tanto o uso da combinação total, quanto o uso de CES são indicados.

Obter um conjunto de partições consenso (candidatas) por meio da combinação total ou do uso de $C E S$ pode não ser uma alternativa interessante para aplicações em que se espera obter uma única partição. Para essas aplicações, é aconselhado aplicar um índice de validação relativo ou uma CIR nas partições candidatas obtidas e selecionar a partição melhor avaliada.

\subsubsection{Aplicação em conjuntos de dados reais}

Com o objetivo de avaliar o arcabouço proposto, experimentos foram executados com os cinco conjuntos de dados reais apresentados na Seção 6.2. Assim como foi feito para os conjuntos de dados artificiais, $n_{\pi}=10$ partições base com diferentes protótipos foram geradas por meio do algoritmo $k$-médias com valores de $k$ variando no intervalo $\left[2, \sqrt{n_{o}}\right]$ para cada conjunto de dados reais. Sem seguida, as partições base foram avaliadas e as correlações entre os índices de validação relativos e o índice externo de Jaccard foram 
calculadas por meio da correlação de Pearson (Seção 2.3.2). Os valores das correlações resultantes são apresentados na Tabela 6.11.

\begin{tabular}{|c|c|c|c|c|c|c|}
\hline & Silhueta S. & Silhueta M.S. & $V R C$ & PBM & Dunn & $D B$ \\
\hline Iris & 0,1474 & $-0,2119$ & 0,4638 & 0,2595 & 0,2626 & $-0,0956$ \\
\hline Wine & 0,9257 & 0,9310 & 0,9271 & 0,9194 & 0,8679 & $-0,8888$ \\
\hline Breast & 0,3736 & 0,7243 & 0,2823 & 0,1917 & 0,8882 & $-0,1500$ \\
\hline Chart & $-0,5532$ & $-0,5541$ & $-0,0431$ & 0,4636 & $-0,5287$ & 0,2027 \\
\hline Yeast & 0,9723 & 0,9517 & 0,9747 & 0,9856 & 0,9680 & $-0,8848$ \\
\hline
\end{tabular}

Tabela 6.11: Correlações entre os valores dos índices de validação relativos e do índice Jaccard sobre os conjuntos de dados reais estudados.

Uma análise da Tabela 6.11 permite concluir que a maioria dos índices de validação relativos estudados tendem a selecionar partições base que pouco se assemelham com a partição de referência para os conjuntos de dados Iris e Chart. Para o restante dos conjuntos de dados, a maioria das correlações possui valores acima de 0,7 , o que indica que os índices estudados resultam em valores de validação maiores quando as partições avaliadas para esses conjuntos se assemelham com as partições de referência. Lembrando novamente que, ao contrário dos outros índices relativos escolhidos, o valor resultante do índice $D B$ decresce com a qualidade da partição avaliada. Isso justifica valores expressivos de correlação negativa para esse índice.

As correlações presentes na Tabela 6.11 auxiliam na interpretação dos resultados dos experimentos referentes aos conjuntos de dados reais estudados, pois mostram em quais conjuntos os índices de validação escolhidos selecionam partições semelhantes as partições de referência. Esses valores estão relacionados ao Passo 5 do arcabouço ilustrado na Figura 6.12, em que o conhecimento prévio sobre o desempenho dos índices aplicados determina o uso de $C E S$. Entretanto, esse tipo de conhecimento nem sempre existe, especialmente em aplicações práticas. Caso não haja conhecimento prévio sobre o desempenho dos índices aplicados, recomenda-se gerar partições candidatas com e sem o uso de $C E S$.

Após a geração das partições base e do cálculo das correlações entre os índices relativos estudados e o índice externo de Jaccard, experimentos foram realizados com a finalidade de comparar as técnicas que obtiveram melhores resultados nas Seções 6.3 e 6.4, bem como verificar se a solução indicada resulta em partições de qualidade igual ou melhor do que os outros métodos comparados. Diferentemente dos experimentos nas Seções 6.3 e 6.4, nesta seção os valores do índice Jaccard das partições consenso em relação às classes conhecidas serão comparados sem a utilização de $A U C$ s. Esta abordagem foi adotada porque o uso da combinação total gera uma única partição. Adicionalmente, selecionar um único resultado para cada método simplifica a comparação. Por esses motivos, apenas conjuntos seleção formados com $10 \%$ do conjunto total serão comparados aqui. Esse percentual foi escolhido por selecionar uma quantidade menor de partições base, o que reduz o custo computacional da combinação e, ao mesmo tempo, por obter resultados de boa qualidade para a maioria dos casos estudados.

A seguir, são apresentados os métodos comparados nos experimentos desta seção: 
1. Combinação Total: consiste em aplicar a combinação de todas as partições base.

2. diversity: método de $C E S$ que possui como objetivo selecionar as partições base de maior diversidade em relação às outras partições base (Seção 6.4.2).

3. CES Silhueta S.: método de CES que utiliza o índice silhueta simplificada individualmente. Esse método será comparado aqui por ter apresentado um bom desempenho nos experimentos da Seção 6.3.

4. CES RS: método de CES que utiliza o CIR RS (Seção 6.4.2). Esse método será comparado aqui por ter apresentado um bom desempenho nos experimentos da Seção 6.4.

5. Melhor avaliado (MA): consiste em avaliar as partições consenso resultantes dos métodos anteriores (enumerados de 1 à 4) com algum índice de validação relativo ou CIR. Em seguida, a partição melhor avaliada é escolhida como o resultado do método. Esse método é equivalente a gerar partições candidatas com CES e combinação total (vide arcabouço ilustrado na Figura 6.12) e, em seguida, avaliar e selecionar a melhor partição candidata como resultado. Ele é recomendado para casos em que não se conhece o desempenho do uso conjunto de $C E S$ com a função de consenso ou o desempenho dos índices relativos utilizados no processo de CES.

É importante destacar que o método MA aplica índices de validação para avaliar e selecionar as partições consenso geradas por outros métodos de combinação, ou seja, as partições avaliadas por esse método estão em um segundo nível, como é mostrado na Figura 6.13. Neste trabalho, a CIR SR (Seção 6.4.2) foi escolhida para avaliar as partições consenso geradas pelos métodos 1-4 e selecionar a melhor partição. Isso foi feito por um conjunto de motivos: CIR são recomendados para aplicações práticas, em que não se conhece o desempenho dos índices de validação relativos de interesse; a CIR SR obteve os melhores resultados entre as CIR nos experimentos apresentados na Seção 6.4; ela possui complexidade computacional linear em relação ao número de objetos $\left(O\left(n_{o}\right)\right)$, o que a torna aplicável em problemas práticos.

Os métodos comparados foram executados 30 vezes para cada conjunto de dados. Os resultados foram avaliados com o índice externo Jaccard em relação às partições de referência. Os mesmos testes de hipóteses utilizados nas Seções 6.3.2 e 6.4.3 foram aplicados para comprovar diferença significativa entre os valores do índice Jaccard obtidos para métodos diferentes. As médias e os desvios padrões desses valores são apresentados nas Tabelas 6.12-6.16. As melhores médias e as médias cujas diferenças estatísticas em relação aos melhores resultados não foram comprovadas pelos testes serão apresentadas em negrito nessas tabelas. 


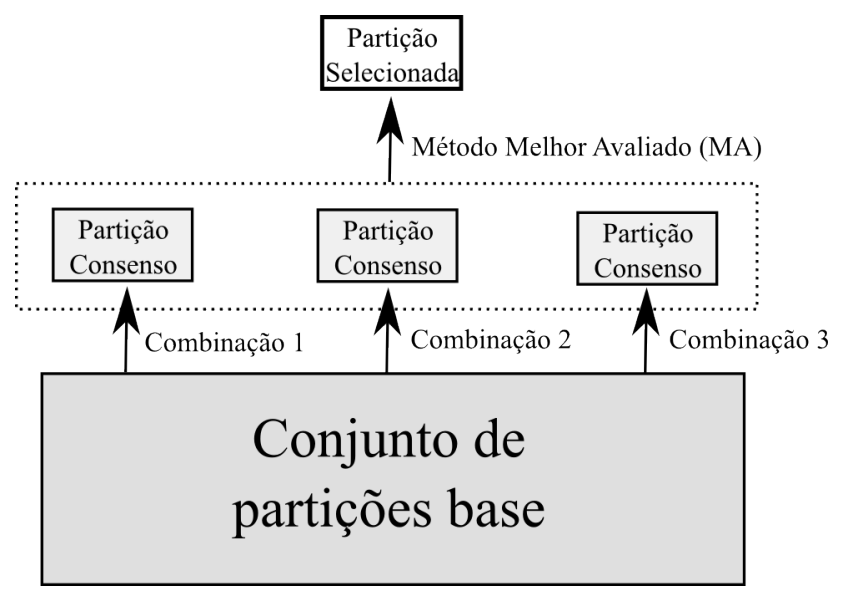

Figura 6.13: Ilustração da aplicação do método MA.

\section{Resultados para CAA}

A função de consenso $C A A$ mostra bons resultados com uso de $C E S$ e com o uso da combinação total nas Seções 6.3 e 6.4, o que indica que a qualidade da partição final gerada por esta função é influenciada por fatores independentes do processo de CES, como a complexidade do conjunto de dados e características intrínsecas ao algoritmo hierárquico utilizado. Por isso, foi indicada a geração de partições candidatas com e sem o uso de CES para essa função de consenso na Seção 6.5. Neste experimento, isso é equivalente ao método MA.

\begin{tabular}{|c|c|c|c|c|c|}
\hline & Combinação Total & diversity & $C E S$ Silhueta S. & $C E S R S$ & Melhor Avaliado (MA) \\
\hline Iris & $\mathbf{0 , 6 5 1 1}(\mathbf{0 , 0 2})$ & $\mathbf{0 , 6 6 2 0}(\mathbf{0 , 0 7})$ & $\mathbf{0 , 6 4 5 5}(\mathbf{0 , 0 5})$ & $0,5877(0,00)$ & $\mathbf{0 , 6 7 5 0}(\mathbf{0 , 0 5})$ \\
\hline Wine & $\mathbf{0 , 8 8 5 4}(\mathbf{0 , 0 3})$ & $0,7348(0,13)$ & $0,7972(0,07)$ & $0,7975(0,03)$ & $0,8112(0,03)$ \\
\hline Breast & $0,8526(0,02)$ & $0,8470(0,02)$ & $\mathbf{0 , 8 7 1 9}(\mathbf{0 , 0 0})$ & $\mathbf{0 , 8 7 2 0}(\mathbf{0 , 0 0})$ & $\mathbf{0 , 8 7 1 6}(\mathbf{0 , 0 0})$ \\
\hline Chart & $\mathbf{0 , 5 6 9 1}(\mathbf{0 , 0 3})$ & $\mathbf{0 , 5 6 9 8}(\mathbf{0 , 0 3})$ & $\mathbf{0 , 5 4 7 2}(\mathbf{0 , 0 5})$ & $\mathbf{0 , 5 3 8 5}(\mathbf{0 , 0 4})$ & $\mathbf{0 , 5 3 3 4}(\mathbf{0 , 0 4})$ \\
\hline Yeast & $\mathbf{0 , 9 7 3 7}(\mathbf{0 , 0 0})$ & $\mathbf{0 , 9 5 7 7}(\mathbf{0 , 0 6})$ & $0,8564(0,00)$ & $0,8561(0,00)$ & $\mathbf{0 , 9 7 2 5}(\mathbf{0 , 0 0})$ \\
\hline
\end{tabular}

Tabela 6.12: Médias e desvios padrões dos valores do índice Jaccard para combinações resultantes da função $C A A$.

Os resultados presentes na Tabela 6.12 indicam que a função $C A A$ obteve os melhores resultados com o uso da combinação total para alguns conjuntos de dados e com o uso de CES para outros, o que reflete os resultados apresentados nas Seções 6.3 e 6.4. Adicionalmente, o método MA obteve resultados sem diferença estatística significativa em relação aos resultados de maior valor médio de Jaccard, para todos os conjuntos de dados com exceção do Wine. Apesar da média de Jaccard das soluções selecionadas pelo MA para o conjunto Wine ser inferior à obtida com o uso da combinação total, ela é superior às médias resultantes dos métodos de $C E S$. Em resumo, a análise dos resultados não indica ou contra-indica o uso exclusivo de $C E S$ para essa função de consenso. Entretanto, selecionar partições consenso geradas por meio do uso da combinação total e métodos de $C E S$ mostrou ser uma boa escolha para a função $C A A$. 


\section{Resultados para CAS}

Assim como a função $C A A$, a função de consenso $C A S$ mostrou sofrer influência de fatores independentes do processo de $C E S$, como a complexidade do conjunto de dados e características intrínsecas ao algoritmo hierárquico utilizado, como é mostrado nos experimentos feitos nas Seções 6.3 e 6.4. Ou seja, essa função apresenta bons resultados com uso de $C E S$ e com o uso da combinação total. Neste experimento, aplicar o método MA resulta na partição melhor avaliada dentre as geradas pelos outros métodos comparados e é recomendado para a função $C A S$.

\begin{tabular}{|c|c|c|c|c|c|}
\hline & Combinação Total & diversity & CES Silhueta S. & $C E S R S$ & Melhor Avaliado (MA) \\
\hline Iris & $\mathbf{0 , 6 6 7 9}(\mathbf{0 , 1 3})$ & $0,5686(0,06)$ & $\mathbf{0 , 6 3 9 2}(\mathbf{0 , 0 5})$ & $\mathbf{0 , 5 8 8 3}(\mathbf{0 , 0 0})$ & $\mathbf{0 , 6 3 5 5}(\mathbf{0 , 0 5})$ \\
\hline Wine & $0,5087(0,12)$ & $0,4339(0,12)$ & $\mathbf{0 , 7 2 7 9}(\mathbf{0 , 1 3})$ & $\mathbf{0 , 7 3 4 0}(\mathbf{0 , 1 3})$ & $\mathbf{0 , 7 1 3 6}(\mathbf{0 , 1 4})$ \\
\hline Breast & $0,5431(0,00)$ & $0,5418(0,00)$ & $\mathbf{0 , 8 5 6 9}(\mathbf{0 , 0 8})$ & $\mathbf{0 , 8 7 2 5}(\mathbf{0 , 0 0})$ & $\mathbf{0 , 8 7 2 2}(\mathbf{0 , 0 0})$ \\
\hline Chart & $\mathbf{0 , 5 5 9 0}(\mathbf{0 , 0 0})$ & $\mathbf{0 , 5 6 3 3}(\mathbf{0 , 0 1})$ & $\mathbf{0 , 5 4 2 5}(\mathbf{0 , 0 5})$ & $\mathbf{0 , 5 5 6 7}(\mathbf{0 , 0 5})$ & $\mathbf{0 , 5 5 6 0}(\mathbf{0 , 0 2})$ \\
\hline Yeast & $\mathbf{0 , 9 7 3 7}(\mathbf{0 , 0 0})$ & $\mathbf{0 , 9 3 5 4}(\mathbf{0 , 0 7})$ & $0,8564(0,00)$ & $0,8561(0,00)$ & $\mathbf{0 , 9 6 9 0}(\mathbf{0 , 0 2})$ \\
\hline
\end{tabular}

Tabela 6.13: Médias e desvios padrões dos valores do índice Jaccard para combinações resultantes da função $C A S$.

Assim como mostrado nos experimentos das seções anteriores deste capítulo, a análise da Tabela 6.13 indica que a função $C A S$ obteve boas partições com $C E S$ para alguns conjuntos de dados e com a combinação total para outros conjuntos. É preciso notar que a seleção feita pelo método MA obteve resultados sem diferença estatisticamente significativa em relação aos resultados com maiores valores médios do índice Jaccard de todos os conjuntos de dados. Esses resultados comprovam as conclusões apresentadas na Seção 6.5.

\section{Resultados para CSPA}

Os resultados dos experimentos presentes nas Seções 6.3 e 6.4 indicam que a maioria dos métodos de CES geram resultados melhores ou equivalentes ao uso da combinação total quando aplicados em conjunto com a função $C S P A$, o que faz com que esses métodos sejam recomendados para essa função na Seção 6.5. Ou seja, foi mostrado que essa função melhora com a qualidade das partições base selecionadas (o que faz referência ao Passo 4 da Figura 6.12). Entretanto, é preciso que os índices de validação utilizados no CES possuam um bom desempenho na avaliação de partições base do conjunto de dados agrupado (referente ao Passo 5 da Figura 6.12). Caso não exista conhecimento sobre o bom desempenho desses índices, é recomendado gerar partições com o uso de $C E S$ e da combinação total.

Os resultados presentes na Tabela 6.14 permitem concluir que houve pouca diferença entre os valores de Jaccard com o uso de CES e a combinação total para os conjuntos de dados Wine, Breast e Yeast. Isso ocorreu porque, para partições desses conjuntos, os índices de validação relativos utilizados possuem alta correlação com o índice Jaccard, como é mostrado na Tabela 6.11. Contudo, as correlações relacionadas aos conjuntos 


\begin{tabular}{|c|c|c|c|c|c|}
\hline & Combinação Total & diversity & $C E S$ Silhueta S. & $C E S R S$ & Melhor Avaliado (MA) \\
\hline Iris & $\mathbf{0 , 8 1 5 9}(\mathbf{0 , 0 2})$ & $\mathbf{0 , 8 0 0 3}(\mathbf{0 , 0 6})$ & $0,6391(0,01)$ & $0,6167(0,03)$ & $\mathbf{0 , 8 0 0 3}(\mathbf{0 , 0 6})$ \\
\hline Wine & $\mathbf{0 , 7 5 5 4}(\mathbf{0 , 0 1})$ & $\mathbf{0 , 7 5 1 7}(\mathbf{0 , 0 3})$ & $\mathbf{0 , 7 4 6 5}(\mathbf{0 , 0 1})$ & $\mathbf{0 , 7 4 7 9}(\mathbf{0 , 0 1})$ & $\mathbf{0 , 7 4 8 9}(\mathbf{0 , 0 1})$ \\
\hline Breast & $0,6029(0,00)$ & $\mathbf{0 , 6 0 4 4}(\mathbf{0 , 0 0})$ & $\mathbf{0 , 6 0 4 8}(\mathbf{0 , 0 0})$ & $\mathbf{0 , 6 0 5 1}(\mathbf{0 , 0 0})$ & $\mathbf{0 , 6 0 4 6}(\mathbf{0 , 0 0})$ \\
\hline Chart & $\mathbf{0 , 6 1 8 4}(\mathbf{0 , 0 1})$ & $\mathbf{0 , 6 2 8 0}(\mathbf{0 , 0 3})$ & $0,5153(0,03)$ & $0,5255(0,03)$ & $\mathbf{0 , 6 2 8 0}(\mathbf{0 , 0 3})$ \\
\hline Yeast & $\mathbf{0 , 4 5 1 0 ( \mathbf { 0 , 0 0 } )}$ & $0,4325(0,01)$ & $\mathbf{0 , 4 5 0 8 ( \mathbf { 0 , 0 1 } )}$ & $0,4432(0,00)$ & $0,4381(0,01)$ \\
\hline
\end{tabular}

Tabela 6.14: Médias e desvios padrões dos valores do índice Jaccard para combinações resultantes da função $C S P A$.

de dados Iris e Chart indicam que as partições selecionadas não se assemelham as classes conhecidas. Sendo assim, o uso de CES baseados nos índices de validação relativos estudados não produz resultados com valores altos de Jaccard para os conjuntos Iris e Chart, como mostra a Tabela 6.14. Para esses conjuntos de dados, a combinação total e o método diversity resultaram nas melhores médias de Jaccard. Adicionalmente, as partições selecionadas com o método MA possuem qualidade equivalente às melhores soluções encontradas pelos métodos comparados, o que consiste na estratégia indicada para os casos em que as partições base não possuem qualidade satisfatória ou não se conhece o desempenho dos índices relativos aplicados (ver Seção 6.5).

\section{Resultados para HGPA}

Durante toda investigação feita neste capítulo, a função $H G P A$ sempre apresentou os melhores resultados com o uso da combinação total. A síntese dos resultados feita na Seção 6.5 indica que a qualidade da partição consenso gerada pela função HGPA aumenta, até certo ponto, com o aumento do número de partições base, sendo pouco sensível a qualidade destas. Por esses motivos, o uso da combinação total é recomendado para essa função, como pode ser visto no arcabouço ilustrado na Figura 6.12.

\begin{tabular}{|c|c|c|c|c|c|}
\hline & Combinação Total & diversity & CES Silhueta S. & $C E S R S$ & Melhor Avaliado (MA) \\
\hline Iris & $\mathbf{0 , 8 3 4 9}(\mathbf{0 , 0 5})$ & $\mathbf{0 , 8 0 1 0}(\mathbf{0 , 0 8})$ & $0,2793(0,06)$ & $0,3017(0,11)$ & $\mathbf{0 , 8 0 1 0}(\mathbf{0 , 0 8})$ \\
\hline Wine & $\mathbf{0 , 8 9 6 2}(\mathbf{0 , 0 2})$ & $0,8503(0,04)$ & $0,2863(0,06)$ & $0,2933(0,06)$ & $0,8503(0,04)$ \\
\hline Breast & $\mathbf{0 , 6 6 9 3}(\mathbf{0 , 0 5})$ & $\mathbf{0 , 6 2 9 9}(\mathbf{0 , 0 7})$ & $0,3536(0,01)$ & $0,3532(0,00)$ & $\mathbf{0 , 6 8 6 8}(\mathbf{0 , 0 3})$ \\
\hline Chart & $\mathbf{0 , 6 1 8 5}(\mathbf{0 , 0 1})$ & $\mathbf{0 , 6 2 7 4}(\mathbf{0 , 0 2})$ & $0,2763(0,07)$ & $0,2815(0,08)$ & $\mathbf{0 , 6 2 7 4}(\mathbf{0 , 0 2})$ \\
\hline Yeast & $\mathbf{0 , 4 7 1 8}(\mathbf{0 , 0 1})$ & $\mathbf{0 , 4 6 5 7}(\mathbf{0 , 0 1})$ & $0,1728(0,00)$ & $0,1703(0,00)$ & $\mathbf{0 , 4 6 9 2}(\mathbf{0 , 0 1})$ \\
\hline
\end{tabular}

Tabela 6.15: Médias e desvios padrões dos valores do índice Jaccard para combinações resultantes da função $H G P A$.

Os resultados da Tabela 6.15 comprovam que o uso da combinação total é a metodologia mais indicada para a função $H G P A$. Contudo, é interessante observar que selecionar soluções por meio dos métodos diversity e MA também obtiveram bons resultados para a maioria dos conjuntos de dados. O bom desempenho do método MA mostra que os índices de validação aplicados foram capazes de avaliar corretamente as partições consenso geradas para a maioria dos conjuntos de dados. 


\section{Resultados para MCLA}

De maneira similar à função $C S P A$, a função $M C L A$ obteve nas Seções 6.3 e 6.4 boas combinações com o uso de $C E S$ para conjuntos de dados em que as partições base selecionadas se aproximam da partição de referência. Quando não se conhece o desempenho dos índices de validação utilizados ou o desempenho não é bom para o conjunto de dados em questão, o uso da combinação total e $C E S$ é indicado.

\begin{tabular}{|c|c|c|c|c|c|}
\hline & Combinação Total & diversity & $C E S$ Silhueta S. & $C E S R S$ & Melhor Avaliado (MA) \\
\hline Iris & $\mathbf{0 , 8 7 2 5}(\mathbf{0 , 0 2})$ & $0,7962(0,11)$ & $0,6833(0,00)$ & $0,6701(0,02)$ & $0,6838(0,00)$ \\
\hline Wine & $\mathbf{0 , 8 1 5 0}(\mathbf{0 , 0 2})$ & $\mathbf{0 , 7 9 4 9}(\mathbf{0 , 0 4})$ & $\mathbf{0 , 8 0 4 2}(\mathbf{0 , 0 2})$ & $\mathbf{0 , 8 0 0 1}(\mathbf{0 , 0 2})$ & $\mathbf{0 , 8 1 0 2}(\mathbf{0 , 0 2})$ \\
\hline Breast & $0,6196(0,05)$ & $0,6083(0,05)$ & $\mathbf{0 , 8 7 8 6}(\mathbf{0 , 0 1})$ & $\mathbf{0 , 8 7 6 0}(\mathbf{0 , 0 0})$ & $\mathbf{0 , 8 7 4 9}(\mathbf{0 , 0 0})$ \\
\hline Chart & $\mathbf{0 , 5 9 6 9}(\mathbf{0 , 0 1})$ & $\mathbf{0 , 6 2 6 6}(\mathbf{0 , 0 3})$ & $0,4218(0,05)$ & $0,4028(0,05)$ & $\mathbf{0 , 6 2 0 5}(\mathbf{0 , 0 4})$ \\
\hline Yeast & $0,5479(0,07)$ & $0,4710(0,04)$ & $\mathbf{0 , 8 4 8 8}(\mathbf{0 , 0 4})$ & $\mathbf{0 , 8 4 0 2}(\mathbf{0 , 0 6})$ & $\mathbf{0 , 8 5 7 1}(\mathbf{0 , 0 1})$ \\
\hline
\end{tabular}

Tabela 6.16: Médias e desvios padrões dos valores do índice Jaccard para combinações resultantes da função $M C L A$.

Segundo os resultados presentes na Tabela 6.16, aplicar CES para selecionar partições base para os conjuntos Wine, Breast e Yeast obteve os melhores resultados ou resultados sem diferença significativa para os melhores. Para os conjuntos Iris e Chart, em que as correlações entre os índices de validação relativos e o índice externo de Jaccard são baixas (ver Tabela 6.11), a combinação total e o método diversity mostraram os melhores resultados. Entretanto, utilizar o método MA obteve partições equivalentes às maiores médias de Jaccard obtidas para a maioria dos conjuntos de dados, o que é indicado pelo Passo 5 da Figura 6.12 para casos em que a qualidade das partições base selecionadas não é boa ou desconhecida.

\subsection{Considerações finais}

Neste capítulo, foi investigado o uso de índices de validação em $C E S$, utilizados individualmente e combinados. Os métodos de CES mostraram-se eficientes nos casos em que as partições base selecionadas, individualmente ou complementarmente, refletem a estrutura procurada dos dados. Caso contrário, a adoção da combinação total obteve melhores resultados. O uso de CIR mostrou-se vantajoso nos casos em que não há conhecimento prévio sobre o desempenho dos índices de validação de interesse, pois mostrou resultados acima da média dos resultados obtidos com o uso individual de índices para a maioria dos conjuntos de dados investigados.

A análise dos resultados obtidos neste capítulo permite afirmar que diferentes funções de consenso obtêm resultados distintos em relação ao uso de $C E S$, como pode ser visto na Tabela 6.10. Algumas funções melhoram seus resultados a partir do aumento do número de partições base, o que torna o uso de $C E S$ inapropriado. Já para outras funções de consenso, o uso de $C E S$ pode resultar em partições finais de qualidade equivalente ou até mesmo superior ao uso da combinação total, se as partições selecionadas possuírem 
qualidade suficiente para caracterizar partes da partição ideal. Nos casos em que há incerteza em relação à qualidade das partições base selecionadas ou ao comportamento da função de consenso, as partições resultantes do uso de CES podem ser comparadas com o resultado da combinação total por meio de índices de validação. A generalização desses resultados permitiu o desenvolvimento de um arcabouço para a utilização de CES em diferentes tipos de cenários de aplicação, ilustrado na Figura 6.12. A adoção dos métodos indicados na Seção 6.5 em experimentos com bases reais permitiu encontrar resultados comparáveis, sem diferença estatisticamente significativa, aos melhores resultados obtidos na maioria dos experimentos investigados.

Uma das áreas de aplicação mais comuns do uso de combinação de agrupamentos consiste na computação distribuída (Strehl \& Ghosh, 2002b; Kuncheva, 2004; Topchy et al., 2004; Tumer \& Agogino, 2008). Isso ocorre porque, em alguns casos, é interessante obter partições de partes distintas do conjunto de dados e combiná-las em uma única partição final. No Capítulo 7, algumas das técnicas de agrupamento investigadas durante a tese serão adaptadas e combinadas fim de solucionar problemas de agrupamento de dados distribuídos. Adicionalmente, novas técnicas são propostas com a mesma finalidade e comparadas com as adaptações. 


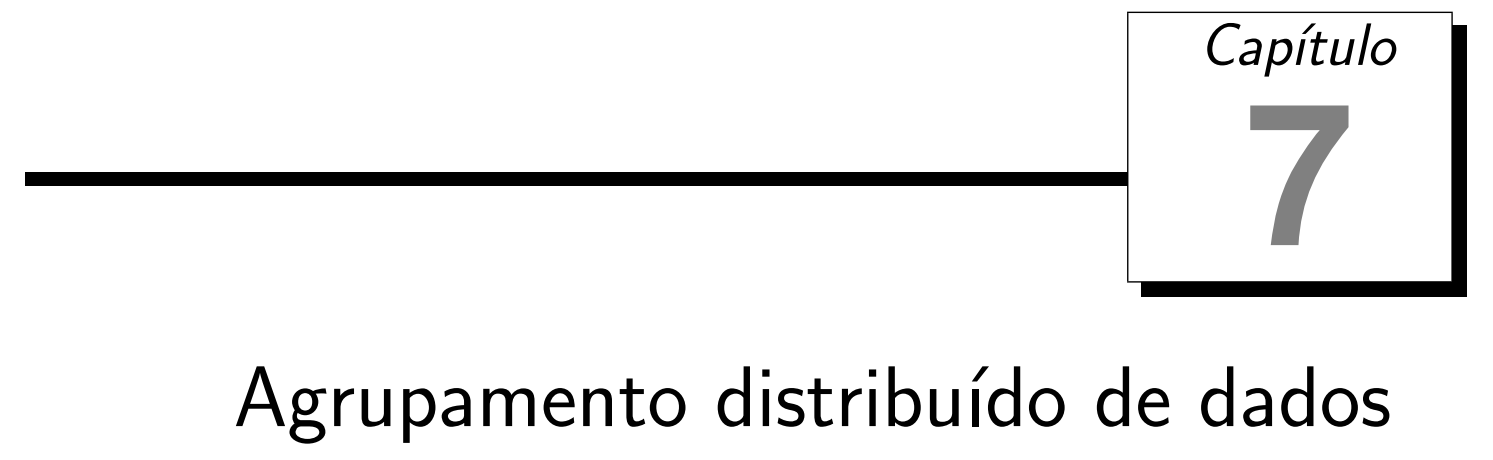

Durante o desenvolvimento do doutorado, foram investigadas diversas técnicas de agrupamento de dados, parte delas envolvendo meta-heurísticas evolutivas (Capítulos 2 e 3). Como consequência, foi mostrado no Capítulo 4 que é possível desenvolver um algoritmo de agrupamento evolutivo que obtenha partições de qualidade equivalente às melhores técnicas investigadas e em tempo computacional consideravelmente menor, tanto no âmbito da complexidade computacional quanto experimental. Boa parte dos algoritmos estudados é guiada por índices de validação relativos e os resultados apresentados no Capítulo 4 comprovam a eficácia desses índices quando aplicados na seleção de partições de qualidade. Por esse motivo, no Capítulo 6, o uso de índices de validação relativos foi investigado na seleção de partições a serem combinadas por meio de funções de consenso (detalhadas no Capítulo 5). Os resultados mostram que, de maneira geral, o uso de índices de validação relativos na seleção de partições base aprimora a qualidade das partições consenso quando as partições selecionadas possuem alguma informação que possa caracterizar a estrutura procurada dos dados.

O crescimento explosivo de coleções de dados faz com que qualquer técnica de mineração de dados tenha que visar desempenho computacional e escalabilidade. Adicionalmente, nem sempre é possível trabalhar com todos os dados na memória local de um único sistema. Nesse contexto, a implementação de técnicas de mineração de dados de forma distribuída é crucial para garantir essas características à medida que a quantidade de dados continua a crescer. Como o trabalho feito durante o doutorado sempre visou o desempenho e a escalabilidade, sem prejudicar a qualidade do agrupamento obtido, problemas da área de mineração de dados distribuídos mostram-se aplicações adequadas para as técnicas desenvolvidas. Portanto, uma das contribuições principais desta tese consiste em adaptar algumas das técnicas estudadas nos capítulos anteriores foram para o contexto de dados distribuídos e, adicionalmente, propor novas técnicas que possuem a 
mesma finalidade. Essa contribuição é apresentada neste capítulo.

Este capítulo é dividido nas seguintes seções: a motivação sobre a pesquisa é feita na Seção 7.1, seguida por uma breve contextualização sobre a área de agrupamentos de dados distribuídos (Seção 7.2) . Uma versão distribuída do algoritmo F-EAC (Seção 3.4) é proposta na Seção 7.3, na qual são mostradas suas estruturas de dados e complexidade computacional. Outros algoritmos de agrupamento distribuídos que objetivam partições próximas das obtidas com o algoritmo $k$-médias distribuído, porém com uma quantidade menor de dados transferidos, são mostrados na Seção 7.4. Experimentos que comparam os algoritmos investigados, em termos de qualidade da partição obtida, tempo computacional e quantidade de dados transferidos, são apresentados na Seção 7.5. As considerações finais sobre a pesquisa apresentada neste capítulo são feitas na Seção 7.6.

\subsection{Motivação}

A quantidade de dados nos campos da ciência e negócios vem crescendo substancialmente ao longo dos anos. Coleções de textos, bioinformática, imagens médicas e outras áreas são geradas e estendidas à medida que o uso de novas tecnologias aumenta. Em virtude desse crescimento, existe uma tendência cada vez maior de se distribuir grandes conjuntos de dados em sítios separados. Em muitos casos os dados encontram-se naturalmente distribuídos, ou seja, foram gerados e armazenados em diferentes sítios. Um exemplo desse tipo de aplicação é a computação em nuvem (cloud computing em inglês), em que empresas oferecem serviços remotos que geram e armazenam grandes quantidades de dados em servidores distintos. Grandes empresas como a Google, IBM, Microsoft e HP oferecem esse tipo de serviço e investem grande parte de seu capital no desenvolvimento de tecnologias voltadas para essa finalidade.

O crescimento e a distribuição de conjuntos de dados geram uma necessidade cada vez maior de técnicas computacionais que sejam capazes de extrair informações relevantes com bom desempenho computacional e escalabilidade. Entretanto, a maioria das técnicas de mineração de dados, ao serem propostas, considera que os dados encontram-se centralizados em um único sítio, como é caso das técnicas de agrupamento apresentadas na Seção 2.4. Centralizar um conjunto de dados que se encontra distribuído pode não ser eficiente, pois a grande quantidade de dados pode gerar um alto custo de transferência, armazenamento e aumentar consideravelmente o tempo do processo de mineração. Em alguns casos, centralizar os dados não é possível devido a limitações computacionais como capacidade da memória de trabalho ou incapacidade de processamento serial dos dados em tempo hábil. Em outros casos, existe a necessidade de preservar a privacidade dos dados, o que é obrigação legal em alguns países da Europa, nos Estados Unidos e em outros (Hijmans, 2010). Esses argumentos dificultam e até impossibilitam trabalhar com amostras centralizadas do conjunto de dados.

Com o objetivo de solucionar as limitações apresentadas anteriormente, versões parale- 
las e distribuídas de algoritmos clássicos de agrupamento foram propostas com a finalidade de aumentar o desempenho e serem aplicados em dados distribuídos sem transferí-los. Entretanto, a grande maioria das versões distribuídas dos algoritmos de agrupamento clássicos sofre dos mesmos problemas de seus predecessores centralizados, como complexidade computacional acima de linear em relação a seus parâmetros críticos ou incapacidade de determinar automaticamente o número de grupos de um conjunto de dados. A versão distribuída mais citada do algoritmo k-médias foi proposta por Dhillon \& Modha (2000), posteriormente aprimorada por Tian et al. (2005) e adaptada para aplicações em redes peer-to-peer por Bandyopadhyay et al. (2006) e Datta et al. (2009). Pouco depois de Dhillon \& Modha (2000), Forman \& Zhang (2000) propuseram uma técnica para paralelizar algoritmos baseados em centróides que inclui não só o algoritmo $k$-médias, mas algoritmos como o $E M$ e o $B I R C H$ (Seções 2.4 .2 e 2.4.5.2). Propostas para paralelizar algoritmos hierárquicos possuem como objetivo principal dividir o cálculo da dissimilaridade dos dados entre unidades de processamento distintas (Olson, 1995; Du \& Lin, 2005) e também foram adaptadas para redes peer-to-peer (Hammouda \& Kamel, 2009). Garg et al. (2006) propuseram uma versão paralela do algoritmo BIRCH que balanceia a carga entre processadores de maneira cíclica.

No Capítulo 4 foi mostrado que algoritmos evolutivos podem ser aplicados para encontrar o número de grupos e a inicialização de protótipos apropriados para o algoritmo $k$-médias em menor tempo computacional do que a maioria das técnicas comparadas. Devido aos bons resultados obtidos com diferentes variantes do F-EAC (Alves et al., 2006; Campello et al., 2009; Horta et al., 2009; Horta \& Campello, 2009; Naldi et al., 2009, 2011), a versão distribuída desse algoritmo foi desenvolvida durante o doutorado e é chamada de DF-EAC (do inglês Distributed Fast Evolutionary Algorithm for Clustering). O $D F-E A C$ obtém, para conjuntos de dados distribuídos, o mesmo resultado que o uso do algoritmo $F-E A C$ obteria se esses dados estivessem centralizados. Detalhes do DF-EAC são apresentados na Seção 7.3.

Outra forma de abordar o problema de agrupar dados distribuídos consiste em utilizar métodos de combinação de agrupamentos (Dimitriadou et al., 2002b; Strehl \& Ghosh, 2002b; Ghosh et al., 2002; Topchy et al., 2004; Agogino \& Tumer, 2006; Tumer \& Agogino, 2008). A principal idéia por trás dessas aplicações resume-se em executar algoritmos de agrupamento em cada sítio de dados a fim de gerar partições locais. Em seguida, as partições locais são utilizadas como partições base a serem combinadas em uma única partição consenso que represente todos os dados distribuídos. Esses métodos podem ser vantajosos quando a latência da transferência de dados entre sítios é alta, pois as informações sobre as partições locais podem ser transferidas uma única vez. Portanto, abordagens desse tipo são propostas na Seção 7.4 e investigadas experimentalmente durante este trabalho.

Ao decorrer deste capítulo serão utilizados conceitos relacionados à área de mineração distribuída de dados e, por esse motivo, uma breve contextualização é feita na Seção 7.2. 


\subsection{Contextualização}

Mineração distribuída de dados (DDM, do inglês Distributed Data Mining) consiste no processo de descobrir padrões ou gerar modelos a partir de dados distribuídos (Zaki, 1999). Quando a principal finalidade em distribuir um algoritmo de mineração de dados consiste na execução paralela de suas partes, esse algoritmo pode ser referenciado como um algoritmo de mineração paralela de dados (PDM, do inglês Parallel Data Mining). Apesar de existir uma sobreposição conceitual entre as áreas de $D D M$ e $P D M$ (Freitas \& Lavington, 1997; Zaki, 2000), esses termos são utilizados com frequência para indicar algoritmos com características distintas:

- $P D M$ tende a fazer referência a algoritmos de alta granularidade aplicados em sistemas fortemente acoplados, enquanto $D D M$ frequentemente faz referência à algoritmos de baixa granularidade aplicados em sistemas fracamente acoplados (Tanenbaum, 1996).

- Algoritmos de PDM são frequentemente utilizados em conjuntos de dados centralizados, isto é, conjuntos de dados integralmente presentes em uma única memória de trabalho compartilhada. Algoritmos de $D D M$ assumem com frequência que o conjunto de dados encontra-se distribuído em memórias não compartilhadas (Tanenbaum, 2001).

- Geralmente, $P D M$ visa o aumento do desempenho computacional, enquanto DDM possui como objetivo principal solucionar problemas em que haja impossibilidade ou seja desinteressante centralizar o conjunto de dados.

Uma revisão que apresenta as áreas de $D D M$ e $P D M$ em maiores detalhes pode ser encontrada em Zaki (1999). Os algoritmos propostos neste capítulo possuem como foco principal solucionar problemas típicos da área de $D D M$, em que o conjunto de dados encontra-se distribuído, seja em sistemas de memória distribuída ou em diferentes sítios de dados, e não seja possível ou interessante centralizar os dados. Segundo Freitas \& Lavington (1997), o processo de $D D M$ consiste essencialmente em aplicar partes de um algoritmo ou diferentes algoritmos em diferentes subconjuntos dos dados e, posteriormente, combinar os resultados em uma única solução final, como é mostrado na Figura 7.1 em que $n_{d n}$ é o número de subconjuntos.

Em problemas de $D D M$, o conjunto de dados pode ser distribuído de duas formas (da Silva et al., 2005):

- Horizontal (homogênea): dados são divididos em subconjuntos com diferentes objetos contendo os mesmos atributos;

- Vertical (heterogênea): dados são divididos em subconjuntos com os mesmos objetos contendo diferentes atributos. 


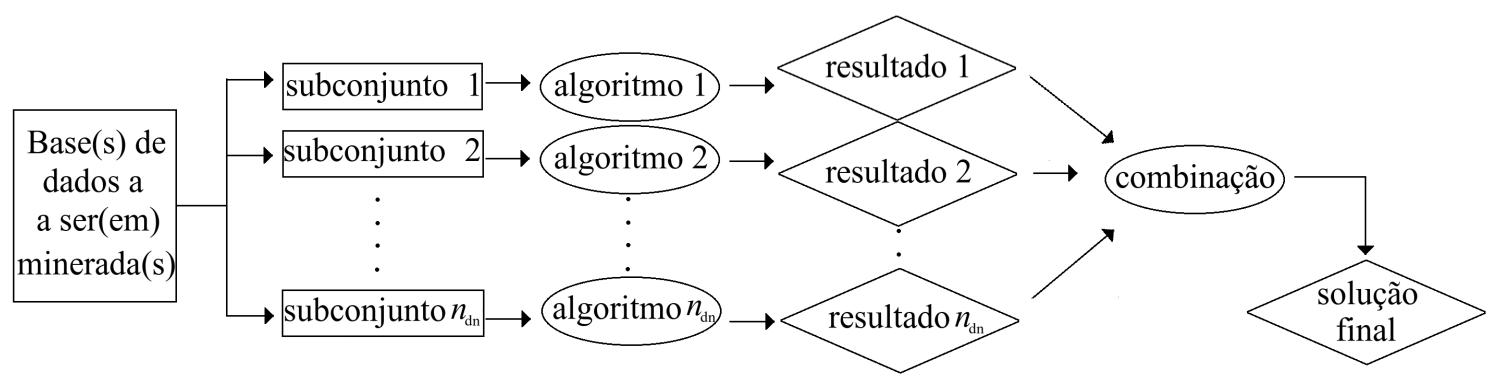

Figura 7.1: Exemplo de algoritmo de $D D M$.

As aplicações de $D D M$ feitas para conjuntos divididos horizontalmente visam cenários em que dados encontram-se naturalmente distribuídos (e.g., gerados em locais geograficamente distribuídos) ou gerados de forma centralizada e distribuídos artificialmente. Aplicações que trabalham com dados distribuídos verticalmente visam estabelecer relações entre os dados sobre diferentes aspectos (atributos) e depois combiná-las. As técnicas propostas aqui serão voltadas para a divisão horizontal dos dados, pois esta possui maior apelo prático.

Em relação ao modelo gerado, os algoritmos de $D D M$ podem ser categorizados entre (Hammouda \& Kamel, 2009):

- Exato: algoritmos distribuídos exatos produzem um modelo final idêntico ao modelo hipotético gerado pelo mesmo processo executado de maneira centralizada com acesso a todo o conjunto de dados;

- Aproximado: algoritmos aproximados produzem um modelo que se aproxima do modelo gerado de maneira centralizada, por meio de métodos que possuem maior desempenho do que os utilizados por algoritmos exatos. Contudo, algoritmos aproximados não garantem a obtenção de um modelo idêntico ao resultante de uma aplicação centralizada equivalente.

Algoritmos de DDM também podem ser categorizados em relação ao tipo de comunicação entre suas partes distribuídas (Bandyopadhyay et al., 2006):

- Múltiplas rodadas de comunicação: algoritmos que necessitam da atualização frequente de informações sobre o conjunto de dados e, por esse motivo, utilizam múltiplas rodadas de comunicação entre suas partes;

- Única rodada de comunicação: algoritmos que geram um modelo local de seus dados, que é transferido uma única vez. Informações adicionais podem ser transferidas, porém toda a comunicação é feita em uma única rodada, sem repetição.

Algumas aplicações práticas necessitam que as informações sobre os dados sejam mantidas em sigilo, ou seja, é preciso que seja mantida a privacidade sobre os valores de seus atributos. Por exemplo, empresas poderiam estar interessadas em colaborar para obter uma estrutura que reflita relações entre clientes, sem permitir que dados sobre seus clientes 
sejam expostos. Para isso, técnicas de manutenção da privacidade foram desenvolvidas, de forma que os tipos mais comuns são (da Silva et al., 2005; Vaidya \& Clifton, 2004; Fung et al., 2010):

- Distorção: protege os dados originais, distorcendo-os com valores aleatórios, mas mantém suas propriedades importantes para o processo de mineração (Inan et al., 2007);

- Criptografia: aplicar métodos de criptografia nos dados originais e permitir que os processos de mineração possam ter acesso apenas a informação estritamente necessária. O acesso é feito por meio de ferramentas desenvolvidas com esse propósito (Clifton et al., 2002).

Técnicas de manutenção da privacidade podem ser úteis quando o algoritmo de $D D M$ necessita de informações que possam expor os valores dos atributos de seus dados. Entretanto, alguns algoritmos não necessitam de acesso direto aos dados, mas de informações derivadas desses dados. É o caso dos algoritmos que combinam informações sobre agrupamentos resultantes de diferentes subconjuntos dos dados, também chamados de agrupamentos locais. O tipo de informação a ser transferido varia com o tipo de distribuição dos dados. Os mais comuns são:

- Dados distribuídos verticalmente: rotulação dos objetos ou matriz de pertinência (Pedrycz, 2002b; Pedrycz \& Rai, 2008b), matriz de similaridade entre objetos (coassociação ou proximidade) (Hu et al., 2006; Loia et al., 2007) e grafos com os grupos formados (Kargupta et al., 2001);

- Dados distribuídos horizontalmente: protótipos (Boutsinas \& Gnardellis, 2002; Pedrycz \& Rai, 2008a; Pedrycz \& Hirota, 2008), distribuição de densidade dos grupos e variância (da Silva \& Klusch, 2006), modelos generativos (Merugu \& Ghosh, 2005) e grafos (Dong et al., 2009).

Grande parte dos métodos de combinação de agrupamentos apresentados no Capítulo 5 são diretamente aplicáveis em partições distribuídas verticalmente, ou seja, partições geradas a partir dos mesmos objetos. Entretanto, partições geradas a partir de objetos distintos não são "combináveis" por esses métodos, como é o caso de agrupamentos locais obtidos a partir de conjuntos distribuídos horizontalmente. Nesses casos, deve-se considerar que os objetos encontram-se no mesmo espaço de atributos, o que permite unir os agrupamentos locais nesse espaço e combiná-los em um agrupamento final. É o caso do algoritmo proposto por Merugu \& Ghosh (2005), que gera e combina modelos dos agrupamentos locais em um modelo médio a partir do cadeias de Markov e o método de Monte Carlo. Dong et al. (2009), por sua vez, agrupam objetos em regiões distintas do espaço de atributos e, em seguida, unem os grupos mais próximos para gerar o agrupamento final. Abordagens semelhantes são utilizadas por Pedrycz \& Hirota (2008) e Pedrycz \& Rai (2008a) em problemas de colaboração entre agrupamentos. 


\subsection{Distributed Fast Evolutionary Algorithm for Clustering (DF- $E A C)$}

O algoritmo $D F-E A C$ foi desenvolvido neste trabalho com o objetivo de obter, para conjuntos de dados distribuídos, o mesmo resultado que o uso do algoritmo $F$-EAC obteria se esses dados estivessem centralizados. Portanto, o DF-EAC é um algoritmo exato. Sua execução é distribuída em nós de processamento, que podem ser de dois tipos:

- Nó de dados: um nó de dados é responsável por todo o processamento de que necessita de acesso direto a um determinado subconjunto dos dados. Cada nó de dados é responsável por um único subconjunto dos dados, de forma que nenhum subconjunto seja processado por mais de um nó de dados. Os nós de dados devem ser capazes de receber/transferir informações oriundas/resultantes de outros nós de dados e do nó mestre.

- Nó mestre: é o nó responsável pela centralização e processamento das informações transferidas pelos nós de dados. Nele são executadas as operações que combinam as informações oriundas de cada um dos nós de dados em uma única solução global.

Um exemplo da arquitetura do algoritmo é apresentado na Figura 7.2, em que as setas sinalizam a transferência de informações entre nós. Nela, um número $n_{d n}$ de nós de dados comunicam-se com um único nó mestre. Trata-se apenas de um exemplo, pois a topologia do $D F-E A C$ pode (e deve) variar com o cenário de aplicação, de forma a reduzir o tempo total de transferência de dados entre os nós e aumentar o desempenho do algoritmo. A comunicação entre nós é feita várias vezes a cada iteração do algoritmo, o que o caracteriza como um algoritmo de múltiplas rodadas de comunicação. É importante destacar a diferença entre um nó do $D F-E A C$ e um sítio de dados. Um nó do $D F-E A C$ é uma parte do algoritmo responsável por um determinado tipo de processamento. Um sítio é uma localização que contém parte dos dados do conjunto a ser agrupado. Sendo assim, diversos nós do $D F-E A C$ podem ser processados de maneira paralela ou concorrente em um mesmo sítio. O único pré-requisito do algoritmo é que todos os nós de dados possam enviar e receber informações para o nó mestre, diretamente ou por meio de nós de dados intermediários.

Como o $D F-E A C$ é equivalente à sua versão centralizada, $F-E A C$, sua estrutura geral em alto nível é descrita pelo Algoritmo 4, apresentado na Seção 3.4. Entretanto, diferentemente do $F$-EAC, existem passos do algoritmo que devem ser executados de forma distribuída, pois necessitam de acesso direto aos dados. Esses passos consistem na inicialização da população (Passo 2), na busca local efetuada pelo algoritmo $k$-médias (Passo 4), no cálculo da aptidão dos indivíduos (Passo 5) e na aplicação dos operadores de mutação (Passo 13). Todos os outros passos do algoritmo são executados pelo nó mestre, pois não necessitam de acesso direto aos dados. 


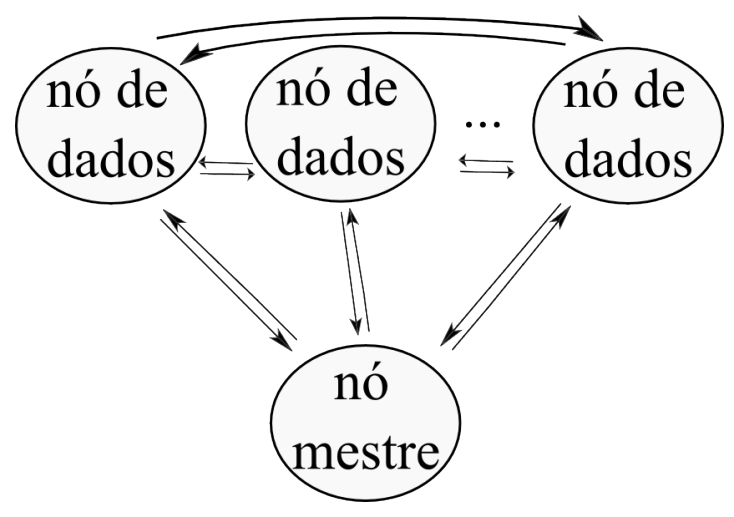

Figura 7.2: Exemplo da estrutura do DF-EAC.

Detalhes da metodologia utilizada em cada um dos passos que necessitam de acesso direto aos dados, bem como aspectos necessários para sua execução distribuída com e sem a manutenção da privacidade dos dados, são apresentados nas próximas seções. É importante destacar que as técnicas de manutenção de privacidade adaptadas para o $D F-E A C$ neste trabalho são exemplos ilustrativos, a fim de demostrar como a exposição direta dos valores dos dados pode ser evitada. Outras técnicas de maior complexidade (e custo computacional) podem ser adaptadas, caso os métodos apresentados como exemplo neste capítulo sejam julgados insuficientes. Revisões sobre métodos de manutenção de privacidade são encontradas em Vaidya \& Clifton (2004); Fung et al. (2010), de modo a permitir ao leitor determinar quais medidas de segurança devem ser tomadas para preservar a privacidade dos dados em aplicações de $D D M$. Portanto, o objetivo do trabalho apresentado nesta seção consiste em propor uma variação distribuída exata do algoritmo $F$-EAC, de maneira que os métodos de manutenção da privacidade dos dados devam ser adaptados conforme a necessidade de segurança intrínseca ao cenário de aplicação do algoritmo.

Na Seção 7.3.1, é mostrado como a codificação e estruturas auxiliares do $F$-EAC podem ser reformuladas para lidar com dados distribuídos horizontalmente. Em seguida, métodos de inicialização de partições de dados distribuídos são discutidos na Seção 7.3.2. Detalhes sobre a busca local do algoritmo DF-EAC são descritos na Seção 7.3.3. Métodos para calcular de forma distribuída a aptidão das partições e grupos são apresentados na Seção 7.3.4. Os operadores de mutação do $F-E A C$ foram adaptados para conjuntos de dados distribuídos e detalhados na Seção 7.3.5. Por fim, a complexidade do $D F-E A C$ é analisada em termos computacionais, de memória e transferência de dados na Seção 7.3.6.

\subsubsection{Codificação e estruturas auxiliares}

Na Seção 3.4.1, foram apresentadas a codificação do genótipo utilizado pelo $F$-EAC e suas estruturas de dados auxiliares. Em sua versão distribuída, o algoritmo $F$-EAC possui dois tipos de codificação e estruturas de dados auxiliares:

- Codificação global: representa informações sobre a partição dos dados e seus 
grupos. Essa codificação é utilizada no nó mestre.

- Codificação local: utilizada em cada nó de dados, a codificação local representa informações sobre o subconjunto de dados ao qual o nó de dados possui acesso.

Para ilustrar como as estruturas de dados do $F-E A C$ são utilizadas no DF-EAC, considere o conjunto de dados formado pelos 10 objetos do conjunto de dados didático (Tabela 3.1) distribuído em três subconjuntos $\left\{\mathbf{x}_{1}, \mathbf{x}_{2}\right\},\left\{\mathbf{x}_{3}, \mathbf{x}_{4}, \mathbf{x}_{5}, \mathbf{x}_{6}\right\}$ e $\left\{\mathbf{x}_{7}, \mathbf{x}_{8}, \mathbf{x}_{9}, \mathbf{x}_{10}\right\}$. Na Figura 7.3 é mostrado como a partição de genótipo $\mathbf{g}=$ [1112222333] é representada no $D F-E A C$, considerando a distribuição descrita anteriormente. Nela é possível ver que o genótipo g é divido entre os nós de dados, de forma que cada nó de dados retrate a qual grupo pertence cada um de seus objetos. A parte do genótipo g presente no $i$-ésimo nó de dados será referenciada como $\mathbf{g}[i]$. Apesar do genótipo original do F-EAC poder ser facilmente obtido pelo nó mestre, por meio da combinação das partes geradas nos nós de dados, isto não é feito por padrão, com o objetivo de aumentar a privacidade sobre os dados e reduzir a comunicação entre nós.

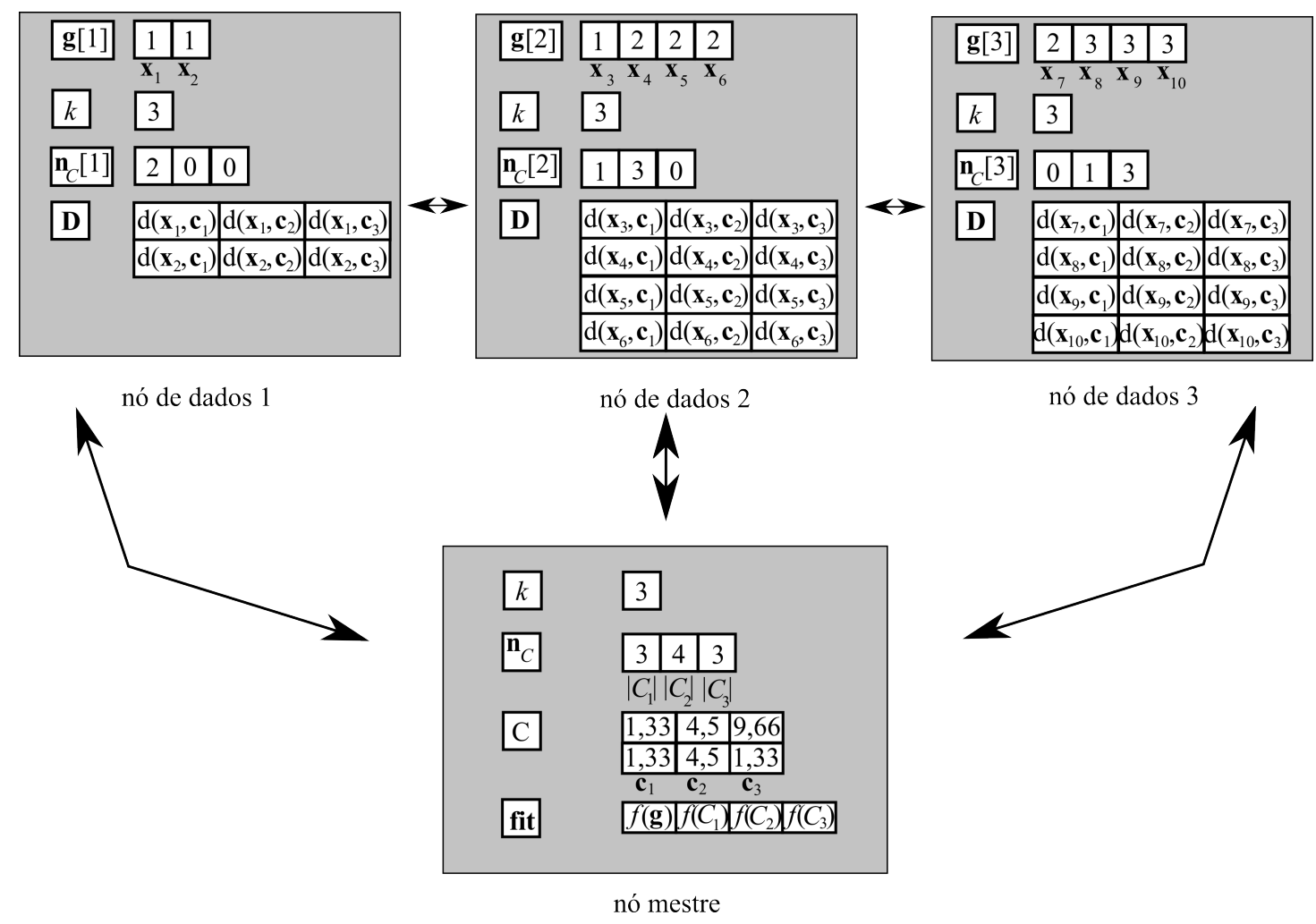

Figura 7.3: Exemplo das estruturas de dados do DF-EAC.

Por ser uma informação relevante, que requer pouco espaço de armazenamento, muito acessada e pouco modificada durante a execução do $D F-E A C$, o número de grupos da partição $k$ é mantido tanto na codificação dos nós de dados como na codificação do nó mestre. Já o vetor $\mathbf{n}_{C}$, que armazena o número de objetos que cada grupo contém, possui diferentes interpretações na codificação local e global. Na codificação local, $\mathbf{n}_{C}$ apresenta quantidades relativas aos objetos do subconjunto de dados local, enquanto na codificação 
global esse vetor apresenta os valores totais obtidos por meio da soma dos vetores locais. Por esse motivo, $\mathbf{n}_{C}[i]$ é utilizado neste trabalho para referenciar o vetor contido no $i$-ésimo nó de dados, enquanto $\mathbf{n}_{C}$ faz referência ao vetor presente no nó mestre.

Como informações sobre os centróides estão relacionadas à partição global dos dados, a matriz $\mathbf{C}$ é armazenada somente no nó mestre. Essas informações podem ser enviadas, completamente ou parcialmente, aos nós de dados quando necessárias. Dependendo da disponibilidade de memória dos nós de dados, é possível manter uma cópia de $\mathbf{C}$ na tentativa de reduzir o custo de transferência do algoritmo. Contudo, como o valor de $k$ costuma ser baixo e os centróides são atualizados com frequência, essa redução pode não resultar em um grande impacto na performance do algoritmo.

Algumas estruturas de dados encontram-se exclusivamente na codificação local ou global. É o caso da estrutura fit que, por lidar apenas com características referentes às partições (aptidão), são armazenadas unicamente no nó mestre. Já a estrutura D está presente somente em nós de dados, pois indica a dissimilaridade entre os objetos do subconjunto de dados do nó e os centróides da partição, informação utilizada apenas em cálculos feitos no próprio nó de dados.

É importante destacar que, assim como no F-EAC, informações contidas em algumas das estruturas mostradas nesta seção podem ser obtidas a partir de outras estruturas, ficando a critério do desenvolvedor encontrar a melhor relação entre o uso de memória e o desempenho computacional do algoritmo. Adicionalmente, a forma em que as estruturas de dados são distribuídas aqui permite a manutenção da privacidade dos dados de um determinado nó em relação a outros nós.

\subsubsection{Inicialização}

O passo da inicialização do algoritmo $D F-E A C$ é responsável pela sincronização de informações entre o nó mestre e os nós de dados. Cada nó de dados irá carregar o subconjunto de dados que é responsável e, caso seja permitido, poderá informar ao nó mestre a quantidade de objetos e a dimensionalidade dos dados. O nó mestre, por sua vez, deve inicializar uma população de tamanho $|P|$ em que os indivíduos possuam $k \in$ $\left\{2, \ldots, k_{\max }\right\}$ grupos gerados aleatoriamente e, em seguida, informar aos nós de dados o número de grupos de cada indivíduo.

Quanto à inicialização dos centróides, estes podem ser gerados a partir de vários métodos. Um deles consiste em requisitar aleatoriamente objetos aos nós de dados e utilizar estes objetos como os centróides iniciais. Contudo, esse método não mantém a privacidade dos dados. Alternativamente, os nós de dados podem gerar protótipos a partir de combinações convexas entre alguns de seus objetos sorteados aleatoriamente, a fim de que os valores dos atributos dos objetos não sejam expostos. Por exemplo, o $i$-ésimo nó de dados poderia selecionar aleatoriamente $n_{o s}$ objetos de seu subconjunto de dados para formar um grupo $C_{t}=\left\{\mathbf{x}_{1 t}, \mathbf{x}_{2 t}, \ldots, \mathbf{x}_{n_{o s} t}\right\}$, tal que $n_{o s} \in\left\{2, \ldots, n_{o}[i]\right\}$ e $n_{o}[i]$ seja o número de objetos no subconjunto do $i$-ésimo nó. Em seguida, um vetor de pesos $\mathbf{w}=\left[\begin{array}{llll}w_{1} & w_{2} & \ldots & w_{n_{o s}}\end{array}\right]$ 
é gerado aleatoriamente, de forma que $w_{j}>0 \quad \forall j$ e $\sum_{j=1}^{n_{o s}} w_{j}=1$, e utilizado para gerar um protótipo $\mathbf{p}$ por meio da combinação convexa $\mathbf{p}=w_{1} \mathbf{x}_{1 t}+w_{2} \mathbf{x}_{2 t}+\ldots+w_{n_{o s}} \mathbf{x}_{n_{\text {os }} t}$. A combinação convexa faz com que o protótipo obtido esteja dentro do casco convexo formado pelos objetos selecionados e mantém a privacidade dos dados ${ }^{1}$. O processo é repetido até que sejam gerados $k$ centróides e posteriormente transmitidos ao nó mestre. Por sua vez, o nó mestre organiza os centróides recebidos e os envia para cada nó de dados durante as próximas etapas do algoritmo.

Outra forma de obter os genótipos de forma distribuída consiste em sortear aleatoriamente os objetos entre os $k$ grupos em cada nó de dados. Esse método possui a desvantagem de gerar protótipos iniciais próximos do centro dos dados, o que pode dificultar o aprimoramento das partições. Entretanto, esse método também mantém a privacidade dos dados, caso não seja permitido grupos com um único integrante (singletons).

\subsubsection{Busca local}

A cada geração, as partições do $D F-E A C$ são ajustadas pelo algoritmo $k$-médias, de modo a executar uma busca local por partições de melhor qualidade. O $k$-médias centralizado, apresentado no Algoritmo 1, é composto por três passos principais:

1. Calcular a dissimilaridade entre objetos e centróides;

2. Definir a qual grupo pertence cada objeto;

3. Atualizar os centróides dos grupos;

O DF-EAC utiliza uma adaptação da versão distribuída do algoritmo $k$-médias proposto por Dhillon \& Modha (2000), que consiste em três passos equivalentes aos do algoritmo centralizado. Na execução do primeiro passo, o nó mestre envia os centróides para todos os nós de dados e aguarda o resultado (espera ocupada). Ao receber os centróides, os nós de dados irão calcular a dissimilaridade entre seus objetos e os centróides. Em seguida, os genótipos $\mathbf{g}[i]$ e o vetor com o número de objetos $\mathbf{n}_{C}[i]$ são atualizados em cada nó de dados, de forma que objetos irão pertencer aos grupos com os centróides mais próximos e complete o segundo passo. No terceiro passo, é calculada a soma dos vetores correspondentes aos objetos de cada grupo em cada nó de dados, aqui chamada de contribuição, a ser posteriormente utilizada para o cálculo do centróide do grupo. Por exemplo, a contribuição do $i$-ésimo nó de dados para o grupo $C_{j}$ consiste em calcular $\mathbf{s}_{C_{j}}[i]=\sum_{\mathbf{x}_{l}[i] \in C_{j}} \mathbf{x}_{l}[i]$, em que $\mathbf{x}_{l}[i]$ assume o valor de todos os objetos do grupo $C_{j}$ no $i$-ésimo nó de dados. As contribuições são transferidas juntamente com o vetor $\mathbf{n}_{C}[i]$ ao nó

\footnotetext{
${ }^{1}$ Se os objetos combinados forem colineares, eventualmente o protótipo gerado poderá ser igual a um dos objetos combinados. Contudo, não há como saber quando esse caso atípico ocorreu, o que impossibilita a identificação do objeto.
} 
mestre, que obtém o número total de objetos de cada grupo por meio da Equação (7.1):

$$
\mathbf{n}_{C}=\sum_{i=1}^{n_{d n}} \mathbf{n}_{C}[i]=\left[\begin{array}{llll}
\left|C_{1}\right| & \left|C_{2}\right| & \ldots & \left|C_{k}\right|
\end{array}\right]
$$

lembrando que $n_{d n}$ é o número de nós de dados. Uma vez obtido o número total de objetos pertencente a cada grupo, os centróides da partição podem ser facilmente calculados por meio da soma das contribuições de cada nó de dados, divida pelo número de objetos nos grupos, como na Equação (7.2):

$$
\mathbf{c}_{j}=\sum_{i=1}^{n_{d n}} \frac{\mathbf{s}_{C_{j}}[i]}{\left|C_{j}\right|}
$$

em que $\mathbf{c}_{j}$ é o centróide do j-ésimo grupo e $\mathbf{s}_{C_{j}}[i]$ é a soma de objetos pertencentes ao grupo $C_{j}$ presentes no $i$-ésimo nó de dados. A visão global do procedimento de busca local distribuído descrito aqui é apresentado na Figura 7.4.

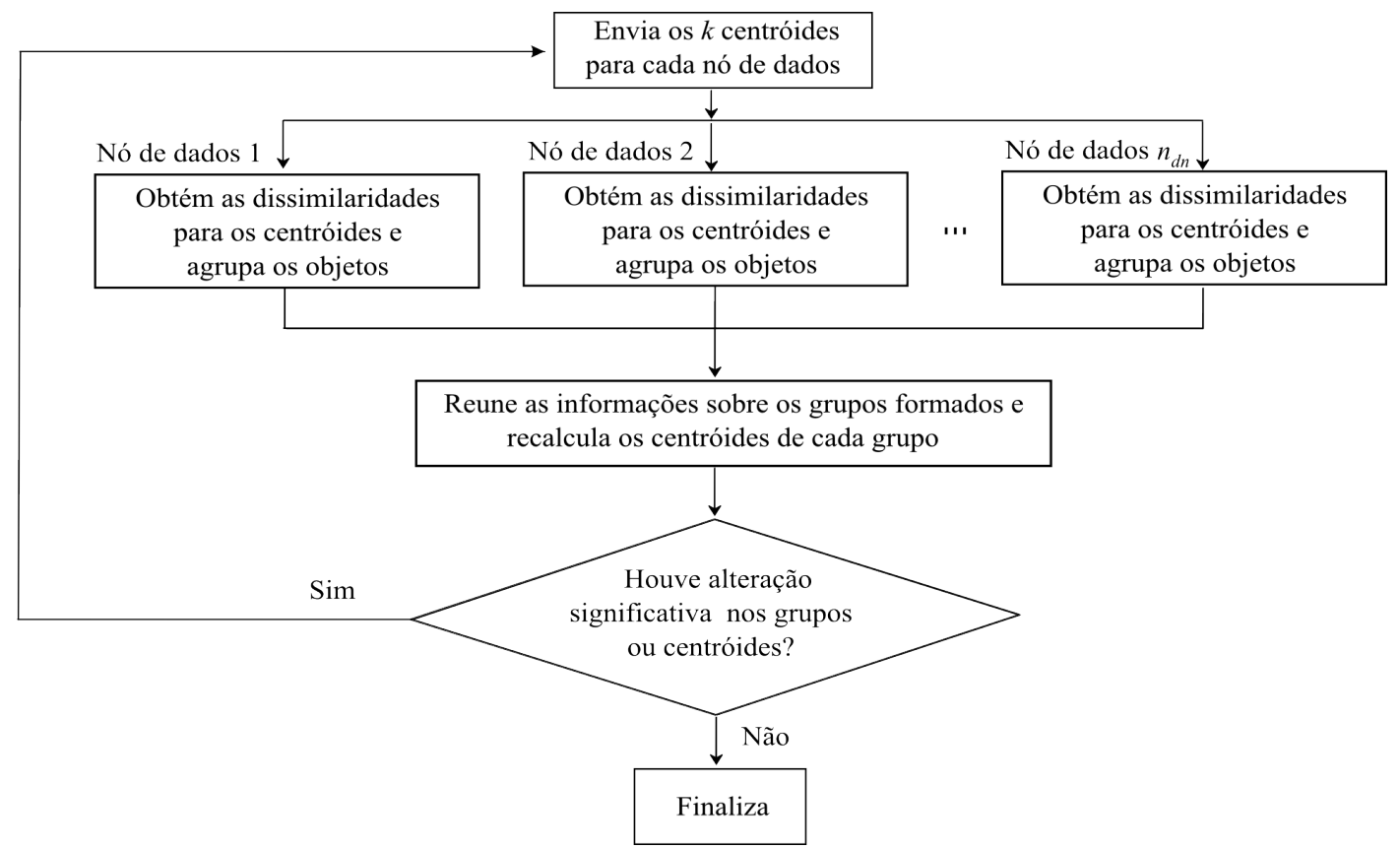

Figura 7.4: Visão global da busca local distribuída.

O algoritmo descrito aqui permite ao $D F-E A C$ obter os mesmos centróides que o algoritmo $F$-EAC obtém para conjuntos de dados centralizados. Entretanto, é possível que alguns nós de dados possuam apenas um objeto $\mathbf{x}_{l}[i]$ em um determinado grupo, o que faz com que $\mathbf{s}_{C_{j}}[i]=\mathbf{x}_{l}[i]$ e revele os valores dos atributos desse objeto a outros nós.

Técnicas de manutenção da privacidade podem ser utilizadas para evitar a exposição dos dados durante o $k$-médias distribuído. Por exemplo, a distorção dos dados pode ser feita no primeiro nó de dados, que envia os dados distorcidos para o próximo nó de dados. Cada nó seguinte recebe os dados distorcidos do nó anterior e soma sua contribuição, ou seja, os valores de seus dados. O processo continua até que todos os nós tenham somado seus dados. Nesse ponto, os dados somados são enviados para o primeiro nó, que 
retira a distorção, calcula os centróides de cada grupo e os envia para o nó mestre. Uma descrição mais detalhada do cálculo de centróides com distorção dos dados é apresentada no Algoritmo 7, executado em cada nó de dados.

Algoritmo 7 Cálculo de centróides com distorção dos dados.

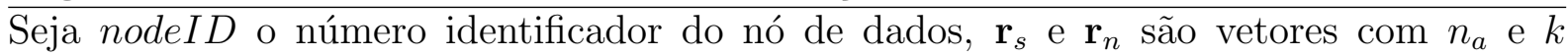
números aleatórios, respectivamente, os centróides de uma partição podem ser calculados de forma distribuída com distorção de dados a partir do algoritmo descrito a seguir:

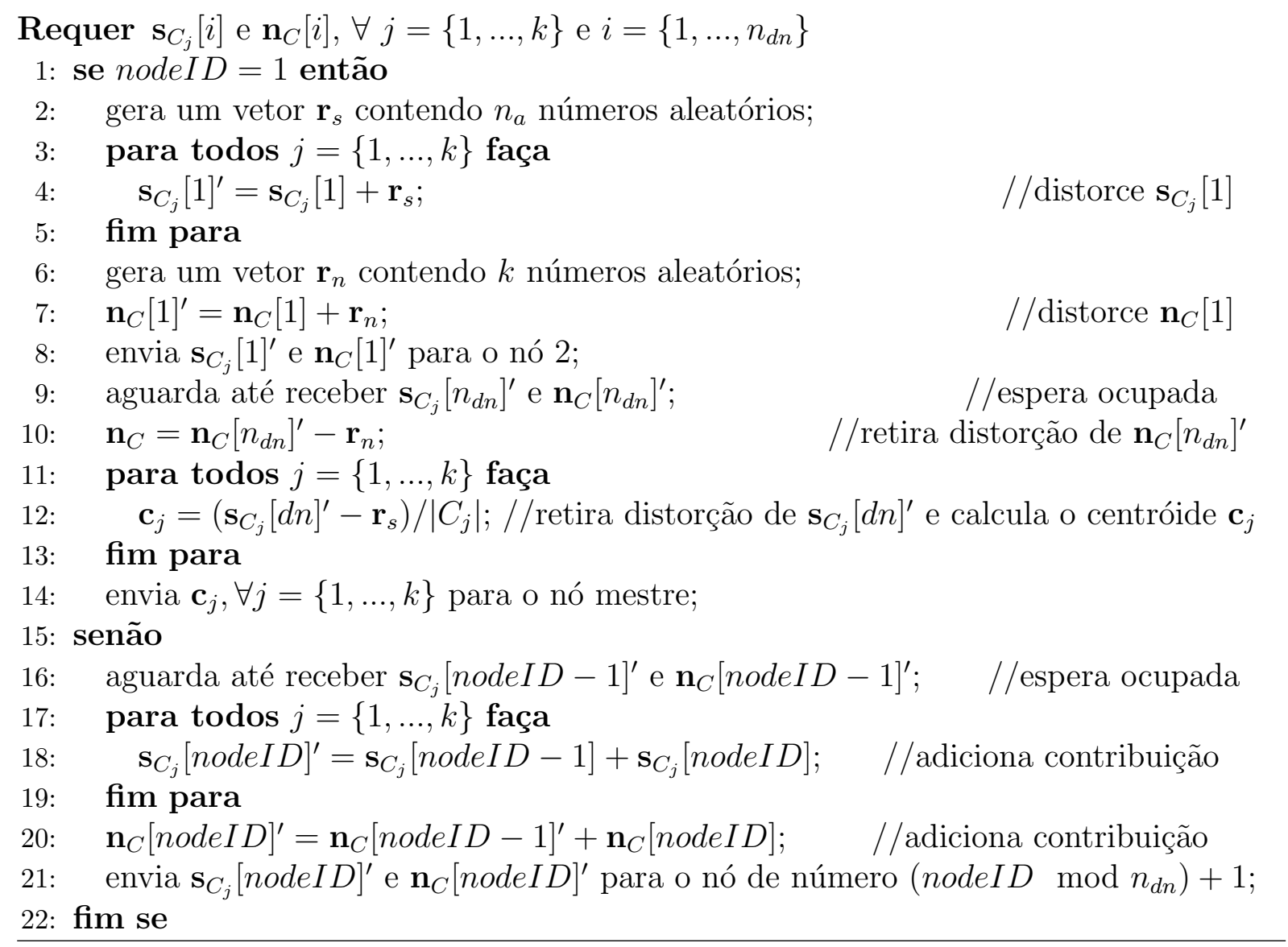

Eventualmente grupos singletons são gerados, o que expõe as características do objeto que esse grupo contém. Esse caso pode ser considerado uma violação da privacidade dos dados, violação que é parcial uma vez que não se sabe de qual nó esse objeto se originou. Uma forma de evitar essa violação consiste em impedir a formação de grupos singletons. Pode-se fazer isso, por exemplo, por meio da eliminação dos grupos desse tipo antes do cálculo dos centróides. Em seguida, é preciso tratar os objetos contidos nos grupos eliminados, colocando-os nos grupos mais próximos ou simplesmente deixando de agrupá-los na iteração do $k$-médias em que seus grupos originais foram eliminados.

A vantagem de se desfazer a distorção (Passo 10) no primeiro nó de dados, em relação a executar o mesmo passo no nó mestre, reside no fato de evitar transferências de dados desnecessárias ao nó mestre. Contudo, para que seja mantida a privacidade dos dados durante esse passo é necessário que haja mais do que dois nós de dados, ou seja, $n_{d n}>2$. Caso contrário, é preciso que $\mathbf{r}_{s}$ e $\mathbf{r}_{n}$ sejam enviados ao nó mestre e a distorção seja desfeita nele. 
É importante notar que a topologia de comunicação entre os nós muda na atualização dos centróides quando distorção é utilizada nos dados. Se o cálculo for feito sem distorção, cada nó de dados pode comunicar-se diretamente com o nó mestre. Quando utilizada a distorção, cada nó de dados envia informações para o próximo nó de maneira cíclica e apenas o primeiro nó envia dados para o nó mestre. A Figura 7.5 ilustra esse processo.

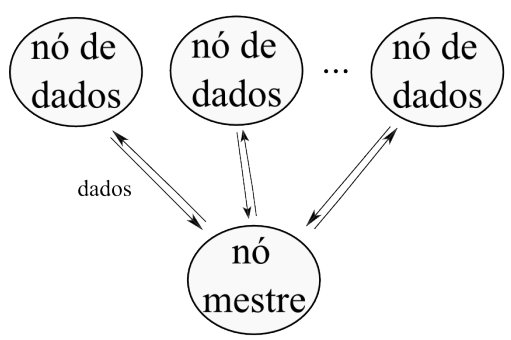

Comunicação sem distorção

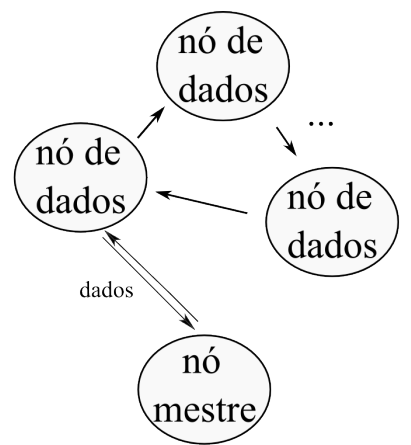

Comunicação com distorção

Figura 7.5: Topologia de comunicação entre nós.

A distorção dos dados é uma técnica simples de manutenção da privacidade dos dados, apropriada para aplicações que utilizam meios de transferência "seguros". Técnicas mais aprimoradas, como criptografia (da Silva et al., 2005), podem ser utilizadas (inclusive em conjunto com distorção) para aumentar a segurança da aplicação. Esse tipo de técnica é recomendada quando a segurança da transferência entre nós não é garantida. Revisões sobre técnicas de manutenção de privacidade em algoritmos de $D D M$ são encontradas em (Oliveira \& Zaïne, 2003; Vaidya \& Clifton, 2004; Fung et al., 2010).

\subsubsection{Cálculo da aptidão}

O índice silhueta simplificada é comumente utilizado para medir a aptidão dos indivíduos do F-EAC. Como pode ser visto na Seção 2.5.2.5, a silhueta de um grupo ou partição está diretamente relacionada com a silhueta de um objeto. Portanto, para calcular a aptidão dos grupos e partições, basta calcular a silhueta dos objetos que residem em cada nó de dados por meio da Equação (2.51). Para isso, os centróides resultantes da busca local são enviados do nó mestre para os nós de dados. Em seguida, é gerado um vetor

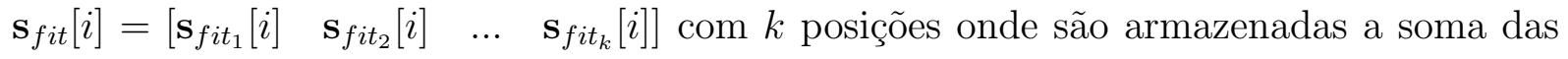
silhuetas dos objetos do $i$-ésimo nó de dados para cada grupo, como calculado na Equação (7.3).

$$
\mathbf{s}_{\text {fit }}[i]=\sum_{\mathbf{x}_{l}[i] \in C_{j}} \text { silhouette }\left(\mathbf{x}_{l}[i]\right)
$$

Os vetores $\mathbf{s}_{f i t}[i]$ são enviados de cada nó de dados para o nó mestre, que os somará em um único vetor $\mathbf{s}_{f i t}=\sum_{i=1}^{n_{d n}} \mathbf{s}_{f i t}[i]$. Grupos com um objeto (singletons) têm sua silhueta reduzida a 0 durante o cálculo da silhueta dos grupos e da partição. Os valores das 
silhuetas simplificadas de grupos com mais de um objeto e partições são obtidos por meio das Equações (2.52) e (2.53) respectivamente.

Durante o cálculo da aptidão não há exposição dos dados e, portanto, pode ser feito em casos em que a privacidade dos dados deve ser mantida.

\subsubsection{Operadores de mutação}

Como apresentado na Seção 3.4.2, o F-EAC possui dois operadores de mutação guiados por aptidão, ou seja, possuem maior probabilidade de afetar grupos com menor valor de aptidão. O primeiro operador $\left(M O_{1}\right)$ consiste em desfazer os grupos selecionados, inserindo seus objetos um a um nos grupos restantes mais próximos. O segundo $\left(\mathrm{MO}_{2}\right)$ consiste em selecionar, para cada grupo a sofrer mutação, um objeto aleatório e o objeto mais distante deste, ambos pertencentes ao grupo em questão. Em seguida, os objetos selecionados tornam-se protótipos dos novos grupos e o restante dos objetos do grupo são adicionados ao grupo de protótipo mais próximo dentre os dois novos grupos.

A versão aprimorada do $M O_{1}$, apresentada na Seção 4.3 .1 e utilizada aqui, desfaz os grupos selecionados e seus objetos tornam-se não agrupados até que sejam inseridos, um a um, nos grupos com os centróides mais próximos durante a execução seguinte do algoritmo $k$-médias. Essa versão não envolve consulta aos dados e, portanto, pode ser executada no nó mestre. Em seguida, o resultado da aplicação do operador é enviado para os nós de dados para atualização das estruturas de dados.

Diferentemente do $M O_{1}$, o $M O_{2}$ necessita de acesso direto aos dados durante sua execução e, portanto, requisita informações aos nós de dados. Para cada grupo a ser mutado, o nó mestre deve sortear aleatoriamente um objeto que ele contenha. Caso o nó mestre possua uma cópia do genótipo g, o sorteio é feito da mesma forma que no algoritmo $F-E A C$ e o objeto sorteado é requisitado ao nó de dados que o contém. Caso contrário, o nó mestre pode sortear um nó de dados e requisitar um objeto selecionado aleatoriamente que pertença ao grupo a ser mutado. A probabilidade de sorteio de um nó de dados deve ser proporcional ao número de objetos do grupo a ser mutado presentes neste nó. Após a seleção do primeiro objeto, esse é enviado ao nó mestre para tornar-se o primeiro protótipo e, em seguida, enviado para todos os nós de dados. Cada nó de dados recebe o primeiro objeto e envia ao nó mestre o objeto mais distante do primeiro objeto, que pertença ao grupo mutado e esteja presente no nó de dados. O objeto mais distante é transferido ao nó mestre, que seleciona dentre os objetos recebidos o mais distante do primeiro protótipo, tornando-o o segundo protótipo. Os dois protótipos são utilizados para atualizar os dados no nó mestre e enviados a todos os nós de dados, para a atualização de suas estruturas de dados locais.

Apesar do método proposto para o $\mathrm{MO}_{2}$ ser equivalente ao utilizado no $F$-EAC, ele resulta em uma grande quantidade de comunicação entre os nós de dados e o nó central. Adicionalmente, não é possível manter a privacidade dos dados selecionados para se tornarem protótipos. Por este motivo, estudos de variantes do $\mathrm{MO}_{2}$ foram feitos. Uma das 
variantes estudadas, aqui chamada de operador de mutação 2 alternativo $\left(M O A_{2}\right)$, seleciona aleatoriamente dois objetos dentre os contidos no grupo a ser mutado, de modo a torná-los os novos protótipos. Essa seleção pode ser feita com ou sem a utilização de g, da mesma forma que descrito para o $\mathrm{MO}_{2}$ original. O protótipo original do grupo mutado é eliminado, tanto nos nós de dados, quanto no nó mestre (se houver) e os objetos restantes são tratados na próxima execução do algoritmo $k$-médias, em que são comparados um a um com todos os protótipos, incluindo os novos, e inseridos no grupo de protótipo mais próximo.

Ao ser aplicada junto com o $F$-EAC, a variante do $M O A_{2}$ descrita anteriormente obteve resultados estatisticamente equivalentes, em termos de qualidade, aos encontrados pelo uso do operador original (vide o Apêndice II). Adicionalmente, ela resultou em uma redução do número médio de gerações executadas pelo $F$-EAC em comparação com o algoritmo original. Por esses motivos, ela será utilizada nos experimentos apresentados neste capítulo.

Entretanto, utilizar dois objetos aleatórios como protótipos expõe seus valores, eliminando sua privacidade. Uma solução consiste em utilizar combinações convexas de objetos, de maneira análoga ao método aplicado para preservar a privacidade dos dados durante a inicialização das partições. Por exemplo, o nó mestre pode requisitar candidatos a novos protótipos aos nós de dados. Por sua vez, os nós de dados que receberam a requisição sorteiam $n_{o s}$ objetos $\left\{\mathbf{x}_{1 t}, \mathbf{x}_{2 t}, \ldots, \mathbf{x}_{n_{o s}}\right\}$ dentre os seus, de forma que pertençam ao grupo mutado e $n_{o s}$ seja um número inteiro aleatório entre 2 e o total de objetos do grupo mutado presente no nó de dados. Em seguida, um vetor de pesos $\mathbf{w}=\left[\begin{array}{llll}w_{1} & w_{2} & \ldots & w_{n_{o s}}\end{array}\right]$ é gerado aleatoriamente de forma que $w_{j}>0 \quad \forall j$ e $\sum_{j=1}^{n_{o s}} w_{j}=1$ e utilizado para gerar um protótipo $\mathbf{p}$ por meio da combinação convexa $\mathbf{p}=w_{1} \mathbf{x}_{1 t}+w_{2} \mathbf{x}_{2 t}+\ldots+w_{n_{o s}} \mathbf{x}_{n_{o s} t}$. Mais uma vez, a combinação convexa faz com que o protótipo obtido esteja no casco convexo formado pelos objetos selecionados e mantenha a privacidade dos dados. Nos casos em que não exista um nó de dados com mais de um objeto para um determinado grupo a ser mutado, novos protótipos podem ser obtidos por meio de combinações convexas entre um objeto desse grupo e seu protótipo atual. Depois de obtidos, os novos protótipos são enviados ao nó mestre, onde se tornam novos grupos. Ao final, a partição é atualizada, tanto no nó mestre, como nos nós de dados.

É importante ressaltar que utilizar combinações convexas para gerar protótipos no $\mathrm{MO}_{2}$ pode influenciar seu resultado e o modifica em relação ao operador original proposto em (Alves et al., 2006; Alves, 2007). Esse tipo de combinação será utilizado nos experimentos a serem apresentados na Seção 7.5, na variante do $D F-E A C$ que envolve a manutenção de privacidade dos dados (referenciada como DF-EAC (P)). Os resultados presentes nessa seção mostram que a utilização de combinações convexas obteve partições de qualidade igual ou superior ao operador $M O A_{2}$, em média. Todavia, também causam aumento na quantidade de dados transferidos. 


\subsubsection{Análise de complexidade do DF-EAC}

Três aspectos principais são considerados neste trabalho ao avaliar a complexidade de um algoritmo: o primeiro está relacionado ao número de operações executadas pelo algoritmo em cada nó de dados; o segundo está relacionado ao espaço em memória primária ocupado pelo algoritmo; o terceiro compreende a quantidade de informação transferida durante sua execução.

Assim como o $F-E A C$, o $D F-E A C$ apresenta seu maior custo computacional durante a execução do algoritmo $k$-médias, que possui complexidade $O\left(t \cdot n_{o} \cdot \hat{k}_{\text {max }}\right)$, em que $n_{o}$ consiste no número de objetos, $\hat{k}_{\max }$ é o número máximo de grupos codificado por um genótipo durante a busca evolutiva e $t$ é o número de iterações do algoritmo $k$ médias. Como $k$-médias é aplicado em cada genótipo de cada geração, a complexidade assintótica computacional do $D F-E A C$ é estimada em $O\left(n_{g} \cdot|P| \cdot t \cdot n_{o} \cdot \hat{k}_{\text {max }}\right)$ no pior caso, para $n_{g}$ gerações e população de tamanho $|P|$. Contudo, nos casos em que a execução distribuída do algoritmo é feita paralelamente, o custo computacional do algoritmo é dividido proporcionalmente à quantidade de dados em cada nó. Seja $n_{o, \max }$ o maior número de objetos contido em um nó de dados, o $D F-E A C$ apresenta complexidade $O\left(n_{g}\right.$. $\left.|P| \cdot t \cdot \hat{k}_{\text {max }} \cdot n_{o, \max }\right)$ se o processamento de seus nós ocorrer de forma paralela. Quando $n_{o, \max } \approx n_{o} / n_{d n}$, em que $n_{d n}$ é o número de nós de dados, esse custo pode ser estimado como $O\left(n_{g} \cdot|P| \cdot t \cdot \hat{k}_{\text {max }} \cdot n_{o} / n_{d n}\right)$.

Analogamente, o maior custo em memória do algoritmo $F$-EAC consiste na alocação da matriz de dissimilaridades entre os objetos e os centróides dos grupos $\mathbf{D}$, estimada em $O\left(n_{o} \cdot \hat{k}_{\text {max }}\right)$ para cada genótipo. No pior caso, o custo do $D F-E A C$ em memória é $O\left(\hat{k}_{\text {max }} \cdot|P| \cdot n_{o, \max }\right)$, o que pode ser estimado como $O\left(\hat{k}_{\text {max }} \cdot|P| \cdot n_{o} / n_{d n}\right)$ se $n_{o, \max } \approx n_{o} / n_{d n}$. Portanto, é possível reduzir o custo em memória do $D F-E A C$ por meio da diminuição do tamanho da população, o que pode gerar um aumento no número de gerações do algoritmo, em contrapartida.

Por último, a maior quantidade de informação transferida entre nós consiste no conjunto de centróides, transferidos a cada iteração do algoritmo $k$-médias. Portanto, como o número de centróides por genótipo é $\hat{k}_{\max }$ no pior caso e cada centróide possui $n_{a}$ atributos, a complexidade de transferência de dados é estimada como $O\left(n_{g} \cdot|P| \cdot t \cdot \hat{k}_{\text {max }} \cdot n_{a} \cdot n_{d n}\right)$. Essa estimativa é válida para comunicações entre o nó mestre e os nós de dados feitas de maneira concorrente ou sequencial, ambas ilustradas na Figura 7.5. É importante notar que o custo de transferência do algoritmo é independente do número total de objetos do conjunto de dados $n_{o}$, o que torna a transferência de dados do $D F-E A C$ escalável em relação a esse parâmetro.

\subsection{Combinações de Agrupamentos Distribuídos (CAD)}

Por ser uma versão exata do $F$-EAC, o $D F-E A C$ herda um conjunto de propriedades desejáveis a um algoritmo de agrupamento, como complexidade computacional assintótica 
linear em relação a todos os seus parâmetros críticos e um desempenho que se destaca em relação a métodos sistemáticos e meta-heurísticas comumente utilizadas em conjunto com o algoritmo $k$-médias (Naldi et al., 2009, 2011), conforme discutido no Capítulo 4. Entretanto, para proporcionar a exatidão do $D F-E A C$, fez se necessária a utilização de múltiplas rodadas de comunicação que, dependendo do tamanho dos dados transferidos e da latência da transferência, pode prejudicar consideravelmente o desempenho do algoritmo.

Uma alternativa ao uso de múltiplas rodadas de comunicação consiste em sumarizar a informação contida nos nós de dados, enviar a informação sumarizada ao nó mestre e executar o agrupamento dos dados a partir das informações sumarizadas. O objetivo consiste em reduzir a quantidade de transmissões entre nós e obter uma partição de qualidade próxima à que seria obtida pelo modelo centralizado. Com esse objetivo, um conjunto de algoritmos aproximados, aqui chamado de Combinações de Agrupamentos Distribuídos (CAD) foi desenvolvido e investigado neste trabalho.

Os algoritmos CAD são compostos por duas etapas: a geração de um modelo local para cada nó de dados e a posterior combinação dos modelos locais em um modelo global final. Como a finalidade dos algoritmos investigados aqui é o agrupamento de dados distribuídos, tanto os modelos locais, como o modelo global consistem em partições e, portanto, serão referenciados aqui como partições locais e partição global. De maneira análoga, por se tratar de um processo de combinação de agrupamentos, as partições locais também são partições base e a partição global consiste na partição consenso ou final. Um exemplo das etapas dos algoritmos CAD e da topologia de comunicação entre os nós de dados e o nó mestre desses algoritmos é apresentado na Figura 7.6.

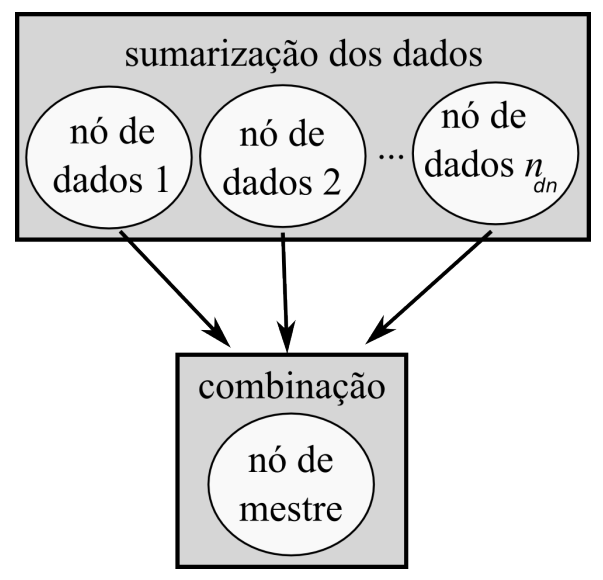

Figura 7.6: Etapas e topologia de comunicação entre nós dos algoritmos CAD.

Como os algoritmos CAD utilizam modelos locais, os dados não são expostos e a privacidade é mantida se grupos com menos de 2 objetos não forem permitidos. As etapas de geração das partições locais e combinação dos algoritmos CAD são apresentadas de nas Seções 7.4.1 e 7.4.2, respectivamente. 


\subsubsection{Geração dos modelos locais}

A primeira etapa dos algoritmos CAD é a geração de partições locais, de forma a gerar estruturas que representem os dados e possam reduzir o custo de armazenamento e comunicação do algoritmo. As partições locais podem ser representadas pelos protótipos de seus grupos. Entretanto, os protótipos são capazes de informar apenas a posição aproximada dos grupos no espaço de dados, o que gera perda da informação relativa à quantidade de objetos nos grupos e suas distribuições. Por esse motivo, o número de objetos contidos em cada grupo também é utilizado na sumarização dos dados neste trabalho. Quanto à distribuição dos dados, testar a aderência de cada grupo gerado em cada nó de dados a algumas distribuições de dados de interesse pode gerar um alto custo computacional, dependendo do teste e das distribuições de dados em questão (Hogg, 1994). Mesmo que seja assumida uma determinada distribuição para todos os grupos, o algoritmo ainda pode possuir um custo computacional considerável, como é caso do algoritmo Expectation Maximization (Seção 2.4.2), que apresenta complexidade $O\left(n_{o} \cdot n_{a}^{3}\right.$ ) para distribuições Gaussianas (Sakuma \& Kobayashi, 2002). Como um dos objetivos deste trabalho é propor métodos de baixa complexidade computacional, os modelos aqui propostos não consideram informações sobre as distribuições dos grupos, tornando o uso destas distribuições um possível tema para investigação.

Neste trabalho, o algoritmo F-EAC (Seção 3.4) será utilizado para gerar as partições locais pelos seguintes motivos:

- Esse trabalho é focado em partições com grupos compactos e isolados. O F-EAC obteve bons resultados para esse tipo de partição em diversos trabalhos (Alves et al., 2006; Horta et al., 2009; Naldi et al., 2009, 2011);

- O F-EAC é capaz de estimar o número de grupos da partição e seus protótipos.

- O algoritmo comprovou possuir bom desempenho, com complexidade linear em relação aos seus parâmetros críticos (como mostrado no Capítulo 4).

Uma vez obtidas as partições locais em cada nó de dados, os centróides e o número de objetos de cada grupo das partições melhor avaliadas pelo algoritmo $F$-EAC são enviados ao nó mestre, a fim de permitir a combinação das partições locais em uma única partição global.

\subsubsection{Combinação de partições}

Ao receber os centróides e número de objetos de cada grupo das partições locais, o nó mestre deve gerar uma partição consenso que represente como os dados são estruturados de maneira global. Devido à distribuição horizontal dos dados, não é possível utilizar diretamente técnicas tradicionais de combinação de agrupamento, como as descritas no 
Capítulo 5. Entretanto, como os objetos contêm os mesmos atributos, ou seja, encontramse no mesmo espaço de dados, é possível aplicar algoritmos de agrupamento sobre os centróides das partições locais, de forma a gerar uma meta-partição.

Seja $M X=\left\{\mathbf{c}_{1}, \mathbf{c}_{2}, \ldots, \mathbf{c}_{n_{\mathbf{c}}}\right\}$ a coleção de centróides de todas as partições locais obtidas na primeira etapa dos algoritmos CAD, em que $n_{\mathbf{c}}$ é o número total de centróides. Uma meta-partição consiste em uma coleção $M \pi=\left\{M C_{1}, M C_{2}, \ldots, M C_{m k}\right\}$ de meta-grupos $M C_{i}$ tais que $M C_{1} \cup M C_{2} \cup \ldots \cup M C_{m k}=M X, M C_{i} \neq \emptyset$ e $M C_{i} \cap M C_{l}=\emptyset$ para $i \neq l$. A partir da meta-partição resultante, é possível obter a partição global dos dados substituindo cada centróide agrupado pelos objetos contidos no grupo que ele representa, o que transforma cada meta-grupo em um grupo da partição global.

Ao agrupar os centróides das partições locais em meta-grupos, é possível utilizar o número de objetos nos grupos das partições locais para fazer um ajuste da posição do centróide do meta-grupo, aqui chamado de meta-centróide mc. Esse ajuste fino consiste em calcular o meta-centróide de um meta-grupo por meio da média dos centróides presentes no meta-grupo, ponderada pelo número de objetos presentes nos grupos que eles representam. Portanto, o $j$-ésimo meta-centróide da meta-partição é calculado por meio da Equação (7.4):

$$
\mathbf{m c}_{j}=\frac{\sum_{\mathbf{c}_{i} \in M C_{j}} \mathbf{c}_{i}\left|C_{i}\right|}{\sum_{\mathbf{c}_{i} \in M C_{j}}\left|C_{i}\right|}
$$

em que $\left|C_{i}\right|$ é a cardinalidade do grupo cujo centróide é $\mathbf{c}_{i}$. O ajuste feito no cálculo dos meta-centróides influencia no resultado da combinação das partições locais. Para ilustrar essa influência, um exemplo de partição com dois grupos $C_{1}$ e $C_{2}$ é apresentado na Figura 7.7 (a). Essa partição exemplo dá origem aos dois centróides $\mathbf{c}_{1}$ e $\mathbf{c}_{2}$ apresentados na Figura 7.7 (b). Se o meta-centróide $\mathbf{m c}$ for gerado a partir de média simples entre $\mathbf{c}_{1}$ e $\mathbf{c}_{2}$, ele não será o centróide dos dados representados por $\mathbf{c}_{1}$ e $\mathbf{c}_{2}$, como pode ser visto na Figura 7.7 (c). Com o ajuste proposto, o meta-centróide mc torna-se o centróide dos objetos em $C_{1}$ e $C_{2}$, como é mostrado na Figura 7.7 (d).

Neste trabalho, três algoritmos foram escolhidos para combinar/agrupar a coleção de centróides $M X$ : o algoritmo hierárquico de ligação simples (Seção 2.4.5), o algoritmo hierárquico de ligação média (Seção 2.4.5) e o algoritmo F-EAC (Seção 3.4). Como os algoritmos hierárquicos resultam em partições aninhadas, as partições geradas em cada nível da hierarquia são avaliadas por um índice de validação relativo (o mesmo utilizado como função de aptidão no $F-E A C)$ e a partição melhor avaliada é escolhida como a partição final.

O cálculo dos valores de validação das partições globais e dos seus grupos é feito de maneira exata, ou seja, deve obter os mesmos resultados que uma execução com dados centralizados. Quando o índice silhueta simplificada (Seção 2.5.2.5) é utilizado na validação, calcular valores exatos implica em transmitir os meta-centróides aos nós de dados e receber a soma das silhuetas para cada grupo, exatamente como mostrado para o $D F-E A C$ 


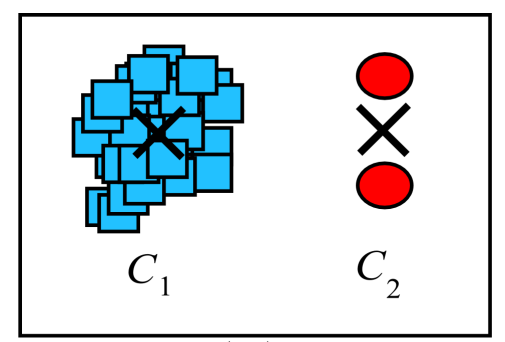

(a)

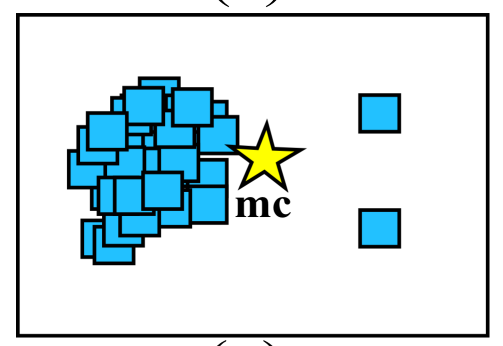

(c)

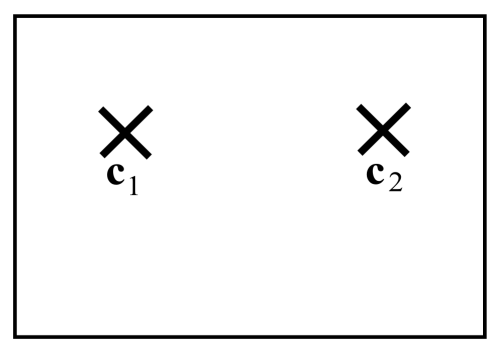

(b)

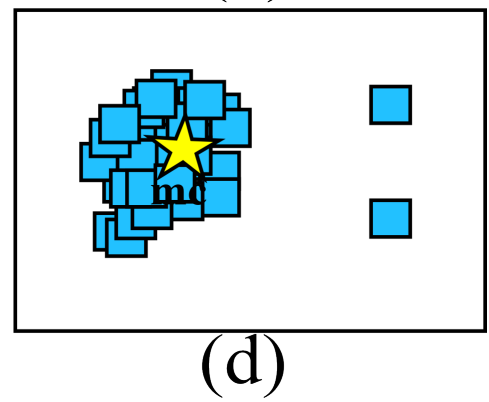

Figura 7.7: Exemplos para o cálculo de meta-centróides: (a) partição exemplo, (b) centróides, (c) meta-centróide calculado pela média dos centróides e (d) meta-centróide calculado pela média ponderada dos centróides.

na Seção 7.3.4. O cálculo exato da silhueta simplificada exige uma rodada de comunicação entre o nó mestre e os nós de dados. Quando os algoritmos hierárquicos são aplicados na segunda etapa, o cálculo da silhueta simplificada das partições correspondentes a todos os níveis da hierarquia pode ser feito com apenas uma rodada de comunicação, que, somada à rodada em que os centróides são transferidos ao nó mestre, caracteriza os algoritmos CAD como algoritmos de múltiplas rodadas de comunicação. A quantidade de rodadas de comunicação é maior quando o algoritmo F-EAC é utilizado para combinar as partições locais, pois valores de silhueta simplificada devem ser calculados a cada geração.

É possível executar os algoritmos CAD em uma única rodada de comunicação, utilizando um índice de validação que não necessite de acesso direto aos dados e, portanto, não necessite de comunicação com os nós de dados. Na Seção 7.4.3, o índice $V R C$ (Seção 2.5.2.1) é apresentado como uma possível alternativa para a redução da quantidade de rodadas de comunicação e de dados transferidos.

\subsubsection{VRC como função de avaliação}

O $V R C$, apresentado na Seção 2.5.2.1, é o índice de validação relativo melhor avaliado por Milligan \& Cooper (1985) e um dos que apresentaram os melhores resultados em pesquisas comparativas feitas por Vendramin et al. (2009, 2010). Quando adotado nos algoritmos CAD apresenta uma vantagem adicional: pode ser calculado de maneira exata a partir das informações locais obtidas na primeira etapa do algoritmo (Seção 7.4.1), sem a necessidade de rodadas de comunicação extras. Para isso, deve-se observar que cada meta-grupo $M C_{i}$ corresponde a um grupo $C_{i}$ da partição global, cujos objetos são representados pelos centróides contidos em $M C_{i}$. Deve-se observar também que o meta- 
centróide $\mathbf{m c}_{\mathbf{i}}$ é precisamente o centróide correspondente ao grupo $C_{i}$, centróide este doravante denominado simplesmente $\mathbf{c}_{\mathbf{i}}$. Em seguida, deve-se obter a soma das distâncias Euclidianas quadráticas internas relativas ao grupo $C_{i}\left(W G S S\left(C_{i}\right)\right)$, originalmente dada pela Equação (2.30), por meio da Equação (7.5).

$$
\begin{aligned}
W G S S\left(C_{i}\right) & =\sum_{\mathbf{x}_{j} \in C_{i}}\left(\mathbf{x}_{j}-\mathbf{c}_{i}\right)^{T}\left(\mathbf{x}_{j}-\mathbf{c}_{i}\right) \\
& =\sum_{\mathbf{x}_{j} \in C_{i}} \sum_{l=1}^{n_{a}}\left(\mathbf{x}_{j}(l)-\mathbf{c}_{i}(l)\right)^{2} \\
& =\sum_{l=1}^{n_{a}} \sum_{\mathbf{x}_{j} \in C_{i}}\left(\mathbf{x}_{j}(l)^{2}-2 \mathbf{x}_{j}(l) \mathbf{c}_{i}(l)+\mathbf{c}_{i}(l)^{2}\right) \\
& =\sum_{l=1}^{n_{a}}\left(\sum_{\mathbf{x}_{j} \in C_{i}} \mathbf{x}_{j}(l)^{2}-2 \mathbf{c}_{i}(l) \sum_{\mathbf{x}_{j} \in C_{i}} \mathbf{x}_{j}(l)+\left|C_{i}\right| \mathbf{c}_{i}(l)^{2}\right) \\
& =\sum_{l=1}^{n_{a}}\left(\sum_{\mathbf{x}_{j} \in C_{i}} \mathbf{x}_{j}(l)^{2}-\left|C_{i}\right| \mathbf{c}_{i}(l)^{2}\right)
\end{aligned}
$$

Como a cardinalidade do $i$-ésimo grupo $\left|C_{i}\right|$ e o centróide $\mathbf{c}_{i}$ são obtidos ao gerar os modelos locais e transferidos para o nó mestre, a única informação adicional necessária para calcular $W G S S\left(C_{i}\right)$ consiste em $\sum_{\mathbf{x}_{j} \in C_{i}} \sum_{l=1}^{n_{a}} \mathbf{x}_{j}(l)^{2}$, em que $\mathbf{x}_{j}(l)$ é o $l$-ésimo atributo do vetor $\mathbf{x}_{j}$. Consequentemente, é possível calcular $W G S S(\pi)$, originalmente dada pela Equação (2.29), por meio da Equação (7.6).

$$
\begin{aligned}
W G S S(\pi) & =\sum_{i=1}^{k} W G S S\left(C_{i}\right) \\
& =\sum_{i=1}^{k} \sum_{l=1}^{n_{a}}\left(\sum_{\mathbf{x}_{j} \in C_{i}} \mathbf{x}_{j}(l)^{2}-\left|C_{i}\right| \mathbf{c}_{i}(l)^{2}\right) \\
& =\sum_{\mathbf{x}_{j} \in X} \sum_{l=1}^{n_{a}} \mathbf{x}_{j}(l)^{2}-\sum_{i=1}^{k} \sum_{l=1}^{n_{a}}\left|C_{i}\right| \mathbf{c}_{i}(l)^{2}
\end{aligned}
$$

O termo $\sum_{\mathbf{x}_{j} \in X} \sum_{l=1}^{n_{a}} \mathbf{x}_{j}(l)^{2}$ é constante para um determinado conjunto de dados, independente de sua partição, e pode ser obtido por meio da soma de contribuições parciais calculadas em cada nó de dados. Nesse caso, a contribuição do $i$-ésimo nó de dados para o cálculo de $\sum_{\mathbf{x}_{j} \in X} \sum_{l=1}^{n_{a}} \mathbf{x}_{j}(l)^{2}$ seria a soma dos quadrados dos atributos de seus objetos, ou seja, $\sum_{j=1}^{n_{o}[i]} \sum_{l=1}^{n_{a}} \mathbf{x}_{j}[i](l)^{2}$. A contribuição de cada nó de dados é transferida ao nó mestre, que obtém $\sum_{\mathbf{x}_{j} \in X} \sum_{l=1}^{n_{a}} \mathbf{x}_{j}(l)^{2}$ por meio de $\sum_{i=1}^{n_{d n}} \sum_{j=1}^{n_{o}[i]} \sum_{l=1}^{n_{a}} \mathbf{x}_{j}[i](l)^{2}$.

Calcular $B G S S\left(C_{i}\right)$, dada pela Equação (2.32), necessita de $\overline{\mathbf{x}}$, a média de todos os objetos do conjunto $X$, que também pode ser facilmente calculada por meio de contribuições locais. Com essa finalidade, o $i$-ésimo nó de dados calcula a soma de seus objetos 
$\sum_{j=1}^{n_{o}[i]} \mathbf{x}_{j}[i]$ e a envia ao nó mestre, que soma as contribuições de cada nó e divide o resultado pelo número total de objetos, o que obtém $\overline{\mathbf{x}}=\sum_{i=1}^{n_{d n}} \sum_{j=1}^{n_{o}[i]} \mathbf{x}_{j}[i] / \sum_{l=1}^{k}\left|C_{l}\right|$.

As contribuições geradas em cada nó de dados são transferidas ao nó mestre, juntamente com os centróides e cardinalidade dos grupos locais, de forma a possibilitar o cálculo exato do índice $V R C$ sem acesso direto aos dados. Dessa maneira, a adoção do $V R C$ na validação de partições faz com que os algoritmos CAD sejam executados em uma única rodada de comunicação.

Apesar do $V R C$ ter sido inicialmente adaptado para validar partições dos algoritmos CAD, é de interesse para este trabalho avaliar sua utilização no $D F$-EAC. Entretanto, uma das principais características do algoritmo $F$-EAC e, consequentemente do $D F-E A C$, é possuir operadores de mutação guiados pela aptidão dos grupos (Seção 3.4.2), ou seja, grupos com menor aptidão possuem maior probabilidade de sofrer mutação. O índice $V R C$ como definido em (Calinski \& Harabasz, 1974) não avalia a qualidade dos grupos individualmente, o que não permite guiar os operadores de mutação do $F$-EAC/DF-EAC.

Neste trabalho, serão avaliadas variantes do algoritmo $F$-EAC que utilizam $V R C$ como função de aptidão, mas não possuem operadores de mutação guiados. Nessas variantes, os grupos são selecionados para mutação com igual probabilidade, como no algoritmo predecessor $E A C$ (Hruschka et al., 2004a, 2006). Por esse motivo, essas variantes serão chamadas aqui de Distributed Evolutionary Algorithm for Clustering (D-EAC). Em verdade, trata-se de uma versão distribuída híbrida entre o $F$-EAC e o $E A C$, pois ela ajusta automaticamente a probabilidade de aplicação de cada operador de mutação como no F-EAC, mas não possui seleção de grupos para mutação guiada por qualidade (para mais informações sobre operadores guiados, ver Seção 3.1).

\subsubsection{Análise de complexidade dos algoritmos $C A D$}

Como apresentado anteriormente, os algoritmos CAD são compostos por duas etapas: a geração dos modelos locais e a combinação das partições obtidas nos nós de dados. Assumindo que o $i$-ésimo nó de dados possui $n_{o}[i]$ objetos, a primeira etapa dos algoritmos CAD possui uma complexidade computacional equivalente a executar o algoritmo $F$-EAC (ver complexidade do $F$-EAC na Seção 4.2.3) em cada nó de dados, ou seja, $O\left(n_{g}\right.$ • $|P| \cdot t \cdot \hat{k}_{\text {max }} \cdot\left(n_{o}[1]+n_{o}[2]+\ldots+n_{o}\left[n_{d n}\right]\right)$, o que resulta em uma complexidade total de $O\left(n_{g} \cdot|P| \cdot t \cdot \hat{k}_{\text {max }} \cdot n_{o}\right)$. Se executado paralelamente, a complexidade é reduzida para $O\left(n_{g} \cdot|P| \cdot t \cdot \hat{k}_{\max } \cdot n_{o, \max }\right)$, em que $n_{o, \max }$ é maior número de objetos em um nó de dados. Se for considerado que $n_{o, \max } \approx n_{o} / n_{d n}$, então a complexidade da primeira etapa dos algoritmos pode ser estimada como $O\left(n_{g} \cdot|P| \cdot t \cdot \hat{k}_{\text {max }} \cdot n_{o} / n_{d n}\right)$. Essa complexidade computacional é igual à estimada para o algoritmo $D F-E A C$, como pode ser visto na Seção 7.3.6. Ou seja, os algoritmos CAD possuem complexidade computacional igual ou maior do que o algoritmo $D F-E A C$, o que dependerá do algoritmo utilizado na segunda etapa.

A segunda etapa dos algoritmos CAD possui complexidade computacional igual ao 
algoritmo de agrupamento aplicado, de forma que o número de objetos de entrada é igual ao número de centróides obtidos na primeira etapa. Como apresentado na Seção 2.4.5, os algoritmos hierárquicos de ligação simples e média possuem complexidade computacional $O\left(n_{o}^{2} \cdot \log n_{o}\right)$ (Jain et al., 1999). Assumindo que $\hat{k}_{\text {max }}$ seja o maior número de grupos obtido pelo $F-E A C$ na primeira etapa dos algoritmos, o número de centróides resultantes da primeira etapa dos algoritmos CAD é estimado como $\hat{k}_{\text {max }} \cdot n_{d n}$, o que faz com que utilizar esses algoritmos hierárquicos na segunda etapa gere custo computacional aproximado de $O\left(\hat{k}_{\text {max }}^{2} \cdot n_{d n}^{2} \cdot\left(\log \hat{k}_{\text {max }}+\log n_{d n}\right)\right)$. Quando o algoritmo $F-E A C$ é aplicado durante a segunda etapa, o custo computacional desta etapa é estimado como $O\left(n_{g} \cdot|P| \cdot t \cdot \hat{k}_{\text {max }}^{2} \cdot n_{d n}\right)$, caso $\hat{k}_{\text {max }}$ também seja o número máximo de grupos obtidos pelo $F$-EAC na segunda etapa dos algoritmos.

Em relação ao custo em memória do algoritmo, a maior estrutura de dados utilizada na primeira etapa é a $\mathbf{D}$, que aloca memória de ordem $O\left(\hat{k}_{\max } \cdot|P| \cdot n_{o, \max }\right)$, de ordem igual a memória alocada pelo algoritmo $D F-E A C$ (ver Seção 7.3.6). Quando o algoritmo $F-E A C$ é aplicado na segunda etapa do algoritmo, $\mathbf{D}$ continua sendo a maior estrutura em memória, com complexidade $O\left(|P| \cdot \hat{k}_{\text {max }}^{2} \cdot n_{d n}\right)$. Nos casos em que os algoritmos hierárquicos são utilizados, o custo em memória máximo da segunda etapa consiste em armazenar as distâncias de todos os centróides para todos os centróides resultantes da primeira etapa do algoritmo, ou seja, $O\left(\hat{k}_{\max }^{2} \cdot n_{d n}^{2}\right)$.

Ao analisar a complexidade da transferência de dados dos algoritmos CAD, dois pontos devem ser considerados: qual o índice de validação escolhido e qual o algoritmo de agrupamento utilizado na segunda etapa. No final da primeira etapa, os algoritmos transmitem os centróides obtidos para o nó mestre, o que gera custo de transferência total de $O\left(\hat{k}_{\max } \cdot n_{a} \cdot n_{d n}\right)$ no pior caso. Como apresentado na Seção 7.4.3, a utilização do índice $V R C$ faz com que os algoritmos CAD possuam uma única rodada de comunicação, de forma que a complexidade total de transferência dos algoritmos seja a complexidade estimada para a primeira etapa, adicionada de informações extra de complexidade de ordem $O(1)$. Isso porque é possível calcular o $V R C$ de qualquer partição gerada na segunda etapa do algoritmo por meio desta informação extra, sem a necessidade de comunicação com os nós de dados, como descrito na Seção 7.4.3.

Caso o índice de validação utilizado seja o silhueta simplificada, é preciso transferir o conjunto de meta-centróides para os nós de dados para todas as partições avaliadas. Como descrito no final da Seção 7.4.2, cada transmissão desse tipo pode ser feita em uma rodada de comunicação que, somada com a rodada em que os centróides resultantes da primeira etapa são transferidos para o nó mestre, caracteriza os CAD com silhueta simplificada algoritmos de múltiplas rodadas de comunicação. Se os algoritmos hierárquicos forem utilizados na segunda etapa, o número total de meta-centróides será $2+3+\cdots+k_{\max } \approx$ $k_{\max }\left(k_{\max }+1\right) / 2$, o que torna a quantidade de dados transferidos da ordem de $O\left(k_{\max }^{2}\right.$. $\left.n_{a} \cdot n_{d n}\right)$ no pior caso. Se o algoritmo $F-E A C$ for utilizado na segunda etapa, $n_{g} \cdot|P|$ partições são avaliadas pelo índice silhueta simplificada, o que faz com que a quantidade 
de dados transferidos seja estimada como $O\left(n_{g} \cdot|P| \cdot \hat{k}_{\text {max }} \cdot n_{a} \cdot n_{d n}\right)$ para o pior caso.

Como pode ser visto na Seção 7.3.6, o custo de transmissão do o algoritmo DF-EAC é $t$ vezes maior do que o custo estimado para o algoritmo CAD com F-EAC na segunda etapa, em que $t$ é o número máximo de iterações do algoritmo $k$-médias. É importante notar que, assim como o DF-EAC, os algoritmos CAD possuem uma complexidade de transferência de dados independente do número de objetos agrupados $n_{o}$, o que também os torna escaláveis em relação à esse aspecto.

\subsection{Experimentos}

Com o objetivo de avaliar os algoritmos descritos nas Seções 7.3 e 7.4, experimentos foram feitos em um conjunto de base de dados distribuídas. Essa avaliação trata-se de uma estimativa aproximada do desempenho de cada algoritmo, de modo a contemplar três aspectos: a qualidade das partições obtidas, o tempo de execução dos algoritmos e a quantidade de dados transferidos entre nós.

Em relação à avaliação da qualidade das partições obtidas, o índice externo de Jaccard (Seção 2.5.1.1) foi utilizado para comparar as partições obtidas com os grupos conhecidos. Quanto maior a semelhança entre os grupos obtidos e os grupos conhecidos, maior é o valor retornado pelo índice.

O tempo de execução foi aferido para cada algoritmo a partir de implementações feitas na ferramenta Matlab, executados em computadores com quatro núcleos de $3.0 \mathrm{Ghz}, 12$ GB de memória RAM com frequência de 1600 Mhz, processando apenas o algoritmo e o sistema operacional. As implementações feitas objetivam estimar o tempo médio dos algoritmos comparados, quando executados em um grupo de computadores com a mesma configuração do sistema descrito anteriormente. As leituras de tempo de execução consideram que as operações efetuadas em diferentes nós sejam executadas paralelamente e sem concorrência sempre que possível. Por esse motivo, apenas o maior tempo de execução resultante de partes do algoritmo executadas em paralelo será considerado na contagem do tempo de execução. As únicas exceções são trechos dos algoritmos em que a execução é obrigatoriamente sequencial, como é o caso do uso de distorção no algoritmo $D F-E A C$ com manutenção de privacidade.

O cálculo da quantidade total de dados transferidos considera que a comunicação entre nós ocorre de forma sequencial ou concorrente, como indica os exemplos de topologias ilustradas nas Figuras 7.5 e 7.6. Como mencionado anteriormente, essas topologias podem (e devem) ser aprimoradas de acordo com o cenário de aplicação. Entretanto, para os experimentos apresentados aqui, elas serão assumidas por questão de simplicidade.

\subsubsection{Conjuntos de dados}

O conjunto de base de dados Artificial2, descrito na Seção 6.2, foi escolhido para esta avaliação pois suas 80 bases possuem uma quantidade razoável de objetos $\left(3800>n_{o}>\right.$ 
800), além de grupos com distribuições Gaussianas levemente sobrepostas que permitem encontrar partições de boa qualidade por meio de algoritmos baseados em $k$-médias. Cada conjunto de dados utilizado foi distribuído em diferentes sítios, segundo as seguintes características:

- Distribuição uniforme de objetos entre os nós de dados: os objetos de cada base de dados foram distribuídos em subconjuntos de cardinalidade próximas, de forma que $n_{o, \max } \approx n_{o} / n_{d n}$

- Quantidades distintas de nós de dados: para aferir o impacto do parâmetro $n_{d n}$, experimentos foram executados com 5, 20 e 80 nós de dados para cada base do conjunto Artificial2;

- Diferentes tipos de balanceamentos de grupo: dada a partição conhecida da base de dados ("gold standard"), o $i$-ésimo grupo desta partição possui uma proporção dos objetos calculada como $p_{C_{i}}=\left|C_{i}\right| / n_{o}$. A proporção de objetos do $i$-ésimo grupo no $j$-ésimo nó de dados é dada por $p_{C_{i}}[j]=\left|C_{i}[j]\right| / n_{o}[j]$, em que $\left|C_{i}[j]\right|$ é o número de objetos do $i$-ésimo grupo no $j$-ésimo nó de dados e $n_{o}[j]$ é o número de objetos no j-ésimo nó de dados. Quando a distribuição é feita de forma balanceada, a proporção dos grupos conhecidos mantém-se nos nós de dados, ou seja, $p_{C_{i}} \approx p_{C_{i}}[j], \forall i \in\{1, \ldots, k\}, j \in\left\{1, \ldots, n_{d n}\right\}$. Entretanto, esse balanceamento não é garantido em aplicações práticas. Por esse motivo, além da distribuição balanceada, os objetos também foram distribuídos de forma a desbalancear a proporção dos grupos conhecidos nos nós de dados, ou seja, fazer com que $p_{C_{i}} \neq p_{C_{i}}[j], \forall i \in\{1, \ldots, k\}, j \in\left\{1, \ldots, n_{d n}\right\}$. De forma geral, o desbalanceamento implementado neste trabalho tenta reduzir ao máximo a presença de objetos de um determinado grupo da partição de referência em um nó de dados escolhido, ao mesmo tempo que tenta aumentar consideravelmente a presença de objetos de outro grupo neste nó. O objetivo desse desbalanceamento é verificar se os algoritmos propostos são capazes de obter partições finais que se aproximem da partição de referência, mesmo que os grupos formados em cada nó de dados não se assemelhem aos grupos dessa partição. Esse desbalanceamento é feito a partir de sorteios, por meio dos passos descritos a seguir:

1. Inicializa-se $j=1$. Todos os objetos são considerados não distribuídos.

2. Escolhe-se um grupo dominante e grupo ausente: para o nó de dados nodeI $D=$ $j$, dois grupos $C_{i}$ e $C_{z}, i \neq z$, da partição conhecida são sorteados dentre os $k$ grupos. Somente grupos que possuem objetos não distribuídos podem ser sorteados e todos possuem a mesma probabilidade de sorteio neste passo.

3. Determina-se a probabilidade de sorteio de cada grupo: no próximo passo, o grupo $C_{i}$ poderá ser sorteado com probabilidade 0,8; O grupo $C_{z}$ assume 
probabilidade 0,0001 de ser sorteado e o restante dos grupos irão possuir probabilidade de sorteio próxima de $0,2 /(k-2)$; Caso a partição contenha somente dois grupos, a probabilidade de sorteio de $C_{i}$ será 0,9999 .

4. Sorteia-se um grupo $C_{s}$ dentre os grupos conhecidos que contenha objetos não distribuídos, de acordo com as probabilidades obtidas no Passo 3. Em seguida, escolhe-se aleatoriamente um objeto $\mathbf{x}$ que pertença ao grupo $C_{s}$ e não tenha sido distribuído. Distribui-se $\mathbf{x}$ para o subconjunto presente no nó de dados $j$.

5. Caso o subconjunto do nó de dados $j$ esteja incompleto $\left(n_{o}[j]<n_{o} / n_{d n}\right)$ e exista objetos não distribuídos, repete-se o Passo 4. Caso contrário, se $j<n_{d n}$, incrementa-se $j=j+1$ e retorna-se ao Passo 2.

Cada nó dos algoritmos comparados será executado exclusivamente (sem concorrência)

em um único sítio. É importante lembrar que, por ser uma versão exata, o $D F-E A C$ obtém o mesmo resultado que uma execução do $F$-EAC com dados centralizados. Isso faz com que esse resultado seja independente da maneira que foi feita a distribuição dos objetos entre os nós de dados. Por esse motivo, resultados com bases distribuídas com desbalanceamento entre grupos serão apresentados apenas para os algoritmos CAD.

\subsubsection{Critérios de parada e algoritmos comparados}

A metodologia utilizada na Seção 4.4.1 tem como objetivo comparar algoritmos que possuem capacidades semelhantes de encontrar partições razoáveis por meio do algoritmo $k$-médias. Ela consiste em buscar por uma partição que possua um valor de avaliação suficientemente alto, também chamado de valor de referência $v_{R}$. Quando uma partição com valor de validação igual ou maior que o valor referência é encontrada pelo algoritmo, ele pára. Nesta seção, esse critério de parada será utilizado para as execuções do $F$-EAC e variantes $(D F-E A C$ e $D$-EAC). Aqui, o valor de referência é calculado como a média dos melhores valores de validação obtidos pelo algoritmo $O M R k$ (Seção 2.4.6.1) sobre $n_{\pi}=30$ execuções.

Entretanto, utilizar apenas o valor de referência $v_{R}$ como critério de parada não é aplicável nos experimentos apresentados nesta seção, pois os algoritmos CAD são algoritmos que aproximam resultados obtidos pelo algoritmo $k$-médias, o que faz com que não seja possível garantir que esses algoritmos obtenham sempre partições com o valores de validação maiores ou iguais a $v_{R}$ e, consequentemente, parem. Por esse motivo, um segundo critério de parada foi adotado para todas as execuções do $F$-EAC e variantes, inclusive as utilizadas pelos algoritmos CAD, que consiste em impor um limite máximo de $g_{\max }=100$ gerações executadas.

Da mesma forma que nos experimentos apresentados nas Seções 4.3.2, 4.4.3 e 4.5.2, as populações geradas pelas variantes do $F$-EAC são inicializadas por meio do sorteio aleatório do número de grupos $k$ e de objetos do conjunto de dados para tornarem-se os protótipos iniciais, para cada indivíduo. Mais uma vez, o valor mínimo $k_{\min }=2$ e valor 
máximo $k_{\max }=n_{o}^{1 / 2}$ serão adotados, pois esta regra garante que o número de grupos a ser estimado $k^{*}$ seja tal que $k^{*}<k_{\text {max }}$ nos experimentos a serem relatados, além de se tratar de uma regra prática usualmente adotada experimentalmente na literatura (Pal \& Bezdek, 1995; Pakhira et al., 2005).

Em relação ao número de indivíduos da população, $|P|$, os experimentos apresentados nas Seções 4.3.2, 4.4.3, 4.5.2 e os experimentos publicados em (Horta et al., 2009; Horta \& Campello, 2009; Horta, 2010), mostram que esse parâmetro não é crítico para a eficácia do F-EAC. Grosso modo, populações grandes tendem a fazer com que a busca evolutiva convirja para uma boa solução em menos gerações, cada qual computacionalmente mais custosa devido ao tamanho da população. Por outro lado, pequenas populações tendem a fazer com que o algoritmo convirja após um número maior de gerações, visto que poucas soluções são processadas a cada geração. Portanto, é esperado que o $D F-E A C$ apresente a mesma robustez quanto à configuração desse parâmetro. Particularmente, o valor $|P|=10$ para o tamanho da população mostra bons resultados nos experimentos presentes nas Seções 4.3.2 4.4.3, 4.5.2 e nos experimentos publicados em (Horta et al., 2009; Horta \& Campello, 2009; Horta, 2010). Por esse motivo, esse valor será assumido para o tamanho de população dos algoritmos evolutivos utilizados nos experimentos apresentados neste capítulo.

Assim como adotado nos experimentos apresentados no Capítulo 4, o critério de parada para o algoritmo $k$-médias consiste em duas verificações: (i) obter uma diferença máxima absoluta das posições dos centróides entre iterações consecutivas do algoritmo abaixo de um limiar $\varepsilon$; ou (ii) um número máximo de iterações (denotado por $t$ ) foi atingido. Em particular, a condição (ii) representa também um compromisso entre a diminuição do número de gerações para a convergência do $F$-EAC e o custo computacional do $k$-médias. Isto é, certo número de iterações do algoritmo $k$-médias pode acelerar a convergência do F-EAC. Porém, quando em excesso, o custo computacional das execuções adicionais da etapa de busca local passa a não mais compensar, como pode ser observado pelo estudo publicado em (Horta et al., 2009). Experimentos apresentados em (Horta et al., 2009; Naldi et al., 2009, 2011) sugerem que $\varepsilon=10^{-3}$ e $t=5$ são suficientes para que o algoritmo encontre soluções satisfatórias. De fato, como o $F$-EAC provê um refinamento cumulativo das soluções, é de se esperar que um número pequeno de iterações como esse seja suficiente.

Os mesmos métodos de inicialização, valores de parâmetros e critérios de parada utilizados no $F$-EAC são aplicados no $D F-E A C$, a fim de proporcionar uma comparação justa entre os algoritmos.

Os algoritmos hierárquicos aplicados na segunda etapa dos algoritmos CAD geram hierarquias que contêm partições formadas com $k_{\text {min }}$ grupos até $k_{\text {max }}$ grupos e não possuem outros critérios de parada. Esses valores são os mesmos utilizados pelas variantes do $F$ $E A C$ neste experimento. A partição melhor avaliada dentre as que formam a hierarquia obtida é escolhida e torna-se a solução do algoritmo. 
Nos experimentos apresentados nas Seções 7.5.3 e 7.5.4, quatro versões dos algoritmos CAD foram aplicadas em bases distribuídas com e sem o desbalanceamento de objetos, de acordo com os grupos conhecidos (descrito na Seção 7.5.1). Adicionalmente, o algoritmo $D F-E A C$ foi aplicado com e sem as técnicas de manutenção de privacidade detalhadas na Seção 7.3. Como a qualidade do resultado do algoritmo DF-EAC é independente da distribuição dos dados, esse algoritmo não é aplicado nas bases distribuídas de modo desbalanceado. As combinações entre as versões implementadas com o tipo de distribuição dos dados deram origem a 10 variantes de aplicação, descritas a seguir:

1. CAD-sl: nesta variante de CAD, os centróides resultantes da aplicação do $F$-EAC nos subconjuntos de dados são combinados por meio do algoritmo hierárquico de ligação simples. Ela é aplicada em subconjuntos formados a partir de grupos distribuídos de forma balanceada.

2. CAD-sl (U): o mesmo que a variante CAD-sl, só que aplicada em subconjuntos com grupos distribuídos de forma desbalanceada.

3. CAD-al: algoritmo CAD em que os centróides resultantes da primeira etapa são combinados por meio do algoritmo hierárquico de ligação média. Esta variante é aplicada em subconjuntos formados a partir de grupos balanceados.

4. CAD-al (U): o mesmo que a variante CAD-al, só que aplicada a subconjuntos com objetos distribuídos de forma desbalanceada em relação aos grupos originais.

5. CAD-FEAC: essa variante aplica o algoritmo $F-E A C$ para combinar os centróides obtidos na primeira etapa do algoritmo e formar a partição final. Aplicado em subconjuntos com grupos balanceados.

6. CAD-FEAC (U): a mesma variante do algoritmo CAD-FEAC, só que aplicada em subconjuntos com grupos desbalanceados.

7. CAD-FEAC (10g): esta variante adota um terceiro critério de parada para o $F$ $E A C$ quando aplicado na segunda etapa do algoritmo CAD, com o objetivo de reduzir o número de gerações do algoritmo. O algoritmo pára após a execução de 10 gerações consecutivas sem o aumento do melhor valor de aptidão encontrado. $\mathrm{O}$ uso desse critério, bem como o número máximo de gerações escolhido, apresentou bons resultados em experimentos publicados em (Naldi et al., 2009) e na Seção 4.5. Por esse motivo, também foi implementado aqui. Aplicada em subconjuntos com grupos balanceados.

8. CAD-FEAC $(10 \mathrm{~g})(\mathrm{U})$ : consiste na variante CAD-FEAC (10g) aplicada em subconjuntos com grupos desbalanceados.

9. DF-EAC: algoritmo DF-EAC descrito na Seção 7.3. 
10. $D F-E A C(\mathrm{P})$ : variante do algoritmo $D F-E A C$ com distorção de dados e os métodos de manutenção de privacidade descritos na Seção 7.3.

\subsubsection{Resultados com silhueta simplificada}

Os experimentos cujos resultados são apresentados nesta seção foram executados utilizando o índice silhueta simplificada na avaliação das partições obtidas. Como descrito anteriormente, o cálculo da validação nos algoritmos propostos é feito de maneira exata e, por esse motivo, exige uma rodada de comunicação no caso do índice silhueta simplificada.

Para medir a significância entre as médias obtidas para cada aspecto avaliado, o teste não paramétrico de Friedman (Hollander \& Wolfe, 1999) foi adotado novamente. Na grande maioria dos experimentos do Capítulo 6, as diferenças comprovadas pelo teste de Friedman também foram comprovadas pelo teste ANOVA, o que está de acordo com a comparação experimental feita pelo próprio Friedman (1940), como citado por Demšar (2006). Isso indica que o ANOVA mostrou-se menos conservador e, por esse motivo, não será utilizado em conjunto com o teste de Friedman nesta seção. Nos casos em que as diferenças entre amostras foram confirmadas pelo teste de Friedman, testes post-hoc foram aplicados juntamente com a correção de Bonferroni (Demšar, 2006) para permitir o controle do nível de significância e determinar quais diferenças são estatisticamente significativas e quais não são. Novamente, o nível de confiança dos testes aplicados é de $95 \%$. Os melhores resultados obtidos e os resultados para os quais não foi possível comprovar diferença estatisticamente significativa em relação aos melhores são apresentados em negrito nas tabelas presentes nesta seção e na Seção 7.5.4.

As variantes de aplicação comparadas foram executadas 30 vezes para cada base de dados do conjunto Artificial2 e as médias dos resultados são apresentadas nas Tabelas 7.1, 7.3 e 7.5 para 5, 20 e 80 nós de dados, respectivamente.

\begin{tabular}{|c|c|c|c|}
\hline Algoritmo & Jaccard & Tempo $(s)$ & Transferência $(K B)$ \\
\hline 1 CAD-sl & $0,7816(0,1503)$ & 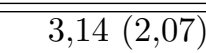 & $25,44(183,42)$ \\
\hline 2 CAD-sl (U) & $0,7499(0,1843)$ & $4,91(7,69)$ & $212,05(183,89)$ \\
\hline 3 CAD-al & $0,7974(0,1582)$ & $3,19(2,08)$ & $255,44(183,42)$ \\
\hline $4 \mathrm{CAD}-a l(\mathrm{U})$ & $0,7725(0,1865)$ & $4,94(7,69)$ & $212,05(183,89)$ \\
\hline 5 CAD-FEAC & $0,7634(0,1425)$ & $15,28(15,60)$ & $2055,53(3235,86)$ \\
\hline 6 CAD-FEAC (U) & $0,7469(0,1684)$ & $26,28(22,06)$ & $2882,62(3628,17)$ \\
\hline 7 CAD-FEAC (10g) & $0,7469(0,1482)$ & $8,05(5,05)$ & $865,79(939,65)$ \\
\hline 8 CAD-FEAC (10g) (U) & $0,7242(0,1729)$ & $11,03(9,34)$ & $948,26(974,23)$ \\
\hline $9 D F-E A C$ & $0,7658(0,1291)$ & $1,69(1,91)$ & $3348,15(6149,13)$ \\
\hline $10 D F-E A C(\mathrm{P})$ & $0,7671(0,1343)$ & $1,59(1,71)$ & $4030,94(5908,49)$ \\
\hline
\end{tabular}

Tabela 7.1: Valores médios e desvios padrões obtidos pelos algoritmos comparados, para o conjunto Artificial2 distribuído em 5 nós de dados.

Como pode ser visto na Tabela 7.1, os experimentos executados com 5 nós de dados indicam que todas as variantes comparadas são capazes de encontrar partições de qualidade razoável, apresentando valores médios do índice de Jaccard acima de 0,7 e muito 
próximas umas das outras. O algoritmo que obteve as partições de melhor qualidade, em média, foi o CAD-al, seguido do algoritmo CAD-sl e do algoritmo DF-EAC.

É importante considerar que os algoritmos CAD são compostos de duas etapas e que, para que o algoritmo aplicado na segunda etapa obtenha sucesso, é preciso que as partições resultantes da primeira etapa possam caracterizar, separadamente ou em conjunto, a estrutura procurada da base de dados. No caso dos experimentos relativos à Tabela 7.1, as partições obtidas na primeira etapa dos algoritmos CAD resultaram em valores medidos pelo índice de Jaccard razoavelmente altos, com média 0,76 e desvio 0,15. Isso indica que essas partições locais aproximam-se da estrutura conhecida dos dados, o que permite aos algoritmos obterem um bom desempenho final.

Em termos de tempo de execução, o algoritmo DF-EAC apresentou as menores médias, seguido dos algoritmos CAD-sl e CAD-al. Em contrapartida, a quantidade de informação transferida pelas variantes do algoritmo $D F-E A C$ é superior a qualquer outro algoritmo, em especial à quantidade transferida pelos algoritmos CAD com algoritmos hierárquicos. Esses resultados indicam que os algoritmos CAD podem encontrar bons resultados e economizar transferências de dados quando obtêm partições locais de qualidade, mas necessitam de maior tempo de execução.

Por ser uma versão aproximada, a variante CAD-FEAC nem sempre obteve partições avaliadas com valores iguais ou acima do valor de referência $v_{R}$, o que fez com que o algoritmo executasse até o limite de 100 gerações ser alcançado nestes casos. Adicionar o limite de 10 gerações sem melhoria no maior valor de aptidão encontrado causou uma redução significativa no tempo de execução e quantidade de dados transferida pelo algoritmo, ao preço de uma pequena redução na qualidade média das partições encontradas.

O desbalanceamento da proporção entre grupos conhecidos dentro dos nós causou uma leve redução na qualidade das partições obtidas pelos algoritmos CAD. Também é possível notar um pequeno aumento no tempo computacional dos algoritmos quando aplicados em bases distribuídas de forma desbalanceada. Adicionalmente, o desbalanceamento reduziu a quantidade média de centróides transferidos da primeira etapa para a segunda em aproximadamente 17\%. Essa redução é explicada pela ausência de alguns dos grupos conhecidos em nós determinados pelo método de desbalanceamento, o que causou uma leve redução na quantidade de dados transferidos entre os nós pelos algoritmos.

Os dados apresentados na Tabela 7.1 permitem comparar as variantes investigadas em termos tempo de execução ou quantidade de dados transferida, separadamente. Entretanto, não é possível determinar se uma variante de aplicação possui melhor desempenho do que outra considerando ambos os aspectos. O que pode ser feito é uma aproximação desse desempenho a partir dos valores médios de tempo de execução e quantidade de dados transferida. É importante destacar que esse desempenho considera o tempo de execução obtido, que é dependente do hardware utilizado. A Tabela 7.2 possui a finalidade de apresentar uma comparação aproximada entre cada par de variantes de aplicação, a partir do tempo médio de execução e da quantidade média de dados transferidos para cada 
algoritmo. O símbolo $\triangle$ indica que a $i$-ésima variante é mais rápida que a $j$-ésima e o símbolo $\nabla$ indica o contrário. Em alguns casos, o resultado depende da velocidade média de transferência dos dados. Nestes casos, o símbolo $>$ seguido de um número $x$ indica que a $i$-ésima variante poderá ser mais veloz do que a $j$-ésima variante se a velocidade média de transferência for maior do que $x$. Já o símbolo $<$ indica que a velocidade média de transferência deve ser menor do que o número $x$ que o segue, para que a $i$-ésima resulte em um melhor desempenho do que a $j$-ésima variante. É importante notar que a estimativa apresentada aqui considera que todas as máquinas envolvidas possuam a mesma configuração da máquina utilizada nos experimentos e que cada nó execute em uma máquina. Também é assumido que não haja paralelismo entre transferência de dados e as execuções dos algoritmos.

\begin{tabular}{|c|c|c|c|c|c|c|c|c|c|c|}
\hline & 1 & 2 & 3 & 4 & 5 & 6 & 7 & 8 & 9 & 10 \\
\hline 1 & - & $>24,58$ & $\triangle$ & $>24,14$ & $\triangle$ & $\triangle$ & $\triangle$ & $\triangle$ & $<2123,24$ & $<2430,77$ \\
\hline 2 & $<24,58$ & - & $<25,20$ & $\triangle$ & $\triangle$ & $\triangle$ & $\triangle$ & $\triangle$ & $<973,33$ & $<1150,74$ \\
\hline 3 & $\nabla$ & $>25,20$ & - & $>24,74$ & $\triangle$ & $\triangle$ & $\triangle$ & $\triangle$ & $<2060,95<2363,77$ \\
\hline 4 & $<24,14$ & $\nabla$ & $<24,74$ & - & $\triangle$ & $\triangle$ & $\triangle$ & $\triangle$ & $<963,73$ & $<1139,72$ \\
\hline 5 & $\nabla$ & $\nabla$ & $\nabla$ & $\nabla$ & - & $\triangle$ & $\nabla$ & $\nabla$ & $<95,07$ & $<144,27$ \\
\hline 6 & $\nabla$ & $\nabla$ & $\nabla$ & $\nabla$ & $\nabla$ & - & $\nabla$ & $\nabla$ & $<18,93$ & $<46,51$ \\
\hline 7 & $\nabla$ & $\nabla$ & $\nabla$ & $\nabla$ & $\triangle$ & $\triangle$ & - & $\triangle$ & $<390,03$ & $<489,87$ \\
\hline 8 & $\nabla$ & $\nabla$ & $\nabla$ & $\nabla$ & $\triangle$ & $\triangle$ & $\nabla$ & - & $<256,75$ & $<326,42$ \\
\hline 9 & $>2123,24$ & $>973,33$ & $>2060,95$ & $>963,73$ & $>95,07$ & $>18,93$ & $>390,03$ & $>256,75$ & - & $<7067,43$ \\
\hline 10 & $>2430,77$ & $>1150,74$ & $>2363,77$ & $>1139,72$ & $>144,27$ & $>46,51$ & $>489,87$ & $>326,42$ & $>7067,43$ & - \\
\hline
\end{tabular}

Tabela 7.2: Velocidade de transferência $(K B / s)$ necessária para que o algoritmo indicado pela linha possa ter um melhor desempenho do que o algoritmo indicado pela coluna, em média, para o conjunto Artificial2 distribuído em 5 nós de dados.

Uma análise dos resultados presentes na Tabela 7.2 indica que os algoritmos CAD com agrupamento hierárquico possuem desempenhos muito próximos (variantes 1-4), melhores do que as variantes de CAD que utilizam F-EAC (de números 5-8). A mesma análise mostra que o algoritmo $D F-E A C$ (variantes 9-10) pode ultrapassar o desempenho dos algoritmos CAD se a transferência dos dados possuir velocidade suficientemente alta. Velocidades de transferência de até $1000 \mathrm{~KB} / \mathrm{s}$ são muito comuns em redes $L A N$ atuais, o que permite que o desempenho do $D F-E A C$ possa ultrapassar alguns dos algoritmos CAD nestes meios de transferência. Esse resultado pode ser obtido até mesmo em outros sistemas, dependendo a velocidade de transferência alcançada e da capacidade de processamento computacional disponível. Contudo, manter a privacidade dos dados por meio de distorção adicionou um custo de transferência extra, o que reduziu o desempenho do algoritmo.

Aumentar o número de nós de dados causou o crescimento do número total de centróides resultantes da primeira etapa dos algoritmos CAD. Isso fez com que a distribuição original dos objetos no conjunto de dados seja sumarizada em uma quantidade maior de centróides, o que evidencia maior informação sobre o posicionamento desses objetos. Com o objetivo de ilustrar como esse processo ocorre, um exemplo de base de dados e centróides obtidos a partir da primeira etapa dos algoritmos CAD para distribuições em 80, 20 e 5 nós de dados é apresentado na Figura 7.8. Apesar do aumento da quantidade de 
informação sobre as posições dos objetos geralmente ser interpretado como algo positivo, para conjuntos com características que dificultam o agrupamento dos dados (como sobreposições entre grupos), isso pode se mostrar problemático. Por exemplo, a base de dados, mostrada na parte superior esquerda da Figura 7.8, apresenta alguns objetos dispersos sobre grupos de maior coesão. À medida que a informação sobre o conjunto de dados é "sumarizada" em quantidades menores de centróides, os grupos tornam-se mais afastados e as sobreposições são amenizadas. Isso facilita o agrupamento "correto" do conjunto de dados, especialmente para o algoritmo hierárquico de ligação simples, conhecido por possuir dificuldades em agrupar conjuntos de dados com grupos sobrepostos.
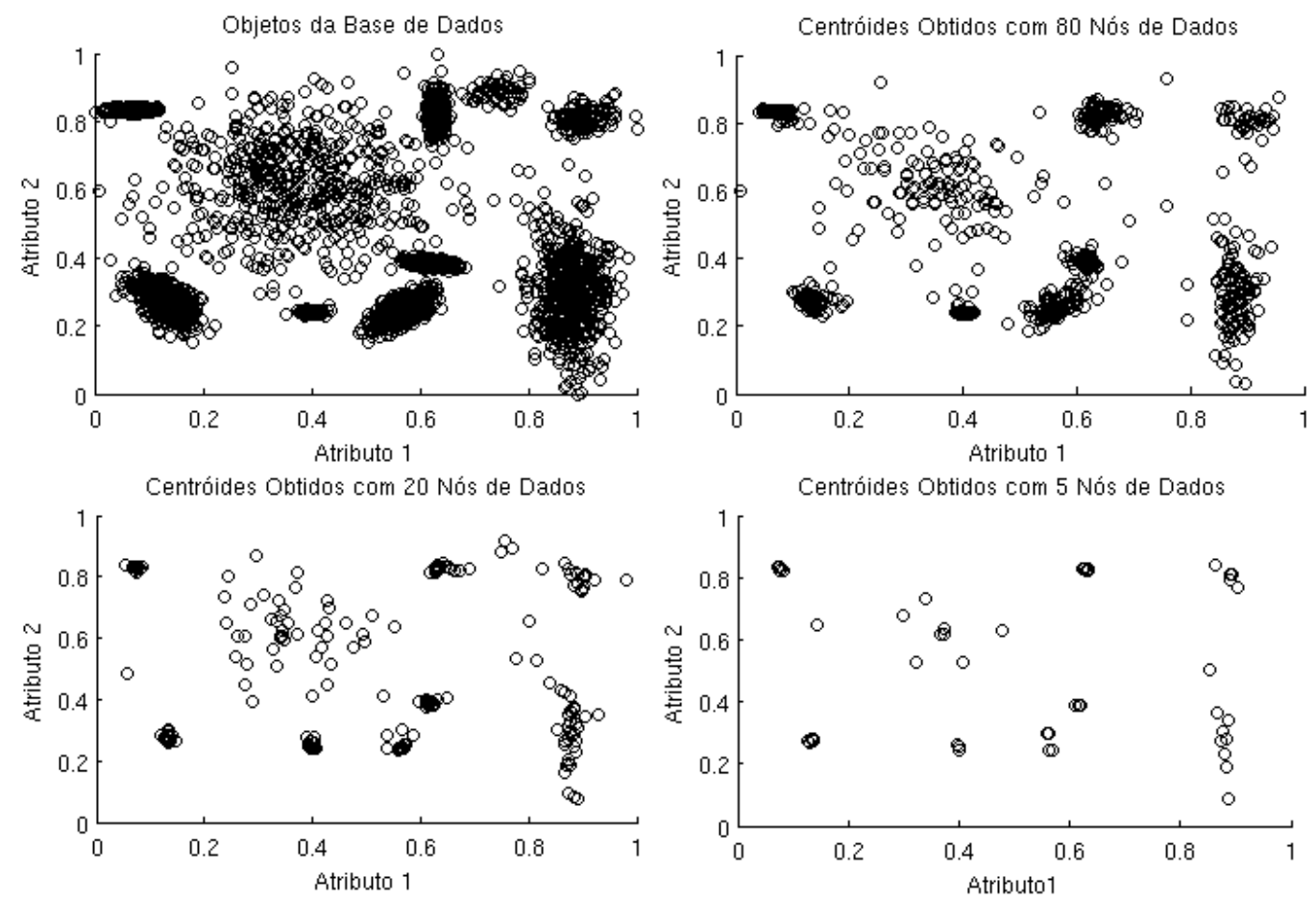

Figura 7.8: Exemplo de base de dados e centróides obtidos a partir da primeira etapa dos algoritmos CAD para distribuições em 80, 20 e 5 nós.

Adicionalmente, ao distribuir o conjunto de dados em uma quantidade maior de nós, o número de objetos em cada nó de dados foi reduzido. Com menos objetos, o nó de dados possui menos informação sobre o conjunto de dados, o que pode causar uma redução na semelhança entre as partições locais e a partição conhecida. Essa semelhança pode ser medida por meio do valor médio e desvio padrão do índice Jaccard. Como as partições locais avaliadas com o índice silhueta simplificada possuem números de grupos próximos das partições conhecidas, uma redução nos valores médios do índice de Jaccard indica um aumento na formação de grupos locais heterogêneos, ou seja, formados a partir de objetos de dois ou mais grupos conhecidos. Uma vez que os grupos obtidos na primeira etapa dos algoritmos são mantidos na segunda, os grupos heterogêneos da primeira etapa são propagados para a partição final. Além disso, os centróides desses grupos estão posicionados entre grupos da partição conhecida, o que pode induzir a formação de novos grupos heterogêneos durante a etapa de combinação das partições locais. 
As médias e desvios padrões obtidos para cada aspecto avaliado, resultantes das partições geradas a partir das bases de dados do conjunto Artificial2 distribuídas em 20 nós de dados, são apresentadas na Tabela 7.3.

\begin{tabular}{|l|r|r|r|}
\hline Algoritmo & Jaccard & Tempo $(s)$ & Transferência $(\boldsymbol{K B})$ \\
\hline \hline 1 CAD-sl & $0,5711(0,2542)$ & $1,66(0,92)$ & $1290,41(840,20)$ \\
\hline 2 CAD-sl $(\mathrm{U})$ & $0,5878(0,2525)$ & $2,07(2,16)$ & $\mathbf{1 2 8 3 , 3 4}(\mathbf{8 3 6 , 6 4})$ \\
\hline 3 CAD-al & $0,6940(0,2520)$ & $2,26(1,49)$ & $1290,41(840,20)$ \\
\hline 4 CAD-al $(\mathrm{U})$ & $0,6874(0,2552)$ & $2,18(2,22)$ & $\mathbf{1 2 8 3 , 3 4 ( 8 3 6 , 6 4 )}$ \\
\hline 5 CAD-FEAC & $0,7650(0,1531)$ & $9,76(10,44)$ & $7857,03(11479,87)$ \\
\hline 6 CAD-FEAC (U) & $\mathbf{0 , 7 7 7 6 ( 0 , 1 6 7 2 )}$ & $14,89(12,97)$ & $15154,84(19411,24)$ \\
\hline 7 CAD-FEAC (10g) & $0,7541(0,1584)$ & $5,27(3,55)$ & $3686,41(3802,90)$ \\
\hline 8 CAD-FEAC (10g) $(\mathrm{U})$ & $0,7596(0,1719)$ & $5,57(3,81)$ & $4351,37(4639,09)$ \\
\hline 9 DF- $E A C$ & $0,7680(0,1270)$ & $\mathbf{0 , 8 9}(\mathbf{0 , 9 5})$ & $12843,76(21723,35))$ \\
\hline 10 DF- $E A C(\mathrm{P})$ & $0,7733(0,1341)$ & $1,17(1,19)$ & $11823,12(11988,04)$ \\
\hline
\end{tabular}

Tabela 7.3: Valores médios e desvios padrões obtidos pelos algoritmos comparados, para o conjunto Artificial2 distribuído em 20 nós de dados.

A análise das Tabelas 7.1 e 7.3 mostra que a mudança do número de nós de dados de 5 para 20 diminuiu a qualidade das partições encontradas pelos algoritmos CAD com agrupamento hierárquico. Como houve pouca redução na qualidade média das partições locais obtidas na primeira etapa (de 0,76 para 0,74, avaliada com o índice Jaccard), é provável que o aumento do número de centróides (de aproximadamente 3 vezes) tenha sido a principal causa dessa queda de qualidade. Como ilustrado na Figura 7.8, o aumento no número de centróides pode evidenciar sobreposições entre grupos. É conhecido na literatura que os algoritmos hierárquicos utilizados, especialmente o de ligação simples, possuem a tendência de aglomerar grupos sobrepostos, o que dificulta encontrar partições que se assemelhem as partições de referência. A redução de valores de Jaccard não ocorreu nas variantes do algoritmo CAD-FEAC, que obteve as partições de melhor qualidade média, e $D F-E A C$, que obteve partições de qualidade muito próximas do algoritmo CADFEAC.

Novamente, executar o CAD-FEAC com critérios de parada baseado em $v_{R}$ (vide Seção 7.5.2) e o valor máximo de 100 gerações fez com que o algoritmo resultasse no maior tempo de execução obtido dentre as variantes. Quando aplicado nas bases distribuídas com desbalanceamento, o algoritmo resultou em uma quantidade de dados transferida superior a qualquer outra variante, inclusive as do algoritmo DF-EAC. Limitar o algoritmo CAD$F E A C$ a executar o máximo de 10 gerações consecutivas sem mudança na melhor aptidão encontrada decresceu consideravelmente o tempo computacional e a quantidade de dados transmitidos, ao custo de uma pequena diminuição na qualidade média das partições obtidas. Isso faz com que a adoção desse terceiro critério de parada seja interessante, especialmente em aplicações voltadas para o desempenho em sistemas com baixa taxa de transferência de dados.

Como pode ser visto na Tabela 7.3, o DF-EAC foi mais uma vez o algoritmo de menores médias de tempo computacional, seja aplicado com ou sem manutenção de privacidade. 
Por ser um algoritmo exato, ele manteve uma qualidade de partição muito próxima daquela obtida pelo próprio algoritmo no cenário com 5 nós de dados (Tabela 7.1), como esperado.

De forma análoga à Tabela 7.2, as velocidades de transferência necessárias para que a variante indicada pela $i$-ésima linha possa ser mais rápida do que a variante da $j$-ésima coluna são apresentadas na Tabela 7.4.

\begin{tabular}{|c|c|c|c|c|c|c|c|c|c|c|}
\hline & 1 & 2 & 3 & 4 & 5 & 6 & 7 & 8 & 9 & 10 \\
\hline 1 & - & $>17,25$ & $\triangle$ & $>13,62$ & $\triangle$ & $\triangle$ & $\triangle$ & $\triangle$ & $<14977,03$ & $<21494,76$ \\
\hline 2 & $<17,25$ & - & $\triangle$ & $\triangle$ & $\triangle$ & $\triangle$ & $\triangle$ & $\triangle$ & $<9788,75$ & $<11716,09$ \\
\hline 3 & $\nabla$ & $\nabla$ & - & $\nabla$ & $\triangle$ & $\triangle$ & $\triangle$ & $\triangle$ & $<8404,61$ & $<9634,29$ \\
\hline 4 & $<13,62$ & $\nabla$ & $\triangle$ & - & $\triangle$ & $\triangle$ & $\triangle$ & $\triangle$ & $<8958,63$ & $<10445,45$ \\
\hline 5 & $\nabla$ & $\nabla$ & $\nabla$ & $\nabla$ & - & $\triangle$ & $\nabla$ & $\nabla$ & $<562,20$ & $<461,79$ \\
\hline 6 & $\nabla$ & $\nabla$ & $\nabla$ & $\nabla$ & $\nabla$ & - & $\nabla$ & $\nabla$ & $\nabla$ & $\nabla$ \\
\hline 7 & $\nabla$ & $\nabla$ & $\nabla$ & $\nabla$ & $\triangle$ & $\triangle$ & - & $\triangle$ & $<2092,21$ & $<1986,75$ \\
\hline 8 & $\nabla$ & $\nabla$ & $\nabla$ & $\nabla$ & $\triangle$ & $\triangle$ & $\nabla$ & - & $<1815,08$ & $<1699,12$ \\
\hline 9 & $>14977,03$ & $>9788,75$ & $>8404,61$ & $>8958,63$ & $>562,20$ & $\triangle$ & $>2092,21$ & $>1815,08$ & - & $>3627,13$ \\
\hline 10 & $>21494,76$ & $>11716,09$ & $>9634,29$ & $>10445,45$ & $>461,79$ & $\triangle$ & $>1986,75$ & $>1699,12$ & $<3627,13$ & - \\
\hline
\end{tabular}

Tabela 7.4: Velocidade de transferência $(K B / s)$ necessária para que o algoritmo indicado pela linha possa ter um melhor desempenho do que o algoritmo indicado pela coluna, em média, para o conjunto Artificial2 distribuído em 20 nós de dados.

Mais uma vez, a diferença entre os desempenhos computacionais das variantes do algoritmo CAD que utilizam algoritmos hierárquicos é mínima (variantes 1-4), como mostrado nas Tabelas 7.3 e 7.4. Elas mostram um desempenho computacional maior do que a grande maioria das outras variantes comparadas. Para que o algoritmo $D F-E A C$ (variantes 9-10) ultrapasse o desempenho dos algoritmos CAD-sl e CAD-al, são necessárias taxas de transferência estimadas acima de $8000 \mathrm{~KB} / \mathrm{s}$. Entretanto, é preciso lembrar que as variantes que aplicam CAD-sl (1-2) e CAD-al (3-4) obtiveram as partições de pior qualidade média entre as variantes comparadas (ver Tabela 7.3).

O desempenho computacional do algoritmo $D F-E A C$ (variantes 9-10) pode ser melhor do que o algoritmo CAD-FEAC (variantes 5-6) para taxas de transferência de dados maiores ou próximas de $500 \mathrm{~KB} / \mathrm{s}$, o que o torna uma boa opção pois as qualidades das partições de ambos os algoritmos são próximas. Entretanto, caso a velocidade de transferência seja menor, a versão CAD-FEAC (10g) (variantes 7-8) mostra uma melhor relação entre a qualidade da partição obtida e desempenho do algoritmo, como pode ser visto nas Tabelas 7.3 e 7.4 .

As médias e desvios padrões dos valores resultantes do índice Jaccard, tempo de execução e quantidade de dados transferidos, para o conjunto de bases Artificial2 distribuído em 80 nós de dados, são apresentados na Tabela 7.5, obtidas pelas 10 variantes de aplicação.

Ao aumentar novamente o número de nós de dados, o número total de centróides gerados na primeira etapa dos algoritmos CAD aumentou, em média, aproximadamente quatro vezes em relação à distribuição em 20 nós de dados. Adicionalmente, a qualidade média das partições locais resultantes da primeira etapa dos algoritmos CAD decresceu de 0,74 para 0,56, medida pelo índice de Jaccard. Esses fatos justificam a degradação considerável da qualidade das partições obtidas pelas variantes 1-4 do algoritmo CAD, baseadas em algoritmos hierárquicos, como pode ser confirmado nas Tabelas 7.1, 7.3 e 


\begin{tabular}{|c|c|c|c|}
\hline Algoritmo & Jaccard & Tempo $(s)$ & Transferência $(K B)$ \\
\hline 1 CAD-sl & $0,2664(0,2410)$ & $0,97(0,65)$ & $5127,95(3342,77)$ \\
\hline 2 CAD-sl (U) & $0,2789(0,2478)$ & $0,91(0,61)$ & $5124,81(3338,31)$ \\
\hline 3 CAD-al & $0,5327(0,2694)$ & $3,76(3,58)$ & $5127,95(3342,77)$ \\
\hline 4 CAD-al (U) & $0,5725(0,2571)$ & $2,50(2,05)$ & $5124,81(3338,31)$ \\
\hline 5 CAD-FEAC & $0,7052(0,2241)$ & $18,41(15,49)$ & $61525,95(74502,38)$ \\
\hline 6 CAD-FEAC (U) & $0,7481(0,1906)$ & $18,07(14,31)$ & $68201,59(80820,47)$ \\
\hline 7 CAD-FEAC (10g) & $0,6921(0,2283)$ & $5,53(3,60)$ & $16158,76(16939,77)$ \\
\hline 8 CAD $-F E A C(10 \mathrm{~g})(\mathrm{U})$ & $0,7348(0,1910)$ & $5,30(3,28)$ & $17386,12(18348,24)$ \\
\hline $9 D F-E A C$ & $0,7653(0,1261)$ & $0,84(0,82)$ & $52939,23(86617,73)$ \\
\hline $10 D F-E A C(\mathrm{P})$ & $0,7724(0,1375)$ & $2,21(2,76)$ & $44296,66(41360,91)$ \\
\hline
\end{tabular}

Tabela 7.5: Valores médios e desvios padrões obtidos pelos algoritmos comparados, para o conjunto Artificial2 distribuído em 80 nós de dados.

7.5. As variantes do CAD que utilizam o algoritmo $F$-EAC (variantes 5-8) apresentaram uma redução consideravelmente menor na qualidade das partições obtidas.

Como esperado de um algoritmo exato, as variantes do DF-EAC mantiveram partições de qualidade similares a partir de distribuições em 5, 20 e 80 nós de dados, como pode ser visto nas Tabelas 7.1, 7.3 e 7.5. A versão sem manutenção de privacidade (variante 9) obteve o menor tempo médio de execução. Adicionalmente, ambas as variantes do $D F-E A C$ transferiram uma quantidade média de dados inferior à obtida pelas variantes 5 e 6 do algoritmo CAD-FEAC. Por esse motivo, o DF-EAC mostrou a melhor relação entre qualidade de partição e tempo de execução para os experimentos feitos com 80 nós de dados. Contudo, a maior quantidade de nós elevou consideravelmente a quantidade de dados transferidos. Por esse motivo, nos casos em que a velocidade de transferência consiste no gargalo do sistema, o algoritmo CAD-FEAC (10g) (variantes 7 e 8) é uma opção interessante, devido à qualidade razoável de suas partições e menor quantidade de dados transferidos.

De forma análoga à Tabela 7.2, as velocidades de transferência necessárias para que a variante indicada pela $i$-ésima linha possa ser mais rápida do que a variante da $j$-ésima coluna são apresentadas na Tabela 7.6, para a distribuição das bases de dados em 80 nós.

\begin{tabular}{|c|c|c|c|c|c|c|c|c|c|c|}
\hline & 1 & 2 & 3 & 4 & 5 & 6 & 7 & 8 & 9 & 10 \\
\hline 1 & - & $\nabla$ & $\triangle$ & $>2,05$ & $\triangle$ & $\triangle$ & $\triangle$ & $\triangle$ & $<376315,48$ & $\triangle$ \\
\hline 2 & $\triangle$ & - & $\triangle$ & $\triangle$ & $\triangle$ & $\triangle$ & $\triangle$ & $\triangle$ & $<657872,58$ & $\triangle$ \\
\hline 3 & $\nabla$ & $\nabla$ & - & $\nabla$ & $\triangle$ & $\triangle$ & $\triangle$ & $\triangle$ & $<16376,02$ & $<25369,39$ \\
\hline 4 & $<2,05$ & $\nabla$ & $\triangle$ & - & $\triangle$ & $\triangle$ & $\triangle$ & $\triangle$ & $<28845,41<138929,90$ \\
\hline 5 & $\nabla$ & $\nabla$ & $\nabla$ & $\nabla$ & - & $<19510,66$ & $\nabla$ & $\nabla$ & $\nabla$ & $\nabla$ \\
\hline 6 & $\nabla$ & $\nabla$ & $\nabla$ & $\nabla$ & $>19510,66$ & - & $\nabla$ & $\nabla$ & $\nabla$ \\
\hline 7 & $\nabla$ & $\nabla$ & $\nabla$ & $\nabla$ & $\triangle$ & $\triangle$ & - & $<5167,41$ & $<7835,22$ & $<8478,86$ \\
\hline 8 & $\nabla$ & $\nabla$ & $\nabla$ & $\nabla$ & $\triangle$ & $\triangle$ & $>5167,41$ & - & $<7977,39$ & $<8734,14$ \\
\hline 9 & $>376315,48$ & $>657872,58$ & $>16376,02$ & $>28845,41$ & $\triangle$ & $\triangle$ & $>7835,22$ & $>7977,39$ & - & $>6282,51$ \\
\hline 10 & $\nabla$ & $\nabla$ & $>25369,39$ & $>138929,90$ & $\triangle$ & $\triangle$ & $>8478,86$ & $>8734,14$ & $<6282,51$ & - \\
\hline
\end{tabular}

Tabela 7.6: Velocidade de transferência $(K B / s)$ necessária para que o algoritmo indicado pela linha possa ter um melhor desempenho do que o algoritmo indicado pela coluna, para o conjunto Artificial2 distribuído em 80 nós de dados.

Novamente, as variantes de números 1-4 do algoritmo CAD apresentaram os melhores desempenhos computacionais, segundo a Tabela 7.6, e as piores partições, segundo o 
critério Jaccard (Tabela 7.5). Devido à grande quantidade de nós de dados e, consequentemente, de transferências de dados, algoritmos que transferem menos dados tendem a obter desempenhos melhores. Para que haja exceções, a taxa de transferência de dados deve ser muito alta, como é indicado na Tabela 7.6.

\subsubsection{Resultados com VRC}

Como mostrado na Seção 7.4.3, o índice $V R C$ pode ser utilizado nos algoritmos CAD de forma a permitir uma única rodada de comunicação entre nós de dados e o nó mestre. Por esse motivo, os experimentos apresentados na Seção 7.5.3 foram refeitos com variantes que utilizam o índice $V R C$ no lugar do índice silhueta simplificada. Lembrando que o algoritmo F-EAC possui operadores evolutivos guiados (Seção 3.4), o que não é aplicável em conjunto com o índice $V R C$, pois este não avalia grupos individualmente (discutido na Seção 7.4.3), as variantes apresentadas nesta seção serão todas chamadas de $E A C$.

As médias e desvios padrões dos valores resultantes do índice Jaccard, tempo de execução e quantidade de dados transferidos são apresentados na Tabela 7.7, obtidas pelas 10 variantes de aplicação dos algoritmos comparados para o conjunto de bases Artificial2 distribuído em 5 nós de dados.

\begin{tabular}{|l|r|r|r|}
\hline Algoritmo & Jaccard & Tempo $(\boldsymbol{s})$ & Transferência $(\boldsymbol{K B})$ \\
\hline \hline 1 CAD-sl & $0,6208(0,2444)$ & $2,33(2,75)$ & $14,29(3,68)$ \\
\hline 2 CAD-sl $(\mathrm{U})$ & $0,6135(0,2414)$ & $1,89(2,08)$ & $\mathbf{1 3 , 5 6}(\mathbf{3 , 1 8})$ \\
\hline 3 CAD- $a l$ & $\mathbf{0 , 6 5 7 9}(\mathbf{0 , 2 5 0 2})$ & $2,52(2,75)$ & $14,29(3,68)$ \\
\hline 4 CAD-al $(\mathrm{U})$ & $\mathbf{0 , 6 4 2 2}(\mathbf{0 , 2 4 7 4})$ & $2,05(2,10)$ & $\mathbf{1 3 , 5 6}(\mathbf{3 , 1 8})$ \\
\hline 5 CAD- $E A C$ & $0,5808(0,2852)$ & $9,25(8,38)$ & $14,29(3,68)$ \\
\hline 6 CAD- $E A C(\mathrm{U})$ & $0,5279(0,2944)$ & $8,86(7,97)$ & $\mathbf{1 3 , 5 6}(\mathbf{3 , 1 8})$ \\
\hline 7 CAD- $E A C(10 \mathrm{~g})$ & $0,5764(0,2793)$ & $4,36(3,35)$ & $14,29(3,68)$ \\
\hline 8 CAD- $E A C(10 \mathrm{~g})(\mathrm{U})$ & $0,5176(0,2915)$ & $3,90(2,96)$ & $\mathbf{1 3 , 5 6}(\mathbf{3 , 1 8})$ \\
\hline 9 D-EAC & $0,5773(0,2605)$ & $\mathbf{0 , 9 9 ( 2 , 0 3 )}$ & $5646,36(14606,91)$ \\
\hline $10 D-E A C(\mathrm{P})$ & $0,6057(0,2538)$ & $1,32(2,68)$ & $8343,04(22063,42)$ \\
\hline
\end{tabular}

Tabela 7.7: Valores médios e desvios padrões obtidos pelos algoritmos comparados, para o conjunto Artificial2 distribuído em 5 nós de dados.

Os valores obtidos pelo índice de Jaccard apresentados na Tabela 7.7 indicam que a variante $\mathrm{CAD}$-al obteve as partições de melhor qualidade média, seguido pelas variantes CAD-sl. A qualidade média das partições obtidas com avaliação feita com $V R C$ é menor em relação às respectivas variantes avaliadas com o índice silhueta simplificada, como pode ser visto comparando as Tabelas 7.1 e 7.7. Adicionalmente, a qualidade das partições locais obtidas pela primeira etapa dos algoritmos CAD decresceu de 0,76 para 0,49 com o uso do índice $V R C$. Diferentemente do que ocorre com o índice silhueta simplificada, as partições selecionadas pelo índice $V R C$ nessa etapa tendem a possuir um número de grupos maior do que o conhecido.

Em termos de tempo computacional, assim como ocorreu com o algoritmo DF-EAC nos experimentos apresentados na Seção 7.5.3, o D-EAC obteve o melhor tempo de execução médio, seguido das variantes de números 1-4 dos algoritmos CAD. Os experimentos 
que utilizaram $V R C$ resultaram em tempos médios de execução menores do que os que utilizaram silhueta simplificada (Tabelas 7.1 e 7.7).

Enquanto a quantidade de dados transferidos pelos algoritmos CAD foi reduzida substancialmente com o uso do índice $V R C$, houve um aumento na quantidade de dados transferida pelas variantes do algoritmo $D$-EAC (terceira coluna das Tabelas 7.1 e 7.7). Esse aumento ocorreu porque as partições geradas durante a execução do $D$-EAC em conjunto com $V R C$ possuem um número maior de grupos (e, consequentemente, de centróides) em média do que as obtidas pelo $D F-E A C$ avaliado pelo índice silhueta simplificada.

Utilizando a mesma simbologia na Tabela 7.2, as velocidades de transferência necessárias para que a variante indicada pela $i$-ésima linha possa ser mais rápida do que a variante da $j$-ésima coluna são apresentadas na Tabela 7.8, para a distribuição das bases de dados em 5 nós.

\begin{tabular}{|c|c|c|c|c|c|c|c|c|c|c|}
\hline & 1 & 2 & 3 & 4 & 5 & 6 & 7 & 8 & 9 & 10 \\
\hline 1 & - & $\nabla$ & $\triangle$ & $\nabla$ & $\triangle$ & $>0,11$ & $\triangle$ & $>0,46$ & $<4200,89<8279,58$ \\
\hline 2 & $\triangle$ & - & $\triangle$ & $\triangle$ & $\triangle$ & $\triangle$ & $\triangle$ & $\triangle$ & $<6267,56<14769,19$ \\
\hline 3 & $\nabla$ & $\nabla$ & - & $\nabla$ & $\triangle$ & $>0,12$ & $\triangle$ & $>0,53$ & $<3667,83<6936,07$ \\
\hline 4 & $\triangle$ & $\nabla$ & $\triangle$ & - & $\triangle$ & $\triangle$ & $\triangle$ & $\triangle$ & $<5291,60<11414,43$ \\
\hline 5 & $\nabla$ & $\nabla$ & $\nabla$ & $\nabla$ & - & $\nabla$ & $\nabla$ & $\nabla$ & $<681,98<<1051,12$ \\
\hline 6 & $<0,11$ & $\nabla$ & $<0,12$ & $\nabla$ & $\triangle$ & - & $<0,16$ & $\nabla$ & $<715,97$ & $<1105,79$ \\
\hline 7 & $\nabla$ & $\nabla$ & $\nabla$ & $\nabla$ & $\triangle$ & $>0,16$ & - & $\nabla$ & $<1668,85<2739,66$ \\
\hline 8 & $<0,46$ & $\nabla$ & $<0,53$ & $\nabla$ & $\triangle$ & $\triangle$ & $\triangle$ & - & $<1933,26<3229,88$ \\
\hline 9 & $>4200,89$ & $>6267,56$ & $>3667,83$ & $>5291,60$ & $>681,98$ & $>715,97$ & $>1668,85$ & $>1933,26$ & - & $\triangle$ \\
\hline 10 & $>8279,58$ & $>14769,19$ & $>6936,07$ & $>11414,43$ & $>1051,12$ & $>1105,79$ & $>2739,66$ & $>3229,88$ & $\nabla$ & - \\
\hline
\end{tabular}

Tabela 7.8: Velocidade de transferência $(K B / s)$ necessária para que o algoritmo indicado pela linha possa ter um melhor desempenho do que o algoritmo indicado pela coluna, em média, para o conjunto Artificial2 distribuído em 5 nós de dados

Como os dados transferidos da primeira etapa dos algoritmos CAD para a segunda são os mesmos para um determinado tipo de distribuição, a maior diferença entre as variantes desses algoritmos dá-se pelo tempo de total de execução. A estimativa presente na Tabela 7.8 indica que o algoritmo $D$-EAC pode aproximar-se, em termos de desempenho computacional, do algoritmo CAD-EAC (5-6) para taxas de transmissão acima de 1000 $\mathrm{KB} / \mathrm{s}$. Taxas bem mais elevadas são necessárias para que o $D-E A C$ ultrapasse as outras versões dos algoritmos CAD. Portanto, a melhor relação entre qualidade de partição, tempo computacional e quantidade de dados transferidos foi obtida pelo CAD-al para os resultados apresentados nas Tabelas 7.7 e 7.8 .

Os mesmos experimentos feitos com a distribuição dos conjuntos de dados em 5 nós foram repetidos com distribuição em 20 nós. As médias e desvios padrões dos valores resultantes do índice Jaccard, tempo de execução e quantidade de dados transferidos são apresentados na Tabela 7.9 .

Semelhante ao que ocorreu nos experimentos feitos com a silhueta simplificada, o aumento do número de nós de dados de 5 para 20 causou uma pequena redução na qualidade de partições obtidas pelos algoritmos CAD. As melhores partições foram obtidas pelo algoritmo $D-E A C$ com privacidade, sem diferença estatisticamente comprovada para o algoritmo CAD-al. 


\begin{tabular}{|c|c|c|c|}
\hline Algoritmo & Jaccard & Tempo $(s)$ & Transferência $(K B)$ \\
\hline 1 CAD-sl & $\overline{0,5176(0,2349)}$ & $1,64(1,68)$ & $56,71(12,99)$ \\
\hline 2 CAD-sl (U) & $0,5475(0,270$ & $1,13(1,01)$ & $49,79(9,89)$ \\
\hline 3 CAD-al & $0,6391(0,236$ & $8,98(10,16)$ & $56,71(12,99)$ \\
\hline 4 CAD-al (U) & $0,5989(0,2747)$ & $7,04(8,97)$ & $49,79(9,89)$ \\
\hline 5 CAD-EAC & $0,5196(0,2821)$ & $9,99(11,93)$ & $56,71(12,99)$ \\
\hline 6 CAD- $E A C(\mathrm{U})$ & $0,4625(0,2838)$ & $8,52(11,63)$ & $49,79(9,89)$ \\
\hline $7 \mathrm{CAD}-E A C(10 \mathrm{~g})$ & $0,5152(0,2781)$ & $4,81(4,10)$ & $56,71(12,99)$ \\
\hline $8 \mathrm{CAD}-E A C(10 \mathrm{~g})(\mathrm{U})$ & $0,4614(0,2841)$ & $3,90(3,88)$ & $49,79(9,89)$ \\
\hline $9 D-E A C$ & $0,5773(0,2625)$ & $0,91(1,68)$ & $21838,19(55784,55))$ \\
\hline $10 D-E A C(\mathrm{P})$ & $0,6408(0,2335)$ & $1,45(1,62)$ & $16379,38(21837,57)$ \\
\hline
\end{tabular}

Tabela 7.9: Valores médios e desvios padrões obtidos pelos algoritmos comparados, para o conjunto Artificial2 distribuído em 20 nós de dados.

O valor médio e desvio padrão do índice de Jaccard para as partições resultantes do algoritmo $D-E A C$ se mantiveram muito próximos para a variante sem privacidade dos dados, como pode ser visto nas Tabelas 7.7 e 7.9. Esse resultado era esperado, uma vez que o $D-E A C$ é uma versão exata. Entretanto, houve aumento significativo na qualidade das partições obtidas pelo $D-E A C(\mathrm{P})$. A causa dessa diferença reside nas técnicas de manutenção de privacidade, em que os operadores utilizados baseiam-se em sorteios entre os nós de dados e combinações convexas entre objetos do nó sorteado, associadas ao uso do índice $V R C$. Esses operadores não existem no $D$-EAC, o que resulta em uma menor variação na qualidade das partições que ele obtém.

Em relação ao tempo de execução, o algoritmo $D$-EAC sem privacidade apresentou o menor valor médio novamente, como pode ser visto na Tabela 7.9. As menores quantidades transferidas foram obtidas pelos algoritmos CAD, como esperado. Variantes aplicadas em distribuições desbalanceadas tendem a gerar menos grupos e, portanto, obter uma menor quantidade de dados transferidos.

Assumindo que os nós de dados estejam em computadores idênticos ao utilizado, as velocidades de transferência necessárias para que a variante indicada pela $i$-ésima linha possa obter um desempenho melhor do que a variante da $j$-ésima coluna, segundo a estimação feita, são apresentadas na Tabela 7.10 para a distribuição das bases de dados em 20 nós.

\begin{tabular}{|c|c|c|c|c|c|c|c|c|c|c|}
\hline & 1 & 2 & 3 & 4 & 5 & 6 & 7 & 8 & 9 & 10 \\
\hline 1 & - & $\nabla$ & $\triangle$ & $>1,28$ & $\triangle$ & $>1,01$ & $\triangle$ & $>3,06$ & $<29808,57<85966,21$ \\
\hline 2 & $\triangle$ & - & $\triangle$ & $\triangle$ & $\triangle$ & $\triangle$ & $\triangle$ & $\triangle$ & $<98184,31$ & $\triangle$ \\
\hline 3 & $\nabla$ & $\nabla$ & - & $\nabla$ & $\triangle$ & $\nabla$ & $\nabla$ & $\nabla$ & $<2698,99$ & $<2167,86$ \\
\hline 4 & $<1,28$ & $\nabla$ & $\triangle$ & - & $\triangle$ & $\triangle$ & $<3,10$ & $\nabla$ & $<3553,88$ & $<2921,19$ \\
\hline 5 & $\nabla$ & $\nabla$ & $\nabla$ & $\nabla$ & - & $\nabla$ & $\nabla$ & $\nabla$ & $<2398,13$ & $<1910,91$ \\
\hline 6 & $<1,01$ & $\nabla$ & $\triangle$ & $\nabla$ & $\triangle$ & - & $<1,86$ & $\nabla$ & $<2861,95$ & $<2308,95$ \\
\hline 7 & $\nabla$ & $\nabla$ & $\triangle$ & $>3,10$ & $\triangle$ & $>1,86$ & - & $\nabla$ & $<5584,32$ & $<4858,47$ \\
\hline 8 & $<3,06$ & $\nabla$ & $\triangle$ & $\triangle$ & $\triangle$ & $\triangle$ & $\triangle$ & - & $<7276,30$ & $<6655,37$ \\
\hline 9 & $>29808,57$ & $>98184,31$ & $>2698,99$ & $>3553,88$ & $>2398,13$ & $>2861,95$ & $>5584,32$ & $>7276,30$ & - & $>10093,23$ \\
\hline 10 & $>85966,21$ & $\nabla$ & $>2167,86$ & $>2921,19$ & $>1910,91$ & $>2308,95$ & $>4858,47$ & $>6655,37$ & $<10093,23$ & - \\
\hline
\end{tabular}

Tabela 7.10: Velocidade de transferência $(K B / s)$ necessária para que o algoritmo indicado pela linha possa ter um melhor desempenho do que o algoritmo indicado pela coluna, em média, para o conjunto Artificial2 distribuído em 20 nós de dados.

Como as quantidades de dados transferidos pelos algoritmos CAD com $V R C$ são muito 
próximas, o aspecto que determina qual variante dos algoritmos CAD possui melhor desempenho computacional é o tempo de execução, como pode ser constatado por meio das Tabelas 7.9 e 7.10. Com o aumento do número de nós de dados, o algoritmo D-EAC necessita de uma taxa de transmissão ainda maior para ultrapassar os algoritmos CAD em termos de desempenho. Esses resultados indicam que o algoritmo CAD-al foi novamente a variante que apresentou a melhor relação entre a qualidade de suas partições e o desempenho, especialmente para sistemas com baixa taxa de transferência de dados.

Por último, os experimentos foram refeitos com a distribuição das bases em 80 nós de dados. A utilização do algoritmo $E A C$ com avaliação feita por $V R C$ nos algoritmos CAD gerou partições com uma quantidade de centróides consideravelmente maior do que sua contraparte baseada em silhueta simplificada. Os histogramas que indicam a quantidade de centróides gerados pela primeira etapa dos algoritmos CAD, obtidos por meio de avaliações feitas com os dois índices, são apresentados na Figura 7.9. Neles, é possível visualizar que o número de centróides gerados por meio da avaliação feita com $V R C$ é consideravelmente maior, próximo do número total de objetos das bases de dados. Isso fez com que a sumarização dos dados na primeira etapa do algoritmo fosse praticamente inexistente, o que não é o objetivo do algoritmo. Portanto, os algoritmos CAD com avaliação por meio de $V R C$ não são indicados quando os nós de dados possuem poucos objetos.
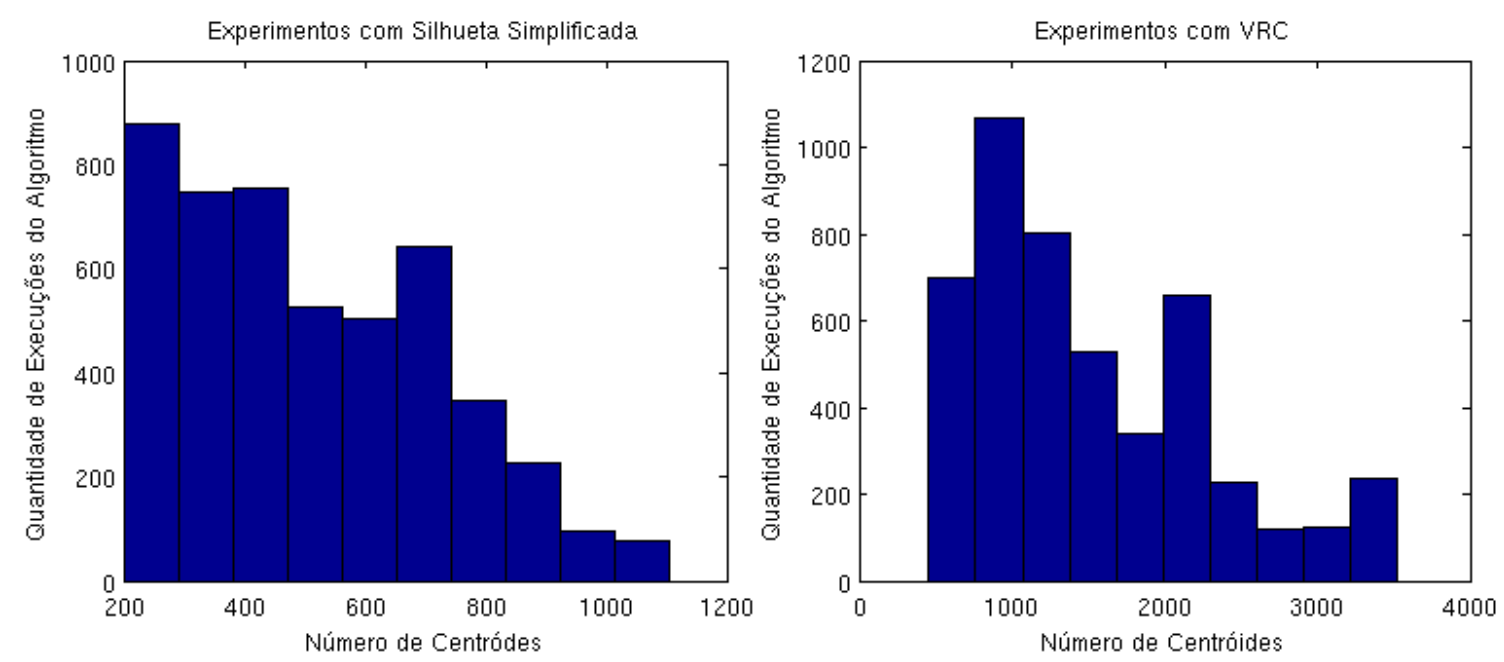

Figura 7.9: Histogramas com o número de centróides obtidos na primeira etapa dos algoritmos CAD com avaliação por silhueta simplificada e $V R C$, para cada execução do algoritmo e distribuição das bases em 80 nós de dados.

As médias e desvios padrões dos valores resultantes do índice Jaccard, tempo de execução e quantidade de dados transferidos pelos algoritmos comparados quando aplicados em bases distribuídas em 80 nós de dados são apresentados na Tabela 7.11.

Uma vez que praticamente não houve sumarização dos dados na primeira etapa dos algoritmos CAD, quase toda a informação sobre os objetos do conjunto de dados esteve presente no nó mestre durante a segunda etapa desses algoritmos. Essa situação causou um aumento na qualidade das partições resultantes da maioria dos algoritmos CAD, 


\begin{tabular}{|c|c|c|c|}
\hline Algoritmo & Jaccard & Tempo $(s)$ & Transferência $(K B)$ \\
\hline $1 \mathrm{CAD}-s l$ & $0,4868(0,2323)$ & $3,49(2,38)$ & $213,48(48,30)$ \\
\hline 2 CAD-sl (U) & $0,4873(0,2370)$ & $3,54(2,43)$ & $208,99(39,77)$ \\
\hline $3 \mathrm{CAD}-a \mathrm{l}$ & $0,7404(0,1948)$ & $79,51(116,19)$ & $213,48(48,30)$ \\
\hline 4 CAD-al (U) & $0,7420(0,1917)$ & $73,24(116,20)$ & $208,99(39,77)$ \\
\hline 5 CAD-EAC & $0,5227(0,2880)$ & $11,91(11,07)$ & $213,48(48,30)$ \\
\hline $6 \mathrm{CAD}-E A C(\mathrm{U})$ & $0,5177(0,2871)$ & $11,87(10,61)$ & $208,99(39,77)$ \\
\hline $7 \mathrm{CAD}-E A C(10 \mathrm{~g})$ & $0,5190(0,2844)$ & $6,26(3,76)$ & $213,48(48,30)$ \\
\hline $8 \mathrm{CAD}-E A C(10 \mathrm{~g})(\mathrm{U})$ & $0,5161(0,2843)$ & $6,16(3,76)$ & $208,99(39,77)$ \\
\hline $9 D-E A C$ & $0,5839(0,2605)$ & $1,20(2,11)$ & $89279,10(223330,44)$ \\
\hline $10 D-E A C(\mathrm{P})$ & $0,6699(0,2205)$ & $5,60(11,54)$ & $71868,01(90569,30)$ \\
\hline
\end{tabular}

Tabela 7.11: Valores médios e desvios padrões obtidos pelos algoritmos comparados, para o conjunto Artificial2 distribuído em 80 nós de dados.

como pode ser visto na Tabela 7.11. A principal exceção foram as variantes 1 e 2 de aplicação do algoritmo CAD-sl, em que o aumento de centróides casou maior evidencia das sobreposições entre grupos (ilustrada na Figura 7.8) e gerou partições de menor qualidade.

As variantes CAD-al resultaram nas partições de maior qualidade média obtidas pelos algoritmos avaliados com o índice $V R C$, segundo os resultados apresentados nas Tabelas 7.7, 7.9 e 7.11. Entretanto, a grande quantidade de centróides gerados na primeira etapa fez com que o tempo de execução das variantes CAD-al aumentasse aproximadamente 10 vezes, já que o algoritmo possui complexidade computacional quadrática em relação a essa quantidade. Também é preciso considerar que o algoritmo de ligação média é aplicado nos algoritmos CAD de forma ponderada (ver Seção 7.4.2), o que requer cálculos extras e reduz o desempenho computacional. Isso não ocorre com o algoritmo de ligação simples, que necessita calcular a dissimilaridade entre os objetos uma única vez. Depois de calculadas, essas dissimilaridades podem ser reutilizadas para a aglomeração dos grupos e obter a hierarquia de agrupamentos (Seção 2.4.5). Adicionalmente, o cálculo das dissimilaridades pode ser aprimorado com funções que executam cálculos vetoriais, como é o caso das implementações feitas para este trabalho.

Como era esperado, a variante exata do algoritmo $D$-EAC manteve aproximadamente a mesma qualidade média das partições obtidas, como pode ser visto nas Tabelas 7.7, 7.9 e 7.11 independente da quantidade de nós de dados. Esse algoritmo mostrou novamente ser o algoritmo de execução mais rápida, se desconsiderado o tempo de transferência de dados. A versão implementada com métodos de manutenção de privacidade apresentou um pequeno aumento no valor médio resultante do índice Jaccard. Contudo, suas variantes (9-10) mostraram uma necessidade de transferência média de mais de 70 MB de dados, bem acima dos outros algoritmos.

Assim como feito nos outros experimentos apresentados neste capítulo, as velocidades de transferência necessárias para que a variante indicada pela $i$-ésima linha possa ser mais rápida do que a variante da $j$-ésima coluna são apresentadas na Tabela 7.12, para a distribuição das bases de dados em 80 nós e avaliação com $V R C$. Velocidades de transferência muito próximas de 0 serão desconsideradas e o algoritmo mais rápido será determinado pela velocidade de execução. 


\begin{tabular}{|c|c|c|c|c|c|c|c|c|c|c|}
\hline & 1 & 2 & 3 & 4 & 5 & 6 & 7 & 8 & 9 & 10 \\
\hline 1 & - & $>88,44$ & $\triangle$ & $>0,06$ & $\triangle$ & $>0,54$ & $\triangle$ & $>1,68$ & $<38802,09$ & $\triangle$ \\
\hline 2 & $<88,44$ & - & $\triangle$ & $\triangle$ & $\triangle$ & $\triangle$ & $\triangle$ & $\triangle$ & $<37964,62$ & $\triangle$ \\
\hline 3 & $\nabla$ & $\nabla$ & - & $\nabla$ & $\nabla$ & $\nabla$ & $\nabla$ & $\nabla$ & $<1137,33$ & $<969,52$ \\
\hline 4 & $<0,06$ & $\nabla$ & $\triangle$ & - & $<0,07$ & $\nabla$ & $<0,07$ & $\nabla$ & $<1236,35$ & $<1059,45$ \\
\hline 5 & $\nabla$ & $\nabla$ & $\triangle$ & $>0,07$ & - & $\nabla$ & $\nabla$ & $\nabla$ & $<8311,89$ & $<11354,06$ \\
\hline 6 & $<0,54$ & $\nabla$ & $\triangle$ & $\triangle$ & $\triangle$ & - & $<0,80$ & $\nabla$ & $<8344,49$ & $<11429,61$ \\
\hline 7 & $\nabla$ & $\nabla$ & $\triangle$ & $>0,07$ & $\triangle$ & $>0,80$ & - & $\nabla$ & $<17602,89$ & $<109365,98$ \\
\hline 8 & $<1,68$ & $\nabla$ & $\triangle$ & $\triangle$ & $\triangle$ & $\triangle$ & $\triangle$ & - & $<17953,61<128746,27$ \\
\hline 9 & $>38802,09$ & $>37964,62$ & $>1137,33$ & $>1236,35$ & $>8311,89$ & $>8344,49$ & $>17602,89$ & $>17953,61$ & - & $>3952,99$ \\
\hline 10 & $\nabla$ & $\nabla$ & $>969,52$ & $>1059,45$ & $>11354,06$ & $>11429,61$ & $>109365,98$ & $>128746,27$ & $<3952,99$ & - \\
\hline
\end{tabular}

Tabela 7.12: Velocidade de transferência $(K B / s)$ necessária para que o algoritmo indicado pela linha possa ter um melhor desempenho do que o algoritmo indicado pela coluna, em média, para o conjunto Artificial2 distribuído em 80 nós de dados.

Como a quantidade de dados transferida pelos algoritmos CAD é aproximadamente a mesma para todas as variantes, o que determina qual variante possui melhor desempenho computacional é o tempo de execução de cada uma. Isso faz da CAD-sl a variante com melhor desempenho, porém que gerou as partições de pior qualidade média, um resultado recorrente na maioria dos experimentos feitos. O algoritmo $D$-EAC sem manutenção de privacidade pode ultrapassar as variantes 3-6 em termos de desempenho, se as taxas de transferência médias forem superiores à $8500 \mathrm{~KB} / \mathrm{s}$. Taxas maiores são necessárias para que o mesmo aconteça com outras variantes dos algoritmos CAD.

\subsection{Considerações Finais}

Neste capítulo foram apresentadas contribuições voltadas para aplicações de agrupamentos em conjuntos de dados distribuídos, na forma de dois tipos de algoritmos. O primeiro tipo de algoritmo, o $D F-E A C$, consiste na versão distribuída exata do algoritmo F-EAC e mostrou, por meio dos experimentos apresentados, ser robusto a variações relativas à distribuição dos dados, uma vez que a qualidade média das partições obtidas por esse algoritmo se manteve estável. Adicionalmente, o DF-EAC possui complexidade linear em relação aos seus parâmetros e apresentou o menor tempo de execução em máquina entre todas as variantes comparadas. Entretanto, devido a ser um algoritmo baseado em múltiplas rodadas de comunicação, o $D F-E A C$ também apresentou as maiores quantidades de dados transferidos entre nós. Portanto, o algoritmo DF-EAC mostra-se uma boa opção para sistemas distribuídos com altas taxas de transferências de dados, pois a qualidade das partições que ele obtém independe da forma em que os dados são distribuídos.

Conclusões semelhantes às obtidas para o $D F-E A C$ podem ser estendidas para o $D$ $E A C$, versão que avalia as partições por meio do índice $V R C$. Contudo, a qualidade média das partições encontradas pelo $D F-E A C$ mostrou-se maior e a quantidade média de dados transferidos foi menor do que a obtida pelo $D$-EAC.

O segundo tipo de algoritmo proposto (CAD) é constituído de um conjunto de algoritmos divididos em duas etapas: agrupar localmente os dados distribuídos e combinar os resultados (protótipos) obtidos por meio de um algoritmo de agrupamento. O objetivo 
principal desses algoritmos consiste em reduzir a quantidade de rodadas de comunicação, bem como a quantidade de dados transferidos, entre os nós. Por esse motivo, são indicados para aplicações caracterizadas por baixas taxas de transferência de dados. Por serem algoritmos aproximados, seu desempenho pode variar conforme as características do conjunto de dados e sua distribuição. De forma geral, os resultados apresentados nas Seções 7.5.3 e 7.5.4 indicam que a qualidade das partições da segunda etapa é proporcional à qualidade das partições locais obtidas na primeira etapa do algoritmo. Esta qualidade, por sua vez, mostrou ser proporcional à quantidade de objetos processados por nó ou, para uma quantidade fixa de objetos, inversamente proporcional à quantidade de nós. Esses fatores sugerem que os algoritmos CAD são mais apropriados para cenários com baixa granularidade. Entretanto, cuidado deve ser tomado ao utilizar o índice $V R C$ na avaliação de partições, pois sua utilização na primeira etapa dos algoritmos CAD causou um aumento substancial na quantidade de protótipos gerados. Esse aumento resultou em uma quantidade de protótipos próxima da quantidade total de objetos para os experimentos feitos com 80 nós, o que gerou uma situação em que o conjunto de protótipos a ser agrupado na segunda etapa do algoritmo é similar ao conjunto de dados. Essa situação nem sempre é interessante, especialmente em aplicações práticas, pois gera a transmissão de grandes quantidades de dados. Sendo assim, quando as partições locais são avaliadas pelo índice $V R C$ e houver uma baixa relação entre as quantidades de objetos e de nós de dados, nem todas as conclusões anteriores, relacionadas aos algoritmos CAD, são aplicáveis.

Quando as partições foram avaliadas pelo índice silhueta simplificada, o algoritmo CAD-FEAC mostrou maior robustez, em termos de qualidade de partição, a mudanças relativas à quantidade de nós de dados do que outras variantes baseadas em algoritmos hierárquicos. Essas mudanças estão relacionadas ao número de centróides obtidos na primeira etapa do algoritmo, à quantidade de objetos presentes em cada nó de dados e à qualidade das partições locais. Entretanto, essa variante apresenta os maiores tempos de execução e quantidade de transferência de dados entre os algoritmos CAD. Para reduzir esses valores, pode-se adotar um limite de gerações sem melhoria na qualidade da melhor partição obtida pelo $F$-EAC, quando aplicado na segunda etapa do algoritmo. O algoritmo CAD-FEAC mostra uma boa relação entre qualidade de partição e desempenho quando esse limite é adotado.

Apesar da avaliação com o índice $V R C$ causar um decréscimo na qualidade média das partições obtidas pelos algoritmos CAD, a quantidade total de dados transferidos por esses algoritmos sofreu uma redução considerável em relação ao uso do índice silhueta simplificada. A versão que obteve melhores resultados com essa avaliação foi a CAD-al, que pode ser recomendada para sistemas com baixas taxas de transferência de dados. Contudo, o CAD-al possui custo computacional quadrático em relação ao número de centróides obtidos na primeira etapa do algoritmo. A análise dos experimentos das Seções 7.5.3 e 7.5.4 permite concluir que esse número de centróides é proporcional à quantidade de 
nós de dados. Adicionalmente, utilizar o índice $V R C$ causou um aumento na quantidade de centróides das partições locais resultantes da primeira etapa do algoritmo, em relação ao índice silhueta simplificada. Por esses motivos, a aplicação do CAD-al com VRC pode não ser interessante nos casos em que o número de nós de dados é grande e cada nó de dados possui poucos objetos. A utilização do DF-EAC obtém melhores resultados nesses casos, por ser um algoritmo exato.

Em resumo, para cenários em que a taxa de transferência de dados entre nós é alta, o uso do $D-F E A C$ é recomendado por ser robusto a variações relacionadas à distribuição dos dados. Nos casos em que a taxa de transferência de dados é baixa e a quantidade de objetos em cada nó for alta, o algoritmo CAD-al avaliado por $V R C$ é recomendado, pela quantidade reduzida de transmissões e dados transmitidos. Já o CAD-FEAC com avaliação por silhueta mostra uma boa relação entre qualidade de partição, desempenho computacional e transferência de dados, sendo recomendado para cenários em que a taxa de transmissão é mediana. 


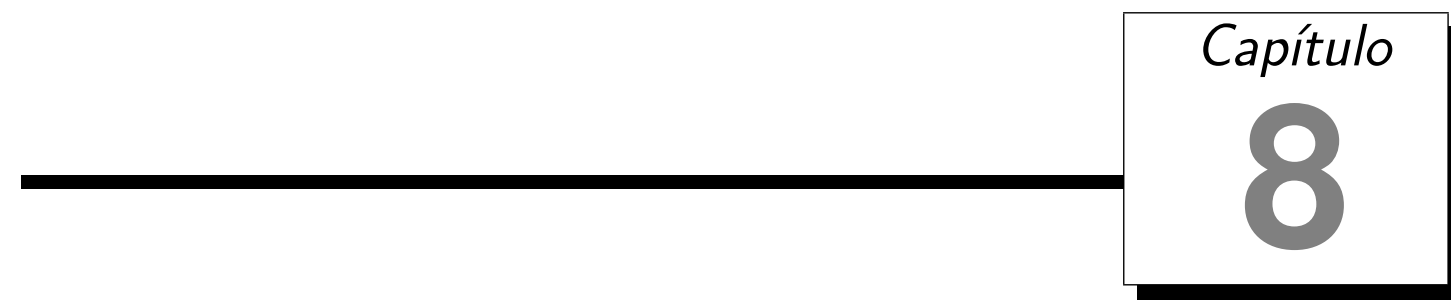

\section{Conclusões}

O trabalho apresentado nesta tese contribui com o desenvolvimento de soluções de qualidade para o agrupamento de dados, que permitem obter um bom desempenho computacional e escalabilidade em relação ao número de objetos presentes no conjunto agrupado. Com essa finalidade, uma variedade de algoritmos de agrupamento foi investigada e as principais características de cada algoritmo foram apresentadas no Capítulo 2. A partir dessa investigação, foi possível concluir que algoritmos distintos ou o mesmo algoritmo com diferentes valores para seus parâmetros resultam em soluções diversas. Uma forma de avaliar comparativamente essas soluções consiste em aplicar índices de validação relativos, também apresentados no Capítulo 2. Esses índices permitem qualificar, dentre as soluções obtidas, a que melhor possui as características procuradas.

Dentre todos os algoritmos de agrupamento analisados, o algoritmo $k$-médias merece destaque por ser de simples implementação, interpretação e possuir complexidade computacional assintótica linear em relação a qualquer um de seus parâmetros críticos. Tais características fizeram com que o algoritmo fosse eleito recentemente como um dos dez algoritmos mais utilizados e influentes na área de mineração de dados (Wu et al., 2008; $\mathrm{Wu}, 2009)$. Isso fez com que ele fosse escolhido para a maioria das investigações desta tese, pois gera soluções eficientes e escaláveis, com grupos facilmente interpretáveis, o que está diretamente relacionado com a primeira hipótese apresentada na Seção 1.2, considerada neste trabalho.

A sensibilidade à seleção do número de grupos e seus protótipos iniciais faz com que o $k$-médias tenha que ser executado múltiplas vezes em aplicações práticas, em que informações sobre tais parâmetros são geralmente desconhecidas. A fim de encontrar o número de grupos e protótipos mais adequados ao $k$-médias para um determinado conjunto de dados, AEs foram investigados nesta pesquisa. Diversos trabalhos pesquisados mostram que esse tipo de meta-heurística é aplicada com sucesso em problemas de agrupamento, como mos- 
trado na revisão feita no Capítulo 3. Uma das contribuições do trabalho feito durante o doutorado consiste em mostrar que AEs podem ser computacionalmente mais eficientes do que abordagens sistemáticas ou até mesmo algoritmos conhecidos da literatura, tanto no âmbito teórico quanto prático, quando aplicados em conjunto com o algoritmo $k$-médias, o que valida a segunda hipótese apresentada na Seção 1.2. Para tanto, análises de complexidade computacional e experimentos comparativos foram feitos e seus resultados são apresentados no Capítulo 4.

Existem aplicações para agrupamento de dados em que diversas soluções encontramse disponíveis, porém procura-se por uma única solução que represente o consenso entre estas soluções. É o caso de aplicações que visam unificar o conhecimento adquirido de diversas fontes sobre um mesmo conjunto de dados, seja a partir de diferentes algoritmos de agrupamento, especialistas ou partes distintas de um conjunto de dados distribuído. Técnicas de combinação de agrupamentos são capazes de executar essa tarefa, de modo a gerar um único resultado a partir de um conjunto de soluções obtidas. Por esse motivo, essas técnicas foram pesquisadas durante o desenvolvimento da tese, categorizadas e apresentadas no Capítulo 5.

Com a finalidade de aprimorar a qualidade das partições obtidas por meio de métodos de combinação de agrupamentos, técnicas de $C E S$ foram aplicadas com sucesso em outros trabalhos da literatura (Fern \& Lin, 2008; Azimi \& Fern, 2009). Uma das principais contribuições deste trabalho foi o estudo de índices relativos de validação de agrupamentos, individualmente e combinados, no processo de CES. Os resultados obtidos, presentes no Capítulo 6, indicam que os métodos de CES são eficazes nos casos em que existem partições base semelhantes à estrutura do conjunto de dados. Adicionalmente, é mostrado que o uso combinado de índices de validação (CIR) em CES produz resultados com qualidade acima da média dos resultados obtidos com os mesmos índices individualmente, na maioria dos experimentos apresentados, o que valida a terceira hipótese presente na Seção 1.2. Isso torna o uso de CIR uma boa opção para aplicações práticas em que o desempenho dos índices de validação escolhidos é geralmente desconhecido.

Os experimentos realizados com as técnicas de CES propostas e investigadas neste trabalho (descritos no Capítulo 6) mostram que alguns algoritmos de combinação de agrupamento têm a qualidade das partições resultantes melhorada com $C E S$, enquanto outros obtêm melhores resultados com a combinação de todas as partições base. Em meio a esses resultados heterogêneos, um arcabouço para a aplicação de $C E S$ foi concebido e aplicado em conjuntos de dados reais. Os resultados indicam que optar pela solução proposta no arcabouço gera partições estatisticamente equivalentes, em termos de qualidade, às melhores partições obtidas para a maioria dos casos investigados.

Por último, o crescimento da quantidade de dados gerados em diversas áreas e sua distribuição entre diferentes sítios torna necessária a aplicação das técnicas investigadas neste trabalho em conjuntos de dados distribuídos. Outra contribuição principal deste trabalho é a proposta de dois tipos de algoritmos de agrupamento distribuídos: o primeiro 
tipo consiste na versão distribuída e exata do algoritmo $F$-EAC, o $D F$-EAC; o segundo tipo é composto por um conjunto de algoritmos que sumariza os dados distribuídos em partições locais e as combina para formar uma partição final (CAD). Diferentes variantes de aplicação de ambos os tipos de algoritmos foram comparadas, tanto em termos teóricos, por meio da análise assintótica de suas complexidades computacionais, quanto em termos práticos, por meio de experimentos comparativos. Os resultados apresentados no Capítulo 7 permitem concluir que o $D F-E A C$ é robusto a variações relativas à distribuição dos dados e possui o melhor tempo de execução, mas em contrapartida necessita transferir quantidades substanciais de dados. Também foi possível concluir que os algoritmos CAD apresentam as menores quantidades de dados transferidos, porém a qualidade de suas partições varia com a qualidade das partições combinadas e a forma em que os dados são distribuídos. Adicionalmente, os resultados presentes no Capítulo 7 validam a última hipótese desta pesquisa, presente na Seção 1.2, de que acombinação de informações sobre os dados, quando obtidas de forma distribuída, pode gerar agrupamentos equivalentes ou próximos dos que seriam obtidos de forma centralizada.

Em resumo, a investigação proposta permite concluir que algoritmos de agrupamento evolutivos são capazes de obter partições de qualidade e, ao mesmo tempo, resultar em um bom desempenho computacional. Também é possível concluir que a qualidade dos resultados obtidos por métodos de combinação, seja de partições ou de índices de validação, é proporcional à qualidade obtida individualmente pelas partes combinadas. Portanto, combinar técnicas mostrou-se uma abordagem interessante quando não há conhecimento prévio sobre o desempenho individual das partes combinadas, a fim de que o bom resultado da maioria dessas partes compense o desempenho ruim de uma minoria. Adicionalmente, resultados promissores foram obtidos ao aplicar a combinação das técnicas evolutivas investigadas no agrupamento de dados distribuídos. Esses resultados abrem caminho para o desenvolvimento de novas pesquisas, como é abordado na Seção 8.1.

\subsection{Trabalhos Futuros}

A pesquisa desenvolvida nesta tese abre caminho para extensões e o desenvolvimento de novas pesquisas. Os resultados experimentais apresentados no Capítulo 7 permitem comparar os algoritmos propostos em termos de qualidade da partição obtida, tempo de execução e quantidade total de dados transmitidos. Por meio desses valores, é possível estimar aproximadamente o desempenho relativo dos algoritmos. Entretanto, não é possível comparar de fato o desempenho de cada algoritmo avaliado sem considerar concomitantemente a quantidade e tamanho dos pacotes de dados transmitidos, quais transmissões podem ocorrer em paralelo com o processamento dos dados, além de outras características intrínsecas do meio de transmissão e a topologia do sistema. Para tanto, é preciso investigar os algoritmos comparados em ambientes de simulação e/ou reais que considerem esses aspectos. 
Adicionalmente, a avaliação do tempo de execução dos algoritmos feita neste trabalho é dependente da máquina utilizada. Uma maneira de dissociar essa avaliação da máquina em que o algoritmo foi executado consiste em contar o número de operações de ponto flutuante utilizadas para cada algoritmo, ao invés do tempo de execução. Essa abordagem permite estabelecer, para aplicações distribuídas, uma relação entre o número de cálculos de ponto flutuante e a quantidade de dados transferidos. Uma vez calculada, essa relação pode ser utilizada para comparar algoritmos independentemente do maquinário empregado.

Outro possível tema de pesquisa consiste em investigar o uso de técnicas de combinação de agrupamentosem conjuntos de dados distribuídos verticalmente. Apesar de menos comum do que a distribuição horizontal dos dados, a distribuição vertical dos dados pode ser útil nos casos em que seja interessante estabelecer relações entre os objetos a partir de diferentes aspectos (atributos) e combiná-las posteriormente. Por exemplo, empresas distintas podem possuir dados diferentes sobre os mesmos clientes e desejam agrupá-los a partir de toda a informação disponível. Adicionalmente, não é possível ou interessante centralizar os dados, seja por interesses comerciais ou confidencialidade dos dados. Esse exemplo é um caso típico no qual os dados encontram-se distribuídos verticalmente. Uma possível solução para tal problema consiste em agrupar os dados localmente em cada empresa e, posteriormente, combiná-los em uma solução consenso. Casos semelhantes e suas soluções fundamentam o tema de pesquisa futura proposto aqui. 


\section{Apêndice I: Análise da influência da quantidade de partições base sobre a partição consenso}

Trabalhos publicados na literatura sobre agrupamento de dados afirmam que a escolha do número de partições base pode afetar o resultado da combinação (Kuncheva et al., 2006; Handl \& Knowles, 2007; Hadjitodorov \& Kuncheva, 2007). Adicionalmente, Fred \& Jain (2005) afirmam que gerar partições base com número de grupos muito maior do que o conhecido $\left(k^{*}\right)$ pode ser necessário para aprimorar a evidência sobre o conjunto de dados e, consequentemente, gerar uma combinação de qualidade.

Nos experimentos envolvendo a combinação de agrupamentos apresentados nas Seções 6.3.2 e 6.4.3, $n_{\pi}$ foi escolhido de forma a gerar grandes conjuntos de partições que possibilitem aos experimentos não ultrapassar a quantidade de memória disponível. Por esse motivo, adotamos $n_{\pi}=5$ em experimentos que envolvem os conjuntos Artificial2 e Artificial3, pois experimentos com $n_{\pi}=10$ não puderam ser executados com a função $M C L A$ para esses conjuntos de dados devido ao limite de memória disponível.

Entretanto, experimentos com $n_{\pi}=10$ e $k \in\left[2,2 \sqrt{n_{o}}\right]$ foram realizados com sucesso para as outras funções consenso estudadas no Capítulo 6. Portanto, é possível analisar se o aumento dos valores de $n_{\pi}$ e $k$ gera impacto na qualidade da partição consenso obtida por essas funções consenso. Adicionalmente, é necessário investigar se esse aumento altera o comportamento das técnicas de $C E S$ utilizadas nos experimentos presentes no Capítulo 6.

Primeiramente, partições base foram obtidas com $n_{\pi}=5$ e $k \in\left[2, \sqrt{n_{o}}\right]$ para os conjuntos de bases Artificial2 e Artificial3, conforme a descrição feita na Seção 6.3. As funções consenso $C A A, C A S, C S P A$ e $H G P A$ foram aplicadas no conjunto total de partições base obtidas e as partições consenso resultantes foram comparadas, por meio do índice Jaccard, com as partições conhecidas. Em seguida, novos conjuntos de partições base foram gerados com $n_{\pi}=10$ e $k \in\left[2,2 \sqrt{n_{o}}\right]$ para os conjuntos de bases Artificial2 e Artificial3, seguindo a mesma metodologia adotada anteriormente. As mesmas funções 
consenso foram aplicadas e seus resultados avaliados com o índice Jaccard.

Os valores médios e desvios padrões do índice Jaccard, resultantes de experimentos com os conjuntos Artificial2 e Artificial3, são apresentados nas Tabelas 8.1 e 8.2. Se houver diferença estatística comprovada, pelo teste Wilcoxon/Man-Whitney com nível de confiança de $95 \%$ (Triola, 1999), entre os resultados dos experimentos feitos com $n_{\pi}=10$ e $k \in\left[2,2 \sqrt{n_{o}}\right]$ e os experimentos executados com $n_{\pi}=5$ e $k \in\left[2, \sqrt{n_{o}}\right]$, a maior média é apresentada em negrito.

\begin{tabular}{|c|c|c|c|c|}
\hline Parâmetros & CAA & $C A S$ & CSPA & HGPA \\
\hline$n_{\pi}=5, k \in\left[2, \sqrt{n_{o}}\right]$ & $0.8944(0.10)$ & $0.7101(0.25)$ & $0.4935(0.05)$ & $0.6102(0.09)$ \\
\hline$n_{\pi}=10, k \in\left[2,2 \sqrt{n_{o}}\right]$ & $0.9187(0.09)$ & $0.7623(0.24)$ & $0.5009(0.05)$ & $\mathbf{0 . 6 4 3 7}(\mathbf{0 . 0 8})$ \\
\hline
\end{tabular}

Tabela 8.1: Valor médio e desvio padrão de Jaccard para partições consenso geradas a partir do conjunto Artificial2.

\begin{tabular}{|c|c|c|c|c|}
\hline Parâmetros & CAA & $C A S$ & $C S P A$ & $H G P A$ \\
\hline$n_{\pi}=5, k \in\left[2, \sqrt{n_{o}}\right]$ & $0.3745(0.17)$ & $0.5664(0.41)$ & $0.4356(0.11)$ & $0.6195(0.09)$ \\
\hline$n_{\pi}=10, k \in\left[2,2 \sqrt{n_{o}}\right]$ & $\mathbf{0 . 4 3 3 3 ( 0 . 1 9 )}$ & $0.6212(0.39)$ & $0.4508(0.11)$ & $\mathbf{0 . 6 5 7 1}(\mathbf{0 . 0 9})$ \\
\hline
\end{tabular}

Tabela 8.2: Valor médio e desvio padrão de Jaccard para partições consenso geradas a partir do conjunto Artificial3.

Os resultados nas Tabelas 8.1 e 8.2 mostram que houve um aumento significante da qualidade das partições consenso dos experimentos executados com a função $H G P A$, com o aumento de $n_{\pi}$ e $k$. O mesmo pode ser afirmado para a função $C A A$ em relação ao Conjunto3. Esses resultados fortalecem a afirmação de que o incremento do número de partições pode aprimorar a precisão de funções consenso obtidas por meio de combinação total. Contudo, a qualidade das outras partições consenso aumentou pouco em relação aos experimentos feitos com $n_{\pi}=5$ e $k \in\left[2, \sqrt{n_{o}}\right]$, o que pode não justificar o maior custo computacional gerado pelo aumento da quantidade de partições base. Esse resultado está de acordo com a investigação feita por Hadjitodorov \& Kuncheva (2007).

Também é importante avaliar se o aumento de $n_{\pi}$ e $k$ interfere no comportamento dos métodos de CES investigados no Capítulo 6. Na Seção 6.3.2, esses métodos de CES foram aplicados nas partições base geradas com $n_{\pi}=5$ e $k \in\left[2, \sqrt{n_{o}}\right]$ para formar partições consenso compostas de 10\%, 25\%, 50\% e 75\% das partições base. Aqui, os mesmos métodos de $C E S$ são aplicados nas partições base geradas com $n_{\pi}=10$ e $k \in\left[2,2 \sqrt{n_{o}}\right]$, com a finalidade de formar partições consenso com 10\%, 25\%, 50\% e $75 \%$ das partições base. Em seguida, todas as partições consenso obtidas foram avaliadas com o índice de Jaccard.

Para comparar o comportamento dos métodos de CES estudados com diferentes quantidades de partições base, as correlações entre os valores de Jaccard obtidos pelos experimentos realizados com $n_{\pi}=5$ e $n_{\pi}=10$ foram medidas por meio do coeficiente de Pearson (Seção 2.3.2). A média dessas correlações é de 0.8589 para o conjunto Artificial2 e 0.8916 para o conjunto Artificial3. Esses resultados indicam que as funções consenso estudadas mantêm um comportamento semelhante com a variação da quantidade de partições base, 
em relação ao uso dos métodos de $C E S$ investigados neste trabalho, o que fortalece as conclusões apresentadas no Capítulo 6. 


\section{Apêndice II: Comparação entre variantes do $\mathrm{MO}_{2}$ para o $\mathrm{F}-\mathrm{EAC}$}

Com o objetivo de reduzir o custo computacional e comunicação entre nós de dados durante a fase de mutação do $D F-E A C$, variantes do $\mathrm{MO}_{2}$ (Algoritmo 6) foram investigadas durante esta pesquisa. Dentre elas, a variante que chamaremos neste trabalho de operador de mutação alternativo $2\left(M O A_{2}\right)$ alternativo, cujos aspectos principais estão presentes no Algoritmo 8.

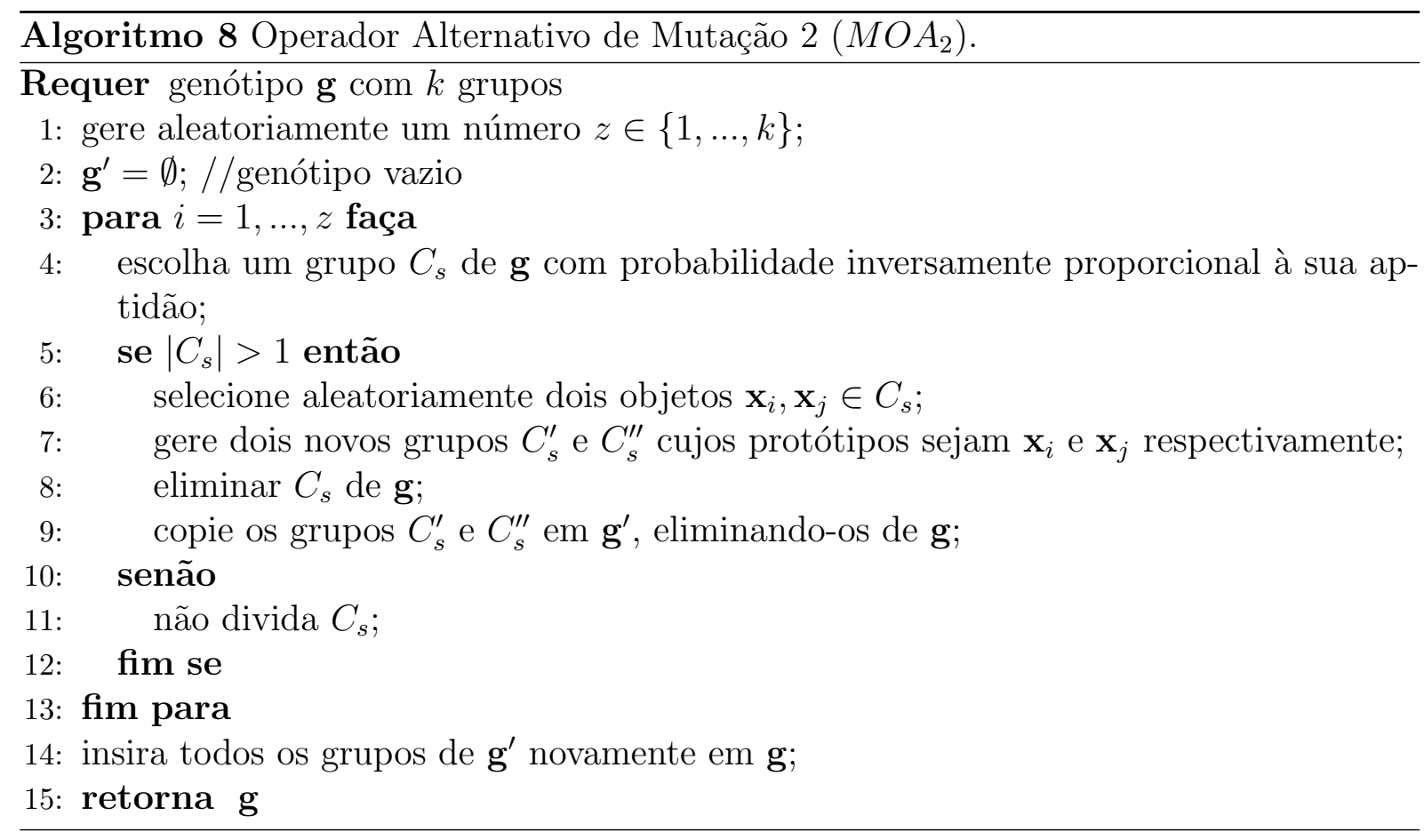

Durante o Passo 8, os objetos do grupo eliminado tornam-se objetos não agrupados. Objetos não agrupados encontram-se em um estado temporário, criado para evitar o processamento necessário para inserir os objetos oriundos dos grupos que sofreram mutação em outros grupos. Estes objetos são representados por zeros no genótipo g (vide Seção 3.4.1). Na etapa seguinte do algoritmo, que consiste na busca local por meio do algoritmo $k$-médias, todos os objetos (agrupados ou não) são inseridos nos grupos com os centróides 
mais similares.

O $\mathrm{MOA}_{2}$ possui um custo computacional menor do que o custo do $\mathrm{MO}_{2}$. Isso porque essa versão atende às duas condições abaixo:

- não atualiza g movendo objetos para novos grupos e não recalcula os centróides a partir destes novos grupos;

- não calcula a dissimilaridade entre vários pares de objetos e não realiza várias comparções entre estas dissimilaridades para achar o objeto mais dissimilar a outro.

Experimentos foram realizados com objetivo de comparar o desempenho do algoritmo $F$-EAC implementado com o $M O A_{2}$ com o F-EAC implementado com o $\mathrm{MO}_{2}$. Cada uma dessas versões do $F$-EAC foi rodada 30 vezes para os conjuntos de dados Artificial2 e Artificial3, descritos na Seção 6.2, que somados contém 160 conjuntos de dados. O critério de parada utilizado consistiu em atingir o valor de aptidão de referência $v_{R}$, seguindo a metodologia descrita na Seção 4.3.2.1. Neste experimento, o método consiste em executar o algoritmo $k$-médias para um número crescente de grupos $k$, dentro do intervalo $\left[2, \sqrt{n_{o}}\right]$. Para cada valor de $k$, um número $n_{\pi, k}$ de partições devem ser geradas com diferentes inicializações. Aqui assumimos $n_{\pi, k}=30$ e o $v_{R}$ é o maior valor de validação obtido dentre o conjunto de partições, aferido pelo índice de validação silhueta simplificada (Seção 2.5.2.5).

Para cada um dos operadores foi criado um vetor, $\mathbf{n}_{\mathbf{g}}$, em que foi armazenado, para cada execução do algoritmo, o número de gerações necessárias para que este atingisse seu critério de parada. Em seguida foram calculadas, para cada operador, a média e o desvio padrão dos valores pertencentes ao vetor $\mathbf{n}_{\mathbf{g}}$. Esse valores são apresentados na Tabela 8.3.

\begin{tabular}{|c|c|c|}
\hline & $\mathrm{MO}_{2}$ & $\mathrm{MOA}_{2}$ \\
\hline Gerações & $39.13(42.48)$ & $35.74(38.74)$ \\
\hline
\end{tabular}

Tabela 8.3: Média e desvio padrão sobre os números de gerações obtidos com 2 operadores comparados.

Além da média e do desvio padrão, dois testes de hipóteses também foram aplicados utilizando-se os valores dos vetores $\mathbf{n}_{\mathbf{g}}$. O primeiro teste é o conhecido $t$-test (Walpole et al., 2006), frequentemente adotado em trabalhos da literatura. O t-test assume que a média das amostras assume distribuição normal. Apesar do teorema do limite central poder ser utilizado para dar suporte a normalidade das médias dos dados, ainda não é garantido que os tamanhos das amostras sejam suficientes para aproximar os resultados de um distribuição normal. Por esse motivo, o conhecido teste estatístico nãoparamétrico Wilcoxon/Mann-Whitney também foi adotado aqui. A eficiência do teste Wilcoxon/Mann-Whitney é próxima de $95 \%$ em relação a testes paramétricos como o teste $\mathbf{t}$ ou o teste $\mathbf{z}$, mesmo quando os dados seguem uma distribuição normal (Triola, 1999). 
Os resultados mostrados na Tabela 8.3 mostram que a variação do F-EAC com $M O A_{2}$ encontra partições com valores de validação iguais ou superiores ao valor de referência em um número menor de gerações, em média. Ambos os testes, t-test e Wilcoxon/MannWhitney, comprovaram diferença estatística entre os resultados obtidos pelas versões comparadas, com significância de $95 \%$. Além disso, devido ao fato de o $M O A_{2}$ ser computacionalmente mais simples do que o $\mathrm{MO}_{2}$, pode-se concluir que o $\mathrm{MOA}_{2}$ seja mais eficiente em relação ao tempo de execução total dos algoritmos. 


\section{Referências Bibliográficas}

Aeberhard, S., D. Coomans, \& O. de Vel (1992). Comparison of classifiers in high dimensional settings. Technical Report 02, Dept. of Computer Science and Dept. of Mathematics and Statistics, James Cook University of North Queensland. Citado na página 129.

Agogino, A. \& K. Tumer (2006). Efficient agent-based cluster ensembles. In AAMAS '06: Proceedings of the fifth international joint conference on Autonomous agents and multiagent systems, New York, NY, USA, pp. 1079-1086. ACM. Citado nas páginas 118 e 167.

Alcock, R. J. \& Y. Manolopoulos (1999). Time-series similarity queries employing a feature-based approach. In 7th Hellenic Conference on Informatics., Ioannina,Greece., pp. 27-29. Citado na página 129.

Alpaydin, E. (2004). Introduction to Machine Learning. The MIT Press. Citado na página 11.

Alves, V., R. Campello, \& E. Hruschka (2006). Towards a fast evolutionary algorithm for clustering. In IEEE Congress on Evolutionary Computation, 2006, Vancouver, Canada, pp. 1776-1783. Citado nas páginas 54, 55, 57, 58, 59, 60, 62, 75, 79, 95, 98, 99, 167, 180 , e 183.

Alves, V. S. (2007). Um algoritmo evolutivo rápido para agrupamento de dados. Dissertação de Mestrado, Universidade Católica de Santos. Citado nas páginas 60, 62, 75, 79,95 , e 180 .

Anderberg, M. R. (1973). Cluster Analysis for Applications. Academic Press Inc. Citado na página 78.

Asuncion, A. \& D. Newman (2007). UCI machine learning repository. Citado na página 129. 
Asur, S., S. Parthasarathy, \& D. Ucar (2006). An ensemble approach for clustering scalefree graphs. In Proceedings of the Workshop on Link Analysis: Dynamics and Static of Large Networks. Citado na página 106.

Au, W.-H., K. Chan, A. Wong, \& Y. Wang (2005, April-June). Attribute clustering for grouping, selection, and classification of gene expression data. Computational Biology and Bioinformatics, IEEE/ACM Transactions on 2(2), 83-101. Citado na página 23.

Ayad, H. G. \& M. S. Kamel (2008). Cumulative voting consensus method for partitions with variable number of clusters. IEEE Trans. Pattern Anal. Mach. Intell. 30(1), 160173. Citado na página 114.

Azimi, J. \& X. Fern (2009). Adaptive cluster ensemble selection. In Twenty-first International Joint Conference on Artificial Intelligence (IJCAI-09), Pasadena, Califonia, USA, pp. 992-997. Citado nas páginas 125, 127, 129, 130, 149, e 210.

Azuaje, F. (2002). A cluster validity framework for genome expression data. Bioinformatics 18(2), 319-320. Citado na página 39.

Baldi, P. \& S. Brunak (1998). Bioinformatics: The Machine Learning Approach. Adaptative Computation and Machine Learning. MIT Press. Citado nas páginas 1 e 13.

Bandyopadhyay, S., C. Giannella, U. Maulik, H. Kargupta, K. Liu, \& S. Datta (2006). Clustering distributed data streams in peer-to-peer environments. Information Sciences 176(14), 1952 - 1985. Streaming Data Mining. Citado nas páginas 167 e 169.

Bandyopadhyay, S. \& U. Maulik (2001). Nonparametric genetic clustering: Comparison of validity indices. IEEE Transactions on Systems, Man and Cybernetics, Part $C$ : Applications and Reviews. 31(1), 120-125. Citado nas páginas 54, 55, 57, 58, e 59.

Bandyopadhyay, S. \& U. Maulik (2002a). An evolutionary technique based on k-means algorithm for optimal clustering in $\mathrm{R}^{n}$. Information Sciences 146(1-4), 221-237. Citado nas páginas 49, 51, 52, 53, e 54 .

Bandyopadhyay, S. \& U. Maulik (2002b). Genetic clustering for automatic evolution of clusters and application to image classification. Pattern Recognition 35, 1197-1208. Citado nas páginas 1, 54, 57, 59, 79, e 89.

Bansal, N., A. Blum, \& S. Chawla (2004). Correlation clustering. Machine Learning 56(13), 89-113. Citado na página 118.

Beasley, D., D. R. Bull, \& R. R. Martin (1993). An overview of genetic algorithms: Part 2, research topics. University Computing 15(4), 170-181. Citado na página 44. 
Bezdek, J., S. Boggavarapu, L. Hall, \& A. Bensaid (1994, Jun). Genetic algorithm guided clustering. In Evolutionary Computation, 1994. IEEE World Congress on Computational Intelligence., Proceedings of the First IEEE Conference on, pp. 34-39. Citado nas páginas 47,51 , e 54 .

Bezdek, J. C. \& N. R. Pal (1998). Some new indexes of cluster validity. IEEE Trans. on Systems, Man and Cybernetics 28(3), 301-315. Citado na página 38.

Bhatnagar, A. \& S. Ghose (2004). A latent class segmentation analysis of e-shoppers. Journal of Business Research 57(7), 758 - 767. Marketing on the web - behavioral, strategy and practices and public policy. Citado na página 1.

Bigus, J. P. (1996). Data Mining with Neural Networks: Solving Business Problems from Application Development to Decision Support. McGraw-Hill. Citado na página 1.

Bishop, C. M. (2006). Pattern Recognition and Machine Learning. Springer. Citado na página 94.

Bishop, C. M. (2007). Pattern Recognition and Machine Learning. Springer. Citado nas páginas 23 e 24.

Blanchard, A. (2007). Understanding and customizing stopword lists for enhanced patent mapping. World Patent Information 29(4), 308 - 316. Citado na página 15.

Bolshakova, N. \& F. Azuaje (2002). Cluster validation techniques for genome expression data. Technical Report 33, University of Dublin. Citado na página 146.

Bolshakova, N., A. Zamolotskikh, \& P. Cunningham (2006). Comparison of the data-based and gene ontology-based approaches to cluster validation methods for gene microarrays. In CBMS '06: Proceedings of the 19th IEEE Symposium on Computer-Based Medical Systems, Washington, DC, USA, pp. 539-543. IEEE Computer Society. Citado na página 13.

Boutsinas, B. \& T. Gnardellis (2002). On distributing the clustering process. Pattern Recognition Letters 23(8), 999 - 1008. Citado na página 170.

Brown, M. P. S., W. N. Grundy, D. Lin, N. Cristianini, C. W. Sugnet, T. S. Furey, M. Ares, \& D. Haussler (2000). Knowledge-based analysis of microarray gene expression data by using support vector machines. Proceedings of the National Academy of Sciences of the United States of America 97(1), 262-267. Citado na página 13.

Bäck, T., D. B. Fogel, \& Z. Michalewicz (2000). Evolutionary Computation 1: Basic Algorithms and Operators. Institute of physics publishing, Bristol and Philadelphia. Citado nas páginas 53, 94, e 96. 
Cabrera, J. B. D., C. Gutiérrez, \& R. K. Mehra (2008). Ensemble methods for anomaly detection and distributed intrusion detection in mobile ad-hoc networks. Inf. Fusion 9(1), 96-119. Citado na página 1.

Calinski, R. B. \& J. Harabasz (1974). A dendrite method for cluster analysis. Communications in Statistics 3, 1-27. Citado nas páginas 36, 58, e 187.

Campello, R. J. G. B. \& E. R. Hruschka (2006). A fuzzy extension of the silhouette width criterion for cluster analysis. Fuzzy Sets and Systems 157, 2858-2875. Citado na página 79.

Campello, R. J. G. B. \& E. R. Hruschka (2009). On comparing two sequences of numbers and its applications to clustering analysis. Information Sciences 179(8), 1025 - 1039. Citado na página 21.

Campello, R. J. G. B., E. R. Hruschka, \& V. S. Alves (2009). On the efficiency of evolutionary fuzzy clustering. Journal of Heuristics 15(1), 43-75. doi: 10.1007/s10732007-9059-6. Citado nas páginas 31, 32, 71, 78, 80, 97, 99, e 167.

Cardoso, M. G. M. S. \& A. P. d. L. F. de Carvalho (2009). Quality indices for (practical) clustering evaluation. Intelligent Data Analysis 13(5), 725-740. Citado na página 145.

Caruana, R., A. Munson, \& A. Niculescu-Mizil (2006). Getting the most out of ensemble selection. In Proceedings of the 2006 Sixth International Conference on Data Mining, pp. 828-833. Citado na página 126.

Casillas, A., M. T. G. de Lena, \& R. Martínez (2003). Document clustering into an unknown number of clusters using a genetic algorithm. Lecture Notes in Computer Science 2807, 43-49. Citado nas páginas 54, 56, 57, 58, e 59.

Clifton, C., M. Kantarcioglu, J. Vaidya, X. Lin, \& M. Y. Zhu (2002). Tools for privacy preserving distributed data mining. SIGKDD Explor. Newsl. 4(2), 28-34. Citado na página 170 .

Cole, R. M. (1998). Clustering with genetic algorithms. MSc Dissertation, Department of Computer Science, University of Western Australia. Citado nas páginas 43, 45, 54, $55,56,57,58$, e 59 .

Corne, D. W., N. R. Jerram, J. D. Knowles, \& M. J. Oates (2001). PESA-II: Region-based selection in evolutionary multiobjective optimization. In Proceedings of the Genetic and Evolutionary Computation Conference (GECCO-2001), San Francisco, California, USA, pp. 283-290. Morgan Kaufmann. Citado na página 59.

Cowgill, M. C., R. J. Harvey, \& L. T. Watson (1999). A genetic algorithm approach to cluster analysis. Computational Mathematics and its Applications 3\%, 99-108. Citado nas páginas $54,55,57,58$, e 59 . 
da Silva, J. C., C. Giannella, R. Bhargava, H. Kargupta, \& M. Klusch (2005). Distributed data mining and agents. Engineering Applications of Artificial Intelligence 18(7), 791 - 807. Citado nas páginas 168, 170, e 178.

da Silva, J. C. \& M. Klusch (2006). Inference in distributed data clustering. Engineering Applications of Artificial Intelligence 19(4), 363 - 369. Recent Advances in Data Mining. Citado na página 170.

Datta, S., C. Giannella, \& H. Kargupta (2009). Approximate distributed k-means clustering over a peer-to-peer network. IEEE Transactions on Knowledge and Data Engineering 21(10), 1372-1388. Citado na página 167.

Davies, D. L. \& D. W. Bouldin (1979). A cluster separation measure. IEEE Trans. on Pattern Analysis and Machine Intelligence 1, 224-227. Citado na página 37.

Davis, L. (1996). Handbook of Genetic Algorithms. International Thomson Computer Press. Citado na página 64.

de Jong, K. A. (2006). Evolutionary Computation: A Unified Approach. MIT Press. Citado na página 53.

de Oliveira, C., A. Meiguins, B. Meiguins, P. Godinho, \& A. Freitas (2007). An evolutionary density and grid-based clustering algorithm. In A. da Silva, V. Soares, \& G. Elias (Eds.), Proc. of the XXIII Brazilian Symposium on Databases (SBBD-2007), pp. 175-189. Sociedade Brasileira de Computação. Citado na página 53.

de Vega, F. \& E. Cantú-Paz (2010). Parallel and Distributed Computational Intelligence, Volume 269 of Studies in Computational Intelligence. Berlin, Heidelberg: Springer Berlin Heidelberg. Citado na página 1.

Deb, K., A. Pratap, S. Agarwal, \& T. Meyrivan (2002). A fast and elitist multi-objective genetic algorithm: NSGA-II. IEEE Transactions on Evolutionary Computation 6(2), 182-197. Citado na página 123.

Demšar, J. (2006). Statistical comparisons of classifiers over multiple data sets. J. Mach. Learn. Res. 7, 1-30. Citado nas páginas 97, 138, 139, e 194.

Denoeud, L. (2006). Data Science and Classification, Chapter Comparison of Distance Indices Between Partitions, pp. 21-28. Springer. Citado na página 36.

Dhillon, I. S. \& D. S. Modha (2000). A data-clustering algorithm on distributed memory multiprocessors. In Revised Papers from Large-Scale Parallel Data Mining, Workshop on Large-Scale Parallel KDD Systems, SIGKDD, London, UK, pp. 245-260. SpringerVerlag. Citado nas páginas 167 e 175.

Dimitriadou, E. (2003). Exploratory Data Analysis and Applications. Tese de Doutorado, Technische Universität Wien. Citado nas páginas 112, 113, 114, e 127. 
Dimitriadou, E., A. Weingessel, \& K. Hornik (1999a). Fuzzy voting in clustering. In G. Brewka, R. Der, S. Gottwald, \& A. Schierwagen (Eds.), Fuzzy-Neuro Systems, pp. 63-74. Leipziger Universitätsverlag. Citado nas páginas 3, 105, 107, e 113.

Dimitriadou, E., A. Weingessel, \& K. Hornik (1999b). Voting in clustering and finding the number of clusters. In AIDA 99 : Proceedings of the International Symposium on Advances in Intelligent Data Analisys, pp. 291-296. Academic Press. Citado na página 113.

Dimitriadou, E., A. Weingessel, \& K. Hornik (2001). Voting-merging: An ensemble method for clustering. In ICANN '01: Proceedings of the International Conference on Artificial Neural Networks, London, UK, pp. 217-224. Citado na página 113.

Dimitriadou, E., A. Weingessel, \& K. Hornik (2002a). A combination scheme for fuzzy clustering. International Journal of Pattern Recognition and Artificial Intelligence 16(7), 901-912. Citado nas páginas 112 e 113.

Dimitriadou, E., A. Weingessel, \& K. Hornik (2002b). A mixed ensemble approach for the semi-supervised problem. In ICANN '02: Proceedings of the International Conference on Artificial Neural Networks, London, UK, pp. 571-576. Citado nas páginas 104, 114, e 167.

Dong, Y., S. Cao, K. Chen, M. He, \& X. Tai (2009). Pfhc: A clustering algorithm based on data partitioning for unevenly distributed datasets. Fuzzy Sets and Systems $160(13)$, 1886 - 1901. Theme: Information Processing and Applications. Citado nas páginas 1 e 170 .

Du, Z. \& F. Lin (2005). A novel parallelization approach for hierarchical clustering. Parallel Computing 31(5), 523 - 527. Citado na página 167.

Duda, R., P. Hart, \& D. Stork (2001). Pattern Classification. John Wiley \& Sons. Citado nas páginas 25, 26, e 36 .

Eiben, A. \& J. Smith (2007). Introduction to Evolutionary Computing. Springer, 2nd edition, Natural Computing Series. Citado na página 44.

Eisen, M. B., P. T. Spellman, P. O. Brown, \& D. Botstein (1998). Cluster analysis and display of genome-wide expression patterns. Proceedings of the National Academy of Sciences of the United States of America 95(25), 14863-14868. Citado na página 21.

Ester, M., H.-P. Kriegel, J. Sander, \& X. Xu (1996). A density-based algorithm for discovering clusters in large spatial databases with noise. In Proceedings of 2nd International Conference on Knowledge Discovery and Data Mining (KDD'96), pp. 226-231. Citado na página 53. 
Ester, M., H. peter Kriegel, J. S, \& X. Xu (1996). A density-based algorithm for discovering clusters in large spatial databases with noise. In Proceeding of 2nd Int. Conf.On Knowledge Discovery and Data Mining, pp. 226-231. AAAI Press. Citado nas páginas 24 e 25.

Ester, M., H. peter Kriegel, M. Wimmer, \& X. Xu (1998). Incremental clustering for mining in a data warehousing environment. In Proceedings 24th Int. Conf. Very Large Data Bases, VLDB, pp. 323-333. Citado na página 24.

Estivill-Castro, V. \& A. T. Murray (1997). Spatial clustering for data mining with genetic algorithms. In Proceedings of the International ICSC Symposium on Engineering of Intelligent Systems, pp. 317-323. Citado nas páginas 48, 51, 52, e 53.

Everitt, B., S. Landau, \& M. Leese (2001a). Cluster Analysis, Arnold Publishers. Arnold Publishers. Citado nas páginas 1 e 18.

Everitt, B. S., S. Landau, \& M. Leese (2001b, May). Cluster Analysis. Arnold Publishers. Citado na página 20.

Faceli, K. (2006). Um framework para análise de agrupamento baseado na combinação multi-objetivo de algoritmos de agrupamento. Tese de Doutorado, Instituto de Ciências Matemáticas e Computação, ICMC-USP. http://www.teses.usp.br/teses/ disponiveis/55/55134/tde-12012007-082216/ [Acessado em 07/04/2007]. Citado nas páginas 9, 104, 106, 109, e 123.

Faceli, K., A. C. P. L. F. de Carvalho, \& M. C. P. Souto (2005a). Algoritmos de agrupamento de dados. Technical Report 249, ICMC-USP. http://www.icmc.usp.br/ ־biblio/relatorios_tecnicos.php. Citado nas páginas 17 e 28.

Faceli, K., A. C. P. L. F. de Carvalho, \& M. C. P. Souto (2005b). Validação de algoritmos de agrupamento. Technical Report 254, ICMC-USP. http://www.icmc.usp.br/ ^biblio/relatorios_tecnicos.php. Citado na página 34.

Falkenauer, E. (1998). Genetic Algorithms and Grouping Problems. John Wiley \& Sons. Citado nas páginas $2,43,45,46,48,52,54,56,57,62$, e 67.

Feldman, R. \& J. Sanger (2006). The Text Mining Handbook: Advanced Approaches in Analyzing Unstructured Data. Cambridge University Press. Citado nas páginas 1 e 83.

Fern, X. Z. \& C. E. Brodley (2004). Solving cluster ensemble problems by bipartite graph partitioning. In Proc. ICML'04, New York, NY, USA, pp. 36. Citado nas páginas 104, 106, 107, 114, 117, e 121.

Fern, X. Z. \& W. Lin (2008). Cluster ensemble selection. Journal of Statistical Analysis and Data Mining 1(3), 128-141. Citado nas páginas 125, 126, 129, 130, 138, 149, e 210 . 
Fisher, R. (1936). The use of multiple measurements in taxonomic problems. Annual Eugenics 7(2), 179-188. Citado na página 129.

Fogel, D. (1995). Evolutionary Computation: Toward a New Philosophy of Machine Intelligence. New York, USA: IEEE Press. Citado nas páginas 59, 62, e 79.

Fontana, A. \& M. C. Naldi (2009). Estudo e comparação de métodos para estimação de números de grupos em problemas de agrupamento de dados. Technical Report 340, Instituto de Ciências Matemáticas e de Computação - Universidade de São Paulo. http: //www.icmc.usp.br/〜biblio/relatorios_tecnicos.php. Citado na página 94.

Forman, G. \& B. Zhang (2000, december). Distributed data clustering can be efficient and exact. ACM SIGKDD Explorations Newsletter 2(2), 34-38. Citado na página 167.

Fralley, C. \& A. E. Raftery (1998). How many clusters? which clustering method? answer via model-based cluster analysis. The Computer Journal 41, 578-588. Citado nas páginas 2 e 9 .

Frank, A. (2004). On kuhn's hungarian method - a tribute from hungary. Technical Report 14, Egrerváry Research Group. http://www.cs.elte.hu/egres. Citado na página 113 .

Fränti, P., J. Kivijärvi, T. Kaukoranta, \& O. Nevalainen (1997). Genetic algorithms for large scale clustering problems. The Computer Journal 40, 547-554. Citado nas páginas $49,51,52,53$, e 54 .

Fred, A. \& A. Jain (2002a). Data clustering using evidence accumulation. In Proceedings of International Conference on Pattern Recognition (ICPR'2002), Quebec, Canada, pp. 276-280. Citado nas páginas 3, 26, e 107.

Fred, A. \& A. Jain (2002b). Evidence accumulation clustering based on the k-means algorithm. In Proceedings of Structural and Syntactic Pattern Recognition (SSPR'2002), Windsor, Canada, pp. 442-451. Citado nas páginas 105, 106, e 110.

Fred, A. \& A. K. Jain (2003). Robust data clustering. In Proceedings of IEEE Computer Society Conference on Computer Vision and Pattern Recognition, (CVPR'2003), Volume II, Madison - Wisconsin, USA. Citado nas páginas 105, 106, 110, e 120.

Fred, A. L. N. (2001). Finding consistent clusters in data partitions. In J. Kittler \& F. Roli (Eds.), Second International Workshop on Multiple Classifier Systems (MCS'2001), Volume 2096 of Lecture Notes in Computer Science, Cambridge, UK, pp. 309-318. Citado nas páginas 105, 106, e 113.

Fred, A. L. N. \& A. K. Jain (2005). Combining multiple clusterings using evidence accumulation. IEEE Transactions on Pattern Analysis and Machine Intelligence 27(6), 835-850. Citado nas páginas 3, 104, 105, 109, 111, 120, 121, 138, e 213. 
Freitas, A. A. \& S. H. Lavington (1997). Mining Very Large Databases with Parallel Processing. Norwell, MA, USA: Kluwer Academic Publishers. Citado na página 168.

Friedman, M. (1940). A comparison of alternative tests of significance for the problem of m rankings. Annals of Mathematical Statistics 11, 86-92. Citado na página 194.

Frossyniotis, D., M. Pertselakis, \& A. Stafylopatis (2002). A multi-clustering fusion algorithm. In I. P. Vlahavas \& C. D. Spyropoulos (Eds.), Methods and Applications of Artificial Intelligence, Proceedings of the 2nd Hellenic Conference on AI (SETN'2002), Volume 2308 of Lecture Notes in Computer Science, Thessaloniki, Greece, pp. 225-236. Springer Verlag. Citado nas páginas 106 e 113.

Fung, B. C. M., K. Wang, R. Chen, \& P. S. Yu (2010). Privacy-preserving data publishing: A survey of recent developments. ACM Comput. Surv. 42(4), 1-53. Citado nas páginas 170,172 , e 178.

Furey, T. S., N. Christianini, N. Duffy, D. W. Bednarski, M. Schummer, \& D. Hauessler (2000). Support vector machine classification and validation of cancer tissue samples using microarray expression data. Bioinformatics 16(10), 906-914. Citado na página 13.

Gablentz, W., M. Köppen, \& E. Dimitriadou (2000). Robust clustering by evolutionary computation. In Online World Conference on Soft Computing in Industrial Applications. Citado na página 107.

Gao, Y., S. Gu, J. Li, \& Z. Liao (2007). A weighted consensus function based on information-theoretic principles to combine soft clusterings. In GRC 'O\%: Proceedings of the 2007 IEEE International Conference on Granular Computing, Washington, DC, USA, pp. 417-422. IEEE Computer Society. Citado na página 119.

Garg, A., A. Mangla, N. Gupta, \& V. Bhatnagar (2006, Dec.). Pbirch: A scalable parallel clustering algorithm for incremental data. In Database Engineering and Applications Symposium, 2006. IDEAS '06. 10th International, pp. 315-316. Citado na página 167.

Gesú, V. D., R. Giancarlo, G. L. Bosco, A. Raimondi, \& D. Scaturro (2005). Genclust: A genetic algorithm for clustering gene expression data. BMC Bioinformatics 6(289), 1-11. Citado na página 1.

Ghosh, J., A. Strehl, \& S. Merugu (2002). A consensus framework for integrating distributed clusterings under limited knowledge sharing. In Proceedings of NSF Workshop on Next Generation Data Mining, pp. 99-108. Citado nas páginas 104 e 167.

Goldberg, D. (1989). Genetic Algorithms in Search, Optimization, and Machine Learning. Addison-Wesley. Citado na página 47. 
Golub, T., P. T. D.K. Slonim and, C. Huard, M. Gaasenbeek, J. Mesirov, H. Coller, M. Loh, J. Downing, M. Caligiuri, C. Bloomfield, \& E. Lander (1999). Molecular classification of cancer: Class discovery and class prediction by gene expression. Science 286(5439), 531-537. Citado na página 1.

Gordon, A. (1999). Classification. Chapman \& Hall/CRC. Citado nas páginas 17 e 36.

Gowda, K. C. \& E. Diday (1991). Symbolic clustering using a new dissimilarity measure. Pattern Recognition 24(6), 567-578. Citado na página 10.

Greene, D., A. Tsymbal, N. Bolshakova, \& P. Cunningham (2004). Ensemble clustering in medical diagnostics. In CBMS '04: Proceedings of the 17th IEEE Symposium on Computer-Based Medical Systems, Washington, DC, USA, pp. 576-581. IEEE Computer Society. Citado nas páginas 106, 107, 108, e 110.

Grzymala-Busse, J. W. \& M. Hu (2001). A comparison of several approaches to missing attribute values in data mining. In Second International Conference in Rough Sets and Current Trends in Computing, Banff, Canada, pp. 378-385. Springer Berlin / Heidelberg. Citado na página 11.

Guha, S., R. Rastogi, \& K. Shim (1998). CURE: an efficient clustering algorithm for large databases. In Proceedings of ACM SIGMOD International Conference on Management of Data, pp. 73-84. Citado na página 28.

Hadjitodorov, S. T. \& L. I. Kuncheva (2007). Selecting diversifying heuristics for cluster ensembles. In 7th International Workshop, pp. 200-209. Citado nas páginas 3, 108, 124,213 , e 214 .

Hadjitodorov, S. T., L. I. Kuncheva, \& L. P. Todorova (2006). Moderate diversity for better cluster ensembles. Information Fusion 7(3), 264-275. Citado nas páginas 105, 106, 107, 108, 110, 126, 129, 130, e 149.

Halkidi, M., Y. Batistakis, \& M. Vazirgiannis (2001). On clustering validation techniques. Intelligent Information Systems Journal 17(2-3), 107-145. Citado nas páginas 23, 25, $28,29,35,41$, e 127.

Hall, L., I. Ozyurt, \& J. Bezdek (1999, Jul). Clustering with a genetically optimized approach. Evolutionary Computation, IEEE Transactions on 3(2), 103-112. Citado na página 78 .

Hammouda, K. \& M. Kamel (2009, May). Hierarchically distributed peer-to-peer document clustering and cluster summarization. Knowledge and Data Engineering, IEEE Transactions on 21(5), 681-698. Citado nas páginas 1, 167, e 169. 
Hand, D. J. \& W. J. Krzanowski (2005). Optimising k-means clustering results with standard software packages. Computational Statistics 6 Data Analysis 49(4), 969 973. Citado na página 78.

Handl, J. \& J. Knowles (2007). An evolutionary approach to multiobjective clustering. IEEE Trans. on Evolutionary Computation 34, 56-76. Citado nas páginas 54, 56, 108, 128,129 , e 213 .

Handl, J., J. Knowles, \& D. B. Kell (2005). Computational cluster validation in postgenomic data analysis. Bioinformatics 21(15), 3201-3212. Citado nas páginas 34, 57, e 59 .

Hao, J. \& J. B. Orlin (1994). A faster algorithm for finding the minimum cut in a directed graph. Journal of Algorithms 17(3), 424-446. Citado na página 26.

Hartigan, J. A. (1985). Statistical theory in clustering. Journal of Classification 2, 63-76. Citado na página 2.

Heilman, C. M. \& D. Bowman (2002). Segmenting consumers using multiple-category purchase data. International Journal of Research in Marketing 19(3), 225 - 252. Citado na página 1.

Hijmans, H. (2010). Recent developments in data protection at european union level. ERA-Forum, Online First 12, 1-13. Citado na página 166.

Hogg, R. V. (1994). Introduction to Mathematical Statistics. Prentice Hall. Citado na página 183.

Hollander, M. \& D. A. Wolfe (1999). Nonparametric Statistical Methods. WileyInterscience. Citado nas páginas 21, 97, 138, e 194.

Horta, D. (2010). Abordagens evolutivas para agrupamento relacional de dados. Dissertação de Mestrado, Instituto de Ciências Matemáticas e de Computação (ICMC). http://www.teses.usp.br/teses/disponiveis/55/55134/ tde-08042010-150736/pt-br.php [Acessado em 09/11/2010]. Citado na página 192.

Horta, D. \& R. J. G. B. Campello (2009). Fast evolutionary algorithms for relational clustering. In The International Conference on Intelligent Systems Design and Applications, Pisa, Tuscany, Italy, pp. 1456-1462. Citado nas páginas 66, 167, e 192.

Horta, D., M. C. Naldi, R. J. G. B. Campello, E. R. Hruschka, \& A. C. P. L. F. Carvalho (2009). In Bio-Inspired Data Mining: Theoretical Foundations and Applications, Foundations of Computational Intelligence, Vol. 4, Chapter Evolutionary Fuzzy Clustering: An Overview and Efficiency Issues, pp. 167-195. Springer-Verlag. Citado nas páginas 167, 183, e 192. 
Hruschka, E., R. J. G. B. Campello, A. A. Freitas, \& A. C. Ponce Leon F. de Carvalho (2009, March). A survey of evolutionary algorithms for clustering. Systems, Man, and Cybernetics, Part C: Applications and Reviews, IEEE Transactions on 39(2), 133-155. Citado nas páginas 2, 4, 43, 44, 45, 49, 53, e 67.

Hruschka, E. R., R. J. G. B. Campello, \& L. N. de Castro (2004a). Evolutionary algorithms for clustering gene-expression data. In Proc. IEEE Int. Conf. on Data Mining, Brighton/England, pp. 403-406. Citado nas páginas 41, 54, 55, 57, 58, 59, 60, 79, e 187.

Hruschka, E. R., R. J. G. B. Campello, \& L. N. de Castro (2004b). Improving the efficiency of a clustering genetic algorithm. In Advances in Artificial Intelligence IBERAMIA 2004: 9th Ibero-American Conference on AI, Puebla, Mexico, November 22-25. Proceedings, Volume 3315, pp. 861-870. Springer-Verlag GmbH, Lecture Notes in Computer Science. Citado nas páginas 41, 54, 55, 57, 58, 59, e 60.

Hruschka, E. R., R. J. G. B. Campello, \& L. N. de Castro (2006). Evolving clusters in gene-expression data. Information Sciences 176(13), 1898-1927. Citado nas páginas $54,55,57,58,59,60,63,98$, e 187.

Hruschka, E. R. \& N. F. F. Ebecken (2003). A genetic algorithm for cluster analysis. Intelligent Data Analysis 7(1), 15-25. Citado nas páginas 54, 55, 56, 57, 58, e 59.

Hu, T., L. Liu, C. Qu, \& S. Y. Sung (2006). Joint cluster based co-clustering for clustering ensembles. In G. Wang, J. F. Peters, A. Skowron, \& Y. Yao (Eds.), Advanced Data Mining and Applications, Lecture Notes in Computer Science, Volume 4093, pp. 284295. Springer Berlin - Heidelberg. Citado na página 118.

Hu, T., Y. Yu, J. Xiong, \& S. Y. Sung (2006). Maximum likelihood combination of multiple clusterings. Pattern Recognition Letters 27(13), 1457 - 1464. Citado na página 170 .

Hu, T., W. Zhao, X. Wang, \& Z. Li (2006). A comparison of three graph partitioning based methods for consensus clustering. In G. Wang, J. F. Peters, A. Skowron, \& Y. Yao (Eds.), Lecture Notes in Computer Science, Volume 4062, pp. 468-475. Springer. Citado na página 121.

Hubert, L. J. \& P. Arabie (1985). Comparing partitions. Journal of Classification 2, 193-218. Citado nas páginas 36 e 121.

Inan, A., S. V. Kaya, Y. SaygIn, E. Savas, A. A. Hintoglu, \& A. Levi (2007). Privacy preserving clustering on horizontally partitioned data. Data\& Knowledge Engineering 63(3), 646 - 666. 25th International Conference on Conceptual Modeling (ER 2006) - 'Four of the best papers presented. Citado na página 170. 
Jaccard, P. (1908). Nouvelles recherches sur la distribution florale. Bull. Soc. Vandoise des Sci. Nat. 44, 223-270. Citado nas páginas 18, 35, 83, e 131.

Jain, A. \& R. Dubes (1988). Algorithms for Clustering Data. Prentice Hall. Citado nas páginas 1, 2, 7, 9, 11, 29, 36, 38, 41, 59, e 139.

Jain, A. K., M. N. Murty, \& P. J. Flynn (1999). Data clustering: a review. ACM Computing Surveys 31(3), 264-323. Citado nas páginas 1, 2, 8, 9, 22, 26, 27, 70, e 188.

Jiang, D. \& A. Zhang (2004). Cluster analysis for gene expression data: A survey. IEEE Transactions on Knowledge and Data Engineering 16(11), 1370-1386. Citado na página 34 .

Jr, H. S. (1968). Cardinality of finite topologies. Journal of Combinatorial Theory 5(1), 82-86. Citado na página 8.

Kargupta, H., W. Huang, K. Sivakumar, \& E. Johnson (2001). Distributed clustering using collective principal component analysis. Knowl. Inf. Syst. 3(4), 422-448. Citado na página 170 .

Karypis, G., R. Aggarwal, V. Kumar, \& S. Shekhar (1999). Multilevel hypergraph partitioning: applications in vlsi domain. IEEE Trans. Very Large Scale Integr. Syst. 7(1), 69-79. Citado na página 115.

Karypis, G. \& V. Kumar (1999). A fast and high quality multilevel scheme for partitioning irregular graphs. SIAM Journal on Scientific Computing 20(1), 359-392. Citado nas páginas 114, 116, 117, e 118.

Kasturi, J. \& R. Acharya (2004). Clustering of diverse genomic data using information fusion. In SAC '04: Proceedings of the 2004 ACM symposium on Applied computing, New York, NY, USA, pp. 116-120. ACM. Citado na página 106.

Kaufman, L. \& P. Rousseeuw (2005). Finding Groups in Data: An Introduction to Cluster Analysis. Wiley Series in Probability and Statisticss. Citado nas páginas 11, 22, e 23.

Kellam, P., X. Liu, N. J. Martin, C. Orengo, S. Swift, \& A. Tucker (2001). Comparing, contrasting and combining clusters in viral gene expression data. In Proceedings of 6th Workshop on Intelligent Data Analysis in Medicine and Pharmacology, pp. 56-62. Citado nas páginas 106 e 110.

Kim, K. \& H. Ahn (2004). Using a clustering genetic algorithm to support customer segmentation for personalized recommender systems. In 13th International Conference on AI, Simulation, Planning in High Autonomy Systems, Jeju Island, Korea, pp. 409415. Springer Berlin / Heidelberg. Citado na página 1.

Kivijärvi, J., P. Fränti, \& O. Nevalainen (2003). Self-adaptive genetic algorithm for clustering. Journal of Heuristics 9(2), 113-129. Citado nas páginas 49, 52, e 53. 
Kononenko, I. \& M. Kukar (2007). Machine Learning and Data Mining: Introduction to Principles and Algorithms. Horwood Publishing Limited. Citado nas páginas 11, 17, e 19.

Krishna, K. \& N. Murty (1999). Genetic k-means algorithm. IEEE Transactions on Systems, Man and Cybernetics 29(3), 433-439. Citado nas páginas 47, 52, 53, e 54.

Krogh, A. \& J. Vedelsby (1995). Neural network ensembles, cross validation, and active learning. In In Advances in Neural Information Processing Systems, Volume 7, pp. 231-238. IEEE Press. Citado na página 104.

Krovi, R. (1992, Jan). Genetic algorithms for clustering: a preliminary investigation. System Sciences, 1992. Proceedings of the Twenty-Fifth Hawaii International Conference on iv, 540-544 vol.4. Citado nas páginas 47, 51, 53, e 54 .

Kuhn, H. W. (1955). The hungarian method for the assignment problem. Naval Research Logistics Quarterly 2, 83-97. Citado na página 113.

Kullback, S. \& R. A. Leibler (1951). On information and sufficiency. Annals of Mathematical Statistics 22(1), 79-86. Citado na página 118.

Kuncheva, L. \& J. C. Bezdek (1997). Selection of cluster prototypes from data by a genetic algorithm. In Procedings of the 5th European Congress on Intelligent Techniques and Soft Computing, pp. 1683-1688. Citado nas páginas 51, 52, e 53.

Kuncheva, L. \& S. Hadjitodorov (2004, October). Using diversity in cluster ensembles. In Systems, Man and Cybernetics, 2004 IEEE International Conference on, Volume 2, pp. 1214-1219. Citado nas páginas 105 e 126.

Kuncheva, L., S. Hadjitodorov, \& L. Todorova (2006, July). Experimental comparison of cluster ensemble methods. In Information Fusion, 2006 9th International Conference on, pp. 1-7. Citado nas páginas 3, 26, 105, 106, 108, 110, 121, 122, 127, 138, e 213.

Kuncheva, L. I. (2004). Combining Pattern Classifiers. John Wiley \& Sons. Citado nas páginas 2, 104, 106, 109, 110, 111, e 164.

Kuncheva, L. I. \& D. P. Vetrov (2006). Evaluation of stability of k-means cluster ensembles with respect to random initialization. IEEE Trans. Pattern Anal. Mach. Intell. 28(11), 1798-1808. Citado nas páginas 104 e 111.

Kuncheva, L. I. \& C. J. Whitaker (2003). Measures of diversity in classifier ensembles and their relationship with the ensemble accuracy. Machine Learning 51(2), 181-207. Citado na página 105.

Larsen, B. \& C. Aone (1999). Fast and effective text mining using linear-time document clustering. In KDD '99: Proceedings of the fifth ACM SIGKDD international conference 
on Knowledge discovery and data mining, New York, NY, USA, pp. 16-22. Citado na página 1.

Law, M., A. Topchy, \& A. Jain (2004, June-2 July). Multiobjective data clustering. Computer Vision and Pattern Recognition, 2004. CVPR 2004. Proceedings of the 2004 IEEE Computer Society Conference on 2, II-424-II-430 Vol.2. Citado na página 104.

Lin, K.-S. \& C.-F. Chien (2009). Cluster analysis of genome-wide expression data for feature extraction. Expert Systems with Applications 36(2, Part 2), 3327 - 3335. Citado nas páginas 1 e 13.

Linger, H., J. Fisher, W. Wojtkowski, W. Wojtkowski, J. Zupancic, K. Vigo, \& J. Arnold (2004). Constructing the Infrastructure for the Knowledge Economy Methods and Tools, Theory and Practice. Springer. Citado na página 83.

Little, R. J. A. \& D. B. Rubin (2002). Statistical Analysis with Missing Data. WileyInterscience. Citado na página 11.

Liu, G. (1968). Introduction to Combinatorial Mathematics. McGraw Hill. Citado na página 8.

Liu, Y., k. Chen, X. Liao, \& W. Zhang (2004). A genetic clustering method for intrusion detection. Pattern Recognition 37(5), 927-942. Citado na página 1.

Loia, V., W. Pedrycz, \& S. Senatore (2007, Dec.). Semantic web content analysis: A study in proximity-based collaborative clustering. Fuzzy Systems, IEEE Transactions on 15(6), 1294-1312. Citado na página 170.

Losee, R. M. (2001). Term dependence: A basis for luhn and zipf models. Journal of the American Society for Information Science and Technology 52(12), 1019-1025. Citado na página 83.

Lu, Y., S. Lu, F. Fotouhi, Y. Deng, \& S. Brown (2004a). Incremental genetic k-means algorithm and its application in gene expression data analysis. BMC Bioinformatics 28(5), 172. Citado nas páginas 1, 47, 52, 53, e 54 .

Lu, Y., S. Lu, F. Fotouhi, Y. Deng, \& S. J. Brown (2004b). Fgka: a fast genetic k-means clustering algorithm. In SAC '04: Proceedings of the 2004 ACM Symposium on Applied Computing, New York, NY, USA, pp. 622-623. ACM. Citado nas páginas 47, 52, 53, e 54.

Lucasius, C. B., A. D. Dane, \& G. Kateman (1993). On k-medoid clustering of large data sets with the aid of a genetic algorithm: background, feasibility and comparison. Analytica Chimica Acta 282, 647-669. Citado nas páginas 48, 51, 52, e 53.

Luhn, H. P. (1958). The automatic creation of literature abstracts. IBM Journal of Research and Development 2, 159-165. Citado na página 16. 
Ma, P. C. H., K. C. C. Chan, X. Yao, \& D. K. Y. Chiu (2006). An evolutionary clustering algorithm for gene expression microarray data analysis. IEEE Trans. Evolutionary Computations 10(3), 296-314. Citado nas páginas 54, 59, e 123.

Ma, Z. (2005). A genetic som clustering algorithm for intrusion detection. In Advances in Neural Networks - ISNN 2005: Second International Symposium on Neural Networks, Volume 3498, Department of Computer Science and Engineering, Chongqing University, Chongqing 400044, China, pp. 421. Lecture Notes in Computer Science, Springer-Verlag GmbH. Citado na página 1.

Machado, J. B., W. C. Amaral, \& R. J. G. B. Campello (2007). Design of obf-ts fuzzy models based on multiple clustering validity criteria. In ICTAI '0\%: Proceedings of the 19th IEEE International Conference on Tools with Artificial Intelligence - Vol.2 (ICTAI 2007), Washington, DC, USA, pp. 336-339. IEEE Computer Society. Citado na página 146.

Mangasarian, O. L. \& W. H. Wolberg (1990). Cancer diagnosis via linear programming. SIAM News 23(5), 1-18. Citado na página 129.

Manning, C. D. \& H. Schütze (1999). Foundations of Statistical Natural Language Processing. MIT Press. Citado nas páginas 13, 14, e 16.

Margineantu, D. \& T. Dietterich (1997). Pruning adaptive boosting. In Proceedings of the 14th International Conference on Machine Learning, pp. 211-218. Citado na página 126.

Martins, C. A., M. Monard, \& E. T. Matsubara (2003). Reducing the dimensionality of bagofwords text representation used by learning algorithms. In Proceedings of 3rd IASTED International Conference on Artificial Intelligence and Applications (AIA2003), Benalmádena, Espanha, pp. 228-233. Acta Press. Citado na página 83.

Matsubara, E., C. A. Martins, \& M. C. Monard (2003). Pretext: uma ferramenta para préprocessamentos de textos utilizando a abordagem bag-of-words. Technical Report 209, ICMC-USP. http://www.icmc.usp.br/ biblio/relatorios_tecnicos.php. Citado nas páginas xvii, 13, 14, e 16 .

Maulik, U. \& S. Bandyopadhyay (2000). Genetic algorithm-based clustering technique. Pattern Recognition 33, 1455 - 1465. Citado nas páginas 49, 51, 52, e 53.

McLachlan, G. \& D. Peel (2000). Finite Mixture Models. John Wiley \& Sons. Citado na página 23.

McLachlan, G. J., R. W. Bean, \& S.-K. Ng (2008). Bioinformatics, Chapter Clustering, pp. 423-439. Springer. Citado na página 13. 
McLachlan, G. J. \& T. Krishnan (1996). The EM Algorithm and Extensions. WileyInterscience. Citado na página 24.

Meilă, M. (2007). Comparing clusterings - an information based distance. J. Multivar. Anal. 98(5), 873-895. Citado na página 34.

Merugu, S. \& J. Ghosh (2005). A privacy-sensitive approach to distributed clustering. Pattern Recognition Letters 26(4), 399-410. Citado na página 170.

Merz, P. (2003). An iterated local search approach for minimum sum-of-squares clustering. In M. Berthold, H.-J. Lenz, E. Bradley, R. Kruse, \& C. Borgelt (Eds.), Advances in Intelligent Data Analysis V, Volume 2811 of Lecture Notes in Computer Science, pp. 286-296. Springer Berlin / Heidelberg. 10.1007/978-3-540-45231-7-27. Citado na página 54.

Merz, P. \& A. Zell (2002). Clustering gene expression profiles with memetic algorithms. In PPSN VII: Proceedings of the 7th International Conference on Parallel Problem Solving from Nature, London, UK, pp. 811-820. Springer-Verlag. Citado nas páginas 49, 52, e 53.

Milligan, G. W. \& M. C. Cooper (1985). An examination of procedures for determining the number of clusters in a data set. Psychometrika 50, 159-179. Citado nas páginas $34,95,127,128,157$, e 185 .

Minghim, R., F. V. Paulovich, \& A. A. Lopes (2006). Content-based text mapping using multi-dimensional projections for exploration of document collections. In R. F. Erbacher, J. C. Roberts, M. T. Gröhn, \& K. Borner (Eds.), Proceedings of SPIE-IS\&GT Electronic Imaging - Visualization and Data Analysis - VDA, Volume 6060, San Jose, USA, pp. 60600S. SPIE Press. Citado na página 85.

Mirkin, B. (2005). Clustering for Data Mining: A Data Recovery Approach. Chapman \& Hal. Citado nas páginas 34 e 93.

Mitchell, M. (1998). An Introduction to Genetic Algorithms. MIT Press. Citado nas páginas 47, 53, 59, 62, e 64 .

Mitchell, T. (1997). Machine Learning. McGraw Hill. Citado nas páginas 1 e 23.

Molla, M., M. Waddell, D. Page, \& J. Shavlik (2004). Using machine learning to design and interpret gene-expression microarrays. AI Magazine (Special Issue on Bioinformatics) 25(1), 23-44. Citado na página 1.

Monti, S., P. Tamayo, J. Mesirov, \& T. Golub (2003). Consensus clustering: A resamplingbased method for class discovery and visualization of gene expression microarray data. Machine Learning 52(1-2), 91-118. Citado nas páginas 104, 107, 109, 110, e 111. 
Mount, D. W. (2004). Bioinformatics: sequence and genome analysis. Cold Spring Harbor Laboratory Press. Citado na página 12.

Murphy, D. (2002). Gene expression studies using microarrays: Principles, problems, and prospects. Advan. Physiol. Educ. 26(4), 256-270. Citado na página 12.

Murthy, C. A. \& N. Chowdhury (1996). In search of optimal clusters using genetic algorithms. Pattern Recogn. Lett. 17(8), 825 - 832. Citado nas páginas 51, 52, 53, e 54 .

Naldi, M. C., R. J. G. B. Campello, E. R. Hruschka, \& A. C. P. L. F. Carvalho (2011). Efficiency issues of evolutionary k-means. Applied Soft Computing. 11(2), 1938-1952. Citado nas páginas 31, 32, 92, 98, 99, 167, 182, 183, e 192.

Naldi, M. C. \& A. C. P. L. F. Carvalho (2005). Classificação de dados de expressão gênica utilizando aprendizado de máquina evolutivo. Revista Eletrônica de Iniciação Científica 5(3), 1-13. Citado na página 13.

Naldi, M. C. \& A. C. P. L. F. Carvalho (2007). Clustering using genetic algorithm combining validation criteria. In Proceedings of the 15th European Symposium on Artificial Neural Networks, ESANN 2007, Volume 1, pp. 139-144. Evere. Citado nas páginas $54,55,59,60$, e 146.

Naldi, M. C., A. C. P. L. F. Carvalho, R. J. G. B. Campello, \& E. R. Hruschka (2007). Soft Computing for Knowledge Discovery and Data Mining, Chapter Genetic Clustering for Data Mining, pp. 113-132. Springer. Citado nas páginas 2, 43, e 45.

Naldi, M. C., K. Faceli, \& A. C. P. L. F. Carvalho (2009). Uma revisão sobre combinação de agrupamentos. Revista de Informática Teórica e Aplicada 16(2), 25-51. Citado na página 104 .

Naldi, M. C., A. Fontana, \& R. J. G. B. Campello (2009). Comparison among methods for $\mathrm{k}$ estimation in k-means. In The 9th International Conference on Intelligent Systems Design and Applications (ISDA)., pp. 1006-1013. Citado nas páginas 31, 32, 94, 167, 182, 183, 192, e 193 .

Ng, A. Y., M. I. Jordan, \& Y. Weiss (2002). On spectral clustering: Analysis and an algorithm. In Advances in Neural Information Processing Systems, Volume 14. Citado na página 117.

Oliveira, S. R. M. \& O. R. Zaïne (2003). Privacy preserving clustering by data transformation. In In Procedings of the 18th Brazilian Symposium on Databases, pp. 304-318. Citado na página 178.

Olson, C. F. (1995). Parallel algorithms for hierarchical clustering. Parallel Computing 21(8), 1313 - 1325. Citado na página 167. 
Pakhira, M., S. Bandyopadhyay, \& U. Maulik (2005). A study of some fuzzy cluster validity indices, genetic clustering and application to pixel classification. Fuzzy Sets Systems 155(2), 191-214. Citado nas páginas 1, 78, 79, 82, 89, 97, e 192.

Pakhira, M. K., S. Bandyopadhyay, \& U. Maulik (2004). Validity index for crisp and fuzzy clusters. Pattern Recognition 37(3), 487 - 501. Citado na página 39.

Pal, N. \& J. Bezdek (1995). On cluster validity for the fuzzy c-means model. IEEE Transactions of Fuzzy Systems 3(3), 370-379. Citado nas páginas 58, 78, 82, 97, e 192.

Pan, S. \& K. Cheng (2007). Evolution-based tabu search approach to automatic clustering. IEEE Transactions on Systems, Man, and Cybernetics, Part C-Applications and Reviews 37(5), 827-838. Citado nas páginas 54, 56, 57, e 59.

Pan, W. (2002). A comparative review of statistical methods for discovering differentially expressed genes in replicated microarray experiments. Bioinformatics 18(4), 546-554. Citado na página 1.

Pan, W., J. Lin, \& C. Le (2002). Model-based cluster analysis of microarray geneexpression data. Genome Biology 3(2), research0009.1-research0009.8. Citado na página 13.

Paulovich, F. V., M. C. F. Oliveira, \& R. Minghim (2007). The projection explorer: A flexible tool for projection based multidimensional visualization. In In SIBGRAPI 0\%: Proceedings of the XX Brazilian Symposium on Computer Graphics and Image Processing (SIBGRAPI 200\%), Washington, DC, USA, pp. 27-36. Citado na página 83.

Pedrycz, W. (2002a). Collaborative fuzzy clustering. Pattern Recognition Letters 23(14), 1675 - 1686. Citado na página 20.

Pedrycz, W. (2002b). Collaborative fuzzy clustering. Pattern Recogn. Lett. 23(14), 16751686. Citado na página 170.

Pedrycz, W. \& K. Hirota (2008). A consensus-driven fuzzy clustering. Pattern Recogn. Lett. $29(9)$, 1333-1343. Citado na página 170.

Pedrycz, W. \& P. Rai (2008a). Collaborative clustering with the use of fuzzy c-means and its quantification. Fuzzy Sets Syst. 159(18), 2399-2427. Citado na página 170.

Pedrycz, W. \& P. Rai (2008b, Aug.). A multifaceted perspective at data analysis: A study in collaborative intelligent agents. Systems, Man, and Cybernetics, Part B: Cybernetics, IEEE Transactions on 38(4), 1062-1072. Citado na página 170.

Pekalska, E. \& R. P. W. Duin (2005). The Dissimilarity Representation for Pattern Recognition: Foundations And Applications (Machine Perception and Artificial Intelligence). River Edge, NJ, USA: World Scientific Publishing Co., Inc. Citado na página 110. 
Pelleg, D. \& A. Moore (2000). X-means: extending k-means with efficient estimation of the number of clusters. In Proceedings of the Seventeenth International Conference on Machine Learning, pp. 727-734. Citado nas páginas 33, 34, e 94.

Porter, M. (1980). An algorithm for suffix stripping. Program 14(3), 130-137. Citado nas páginas 15 e 83.

Punera, K. \& J. Ghosh (2008). Consensus-based ensembles of soft clusterings. Applied Artificial Intelligence 22(7), 780-810. Citado nas páginas 104 e 118.

Qian, Y. \& C. Suen (2000). Clustering combination method. Pattern Recognition, 2000. Proceedings. 15th International Conference on 2, 732-735 vol.2. Citado na página 106.

Rand, W. M. (1971). Objective criteria for the evaluation of clustering methods. Journal of the American Statistical Association 66(336), 846-850. Citado na página 35.

Rayward-Smith, V. (2005, Sept.). Metaheuristics for clustering in kdd. In Evolutionary Computation, 2005. The 2005 IEEE Congress on, Volume 3, Edinburgh, UK, pp. 23802387 Vol. 3. Citado nas páginas 2 e 71.

Romesburg, C. (2004). Cluster Analysis for Researchers. Lulu Press North Carolina. Citado na página 27.

Rousseeuw, P. J. (1987). Silhouettes: a graphical aid to the interpretation and validation of cluster analysis. Journal of Computational and Applied Mathematics 20, 53-65. Citado nas páginas 40, 41, e 58.

Ruta, D. \& B. Gabrys (2004). Classifier selection for majority voting. Information Fusion 6(1), 63-81. Citado na página 105.

Sakuma, J. \& S. Kobayashi (2002, Nov.). Non-parametric expectation-maximization for gaussian mixtures. In Neural Information Processing, 2002. ICONIP '02. Proceedings of the 9th International Conference on, Volume 1, pp. 517-522 vol.1. Citado nas páginas 24 e 183.

Salton, G. \& C. Buckley (1988). Term-weighting approaches in automatic text retrieval. Information Processing and Management 24(5), 513-523. Citado na página 14.

Saraçoğlu, R., K. Tütüncü, \& N. Allahverdi (2007). A fuzzy clustering approach for finding similar documents using a novel similarity measure. Expert Syst. Appl. 33(3), 600-605. Citado na página 1.

Sarafis, I. (2005). Data Mining Clustering of High Dimensional DataBases with Evolutionary Algorithms. Tese de Doutorado, Heriot-Watt University, UK. Citado na página 55. 
Sarafis, L., P. W. Trinder, \& A. M. S. Zalzala (2007). Nocea: a rule-based evolutionary algorithm for efficient and effective clustering of massive high-dimensional databases. Applied Soft Computing 7(3), 668-710. Citado na página 55.

Scheunders, P. (1997). A genetic c-means clustering algorithm applied to color image quantization. Pattern Recognition 30(6), 859-866. Citado nas páginas 49, 51, e 53.

Sebastiani, F. (2002). Machine learning in automated text categorization. ACM Computing Surveys 34(1), 1-47. Citado na página 13.

Setúbal, J. C. \& J. Meidanis (1997). Introduction to Computational Molecular Biology. PWS Publishing Company. Citado na página 12.

Sharan, R., R. Elkon, \& R. Shamir (2002). Cluster analysis and its applications to gene expression data. In Proceedings of the Ernst Schering Workshop on Bioinformatics and Genome Analysis, pp. 83-108. Springer Verlag. Citado na página 1.

Sharan, R. \& R. Shamir (2000). Click: A clustering algorithm with applications to gene expression analysis. In Proceedings of the Eighth International Conference on Intelligent System for Molecular Biology (ISMB00), pp. 307-316. AAAI Press, Menlo Park, CA. Citado na página 25.

Sheng, W. \& X. Liu (2004, 20-23 June). A hybrid algorithm for k-medoid clustering of large data sets. In Proceedings of the 2004 IEEE Congress on Evolutionary Computation, Portland, USA, pp. 77-82. IEEE Press. Citado nas páginas 48, 51, 52, 53, e 54.

Shi, J. \& J. Malik. (2000). Normalized cuts and image segmentation. IEEE Transactions On Pattern Analysis And Machine Intelligence 22, 888-905. Citado na página 118.

Shu-Chuan Chu, J. F. R. \& J. S. Pan (2002). An efficient k -medoids-based algorithm using previous medoid index, triangular inequality elimination criteria, and partial distance search. Lecture Notes in Computer Science: Data Warehousing and Knowledge Discovery 2454, 301-311. Citado nas páginas 23 e 41.

Singh, V., L. Mukherjee, J. Peng, \& J. Xu (2010, maio). Ensemble clustering using semidefinite programming with applications. Machine Learning 79(1-2), 177-200. Citado nas páginas 119 e 138.

Sneath, P. \& R. Sokal (1973). Numerical Taxonomy. Freeman. Citado na página 1.

Souto, M. C. P., D. S. A. Araujo, \& B. L. C. Silva (2006). Cluster ensemble for gene expression microarray data: Accuracy and diversity. In IEEE International Joint Conference on Neural Networks (IJCNN), pp. 4176-4181. IEEE. Citado na página 122.

Stav, D., I. Bar, \& J. Sandbank (2008). Gene expression subtraction of non-cancerous lung from smokers and non-smokers with adenocarcinoma, as a predictor for smokers 
developing lung cancer. Journal of Experimental and Clinical Cancer Research 27(1), 45. Citado na página 13.

Steinbach, M., G. Karypis, \& V. Kumar (2000). A comparison of document clustering techniques. Technical Report 34, University of Minnesota. Citado nas páginas 32 e 33.

Steinley, D. (May 2006). K-means clustering: A half-century synthesis. British Journal of Mathematical and Statistical Psychology 59, 1-34(34). Citado na página 29.

Strehl, A. \& J. Ghosh (2002a). Cluster ensembles - a knowledge reuse framework for combining multiple partitions. In Proceedings of AAAI, Edmonton, Canada, pp. 93-98. Citado na página 120.

Strehl, A. \& J. Ghosh (2002b). Cluster ensembles: A knowledge reuse framework for combining multiple partitions. JMLR 3, 583-617. Citado nas páginas xxii, 3, 104, 105, 106, 107, 109, 110, 114, 115, 119, 120, 121, 122, 126, 127, 138, 164, e 167.

Swift, S., A. Tucker, J. Crampton, \& D. Garway-Heath (2007). An improved restricted growth function genetic algorithm for the consensus clustering of retinal nerve fibre data. In GECCO '0\%: Proceedings of the 9th annual conference on Genetic and evolutionary computation, New York, NY, USA, pp. 2174-2181. ACM. Citado na página 124.

Tan, P.-N., M. Steinbach, \& V. Kumar (2005). Introduction to Data Mining. Addison Wesley. Citado nas páginas 9, 25, e 37.

Tanenbaum, A. S. (1996). Computer Networks. Prentice Hall. Citado na página 168.

Tanenbaum, A. S. (2001). Modern Operating Systems (2nd Edition) (GOAL Series). Prentice Hall. Citado na página 168.

Tanimoto, T. T. (1958). An elementary mathematical theory of classification and prediction. Technical Report 13, IBM Report. Citado na página 21.

Tian, J., L. Zhu, S. Zhang, \& L. Liu (2005). Improvement and parallelism of k-means clustering algorithm. Tsinghua Science \& Technology 10(3), 277 - 281. Citado na página 167.

Topchy, A., A. Jain, \& W. Punch (2003). Combining multiple weak clusterings. In Proceedings of the IEEE International Conference on Data Mining (ICDM'2003), Melbourne, Florida, USA, pp. 331-338. Citado nas páginas 3, 104, 105, 108, e 120.

Topchy, A., A. Jain, \& W. Punch (2004). A mixture model for clustering ensembles. In Proceedings of the SIAM International Conference on Data Mining (SDM'2004), Lake Buena Vista, Florida, USA, pp. 331-338. Citado nas páginas 3, 104, 105, 106, 108, 118,164 , e 167. 
Topchy, A. P., M. H. C. Law, A. K. Jain, \& A. L. Fred (2004). Analysis of consensus partition in cluster ensemble. icdm 00, 225-232. Citado nas páginas 107 e 111.

Triola, M. F. (1999). Elementary Statistics. Addison Wesley Longman. Citado nas páginas 86,214 , e 218.

Tseng, L. \& . Yang, S.B. (2001). A genetic approach to the automatic clustering problem. Pattern Recognition 34, 415-424. Citado nas páginas 54, 55, 57, 58, e 59.

Tumer, K. \& A. K. Agogino (2008). Ensemble clustering with voting active clusters. Pattern Recogn.Lett. 29(14), 1947-1953. Citado nas páginas 105, 114, 119, 120, 122, 127,164 , e 167.

Vaidya, J. \& C. Clifton (2004, Nov.-Dec.). Privacy-preserving data mining: why, how, and when. Security \& Privacy, IEEE 2(6), 19-27. Citado nas páginas 170, 172, e 178.

Vendramin, L., R. J. G. B. Campello, \& E. R. Hruschka (2008). A robust methodology for comparing performances of clustering validity criteria. In Simpósio Brasileiro de Inteligência Artificial (SBIA), Volume 5249 of Lecture Notes in Artificial Intelligence (LNCS/LNAI), Salvador, pp. 237-247. Citado nas páginas 34, 41, e 84.

Vendramin, L., R. J. G. B. Campello, \& E. R. Hruschka (2009). On the comparison of relative clustering validity criteria. In SIAM International Conference on Data Mining, Sparks/USA, pp. 733-744. Citado nas páginas 34, 41, 58, 84, 95, 127, 130, 132, 157, e 185 .

Vendramin, L., R. J. G. B. Campello, \& E. R. Hruschka (2010). Relative clustering validity criteria: A comparative overview. Statistical Analysis and Data Mining 3(4), 209-235. Citado nas páginas 34, 41, 58, 84, 95, 127, 128, 130, 157, e 185.

Walpole, R. E., R. Myers, \& S. L. Myers (2006). Probability $\&$ Statistics for Engineers 86 Scientists. Macmillan. Citado nas páginas 97, 138, e 218.

Ward, J. H. (1963). Hierarchical grouping to optimize an objective function. Journal of the American Statistical Association 58(301), 236-244. Citado na página 27.

Weingessel, A., E. Dimitriadou, \& K. Hornik (2003). An ensemble method for clustering. In Distributed Statistical Computing (DSC'2003), Wien, Austria, pp. 1-12. Citado nas páginas 106 e 112.

Witten, I. H. \& E. Frank (2005). Data Mining - Practical Machine Learning Tools and Techniques with Java Implementations (2nd ed.). Morgan Kaufmann Publishers. Citado na página 94.

Wu, X. (2009). Top ten algorithms in data mining. Taylor \& Francis. Citado nas páginas $1,29,30,70$, e 209. 
Wu, X., V. Kumar, J. R. Quinlan, J. Ghosh, Q. Yang, H. Motoda, G. J. McLachlan, A. Ng, B. Liu, P. S. Yu, Z.-H. Zhou, M. Steinbach, D. J. Hand, \& D. Steinberg (2008). Top 10 algorithms in data mining. Knowledge and Information Systems 14(1), 1-37. Citado nas páginas 29, 30, 70, e 209.

Xu, R. \& I. Wunsch, D. (2005, May). Survey of clustering algorithms. IEEE Transactions on Neural Networks 16(3), 645-678. Citado nas páginas 1, 21, 23, 25, e 29.

Yang, Y. H., S. Dudoit, P. Luu, \& T. P. Speed (2001). Normalization for cDNA microarray data. In SPIE BiOS 2001, San Jose, California. Citado na página 12.

Yeung, K., M. Medvedovic, \& R. Bumgarner (2003). Clustering gene-expression data with repeated measurements. Genome Biology 4(5), R34. Citado na página 129.

Yeung, K. Y., K. Y. Yeung, D. R. Haynor, D. R. Haynor, W. L. Ruzzo, \& W. L. Ruzzo (2001). Validating clustering for gene expression data. Bioinformatics 17, 309-318. Citado na página 34 .

Youness, G. \& G. Saporta (2004). Une méthodologie pour la comparaison de partitions. Revue de Statistique Appliquée 52(1), 97-120. Citado na página 36.

Yu, B. (2008). An evaluation of text classification methods for literary study. Literary Linguist Computing 23(3), 327-343. Citado na página 15.

Yu, Z., H. Wong, \& H. Wang (2007). Graph based consensus clustering for class discovery from gene expression data. Bioinformatics 23, 2888-2896. Citado nas páginas 117 e 118.

Zaki, M. (2000). Parallel and distributed data mining: An introduction, Volume pp, Chapter 1, pp. 804-827. Berlin, Heidelberg: Springer. Citado na página 168.

Zaki, M. J. (1999). Parallel and distributed data mining: A survey. IEEE Concurrency $7(4), 14-25$. Citado na página 168.

Zhang, T., R. Ramakrishnan, \& M. Livny (1996). BIRCH: an efficient data clustering method for very large databases. In Proceedings of the 1996 ACM SIGMOD International Conference on Management of Data, Montreal, Canada, pp. 103-114. Citado na página 27.

Zipf, G. K. (1949). Human Behavior and the Principle of Least Effort. Addison-Wesley, Reading MA. Citado nas páginas 15 e 16.

Zitzler, E. (1999). Evolutionary Algorithms for Multiobjective Optimization: Methods and Applications. Tese de Doutorado, Swiss Federal Institute of Technology (ETH). Citado nas páginas 145 e 146. 
Zitzler, E. \& L. Thiele (1999). Multiobjective evolutionary algorithms: A comparative case study and the strength pareto approach. IEEE Transactions on Evolutionary Computation 3(4), 257-271. Citado na página 123. 